\title{
ENHANCED BOILING HEAT TRANSFER IN HORIZONTAL TEST BUNDLES
}

\author{
Topical Report
}

By R. R. Trewin, M. K. Jensen, A. E. Bergles

August 1994

Work Performed Under Contract No. DE-FC07-88ID12772

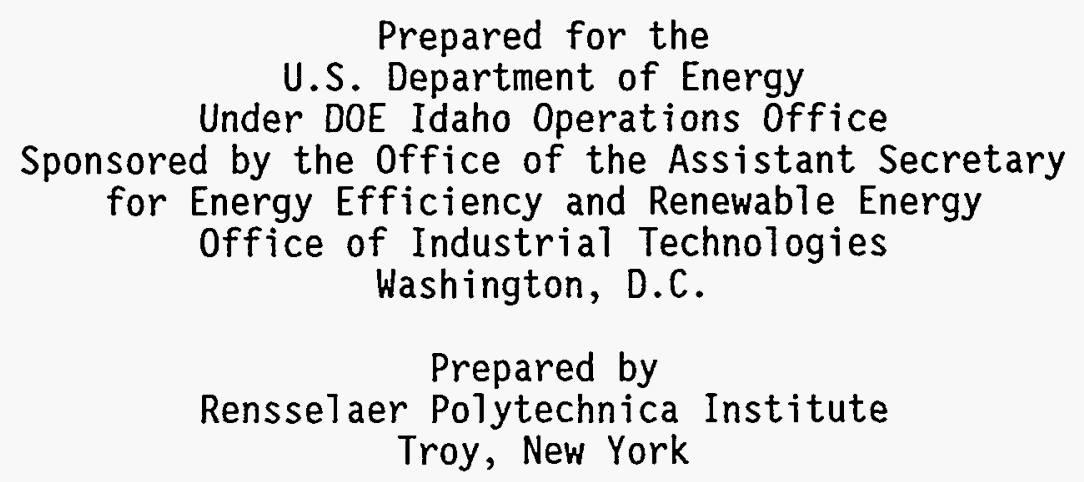




\section{DISCLAIMER}

This report was prepared as an account of work sponsored by an agency of the United States Government. Neither the United States Government nor any agency thereof, nor any of their employees, make any warranty, express or implied, or assumes any legal liability or responsibility for the accuracy, completeness, or usefulness of any information, apparatus, product, or process disclosed, or represents that its use would not infringe privately owned rights. Reference herein to any specific commercial product, process, or service by trade name, trademark, manufacturer, or otherwise does not necessarily constitute or imply its endorsement, recommendation, or favoring by the United States Government or any agency thereof. The views and opinions of authors expressed herein do not necessarily state or reflect those of the United States Government or any agency thereof. 


\section{DISCLAIMER}

Portions of this document may be illegible in electronic image products. Images are produced from the best available original document. 


\begin{tabular}{|c|c|}
\hline $\begin{array}{l}\text { REPORT DOCUMENTATION } 2 \text { MGONT NO. } \\
\text { PAGE }\end{array}$ & 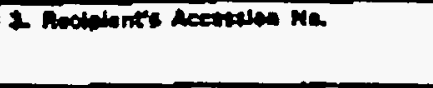 \\
\hline \multirow{2}{*}{$\begin{array}{l}\text { 4. Th and Gabtul } \\
\text { ENHANCBD BOTLIXG EBAT IBANSFER } \\
\text { IN BORIZONTAT IUBE BUNDTES }\end{array}$} & December 1992 \\
\hline & 6 \\
\hline 7. Authorts R.R. Trewin, K.K. Jengen, and A.Z. Bergles & 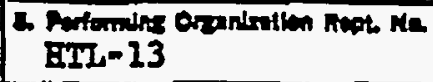 \\
\hline \multirow{2}{*}{ 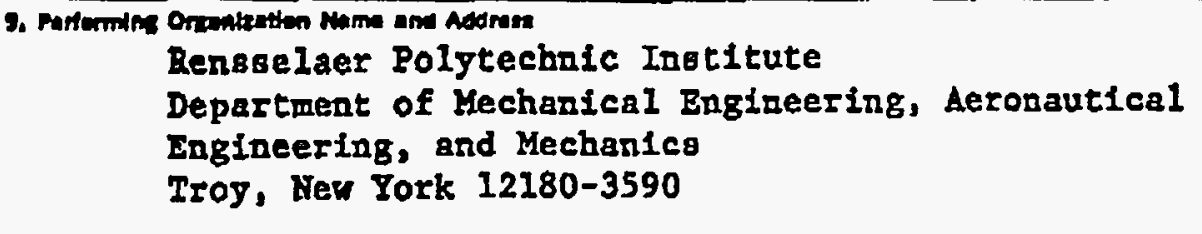 } & 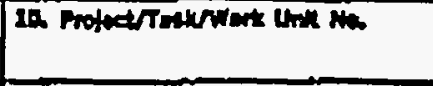 \\
\hline & 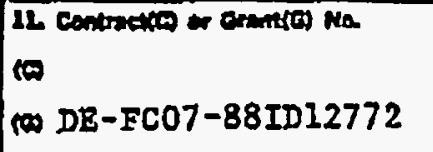 \\
\hline \multirow{2}{*}{ 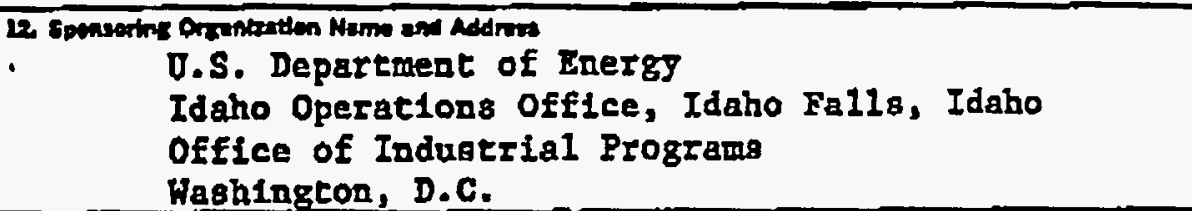 } & $\begin{array}{l}\text { 12. Trwe of Rement \& Parind Commed } \\
\text { Topical }\end{array}$ \\
\hline & 24 \\
\hline
\end{tabular}

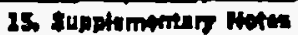

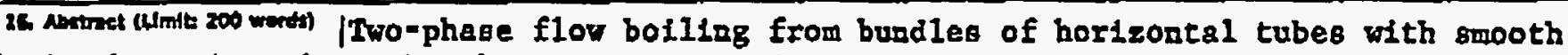
and enhanced surfaces has been inveotigated. Bxperiments were conducted in pure refrigerant R-113, pure R-11, and mixtures of R-11 and R-113 of approximstely 25, 50 , and $75 \%$ of R-113 by mass. Tests were conducted in two staggered tube bundles conslating of fifteen rows and five columg latd out in equilateral triangular arrays with pitch-to-dlameter ratios of 1.17 and 1.5. The enhanced surfaces tested included a knurled surface (Wolverlae's Tuxbo-B) and a porous surface (Linde's Blgh Flux). Pool bolling tests were conducted for each surface so that reference values of the heat transfer coefflcient could be obtained.

Boiling heat transfer experiments in the tube bundles were conducted at pressures of 2 and 6 bar, heat flux values from 5 to $80 \mathrm{kw} / \mathrm{m}^{2} \mathrm{~g}$, and qualities from 07 to $80 \%$. Values of the heat transfer coefficients for the eahanced aurfaces were olgaficantly larger than for the smooth tubes and were comparable to the values obtained in pool bo1ling. It was found that the performance of the enhanced tubes could be predicted uging the pool boiling resulte. The degradation in the smooth tube heat transfer coefficlents obtained in fluld mixtures was found to depend on the difference between the molar. concentration in the liquid and vapor.

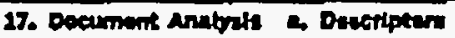

hest exchangers

enhancement

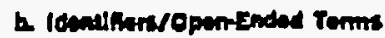

she11-and-tube beat exchangers

enhanced tuber

power and process industrles.

a. cosati maklonus

2l. Arallawlity Baremen:

Available from OSTI, P.0. Box 62

Oak Ridge, TK 37830 or NTIS 5285

Port Royal Road, SpringEield, $\nabla A 22161$

\begin{tabular}{|c|c|c|}
\hline & 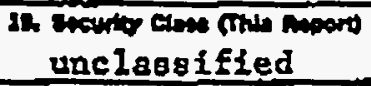 & $\begin{array}{l}\text { in. Ma of Pasas } \\
17+292 \\
\end{array}$ \\
\hline 22161 & 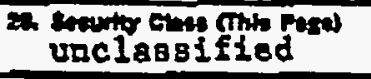 & E. Price \\
\hline
\end{tabular}




\section{ACKNOWLEDGEMENTS}

We wish to thank Dr. Euan F. C. Somerscales, Dr. Richard T. Lahey, Jr. and Dr. Deborah A. Kaminski for their time and effort spent during this project.

Funding for this project was provided by the Department of Energy, Dr. M.S. Sohal, under DE-FC07-88ID12772. Supplemental support was provided by the Clark and Crossan Endowed Chair. The tubing and Turbo-B surfaces were provided by P. Thors of Wolverine Tube, and E. G. Ragi of U.O.P. Engineered Products supplied the High Flux surfaces. The support of these funds and materials is appreciated. 


\section{CONTENTS}

ABSTRACT $\ldots \ldots \ldots \ldots \ldots \ldots \ldots \ldots \ldots \ldots \ldots \ldots \ldots \ldots \ldots \ldots$ iii

ACKNOWLEDGEMENTS. . . . . . . . . . . . . . iv

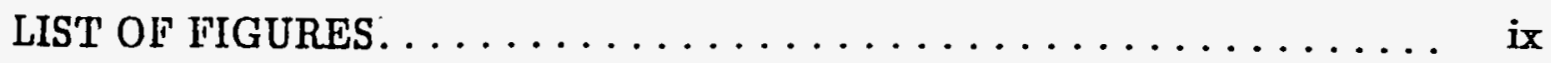

NOMENCLATURE. .................. xiv

CHAPTER 1 INTRODUCTION AND HISTORICAL REVIEW....... 1

Background. . . . . . . . . . . .

Boiling on Single, Smooth, Horizontal Cylinders . . . . . . . 6

Pool Boiling from Cylinders with Enhanced Surfaces......... 8

Shellside Boiling on Smooth Horizontal Tube Bundles . . . . . . 8

Nucleate pool boiling and single-phase convection ........ 12

Nucleate pool boiling and thin film vaporization ........ 13

Nucleate pool boiling, single-phase convection and thin film vaporization ................. 14

Shellside Boiling on Horizontal Tube Bundles with Enhanced Surfaces . . . . . . . . . . . . . . . . 15

Boiling on Horizontal Tubes in Fluid Mixtures . . . . . . . . 16

Shellside Boiling on Tube Bundles in Fluid Mixtures. . . . . . 17

Conclusions. . . . . . . . . . . . . . . . 18

Scope of Investigation $\ldots \ldots \ldots \ldots \ldots \ldots \ldots \ldots \ldots \ldots \ldots \ldots$

CHAPTER 2 POOL BOILING APPARATUS AND DATA

ACQUISITION/REDUCTION . . . . . . . . . . 23

Experimental Apparatus and Instrumentation $\ldots \ldots \ldots \ldots \ldots \ldots$

Operating Procedure and Data Reduction $\ldots \ldots \ldots \ldots \ldots \ldots \ldots, 30$ 
CHAPTER 3 EXPERIMENTAL RESULTS AND DISCUSSION OF

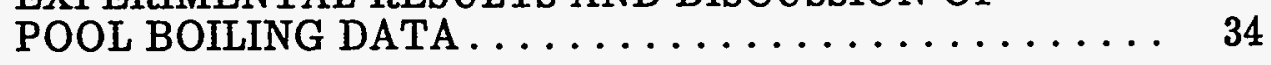

Pure $\mathrm{R}-113$ Results $\ldots \ldots \ldots \ldots \ldots \ldots \ldots \ldots \ldots \ldots \ldots \ldots$

Pure R-11 Results . . . . . . . . . . . . . . . 47

Binary Mixture Results $\ldots \ldots \ldots \ldots \ldots \ldots \ldots \ldots \ldots \ldots \ldots$

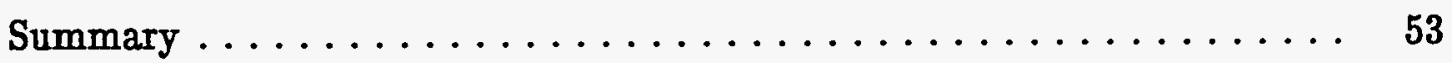

CHAPTER 4 EXPERIMENTAL TUBE BUNDLE APPARATUS AND EXPERIMENTAL PROCEDURE . . . . . . . . . 57

Description on the Refrigerant Flow Loop . . . . . . . . . . 61

Detailed Description of the Test Chamber .............. 65

Experimental Procedure.................... 74

Data Reduction. ....................... 82

CHAPTER 5 SHELLSIDE BOILING EXPERIMENTAL RESULTS

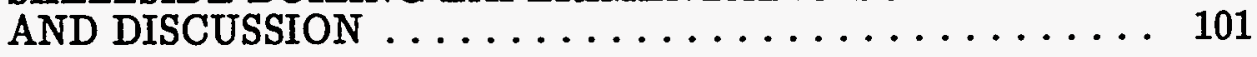

Single-Phase Data and Results . . . . . . . . . . . . . 101

Boiling Heat Transfer Results in Pure Refrigerants . . . . . . . . . 106

Smooth tube results in pure $\mathrm{R}-113 \ldots \ldots \ldots \ldots \ldots \ldots \ldots$

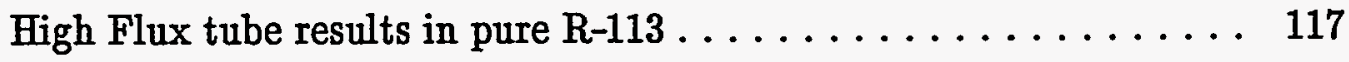

Turbo-B results in pure $\mathrm{R}-113 \ldots \ldots \ldots \ldots \ldots \ldots \ldots \ldots \ldots$

Results obtained in pure $\mathrm{R}-11 \ldots \ldots \ldots \ldots \ldots \ldots \ldots$

Boiling Heat Transfer Results in Refrigerant Mixtures. . . . . . . . 142

Results from the $75 \%$ R-11/25\% R-113 Mixture . . . . . . . 142

Results from the $50 \%$ R-11/50\% R-113 Mixture . . . . . . . 147

Results from the $25 \%$ R-11/75\% R-113 Mixture . . . . . . . . 149

Comparison of results. ................... 155 


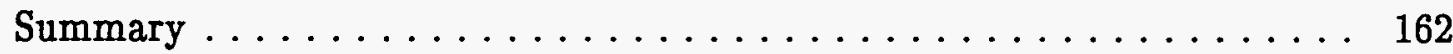

CHAPTER 6 CONCLUSIONS AND RECOMMENDATIONS . . . . . . 166

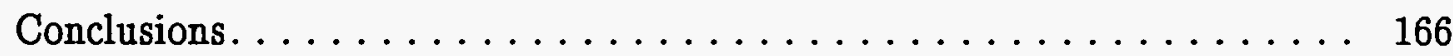

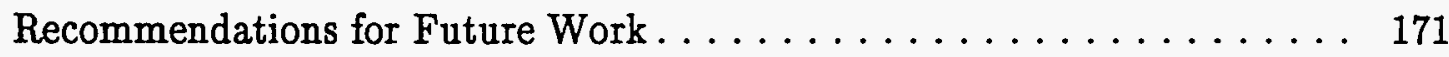

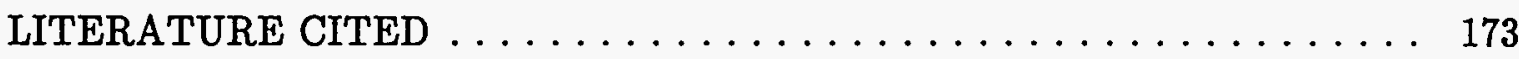

APPENDIX A TABULATION OF EXPERIMENTAL DATA . . . . . 180

Nomenclature . . . . . . . . . . . . . . . . . . . 180

Pool Boiling Data . . . . . . . . . . . . . . . . . 182

Pure $\mathrm{R}-113$ data $\ldots \ldots \ldots \ldots \ldots \ldots \ldots \ldots \ldots \ldots \ldots \ldots \ldots \ldots$

Pure $\mathrm{R}-11$ data $\ldots \ldots \ldots \ldots \ldots \ldots \ldots \ldots \ldots \ldots \ldots \ldots$

Data from the $75 \%$ R-11/25\% R-113 Mixture . . . . . . . . . 190

Data from the $50 \%$ R-11/50\% R-113 Mixture . . . . . . . . . 193

Data from the $25 \%$ R-11/75\% R-113 Mixture . . . . . . . . . 196

Bundle Boiling Data . . . . . . . . . . . . . . . . . . 199

Smooth tube data in R-113 for bundle with $\mathrm{p} / \mathrm{d}=1.17 \ldots \ldots \ldots 199$

Smooth tube data in $\mathrm{R}-113$ for bundle with $\mathrm{p} / \mathrm{d}=1.50 \ldots \ldots \ldots 207$

Turbo-B data in $\mathrm{R}-113$ for bundle with $\mathrm{p} / \mathrm{d}=1.50 \ldots \ldots \ldots \ldots 215$

High Flux data in R-113 for bundle with $\mathrm{p} / \mathrm{d}=1.17 \ldots \ldots \ldots .222$

Data obtained in Pure $\mathrm{R}-11 \ldots \ldots \ldots \ldots \ldots \ldots \ldots$

Data from the $25 \%$ R-11/75\% R-113 Mixture . . . . . . . . . 242

Data from the $50 \%$ R-11/50\% R-113 Mixture . . . . . . . . . 249

Data from the $25 \%$ R-11/75\% R-113 Mixture . . . . . . . . . 255

Single-phase data. . . . . . . . . . . . . . . . 261 


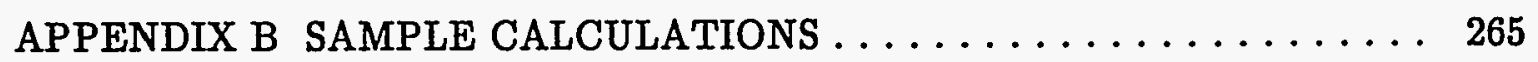

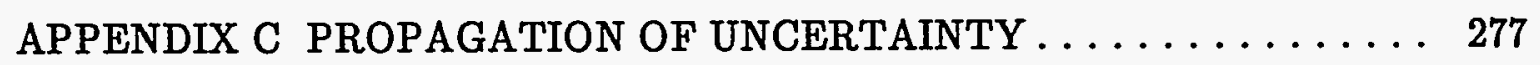

APPENDIX D SATURATION TEMPERATURE DETERMINATION. . . . 287 


\section{LIST OF FIGURES}

Figure 1.1. Schematics of (a) kettle and (b) full bundle

reboilers. ..................... 5

Figure 1.2. Schematic of enhanced surfaces (Bergles 1988). $\ldots \ldots \ldots \ldots 9$

Figure 1.3. Pool boiling performance for smooth and enhanced tubes

(Yilmaz et al. 1980). . . . . . . . . . . . . . . . . 10

Figure 1.4. Boiling curve hysteresis for High Flux tubes

(Bergles and Chyu 1982).

Figure 2.1. Pool boiling experimental apparatus

(Jung and Bergles 1989). . . . . . . . . . . . . . 25

Figure 2.2. Test section schematic for the High Flux tubes. . . . . . . 26

Figure 2.3. Test section schematic for the smooth and Turbo-B tubes

in pool boiling (Jung and Bergles 1989). . . . . . . . . 28

Figure 3.1. Boiling curves for tubes with smooth, Turbo-B, and

High Flux surfaces at $P=103 \mathrm{kPa} . \ldots \ldots \ldots \ldots \ldots \ldots \ldots$

Figure 3.2. Critical heat flux data for the smooth tube in pool

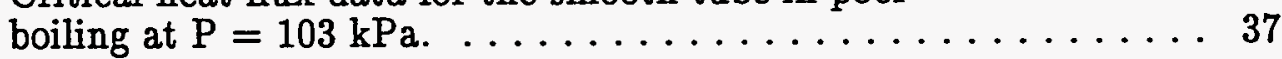

Figure 3.3. Comparison of High Flux and smooth tube pool data

obtained in $\mathrm{R}-113$ at $\mathrm{P}=103 \mathrm{kPa}$ with results from

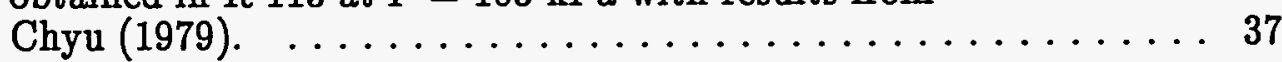

Figure 3.4. Comparison of Turbo-B tube pool boiling data with

results from Webb and Pais (1991). ............ 40

Figure 3.5. Axial cross section fo the Turbo-B tube

(enlarged 9x). . ..................... 41

Figure 3.6. Cross section of the High Flux surface enlarged 100x

(Gottzmann 1973).

Figure 3.7. Comparison of very open and very closed porosity

Turbo-B tube pool boiling data in $\mathrm{R}-113$ at $\mathrm{P}=103 \mathrm{kPa}$. . . . 44

Figure 3.8. Pool boiling correlations for smooth, Turbo-B, and

High Flux tubes at $\mathrm{P}=103 \mathrm{kPa}$. 
Figure 3.9 Saturated pool boiling curve for the smooth tube in

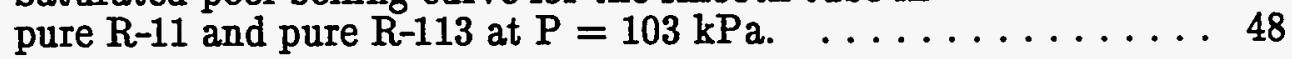

Figure 3.10 Saturated pool boiling curve for the Turbo-B tube in pure $\mathrm{R}-11$ and pure $\mathrm{R}-113$ at $\mathrm{P}=103 \mathrm{kPa}$. ......... 50

Figure 3.11 Saturated pool boiling curve for the High Flux tube in pure $\mathrm{R}-11$ and pure $\mathrm{R}-113$ at $\mathrm{P}=103 \mathrm{kPa} . \ldots \ldots \ldots \ldots . \ldots \ldots$

Figure 3.12 Saturated pool boiling curve for the smooth tube in mixtures of $\mathrm{R}-11$ and $\mathrm{R}-113$ at $\mathrm{P}=103 \mathrm{kPa}$. . . . . . 52

Figure 3.13 Saturated pool boiling curve for the Turbo-B tube in mixtures of $\mathrm{R}-11$ and $\mathrm{R}-113$ at $\mathrm{P}=103 \mathrm{kPa} . \ldots \ldots \ldots \ldots . \ldots 54$

Figure 3.14 Boiling performance of the smooth and enhanced in mixtures of $\mathrm{R}-11$ and $\mathrm{R}-113$ at $\mathrm{P}=103 \mathrm{kPa}$. ........ 55

Figure 4.1 Streamlines in a tube bundle (Cornwell et al. 1980) and area simulated by experimental apparatus. 59

Figure 4.2 Lines of constant heat transfer coefficients $\left(\mathrm{kW} / \mathrm{m}^{2} \mathrm{~K}\right)$ at a heat flux of $20 \mathrm{~kW} / \mathrm{m}^{2}$ (Cornwell et al. 1980). ....... 60

Figure 4.3 Schematic of the refrigerant flow loop. $\ldots \ldots \ldots \ldots \ldots \ldots$

Figure 4.4 Schematic of the test chamber shell. $\ldots \ldots \ldots \ldots \ldots 6$

Figure 4.5 Cross section of the test chamber. . . . . . . . . 67

Figure 4.6 Schematic of the test chamber mounting plate. $\ldots \ldots \ldots \ldots 69$

Figure 4.7 Electric power connections and instrumentation for

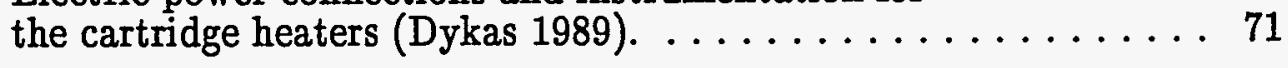

Figure 4.8 Electrical snubber circuits for the heated tubes in the sidewalls. . . . . . . . . . . . . . 73

Figure 4.9 Schematic of the flow loop venting apparatus. $\ldots \ldots \ldots \ldots 75$

Figure 4.10 Schematic of the flow loop pressurizer. $\ldots \ldots \ldots \ldots \ldots \ldots$

Figure 4.11 Specific gravity for R-11/R-113 mixtures at $20^{\circ} \mathrm{C}$ and $101 \mathrm{kPa} . \ldots \ldots \ldots \ldots \ldots \ldots \ldots \ldots \ldots \ldots \ldots$ 
Figure 4.12 Phase diagram for mixtures of $\mathrm{R}-11$ and $\mathrm{R}-113 . \ldots \ldots \ldots 2$

Figure 5.1 Single-phase heat transfer coefficients in the tube bundle. . . . . . . . . . . . . . . . . . 102

Figure 5.2 Bundle-average non-dimensional single-phase heat transfer data. . . . . . . . . . . . . . . . . . . . 104

Figure 5.3 Single-phase pressure drops across the tube bundle. $\ldots \ldots \ldots 105$

Figure 5.4 Effect of heat flux and tube row/quality on the smooth tube heat transfer coefficient. . . . . . . . . . . . . 108

Figure 5.5 Effect of mass flux and pressure on the smooth tube heat transfer coefficient. . . . . . . . . . . . . . . . . 109

Figure 5.6 Non-dimensional heat transfer coefficients as a function of quality and density ratio (Kandlikar 1990).

Figure 5.7 Nucleate boiling on the bottom of smooth tubes in a bundle.

Figure 5.8 Effect of pitch-to-diameter ratio on the smooth tube heat

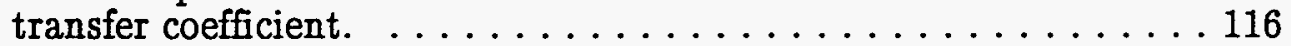

Figure 5.9 Effect of the heat flux and tube row/quality in the High Flux tube heat transfer coefficient. ............. 118

Figure 5.10 Onset of nucleate boiling for a High Flux tube bundle at $\mathrm{P}=200 \mathrm{kPa}$ and $\mathrm{G}=150 \mathrm{~kg} / \mathrm{m}^{2} \mathrm{~s}$.

Figure 5.11 Onset of nucleate boiling for a smooth tube bundle at $\mathrm{P}=200 \mathrm{kPa}$ and $\mathrm{G}=150 \mathrm{~kg} / \mathrm{m}^{2} \mathrm{~s}$.

Figure 5.12 Boiling curves for single tubes in pool boiling and for tube bundles.

Figure 5.13 Effect of mass flux on the High Flux heat transfer

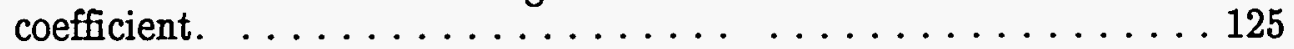

Figure 5.14 Effect of heat flux and pressure on the High Flux

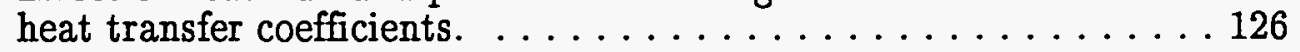

Figure 5.15 Effect of heat flux and tube row/quality on the Turbo-B heat transfer coefficient. 
Figure 5.16 Effect of mass flux on the Turbo-B heat transfer coefficient. ........................ 136

Figure 5.17 Effect of pressure on the Turbo-B heat transfer coefficient. $\ldots \ldots 137$

Figure 5.18 Heat transfer coefficients for all three surfaces in pure R-11.

Figure 5.19 Effect of heat flux on the heat transfer coefficients for all three surfaces in a mixture of $75.8 \% \mathrm{R}-11$ and $\mathrm{G}=49 \mathrm{~kg} / \mathrm{m}^{2} \mathrm{~s}$.

Figure 5.20 Effect of heat flux on the heat transfer coefficients for all three surfaces in a mixture of $75.8 \% \mathrm{R}-11$ and $\mathrm{G}=224 \mathrm{~kg} / \mathrm{m}^{2} \mathrm{~s}$.

Figure 5.21 Effect of heat flux on the heat transfer coefficients for all three surfaces in a mixture of $46.5 \% \mathrm{R}-11$ and $\mathrm{G}=46 \mathrm{~kg} / \mathrm{m}^{2} \mathrm{~s}$.

Figure 5.22 Effect of heat flux on the heat transfer coefficients for all three surfaces in a mixture of $23.8 \% \mathrm{R}-11$ and $\mathrm{P}=200 \mathrm{kPa}$.

Figure 5.23 Effect of heat flux on the heat transfer coefficients for all three surfaces in a mixture of $23.1 \% \mathrm{R}-11$ and $\mathrm{P}=600 \mathrm{kPa}$.

Figure 5.24 Effect of mixture concentration and pressure on the heat transfer coefficients for $\mathrm{q}^{\prime \prime}=60 \mathrm{~kW} / \mathrm{m}^{2}$.

Figure 5.25 Effect of mixture concentration and heat flux on the heat transfer coefficients.

Figure 5.26 Trends in heat transfer coefficients and the difference between the liquid and vapor mixture concentrations (Stephan 1982).

Figure 5.27 A comparison between (a) the difference between the liquid and vapor concentrations of R-11 and (b) experimental trends in heat transfer coefficients at $\mathrm{q}^{\prime \prime}=60 \mathrm{~kW} / \mathrm{m}^{2}$ and $\mathrm{P}=200 \mathrm{kPa}$.

Figure 5.28 Comparison of experimental values for smooth tube heat transfer coefficients and predicted values using a Stephan-Körner type correlation. 


\section{Page}

Figure D.1 Experimental apparatus for measuring the boiling point . . . . 288

Figure D.2 Bath temperature is increased to about $5^{\circ} \mathrm{C}$ above the minimal boiling point of the fluid. . . . . . . . . . . 290

Figure D.3 Bath temperature is lowered to about $2^{\circ} \mathrm{C}$ below liquid temperature during degassing. . . . . . . . . . . . . . 291

Figure D.4 Experimental values for saturation temperature

of liquid and vapor $R-113 . \ldots \ldots \ldots \ldots \ldots \ldots \ldots 292$ 


\section{NOMENCLATURE}

$A_{\mathrm{s}} \quad$ heat transfer surface area of single tube, $\mathrm{m}^{2}$

$A_{\text {min }} \quad$ minimum cross-sectional flow area, $\mathrm{m}^{2}$

$A_{\mathrm{t}} \quad$ total surface area of heated tubes, $\mathrm{m}^{2}$

$c_{\mathrm{p}} \quad$ specific heat at constant pressure, $\mathrm{J} / \mathrm{Kg} \cdot \mathrm{K}$

$D_{0} \quad$ tube outside diameter, $\mathrm{m}$

$F \quad$ maximum number of independent, intensive variables required to specify

the thermodynamic state, equation (4.17)

g gravitational constant, $9.81 \mathrm{~m} / \mathrm{s}^{2}$

G $\quad$ mass flux, $\mathrm{kg} / \mathrm{m}^{2} \cdot \mathrm{s}$

$h$ heat transfer coefficient, $\mathrm{W} / \mathrm{m}^{2} \cdot \mathrm{K}$

$h_{\mathrm{n}} \quad$ local heat transfer coefficient at row $\mathrm{n}, \mathrm{W} / \mathrm{m}^{2} \cdot \mathrm{K}$

$\bar{h}$ bundle averaged heat transfer coefficient, equation $(4.30), \mathrm{W} / \mathrm{m}^{2} \cdot \mathrm{K}$

$i \quad$ enthalpy, $\mathrm{J} / \mathrm{kg}$

I electrical current, A

$k \quad$ fluid thermal conductivity, $\mathrm{W} / \mathrm{m} \cdot \mathrm{K}$

$L \quad$ tube length, $\mathrm{m}$

$m \quad$ number of species in mixture, equation (4.17)

$\dot{m}$ mass flow rate, $\mathrm{kg} / \mathrm{s}$

$n \quad$ tube row number

$\mathrm{Nu} \quad$ Nusselt number based on tube inside diameter, $h d / k$

$p \quad$ tube pitch, $\mathrm{m}$

$P \quad$ pressure, $\mathrm{kPa}$

Pr Prandtl number, $\mu c_{\mathrm{p}} / k$ 


\begin{tabular}{|c|c|}
\hline$q^{\prime \prime}$ & heat flux for an individual tube, $\mathrm{W} / \mathrm{m}^{2}$ \\
\hline$q_{n}^{\prime \prime}$ & heat flux for an individual tube at row $\mathrm{n}, \mathrm{W} / \mathrm{m}^{2}$ \\
\hline$Q_{1-\mathrm{n}}$ & total heat transfer rate from tube $\mathrm{s}$ in rows 1 through $\mathrm{n}, \mathrm{W}$ \\
\hline$Q_{\text {tot }}$ & total heat transfer rate, $\mathrm{W}$ \\
\hline$r$ & radial coordinate, $\mathrm{m}$ \\
\hline$R_{\mathrm{tc}}$ & radial distance from tube axis to thermocouple location, $m$ \\
\hline $\operatorname{Re}$ & Reynolds number based on minimum flow area, $\dot{m} D_{0} / A_{\min } \mu$ \\
\hline$T_{\mathrm{fv}}$ & temperature at flashing valves, ${ }^{\circ} \mathrm{C}$ or $\mathrm{K}$ \\
\hline$T_{1}$ & local liquid temperature, equation ( 3.20$)$ \\
\hline$T_{\text {sat }}$ & saturation or bubble point temperature, $\mathrm{K}$ \\
\hline$T_{\mathrm{tc}}$ & local temperature at thermocouple, ${ }^{\circ} \mathrm{C}$ or $\mathrm{K}$ \\
\hline$T_{\mathrm{w}}$ & local tube surface temperature, ${ }^{\circ} \mathrm{C}$ or $\mathrm{K}$ \\
\hline$T_{\mathrm{w}, \text { ave }}$ & tube average wall temperature, ${ }^{\circ} \mathrm{C}$ or $\mathrm{K}$ \\
\hline$\Delta T_{\text {sat }}$ & $\begin{array}{l}\text { arithmetic-mean difference between tube wall and saturated fluid } \\
\text { temperature, } \mathrm{K}\end{array}$ \\
\hline$V$ & electrical voltage, $\mathrm{V}$ \\
\hline$\dot{V}$ & volume flow rate, $\mathrm{m}^{3} / \mathrm{s}$ \\
\hline$x$ & thermodynamic quality \\
\hline$x_{n}$ & thermodynamic quality at tube row $n$ \\
\hline$y_{\mathrm{i}}^{\prime}$ & mass fraction in the liquid phase of component $\mathrm{i}, \mathrm{kg} / \mathrm{kg}$ \\
\hline$y_{\mathrm{i}}^{\prime \prime}$ & mass fraction in the vapor phase of component $\mathrm{i}, \mathrm{kg} / \mathrm{kg}$ \\
\hline$y_{\mathrm{b}, \mathrm{i}}^{\prime}$ & overall mass fraction of component $\mathrm{i}$ in the fluid, $\mathrm{kg} / \mathrm{kg}$ \\
\hline$\tilde{y}_{i}^{\prime}$ & mole fraction in the liquid phase of component $\mathrm{i}, \mathrm{kmol} / \mathrm{kmol}$ \\
\hline$\tilde{y}_{i}^{\prime \prime}$ & mole fraction in the vapor phase of component $\mathrm{i}, \mathrm{kmol} / \mathrm{kmol}$ \\
\hline$\tilde{y}_{\mathrm{b}, \mathrm{i}}^{\mathrm{i}}$ & overall mole fraction of component $\mathrm{i}$ in the fluid, $\mathrm{kmol} / \mathrm{kmol}$ \\
\hline
\end{tabular}


Greek Symbols

$\begin{array}{ll}\alpha & \text { thermal diffusivity, } k / \rho c_{\mathrm{p}}, \mathrm{m}^{2} / \mathrm{s} \\ \Delta & \text { difference } \\ \mu & \text { viscosity } \\ \nu & \text { viscosity } \\ \rho & \text { density, } \mathrm{kg} / \mathrm{m}^{3} \\ \sigma & \text { surface tension, } \\ \Sigma & \text { summation } \\ \varphi & \text { number of phases }\end{array}$

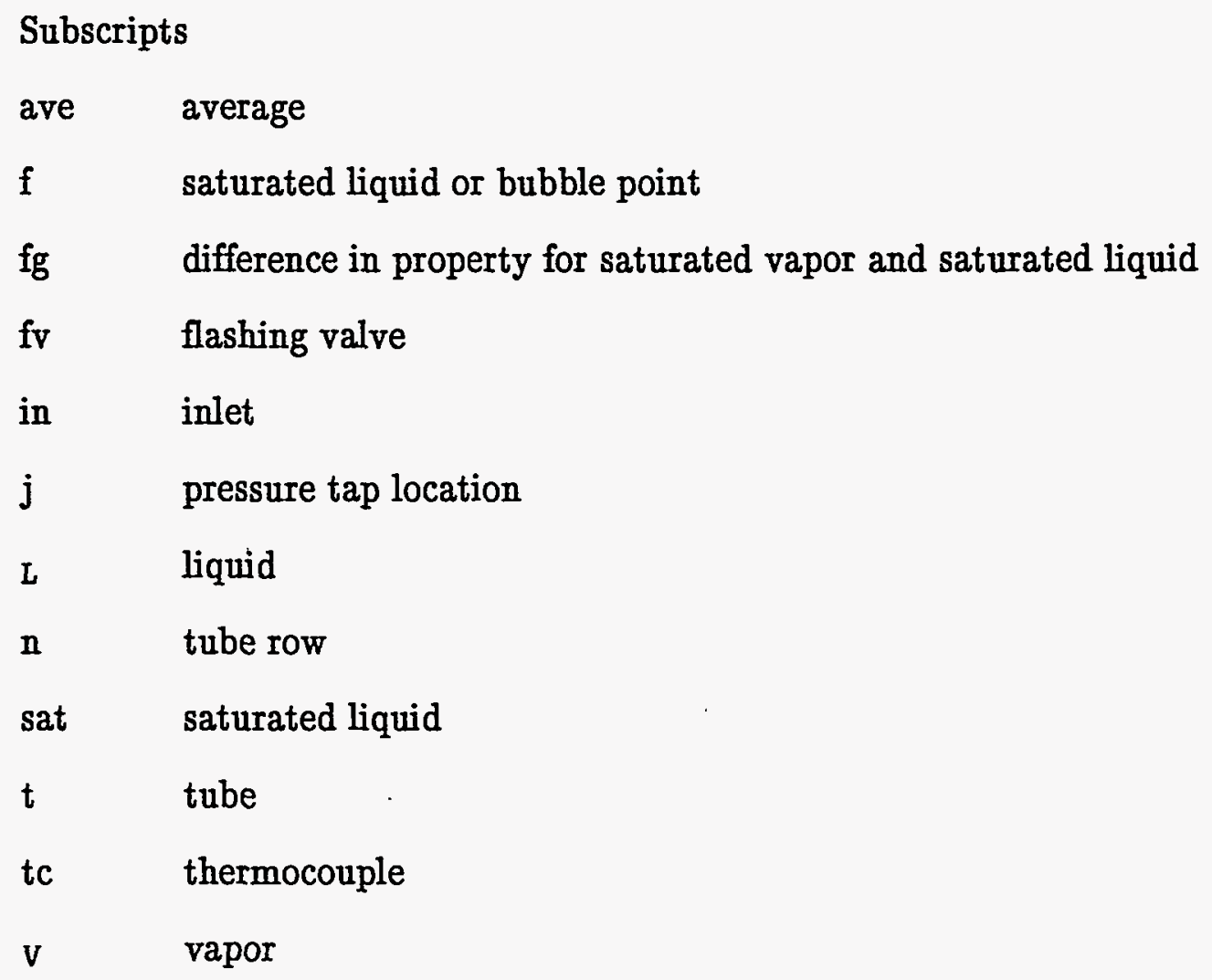




\section{Superscripts}

1 liquid phase

" vapor phase

$\sim \quad$ molar property

xvii 


\section{CHAPTER 1}

\section{INTRODUCTION AND HISTORICAL REVIEW}

In the United States the production of new heat exchangers is a $\$ 1.7$ billion industry (Frost and Sullivan 1992) and is a $\$ 2.9$ bilion industry in Western Europe. The type of heat exchangers include shell-and-tube, coils, and plate and frame configurations, among others, with roughly half of the new heat exchangers being produced of the shell-and-tube configuration. Indeed, shell-and-tube heat exchangers represent the most widespread and commonly used heat exchanger configuration in the process industries (Bell 1986) and can be found in the chemical, petroleum, power, and air conditioning/refrigeration industries. These shell-and-tube heat exchangers commonly employ two-phase heat transfer and Hewitt (1981) estimates that at least $60 \%$ of all process industry heat exchanger equipment involves two-phase flow. It is not surprising, then, that shell-and-tube heat exchangers with shellside boiling are used extensively in a variety of applications. For example, a recent review of shellside boiling with crossflow in horizontal multitube bundles (Jensen 1989) lists, among the many applications, kettle and thermosyphon reboilers, submerged evaporators, waste heat boilers, and steam generators. In particular, horizontal shellside thermosyphon reboilers and kettle reboilers are commonly used in petroleum and chemical processing plant to vaporize process fluid mixtures and in the production of cryogenic fluids and have substantial advantages over vertical tube units (Yilmaz 1987). Additionally, the horizontal configuration is also used in waste heat boilers and in direct expansion chillers in large refrigeration systems. 
Frost and Sullivan (1992) report that the heat exchanger industry is "mature, cyclic and fragmented" and that product differentiation is practically nonexistent. This is due, at least in part, to inadequately developed design techniques which, according to Palen (1983), are due to a lack of data in the open literature on multitube bundles. The present design of these heat exchangers is conservative because the boiling heat transfer and two-phase pressure drop behavior of multitube bundles is not well known when the flow is perpendicular to the tubes (Jensen 1988). Design techniques have been established which conservatively predict the average or overall performance of the tube bundle, but knowledge of what is occurring at individual tubes is ignored. Niels (1979) found that large design improvements are possible and that some design procedures result in an overdesign of kettle evaporators by $300 \%$.

Because shellside boiling from horizontal tube bundles is commonly used, even modest improvements in the design of shell-and-tube heat exchangers with shellside boiling could result in large savings. One improvement would be to use enhanced tubes in the bundle rather than smooth tubes. There are several ways to obtain energy savings from an enhanced tube heat exchanger. Enhanced heat exchangers can make use of smaller temperature driving potentials between the heat source and the working fluid, thus lowering the operating costs. When a given temperature difference is available, the savings can result from an increase in the heat flux at the heated surface; the savings can be realized through the use of smaller heat exchangers which use less material and require less fabrication effort and which reduce shipping, installation, and maintenance costs. In addition, smaller heat exchangers can be designed so that the pumping power can be reduced resulting in a direct energy savings. 
For shell-and-tube heat exchangers, enhanced boiling heat transfer surfaces present the possibility of especially large savings. The possibility exists of saving over $\$ 300$ million annually by using enhancement techniques (Robello 1986). Ragi and O'Neill (1980) report several examples of very substantial savings. Reboilers were retrofitted with tubes having sintered surfaces and the payback periods were one or two months. Arai et al. (1977) also report substantial savings when using enhanced surfaces in refrigeration applications.

In addition to financial savings, more efficient heat exchangers can help address issues concerning the environment. As demands on the world's energy resources increase and the negative impact of our present methods of energy usage on the environment becomes more and more critical, the need for methods of reducing our energy usage becomes more urgent. Strategies for reducing energy consumption that could be implemented relatively quickly include the increased usage of enhanced surfaces in shell-and-tube heat exchangers. The use of enhanced surfaces also could result in decreasing the size of heat exchangers that contain potentially damaging fluids, thus reducing the risk to the environment in the case of leaks.

The elimination of CFC's in refrigerating/air-conditioning equipment will probably result in the increased use of refrigerant mixtures as replacements. Therefore, the performance of tubes with enhanced surfaces in fluid mixtures will need to be determined in order for the cost savings mentioned above to be extended to new, environmentally benign refrigeration and air-conditioning equipment.

Before the large savings mentioned above can be widely realized, the overall performance of heat exchangers with enhanced horizontal tube bundles needs to be investigated further. Information about the flow behavior, heat transfer 
characteristics, and pressure gradients at particular locations within a tube bundle is needed in order to develop better designs and more efficient heat exchangers. Additional information on the heat transfer performance of smooth and enhanced tubes in mixtures of miscible, volatile fluids is required in order to better design the heat exchangers common in the chemical, process, and air-conditioning industries. Therefore, this study will investigate the local heat transfer performance of individual tubes in a horizontal tube bundle in order to better understand the mechanisms involved in boiling heat transfer from horizontal tube bundles with enhanced surfaces.

\section{Background}

The information required to achieve the improved designs mentioned above can be determine once the extent of the present knowledge has been ascertained. The current knowledge regarding the parametric trends for heat transfer coefficients in tube bundles is discussed along with the information available in the open literature concerning the governing mechanisms. The available mechanistic models will be discussed. Nucleate pool boiling from single tubes is often the reference data to which the data obtained in tube bundles are compared and, therefore, will also be presented.

Kettle and full bundle reboilers (Fig. 1.1) are common types of shell-and-tube heat exchangers which incorporate shellside boiling with crossflow in horizontal multitube bundles. The full bundle reboiler is a one-pass heat exchanger where the pressure drop is imposed across the tube bundle and the flow is

predominantly in one direction. In the kettle reboiler, the tube bundle occupies only 


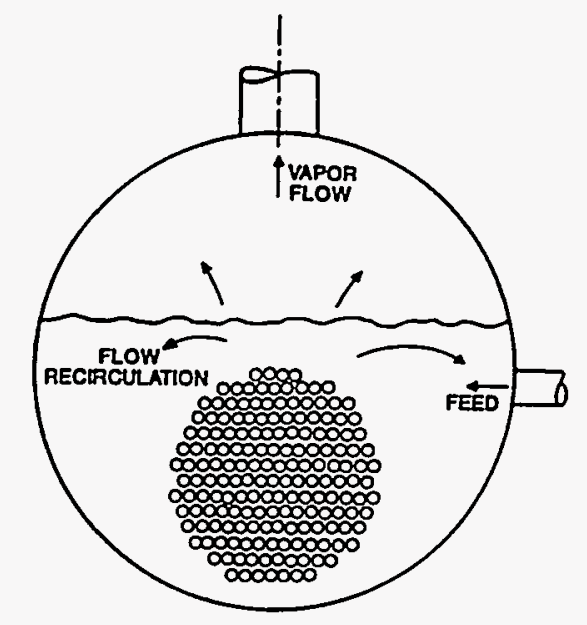

Process Reboiler

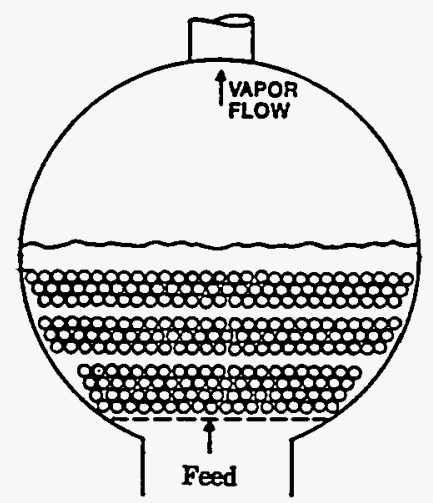

Refrigerant Evaporator

(b)

Figure 1.1. Schematics of (a) kettle and (b) full bundle reboilers. 
a portion of the total cross section of the shell. The vapor and liquid mixture in the interior of the bundle flows upward but the liquid at the sides of the shell flows downwards due to the hydrostatic driving head. Therefore, a recirculating flow is established in a kettle reboiler.

Early designers of kettle reboilers based their thermal design on single-tube pool boiling correlations with correction factors to account for the influence of tube bundle dimensions and geometry (Niels 1979). However, initial investigations into heat transfer coefficients for horizontal tube bundles (Palen and Taborek 1962) showed that the heat transfer coefficient, based on inexact plant data, was smaller than that for a single tube in pool boiling. Using more accurate data, it was later found that the average heat transfer coefficient, given as a function of the heat duty and overall driving temperature difference, for a bundle of plain tubes was larger than for a single plain tube (Palen et al. 1972). Unfortunately, this overall approach to the evaluation of shellside boiling did not provide enough information to shed any light on what was actually occurring at different locations in the bundle. This lack of quantitative information prompted research into the local values for heat transfer coefficients within the tube bundle.

\section{Boiling on Single, Smooth, Horizontal Cylinders}

In order to determine the effects on a tube in a bundle due to the presence of surrounding tubes, Hwang and Yao (1984) and Wege and Jensen (1984) proposed studying a single tube in pool and forced convection boiling. In this way, different parameters could be accurately known and the effects could be separated. These separate effects could then be combined into a general design technique. In addition, nucleate pool boiling from a single, horizontal tube is frequently used as a reference 
point from which to evaluate the effect of the tube bundle on the local heat transfer enhancement or as an input parameter for correlating the heat transfer coefficients of horizontal cylinders in tube bundles with crossflow. Although single tubes with enhanced boiling surfaces have been researched extensively (Bergles 1978, Webb 1981), more information is needed on the use of these tubes in bundles.

Yilmaz and Westwater (1980) investigated pool and forced convective boiling from single horizontal cylinders and found that the forced convective heat transfer coefficient increased with liquid velocity. The total forced convective heat flux could be estimated by simply adding the nucleate pool boiling heat flux and the single-phase, forced convective heat flux. Fand et al. (1976) also found an increase in the forced convective heat transfer coefficient with increasing liquid velocity.

Bitter (1972) conducted experiments in $\mathrm{R}-11$ with heat flux values less than $30 \mathrm{~kW} / \mathrm{m}^{2}$ and found an increase in the forced convective heat transfer coefficient with increasing liquid velocity and with the addition of vapor in the upstream liquid flow. This is consistent with the results of McKee and Bell (1969) who found that the forced convective heat transfer coefficients were not significantly different from the pool boiling values except at heat fluxes lower than $30 \mathrm{~kW} / \mathrm{m}^{2}$ and at velocities greater than $1.64 \mathrm{~m} / \mathrm{s}(5.4 \mathrm{ft} / \mathrm{sec})$. Hwang and Yao (1984), who performed experiments in $\mathrm{R}-113$, found similar results in that the forced convective heat transfer coefficients were not significantly different from the pool boiling values when the boiling became fully developed (at heat fluxes lower than $20 \mathrm{~kW} / \mathrm{m}^{2}$ for velocities less than $0.235 \mathrm{~m} / \mathrm{s}$ ). In addition, Hwang and Yao (1984) and Wege and Jensen (1984) found that increasing the upstream quality of a two-phase mixture increased the heat transfer coefficient significantly at low heat fluxes, but that the effect of the upstream quality decreased with increasing heat flux. 


\section{Pool Boiling from Cylinders with Enhanced Surfaces}

A number of enhancement technologies are reported in the literature (Bergles 1981). In particular, some of the most common enhanced surfaces are Wieland's Gewa-T, Hitachi's Thermoexcel-E, Wolverine's Turbo-B, and Linde's High Flux shown in Fig. 1.2. Pais and Webb (1991) have compiled a literature survey of pool boiling on single tubes with enhanced surfaces that are produced by rolling the surface (see Fig. 1.2b,c,d), and by sintering small particles to the surface (see Fig. 1.2e). Pais and Webb report that the enhanced surfaces perform significantly better than smooth tubes, often by an order of magnitude.

Pool boiling heat transfer from horizontal tubes with enhanced surfaces was also reported by Yilmaz et al. (1980) who found that the heat transfer from enhanced surfaces can be an order of magnitude larger than that from smooth tubes (Fig. 1.3). The increased heat transfer possible with enhanced tubes over smooth tubes makes them a strong candidate for use in tube bundles also.

A possible disadvantage of using enhanced surfaces is the delayed onset of nucleation resulting in a boiling curve hysteresis. Pool boiling from horizontal tubes with a porous metallic coating was investigated by Bergles and Chyu (1982) who first reported a large boiling curve hysteresis for this surface in wetting fluids (Fig. 1.4). Possible explanations include the reduced tendency for vapor from the first nucleation sites to spread over the surface and activate other nucleation sites.

\section{Shellside Boiling on Smooth, Horizontal Tube Bundles}

Investigations have been performed on tube bundles in natural circulation; individual tubes in the bundle were instrumented to obtain the distribution of local heat transfer coefficients. The results from a number of investigations have shown 


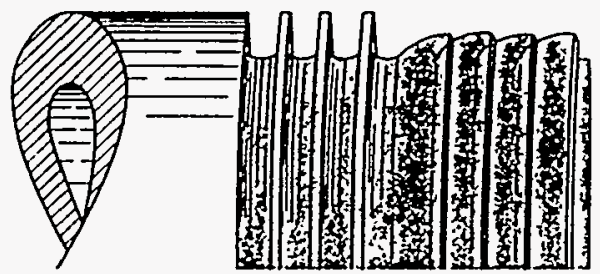

a.
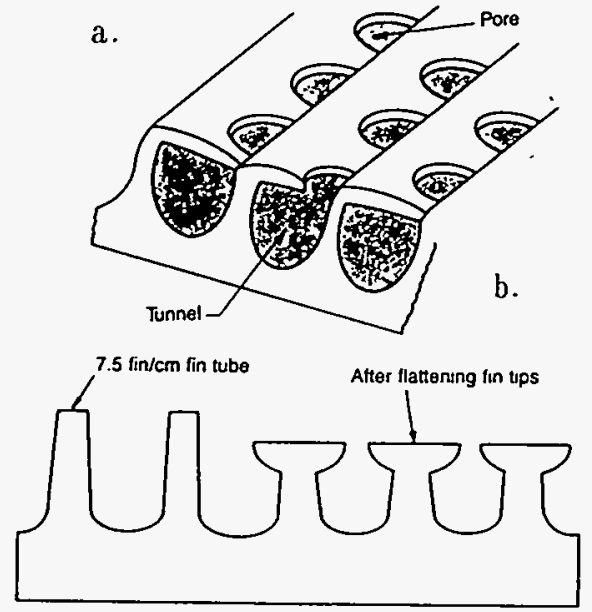

c.
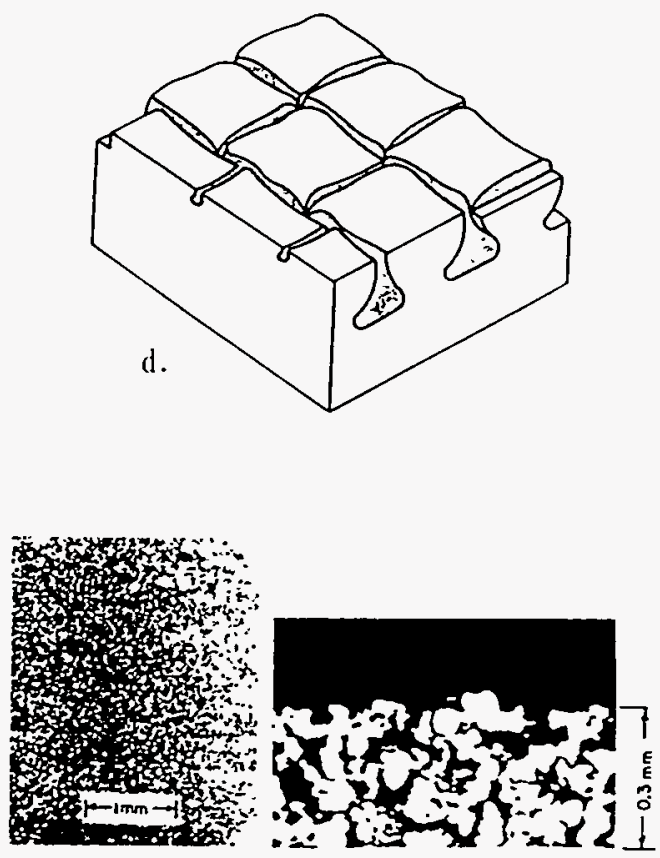

e.

Enhanced boiling surfaces.

a. Rolled-over low fins.

b. Tunnel-and-pore arrangement.

c. Flatened low fins.

d. Knurled low fins (Turbo-B).

e. Sintered porous metallic matrix surface (High Flux).

Figure 1.2. Schematic of enhanced surfaces (Bergles 1988). 


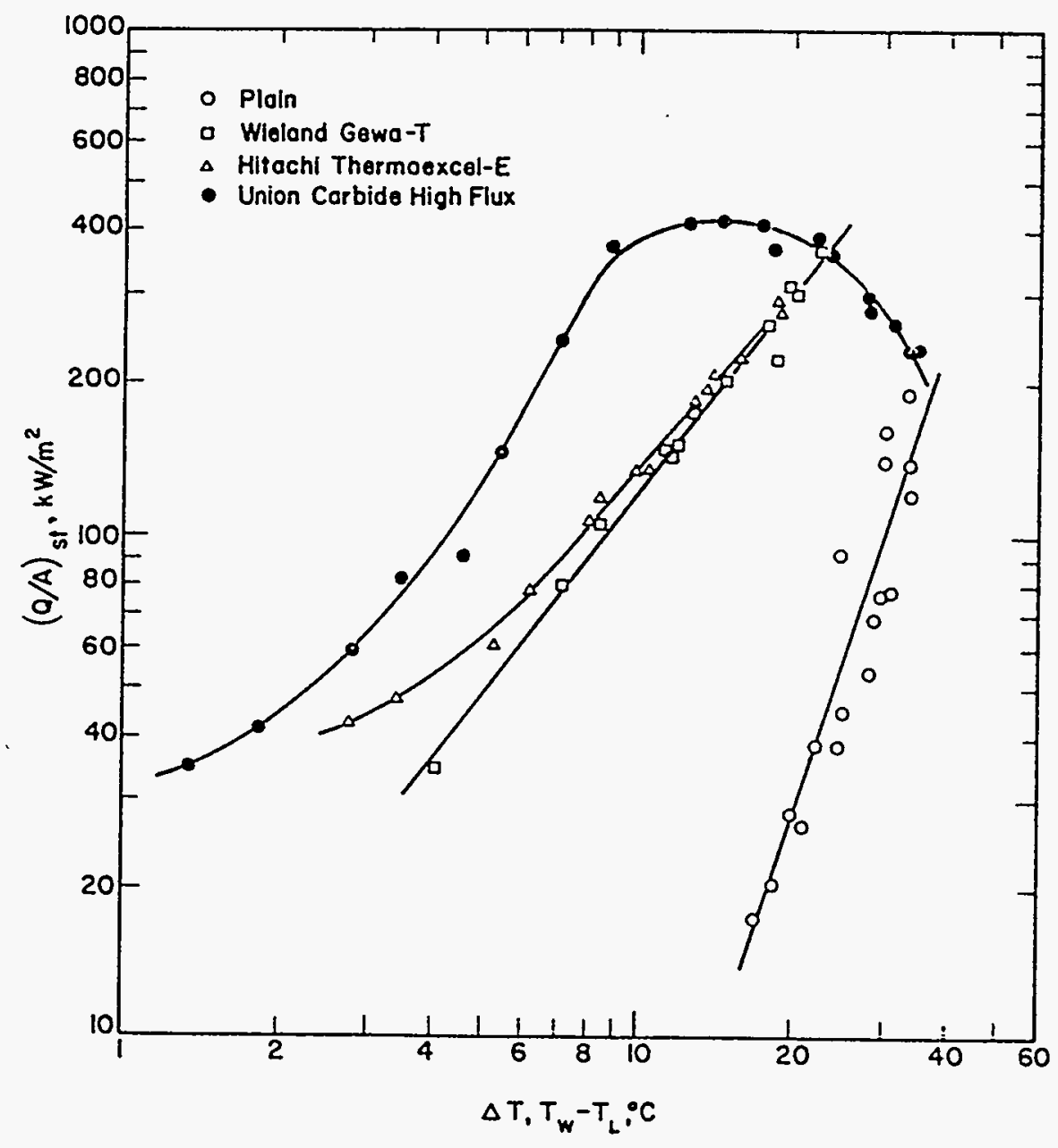

Figure 1.3. Pool boiling performance for smooth and enhanced tubes (Yilmaz et al. 1980). 


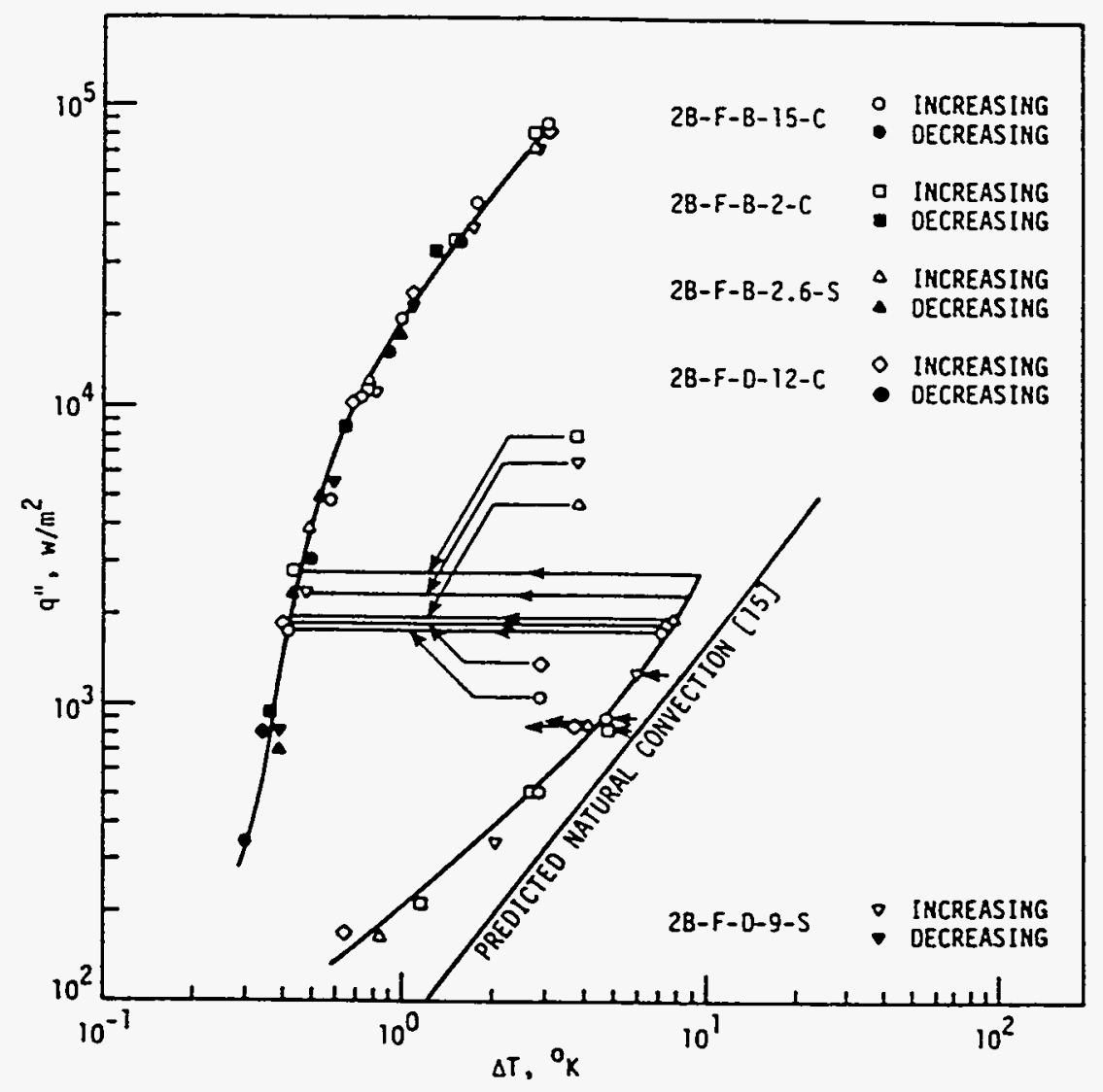

Figure 1.4. Boiling curve hysteresis for High Flux tubes (Bergles and Chyu 1982). 
that there is generally an increase in the local heat transfer coefficient with each downstream tube as compared to a single tube in established nucleate pool boiling (Cornwell et al. 1980, Cornwell and Schuller 1982, Wallner 1971, Nakaj̈ma 1978) and that the variation in heat transfer coefficients throughout the bundle decreased with increasing heat flux (Grant et al. 1980). Unfortunately, the local quality and mass flux were not known. The difficulty in quantifying the effect of these parameters has prompted studies where a section of a tube bundle was modeled with forced convection (Polley et al. 1980, Hwang and Yao 1986, Jensen and Hsu 1987, Robinson and Katz 1951, Meyers and Katz 1953). This allowed for the mass flux and local values of quality to be calculated.

As a result of these studies and those in natural circulation, it is believed that either a thinning of the liquid film next to the heated surface (thin film vaporization), increased turbulence, or larger induced liquid velocity caused by an increase in the void fraction is responsible for the increased heat transfer coefficient as compared to pool boiling at low heat fluxes. Most of the suggested models correlate the governing heat transfer mechanism by using the nucleate pool boiling mechanism alone or by superimposing two or three of the mechanisms using various weighting factors. The methods that have been used to model tube bundles thus far superimpose (1) a nucleate pool boiling and a liquid phase convection component, (2) a thin film vaporization and a nucleate pool boiling component, or (3) a nucleate pool boiling, a liquid phase convection, and a thin film vaporization component (Nakajima 1978, Cornwell 1990, Fujita et al. 1990). These models are discussed below.

Nucleate pool boiling and single-phase convection. When nucleate pool boiling and convection are superimposed, the larger heat transfer coefficient 
(relative to pool boiling) at low heat fluxes is attributed to increased convection due to the two-phase flow analogous to enhancement for single-phase convective flow at increased fluid velocities. On the other hand, at high heat fluxes, the similarity between a single tube in fully established pool boiling and a tube in a bundle is attributed to the convection effects being dominated by the nucleation effects at the tube surface. Therefore, correlations used to predict local heat transfer coefficients in a tube bundle usually incorporate a trade-off between the nucleation and the convection effects.

Many of the existing correlations for tube bundles are similar to correlations for flow inside a tube and usually fall into one of two categories. The first type calculates the heat transfer coefficients from convection and nucleation separately and then adds the contributions together. Chen (1966) proposed a correlation for flow inside a tube which has been extended to tube bundles (Palen and Yang 1983, Hwang and Yao 1986, Jensen and Hsu 1987). The second type correlates the ratio of the two-phase heat transfer coefficient to the single-phase liquid heat transfer coefficient as a function of the Martinelli parameter (to characterize convection) and the Boiling number (to characterize nucleation). However, such correlations, similar to those by Kandlikar (1990) and Shah (1982), have not been extended to tube bundles.

Nucleate pool boiling and thin film vaporization. In the case where nucleate pool boiling and thin film vaporization are superimposed, as in the model by Nakajima (1978), the nucleate pool boiling component is weighted using the void fraction as a multiplier and the thin film vaporization component is weighted using the liquid fraction as a multiplier. Nakajima's model includes an average thickness of the film between the vapor bubbles and the tube wall; an expression for the film 
thickness was developed from theoretical considerations and experimental data for bubble size, velocity, and frequency. The author also gives an expression for the void fraction, but it is limited to the tube bundle used in the experiments.

Nucleate pool boiling, single-phase convection, and thin film vaporization. Cornwell (1987) has developed a third type of model to include all of the three components mentioned above, thereby extending the ideas of Nakajima. The total heat transfer coefficient is the sum of the components due to nucleation, convection, and thin film vaporization occurring under bubbles which slide around the perimeter of the tube. He calculated the thin film vaporization component of the heat transfer and showed that nucleate boiling was much smaller than thin film vaporization for downstream tubes at low heat fluxes.

The success of the methods listed above for correlating heat transfer coefficients for smooth tubes has been limited. Polley et al. (1980) and Hwang and Yao(1988) report an ability to predict their own data to within $\pm 20 \%$, but a modified Chen's method can be used as a design tool with an expected accuracy of $\pm 40 \%$ (Jensen 1988). Less effort has been made to correlate local heat transfer coefficients in a tube bundle for enhanced surfaces. Müller and Hahne (1981) have developed a correlation for bundle-average heat transfer coefficients for tubes with a finned surface, but did not obtain a correlation for local values. Even less work has been done to predict local heat transfer coefficients in a bundle of tubes having sintered or knurled surfaces.

For these models, the average vapor and liquid velocities are needed in order to evaluate the component parts of the correlations. For example, Cornwell's model requires that the single-phase convection be calculated using the local liquid velocity derived from the void fraction, and Nakajima's model correlates the thin 
film vaporization heat transfer coefficient as a function of the superficial vapor velocity which can be calculated knowing the void fraction. Unfortunately, data reported on local void fractions in horizontal tube bundles are limited (Schrage et al. 1987, Dowlati et al. 1988, Chan and Shoukri 1987) which seriously limits the ability to verify these correlations. Therefore, the results of these correlations must be considered to be speculative.

Shellside Boiling on Horizontal Tube Bundles with Enhanced Surfaces

There has been less research on the use of enhanced surfaces in tube bundles than for smooth tubes. The studies generally have been conducted on finned, cold-worked, and porous surfaces. The works of Meyers and Katz (1953), Danilova and Dyundin (1972), Hahne and Mueller (1983), and Yilmaz and Palen (1981) have shown that the enhanced convection due to the rising bubbles has the same effect on the performance of bundles of finned tubes as on bundles of smooth tubes. In particular, heat transfer coefficients increase with tube row at low heat fluxes, but the variation with tube row decreases with increasing heat flux.

Of more interest is the performance of tubes with formed and sintered surfaces. Stephan and Mitrovic (1981) compared the performance of tubes with finned surfaces to tubes with $\mathrm{T}$-shaped fins having approximately the same surface area (the Gewa-T surface). The Gewa-T surface performed significantly better than the finned surface. The enhancement was attributed to vapor traveling around the tube perimeter before leaving at the top resulting in increased thin film vaporization in the channel. In addition, the value of the heat transfer coefficient was not found to vary with the position in the bundle. 
Arai et al. (1977) investigated the heat transfer coefficients of tubes having the Thermoexcel-E surface and compared heat transfer coefficients of single tubes with those from tube bundles. In addition to determining an optimum pore size, they reported larger values of the average heat transfer coefficient for the bundle than for single tubes. This is in contradiction with the results of Yilmaz et al. (1981) who investigated the performance of the Gewa-T surface. They found that the heat transfer coefficients from tube bundles were the same or even less than those from single tubes. They attributed this decrease to a suppression of nucleate boiling. In addition, the heat transfer coefficients from the tubes with enhanced surfaces were greater than those from tubes with smooth surfaces both in a tube bundle and as single tubes.

Tubes with porous surfaces, such as Union Carbide's High Flux, have been of particular interest due to the large heat transfer coefficients obtainable (Czikk et al., 1970 and O'Neill et al., 1980). Koyama and Hashizume (1983) and Fujita et al. (1984) have reported that the heat transfer coefficients for a tube bundle were the same as for a single tube. The lack of any additional enhancement due to convective effects is the result of the nucleation-dominated heat transfer mechanism for this surface. The heat transfer process occurs in the subsurface cavities where the free stream has little effect.

\section{Boiling on Horizontal Tubes in Fluid Mixtures}

Heat transfer coefficients in pool boiling of miscible mixtures may be much lower than could be expected from the data for boiling in the individual components of the mixture. Stephan (1982) offers several explanations for this phenomenon. The vapor from the boiling process is richer in the more volatile component, leaving 
the liquid next the heated surface richer in the less volatile component. The local boiling temperature increases as does the surface temperature. However, the heat transfer coefficient is based on the bubble point of the bulk fluid and does not account for the increased boiling temperature next to the heated surface. Therefore, the increased surface temperature results in a lower heat transfer coefficient. Additional mechanisms exist to explain the decrease in the heat transfer in mixtures compared to pure fluids. According to Thome and Shock (1984), the bubble growth rate in binary mixtures is reduced, the bubble radius is increased, and the bubble frequency decreases when the difference in mole fraction between vapor and liquid composition increases (but also depends on the heat flux).

Fink et al. (1982) measured the forced convective flow boiling heat transfer coefficients in a mixture of $\mathrm{R}-113$ and $\mathrm{R}-11$ for various degrees of subcooling. In general, the degradation in multicomponent heat transfer coefficients was found to increase with increasing heat flux. Alpay and Balkan (1989) performed experiments on smooth and finned surfaces and found that the degradation in multicomponent heat transfer coefficients increased with the difference between the vapor and liquid composition for the most volatile component. Similar results were found by Bajorek et al. (1989).

Shellside Boiling on Tube Bundles in Fluid Mixtures

Very few investigations into boiling from horizontal tube bundles in multicomponent fluids are reported in the open literature. Montgomery and Park (1971) and Wall and Park (1978) investigated the performance of a bundle of four smooth tubes boiling in a miscible mixture. Wall and Park (1978) reported that the reduction in the heat transfer coefficients in the mixture as compared to those for 
pure components is greater for larger values of wall to bulk fluid temperature differences. No reports of investigations into boiling from horizontal tube bundles with enhanced surfaces in multicomponent fluids could be found.

\section{$\underline{\text { Conclusions }}$}

The parametric trends in the heat transfer coefficients with varying heat flux, mass flux and quality have been explored for pool boiling and boiling in tube bundles. Phenomonological models have been proposed but have not been able to satisfactorily predict the data mentioned above.

A variety of parameters have been used to predict the convection mechanism (which is the dominant mechanism at low heat fluxes and mass fluxes), e.g. convection number, single-phase heat transfer coefficient, Martinelli parameter, and thin film convection heat transfer coefficient. Likewise, boiling number and established nucleate pool boiling heat transfer coefficient have been used to characterize the nucleation component (which is the dominant component at high heat fluxes when the transfer coefficient is only slightly dependent on quality). However, because different models incorporating different parameters each are able to predict the two-phase heat transfer coefficients, at least qualitatively, the mechanisms governing the two-phase heat transfer for horizontal tube bundles in crossflow have not been established. Although nucleation has been fairly well established as the dominate mechanism at high heat fluxes (where the heat transfer coefficient is a weak function of quality), both single-phase convection and thin film vaporization are able to explain qualitatively the phenomena at low heat fluxes (where the heat transfer coefficient is a strong function of quality). Hence, the transition boundaries between the dominant mechanisms have not been established 
so that there is difficulty in determining which parameters to correlate in addition to how to correlate them.

There are very few data on the performance of sintered surfaces and even fewer on knurled surfaces in tube bundles. Some researchers have found that tubes with enhanced surfaces perform better in a bundle than as single tubes while others have found just the opposite. Forced convection does not affect the heat transfer coefficients of enhanced tubes as much as smooth tubes, apparently because the heat transfer mechanisms take place in the subsurface cavities where the free stream cannot intrude. The small variation with heat flux on the heat transfer coefficient for the Turbo-B surface has not been explained.

\section{Scope of Investigation}

Based on the conclusions of the literature survey, the performance of individual, enhanced tubes in a bundle needs to be established. The purpose of this research effort is to investigate enhanced boiling heat transfer in horizontal tube bundles in pure fluids and fluid mixtures. The local heat transfer coefficients throughout the tube bundle will be determined experimentally so that detailed information can be obtained regarding the effect of important operating parameters.

The parametric trends of the heat transfer coefficients will be determined for varying pressures, mass fluxes, and heat fluxes so that their effects on the heat transfer coefficient for smooth and enhanced tube bundles can be determined. In addition, the effect of different tube bundle layouts and surface geometry on the local heat transfer coefficients will be investigated; two staggered tube bundles will be tested using smooth, Linde High Flux, and Wolverine Turbo-B surfaces. 
Furthermore, the performance of both the smooth and enhanced tubes will be investigated in tube bundles and pool boiling when the working fluid is a binary mixture. The experimental results will be examined in order to establish the dominant heat transfer mechanisms and to determine important design parameters. It is hoped that this information will allow for more precise design procedures and promote the adoption of enhanced surfaces in heat exchangers with boiling on the shellside of horizontal tube bundles.

This work will determine what the important mechanisms are in two-phase heat transfer on horizontal bundles of plain and enhanced tubes in a vertical crossflow, how they interact, and what conditions are needed for one of the possible mechanisms to dominate. This information will be used to help correlate the heat transfer coefficients for these tubes. The parametric trends for different flow and operating conditions for plain and enhanced tubes will be established experimentally, and some detailed observations of the flow structure around individual tubes will be made to gain additional insight into the participating mechanisms. The necessary insight into the hydrodynamics around a tube in a bundle will be gained by visual observations of the flow and through the use of high-speed photography and video recordings.

The determination of the local phenomena will be facilitated by examining how surrounding tubes influence a tube in a tube bundle. Measuring the heat transfer coefficients for a single tube will provide a basis for comparison with the results for a tube in a bundle. In order to establish the performance of a single tube, experiments involving single tubes in pool boiling will be conducted. The pool boiling heat transfer data will then be used to select the optimum surface structure for the enhanced surfaces and it also will be used as reference values for determining 
the effect of surrounding tubes on a tube in a bundle. In addition, pool boiling heat transfer characteristics are frequently used in tube bundle correlations.

In order to establish the performance of enhanced tubes in tube bundles, the parametric trends of the local heat transfer coefficients will be determined for varying operating parameters. A test chamber containing a horizontal tube bundle will be used to measure the heat transfer coefficients from individual tubes in vertical crossflow. The test chamber will allow the total mass flux and heat flux to be measured so that the local quality can be measured. Two different system pressures will be used along with two different tube bundle layouts (pitch-to-diameter ratios of 1.50 and 1.17). Pure refrigerants and refrigerant mixtures will be used in order to quantify the effect of fluid mixtures on the heat transfer coefficients. Hence, heat transfer coefficients in staggered bundles of varying pitch-to-diameter ratios, mass fluxes, heat fluxes, pressures, and qualities will be investigated for plain, cold worked and sintered surfaces.

Pool boiling experiments will provide heat transfer coefficients for single tubes in pure refrigerants and refrigerant mixtures at near atmospheric pressure. These data will provide the necessary information for selecting the optimum enhanced surfaces and for establishing the effect of the surrounding tubes in a tube bundle on the heat transfer coefficients for individual tubes.

The information described above will be used to correlate the heat transfer coefficients in bundles of enhanced tubes. The correlations thus obtained would be helpful in modeling shell-and-tube heat exchangers of the once-through cross-flow type where the horizontal components of the flow are small compared to the vertical components. Modeling the entire bundle of a shell-and-tube heat exchanger of the 
kettle reboiler type is difficult with this type of analysis due to the two-dimensional nature of the recirculating flow. However, valuable insight can be gained into the phenomena occurring in much of the center of the bundle, where the flow becomes predominantly vertical. 
CHAPTER 2

\section{POOL BOILING APPARATUS AND DATA ACQUISITION/REDUCTION}

In order to determine the relationship between the thermal performance of a single tube and a tube in a bundle, reference data were collected for single tubes in pool boiling. A pool boiling apparatus was used to collect pool boiling data for single, horizontal tubes having smooth or enhanced surfaces. Data were collected so that the differences in the performance between the different types of enhanced and smooth tubes could be ascertained along with insight into the mechanisms involved in the heat removal process. In addition, the precision of the pool boiling apparatus was sufficient to discern any appreciable difference in data collected from enhanced tubes differing only in the porosity of the surface.

The experimental apparatus provided a constant heat flux to instrumented tubes mounted horizontally in a pool of refrigerant or refrigerant mixtures. The apparatus permitted data to be collected in saturated fluids at near atmospheric pressure and at heat flux values up to $10^{5} \mathrm{~W} / \mathrm{m}^{2}$. The instrumentation allowed for the measurement of the tube wall temperatures, electric resistance heating power, the pressure at the test section, and fluid temperature so that the heat flux and wall superheats could be obtained.

\section{Experimental Apparatus and Instrumentation}

The thermal performance of single tubes having smooth and enhanced surfaces was determined in the pool boiling apparatus so that the effects of 
surrounding tubes could be eliminated. The general pool boiling apparatus shown in Fig. 2.1 was designed similar to the one used by Bergles and Chyu (1982) and is described in detail by Jung and Bergles (1989). It consists of a Pyrex tank containing a water bath and a smaller Pyrex tank that contains the refrigerant and the test section. The electrically-heated cylindrical test section was mounted to a rigid, vertical supporting wall on one end and was insulated with a Plexiglas plug on the other end. Electrical connections supplying the power to the test section were inserted through the lid of the smaller Pyrex tank along with the thermocouple wires used to instrument the test section and measure the fluid temperature. A cooling coil was mounted just below the lid of the tank and had cold water circulating through it so that the refrigerant vapor condensed and refluxed back into the pool. In addition, an open reflux condenser was inserted through the lid which ensured that atmospheric pressure was maintained at the surface of the refrigerant without allowing refrigerant vapor to escape. The refrigerant in the smaller tank was insulated by surrounding it with constant temperature water in the larger tank. Water from the bath tank was recirculated through an external, temperature-controlled source that kept the water at 1 to $2^{\circ} \mathrm{C}$ above the saturation temperature of the refrigerant. .

The test section was manufactured out of a copper cylinder $120.7 \mathrm{~mm}$ long with an outside diameter of $19.1 \mathrm{~mm}$ and an inside diameter of $6.4 \mathrm{~mm}$. The test section with the High Flux surface was mounted in the same way as in the tube bundle apparatus (see Fig. 2.2). Therefore, the sealing method which was required for the tube bundle experiments also was used in the pool boiling experiments even though sealing was not required. One end of the cylinder was machined down to create a neck $19.1 \mathrm{~mm}$ long, with an outside diameter of $15.1 \mathrm{~mm}$, which 


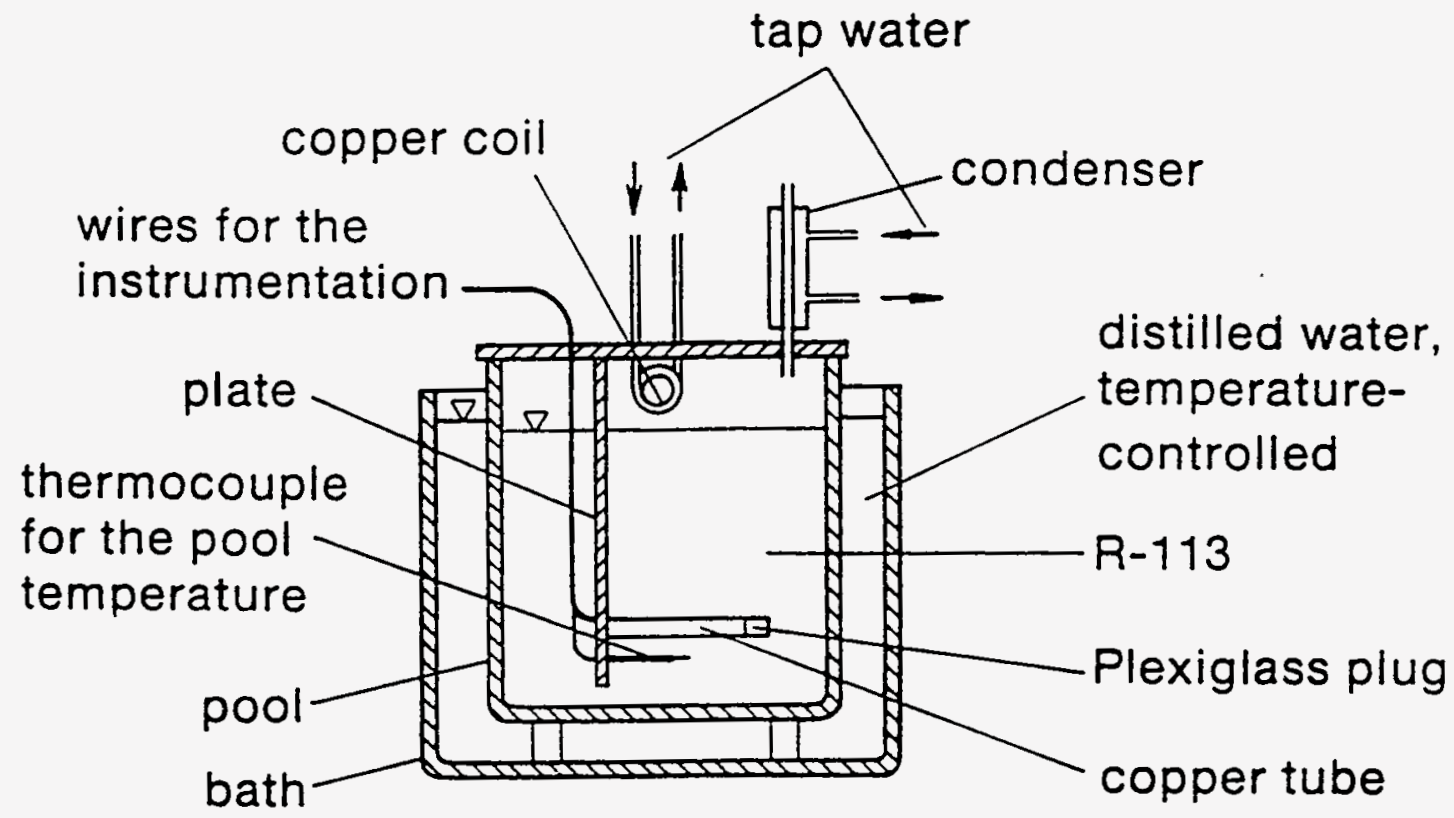

Figure 2.1. Pool boiling apparatus (Jung and Bergles 1989). 


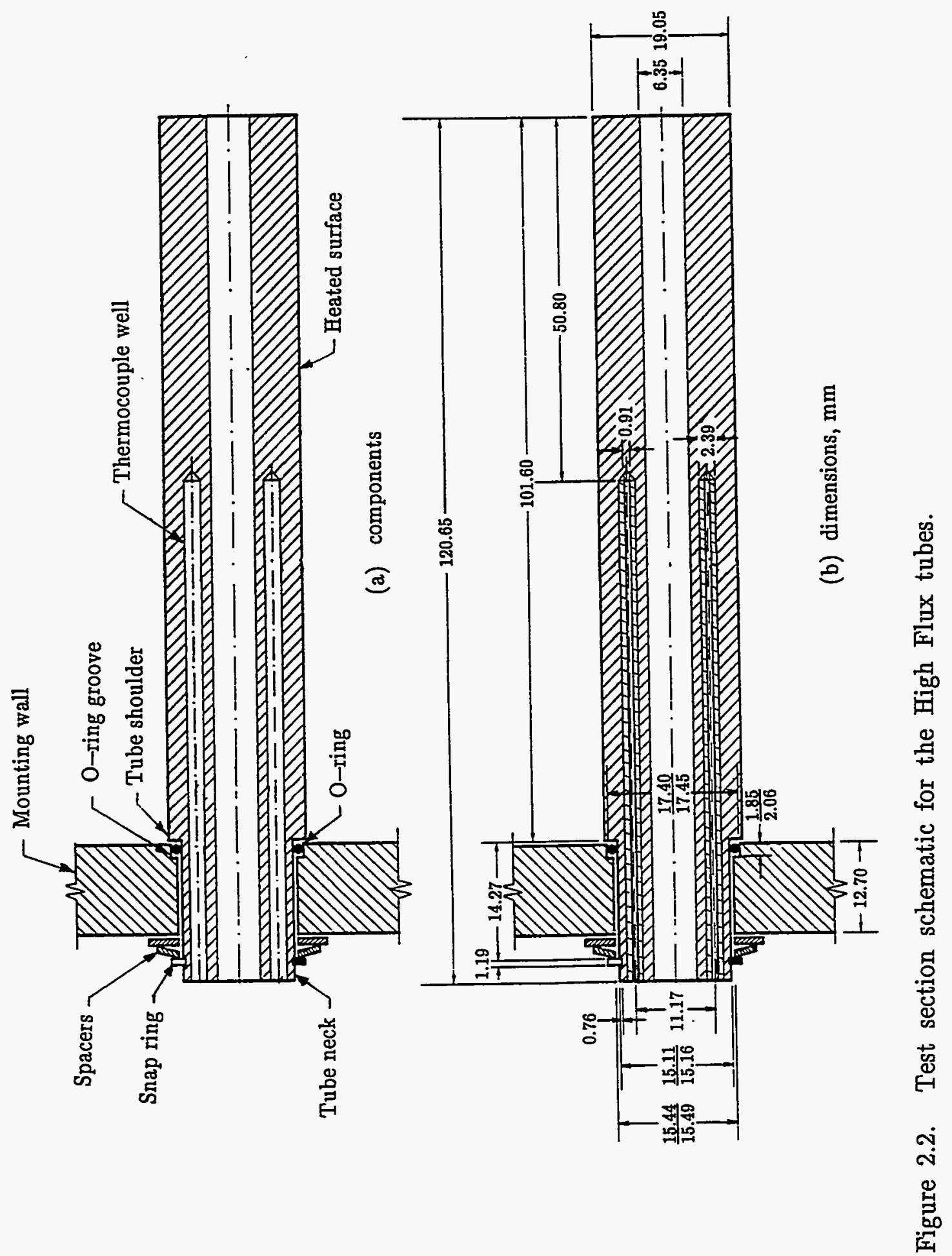


protruded through the mounting wall. The neck was machined with a snap-ring groove and was inserted through the mounting plate. A snap ring secured the shoulder of the test section to the mounting plate so that they were kept perpendicular to each other. The mounting plate had an o-ring groove machined in it, and an o-ring was used to provide a seal between the test section and the mounting plate.

The test sections with the smooth and Turbo-B surfaces were mounted differently than what was used for the High Flux test sections. These tubes were attached to the mounting wall using two threaded screws as shown in Fig. 2.3. The test sections were insulated from the mounting wall with a Buna-N gasket.

The test sections were instrumented with thermocouples inserted into four thermocouple wells as shown in Fig. 2.2 (a). The thermocouple wells were manufactured by drilling four holes located 90 degrees apart in the tube parallel to the axis from the end of the tube neck to a location halfway to the end of the heated surface. A relatively large hole $2.39 \mathrm{~mm}$ in diameter was drilled so that a sufficiently rigid drill bit could be used to provide a straight thermocouple well. Sleeves made from small copper tubing, with an outside diameter approximately equal to the diameter of the thermocouple well (to provide a snug fit), were forced into the wells as shown in Fig. 2.2 (b). The inside diameter of the sleeves was equal to $0.91 \mathrm{~mm}$ which provided for a snug fit between the sleeve and the 36-gage T-type (copper-constantan) thermocouple wire. T-type thermocouples were manufactured in an inert environment and were calibrated to within $0.1^{\circ} \mathrm{C}$. The thermocouple beads were pressed against the bottom of the thermocouple wells, and the thermocouples were secured to the test sections with epoxy. 


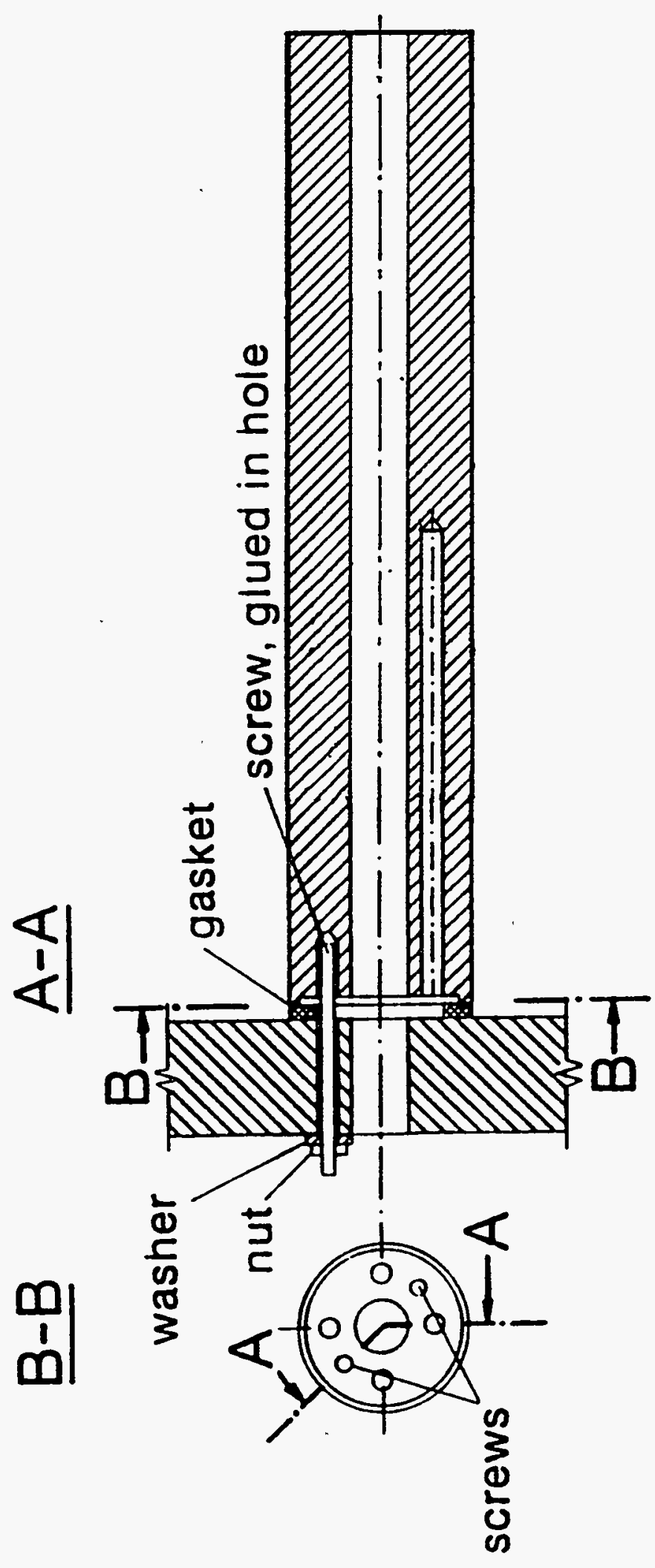

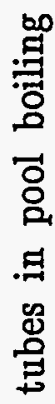

皇

맘

영

总

总

节

㝵

月

엉

总兽

ஸे 
Test section heating was provided by inserting a $101.6 \mathrm{~mm}$ long, $6.35 \mathrm{~mm}$ diameter, $500 \mathrm{~W}$ electric resistance cartridge heater into the test section, and power was supplied from a $0-120 \mathrm{~V}$ variable transformer. The cartridge heater was manufactured $0.05 \mathrm{~mm}$ smaller in diameter than the inside diameter of the test section to provide a snug fit and a uniform heat flux from the heater to the copper tube. Both ends of the test section were sealed to the cartridge heater with epoxy.

The current supplied to the cartridge heater was measured using a $15 \mathrm{~A} / 100 \mathrm{mV}$ shunt. The voltage across and current supplied to the cartridge heater were measured with a Hewlett-Packard family 9000, model 310 computer and an HP-3241A data acquisition system. In addition, the data acquisition system measured the temperature of the refrigerant, the water bath, and the four test section wall temperatures. The atmospheric pressure was determined using a precision mercury barometer, and a precision manometer was used to verify that the pressure difference between the room and the vapor space inside the apparatus was negligible.

When experiments involving refrigerant mixtures were performed, three test sections, one with each type of surface, were attached to the mounting plate $0.1254 \mathrm{~m}$ apart so that the tests for each surface could be completed without removing the lid and allowing the concentration to change. Tests with three smooth tubes in pure refrigerant were conducted to ensure that the multiple mounting did not affect the heat transfer coefficients. 


\section{Operating Procedure and Data Reduction}

Experiments were conducted in pure R-113, pure R-11, and three mixture concentrations: $25 \%, 50 \%$, and $75 \%$ of $R-113$ by mass. Because $R-11$ was the pure fluid used just prior to the mixture tests, mixture concentrations were determined by measuring the volume of $\mathrm{R}-113$ added to the pool. Prior to each set of experiments for a particular concentration, a volume of refrigerant was removed and a measured volume of pure $\mathrm{R}-113$ was added so that the mixture concentration could be calculated.

Prior to taking data for each test section, the pool of refrigerant was heated to the saturation temperature and degassed by heating the pool with the test section and the water jacket. The test section boiled at a heat flux of approximately

$30 \mathrm{~kW} / \mathrm{m}^{2}$ for at least 30 minutes in order to degas the refrigerant. The removal of dissolved gas from the refrigerant was necessary to prevent early nucleation from the tube surface.

The power to the cartridge heater was then turned off and the temperature of the test section was allowed to decrease to the saturation temperature. Power was then supplied again to the test section, and the temperature of the test section and pool were allowed to come to steady state. The criterion used for steady state was a change of less than $0.1 \%$ over 30 seconds for all the voltages and temperatures measured.

After the data were taken and stored, the power to the cartridge heater was increased slightly, and the temperature of the test section again was allowed to come to steady state. This procedure was repeated for each data point until the maximum cartridge heater power was reached. The power to the cartridge heater 
was then decreased slightly and the temperature of the test section and the pool were again allowed to come to steady state. In this way, data were taken at different heat flux values as the power was decreased. The experiment for a particular test section was complete when the minimum power to the cartridge heater was reached.

The values for the heat transfer coefficient are obtained by dividing the heat flux by the difference between the average tube surface temperature and the saturation temperature of the fluid:

$$
h_{\mathrm{t}}=q_{t} /\left(T_{\mathrm{w}}-T_{\mathrm{sat}}\right)
$$

The heat flux was calculated by dividing the power supplied to the cartridge heater by the area of the heated surface. For the enhanced surfaces, the surface area was calculated using the radius to the outside of the enhanced surface structure. The power supplied was calculated using the voltage across and the current through the cartridge heater. Specifically,

$$
q_{\mathrm{t}}=\left(V_{\mathrm{t}} I_{\mathrm{t}}\right) / A_{\mathrm{t}}
$$

where

$$
I_{\mathrm{t}}=(1 / 15) V_{\mathrm{sh}}
$$

The right-hand side of equation (2.3) includes the precision resistance value $(1 / 15)$ for the shunt in ohms. 
The surface temperature of the test section wall was calculated using the one-dimensional conduction equation for a cylinder:

$$
T_{\mathrm{w}}=T_{\mathrm{tc}}-\frac{q_{\mathrm{t}} D_{\mathrm{t}}}{2 k_{\mathrm{t}}} \ln \left(D_{\mathrm{t}} / d_{\mathrm{tc}}\right)
$$

Equation (2.4) assumes that the heat flux is uniform, which was ensured by providing a snug fit between the cartridge heater and the test section.

The saturation temperatures for the two pure fluids, $R-113$ and $R-11$, were evaluated as a function of pressure through the use of the property tables listed in ASHRAE (1985) and verified experimentally as described in Appendix D. When the working fluid was a mixture of $R-113$ and $R-11$, the bubble point was used in place of the saturation temperature. The bubble point was measured using a thermocouple placed in the bubbly flow just above the test section during the degassing process, and is described in Appendix D. The pressure at the center line of the test section was calculated by adding the hydrostatic pressure contribution (calculated using the nominal height of liquid above the test section) to the measured atmospheric pressure.

The temperature measurements as input from the data acquisition system were calibrated experimentally to $0.1^{\circ} \mathrm{C}$. As seen in equation (2.4), the wall temperature is a function of the temperature at the thermocouple location, heat flux, thermal conductivity, and location of the thermocouple. A propagation-of-uncertainty analysis was performed and is given in Appendix C. The analysis shows that for uncertainties in the surface temperature were less than $0.12^{\circ} \mathrm{C}$ and that the uncertainty in the saturation temperature, resulting from uncertainties in the pressure measurement, were less than $0.04^{\circ} \mathrm{C}$. Therefore, the 
uncertainty in the wall superheat was calculated as $0.13^{\circ} \mathrm{C}$. The uncertainties in the heat flux, as a result of uncertainties in surface area and voltage measurements, were less than $5 \%$. 


\section{CHAPTER 3}

\section{EXPERIMENTAL RESULTS AND DISCUSSION OF POOL BOILING DATA}

Pool boiling experiments were performed in order to determine the thermal performance of single, horizontal tubes with different surfaces boiling in a pool of refrigerant. The results of the experiments were used as a reference for the tube bundle data and to validate the experimental tube bundle apparatus and procedure. Single tubes with plain and enhanced surfaces were tested in the pool boiling apparatus containing $\mathrm{R}-113, \mathrm{R}-11$, or mixtures of both. Heat flux and wall temperature superheat data were collected in order to determine the effect of changing heat flux and various fluids on the heat transfer coefficients.

\section{Pure R-113 Results}

The boiling curves for tubes with the smooth, knurled (Turbo-B), and sintered (medium and small porosity High Flux) surfaces in pure R-113 are shown in Fig. 3.1. The natural convection correlation curve developed by McAdams (1954) is plotted for comparison. The smooth tube results for increasing heat fluxes (from approximately $0.2 \mathrm{~kW} / \mathrm{m}^{2}$ up to approximately $2 \mathrm{~kW} / \mathrm{m}^{2}$ ) were predicted fairly well using the McAdams correlation, which validated the experimental apparatus and procedure.

Data from the smooth tube for heat fluxes from $2 \mathrm{~kW} / \mathrm{m}^{2}$ to $7 \mathrm{~kW} / \mathrm{m}^{2}$ deviates slightly from the natural convection line due to the presence of nucleate boiling at a few sites. The entirety of the heated surface did not nucleate until the 


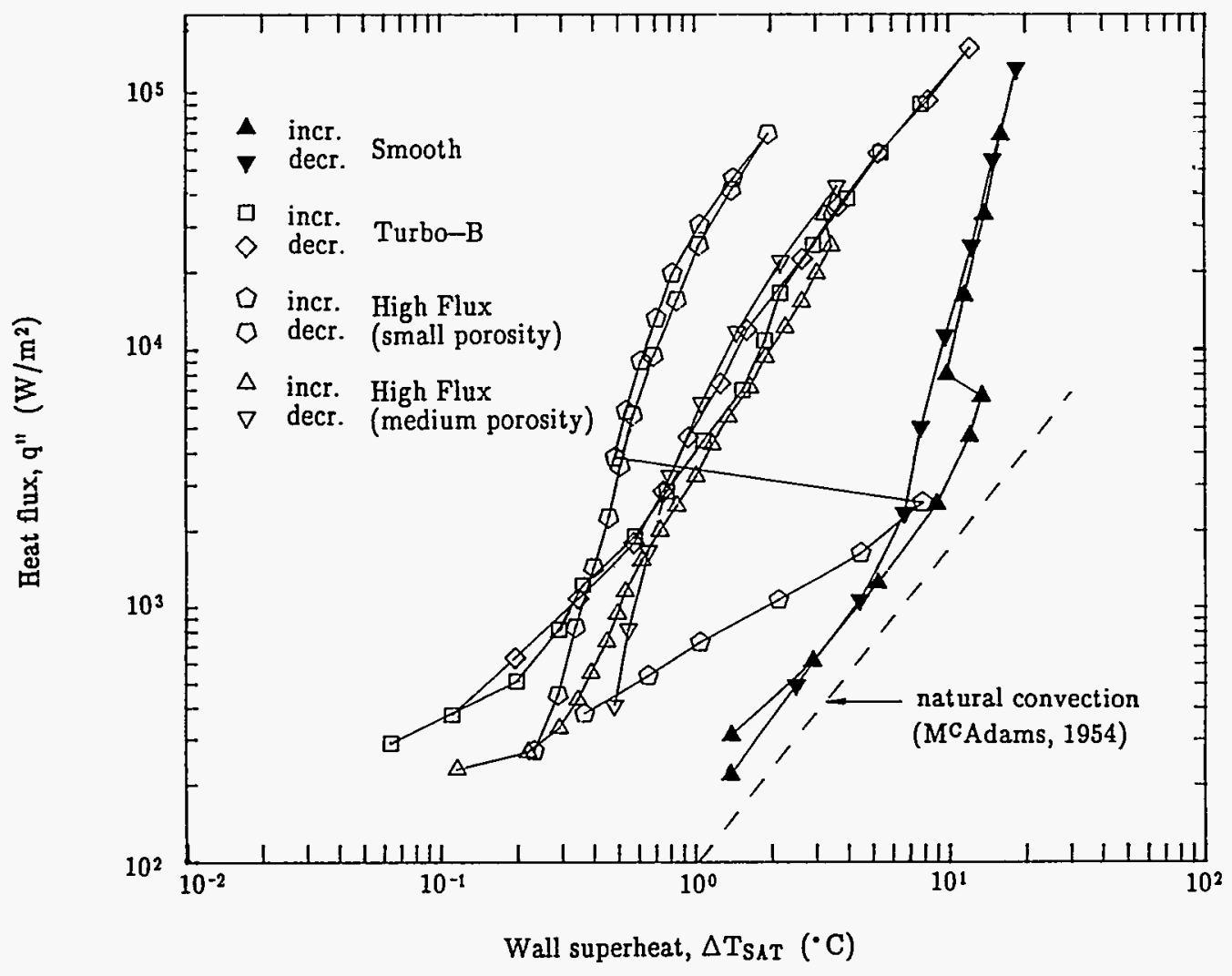

Figure 3.1. Boiling curves for tubes with smooth, Turbo-B, and High Flux surfaces at $\mathrm{P}=103 \mathrm{kPa}$. 
heat flux was increased to approximately $8 \mathrm{~kW} / \mathrm{m}^{2}$, at which time the nucleate boiling resulted in a significantly smaller wall superheat value that shifted the boiling curve to the left. Occasionally this shift in the boiling curve occurred over a range of heat fluxes, which was not repeatable. Visual observations revealed that nucleation was initiated in patches on the heated surface and that these patches grew with increasing heat flux. Similar observations were noted by Bergles and Chyu (1982).

Data taken at heat fluxes greater than $8 \mathrm{~kW} / \mathrm{m}^{2}$ were generally the same regardless of whether the heat flux was increased or decreased. Data obtained for decreasing heat fluxes less than $8 \mathrm{~kW} / \mathrm{m}^{2}$ were to the left of the data obtained for increasing heat fluxes due to the continued presence of nucleation sites, thereby creating the so-called boiling curve hysteresis.

Figure 3.1 also shows that data from the small porosity High Flux surface has the smallest wall superheat for decreasing heat fluxes greater than $1.5 \mathrm{~kW} / \mathrm{m}^{2}$ and so performed the best in this heat flux range. The Turbo-B surface performed better than the smooth and medium porosity High Flux surfaces for heat fluxes less than $10 \mathrm{~kW} / \mathrm{m}^{2}$, but the medium porosity High Flux surface performed better than the Turbo-B and smooth surfaces for heat fluxes greater that $10 \mathrm{~kW} / \mathrm{m}^{2}$. At low heat fluxes, the heat transfer coefficients for a given wall superheat are generally at least an order of magnitude better for the enhanced tubes than the smooth tubes.

At higher heat fluxes, the difference between the results for the smooth and enhanced surfaces diminishes and the boiling curves for the smooth and Turbo-B surfaces merge together. Figure 3.2 shows the boiling curve for a smooth tube up to a heat flux value of $200 \mathrm{~kW} / \mathrm{m}^{2}$. The sudden shift in the boiling curve to the right indicates that the critical heat flux ( $\mathrm{CHF}$ ) has been reached which was verified by 


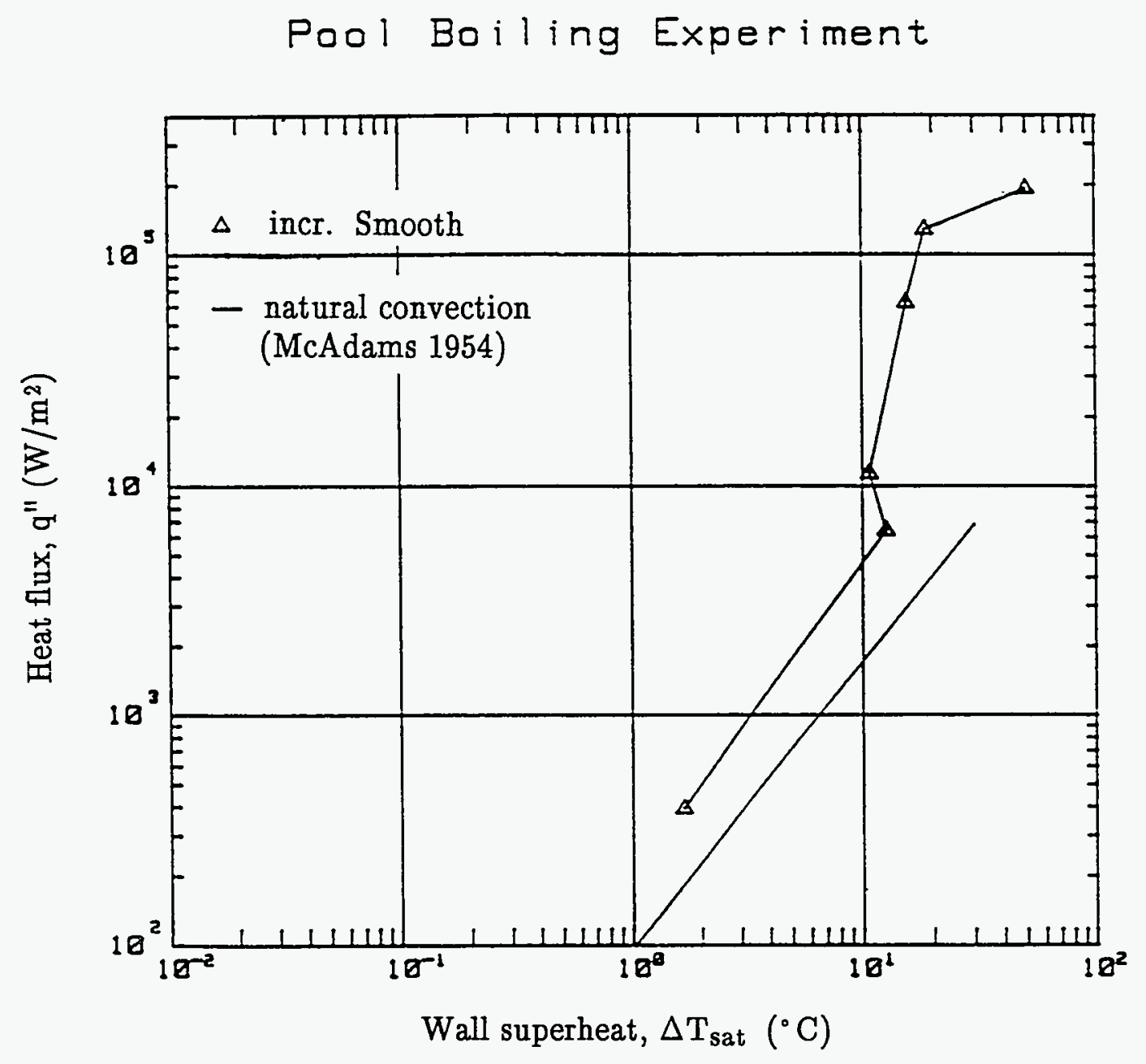

Figure 3.2. Critical heat flux data for the smooth tube in pool boiling at $\mathrm{P}=103 \mathrm{kPa}$. 
visual observations of film boiling. It appears that the CHF value for the Turbo-B and medium porosity High Flux tubes will be approximately the same as that of the smooth tube (approximately $200 \mathrm{~kW} / \mathrm{m}^{2}$ ) which indicates that the surface enhancement is ineffective when operating too close to the $\mathrm{CHF}$ value.

The results shown in Fig. 3.1 agree with results of other researchers. For example, the results of the smooth and small porosity High Flux surfaces are similar to those obtained by Chyu (1979), as seen in Fig. 3.3. Webb and Pais (1991) report very good agreement between heat transfer coefficients from their Turbo-B tube and values from the present study as shown in Fig. 3.4.

The small porosity High Flux surface produced the largest hysteresis in the boiling curve of approximately $10^{\circ} \mathrm{C}$ while the Turbo-B produced almost no overshoot. A possible explanation for the lack of a large temperature overshoot for the Turbo-B surface is that the subsurface geometry of the Turbo-B tube is connected by a spiraling channel. Figure 3.5 shows a cross section of the Turbo-B surface enlarged 20 times. Note that the subsurface channels remain open even though the pore openings are sometimes closed and the outside surface is sometimes compressed an additional amount. This channel would make it possible for vapor from just a few active nucleation sites inside the channel on the bottom of the tube to travel circumferentially around the tube and activate other extinct nucleation sites. Such a process would be less likely for tubes with the High Flux surface where the connecting subsurface channels are interrupted as shown in Fig. 3.6. Indeed, visual observations verified that the onset of nucleation for the High Flux tubes occurred in patches on the tube surface and at varying heat fluxes. 


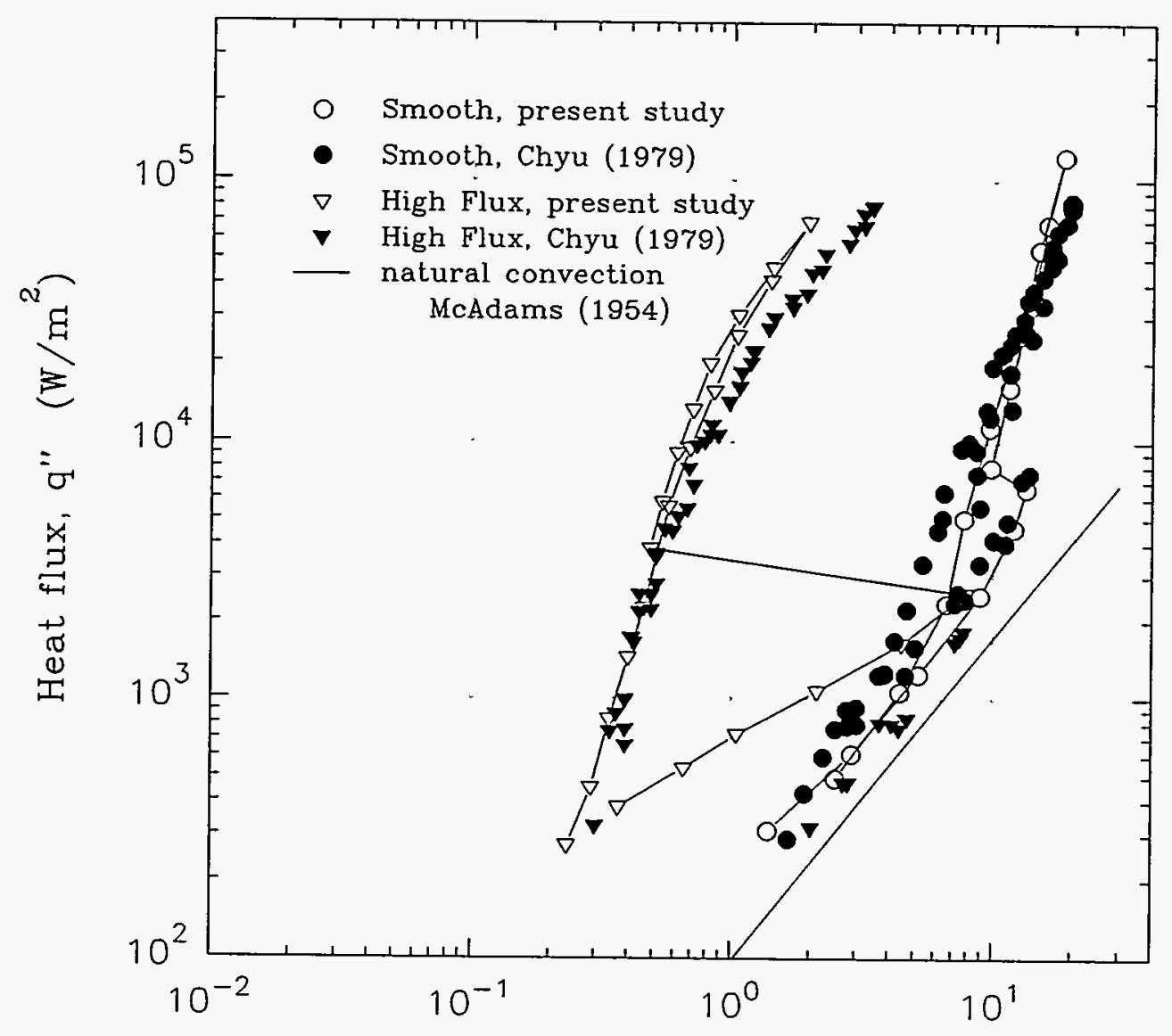

Wall superheat, $\Delta \mathrm{T} \quad\left({ }^{\circ} \mathrm{C}\right)$

Figure 3.3. $\quad$ Comparison of High Flux and smooth tube pool data obtained in $\mathrm{R}-113$ at $\mathrm{P}=103 \mathrm{kPa}$ with results from Chyu (1979). 


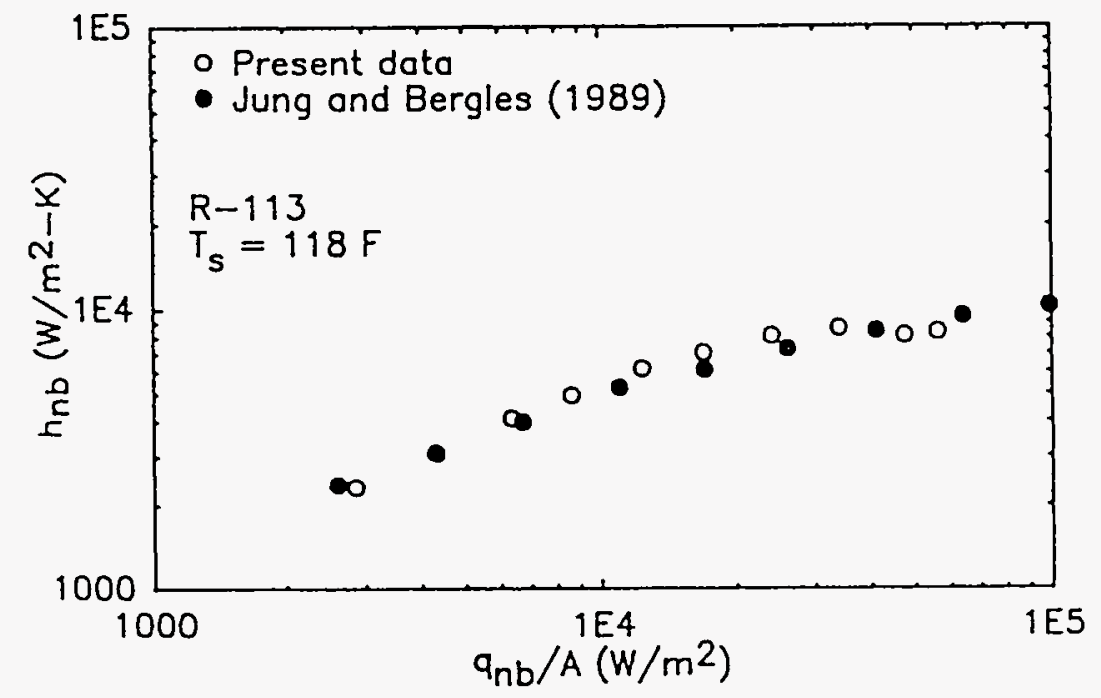

Figure 3.4. Comparison of Turbo-B tube pool boiling data with results from Webb and $P$ ais (1991). 


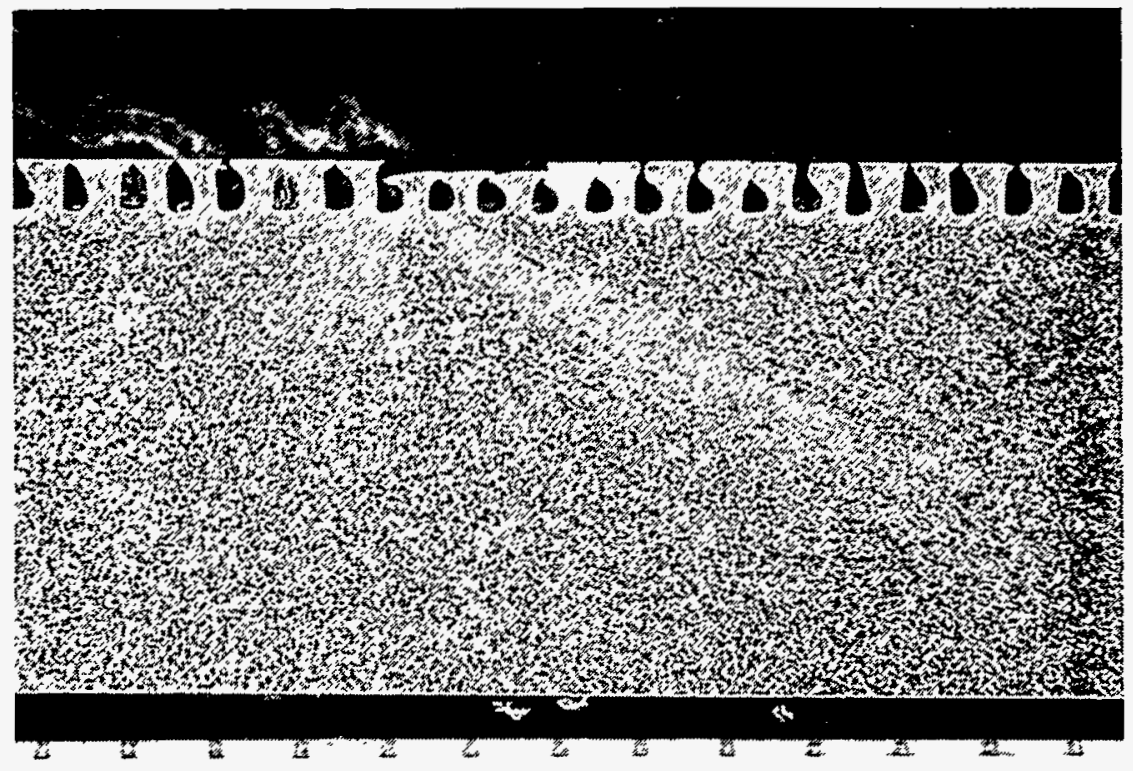

Figure 3.5. Axial cross section of the Turbo-B tube (enlarged 9x). 


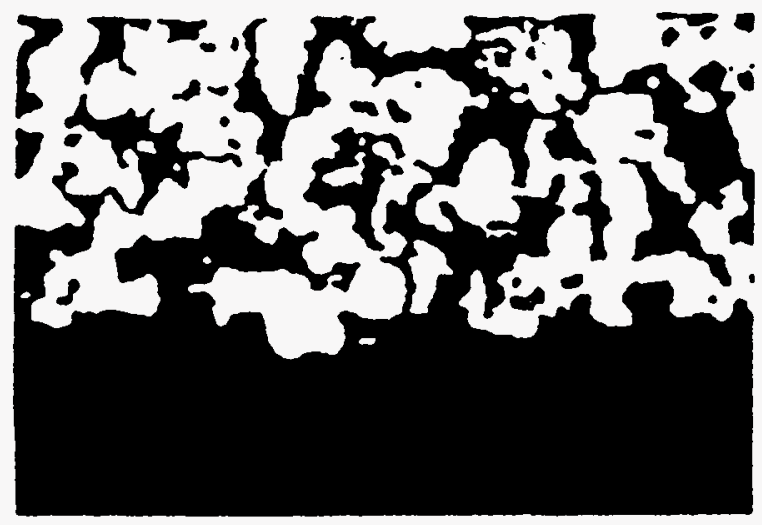

Figure 3.6.

Cross section of the High Flux surface enlarged 100x (Gottzmann et al. 1973). 
In the fully established nucleate boiling range, the size of the pore opening has very little influence on the boiling curve for the Turbo-B surface. As reported by Jung and Bergles (1989), three boiling curves were obtained for Turbo-B tubes with surface opening sizes designated small, medium, and large, and the results were nearly identical. Subsequently, Turbo-B tubes with surface opening sizes designated "very open" and "very closed" were tested and the results are shown in Fig. 3.7. Even for these extreme pore sizes, the boiling curves show very little effect, especially for heat fluxes greater than $2000 \mathrm{~W} / \mathrm{m}^{2}$. These results support the conclusion that the basis heat transfer mechanism takes place in the subsurface channel alone and that the bubble departure process at the pore has little influence.

The porosity of the High Flux surface, on the other hand, has a strong effect on the nucleate boiling heat transfer, as seen by comparing the "High Flux, small" and "High flux, medium" results shown in Fig. 3.1. Evidently, the bubble departure process is very important in the heat removal process for the High Flux surface.

It is interesting to note that while the slope of the $\mathrm{q}^{\prime \prime} \sim \Delta T$ boiling curves for the smooth and High Flux surfaces are steep, the slope of the boiling curve for the Turbo-B surface is approximately unity. This implies that the heat transfer coefficients for the Turbo-B tubes varied only slightly with heat flux. The heat transfer coefficients for the High Flux and smooth tubes, on the other hand, depended strongly on the heat flux so that the two enhanced surfaces performed very differently in this respect. The weak heat flux dependency on the heat transfer coefficients for the Turbo-B tubes is possibly the result of thin film vaporization and will be discussed in Chapter 5 . 


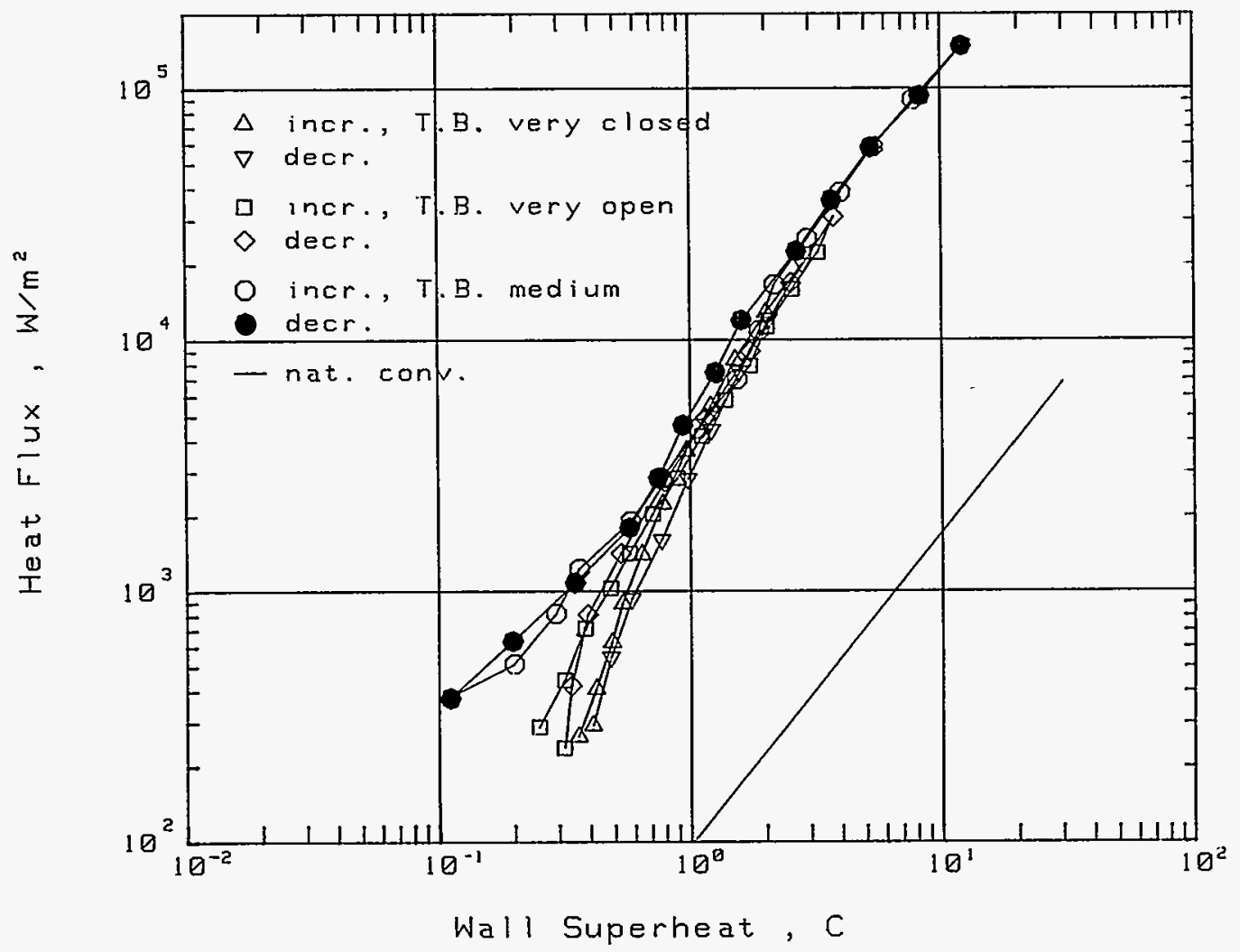

Figure 3.7.

Comparison of very open and very closed porosity Turbo-B tube pool data in $\mathrm{R}-113$ at $\mathrm{P}=103 \mathrm{kPa}$. 
A "least-squares" type of linear regression was performed on the pool boiling data for the three sets of surfaces used in the tube bundle experiment. The correlation curve and fully established nucleate pool boiling data are shown in Fig. 3.8 for the smooth, Turbo-B, and medium porosity High Flux surfaces. The equation for the smooth tube data is:

$$
q^{\prime \prime}=1.067\left(\Delta T_{\text {sat }}\right)^{4.012}
$$

The correlation approximates the data to within $2.4 \%$ in the range of heat fluxes from $2.3 \mathrm{~kW} / \mathrm{m}^{2}$ to $123 \mathrm{~kW} / \mathrm{m}^{2}$. The exponent on $\Delta T_{\text {sat }}$, which is the slope of the correlation curve, is very nearly the same as given by other researchers including Stephan and Abdelsalam (1980) who use a value of 3.92. For the Turbo-B data, the equation is:

$$
q^{\prime \prime}=6149\left(\Delta T_{\text {sat }}\right)^{1.283}
$$

which approximates the data to within $1.1 \%$ in the range of heat fluxes from $1.6 \mathrm{~kW} / \mathrm{m}^{2}$ to $152 \mathrm{~kW} / \mathrm{m}^{2}$. The exponent on $\Delta T_{\text {sat }}$ is close to unity and confirms that the heat transfer coefficient is a weak function of heat flux. For the High Flux data, the equation is:

$$
q^{\prime \prime}=4227\left(\Delta T_{\text {sat }}\right)^{2.033}
$$

which approximates the data to within $3.1 \%$ in the range of heat fluxes from 1.6 $\mathrm{kW} / \mathrm{m}^{2}$ to $43 \mathrm{~kW} / \mathrm{m}^{2}$. The value of the exponent on $\Delta T_{\text {sat }}$ is between that for the 


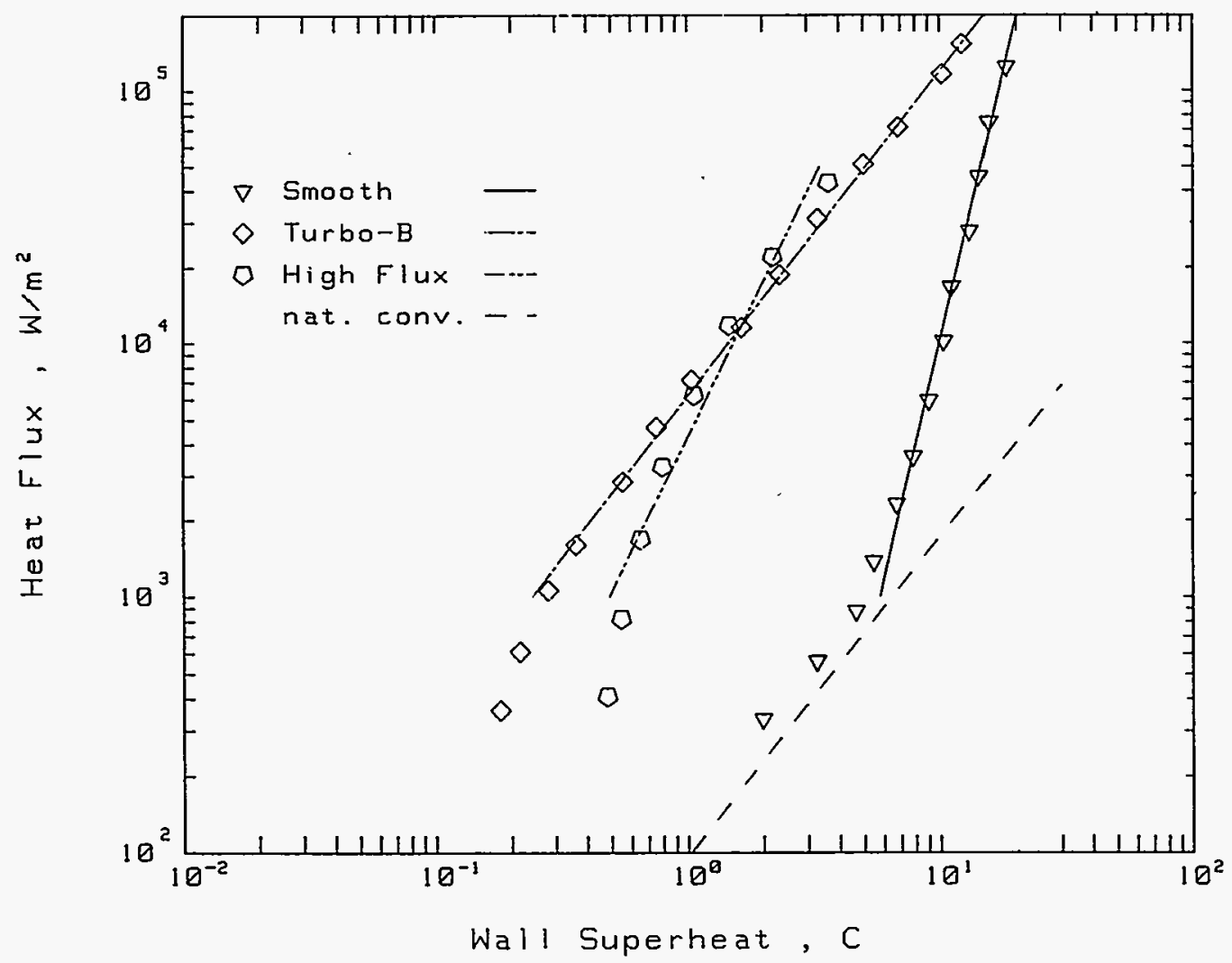

Figure 3.8. Pool boiling correlations for smooth, Turbo-B, and High Flux tubes at $\mathrm{P}=103 \mathrm{kPa}$. 
smooth and Turbo-B surfaces for the applicable range of heat fluxes. Note, however, that while a linear regression appears to correlate the data for the smooth and Turbo-B surfaces fairly well, a non-linear regression would have been necessary to predict the gradually decreasing slope in the data for the High Flux surface.

\section{Pure R-11 Results}

As seen in Fig. 3.9 for the smooth tube, the pool boiling data in pure $\mathrm{R}-11$ are nearly the same as in pure $\mathrm{R}-113$ for fully established nucleate boiling. The performance is only slightly better in $R-11$ than in $R-113$ at low heat fluxes (less than $\left.10 \mathrm{~kW} / \mathrm{m}^{2}\right)$.

The relative performance of the smooth in $R-113$ and $R-11$ can be determined by examining a model for nucleate pool boiling as described by Forster and Zuber (1955)

$$
\mathrm{q}^{\prime \prime}=\mathrm{C}_{1}\left[\begin{array}{llll}
i_{\mathrm{fg}}^{1 / 2} & \rho_{\mathrm{v}}^{3 / 8} & \rho_{\mathrm{L}}^{1 / 2} & c_{\mathrm{p}}^{11 / 24} \\
\hline \sigma_{\mathrm{L}}^{1 / 2} & T_{\mathrm{sat}}^{3 / 2} & \mu_{\mathrm{L}}^{7 / 24} & k_{\mathrm{L}}^{25 / 24}
\end{array}\right]\left(T_{\mathrm{w}}-T_{\text {sat }}\right)^{2}
$$

In general, the heat transfer coefficient in $\mathrm{R}-11$ should be similar to those in $\mathrm{R}-113$ due to their similar properties. For example, the vapor density and surface tension of $\mathrm{R}-113$ is slightly greater than for $\mathrm{R}-11$ but the thermal conductivity and heat of vaporization is slightly greater for $R-11$ than for $R-113$. At $100 \mathrm{kPa}$ and a given wall superheat, equation (3.4) predicts that the heat flux for $R-113$ is approximately $15 \%$ larger than for $\mathrm{R}-11$. Alternatively, the ratio $\left(T_{\mathrm{sat}} / p_{\mathrm{v}} i_{\mathrm{fg}}\right)^{\frac{1}{2}}$ used to predict the pressure effect also predicts a slightly larger heat transfer coefficient 


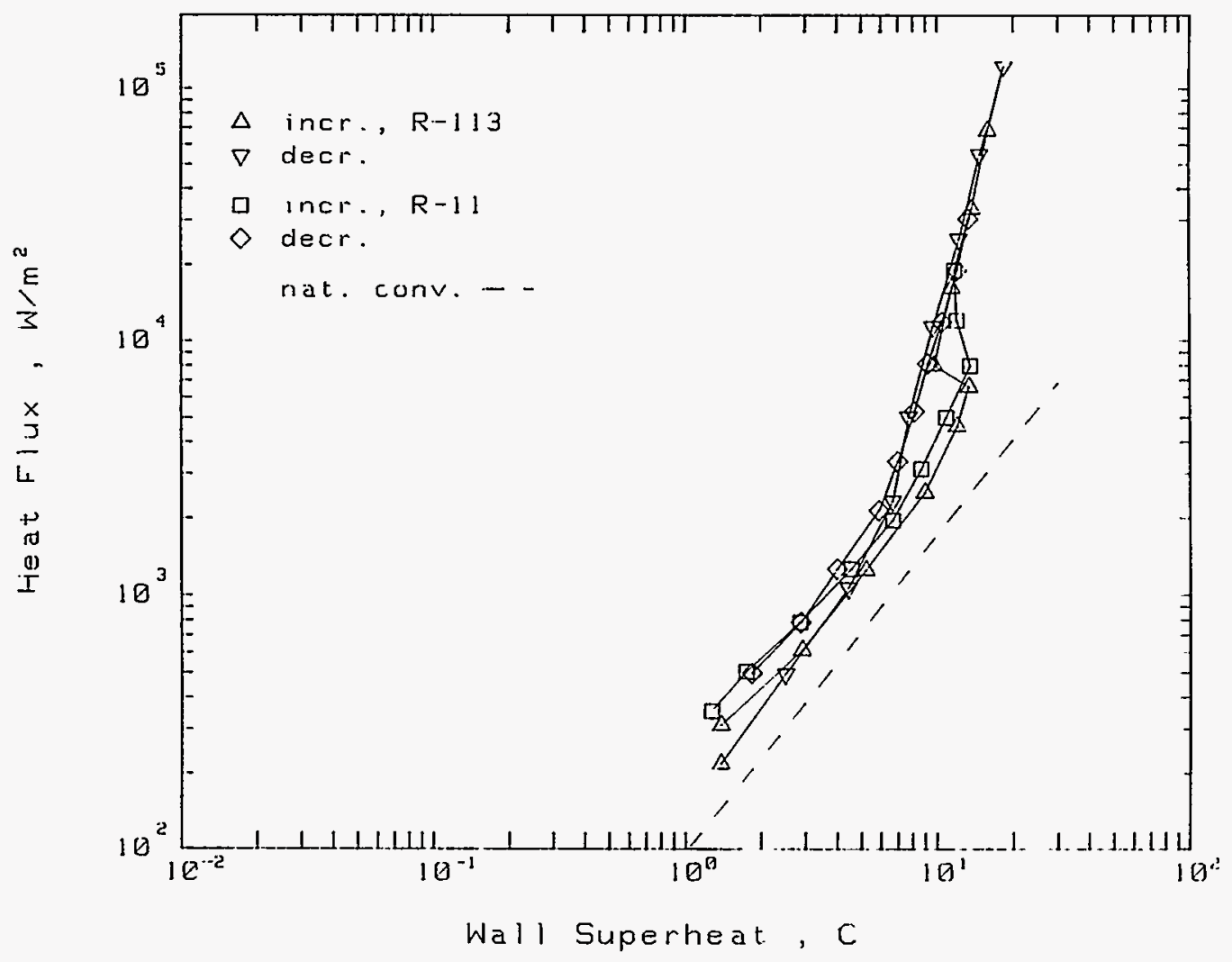

Figure 3.9. Saturated pool boiling curve for the smooth tube in pure $\mathrm{R}-11$ and pure $\mathrm{R}-113$ at $\mathrm{P}=103 \mathrm{kPa}$. 
in $\mathrm{R}-113$ than in $\mathrm{R}-11$. The lack of any significant differences between the experimental data obtained in $\mathrm{R}-113$ and $\mathrm{R}-11$ can be attributed to experimental uncertainty.

Figure 3.10 shows that the performance of the Turbo-B tube in $\mathrm{R}-11$ was better than in $\mathrm{R}-113$ for heat fluxes greater than $5 \mathrm{~kW} / \mathrm{m}^{2}$. The performance was poorer in $\mathrm{R}-11$ than in $\mathrm{R}-113$ for heat fluxes less than $1 \mathrm{~kW} / \mathrm{m}^{2}$ and was approximately equal for intermediate heat flux values. The performance of the small porosity High Flux surface, as shown in Fig. 3.11 was better in $\mathrm{R}-11$ than in $\mathrm{R}-113$ for heat flux values less than $30 \mathrm{~kW} / \mathrm{m}^{2}$ with the greatest increase in the performance occurring at the smallest heat flux value.

\section{Binary Mixture Results}

Figure 3.12 shows the boiling curves for the smooth tube in mixtures of $\mathrm{R}-113$ and $\mathrm{R}-11$. Boiling curves for the smooth tube in pure $\mathrm{R}-113$ and pure $\mathrm{R}-11$ are also shown for comparison. In general, the performance of the smooth surface does not change significantly with mixture concentration. The performance is only slightly better in pure $\mathrm{R}-113$ than in $25 \% \mathrm{R}-11$ for heat flux values greater than $10 \mathrm{~kW} / \mathrm{m}^{2}$. For a mixture of $50 \% \mathrm{R}-11$ and $50 \% \mathrm{R}-113$, the performance is only slightly better in the range from $1 \mathrm{~kW} / \mathrm{m}^{2}$ to $10 \mathrm{~kW} / \mathrm{m}^{2}$ than the performance in the same range of heat fluxes for a mixture with $25 \% \mathrm{R}-11$ and for pure $\mathrm{R}-113$. The smooth tube performed better in a mixture of $75 \% \mathrm{R}-11$ and $25 \% \mathrm{R}-113$ than in pure $\mathrm{R}-11$ for a range of heat flux values from 1 to $10 \mathrm{~kW} / \mathrm{m}^{2}$, worse for heat flux values less than $1 \mathrm{~kW} / \mathrm{m}^{2}$, and the same for heat flux values greater than $10 \mathrm{~kW} / \mathrm{m}^{2}$. 


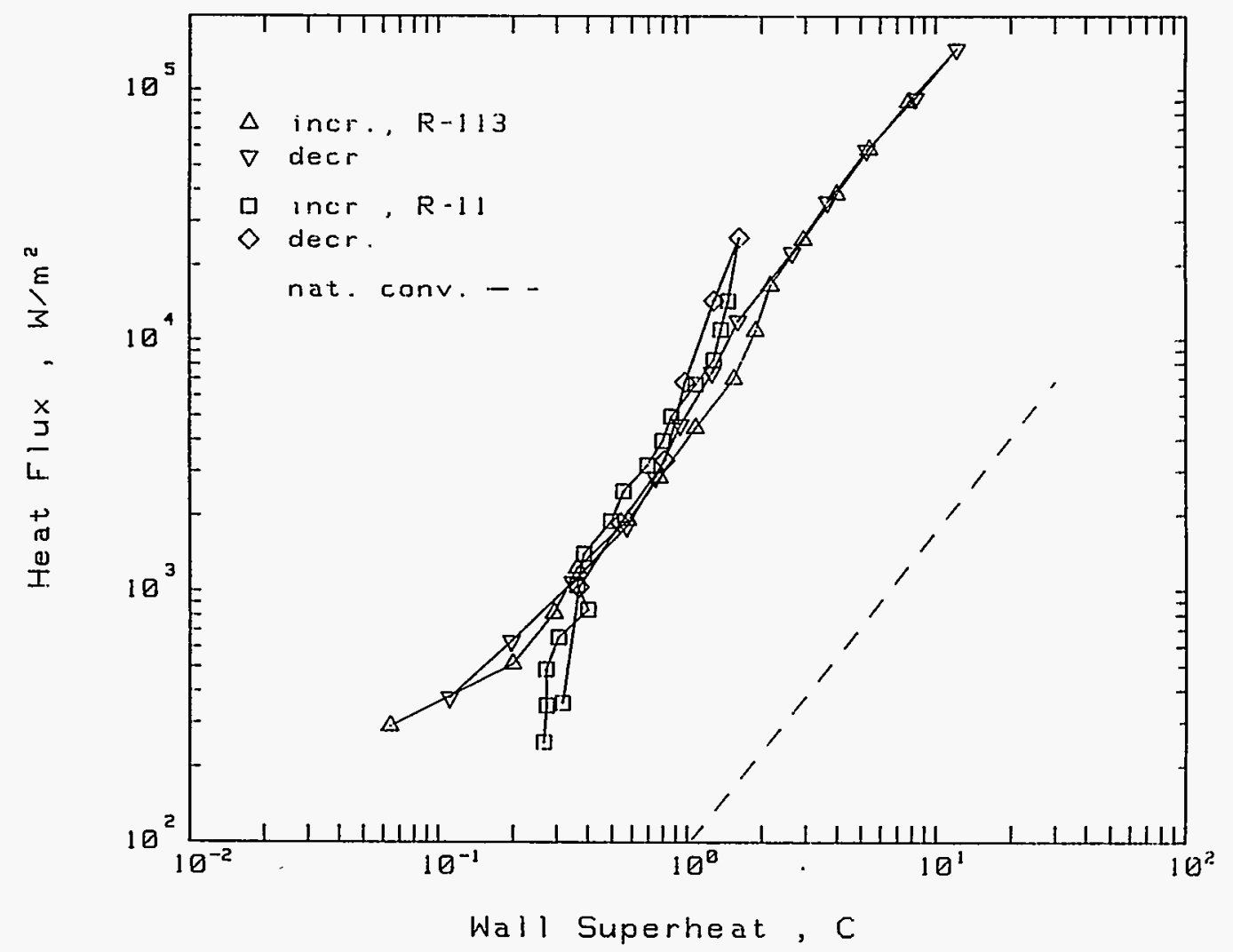

Figure 3.10. Saturated pool boiling curve for the Turbo-B tube in pure $R-11$ and pure $R-113$ at $P=103 \mathrm{kPa}$. 


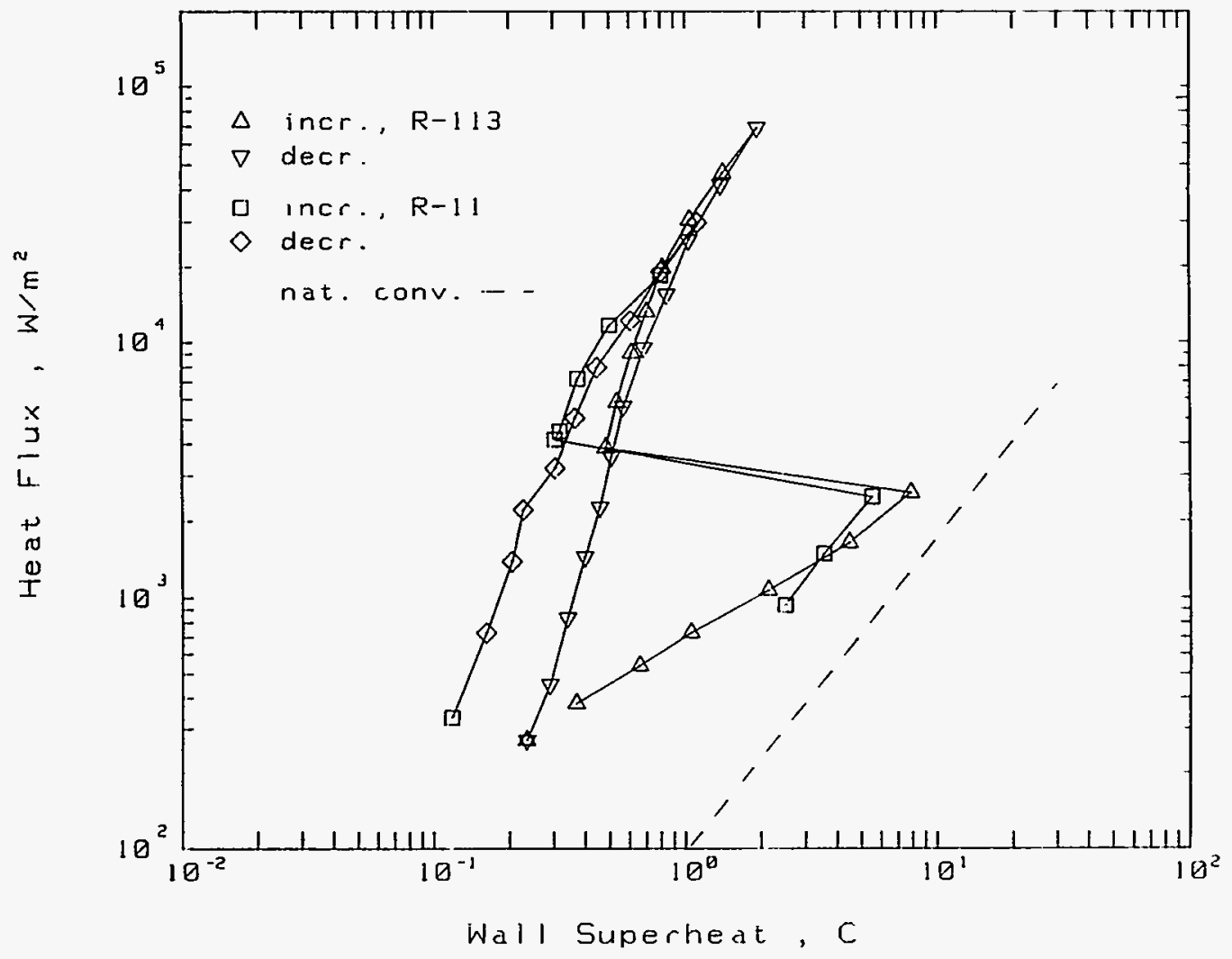

Figure 3.11. Saturated pool boiling curve for the High Flux tube in pure $\mathrm{R}-11$ and pure $\mathrm{R}-113$ at $\mathrm{P}=103 \mathrm{kPa}$. 


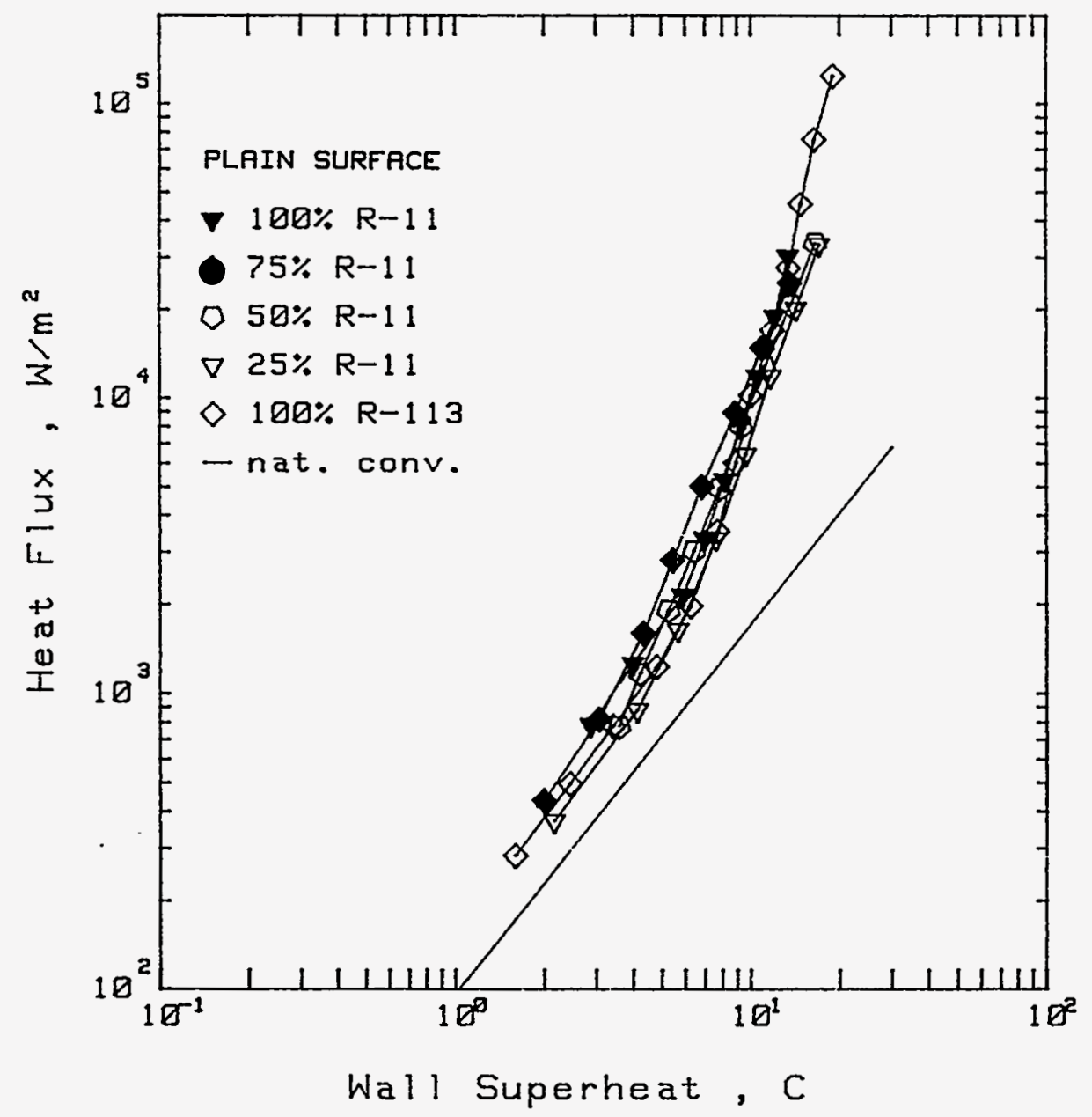

Figure 3.12. $\quad$ Saturated pool boiling curve for the smooth tube in mixtures of $\mathrm{R}-11$ and $\mathrm{R}-113$ at $\mathrm{P}=103 \mathrm{kPa}$. 
Boiling curves for the Turbo-B surface are shown in Fig. 3.13. Generally, the performance is best in pure $\mathrm{R}-11$, slightly poorer for pure $\mathrm{R}-113$, and as the amount of $\mathrm{R}-113$ in the mixture is increased, the boiling curve is shifted to the right. The same trends were found for the small porosity High Flux tube as shown in Fig. 3.14. It is interesting to note that for the High Flux surface, the onset of fully established nucleate boiling occurred between $2 \mathrm{~kW} / \mathrm{m}^{2}$ and $3 \mathrm{~kW} / \mathrm{m}^{2}$.

\section{Summary}

Pool boiling tests were conducted for each of the three surfaces so that reference values of the heat transfer coefficient could be obtained. Values of the heat transfer coefficient for the enhanced tubes were generally an order of magnitude larger than for the smooth tubes. Heat transfer coefficients for the porous surface were generally the largest; however, a large hysteresis in the boiling curve was found. Visual observations revealed that only patches of the High Flux surface nucleated initially and that nucleation covered more of the surface as the heat flux increased. Heat transfer coefficients for the Turbo-B tube, on the other hand, showed very little hysteresis in the boiling curve.

The pool boiling experiments conducted in pure $\mathrm{R}-11$ showed that, as for the pure R-113 experiments, the enhanced tubes performed better than the smooth tubes. Indeed, the performance of the smooth and High Flux tubes in pure R-11 was approximately equal to that in pure $R-113$, except for heat fluxes less than $10 \mathrm{~kW} / \mathrm{m}^{2}$ where the performance in $\mathrm{R}-11$ was slightly greater than in $\mathrm{R}-113$. The performance of the Turbo-B tube was also slightly better in $\mathrm{R}-11$ than in $\mathrm{R}-113$. 


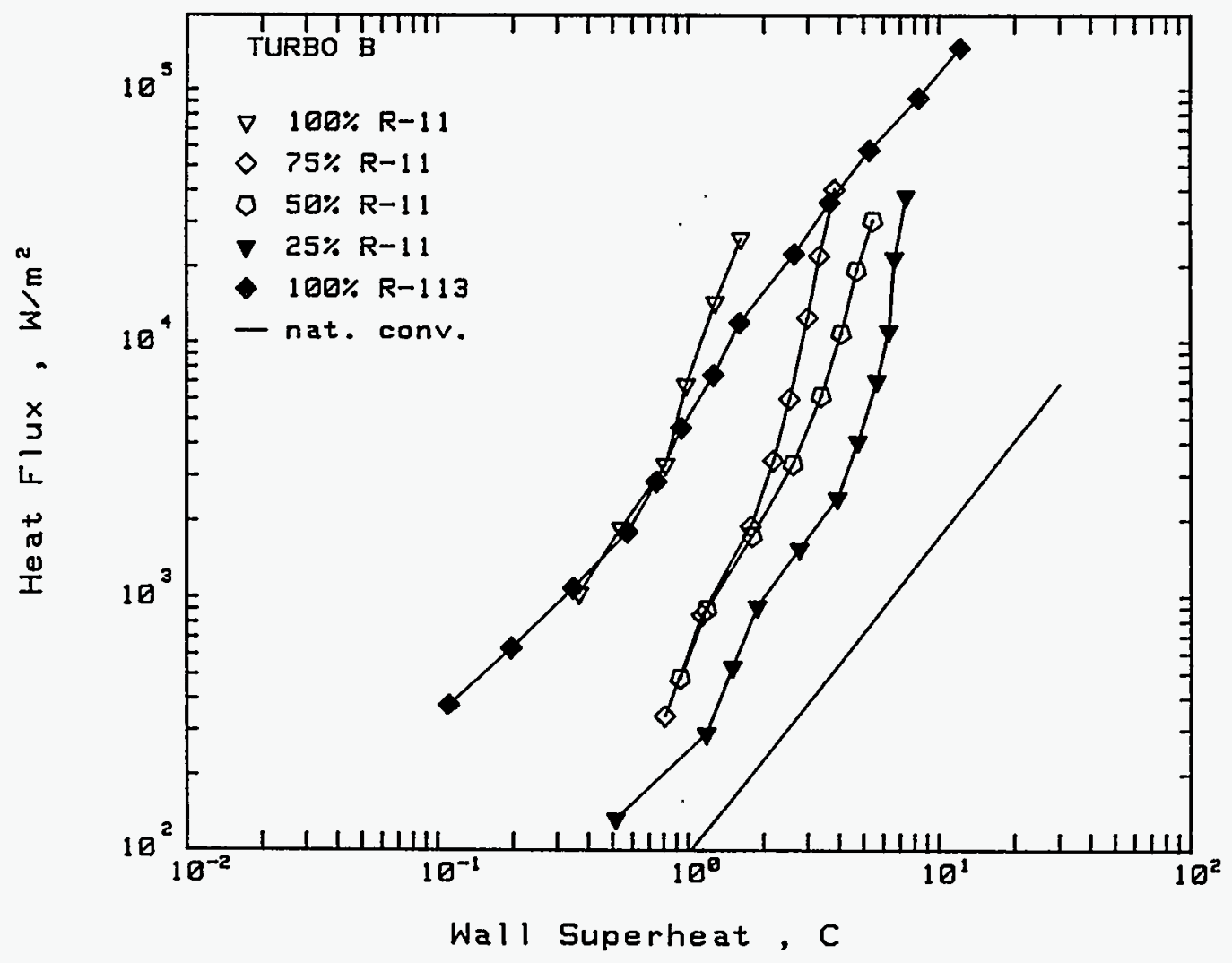

Figure 3.13. $\quad$ Saturated pool boiling curve for the Turbo-B tube in mixtures of $R-11$ and $R-113$ at $P=103 \mathrm{kPa}$. 


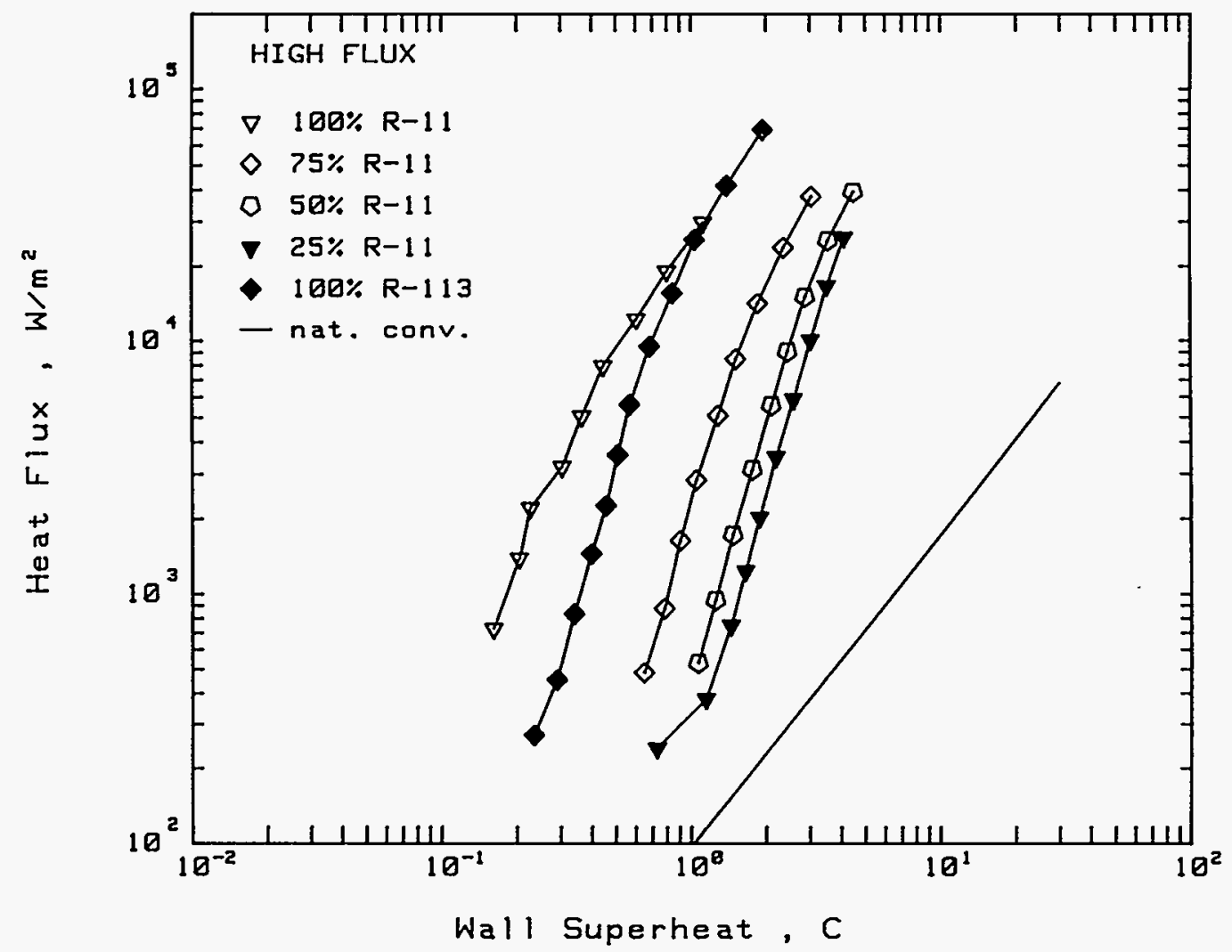

Figure 3.14. Saturated pool boiling curve for the High Flux tube in mixtures of $\mathrm{R}-11$ and $\mathrm{R}-113$ at $\mathrm{P}=103 \mathrm{kPa}$. 
Pool boiling heat transfer coefficients in fluid mixtures were less than those in pure fluids for all three surfaces. However, for a given heat flux and mixture concentration, the enhanced surfaces consistently performed better than the smooth tube. The High Flux tube performed slightly better than the Turbo-B tube, as was the case for the pure fluid experiments. The performance of all three surfaces decreased as the concentration of $\mathrm{R}-11$ decreased, with the largest reduction occurring in a mixture of $25 \% \mathrm{R}-11 / 75 \% \mathrm{R}-113$. 


\section{CHAPTER 4}

\section{EXPERIMENTAL TUBE BUNDLE APPARATUS \\ AND EXPERIMENTAL PROCEDURE}

An experimental tube bundle apparatus was designed to measure the thermal and hydraulic performance of tube bundles with a variety of enhanced surfaces. In particular, a need to obtain more information on the heat transfer coefficients for single tubes in pure refrigerants and refrigerant mixtures and pressure drops throughout a tube bundle guided the development of the apparatus.

In order to gain more information on the mechanisms involved in nucleate boiling in horizontal tube bundles, the experimental apparatus was designed so that measurements could be made of the mass flux, the pressure drop across the tube bundle, the power supplied to the tube bundle and individual tubes within the bundle, the fluid temperatures throughout the bundle, and the wall temperatures of individual tubes in bundles of tubes having different surface enhancements and various pitch-to-diameter ratios. The experimental apparatus permitted data to be obtained in saturated fluids at pressures from 2 to 6 bar, at heat flux values up to $80 \mathrm{~kW} / \mathrm{m}^{2}$, and for mass flux values (based on the minimum flow area) up to 500 $\mathrm{kg} / \mathrm{m}^{2} \mathrm{~s}$. Using this apparatus, the fluid properties, the quality, and pressure drop could be calculated throughout the tube bundle, and the heat flux, wall superheats, and heat transfer coefficients for individual tubes were determined. Visual observations provided qualitative information, such as the distribution of nucleation sites on the surface of the tube surface and phase distribution in the main flow, so that a mechanistic interpretation of the behavior of the smooth and enhanced tubes could be formulated. 
The tube bundle apparatus provided shellside boiling on horizontal tubes with flow on the tubeside in the vertical upflow direction in order to simulate the operation of kettle reboilers, submerged evaporators, waste heat boilers, and other similar heat transfer equipment. The outside tube diameter of $19.1 \mathrm{~mm}$ and staggered tube array were chosen as a typical of actual applications. The pitch-to-diameter ratios of 1.17 and 1.50 spanned the range of values commonly found in industry. The tube length and number of rows were sufficient to minimize the effects of the walls at the ends of the tubes and the walls on the sides of the bundle thereby approximating a predominantly one-dimensional flow around a center column of instrumented tubes.

Work by Cornwell et al. (1980) revealed that the flow through a kettle reboiler is non-uniform in general but that in the middle portion of the bundle the flow is predominantly upward. The tube bundle apparatus used in this project simulated this middle section of the bundle which is denoted by the shaded area in Fig. 4.1 for constant heat flux conditions. For the present work, the flow was forced through a section of a tube bundle with a known mass flow rate so that the inlet and local flow conditions could be quantified.

The tube bundle was designed so that the effect of lower tubes on the heat transfer coefficients of the upper tubes could be detected. Single-phase heat transfer coefficients exhibit a variation with tube row for the first three to five rows (ESDU 1973, Zukauskas 1987). However, Cornwell et al. (1980) reported a significant variation in the local two-phase heat transfer coefficients throughout a bundle of tubes in a square array with 17 rows with a constant heat flux of 20 $\mathrm{kW} / \mathrm{m}^{2}$ as shown in Fig. 4.2. A tube bundle with 15 rows was deemed large enough to detect the effect of location in the bundle on the heat transfer coefficient. 


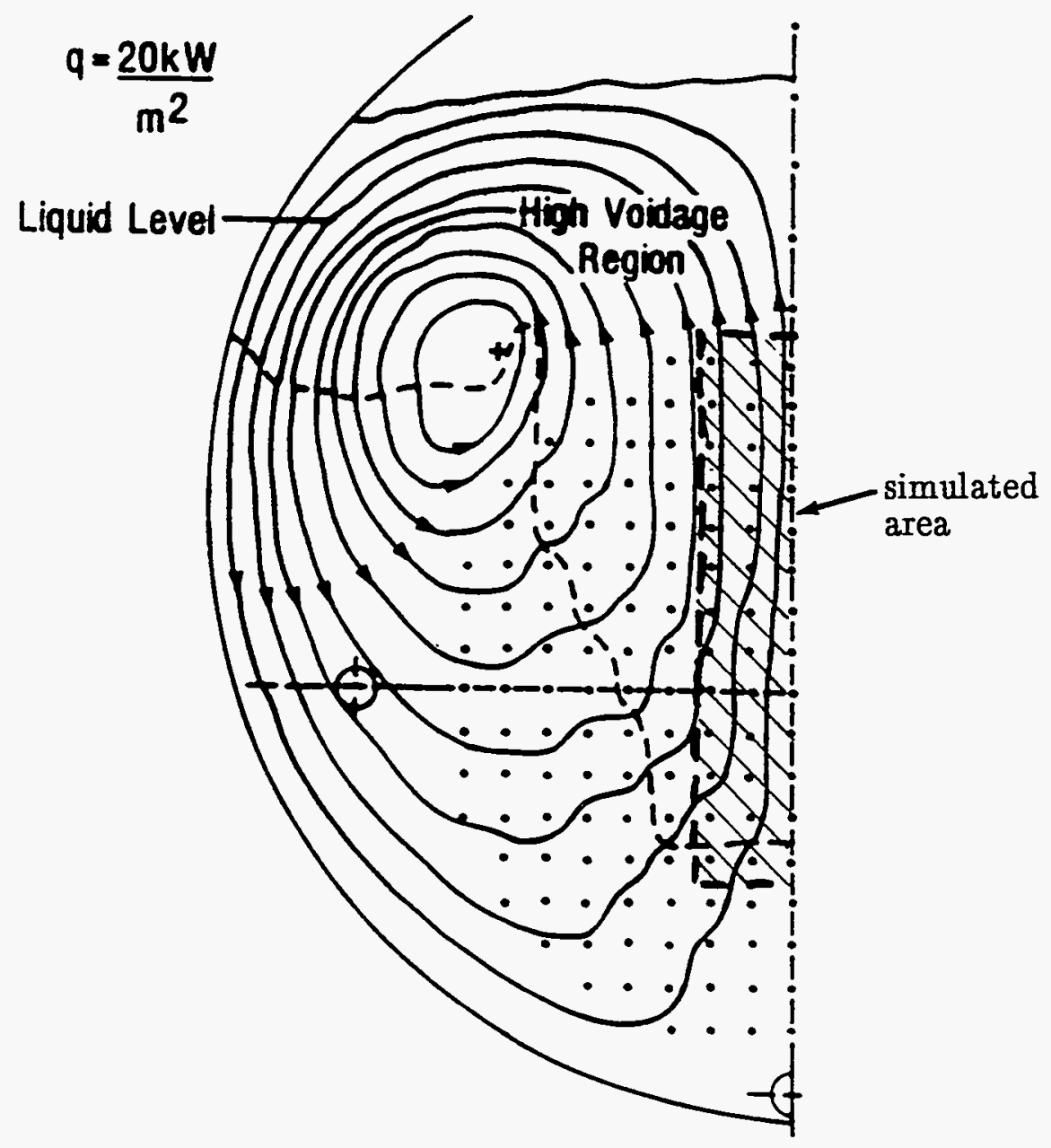

Figure 4.1.

Streamlines in a tube bundle (Cornwell et al. 1980) and area simulated by experimental apparatus. 


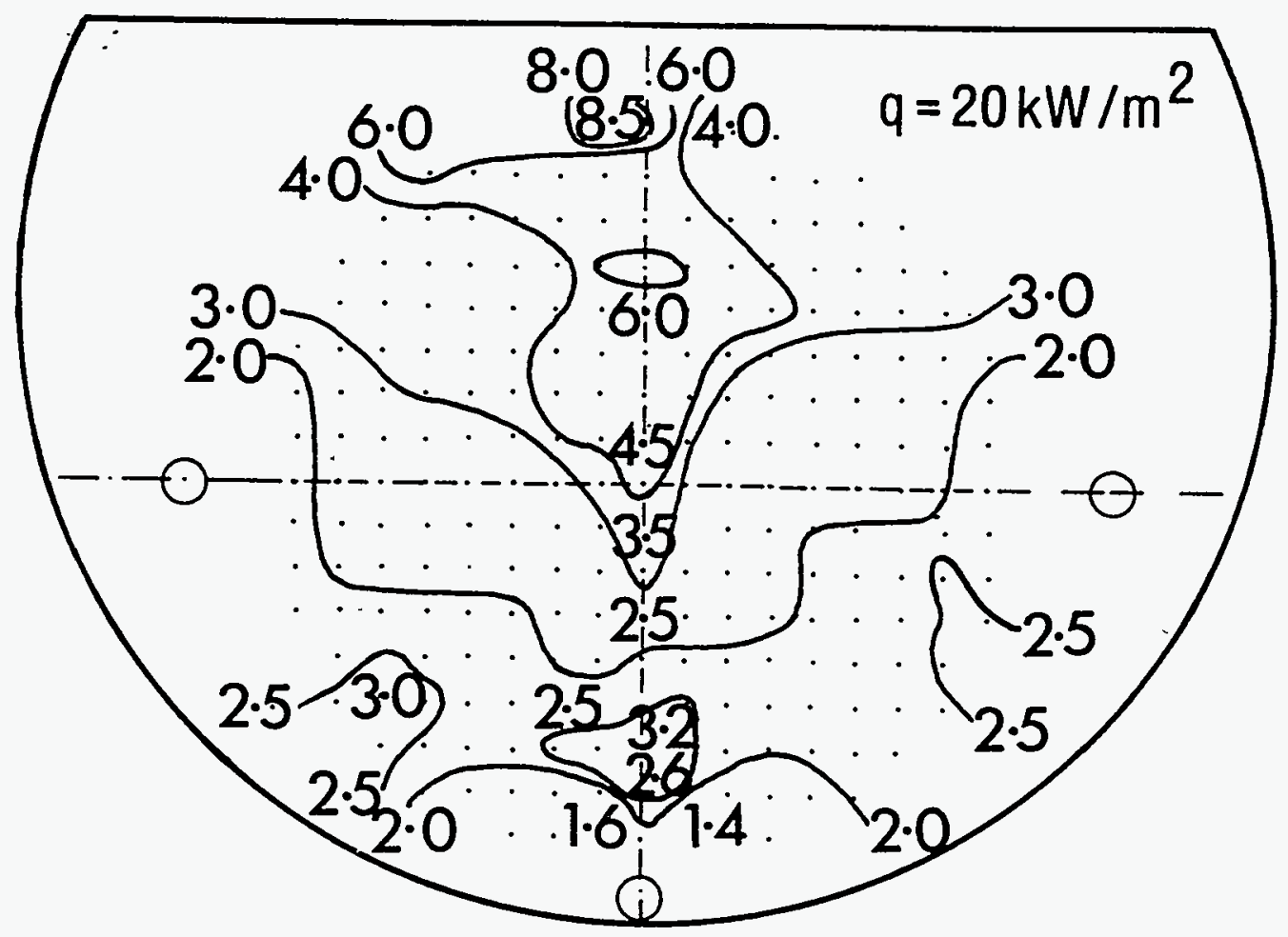

Figure 4.2. Lines of constant heat transfer coefficients $\left(\mathrm{kW} / \mathrm{m}^{2} \mathrm{~K}\right)$ at a heat flux of $20 \mathrm{~kW} / \mathrm{m}^{2}$ (Cornwell et al. 1980). 


\section{Description of the Refrigerant Flow Loop}

A refrigerant flow loop, which used pure $\mathrm{R}-113$, pure $\mathrm{R}-11$, and mixtures of both, was used to provide the appropriate operating conditions for the experimental test chamber. A schematic of the refrigerant loop is shown in Fig. 4.3 and was constructed by modifying an existing loop described by Dykas (1989). The flow loop contains the test chamber, a positive displacement pump, a storage tank, preheaters, condenser, and other assorted pieces of equipment.

The refrigerant was circulated through the loop by a Wanner Engineering Hydra-Cell Model D-25 positive displacement pump. The pump had a maximum capacity of $1.6 \mathrm{~L} / \mathrm{s}$ and was driven by a Fincor $5 \mathrm{hp}, 1725 \mathrm{rpm}$ electric motor. An adjustable-frequency inverter controlled the motor speed so that the pump could deliver any flowrate for the refrigerant up to the maximum. Pulsations in the flowrate at the outlet of the pump were dampened using a bladder-type Tobul accumulator. As a safety precaution with these CFC fluids, a pressure relief valve downstream of the pump allowed the refrigerant to flow into the storage tank in the event that flow through the rest of the loop was interrupted.

Refrigerant leaving the pump flowed through a Cuno model CT102 filter with filter cartridges rated at 100 microns. Downstream of the filter was a bypass branch with a bypass control needle valve which was used when the mass flow rate through the test chamber was to be reduced to very small values.

Refrigerant flow to the test section flowed through one of two flowmeters depending on the flow rate. Both were Flow Technology, Inc. turbine flowmeters. One flowmeter was calibrated to measure volume flow rates from $0.01 \mathrm{~L} / \mathrm{s}(0.2 \mathrm{gpm})$ to $0.13 \mathrm{~L} / \mathrm{s}(2 \mathrm{gpm})$ while the other was calibrated to measure flow rates from 


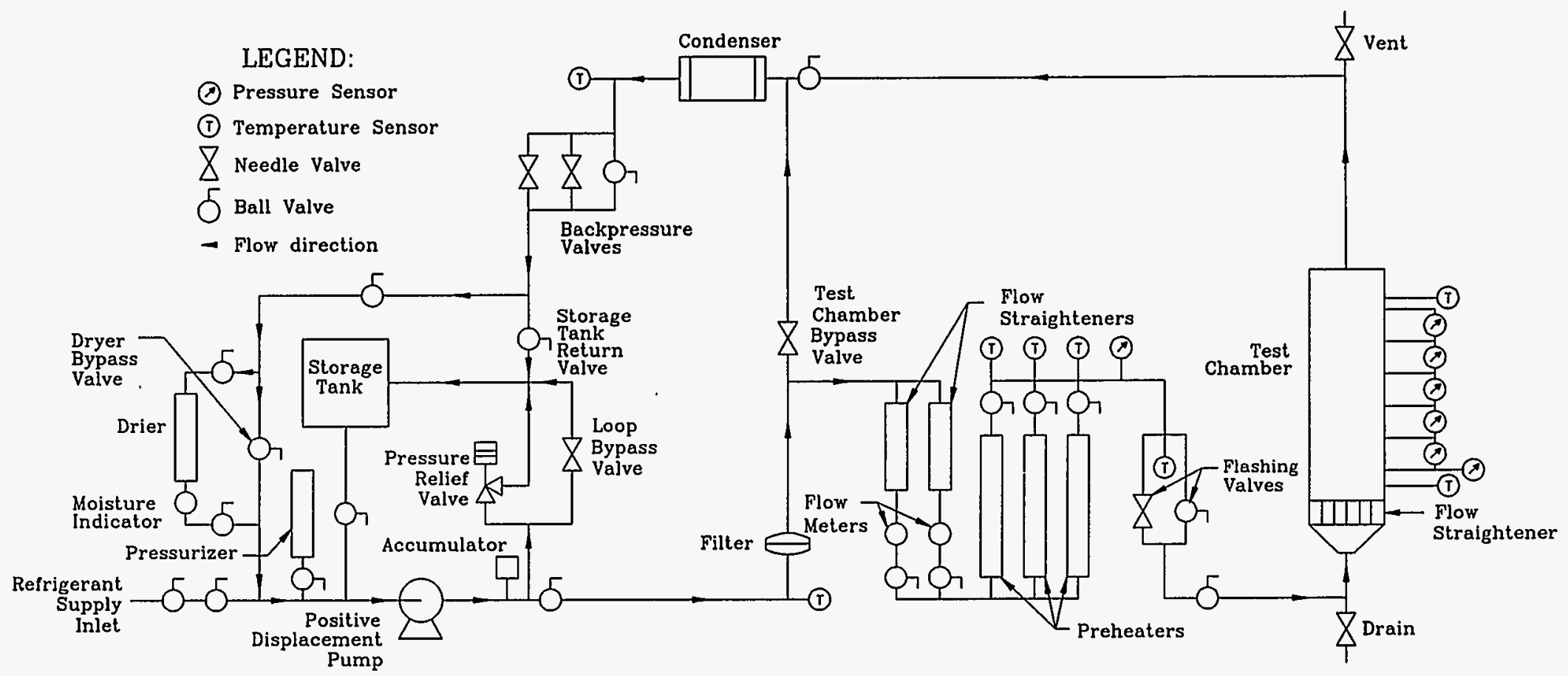

Figure 4.3. Schematic of the refrigerant flow loop. 
$0.13 \mathrm{~L} / \mathrm{s}(2 \mathrm{gpm})$ to $1.3 \mathrm{~L} / \mathrm{s}(20 \mathrm{gpm})$. Immediately upstream of each flowmeter were flow straighteners which eliminated any swirl in the flow and ensured a uniform entrance condition. A thermocouple measured the temperature of the refrigerant upstream of the flowmeters so that the density could be calculated and the mass flowrate determined.

From the flowmeters the refrigerant flowed through a bank of three preheaters in parallel. Each was an Indeeco immersion-type electric heater. Two of them were rated at $20 \mathrm{~kW}$ each and had separate control switches so that they could be set independently either fully on or off. The voltage supplied to the third preheater was controlled by a variable transformer so that any power level from 0 to $15 \mathrm{~kW}$ could be obtained. Thermocouples were installed at the exit of each preheater to monitor the temperature of the refrigerant in order to prevent the flow from becoming saturated.

Slightly downstream of the bank of preheaters was a pressure gauge, a thermopile consisting of four thermocouples, and a set of flashing valves to control the pressure in the preheaters. The pressure gauge was used in conjunction with the thermocouple readings at the exit of the preheaters to ensure that the refrigerant did not reach saturation and that liquid only flowed from the preheaters. Maintaining a single-phase liquid in the preheaters permitted the straight-forward calculation of the enthalpy of the refrigerant from the temperature measurement of the liquid at the exit of the preheaters.

The refrigerant flowed through insulated stainless steel piping from the preheaters through the flashing valves to the test chamber containing the tube bundle. The test chamber was oriented vertically so that the refrigerant flowed upward. At the inlet of the tube bundle was a thermocouple to measure the 
refrigerant temperature and a pressure tap connected to two bourdon-tube pressure gauges that were used to monitor the operating pressure in the test chamber. One pressure gauge was used to measure gauge pressures from 0 to $0.275 \mathrm{MPa}$ (40 psi) and the other was used to measured gauge pressures up to $1.034 \mathrm{MPa}$ (150 psi). At the exit of the test chamber was attached a $50.8 \mathrm{~mm}$ ( 2 in.) stainless steel pipe that continued vertically upwards to a vent used in the refrigerant degassing process.

Slightly upstream of the vent, the piping branched to a water-cooled condenser where the refrigerant vapor was condensed. Any refrigerant that was bypassed around the test chamber was mixed with the refrigerant from the test chamber at a location just upstream of the condenser. The entire flow was then cooled to approximately $15^{\circ} \mathrm{C} \pm 5^{\circ} \mathrm{C}$ depending on the temperature of the cooling water. Downstream of the condenser was a set of three backpressure valves used to control the pressure in test chamber and condenser.

The refrigerant then flowed through a Sporlan drier that used a desiccant to remove hydrochloric acid, hydrofluoric acid, and moisture from the refrigerant. A moisture-sensitive element that changed color when the moisture content of the refrigerant was above $20 \mathrm{ppm}$ was installed downstream of the drier and was used to verify that the drier was operating properly. From the drier, the refrigerant flowed either to the pump inlet or the storage tank. The storage tank had an opening in the top under which was mounted a water-cooled condenser. 


\section{Detailed Description of the Test Chamber}

The tube bundle test chamber was developed specifically for this study to produce shellside boiling over horizontal tubes where the predominant flow direction is vertically upward. The chamber consisted of five major components: shell, mounting plate, window, side-walls, and heated tubes. The shell was the main component in forming the enclosure and is shown in Fig. 4.4. The top, bottom, sides, and flanges were made of $6.35 \mathrm{~mm}$ (1/4 in.) thick stainless steel. A $25.4 \mathrm{~mm}$ (1 in.) diameter pipe was connected to the inlet of the test chamber shell so that the test chamber could be easily installed in the refrigerant flow loop. The inlet to the test chamber shell consisted of brass screens, a diverging section containing flow vanes, and a section containing a honeycomb flow straightener, as shown in Fig. 4.5. The screens were placed at the end of the inlet pipe so that any fluid entering the test chamber was evenly distributed across the flow area. The stainless steel flow vanes allowed for a smooth transition from the inlet pipe to the rectangular body of the test chamber. Any swirl in the flow was removed by the stainless steel flow straightener.

The mounting plates were constructed so that 68 heating tubes could be securely sealed in the test chamber with a precise orientation and spacing. The mounting plate also provided the means for sealing the pressure taps and thermocouple ports. The two mounting plates were built out of $12.7 \mathrm{~mm}(1 / 2 \mathrm{in}$.) thick 304 stainless steel. The holes used for mounting the heated tubes were spaced in an equilateral triangle of 5 columns and 15 rows with a pitch-to-diameter ratio of 1.50 on one and 1.17 on the other. The mounting plates were bolted, one at a time, to the flange of the test chamber shell and were easily interchanged. As seen 


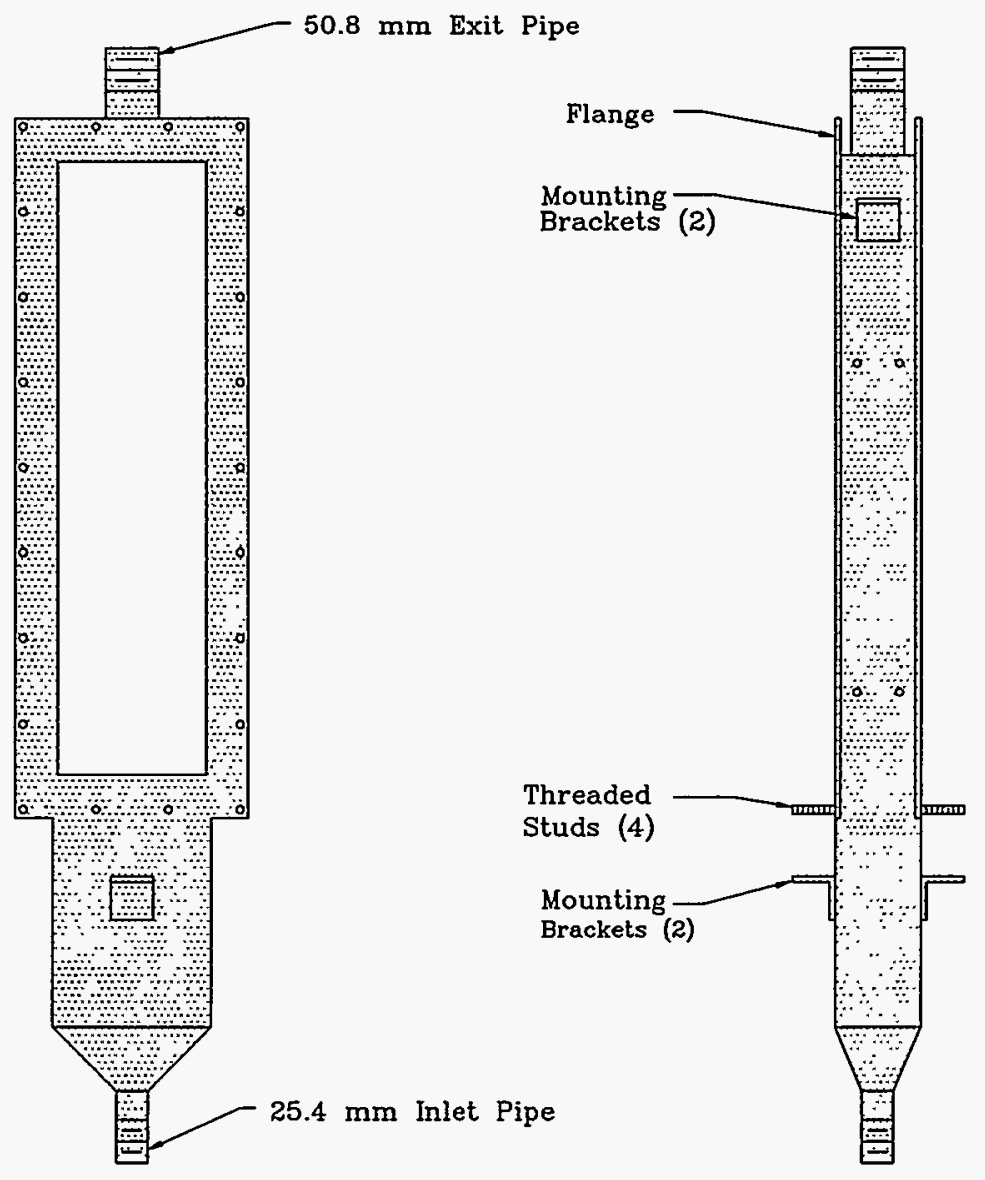

(a) Front view

(b) Side view

Figure 4.4. Schematic of the test chamber shell. 


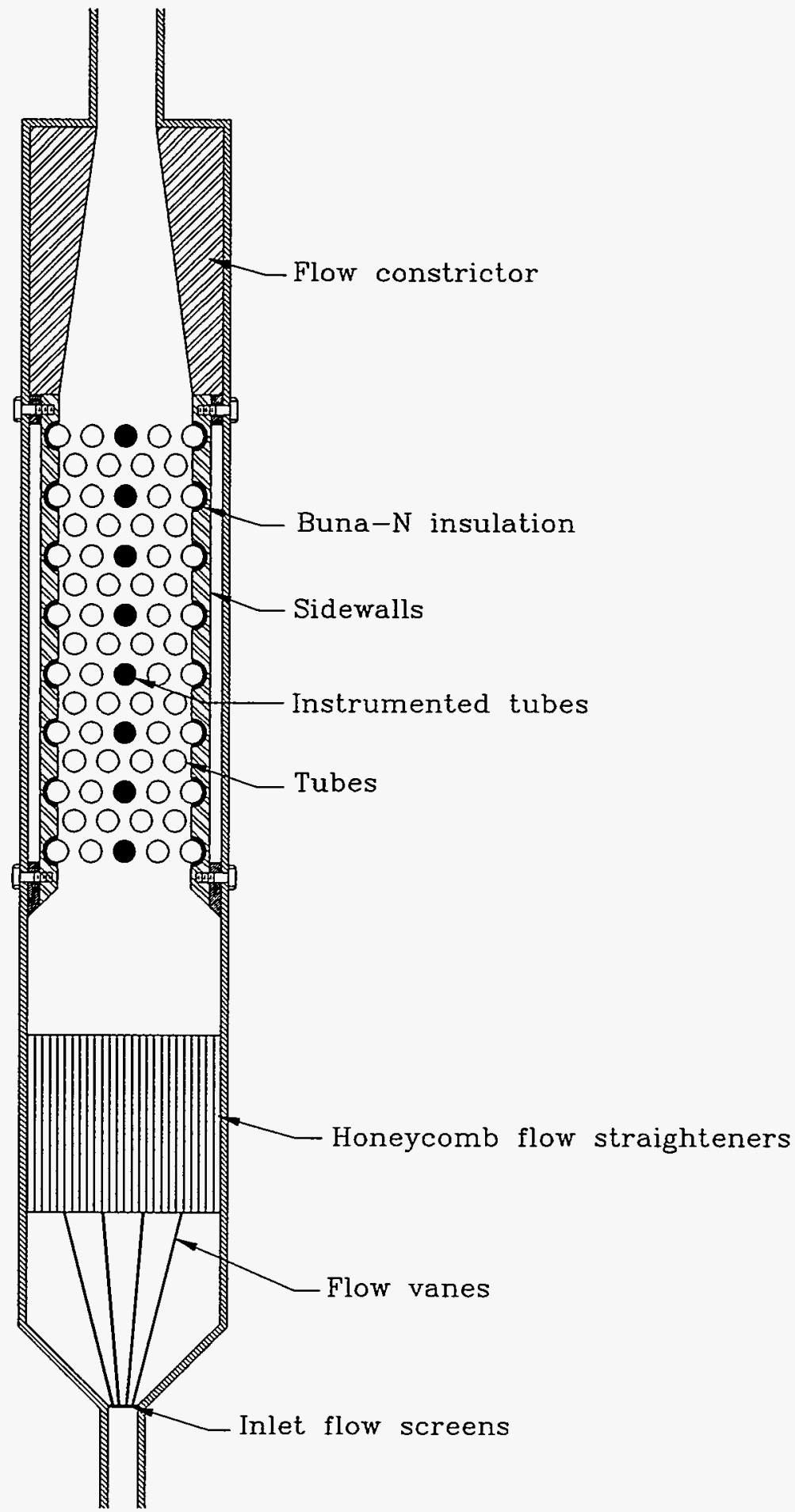

Figure 4.5. Cross section of the test chamber. 
in Fig. 4.5, an o-ring groove was machined around the perimeter of the mounting plate next to the bolt holes. The mounting plates were sealed with a Buna-N o-ring and a soft Teflon cord.

A cross section of the holes used for mounting the heated tubes is shown in Section A-A of Fig. 4.6. The holes incorporate o-ring grooves, and Buna-N o-rings were used to seal the openings. Six pressure taps were drilled in the mounting plate between tube holes in the middle column so that the local saturation temperature and two-phase pressure drop could be measured. The pressure taps were located at the inlet, exit, and just upstream of the third, seventh, eleventh, and fifteenth tube rows. The pressure taps were connected in such a way that the pressure drop between successive taps could be measured by a Validyne pressure transducer. Thermocouple ports were constructed in the mounting plates just upstream of the bundle and at the exit so that fluid temperatures could be measured. Swagelok fittings with pipe threads to provide sealing were threaded into the mounting plate at each thermocouple port. Stainless steel $1.6 \mathrm{~mm}$ o.d. hypodermic tubing was inserted through the Swagelok fittings and protruded 50.8 $\mathrm{mm}(2 \mathrm{in}$.) into the flow channel. Copper-constantan thermocouples were sealed inside the tubing using epoxy such that only the bead of the thermocouple was exposed to the flow.

The window provided easy viewing of the flow so that a qualitative assessment of the hydrodynamics could be made. Lexan was used because of its chemical compatibility with $\mathrm{R}-113$ and $\mathrm{R}-11$, machinability, and clarity. Two layers of Lexan were used. The inner layer was made of $6.35 \mathrm{~mm}(1 / 4 \mathrm{in}$.) thick Lexan and was constructed with bolt holes and an o-ring groove so that the window could be sealed to the test chamber shell flange with a Buna-N o-ring and a soft 


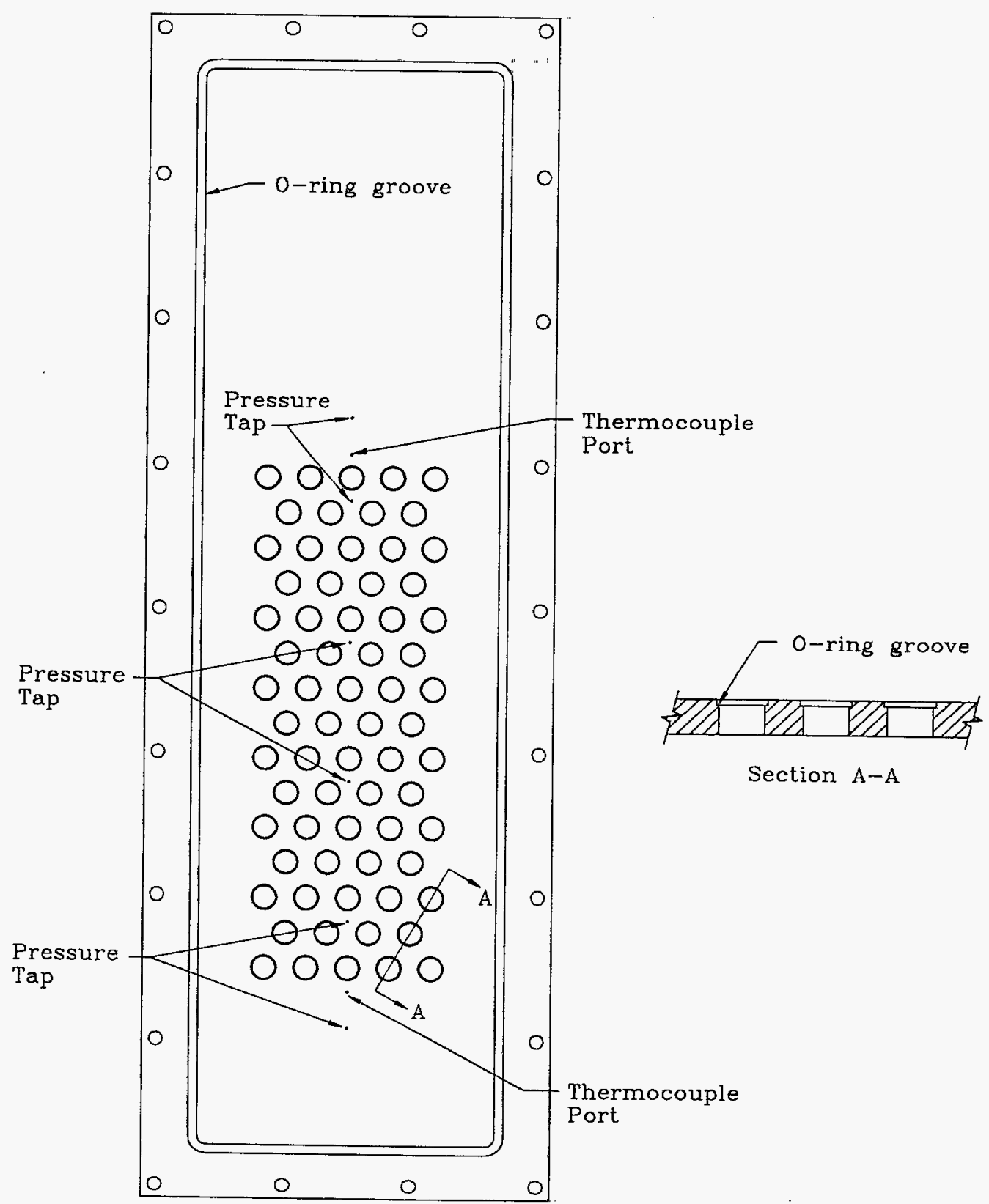

Figure 4.6. Schematic of the test chamber mounting plate. 
Teflon cord (the same as for the mounting plate). The outer layer was made of 25.4 $\mathrm{mm}$ ( 1 in.) thick Lexan to reinforce the inner layer and to prevent the window assembly from deflecting when subjected to the operating pressures.

The heated tubes were attached horizontally to the mounting plate. The middle column of tubes was instrumented with thermocouples which penetrated axially through to the midpoint of the heated surface. The construction of the instrumented tubes, regardless of the type of surface, was identical to the construction of the High Flux tubes used in the pool boiling experiment as described in Chapter 2. Those heated tubes that were not in the middle column also were constructed identically to the High Flux tubes used in the pool boiling experiment, except for the absence of thermocouple wells. The $101.6 \mathrm{~mm}$ (4 in.) long, $19.1 \mathrm{~mm}$ (3/4 in.) o.d. copper tubes were attached to the mounting plate with snap-rings, and the joints between the tubes and the mounting plate were sealed with Buna-N o-rings. The end of the tube next to the window was sealed with a Buna-N disc that was attached to the tube with epoxy.

Cartridge heaters were inserted into the end of the tube protruding through the mounting plate. The cartridge heaters were identical to those used in the pool boiling experiment and were connected to one of three variable transformers, as shown in Fig. 4.7. Each variable transformer supplied a variable voltage (up to 240 V) to a pair of bus bars and the leads from the cartridge heaters were connected electrically in parallel to one of the pairs of bus bars. Approximately one-third of the cartridge heaters were connected to each set of bus bars. Three shunts (each 50 amp $-50 \mathrm{mV}$ ) were used to measure the current through the bank of cartridge heaters; one shunt was used to measure the current from each variable transformer. In addition to the shunts shown in Fig. 4.7, a battery of eight shunts 


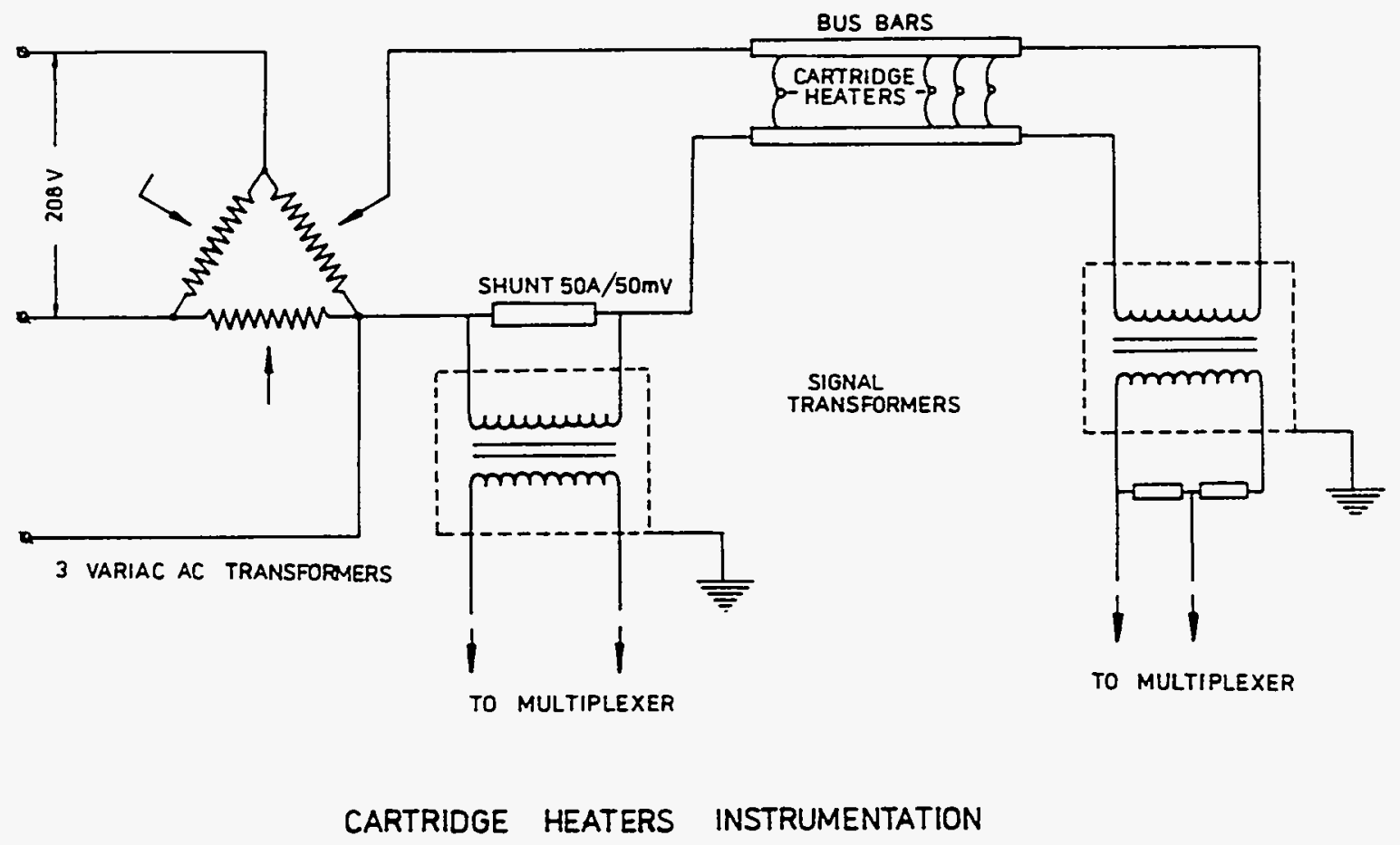

Figure 4.7.

Electrical power connections and instrumentation for the cartridge heaters (Dykas 1989). 
(each $5 \mathrm{amp}-200 \mathrm{mV}$ ) was installed. One shunt was installed in a lead from the bus bar to each of the instrumented tubes so the current could be measured individually.

In order to minimize the effect of the outside walls, the outside two columns of heated tubes were inbedded half way into the sidewalls. Because these tubes had half of the heated surface area of the other tubes, the power supplied was reduced by half also. This was accomplished by inserting a "snubber circuits" into a lead from the bus bars to each of the cartridge heaters that were installed in the outside columns. The snubber circuits, shown in Fig. 4.8, were adjusted so that the voltage supplied to these cartridge heaters was reduced by a factor of $1 / \sqrt{2}$, thereby reducing the power supplied by half.

A computer controlled data acquisition system (DAS) was used to collect and generate primary data. The DAS consisted of a Hewlett-Packard family 9000 , model 310 micro-computer, a Hewlett-Packard 3497A data acquisition/control unit, a Hewlett-Packard 3457A digital multimeter, and a Kaye Instruments model K170-75C thermocouple ice point reference. A maximum of 60 thermocouple signals could be measured by the DAS. The thermocouples were connected in series with the ice point reference junction, and the voltage was measured across both the thermocouple and the reference junction by the multimeter. An additional 25 voltage signals could also be input to the DAS. The multimeter could measure the magnitude of d.c. signals, the r.m.s. values of a.c signals, or the frequencies of the signals input to these channels. 


\section{LEGEND}

a anode

c cathode

g gate

C1 Capacitor, $0.1 \mathrm{pf}, 25 \mathrm{~V}$

C2 Capacitor, $0.1 \mathrm{pf}, 400 \mathrm{~V}$

D1 Diode, $1 \mathrm{~A}, 400 \mathrm{~V}$

D2 Diode, 12 A, $600 \mathrm{~V}$

R1 Resistor, $100 \mathrm{ohm}, 0.5 \mathrm{~W}$

R2 Resistor, $68 \mathrm{kohm}, 1 \mathrm{~W}$

R3 Resistor, 47 ohm, $0.5 \mathrm{~W}$

T1 Transistor, $50 \mathrm{~mA}, 35 \mathrm{~V}$, RCA model SK9123

SCR SCR, 12.5 A, 600 V, RCA model SK3527

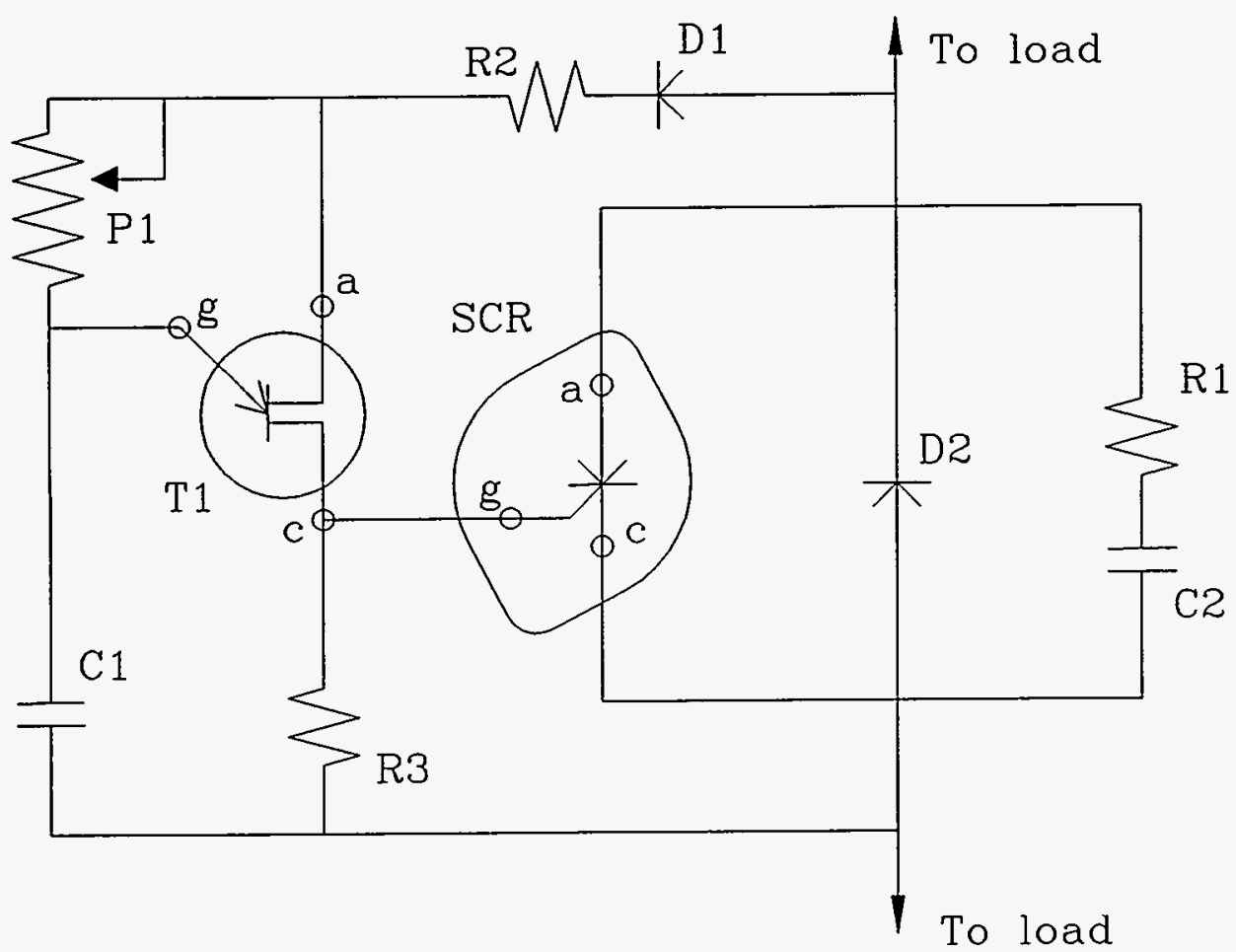

Figure 4.8.

Electrical snubber circuits for the heated tubes in the sidewalls. 


\section{Experimental Procedure}

The flow loop was filled with refrigerant by connecting storage drums containing the refrigerant to the refrigerant supply inlet shown in Fig. 4.2. The pump was turned on, and the return lines from the storage tank and dryer were closed in order to draw the liquid refrigerant into the flow loop. The pump forced the liquid through the loop and into the storage tank where air was allowed to escape through the top. The condenser in the top of the storage tank prevented refrigerant vapor from escaping through the top of the storage tank. In this way, the loop was filled with very little refrigerant being allowed to escape to the atmosphere.

Prior to taking data in pure refrigerant, any noncondensable gas dissolved in the refrigerant had to be removed. Therefore, a valve was installed at the high point in the refrigerant loop, which was directly above the test chamber, so that any dissolved air could be vented as it came out of solution. Before each day of testing, the vent was opened and refrigerant was circulated through the flow loop. The pressure at the inlet to the tube bundle was set at approximately $30 \mathrm{kPa}(4 \mathrm{psi})$ in order to overcome the hydrostatic head necessary for liquid to fill the horizontal pipe branching to the condenser (see Fig. 4.9). The liquid was then heated to within $0.1^{\circ} \mathrm{C}$ of the pure refrigerant saturation temperature at the inlet to the tube bundle. As the refrigerant approached the saturation temperature, the noncondensable gas came out of solution, and its presence could easily be observed in the test chamber window. The refrigerant was pumped from the preheaters to the vent at very low mass flow rates, about $0.2 \mathrm{~kg} / \mathrm{s}$, in order to minimize the mixing of the gas and refrigerant and to aid in the detection of gas bubbles. The 


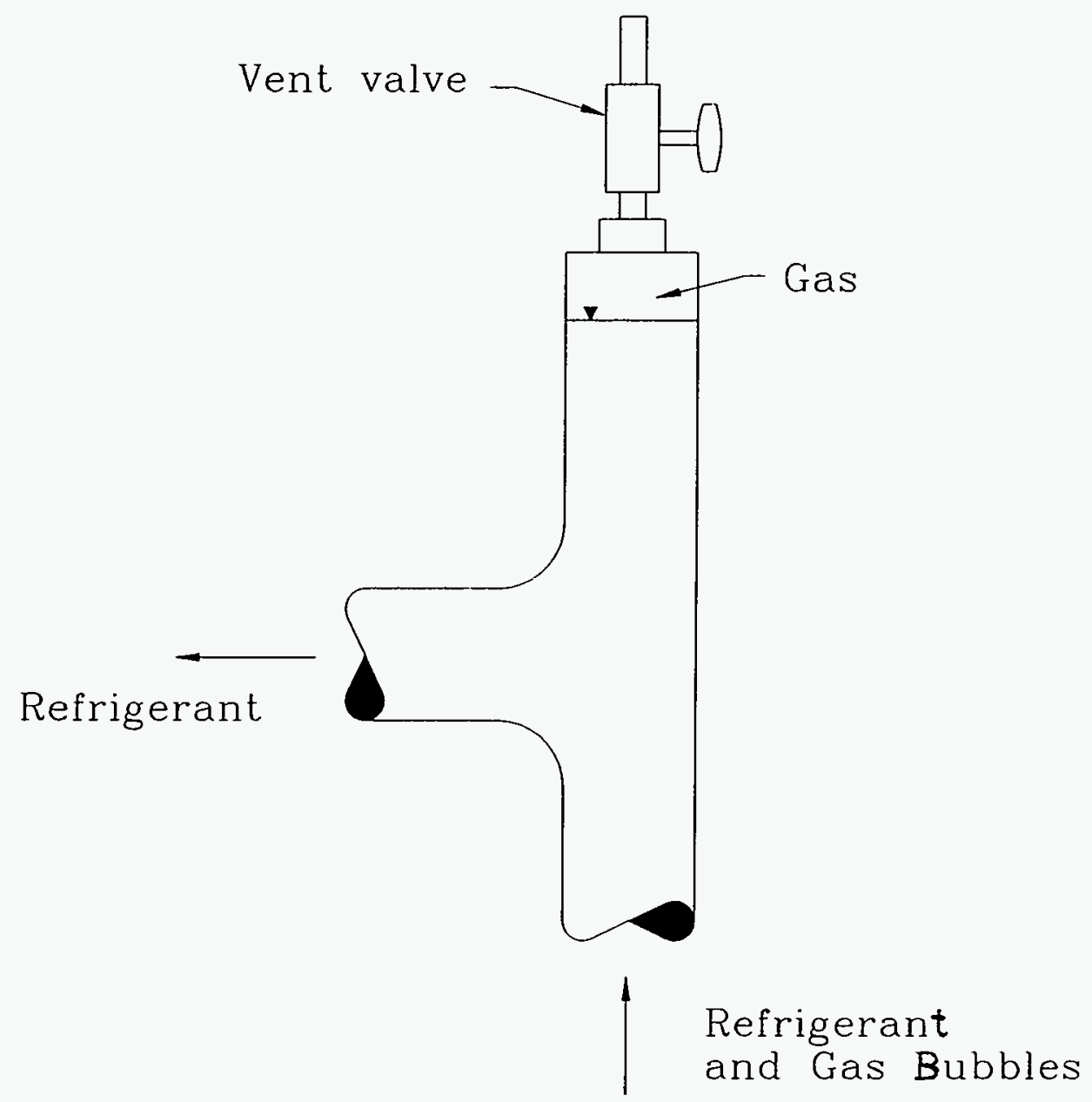

Figure 4.9. Schematic of the flow loop venting apparatus. 
velocity of the refrigerant was approximately $0.125 \mathrm{~m} / \mathrm{s}$ through the inlet pipe, $0.0333 \mathrm{~m} / \mathrm{s}$ through the tube bundle, and $0.0625 \mathrm{~m} / \mathrm{s}$ through the outlet pipe.

The amount of dissolved gas in saturated $\mathrm{R}-113$ was measured using an Aire-ometer. The amount of air before degassing was $46 \% \pm 1 \%$ by volume. After the refrigerant was heated to within $0.1^{\circ} \mathrm{C}$ of saturation and no bubbles were observed through the window, the amount of dissolved gas was again measured and was found to be less than $1 \%$ by volume. Therefore, the degassing process was shown to effectively remove the dissolved air.

The procedure for obtaining the desired operating conditions for pure refrigerants in the test chamber consisted of establishing the desired flowrate, test chamber inlet pressure, inlet fluid conditions, and heat flux from the bundle of heated tubes. Initially, all of the valves were opened except for the test chamber bypass valve, storage tank return valve, vent, and flow loop bypass valve. The pump was turned on and the flowrate was adjusted by changing the speed of the pump motor, using the the frequency controller. When the test chamber bypass valve was closed, all of the liquid from the pump flowed through the tube bundle. When the mass flux through the tube bundle was less than $50 \mathrm{~kg} / \mathrm{m}^{2} \mathrm{~s}$ and the pressure was $600 \mathrm{kPa}$, the speed of the pump motor was too low to prevent overheating. For these operating conditions, the test chamber bypass valve was adjusted so that liquid from the pump could flow both through the tube bundle and the storage tank. This allowed for an increase in the flow from the pump without increasing the flow through the tube bundle so that pump motor speed could be increased and overheating could be prevented. 
The flashing valves were then adjusted so that the pressure in the preheaters was approximately 3.4 bar ( $50 \mathrm{psi}$ ) above the intended operating pressure in the test chamber. Next, the pressure in the test chamber was increased to the desired operating pressure by adjusting the backpressure valves. An adjustment of the pump motor frequency was often necessary after changing the pressure in the preheaters or test chamber and was always necessary if the test chamber bypass valve was not c'osed.

The test chamber inlet fluid temperature was then increased by applying heat from the preheaters. In addition, water was circulated through the condenser so that the heat added to the refrigerant by the preheaters was removed before the refrigerant returned to the pump inlet. The number of preheaters turned on and the power level setting for the variable voltage preheater depended on the mass flow rate of the refrigerant and the desired fluid temperature at the output of the preheaters. Because the maximum power available from the variable preheater was not as large as from the other two preheaters with fixed power outputs, it was occasionally necessary to adjust the flowrate through the preheaters to a value slightly different from the desired flowrate.

After the desired flowrate, inlet pressure, and inlet fluid temperature was attained in the test chamber, the variable transformers connected to the cartridge heaters were adjusted until the desired heat flux was attained from the heated tube bundle. If the conditions were such that boiling took place on the heated tubes, then the additional volume of the refrigerant vapor resulted in a displacement of refrigerant liquid into the storage tank. During this transient, the test chamber pressure increased. The pressure in the test chamber returned to a value approximately equal to the original when the volume of liquid added to the storage 
tank equaled the increase in the volume of vapor present in the test chamber and piping. Analogously, the test chamber experienced a transient decrease in pressure whenever the volume of vapor in the loop was decreased. In both cases, the final inlet pressure in the test section was slightly different from the original due to a change in the two-phase pressure drop, and the backpressure valves were adjusted to restore the original inlet pressure.

When R-113 was used as the working fluid and vapor was being generated in the flow loop, the storage tank was used to hold that amount of liquid refrigerant which was displaced by the vapor. The storage tank was connected to the inlet of the pump, and the pressure in the storage tank remained nearly at atmospheric pressure. Therefore, the pressure at the inlet to the pump remained only slightly above atmospheric pressure. However, when pure $\mathrm{R}-11$ or mixtures of $\mathrm{R}-11$ and R-113 were used, the inlet to the pump had to be pressurized in order to prevent the refrigerant from flashing and causing cavitation. A system pressurizer as shown in Fig. 4.10 was, therefore, installed to maintain the pressure in the loop from the backpressure valves to the pump inlet at approximately $138 \mathrm{kPa}(20 \mathrm{psi})$. The storage tank was isolated from the rest of the loop so that as the volume of vapor in the loop increased, all of the excess refrigerant was forced into the refrigerant-side of the pressurizer and expanded the rubber bladder. A relief valve on the gas-side of the bladder allowed the nitrogen to escape so that the pressure in the pressurizer was maintained near the desired pressure for the pump inlet. As the volume of vapor in the loop decreased, the bladder contracted and liquid was forced back into the loop using compressed nitrogen. The pressure in the nitrogen-side of the pressurizer was maintained using a compressed gas regulator that was connected to the compressed nitrogen and was set slightly above the desired pump inlet pressure. 


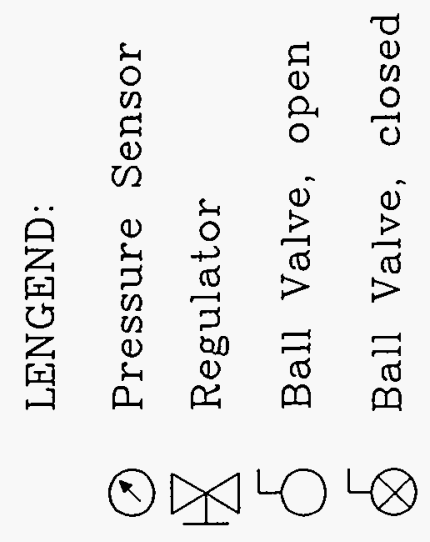

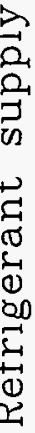

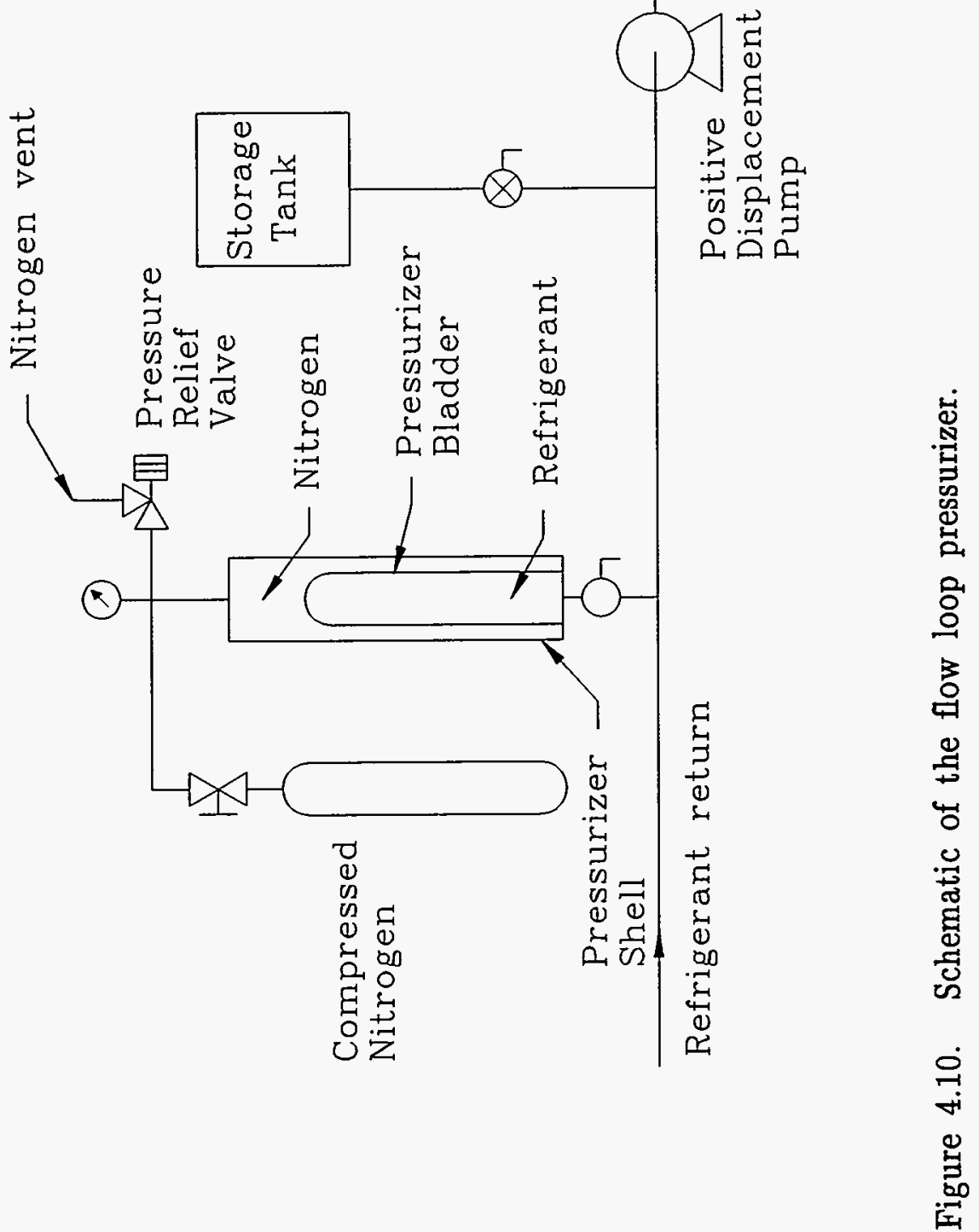


In this way, sufficient liquid was returned to the flow loop to maintain the desired pressure at the pump inlet.

Before collecting nucleate boiling heat transfer data, single-phase heat transfer data were obtained in order to confirm the validity of the experimental apparatus. Because the single-phase heat transfer coefficients were obtained in subcooled $R-113$, the preheaters were set so that inlet temperature of the $R-113$ was between 22 and $26^{\circ} \mathrm{C}$, and the backpressure valves were set so that the gage pressure in the test chamber was approximately 0.7 bar (10 psi).

After steady-state flow conditions were reached, the DAS automatically recorded the signals from the thermocouples throughout the flow loop and tube bundle, the frequency of the signal from the flowmeter, the d.c voltage from the pressure transducer, and the a.c. voltages from the shunts and bus bars. The atmospheric pressure and test chamber inlet gauge pressure were read and input to the DAS manually. The data were then reduced as described in the next section. The next set of operating conditions was achieved by adjusting the pump motor frequency, power to the cartridge heaters, and/or backpressure valves. Additional single-phase heat transfer data were collected by repeating this procedure until sufficient data were obtained to verify the validity of the experimental apparatus.

Two-phase heat transfer data were obtained first for the bundle of smooth tubes. The test chamber operating conditions were achieved by beginning with the procedure described above. In addition, the power supplied to the tube bundle was increased until the quality of the refrigerant at the exit of the tube bundle was between 65 and $80 \%$. Data were collected after the system reached steady state. The power supplied to the tube bundle was then reduced, and the system was again allowed to come to steady state. Taking data at the largest heat flux values first 
insured that nucleate boiling took place over as much of the tube surface as possible. After data were collected for all the heat flux values, the flow rate through the bundle was changed and the power supplied to the tube bundle was again increased until the output quality was between 65 and $80 \%$. This procedure was repeated until data were collected for each value of the mass flux. The test chamber pressure was then increased, and data were collected at the full range of heat flux and mass flux values, as described above.

After data were collected for the smooth tubes mounted to the mounting plated with a pitch-to-diameter ratio of 1.50 , tubes with the Turbo-B surface were installed, and data were collected using the procedure outlined above. Next, the smooth tubes were mounted to the mounting plate with a pitch-to-diameter ratio of 1.17 and more data were collected in pure $\mathrm{R}-113$. This bundle of tubes was replaced with tubes having the High Flux surface, and the procedure for collecting data was repeated.

The mounting plate with a pitch-to-diameter ratio of 1.50 was then used to collect data using pure R-11. For these experiments, the tube bundle consisted of High Flux tubes in the bottom third, smooth tubes in the middle, and Turbo-B tubes in the upper third. Before the loop was filled with pure $R-11$, the $R-113$ was degassed and stored in flexible bags for use later during the tests involving refrigerant mixtures. The flow loop was then modified by installing the pressurizer shown in Fig. 4.10 before the loop was filled with pure $\mathrm{R}-11$, and data were collected using the procedure outlined above.

This same bundle of tubes was used to collect data in mixtures of $\mathrm{R}-11$ and $\mathrm{R}-113$ for concentrations of 25,50 , and $75 \%$ by mass of $\mathrm{R}-11$ in the $\mathrm{R}-113$. The procedure for obtaining refrigerant mixtures involved first verifying that the pure 
$\mathrm{R}-11$ did not contain dissolved gas by measuring a sample of the $\mathrm{R}-11$ using the Aire-ometer. Next, bags containing degassed R-113 were connected to the flow loop, and the refrigerant mixture was circulated through the loop. The flexible bags allowed the $\mathrm{R}-113$ to be emptied into the flow loop without allowing air to come in contact with the refrigerant. After circulating for several hours, the concentration of the mixture was measured approximately by using hydrometers to measure the specific gravity and then using the graph shown in Fig. 4.11 to determine the mixture concentration. Pure R-113 was added to the flow loop until the desired mixture concentration was attained. Precise values (within $0.1 \%$ ) of the mixture concentration were obtained using mass spectrometry. Three samples were collected for each mixture: before the experiments at $200 \mathrm{kPa}$, between the experiments at 200 and $600 \mathrm{kPa}$, and after the experiments at $600 \mathrm{kPa}$. Because the mass spectrometry analysis required several weeks, the data were collected using the values for the mixture concentration using the hydrometers. The raw data were reduced again when the mixture concentration determined using mass spectrometry was known.

\section{Data Reduction}

Heat transfer coefficients were calculated immediately after the data collection process using a computer program run on the microcomputer of the DAS. The heat transfer coefficients calculated for the two-phase experiments were defined as the ratio of the heat flux from the heated tube to the difference between the average tube wall surface temperature and the saturation temperature of the refrigerant at the local pressure just upstream of the tube; this pressure was 


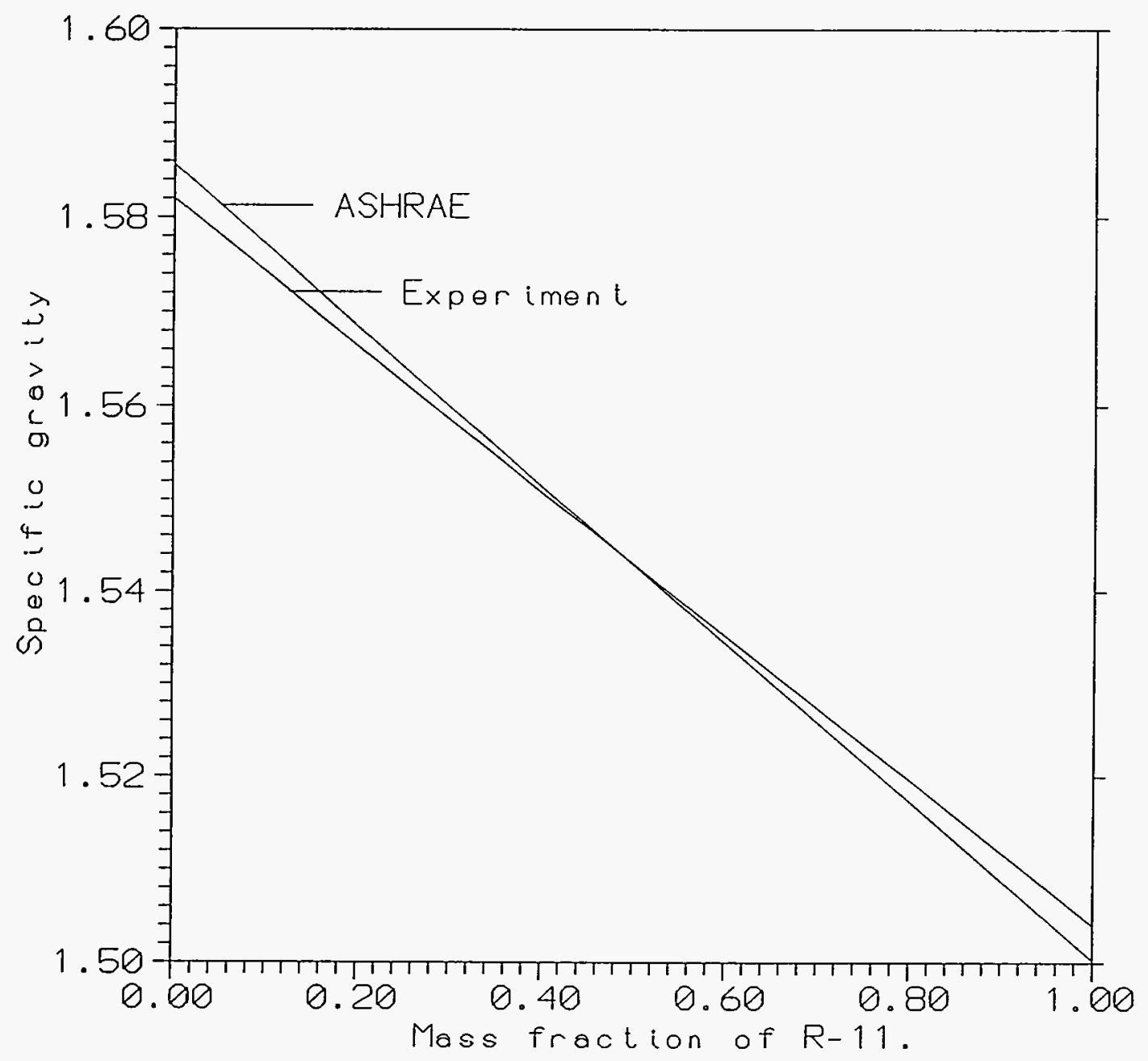

Figure 4.11. Specific gravity for $\mathrm{R}-11 / \mathrm{R}-113$ mixtures at $20^{\circ} \mathrm{C}$ and $101 \mathrm{kPa}$. 
obtained by linear interpolation of the pressures at the closest pressure taps. The equation for the heat transfer coefficient is given as:

$$
h_{\mathrm{n}}=\frac{q_{\mathrm{n}}^{\prime \prime}}{T_{\mathrm{w}, \text { ave }}-T_{\text {sat }}}
$$

Single-phase heat transfer coefficients were based on the difference between the average tube wall surface temperature and the temperature of the liquid refrigerant just upstream of the heated tube:

$$
h_{\mathrm{n}}=\frac{q_{\mathrm{n}}^{\prime \prime}}{T_{\mathrm{w}, \text { ave }}-T_{\mathrm{L}}}
$$

The heat flux for an individual tube was defined as the ratio of the supplied power to the surface area exposed to the fluid. The power supplied to the heated tube was calculated as the product of the current through the cartridge heater and the voltage across the cartridge heater:

$$
q_{\mathrm{n}}^{\prime \prime}=\frac{I_{\mathrm{n}} V_{\mathrm{n}}}{A_{\mathrm{s}}}
$$

where the current, $I_{n}$, was measured by the DAS for each cartridge heater and the voltage drop, $V_{n}$, was measured across those set of bus bars to which the cartridge heater was attached. The area of an individual tube was given by:

$$
A_{\mathrm{s}}=\pi D_{0} L
$$


where length of the tube, $L$, was measured to be $0.1016 \mathrm{~m}$. The diameters of the enhanced tubes were measured at the outside of the enhancement material. The enhanced tubes and the smooth tubes all had an average diameter of $19.1 \mathrm{~mm}$.

The surface temperatures of the heated tubes were calculated using a one-dimensional, steady-state heat conduction equation for a cylinder:

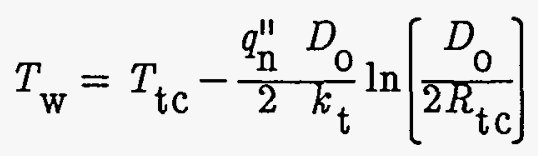

where $R_{\mathrm{tc}}$ is the radial distance from the center of the tube to the center of the thermocouple well. The heat flux at the outside tube surface, $q_{n}^{\prime \prime}$, is given by equation (4.3) and the temperature at the thermocouple position, $T_{\mathrm{tc}}$, is measured by the DAS. The average tube wall surface temperature, $T_{\mathrm{w}, \mathrm{ave}}$, was then calculated as the arithmetic average of the four temperatures calculated as in equation (4.5) from the four thermocouple measurements.

The saturation temperature of the refrigerant was calculated as a function of the pressure. When pure $\mathrm{R}-113$ was the working fluid, two equations given by Jensen (1980) were used for determining the saturation temperature. The expression for the saturation temperature in the range of absolute pressures from 2 bar (29.48 psi) to 4 bar ( $58.49 \mathrm{psi})$ was given as

$$
T_{\text {sat }}=545.741+2.862 P_{\mathrm{n}}-0.01423 P_{\mathrm{n}}^{2}
$$


and in the range of absolute pressures from 4 bar (58.49 psi) to 7 bar(108.2 psi) as

$$
T_{\text {sat }}=578.073+1.741 P_{\mathrm{n}}-0.004424 P_{\mathrm{n}}^{2}
$$

where $P_{n}$ is the local absolute pressure (given in psia) at tube $n$.

The local pressure was determined by first measuring the inlet pressure to the tube bundle, $P_{0}$, using the bourdon tube pressure gauge. Next, the pressure drops across adjacent pressure taps throughout the tube bundle, $\Delta P_{(j-1)}$ to $j$, were measured with the pressure transducer so that the local pressures at the pressure taps, $P_{\mathrm{j}}$, could be calculated as

$$
P_{\mathrm{j}}=P_{0}+\sum_{\mathrm{i}=1}^{\mathrm{j}} \Delta P_{(\mathrm{i}-1) \text { to } \mathrm{i}}
$$

The local pressures at the heated tubes, $P_{n}$, could then be calculated by interpolating between the pressures at the pressure taps based on the distance from the heated tube location to the nearest pressure tap locations.

The above procedure for determining the local pressures and temperatures was used during experiments when the outlet was subcooled. However, more precise values could be obtained when two-phase flow existed at the tube bundle outlet. When the refrigerant at the outlet was saturated, the outlet pressure was assumed to be the saturation pressure based on the outlet temperature. The 
saturation pressure at the outlet, $P_{5}(\mathrm{kPa})$, was calculated from the outlet temperature, $T_{\mathrm{o}}(\mathrm{K})$, using an equation based on the results of Downing (1974):

$$
\log \left(6.89 P_{5}\right)=\mathrm{C}_{1}-\mathrm{C}_{2} / T_{0}-\mathrm{C}_{3} \log \left(9 T_{0} / 5\right)+\mathrm{C}_{4}
$$

where

$$
\begin{aligned}
& C_{1}=33.0655 \\
& C_{2}=-2406.1 \\
& C_{3}=-9.2635 \\
& C_{4}=0.003697
\end{aligned}
$$

The pressures at the pressure taps were then calculated using the pressure drops measured across adjacent pressure taps as

$$
P_{5-\mathrm{j}}=P_{5}-\sum_{\mathrm{i}=1}^{\mathrm{j}} \Delta P_{(5-\mathrm{i})} \text { to }(6-\mathrm{i})
$$

When the inlet temperature of the refrigerant was below the saturation temperature, the refrigerant temperature was calculated using the measured inlet temperature, $T_{\text {in }}$. An energy balance was performed row by row through the tube bundle in order to calculate the bulk fluid temperature immediately upstream of 
each row having an instrumented tube. The bulk fluid temperature of the refrigerant was calculated as:

$$
T_{\mathrm{f}, \mathrm{n}}=T_{\mathrm{in}}+\frac{Q_{1-\mathrm{n}}}{\dot{m} c_{\mathrm{p}}}
$$

where $Q_{1-\mathrm{n}}$ was the heat transferred from all the tubes in rows 1 through $\mathrm{n}$. The power delivered to each set of cartridge heaters through a given set of bus bars was calculated as the product of the current and voltage measured by the DAS. The power delivered by the cartridge heaters was uniform throughout a given portion of the tube bundle so that the power delivered by the tubes in rows 1 through $n$ was assumed to be proportional to the number of tube rows.

The quality at the inlet to the tube bundle was calculated using the inlet temperature and the saturation temperature corresponding to the inlet pressure. Assuming that the refrigerant flowing through the flashing valves underwent an isenthalpic process, the inlet quality could be calculated as:

$$
x_{\text {in }}=\frac{c_{\mathrm{p}}\left(T_{\mathrm{fv}}-T_{\text {sat,in }}\right)}{{ }_{\mathrm{fg}}}
$$

where $c_{\mathrm{p}}$ is the specific heat of the pure refrigerant, $T_{\mathrm{fv}}$ is the temperature immediately upstream of the flashing valves, $T_{\text {sat,in }}$ is the temperature at the inlet to the tube bundle, and $i_{\mathrm{fg}}$ is the enthalpy of vaporization for the pure refrigerant. 
The quality immediately downstream of the $\mathrm{n}^{\text {th }}$ tube row was calculated by performing an energy balance on the first $n$ tube rows:

$$
x_{\mathrm{n}}=x_{\mathrm{in}}+\frac{Q_{1-\mathrm{n}}}{\dot{m} i_{\mathrm{fg}}}
$$

The mass flux was calculated using the volume flow rate measured by the turbine flowmeters and the density of the refrigerant, which was calculated as a function of temperature. The volumetric flow rate was calculated as a function of the frequency of the pulses generated by the turbine flowmeter. The total mass flow rate, $\dot{m}$, was then calculated as the product of the volumetric flow rate and the refrigerant liquid density. Finally, the mass flux, $G$, was calculated based on the minimum flow area between the heated tubes. The equation used to calculate the mass flux was

$$
G=\frac{\dot{m}}{4\left(p-D_{0}\right) L}
$$

where $p$ is the tube bundle pitch and the 4 in the denominator is a result of having five heated tubes (four flow areas) in each row. Sample calculations for property evaluations and reducing the data obtained in pure $\mathrm{R}-113$ can be found in Appendix B.

The procedure for reducing data taken in pure $\mathrm{R}-11$ was the same as for pure R-113 except that routines for calculating the thermodynamic and physical properties of $R-11$ had to be substituted for those of $R-113$. A computer program to calculate properties of refrigerant mixtures, developed by the National Institute 
of Science and Technology (National Bureau of Standards 1986) was used to calculate the properties of pure $\mathrm{R}-11$. The calculated values were compared with tabulated values from ASHRAE (1985) and were all within $0.5 \%$.

The procedure for reducing data taken in mixtures of $R-11$ and $R-113$ was generally similar to the procedure for pure refrigerants except that additional procedures for determining the properties of the mixture and for determining the mixture concentration throughout the bundle were required. Because the tube bundle used in the experiments involving refrigerant mixtures contained all three surfaces, the local mole fractions were determined so that the local quality and mixture concentration were known.

The mixture properties were calculated using the computer program developed by the National Institute of Science and Technology (National Bureau of Standards 1986) which calculates thermodynamic properties (saturation pressure, specific volume, enthalpy, specific heats, etc.) for a given temperature or saturation temperature for a given pressure. In either case, the concentration of the mixture is required. This computer program requires numerical coefficients for the pure refrigerants and the mixture. Coefficients for eleven pure refrigerants were provided including those for $\mathrm{R}-113$ and $\mathrm{R}-11$. Coefficients for seven mixtures were also provided, but the coefficient for the $R-113 / R-11$ combination used in this project was not given. Therefore, a procedure was devised for obtaining the numerical coefficient from experimental pool boiling data, as discussed in Appendix E. 
In order to calculate the composition throughout the tube bundle, the maximum number of independent, intensive variables required to specify the thermodynamic state was determined using Gibb's phase rule:

$$
F=2-\varphi-m
$$

where $F$ is the maximum number of independent, intensive variables required to specify the thermodynamic state, $\varphi$ is the number of phases present, and $m$ is the number of species in the solution. For a vapor/liquid system containing two chemical species in equilibrium, the number of variables required to specify the thermodynamic state is two. The two variables normally chosen are pressure and either the temperature or the mole fraction of one of the constituents. These variables are commonly represented on two-dimensional phase diagrams where temperature is plotted as a function of the mole fraction of the most volatile component for a given pressure. An example is shown in Fig. 4.12 for a mixture of $\mathrm{R}-11$ and $\mathrm{R}-113$ at a pressure of 103,202 , and $606 \mathrm{kPa}$, which were generated using the mixture properties program.

Because the pressure and temperature were known at the outlet, the computer program could be used to calculate mole fractions using an iterative process. The measured outlet temperature and an estimate for the mole fraction of $\mathrm{R}-113$ in the liquid phase, $y_{\mathrm{R} 113}^{\mathrm{H}}$, was input to the computer program and the saturation pressure was calculated. This value was compared with the experimentally determined value for the outlet pressure. The mole fraction, $y_{\mathrm{R} 113}^{\prime}$, was adjusted until the output saturation pressure was within $0.1 \%$ of the 


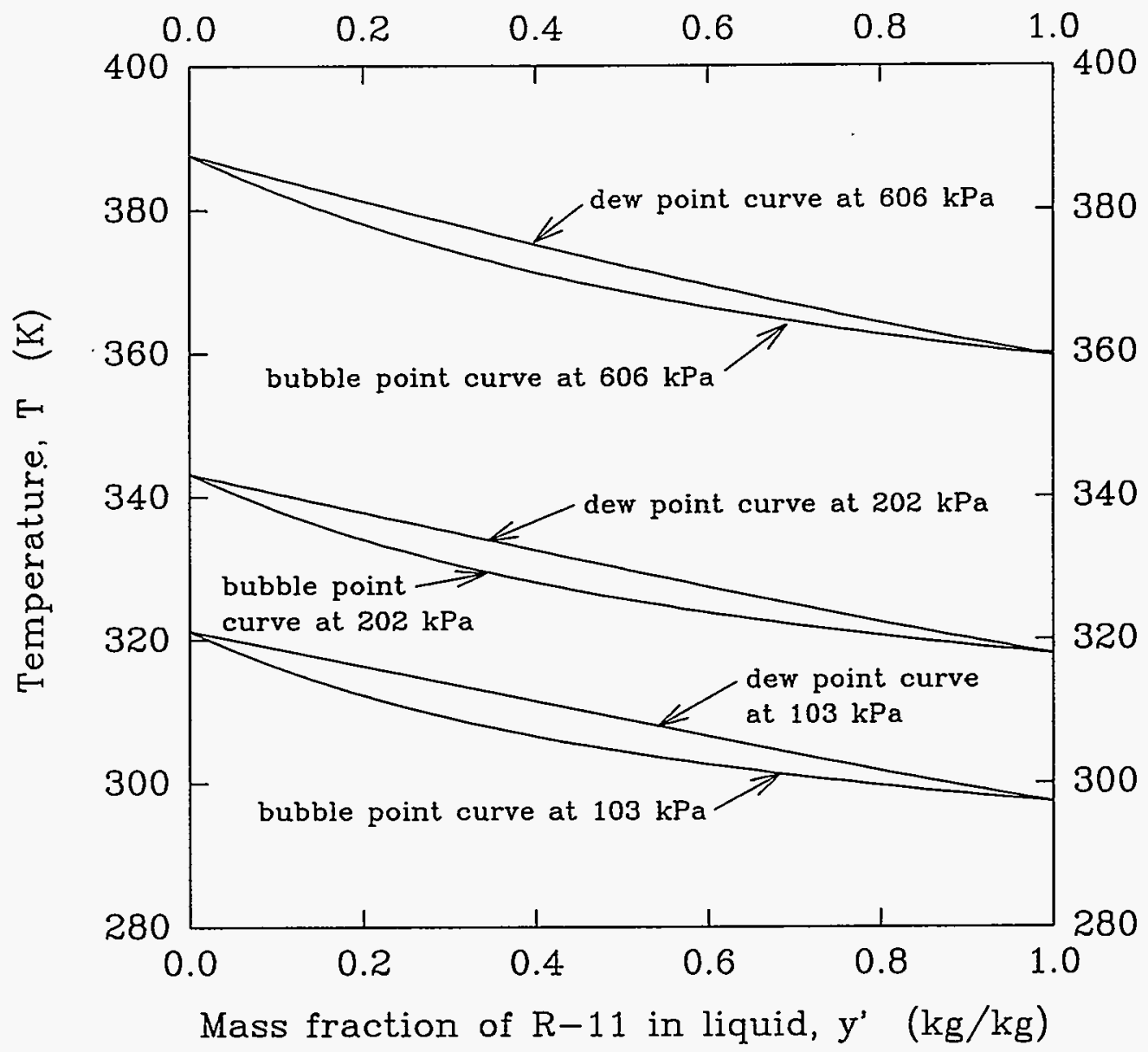

Figure 4.12. Phase diagram for mixtures of $R-11$ and $R-113$. 
experimental value. The mole fraction of $R-11$ in the liquid, $\tilde{y}_{\mathrm{R} 11}^{\prime}$, was calculated from

$$
\tilde{y}_{\mathrm{R} 11}^{\prime}=1-\tilde{y}_{\mathrm{R} 113}^{\prime}
$$

The same iterative procedure was used to determine the vapor mole fractions of $\mathrm{R}-113, \tilde{y}_{\mathrm{R} 113}^{\prime \prime}$, and R-11, $\tilde{y}_{\mathrm{R} 11}^{\prime \prime}$.

Knowledge of the mole fractions also permitted the determination of the outlet quality, which could be calculated using an equation similar to that for the pure fluids:

$$
x_{\text {out }}=\frac{\tilde{i}_{\text {out }}-\tilde{i}_{\mathrm{f}}}{\tilde{i}_{\mathrm{fg}}}
$$

where the saturation enthalpy of the liquid mixture, $\tilde{i}_{\mathrm{f}}$, and the enthalpy of vaporization for the mixture, $\tilde{i}_{\mathrm{fg}}$, were calculated using the mixture properties program, and the enthalpy of the mixture at the outlet was calculated using:

$$
\begin{aligned}
\tilde{i}_{\text {out }}= & \left(\tilde{y}_{\mathrm{R} 113}^{\prime} \tilde{\dot{m}}_{\mathrm{L}} \tilde{i}_{\mathrm{R} 113}+\tilde{y}_{\mathrm{R} 11}^{1} \tilde{\dot{m}}_{\mathrm{L}} \tilde{i}_{\mathrm{R} 11}\right. \\
& \left.+\tilde{y}_{\mathrm{R} 113}^{\prime \prime} \tilde{\dot{m}}_{\mathrm{V}} \tilde{i}_{\mathrm{R} 113}+\tilde{y}_{\mathrm{R} 11}^{\prime \prime} \tilde{\dot{m}}_{\mathrm{V}} \tilde{i}_{\mathrm{R} 11}\right) / \tilde{\dot{m}}
\end{aligned}
$$


In equation (4.18), the molar flowrate of the liquid, $\dot{m}_{\mathrm{L}}$, was calculated by first performing a component balance on the $\mathrm{R}-113$ :

$$
\tilde{y}_{\mathrm{b}, \mathrm{R} 113}^{\prime}=\frac{\tilde{y}_{\mathrm{R} 113}^{\prime} \tilde{\dot{m}}_{\mathrm{L}}+\tilde{y}_{\mathrm{R} 113}^{\prime \prime} \tilde{\dot{m}}_{\mathrm{V}}}{\tilde{\dot{m}}_{\mathrm{L}}+\tilde{\dot{m}}_{\mathrm{V}}}
$$

where the overall mole fraction of $\mathrm{R}-113$ at the test chamber inlet, $\tilde{y}_{\mathrm{b}, \mathrm{R} 113}^{\prime}$, was measured experimentally using mass spectrometry. Using the relation:

$$
\tilde{\dot{m}}=\tilde{\dot{m}}_{\mathrm{L}}+\tilde{\dot{m}}_{\mathrm{V}}
$$

$\mathrm{Eq}(4.19)$ becomes:

$$
\tilde{\dot{m}}_{\mathrm{L}}=\tilde{\dot{m}} \frac{\tilde{y}_{\mathrm{b}, \mathrm{R} 113}^{\mathrm{N}}-\tilde{y}_{\mathrm{R} 113}^{\prime \prime}}{\tilde{y}_{\mathrm{R} 113}^{\prime}-\tilde{y}_{\mathrm{R} 113}^{\prime \prime}}
$$

The molar flow rate of the vapor, $\tilde{\dot{m}}_{\mathrm{V}}$, can easily be calculated using equation (4.20). The outlet enthalpy as calculated from equation (4.18) was checked by comparing it with the value determined by performing an overall energy balance on the tube bundle. An energy balance performed on the entire bundle results in

$$
\tilde{i}_{\text {out }}=\tilde{i}_{\text {in }}+Q_{\text {tot }} / \tilde{\dot{m}}
$$


where $Q_{\text {tot }}$ is the total heat transfer from the tube bundle. Values of $\tilde{i}_{\text {out }}$ calculated using equation (4.18) were within $5 \%$ of the values of $\tilde{i}_{\text {out }}$ calculated using equation (4.22).

The inlet quality was seldom identically equal to zero. Therefore, if the inlet pressure was less than the saturation pressure as calculated from the measured inlet temperature, then a procedure similar to the one described above for calculating the outlet quality was also used to calculate the inlet quality. The measured inlet temperature and a guess for the mole fractions in the liquid were input to the mixture properties program and the calculated pressure was compared with the measured pressure. New guesses for the mole fraction were input until the calculated pressure was within $0.1 \%$ of the measured value. When the enthalpy at the inlet was known, the inlet quality was calculated as

$$
x_{\text {in }}=\frac{\tilde{i}_{\text {in }}-\tilde{i}_{\mathrm{f}}}{\tilde{i}_{\mathrm{fg}}}
$$

If the inlet is slightly subcooled (the measured inlet pressure is slightly higher than the saturation pressure) then the inlet quality is calculated as

$$
x_{\text {in }}=\tilde{c}_{\mathrm{p}}\left(T_{\mathrm{in}}-T_{\mathrm{f}}\right) / \tilde{i}_{\mathrm{fg}}
$$

where $\tilde{c}_{\mathrm{p}}, T_{\mathrm{f}}$, and $\tilde{i}_{\mathrm{fg}}$ were calculated using the mixture property program and the measured inlet pressure.

A slightly different procedure was used to determine the quality at each instrumented tube. Because the temperature of the liquid mixture was not 
measured throughout the bundle, the enthalpy at a given tube row was used. The enthalpy at row $n$ was calculated using an energy balance over the first $n$ rows:

$$
\tilde{i}_{\mathrm{n}}=\tilde{i}_{\text {in }}+Q_{1-\mathrm{n}} / \tilde{\dot{m}}
$$

where $Q_{1-n}$ is an integral value of the measured heat input from the inlet to row $n$. The enthalpy at row $n$ was also calculated using an equation similar to equation (4.18):

$$
\begin{aligned}
\tilde{i}_{\mathrm{n}}=\left(\tilde{y}_{\mathrm{R} 113}^{\prime} \tilde{\dot{m}}_{\mathrm{L}} \tilde{i}_{\mathrm{R} 113}+\tilde{y}_{\mathrm{R} 11}^{\prime} \tilde{\dot{m}}_{\mathrm{L}} \tilde{i}_{\mathrm{R} 11}\right. \\
\left.\quad+\tilde{y}_{\mathrm{R} 113}^{\prime \prime} \tilde{\dot{m}}_{\mathrm{V}} \tilde{i}_{\mathrm{R} 113}+\tilde{y}_{\mathrm{R} 11}^{\prime \prime} \tilde{\dot{m}}_{\mathrm{V}} \tilde{i}_{\mathrm{R} 11}\right) / \tilde{\dot{m}}
\end{aligned}
$$

where the molar enthalpies and molar flow rates were evaluated using the local values for the molar concentrations.

The procedure for determining the local molar concentrations involved iterating on the local fluid temperature until the enthalpy as calculated using equation (4.26) was within $0.1 \%$ of the value obtained using equation (4.25). The procedure began with a guess for the temperature at row $n$ so that the mixture properties could be calculated using the mixture property program. The molar concentrations were determined for the measured pressure and guessed value for the temperature using the iterative procedure described above. The molar flow rates of the liquid and vapor were calculated as in equation (4.21) and the enthalpy was calculated as in equation (4.26). If this value did not match the value obtained in equation (4.25), then a new guess for the local temperature was made and the 
process was repeated until $\tilde{i}_{\mathrm{n}}$ from equation (4.26) was within $0.1 \%$ of the value from equation (4.25). Thus, the procedure for determining the local enthalpy involved a double iteration.

Once the local enthalpy was known, the quality at row $n$ was calculated as:

$$
x_{\mathrm{n}}=\frac{\tilde{i}_{\mathrm{n}}-\tilde{i}_{\mathrm{f}}}{\tilde{i}_{\mathrm{fg}}}
$$

This procedure was repeated to find the local conditions at each tube row. After the thermodynamic state had been fixed for the $15^{\text {th }}$ row, the temperature could be compared with the measured outlet temperature as an additional check. The value for the outlet temperature as computed above was generally within $0.2^{\circ} \mathrm{C}$ of the measured value.

The double iteration procedure described above for calculating the temperature throughout the tube bundle was found to be very time consuming. In order to reduce the number of iterations involved, values of the equilibrium ratio ( $\mathrm{K}$-values) were calculated. $\mathrm{K}$-values for the $\mathrm{R}-113$ were defined as

$$
K_{\mathrm{R} 113} \equiv \tilde{y}_{\mathrm{R} 113}^{\prime \prime} / \tilde{y}_{\mathrm{R} 113}^{\prime}
$$

$\mathrm{K}$-values were calculated for a range of pressures and temperatures. In order to use these values in a computer program, a regression analysis was performed. The appropriate form of the equation for the regression analysis was determined using an approximate relation for the $\mathrm{K}$-value:

$$
K_{\mathrm{R} 113} \approx P_{\text {sat, },_{\mathrm{R} 113}} / P
$$


where the saturation pressure was approximated using the Clausius-Clapyron equation:

$$
\ln \left(P_{\text {sat }}\right)=A-B / T
$$

and where A and B are constants to be determined. Solving for $P_{\text {sat }}$ and inserting it into equation (4.29):

$$
K \approx \exp (A-B / T) / P
$$

The regression analysis resulted in a correlation for $K_{R 113}$ in which $A$ and $B$ were found to be 15.352 and 3194.422 respectively. A similar procedure was used to produce a correlation for the $\mathrm{K}$-values of $\mathrm{R}-11$ and the constants in the correlation were found to be 15.527 and 3297.124 . In this way, precise $K-$ values could be calculated without using ideal mixture assumptions.

In order to make use of the $\mathrm{K}-$ values, equations (4.19) and (4.20) were combined to get

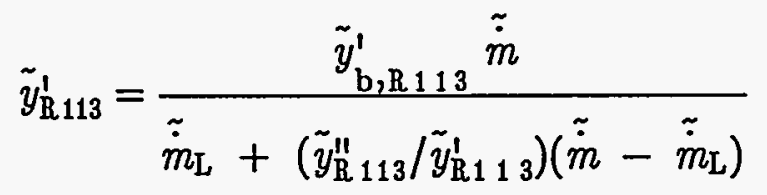


Similarly for R-11:

$$
\tilde{y}_{\mathrm{R} 11}^{\prime}=\frac{\tilde{y}_{\mathrm{b}, \mathrm{R} 11}^{\prime} \dot{\dot{m}}}{\tilde{\dot{m}}_{\mathrm{L}}+\left(\tilde{y}_{\mathrm{R} 11}^{\prime \prime} \tilde{y}_{\mathrm{R} 11}^{\prime}\right)\left(\tilde{\dot{m}}-\tilde{\dot{m}}_{\mathrm{L}}\right)}
$$

Substituting equations (4.32) and (4.33) into the relationship

$$
\tilde{y}_{\mathrm{R} 113}^{\prime}+\tilde{y}_{\mathrm{R} 11}^{\prime}=1
$$

we get

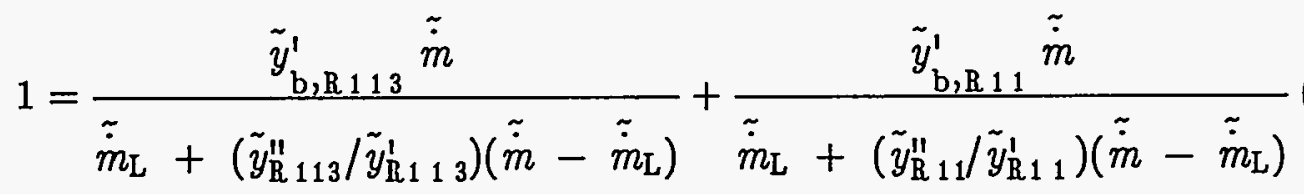

$\mathrm{K}$-values can now be substituted into equation (4.35) to get:

$$
1=\frac{\tilde{y}_{\mathrm{b}, \mathrm{R} 113}^{\prime} \tilde{\dot{m}}}{\tilde{\dot{m}}_{\mathrm{L}}+K_{\mathrm{R} 13}\left(\tilde{\dot{m}}-\tilde{\dot{m}}_{\mathrm{L}}\right)}+\frac{\tilde{y}_{\mathrm{b}, \mathrm{R} 11}^{\prime} \tilde{\dot{m}}}{\tilde{\dot{m}}_{\mathrm{L}}+K_{\mathrm{R} 11}\left(\tilde{\dot{m}}-\tilde{\dot{m}}_{\mathrm{L}}\right)}
$$

The inlet conditions $\tilde{y}_{\mathrm{b}, \mathrm{R} 113}^{\prime}$ and $\tilde{y}_{\mathrm{b}, \mathrm{R} 11}^{\prime}$ were measured experimentally so that the only unknown in equation (4.36) is $\tilde{\dot{m}}_{\mathrm{L}}$. Solving equation (4.36) for $\tilde{\dot{m}}_{\mathrm{L}}$ results in a quadratic equation that can solved without iterating. Therefore, equation (4.36) could be used instead of equation (4.21), and the iteration involved with solving for the local molar concentration as a function of temperature and pressure could be 
avoided resulting in significant time savings. Identical results were obtained using both methods of data reduction.

Appendix $\mathrm{C}$ gives the uncertainty analysis for this data reduction method and lists the uncertainty in the measured parameters. The uncertainty of the heat flux was $\pm 1.0 \%$. The uncertainty was $0.12^{\circ} \mathrm{C}$ for the thermocouple readings which led to an uncertainty of $0.15^{\circ} \mathrm{C}$ for the wall temperature. The pressure readings had an uncertainty of $\pm 0.5 \%$ and the uncertainty for the saturation temperature $0.12^{\circ} \mathrm{C}$ so that the uncertainty in the wall superheat was $\pm 1.4 \%$. The resulting uncertainty in the heat transfer coefficient depends on the wall superheat but is usually less than $3.5 \%$ of the absolute value. The mass flux had an uncertainty of $\pm 3.0 \%$ which resulted in an uncertainty for the quality of $\pm 0.5 \%$. 


\section{CHAPTER 5}

\section{SHELLSIDE BOILING EXPERIMENTAL RESULTS AND DISCUSSION}

The tube-bundle test chamber was used to conduct experiments to determine the effects of flow conditions, bundle geometry, multicomponent fluids, and heated-tube surface structure on the thermal-hydraulic performance of horizontal tube bundles. Single-phase experiments were performed to establish the validity of the experimental apparatus. Two-phase heat transfer coefficients were obtained from individual tubes for a range of mass fluxes, heat fluxes, qualities, and pressures in two bundles having different pitch-to-diameter ratios. Experiments were conducted in pure $\mathrm{R}-113$, pure $\mathrm{R}-11$, and mixtures of both with tube-bundle inlet concentrations of approximately $25 \%, 50 \%$, and $75 \% \mathrm{R}-11$ by mass.

\section{Single-Phase Data and Results}

Single-phase heat transfer coefficients were obtained for individually heated tubes in the tube bundle in order to establish the validity of the experimental apparatus and procedure. The heat transfer coefficients for the individual tubes obtained by experiment were compared with values predicted by a correlation developed by ESDU (1973) for smooth tubes. Figure 5.1 shows the heat transfer coefficients for individual tubes as a function of tube row. The predicted value of the heat transfer coefficient for the first row is considerably smaller than for subsequent rows. The same trend is found in the experimental values of the heat transfer coefficient for smooth tubes, although the difference between the first and subsequent rows for the experimental data is not as large as the difference between the first and subsequent rows as predicted by the ESDU correlation. 


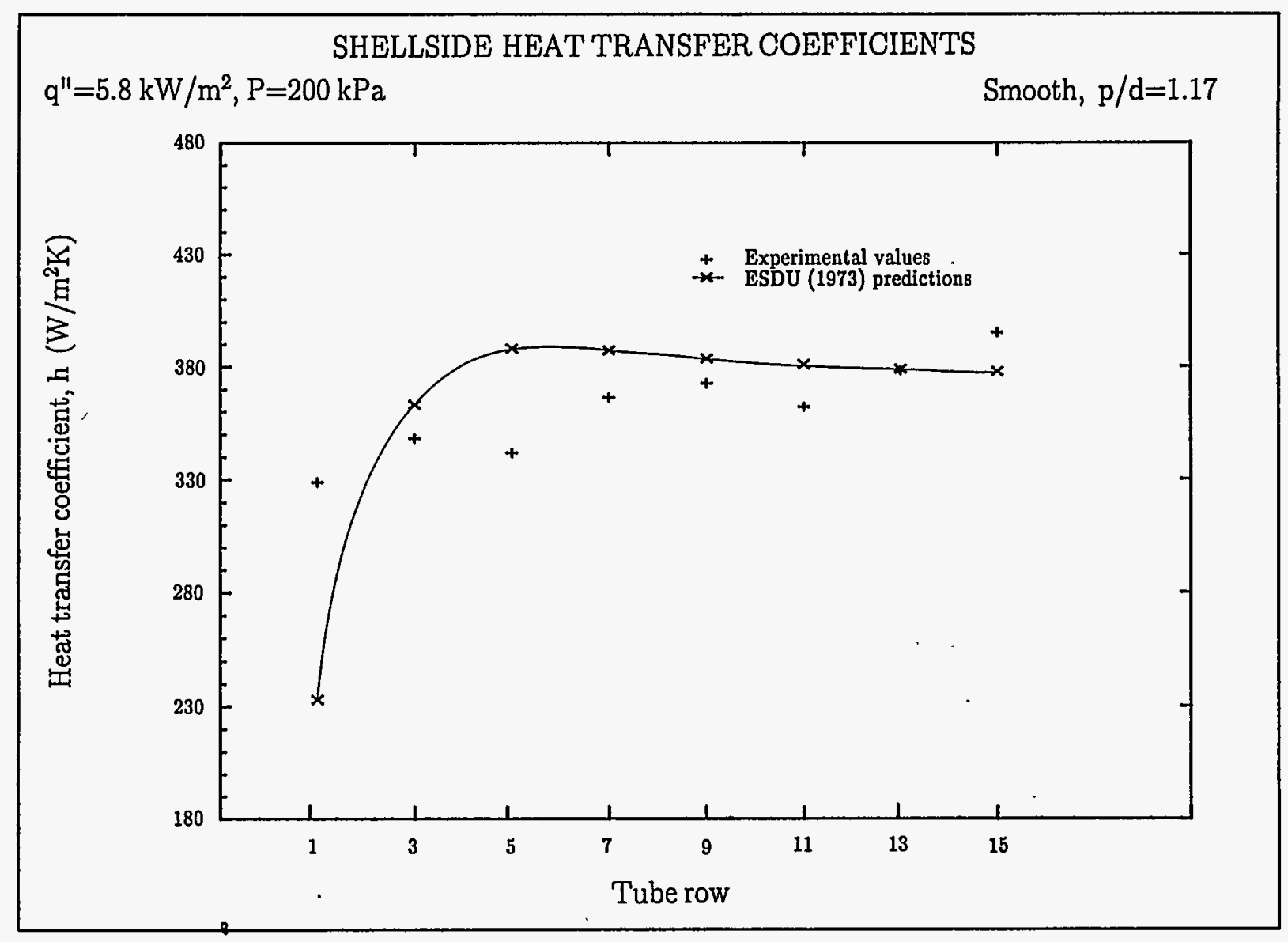

Figure 5.1. Single-phase heat transfer coefficients in the tube bundle. 
Average values of the heat transfer coefficient for the tube bundle were also compared with established correlations. The average heat transfer coefficient for the tube-bundle was calculated as the arithmetic average of individual values for rows 1 though 13. The last tube row was not included in order to avoid any exit effects in the experimental data so that the experimental values for the average heat transfer coefficient could be directly compared with values given by Zukauskas (1987) and ESDU (1973).

Figure 5.2 shows experimental and predicted bundle-average values for the non-dimensional heat transfer coefficient $\left(\mathrm{Nu} / \mathrm{Pr}^{0.34}\right)$ as a function of Reynolds number where the Reynolds number is based on the total mass flow of the fluid flowing through the minimum flow area of the bundle. The experimental heat transfer coefficients for bundles of smooth tubes and bundles of tubes with enhanced surfaces were within the experimental uncertainties of each other. This indicates that the surface roughness of the enhanced tubes is sufficiently small to have a negligible effect on the single-phase heat transfer. Values for the non-dimensional heat transfer coefficient predicted using the correlation given by Zukauskas were very close to those predicted by the ESDU correlation for the Reynolds number of interest, even though the curves for the two correlations have different slopes.

The single-phase pressure drop across the tube bundle also was measured and compared to predictions using the ESDU (1979) correlation. Figure 5.3 shows the experimental and predicted total pressure drop across the tube bundle as a function of Reynolds number. The total pressure drop was measured experimentally using the procedure outlined in Chapter 4 , and the predicted values were obtained by adding the unrecoverable component of the static pressure drop given by ESDU to the hydrostatic head calculated from the bundle height and density of the R-113. 


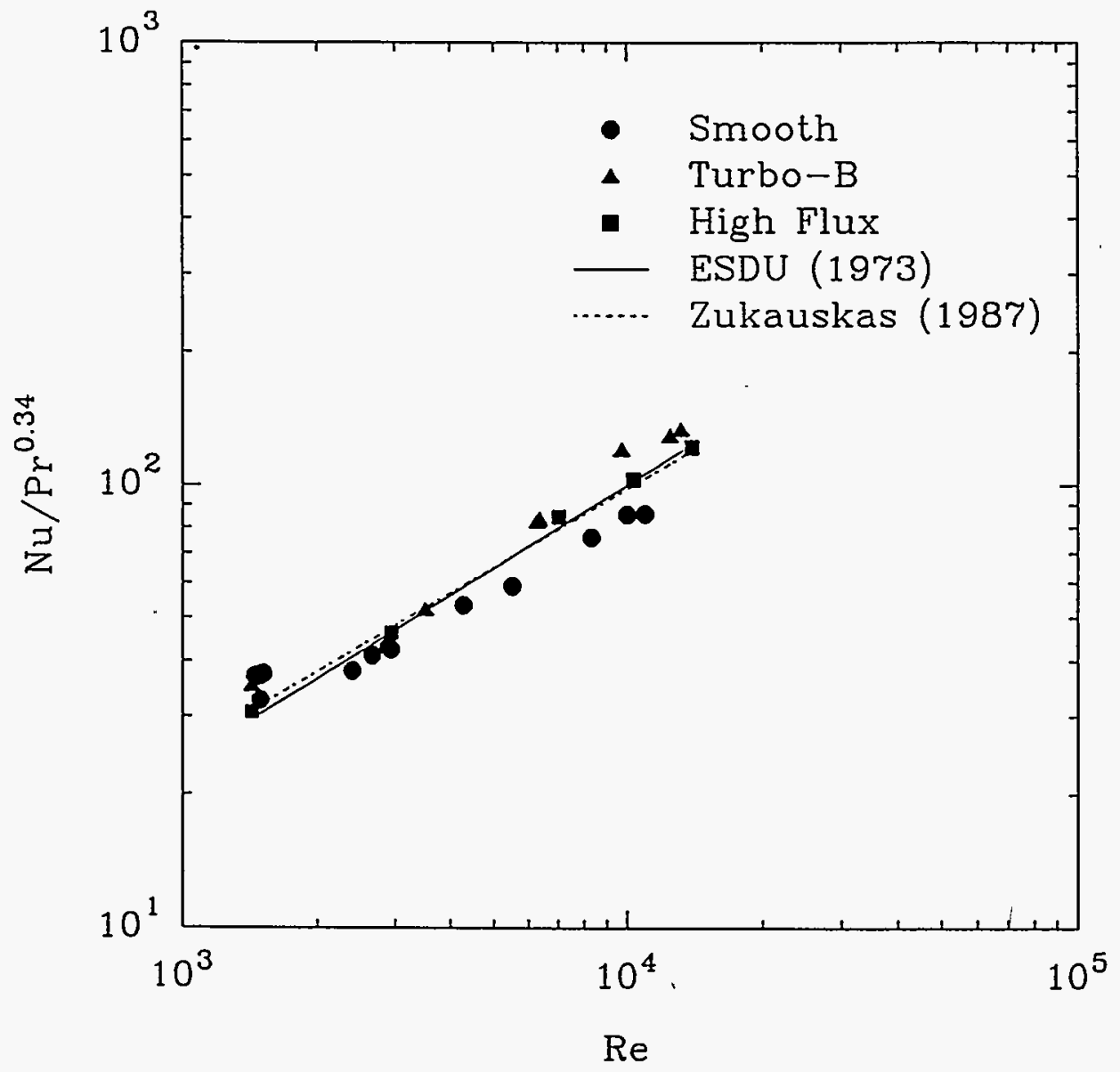

Figure 5.2.

Bundle-average non-dimensional single-phase heat transfer data. 


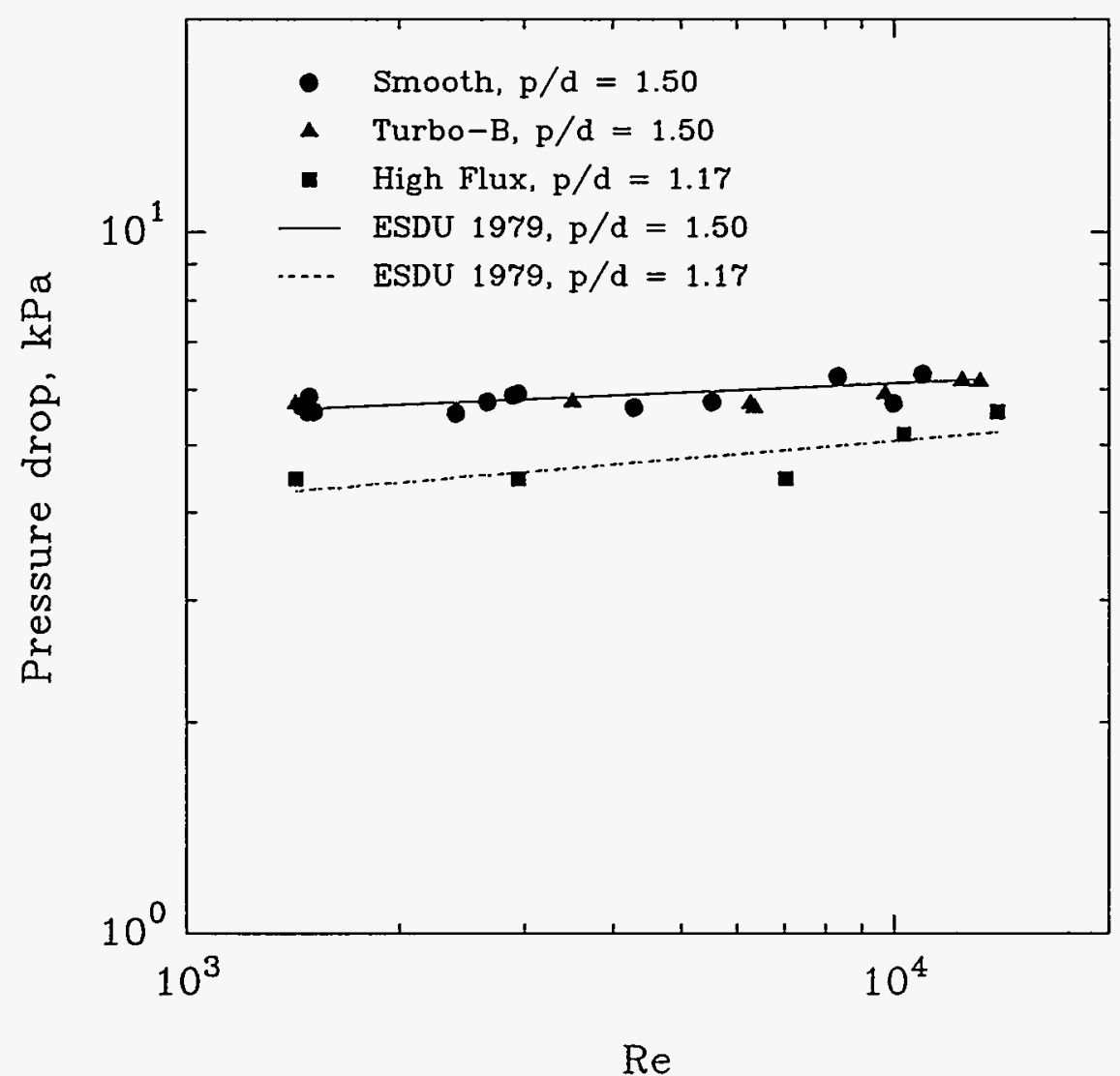

Figure 5.3.

Single-phase pressure drops across the tube bundle. 
The experimental values for all three surfaces are generally within the experimental uncertainty of the predicted values, which demonstrates, again, that the structured surface of the enhanced tubes is small enough to prevent a significant increase in the single-phase pressure drop. The results for both the heat transfer and pressure drop are within the experimental uncertainty of values obtained from established correlations thereby establishing the validity of the experimental apparatus and procedure.

\section{Boiling Heat Transfer Results in Pure Refrigerants}

Bundles of tubes having smooth, High Flux, and Turbo-B surfaces were used to perform bundle boiling experiments in pure $\mathrm{R}-113$ and pure $\mathrm{R}-11$. Two-phase heat transfer coefficients were obtained for individual tubes in the tube-bundles. Bundles having pitch-to-diameter ratios of 1.17 and 1.50 were used. The experiments were conducted for a range of pressures, mass fluxes, and heat fluxes so that the effect of these parameters on the tube-bundle performance could be ascertained.

\section{Smooth tube results in pure $\mathrm{R}-113$}

Two-phase heat transfer coefficients were obtained for smooth tubes in bundles having pitch-to-diameter ratios of 1.50 and 1.17. For the bundle with a pitch-to-diameter ratio of 1.17 , experiments were performed for mass fluxes ranging from 50 to $500 \mathrm{~kg} / \mathrm{m}^{2} \mathrm{~s}$ and heat fluxes ranging from 5 to $80 \mathrm{~kg} / \mathrm{m}^{2}$ at pressures of approximately 200 and $600 \mathrm{kPa}$. Experiments were performed for mass fluxes ranging from 50 to only $225 \mathrm{~kg} / \mathrm{m}^{2} \mathrm{~s}$ in the tube-bundle with a 
pitch-to-diameter ratio of 1.50 due to limitations in preheater power and the requirement that the inlet flow be near saturation.

Figure 5.4 shows two-phase heat transfer coefficients as a function of tube row obtained in the bundle with a pitch-to-diameter ratio of 1.17 for a mass flux of $230 \mathrm{~kg} / \mathrm{m}^{2} \mathrm{~s}$ and a pressure of $200 \mathrm{kPa}$. Data were obtained for heat flux values ranging from 5 to $70 \mathrm{~kW} / \mathrm{m}^{2}$. The heat transfer coefficients increase significantly with heat flux. For a given heat flux value, however, the heat transfer coefficients are nearly independent of tube row. Because the total mass flux, pitch-to-diameter ratio, and heat flux were constant throughout the tube-bundle, the abscissa is directly proportional to the flow quality for a given heat flux value. Therefore, Fig. 5.4 also shows that the heat transfer coefficient did not change significantly with flow quality.

Note that in Fig 5.4 for the small heat flux value of $5.1 \mathrm{~kW} / \mathrm{m}^{2}$, the change in the heat transfer coefficient from the first row to the last was only $400 \mathrm{~W} / \mathrm{m}^{2} \mathrm{~K}$ but that this is $44 \%$ of the average value $\left(900 \mathrm{~W} / \mathrm{m}^{2} \mathrm{~K}\right)$. At a slightly larger heat flux value of $20 \mathrm{~kW} / \mathrm{m}^{2}$, the change in the heat transfer coefficient from the first row to the last was $500 \mathrm{~W} / \mathrm{m}^{2} \mathrm{~K}$ but this is only $20 \%$ of the average value. Therefore, the effect of changing quality on the heat transfer coefficient was small except for relatively small heat flux values.

Figure 5.5 shows two-phase heat transfer coefficients as a function of tube row for a heat flux of $20 \mathrm{~kW} / \mathrm{m}^{2}$. Data taken at mass fluxes of approximately 50 and $500 \mathrm{~kg} / \mathrm{m}^{2} \mathrm{~s}$ are shown for pressures of approximately 200 and $600 \mathrm{kPa}$. The effect of mass flux can be seen by comparing the data at $52 \mathrm{~kg} / \mathrm{m}^{2} \mathrm{~s}$ and $200 \mathrm{kPa}$ to the data taken at $506 \mathrm{~kg} / \mathrm{m}^{2} \mathrm{~s}$ and $200 \mathrm{kPa}$. The differences between the heat transfer coefficients at 52 and $500 \mathrm{~kg} / \mathrm{m}^{2} \mathrm{~s}$ are less than $20 \%$ for each tube row 


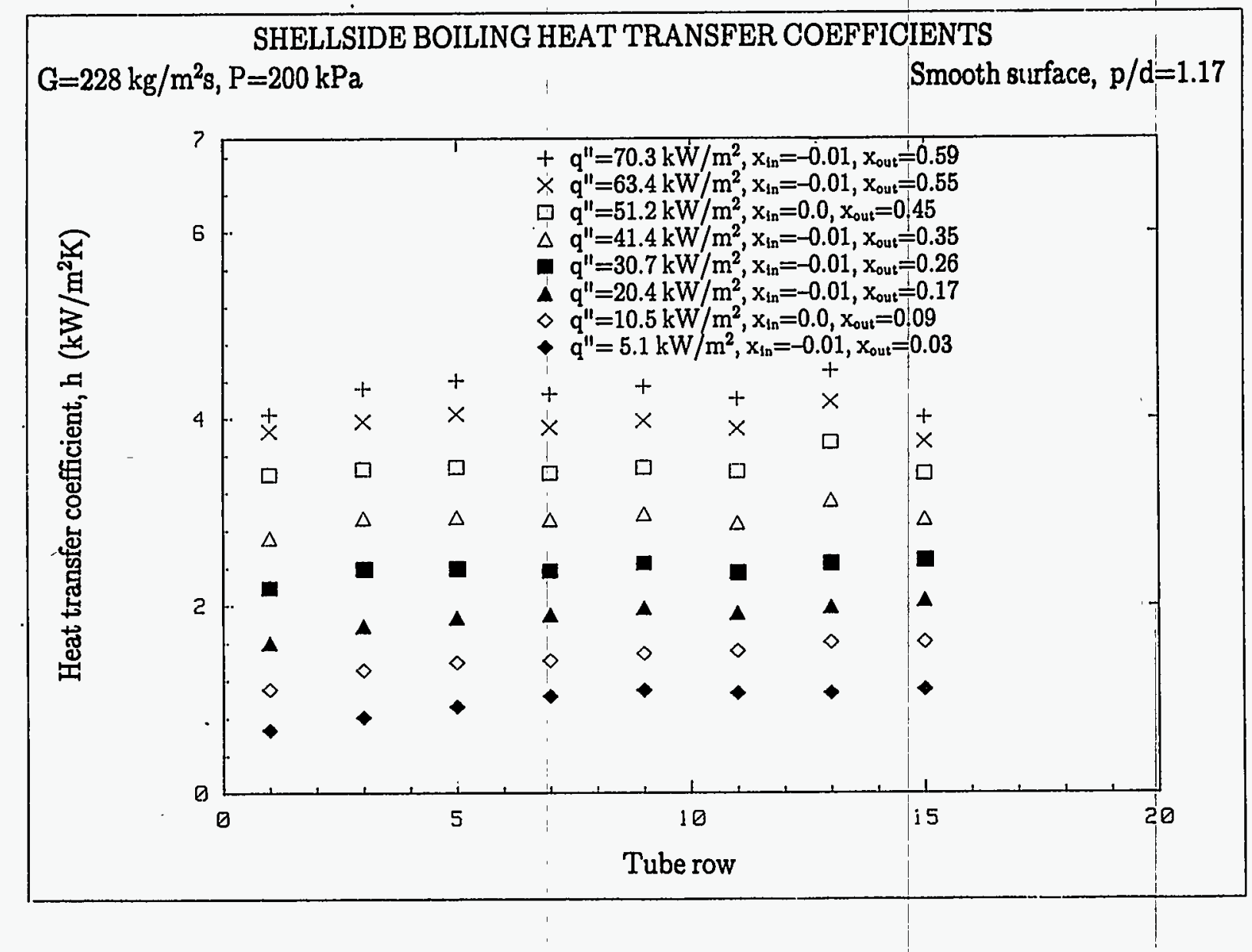

Figure 5.4. Effect of heat flux and tube row/quality on the smooth tube heat transfer coefficients. 


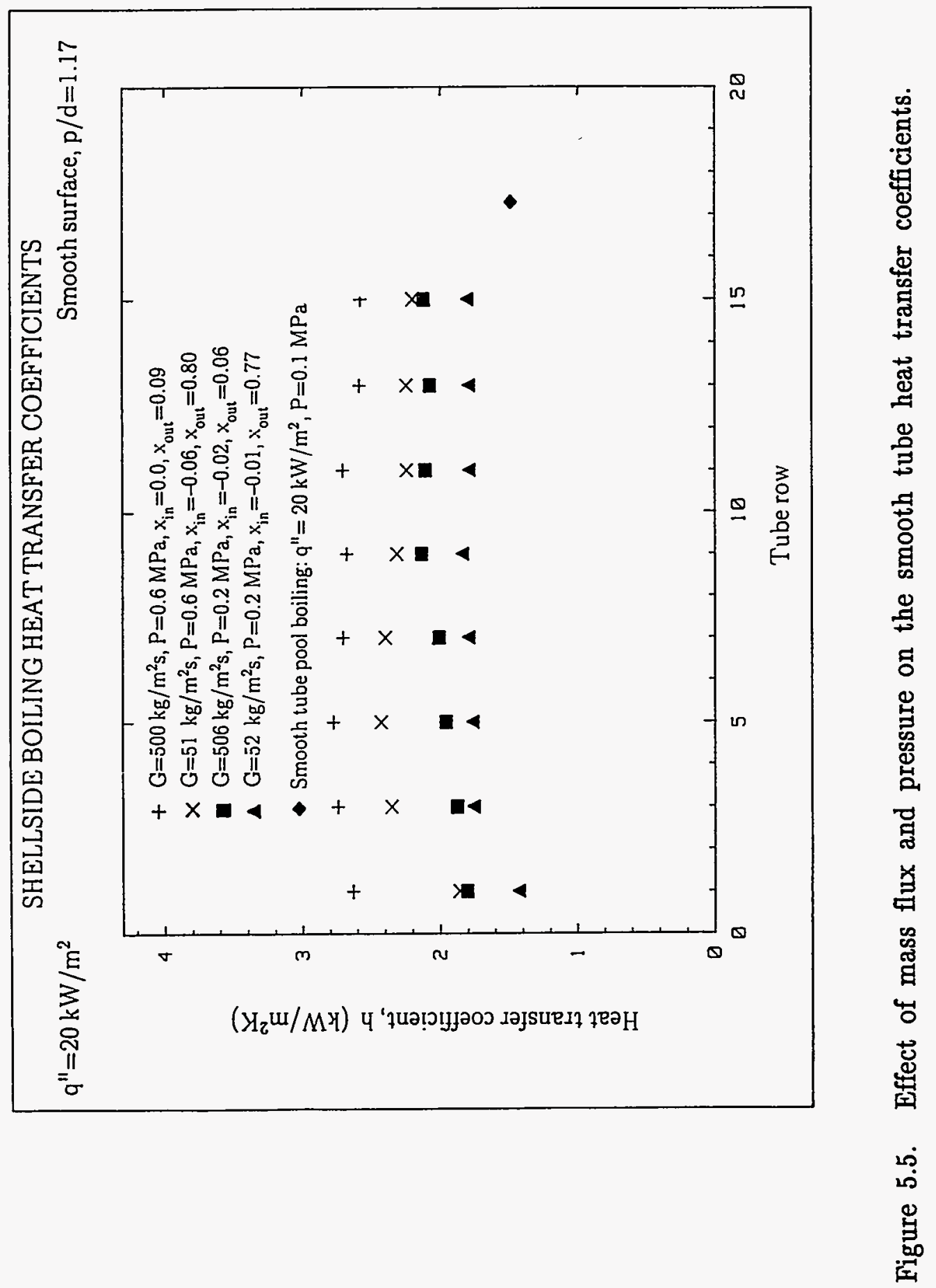


except the first row, even though the heat flux is relatively small $\left(20 \mathrm{~kW} / \mathrm{m}^{2}\right)$. The same is true of data taken at $600 \mathrm{kPa}$. In addition, there is only a very slight increase in the heat transfer coefficient with tube row for the data taken at $200 \mathrm{kPa}$ and a slight decrease for the data taken at $600 \mathrm{kPa}$. Therefore, the effect of varying the mass flux by an order of magnitude is minimal on the heat transfer coefficient for smooth tubes.

The insensitivity of the heat transfer coefficient to changes in mass flux is characteristic of heat transfer dominated by nucleate boiling. Conceivably, a balance of nucleate boiling and single-phase convection could also explain the lack of a mass flux effect if an increased mass flux resulted in a decrease in the nucleate boiling component equal to the increase in the single phase convection component.

One possible argument for a balance between nucleate boiling and single-phase convective heat transfer rests on an inverse relationship between the bubble departure diameter and the liquid velocity. Mikic and Rohsenow (1969) proposed that nucleate boiling is a function of the bubble departure diameter as follows:

$$
q_{\mathrm{nuc}}^{\prime \prime}=C_{1} D_{\mathrm{b}}^{2} \sqrt{f} n \Delta T
$$

In the presence of free stream convection, an estimate for the bubble departure diameter can be obtained by a balance between drag forces and surface tension forces:

$$
F_{\mathrm{d}}=F_{\sigma}
$$

where

$$
F_{\mathrm{d}}=C_{2} D_{\mathrm{b}}^{2} \rho_{\mathrm{L}} u_{\mathrm{L}}^{2}
$$


and

$$
F_{\sigma}=C_{3} \sigma D_{\mathrm{b}}
$$

After substituting equations (5.3) and (5.4) into equation (5.2) and rearranging,

$$
D_{\mathrm{b}}=C_{4} \sigma /\left(\rho_{\mathrm{L}} u_{\mathrm{L}}^{2}\right)
$$

Equation (5.5) shows that the bubble departure diameter and, therefore, the nucleate boiling heat flux decrease with increasing liquid velocity/mass flux. A correlation by ESDU (1973) gives the single-phase convective heat flux as a function of liquid velocity as

$$
\mathrm{q}_{\mathrm{sc}}^{\prime \prime}=C_{5} \operatorname{Re}^{0.635} \operatorname{Pr} 0.34 \Delta T
$$

so that the heat flux increases with mass flux. If the increase in the single-phase convective heat transfer is equal to the decrease in the nucleate boiling heat transfer, then the heat transfer coefficient will not vary with mass flux.

In addition to the lack of a mass flux effect, the lack of a tube row/quality effect also might be explained using a balance between nucleation and single-phase convective heat transfer. The liquid velocity can be related to fluid properties so that regions where such a balance might occur could be identified. The velocity of the liquid changes throughout the bundle as

$$
u_{\mathrm{L}}=\frac{G(1-x)}{\rho_{\mathrm{L}}(1-\alpha)}
$$


where $\mathrm{x}$ and $\alpha$ depend on the tube row. Dowlati et al. (1988) developed a correlation for the void fraction through a tube bundle as

$$
\alpha=0.88\left[j_{\mathrm{g}} \sqrt{\rho_{\mathrm{g}} /\left(\rho_{\mathrm{L}}-\rho_{\mathrm{g}}\right)} \sqrt{1 / \mathrm{g} D_{\mathrm{t}}}\right]^{0.57}
$$

so that equations (5.7) and (5.8) can be used to calculate the liquid velocity as a function of $x$ and $\rho_{\mathrm{g}} /\left(\rho_{\mathrm{L}}-\rho_{\mathrm{g}}\right.$ ) (which is approximately equal to $\rho_{\mathrm{g}} / \rho_{\mathrm{L}}$ ). Kandlikar (1990) showed that the non-dimensional heat transfer coefficient $\left(h / h_{\mathrm{sc}}\right)$ can remain constant or even decrease for some combinations of $x$ and $\rho_{\mathrm{g}} / \rho_{\mathrm{L}}$, as seen in Fig. 5.6.

While it is conceivable that the lack of a mass flux or tube row/quality effect on the heat transfer coefficient is a result of the fluid properties, the required balance between the nucleate boiling and single-phase convective heat transfer is highly speculative. Visual observations revealed the presence of bubble generation over nearly the entire surface of the smooth tubes, especially for heat flux values greater than $20 \mathrm{~kW} / \mathrm{m}^{2}$, as seen in Fig. 5.7. Therefore, the lack of a mass flux or tube row/quality effect on the heat transfer coefficient is a result of a heat transfer process dominated by fully established nucleate boiling.

Figure 5.5 shows that the heat transfer coefficient was sometimes smaller for the first tube row than for subsequent rows, particularly for small mass flux values. In addition, the heat transfer coefficient for the first tube row taken at $200 \mathrm{kPa}$ and $52 \mathrm{~kg} / \mathrm{m}^{2} \mathrm{~s}$ was smaller than the pool boiling value at the same heat flux and approximately $100 \mathrm{kPa}$. This relatively small value for the heat transfer coefficient at the first tube row was evident even for heat flux values as large as $80 \mathrm{~kW} / \mathrm{m}^{2}$, which is much larger than the largest heat flux value required to establish fully 


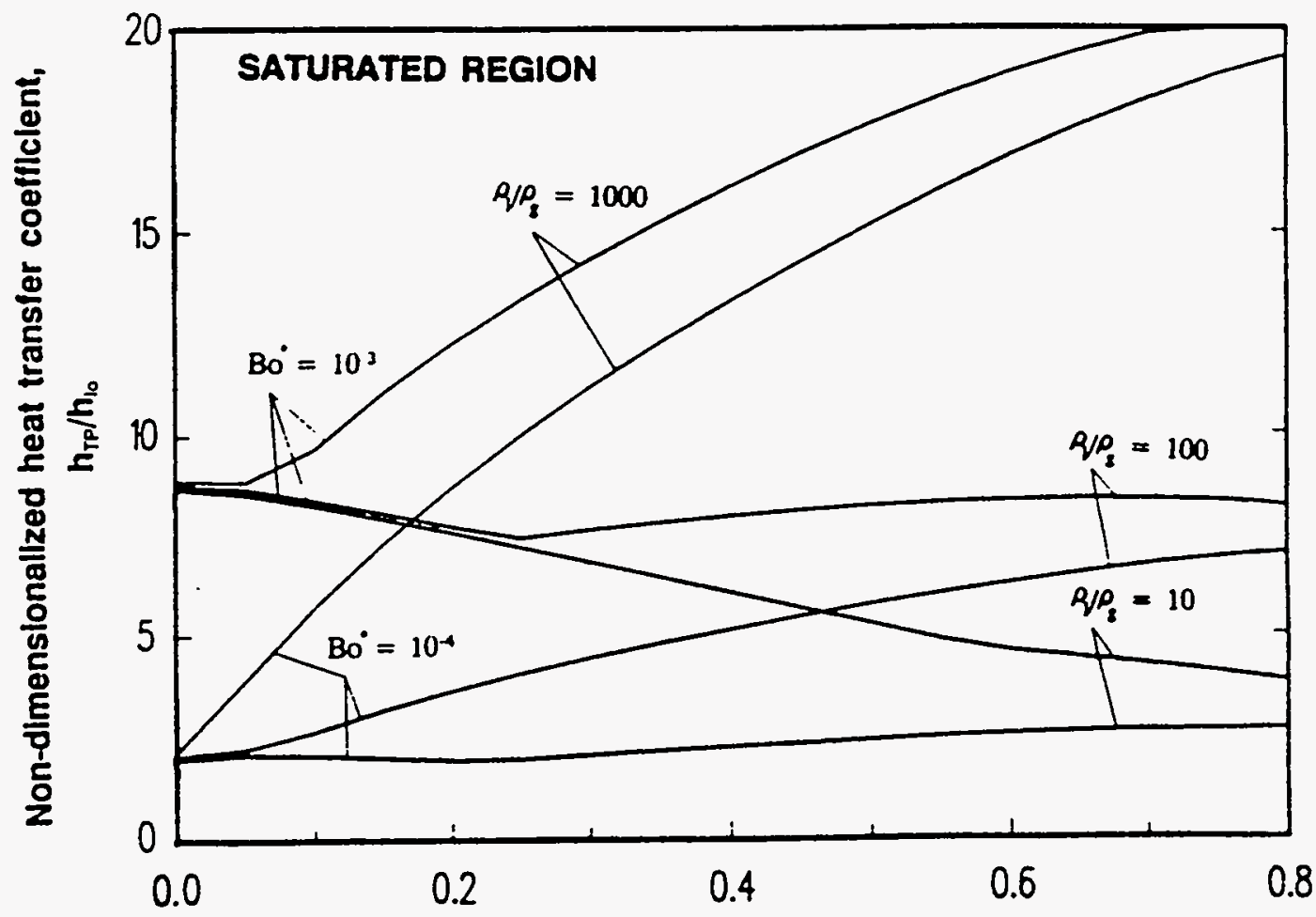

Quality, $x$

Figure 5.6. Non-dimensioinal heat transfer coefficients as a function of quality and density ratio (Kandlikar 1990). 


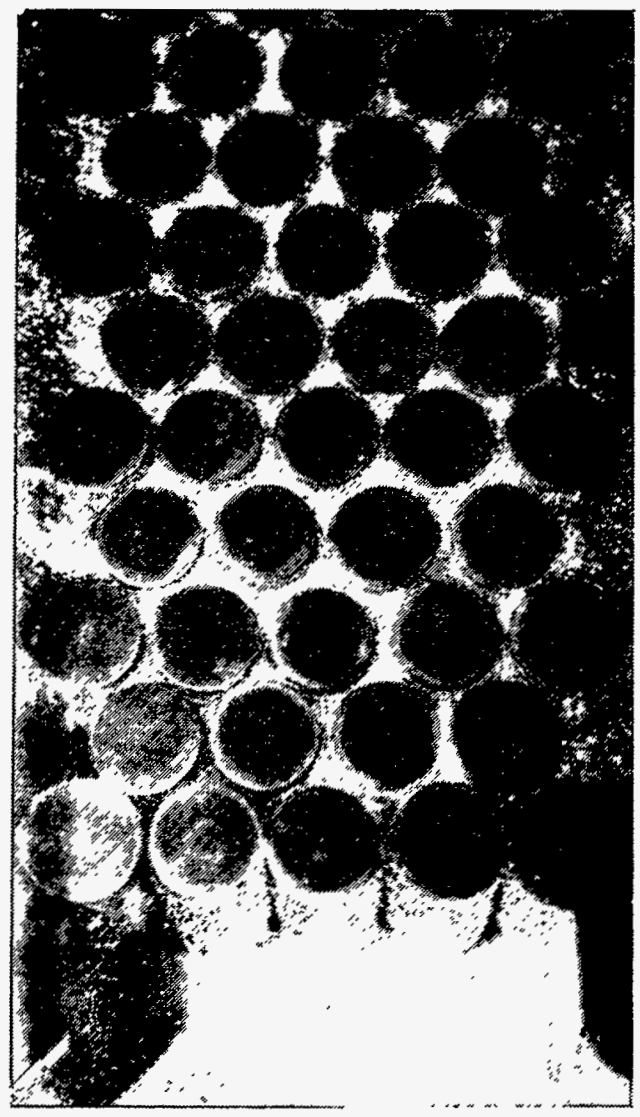

Figure 5.7. Nucleate boiling on the bottom of smooth tubes in a bundle. 
developed nucleate boiling for pool boiling. The data obtained in the tube-bundle experiments suggest that fully established nucleate boiling is sometimes suppressed at the first tube row. This trend is more prominent in the High Flux tubes and will be discussed below in more detail.

The effect of pressure on the heat transfer coefficient can be seen by comparing the data shown in Fig. 5.5 taken at $50 \mathrm{~kg} / \mathrm{m}^{2} \mathrm{~s}$, for example. An increase in the pressure from 200 to $600 \mathrm{kPa}$ increased the average heat transfer coefficient for the interior tube rows from approximately $1.8 \mathrm{~kW} / \mathrm{m}^{2} \mathrm{~K}$ to approximately 2.4 $\mathrm{kW} / \mathrm{m}^{2} \mathrm{~K}$ (approximately $600 \mathrm{~W} / \mathrm{m}^{2} \mathrm{~K}$ ). The increase in the average heat transfer coefficient is also $600 \mathrm{~W} / \mathrm{m}^{2} \mathrm{~K}$ for the data taken at a mass flux of $500 \mathrm{~kg} / \mathrm{m}^{2} \mathrm{~s}$. As a result, the heat transfer coefficients taken at $600 \mathrm{kPa}$ were approximately $33 \%$ larger than those taken at $200 \mathrm{kPa}$, regardless of mass flux.

The effect of the pitch-to-diameter ratio on the heat transfer coefficients is shown in Fig. 5.8 where heat transfer coefficients as a function of tube row are given for a mass flux of $219 \mathrm{~kg} / \mathrm{m}^{2} \mathrm{~s}$ and a pressure of $200 \mathrm{kPa}$. Figure 5.8 shows that, even for the relatively small heat flux value of $10 \mathrm{~kW} / \mathrm{m}^{2}$, the heat transfer coefficients for the bundle of smooth tubes with the pitch-to-diameter ratios of 1.17 are only slightly larger than the data from the bundle with the pitch-to-diameter ratio of 1.50. With increasing heat flux, the difference becomes even less. Figure 5.8 shows that, for the data taken at $40 \mathrm{~kW} / \mathrm{m}^{2}$, the results from the two tube-bundles with different pitch-to-diameter ratios overlap. There is generally no significant difference between the data from different tube layouts for similar operating conditions at any but the lowest heat flux values. 


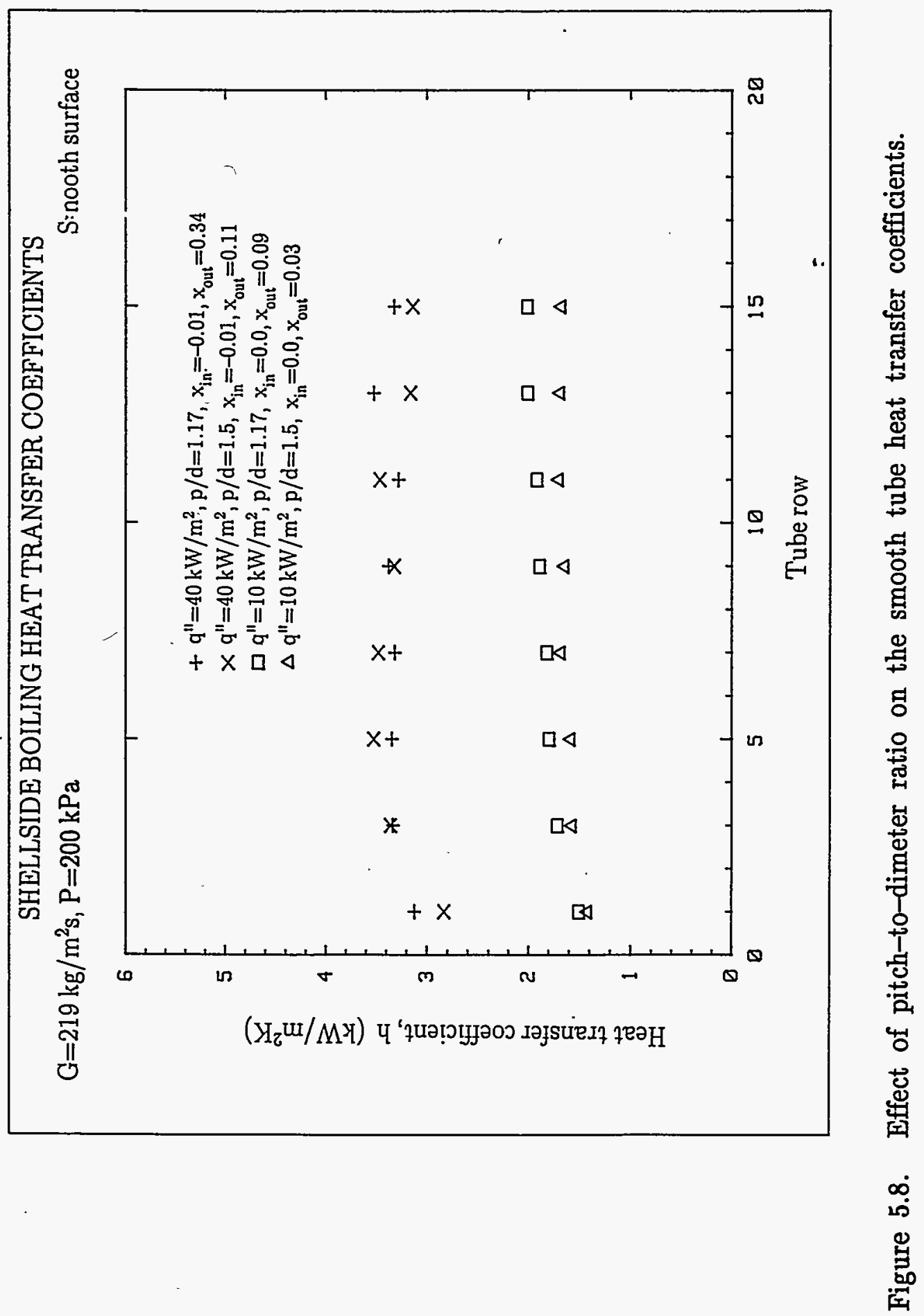


High Flux tube results in pure $\mathrm{R}-113$

The heat transfer coefficients for the High Flux tubes were obtained in the tube bundle with a pitch-to-diameter ratio of 1.17. Experiments in the tube bundle with a pitch-to-diameter ratio of 1.50 , which would have provided a measure of the convective effects, were not performed because the pitch-to-diameter ratio was found to generally have a negligible effect on the heat transfer coefficients for smooth tubes and because the High Flux surface is even less susceptible to convective effects than the smooth surface.

Two-phase heat transfer coefficients as a function of tube row are shown in Fig. 5.9 for a mass flux of $352 \mathrm{~kg} / \mathrm{m}^{2} \mathrm{~s}$ and a pressure of $200 \mathrm{kPa}$. For a given heat flux, the heat transfer coefficient is nearly independent of tube row, except for the first two instrumented tubes. Therefore, as with the smooth tube results, the heat transfer coefficients are independent of quality because changes in tube row correspond to changes in quality. Some scatter in the data is present due to the uncertainty in the heat transfer coefficients; the uncertainty is primarily a result of the relatively small values for the wall superheats.

Figure 5.9 also shows that the heat transfer coefficient increases for the first three tube rows before attaining a constant value independent of flow quality. These results are even more dramatic than those for the first three rows of smooth tubes. Visual observations support the hypothesis that fully established nucleate boiling is somewhat suppressed in a tube bundle as compared to a single tube in pool boiling. Indeed, patches of the High Flux surface failed to nucleate even at heat flux values as high as $80 \mathrm{~kW} / \mathrm{m}^{2}$ and qualities as high as 0.76 .

One explanation for this is associated with the possibility that the maximum heat flux attainable by the experimental apparatus was not sufficient to initiate 


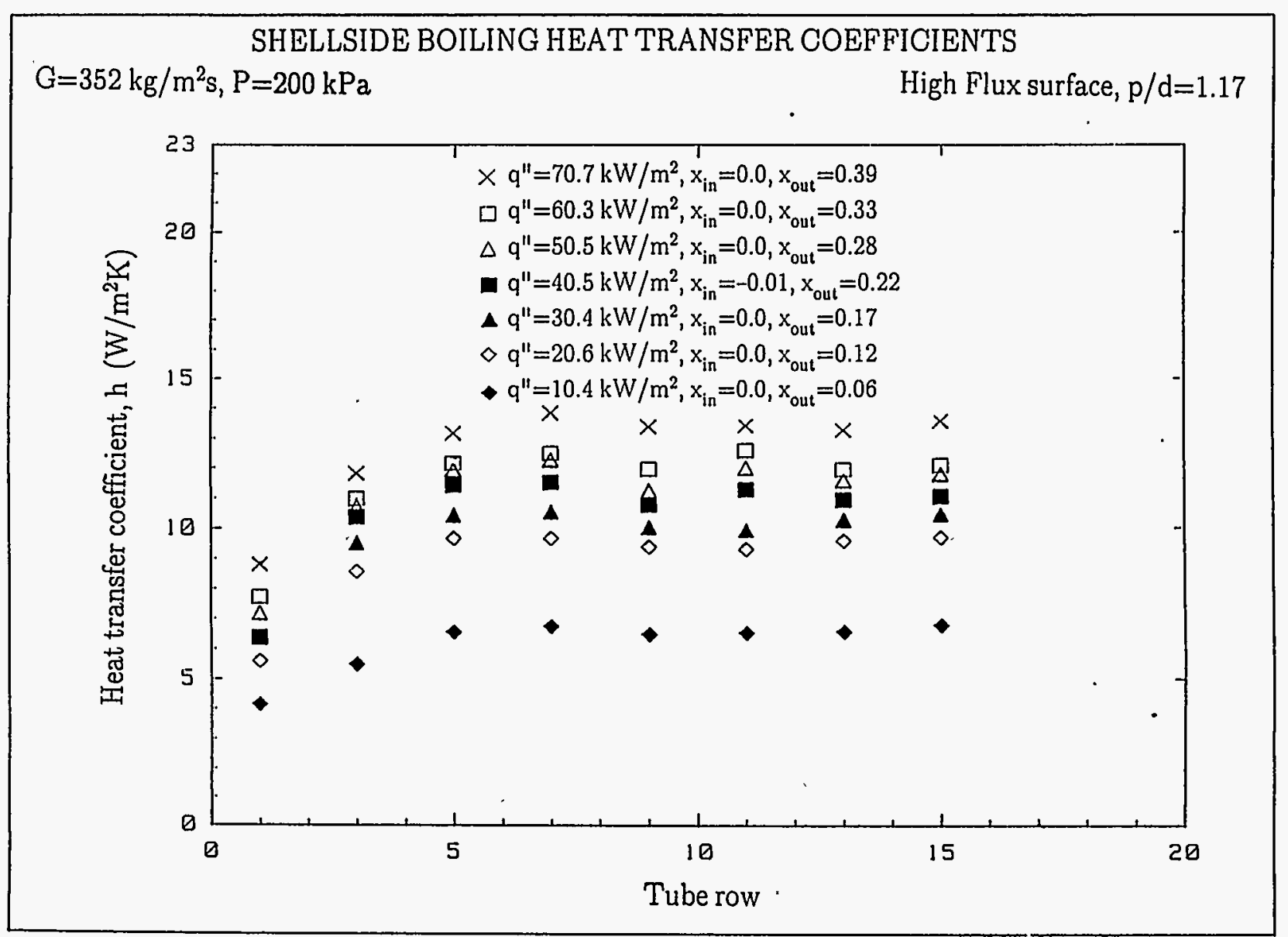

Figure 5.9. Effect of heat flux and tube row/quality on the High Flux tube heat transfer coefficients. 
fully established nucleate boiling for the High Flux tubes, even though the data were collected for each mass flux starting with the highest heat flux value. As observed in the pool boiling experiment and reported by other researchers (Bergles and Chyu 1982), the High Flux surface does not always nucleate initially over its entire surface as the heat flux is increased. Once part of the surface nucleates, the nucleation process does not spread in the High flux surface as easily as on the smooth surface, because vapor traveling around the perimeter of a smooth tube is more likely to activate extinct nucleation sites than in the High Flux surface where the subsurface cavities are not all interconnected. However, the high conductivity, thick-walled construction of the heated tube tends to maintain the entire surface at a uniform temperature. Therefore, when one area of the heated surface nucleates, the surface area is generally large enough so that the temperature of the entire heated surface is reduced. The heat flux must then be increased sufficiently so that the required incipience superheat is achieved at the locations where nucleation has not been initiated.

In the tube bundle, the increased velocity of the free stream fluid helps to reduce the temperature of the non-nucleated portion of the heated surface below that for a tube in pool boiling so that an even larger heat flux is required to achieve the superheat necessary to initiate nucleation. This explains the areas of non-nucleating heated surface of the High Flux tubes observed in the tube bundle experiments even at the top row at heat fluxes as high as $80 \mathrm{~kW} / \mathrm{m}^{2}$.

Nucleate boiling in the first rows of the High Flux tube bundle is further delayed due to a lack of vapor rising from tubes lower in the bundle. The bundle of smooth tubes does not show this effect as dramatically, because vapor from the bottom of even the first tube can more easily travel around the circumference and 
activate extinct nucleation sites, thereby initiating nucleate boiling earlier than for the High Flux tubes.

The combination of the piece wise onset of nucleation and the effect of rising bubbles on the High Flux surface can be seen by observing the trends in the heat transfer coefficients as the heat flux is increased from very small values before nucleation has been initiated. Figure 5.10 shows the tube bundle results for the High Flux tubes as the heat flux is increased from 0.6 to $5.1 \mathrm{~kW} / \mathrm{m}^{2}$. For comparison, similar results are shown for the smooth tube bundle in Fig. 5.11. The heat transfer coefficients for the High Flux tubes at $5.1 \mathrm{~kW} / \mathrm{m}^{2}$ are approximately equal to the values obtained after the heat flux has been increased to the maximum value and then decreased. Large increases in the heat transfer coefficients from one heat flux to the next higher value indicate the onset of nucleation. Note that nucleation occurs in upper portions of the bundle first where the volume of vapor is the largest. Also note the relatively uniform spacing in the heat transfer coefficients for the smooth tubes indicating that nucleation was easily established and very little temperature overshoot occurred.

The heat transfer coefficients for High Flux tubes are significantly affected by changes in the heat flux. Figure 5.9 shows that the change in the average heat transfer coefficient with changing heat flux is largest at low values for the heat flux. These same data were plotted on a typical boiling curve as shown in Fig. 5.12 where each data point for tube bundle boiling was calculated using the arithmetic average of the heat flux and wall superheat for the instrumented tubes in rows 3 through 13 . Recall that the pool boiling data were obtained at near atmospheric pressure and the data obtained in the tube bundle were taken at $200 \mathrm{kPa}$. The data obtained in the tube bundle result in a boiling curve which is very steep in the range of low heat 


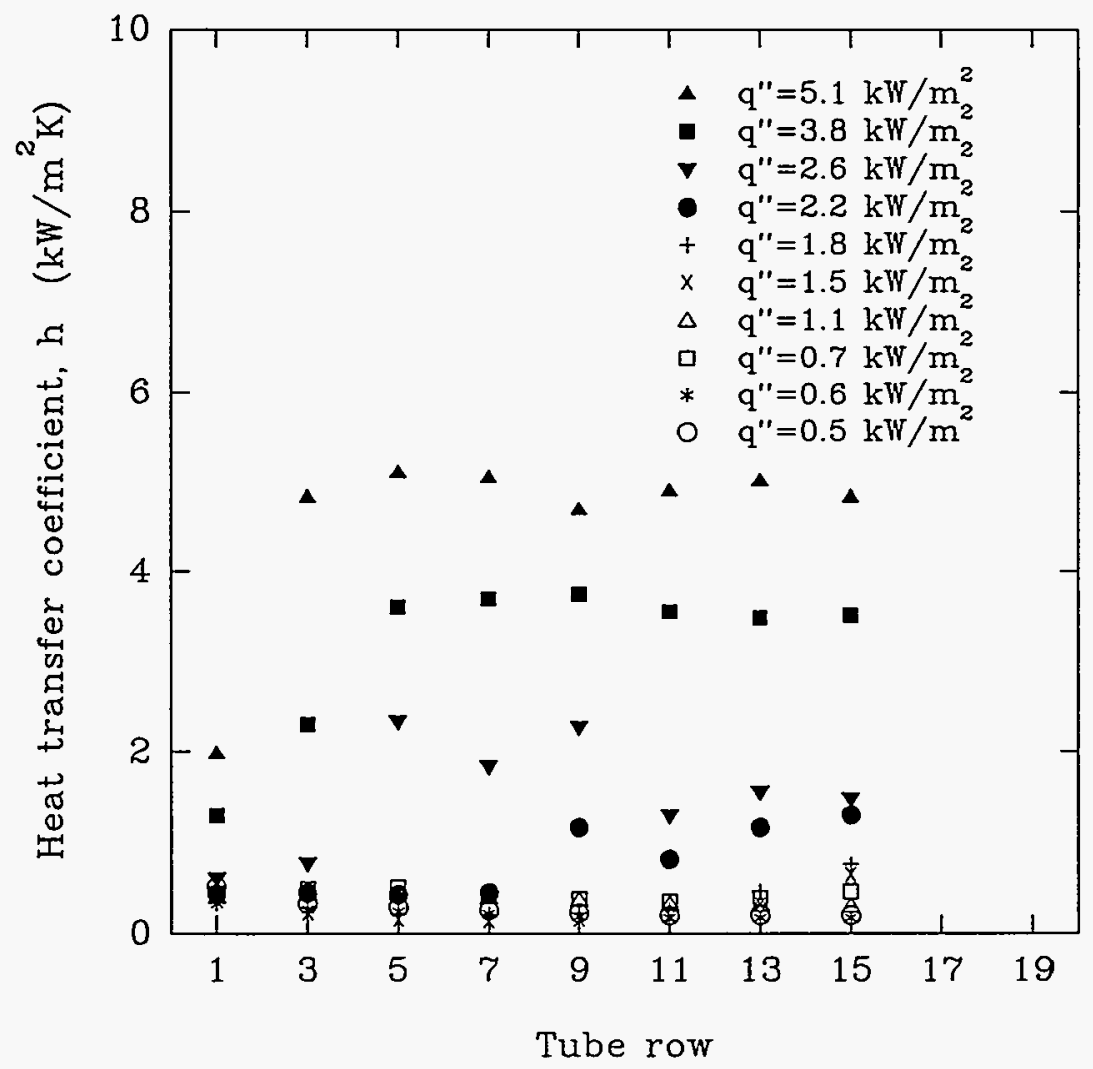

Figure 5.10. Onset of nucleate boiling for a High Flux tube bundle at $\mathrm{P}=200 \mathrm{kPa}$ and $\mathrm{G}=150 \mathrm{~kg} / \mathrm{m}^{2} \mathrm{~s}$. 


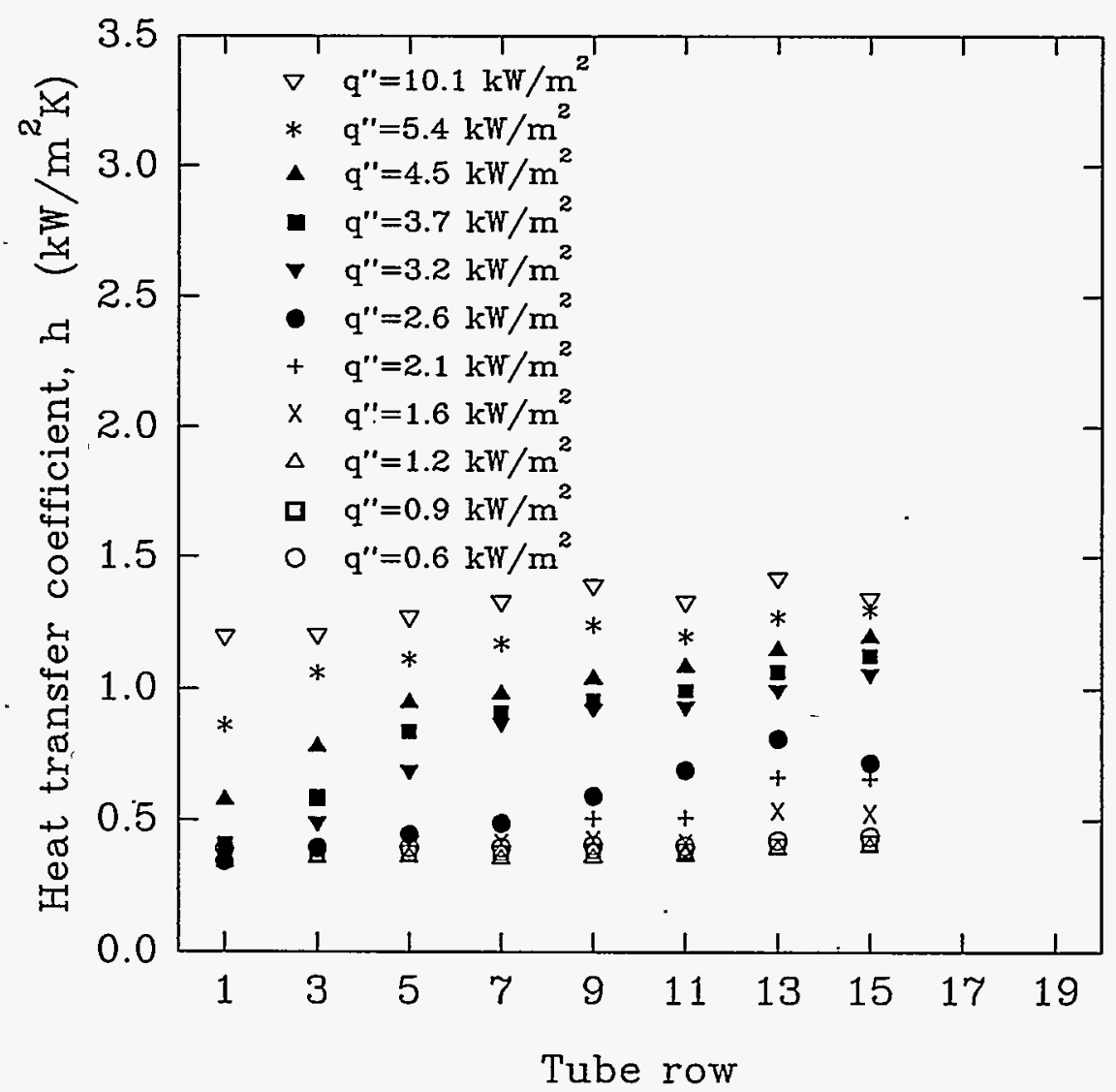

Figure 5.11. Onset of nucleate boiling for a smooth tube bundle at $\mathrm{P}=200 \mathrm{kPa}$ and $\mathrm{G}=100 \mathrm{~kg} / \mathrm{m}^{2} \mathrm{~s}$. 


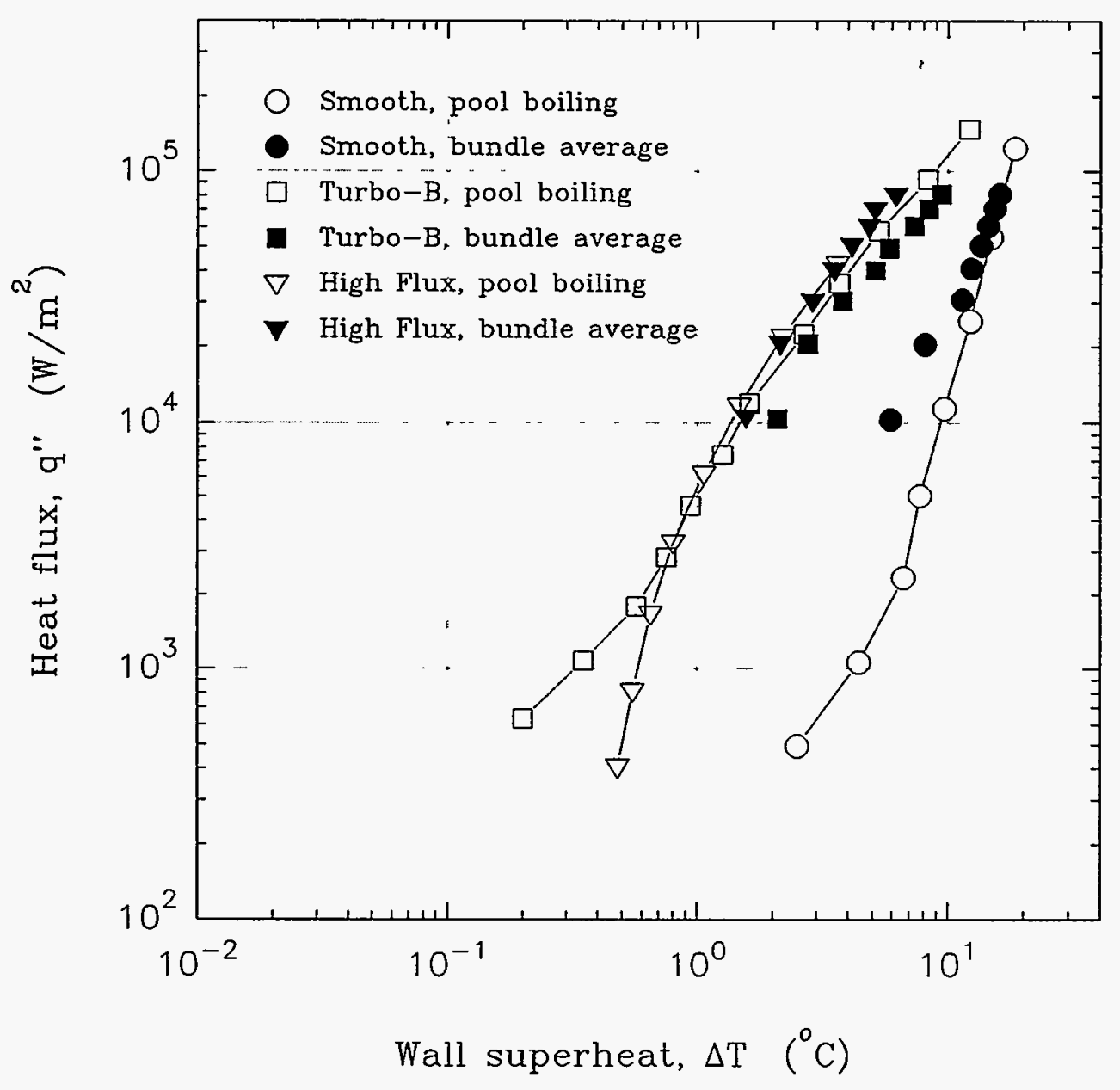

Figure 5.12. Boiling curves tube bundles at $\mathrm{P}=202 \mathrm{kPa}$, and for single tubes in pool boiling at $\mathrm{P}=103 \mathrm{kPa}$. 
flux. Figure 5.12 also shows that the boiling curve for High Flux tubes in pool boiling is steepest at low values of heat flux. Therefore, the trend for the two-phase heat transfer coefficient in a tube bundle is the same as for pool boiling. This coincidence strongly suggests that nucleate boiling is the predominant mechanism for heat removal throughout the bundle.

The effect of changes in mass flux on the heat transfer coefficient can be seen in Fig. 5.13 where the heat transfer coefficient is plotted versus tube row for a constant heat flux value of $20 \mathrm{~kW} / \mathrm{m}^{2}$ and $200 \mathrm{kPa}$ and mass flux values ranging from 53 to $504 \mathrm{~kg} / \mathrm{m}^{2} \mathrm{~s}$. The large scatter in the data is a result of very low wall superheat for the High Flux surface. All the data are within the experimental uncertainty of the average value for the heat transfer coefficient. Therefore, even though the mass flux changes by an order of magnitude, the effect on the heat transfer coefficient is insignificant even for relatively small heat flux values. This is expected from the dominance of the nucleate boiling.

The effect of pressure on the heat transfer coefficient is shown in Fig. 5.14 where the heat transfer coefficient is plotted versus the tube row for a mass flux of $500 \mathrm{~kg} / \mathrm{m}^{2} \mathrm{~s}$. Data taken at heat flux values of 10,40 , and $80 \mathrm{~kW} / \mathrm{m}^{2}$ are given for pressures of 200 and $600 \mathrm{kPa}$ each. Figure 5.14 shows that the heat transfer coefficients increase with pressure for a given heat flux. For example, the average heat transfer coefficient at $10 \mathrm{~kW} / \mathrm{m}^{2}$ is approximately $2000 \mathrm{~W} / \mathrm{m}^{2} \mathrm{~K}(22 \%)$ greater at $600 \mathrm{kPa}$ than at $200 \mathrm{kPa}$. In addition, the pressure enhancement increases with increasing heat flux. The average heat transfer coefficient at $600 \mathrm{kPa}$ and 80 $\mathrm{kW} / \mathrm{m}^{2}$ is $6000 \mathrm{~W} / \mathrm{m}^{2} \mathrm{~K}(32 \%)$ greater than at $200 \mathrm{kPa}$ and $80 \mathrm{~kW} / \mathrm{m}^{2}$. In general, the heat transfer coefficient was $30 \%$ greater at $600 \mathrm{kPa}$ and at $200 \mathrm{kPa}$. This 


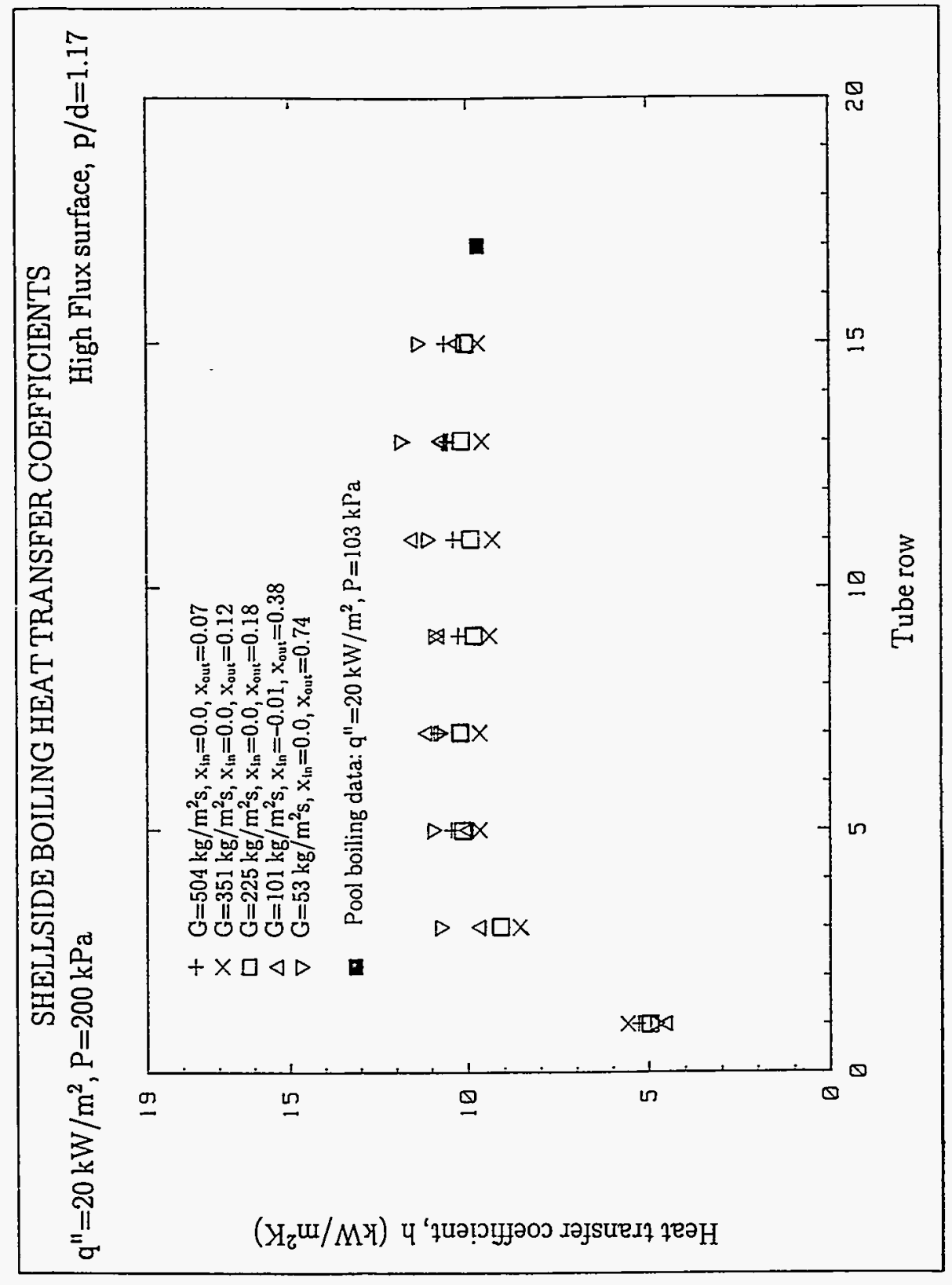

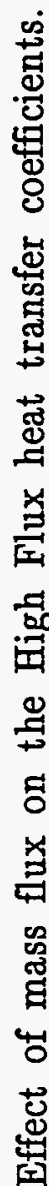

กัต

总 


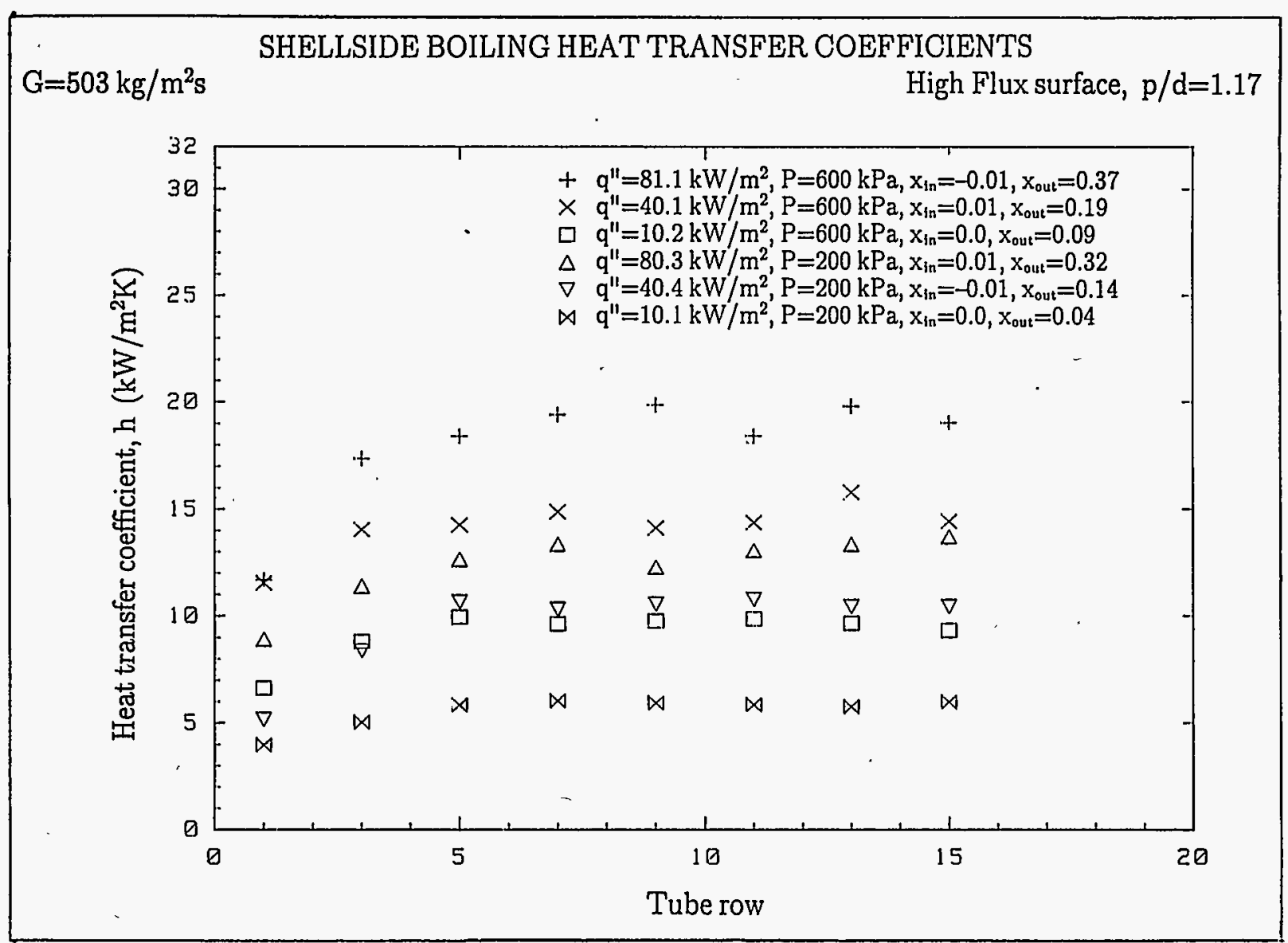

Figure 5.14. Effect of heat flux and pressure on the High Flux heat transfer coefficients. 
percentage increase in the heat transfer coefficient is only slightly smaller than the smooth tube value of $33 \%$.

The trends in the data generally suggest that the pressure effect is the result of changes in the nucleate boiling mechanism. It follows from the work of Mikic and Rohsenow (1969) that the heat transfer coefficient is a function of the number of nucleation sites and the bubble departure diameter. Using mechanical and phase equilibrium for a hemispherical bubble, the required vapor temperature in the bubble can be shown to be

$$
T_{\mathrm{v}}=T_{\mathrm{sat}}+\frac{2 \sigma}{\mathrm{r}_{\mathrm{b}}} \frac{T_{\mathrm{sat}} \mathrm{v}_{\mathrm{fg}}}{i_{\mathrm{fg}}}
$$

Assuming a linear temperature variation normal to the heated surface in the liquid using thermal equilibrium, the required wall superheat for bubble growth can be shown to be

$$
T_{\mathrm{w}}-T_{\mathrm{sat}}=\frac{2 \sigma}{\mathrm{r}_{\mathrm{b}}} \frac{T_{\mathrm{sat}} \mathrm{v}_{\mathrm{fg}}}{i_{\mathrm{fg}}}+\frac{\mathrm{q}^{\prime \prime} \mathrm{r}}{\mathrm{k}_{\mathrm{l}}}
$$

The minimum and maximum radius for bubble growth can be determined by solving equation (5.10) for the bubble radius:

$$
\mathrm{r}=\frac{T_{\mathrm{w}}-T_{\mathrm{sat}} \pm \sqrt{\left(T_{\mathrm{w}}-T_{\mathrm{sat}}\right)^{2}-\frac{\mathrm{q}^{\mathrm{II}} 8 \sigma}{\mathrm{k}_{1}} \frac{T_{\mathrm{sat}} \vartheta_{\mathrm{fg}}}{i_{\mathrm{fg}}}}}{2 \mathrm{q}^{\prime \prime} \mathrm{r} / \mathrm{k}_{\mathrm{l}}}
$$

As seen in equation (5.11), the range of radii which provide for bubble growth increases with $\sqrt{\left(T_{\mathrm{w}}-T_{\mathrm{sat}}\right)^{2}-\frac{\mathrm{q}^{\prime \prime} 8 \sigma}{\mathrm{k}_{1}} \frac{T_{\mathrm{sat}} \vartheta_{\mathrm{fg}}}{i_{\mathrm{fg}}}}$ and so increases with decreasing values of $\left(T_{\mathrm{sat}} v_{\mathrm{fg}} / i_{\mathrm{fg}}\right)^{\frac{1}{2}}$. Because the number of nucleation sites should 
increase with an increase in the range of radii, the number of nucleation sites, which could provide bubble growth, increases with increasing values of $\left(i_{\mathrm{fg}} / T_{\mathrm{sat}} v_{\mathrm{fg}}\right)^{\frac{1}{2}}$. Note that $\cdot\left(i_{\mathrm{fg}} / T_{\mathrm{sat}} v_{\mathrm{fg}}\right)^{\frac{1}{2}}$ is approximately equal to $\left(\rho_{\mathrm{v}} i_{\mathrm{fg}} / T_{\mathrm{sat}}\right)^{\frac{1}{2}}$.

The departure diameter given by Cole and Rohsenow (1968) is a function of $\left(T_{\text {sat }} / \rho_{\mathrm{v}} i_{\mathrm{fg}}\right)$. The heat flux is a product of the number of nucleation sites and the bubble departure diameter, and so the heat flux increases with increasing values of $\left(T_{\mathrm{sat}} / \rho_{\mathrm{v}} i_{\mathrm{fg}}\right)^{\frac{1}{2}}$ which is a relatively strong function of pressure over the pressure range of interest. For example, the ratio of $\left(T_{\mathrm{sat}} / \rho_{\mathrm{v}} i_{\mathrm{fg}}\right)^{\frac{1}{2}}$ at $600 \mathrm{kPa}$ to that at $200 \mathrm{kPa}$ for $\mathrm{R}-113$ is 1.3 . This is the same value as the ratio of heat transfer coefficients at $600 \mathrm{kPa}$ and $200 \mathrm{kPa}$. The pressure effect on the heat transfer coefficient is seen to be predicted reasonably using $\left(T_{\mathrm{sat}} / \rho_{\mathrm{v}} i_{\mathrm{fg}}\right)^{\frac{1}{2}}$. Therefore, bubble growth and departure are seen to be the dominant heat transfer mechanism for the High Flux surface.

\section{Turbo-B tube results in pure $\mathrm{R}-113$}

Data from a tube bundle with the Turbo-B surface were collected in the bundle with the pitch-to-diameter ratio of 1.50 for a range of mass fluxes from 50 to $335 \mathrm{~kg} / \mathrm{m}^{2} \mathrm{~s}$, heat fluxes from 5 to $80 \mathrm{~kW} / \mathrm{m}^{2}$, and pressures of 200 and $600 \mathrm{kPa}$. The upper value of the mass flux range was limited by the ability to maintain a saturated inlet condition, which was determined by the maximum preheater power. As was the case with the High Flux tube bundle, the Turbo-B surface was tested in only one bundle geometry due to the insensitivity of the Turbo-B surface to convective effects.

The heat transfer coefficients for Turbo-B tubes are shown in Fig. 5.15 where the heat transfer coefficient is plotted versus tube row for an average mass 


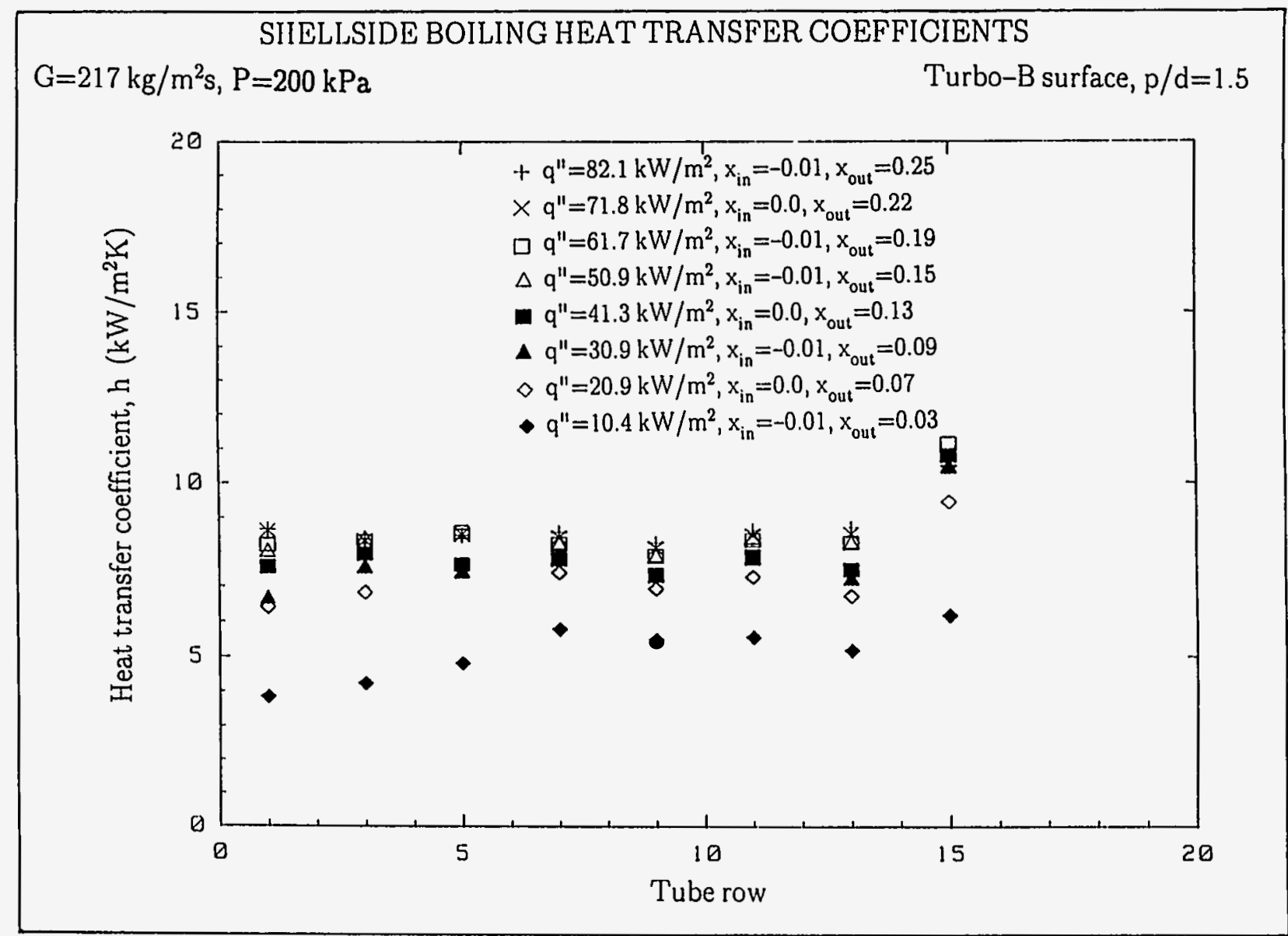

Figure 5.15. Effect of heat flux and tube row/quality on the Turbo-B heat transfer coefficients. 
flux of $217 \mathrm{~kg} / \mathrm{m}^{2} \mathrm{~S}$ and a pressure of $200 \mathrm{kPa}$. As was the case for tubes with the smooth and High Flux surfaces, the heat transfer coefficients for the Turbo-B tubes do not change significantly with tube row or quality. In general, the heat transfer coefficient for the first row is nearly the same as for the subsequent rows. Recall that the Turbo-B surface exhibited very little temperature overshoot during pool boiling. Because a lower heat transfer coefficient at the first tube row in a bundle is the result of a delay in the incipience of boiling, as postulated for the High Flux tubes, one would expect that the Turbo-B surface, which attained incipient boiling at the smallest wall superheat among all three surfaces in pool boiling, would be the surface with the least decrease at the first row in the tube bundle.

As described in Chapter 3, the early onset of nucleate boiling is attributed to the subsurface circumferential channels, which tend to keep vapor from lower nucleation sites next to the heated surface as the vapor travels around the circumference. The volume of vapor increases as it travels upward through superheated liquid and activates extinct nucleation sites along the way, which promotes the early establishment of nucleate boiling.

Figure 5.15 also shows that the heat transfer coefficients vary with heat flux, although not as much as for the smooth or High Flux tubes. The reduced effect of heat flux on the heat transfer coefficients is suggested to be a result of the large volume of vapor in the subsurface channels. This leads to a thinning of the liquid layer next to the heated surface and a suppression of nucleate boiling that promotes thin film vaporization in the upper portions of the subsurface channels. A heat transfer coefficient for thin film vaporization can be shown to be a weak function of heat flux by modeling the effect of an increased operating temperature on the heat transfer coefficient. 
For turbulent flow in a thin liquid film, Collier (1981) gives the steady-state momentum equation as

$$
\tau=\rho\left(\nu+\epsilon_{\mathrm{m}}\right) \frac{\partial \mathbf{u}_{\mathrm{z}}}{\partial \mathrm{y}}
$$

and the steady-state energy equation as

$$
q^{\prime \prime}=-\rho c_{p}\left(\alpha+\epsilon_{h}\right) \frac{\partial T}{\partial y}
$$

where conduction is in the direction normal to the heated surface only ( $y$-direction) and fluid flow is along the heated surface in one direction only ( $\mathrm{z}$-direction). The velocity profile can be described using the universal velocity distribution given by White (1981):

$$
\begin{array}{ll}
\mathrm{u}^{+}=\mathrm{y}^{+} & \text {for } 0<\mathrm{y}^{+}<5 \\
\mathrm{u}^{+}=-3.05+\ln \left(\mathrm{y}^{+}\right) & \text {for } 5<\mathrm{y}^{+} \leq 30 \\
\mathrm{u}^{+}=5.5+2.5 \ln \left(\mathrm{y}^{+}\right) & \text {for } \mathrm{y}^{+}>30
\end{array}
$$

where $\mathrm{u}^{+}=\frac{\mathrm{u}_{\mathrm{z}}}{\mathrm{u}^{*}}$ and $\mathrm{y}^{+}=\frac{\mathrm{u}^{*}}{\nu} \mathrm{y}$. Equation (5.12) can be rewritten as

$$
\tau=\rho\left(1+\epsilon_{\mathrm{m}} / \nu\right)\left(\tau_{\mathrm{w}} / \rho\right) \frac{\partial \mathrm{u}^{+}}{\partial \mathrm{y}^{+}}
$$

where the wall shear stress is in the laminar sublayer so that

$$
\tau_{\mathrm{w}}=\mu \frac{\partial \mathrm{u}_{\mathrm{z}}}{\partial \mathrm{y}}
$$


The wall shear stress was evaluated using an expression by Hewitt and Hall-Taylor (1970) who give the velocity profile in concurrent, upward annular flow as:

$$
\mathrm{u}=20 \mathrm{U} \mathrm{y} / \delta^{2}
$$

so that the wall shear stress becomes

$$
\tau_{\mathrm{w}}=20 \mu \mathrm{U} / \delta^{2}
$$

The energy equation, equation (5.13), can be rewritten as

$$
\mathrm{q}^{\prime \prime}=-\rho \mathrm{c}_{\mathrm{p}}\left(\alpha+\epsilon_{\mathrm{h}}\right) \mathrm{u}^{*} / \nu \frac{\partial \mathrm{T}}{\partial \mathrm{y}^{*}}
$$

and integrated to obtain:

$$
\frac{T_{1}-T_{\mathrm{w}}}{\mathrm{q}_{\mathrm{w}}^{n}}=\int_{0}^{\delta^{+}} \frac{\nu}{\rho \mathrm{c}_{\mathrm{p}}\left(\alpha+\epsilon_{\mathrm{h}}\right) \mathrm{u}^{*}} \mathrm{dy}^{+}
$$

where the left hand side is equal to $1 / h$. The procedure for calculating the heat transfer coefficient involves inserting the universal velocity distribution (equations $5.14-5.16$ ) into equation (5.17) and solving for $\epsilon_{\mathrm{m}}$ which is then assumed to be equal to $\epsilon_{\mathrm{h}}$. The expression for $\epsilon_{\mathrm{h}}$ is then inserted into equation (5.21) and the integration performed to solve for the heat transfer coefficient. 
In the range of $0<y^{+}<5$, the heat transfer coefficient can be shown to be

$$
h=\rho c_{p} u^{*} / F
$$

where

$$
F=\delta^{+} \operatorname{Pr}
$$

The heat flux effect on the heat transfer coefficient can be determined heuristically by calculating the ratio of the heat transfer coefficients at different film temperatures. Combining equations (5.20), (5.23), and (5.24) and assuming a constant value for the liquid layer and mean liquid velocity, the ratio of the heat transfer coefficients is found to be:

$$
\mathrm{h}_{2} / \mathrm{h}_{1}=(k \sqrt{\rho / \mu})_{2} /(k \sqrt{\rho / \mu})_{1}
$$

The heat flux effect can be seen by using equation (5.25) for a heat flux of 80 $\mathrm{kW} / \mathrm{m}^{2}\left(71^{\circ} \mathrm{C}\right)$ and a heat flux of $10 \mathrm{~kW} / \mathrm{m}^{2}\left(75^{\circ} \mathrm{C}\right)$.

$$
\mathrm{h}_{75} / \mathrm{h}_{71}=(k \sqrt{\rho / \mu})_{75} /(k \sqrt{\rho / \mu})_{71}
$$

For pure $\mathrm{R}-113$ this ratio is equal to 0.99 which indicates that, for thin film vaporization, the effect of heat flux is minimal on the heat transfer coefficient. A combination of nucleate boiling in the lower regions of the subsurface channel and thin film vaporization in the upper regions would explain the small variation in the heat transfer coefficient with changes in the heat flux. 
In the range of $5<\mathrm{y}^{+}<30$, a similar procedure can be used to show that the heat transfer coefficient can be expressed as in equation (5.23) but where the function, F, has been expanded to

$$
\mathrm{F}=5 \operatorname{Pr}+5 \ln \left(1+\operatorname{Pr}\left(\left(\delta^{+} / 5\right)-1\right)\right)
$$

The first term on the right hand side of equation (5.27) is the largest and, to a first approximation, equation (5.25) still holds. Finally, in the range of $y^{+}>30$, the heat transfer coefficient again can be shown to be the same as in equation (5.23) where the function, $F$, has been expanded to

$$
\mathrm{F}=5 \operatorname{Pr}+5 \ln (1+5 \operatorname{Pr})+\mathrm{G}
$$

where

$$
\begin{gathered}
\mathrm{G}=\frac{2.5}{\mathrm{H}} \ln \left[\left[\frac{5 \delta^{+} / \mathrm{Pr}+1-\mathrm{H}}{5 \delta^{+} / \mathrm{Pr}+1+\mathrm{H}}\right]\left[\frac{150 / \mathrm{Pr}+1+\mathrm{H}}{150 / \mathrm{Pr}+1-\mathrm{H}}\right]\right] \\
\mathrm{H}=\left[1+\frac{10 \mathrm{M}}{\mathrm{Pr} \delta^{+}}\right]^{\frac{1}{2}} \\
\mathrm{M}=\frac{\mathrm{F}_{0} \delta^{+} \nu}{\tau_{0} \mathrm{u}^{*}}
\end{gathered}
$$

and

$$
F_{0}=\frac{d P}{d z}+g \rho_{1}-\frac{1}{A_{c s}}\left[\frac{d\left(U_{1} \dot{m}_{1}\right)}{d z}-U_{i} \frac{d \dot{m}_{1}}{d z}\right]
$$

The expression for $F_{0}$ was derived from the momentum equation where $U_{1}$ is the average liquid velocity, $U_{i}$ is the velocity at the liquid-vapor interface, and $\dot{\mathrm{m}}_{1}$ is the mass flow rate in the liquid layer. The largest term on the right hand side of 
equation (5.28) is the first term so that, again, equation (5.25) holds to a first approximation.

The convection effects on the Turbo-B surface can be seen in Fig. 5.16 where the heat transfer coefficient is plotted versus tube row for mass flux values of 50 , 100,225 , and $335 \mathrm{~kg} / \mathrm{m}^{2} \mathrm{~s}$ at a constant heat flux value of $40 \mathrm{~kW} / \mathrm{m}^{2}$ and a pressure of $200 \mathrm{kPa}$. The Turbo-B surface shows very little variation in the heat transfer coefficient with mass flux. For a given tube row, the heat transfer coefficients for each mass flux is within $15 \%$ of the average value which indicates that convective effects are not significant and justifies the use of only one bundle geometry. As for the High Flux surface, the structured surface of the Turbo-B tubes prevents the convective effects of the main stream from penetrating the subsurface where the heat transfer processes occur.

Figure 5.17 shows the heat transfer coefficients as a function of tube row for pressures of 200 and $600 \mathrm{kPa}$ at heat flux values of 10,40 , and $80 \mathrm{~kW} / \mathrm{m}^{2}$ for a mass flux of $109 \mathrm{~kg} / \mathrm{m}^{2} \mathrm{~s}$. The effect of pressure on the heat transfer coefficient can be seen by comparing heat transfer coefficients at a given mass flux. For example, the increase in the heat transfer coefficient due to pressure increase is less than 1000 $\mathrm{W} / \mathrm{m}^{2} \mathrm{~K}$ at a heat flux value of $80 \mathrm{~kW} / \mathrm{m}^{2}$ which is an increase of less than $12 \%$. In general, the pressure effect is significantly smaller for the Turbo-B surface than for either of the other two surfaces. The pressure effect on the heat transfer coefficient can be determined by using equation (5.25) and assuming a constant value for the liquid layer and mean liquid velocity, the ratio of the heat transfer coefficients is found to be:

$$
\mathrm{h}_{600} / \mathrm{h}_{200}=(k \sqrt{\rho / \mu})_{600} /(k \sqrt{\rho / \mu})_{200}
$$




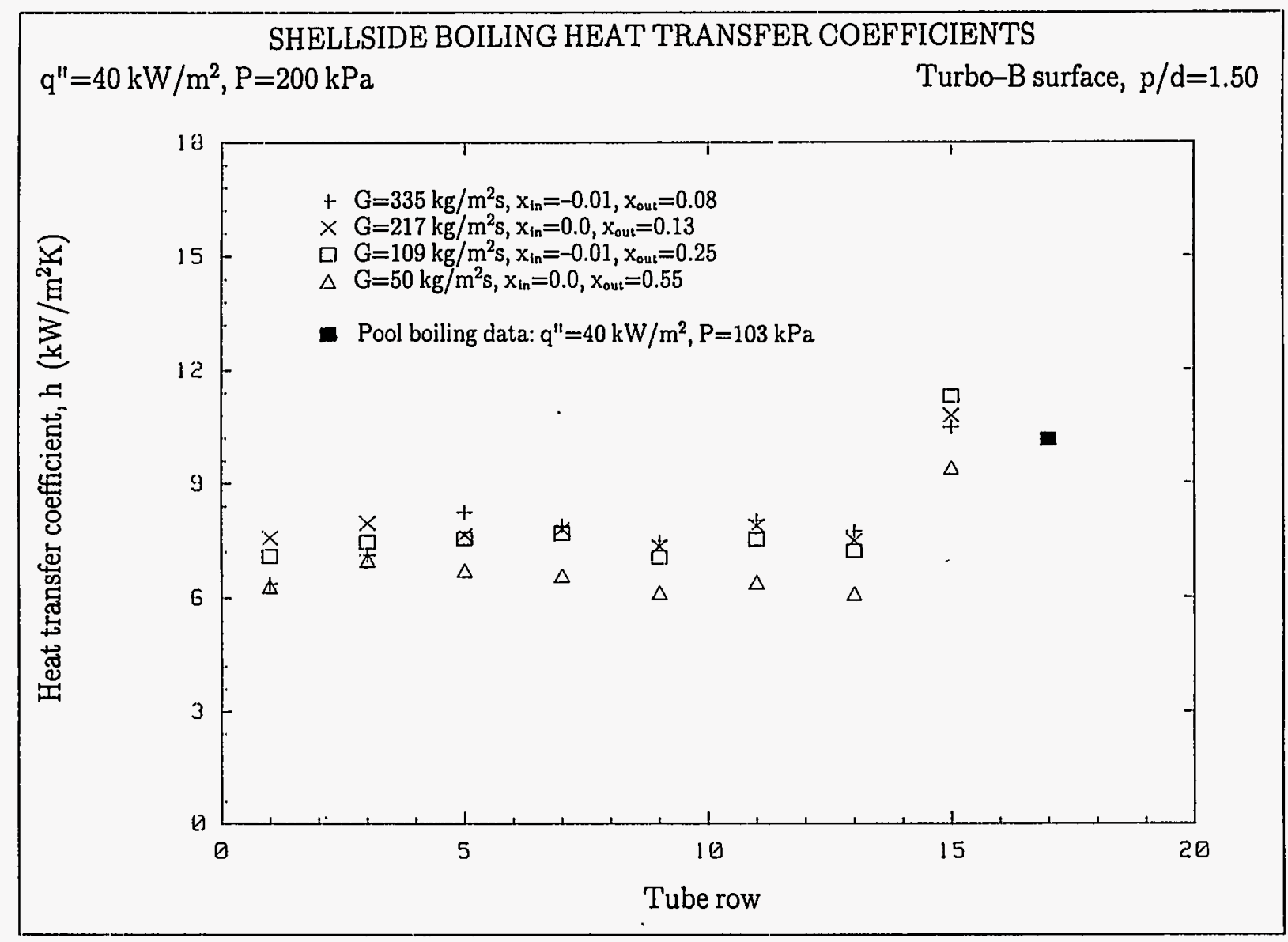

Figure 5.16. Effect of mass flux on the Turbo-B heat transfer coefficients. 


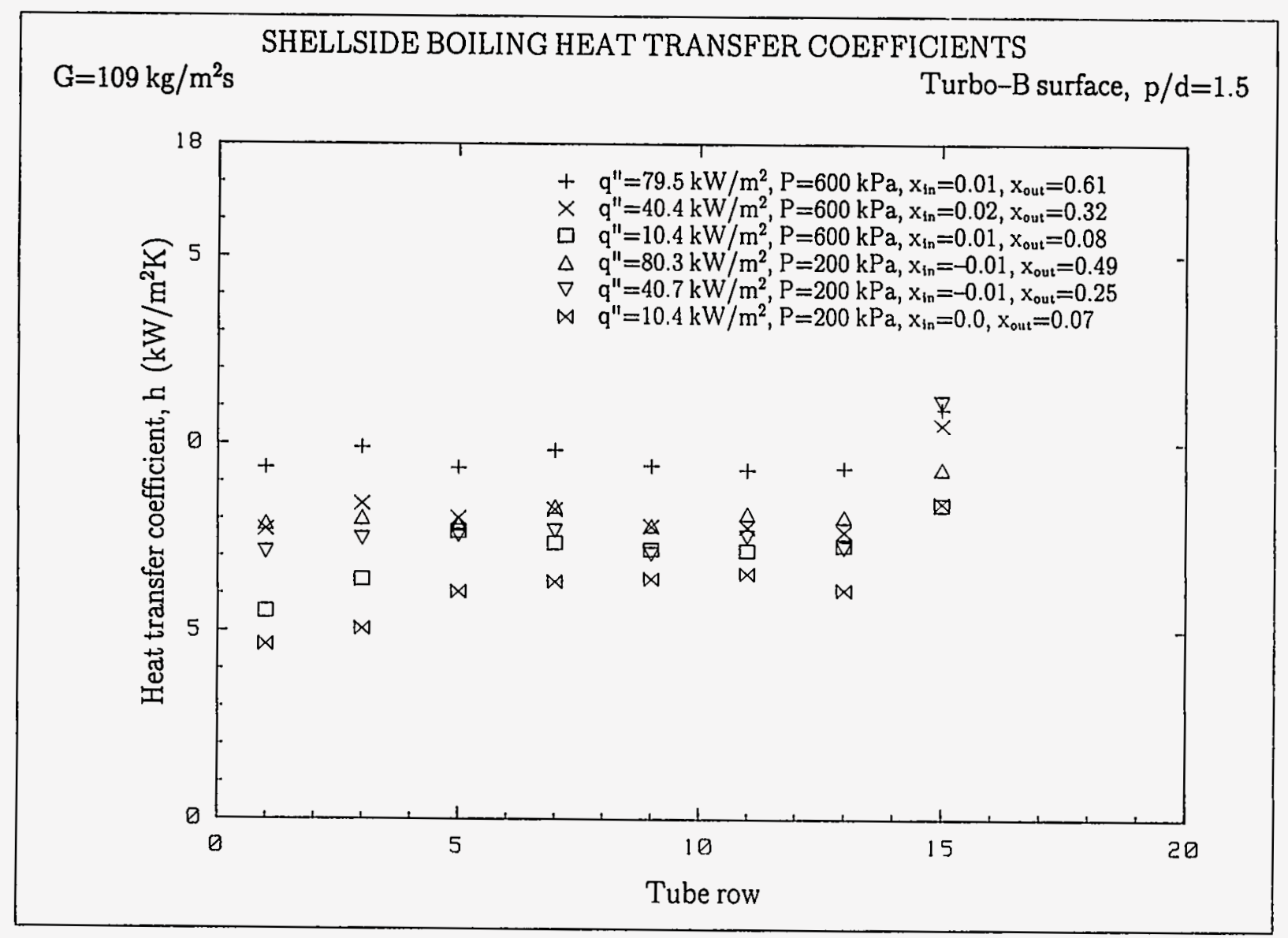

Figure 5.17. Effect of pressure on the Turbo-B heat transfer coefficients. 
which is equal to 0.95 for pure R-113. Again, a combination of nucleate boiling in the lower regions of the subsurface channel and thin film vaporization in the upper regions would explain the small variation in the heat transfer coefficient with changes in pressure.

\section{Results obtained in pure $\mathrm{R}-11$}

Heat transfer coefficients were obtained with pure $\mathrm{R}-11$ as the working fluid in tube bundles containing all three surfaces. The bundle geometry with the tube pitch-to-diameter ratio of 1.50 was used in order to facilitate visual observations even though the use of this bundle geometry restricted the mass flux to less than $350 \mathrm{~kg} / \mathrm{m}^{2} \mathrm{~s}$ due to preheater limitations. The bundle was divided into a top, middle, and bottom third with tubes having a different surface in each. Tubes with each surface occupied only a third of the bundle because of the lack of an effect of tube row on the heat transfer coefficient had been established in the tests with pure $\mathrm{R}-113$. The bottom (upstream) five rows of the the tube bundle contained tubes with the High Flux surface, rows six through ten contained tubes with the smooth surface, and the top five rows contained tubes with the Turbo-B surface. This arrangement for the different types of tube surfaces was selected based on information concerning the onset of nucleation for the different tube surfaces. In particular, the High Flux surface exhibited the largest hysteresis in the boiling curve and, therefore, tubes with this surface were placed in the lower portion of the tube bundle. This arrangement avoided the situation where bubbles from tubes with other surfaces, which might nucleate earlier, would flow past the tube with the High Flux surface and prematurely activate extinct nucleation sites. Because the 
Turbo-B surface exhibited the least hysteresis in the boiling curve, tube with this surface were installed in the top rows.

Typical heat transfer coefficient values are shown in Fig. 5.18 for a mass flux of $110 \mathrm{~kg} / \mathrm{m}^{2} \mathrm{~s}$ and a pressure of $200 \mathrm{kPa}$ at heat flux values ranging from 5 to 80 $\mathrm{kW} / \mathrm{m}^{2}$. The heat transfer coefficients for the High Flux tubes are shown in rows 1 through 5 and follow the same trends as in pure $R-113$. For example, the heat transfer coefficients depend strongly on the heat flux as was the case in pure R-113. In addition, the heat transfer coefficients are slightly smaller in the first row than in the third and fifth rows as was the case for the pure $\mathrm{R}-113$ results.

Heat transfer coefficients obtained from smooth tubes are also shown in Fig. 5.18 in rows 7 and 9. Again, a strong heat flux dependency on the heat transfer coefficient is observed, and it is similar to the trends obtained in pure $\mathrm{R}-113$. The heat transfer coefficients obtained in pure $\mathrm{R}-11$ were slightly smaller than those obtained in pure R-113. For example, at a mass flux of $50 \mathrm{~kg} / \mathrm{m}^{2} \mathrm{~s}$, heat flux of 60 $\mathrm{kW} / \mathrm{m}^{2}$, and a pressure of $200 \mathrm{kPa}$, the average experimental value of the heat transfer coefficient for the smooth tubes is $3.9 \mathrm{~kW} / \mathrm{m}^{2} \mathrm{~K}$ in pure $\mathrm{R}-11$ and 4.2 $\mathrm{kW} / \mathrm{m}^{2} \mathrm{~s}$ in pure $\mathrm{R}-113$. This represents an $8 \%$ increase in the heat transfer coefficient for pure $R-113$ over the value in pure $R-11$. Fink et al. (1982) also found that the heat transfer coefficient in pure R-11 was smaller that in pure R-113. For example, at a pressure of $175 \mathrm{kPa}$ and a heat flux of $57 \mathrm{~kW} / \mathrm{m}^{2}$, Fink et al. (1982) report that the heat transfer coefficient in pure $\mathrm{R}-113$ was $13 \%$ greater than the heat transfer coefficient in pure $\mathrm{R}-11$. This is very close the predicted difference using the model for nucleate boiling by Forster and Zuber (1955) as discussed in Chapter 2. Fink et al. attribute the difference in the heat transfer 


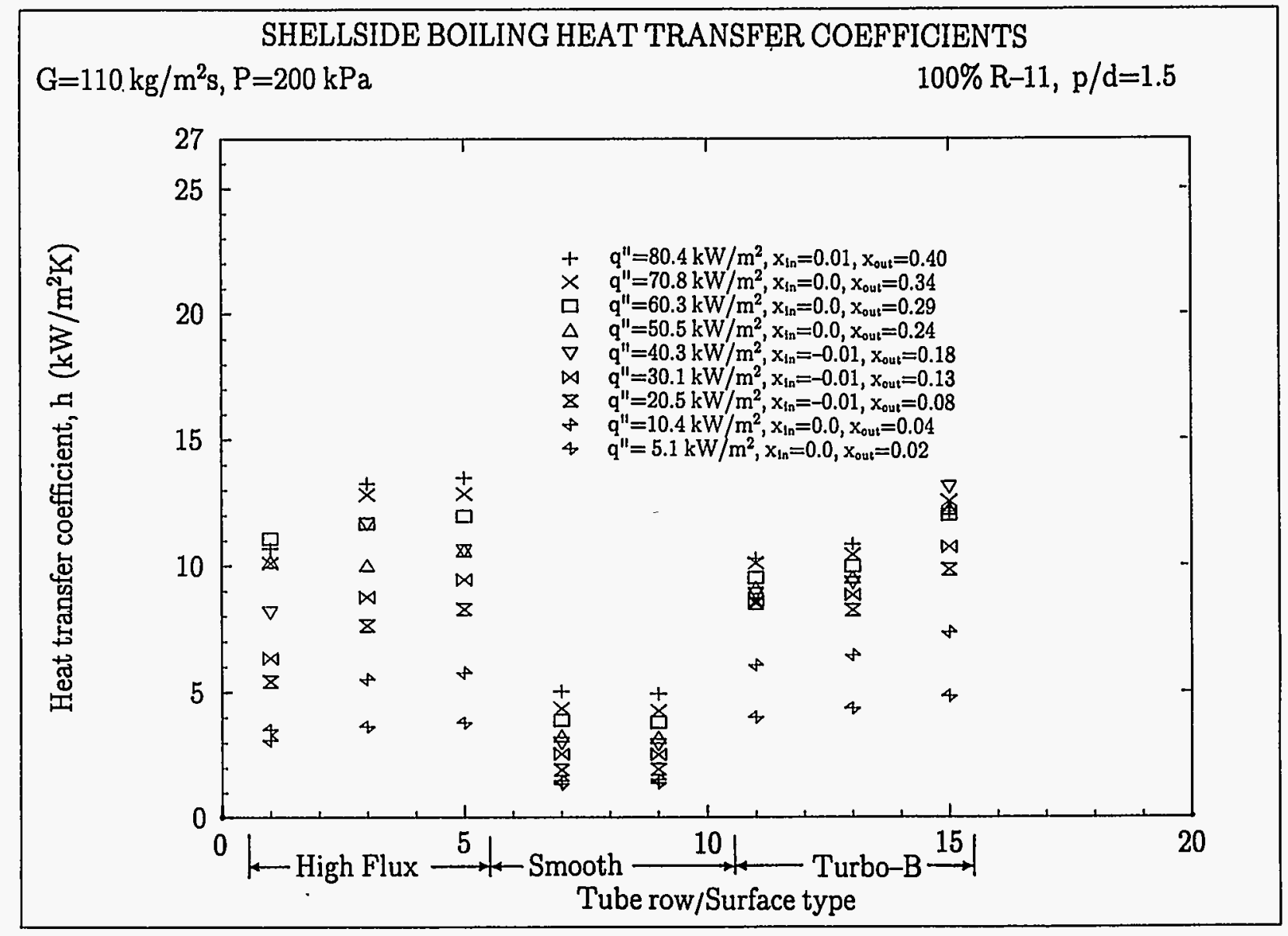

Figure 5.18. Heat transfer coefficients for all three surfaces in pure R-11. 
coefficients to a lower bubble growth rate in $\mathrm{R}-11$ due to a larger enthalpy of vaporization, which results in fewer active nucleation sites.

The heat transfer coefficients shown in Fig. 5.18 for rows 11 through 15 were obtained from tubes with the Turbo-B surface. The dependency on the heat flux was less than for the High Flux tubes as seen in rows 1 through 5. Again, these results are similar to those obtained in pure $\mathrm{R}-113$, including the presence of exit effects for the Turbo-B surface. When compared with the results obtained in pure R-113, the $\mathrm{R}-11$ results are slightly higher. For example, the heat transfer coefficient at $60 \mathrm{~kW} / \mathrm{m}^{2}$ and $200 \mathrm{kPa}$ is approximately $9.3 \mathrm{~kW} / \mathrm{m}^{2} \mathrm{~K}$ in pure $\mathrm{R}-11$ and $8.3 \mathrm{~kW} / \mathrm{m}^{2} \mathrm{~K}$ in pure $\mathrm{R}-113$. This represents an increase of $12 \%$ in the heat transfer coefficient in pure $R-11$ over that in pure $R-113$. This trend is the opposite of that for the smooth and High Flux surfaces. A possible explanation can be attributed to thin film vaporization as the primary mechanism for removing heat.

The mechanism of thin film vaporization, as given in equation (5.25), also predicts that the heat transfer coefficient in pure $\mathrm{R}-11$ is larger than in pure $\mathrm{R}-113$. For example, at a pressure of $200 \mathrm{kPa}$, the ratio:

$$
h_{\mathrm{R} 11} / h_{\mathrm{R} 113}=(k \sqrt{\rho / \mu})_{\mathrm{R} 11} /(k \sqrt{\rho / \mu})_{\mathrm{R} 113}
$$

is equal to 1.26 which is greater than the percentage increase of data obtained in $\mathrm{R}-11$ over those in $\mathrm{R}-113$ from experiments and indicates that the heat removal process in the Turbo-B surface is a mixture of nucleation and thin film vaporization. 


\section{Boiling Heat Transfer Results in Refrigerant Mixtures}

Two-phase heat transfer coefficients were obtained in the same tube bundle used to collect data in pure $\mathrm{R}-11$. The bundle had a tube pitch-to-diameter ratio of 1.50 and the bottom five rows of the the tube bundle contained tubes with the High Flux surface, rows six through ten contained tubes with the smooth surface, and the top five rows contained tubes with the Turbo-B surface. Experiments were conducted in mixtures of $\mathrm{R}-113$ and $\mathrm{R}-11$ with inlet concentrations of approximately $25 \%, 50 \%$, and $75 \% \mathrm{R}-11$ by mass. The experiments were conducted for pressures of 200 and $600 \mathrm{kPa}$, mass flux values of 50 and $225 \mathrm{~kg} / \mathrm{m}^{2} \mathrm{~s}$, and heat flux values from 5 to $80 \mathrm{~kW} / \mathrm{m}^{2}$ so that the effect of these parameters on the tube bundle performance could be determined.

\section{Results from the $75 \% \mathrm{R}-11 / 25 \% \mathrm{R}-113$ mixture}

Heat transfer coefficients for tubes with each of the three surfaces are shown in Fig. 5.19 for a mass flux of $50 \mathrm{~kg} / \mathrm{m}^{2} \mathrm{~s}$, a pressure of $200 \mathrm{kPa}$, and heat flux values from 5 to $60 \mathrm{~kW} / \mathrm{m}^{2}$. The inlet mass concentration of $\mathrm{R}-11$ in the liquid is $75.8 \%$ and decreases with increasing tube row due to evaporation of the mixture. The rate at which the concentration of $\mathrm{R}-11$ in the liquid decreases depends on the mass flux and heat flux. For example, at a heat flux of $60.4 \mathrm{~kW} / \mathrm{m}^{2}$, the mass concentration of $\mathrm{R}-11$ in the liquid decreased to $72.5 \%$ at the seventh tube row, which is the first row of instrumented smooth tubes. At the eleventh tube row, which is the first Turbo-B tube row, the mass concentration of $\mathrm{R}-11$ in the liquid decreased to 70.4\%. The mass concentration of $\mathrm{R}-11$ in the liquid at the outlet of the tube bundle was $67.1 \%$. The concentration changes throughout the bundle at 


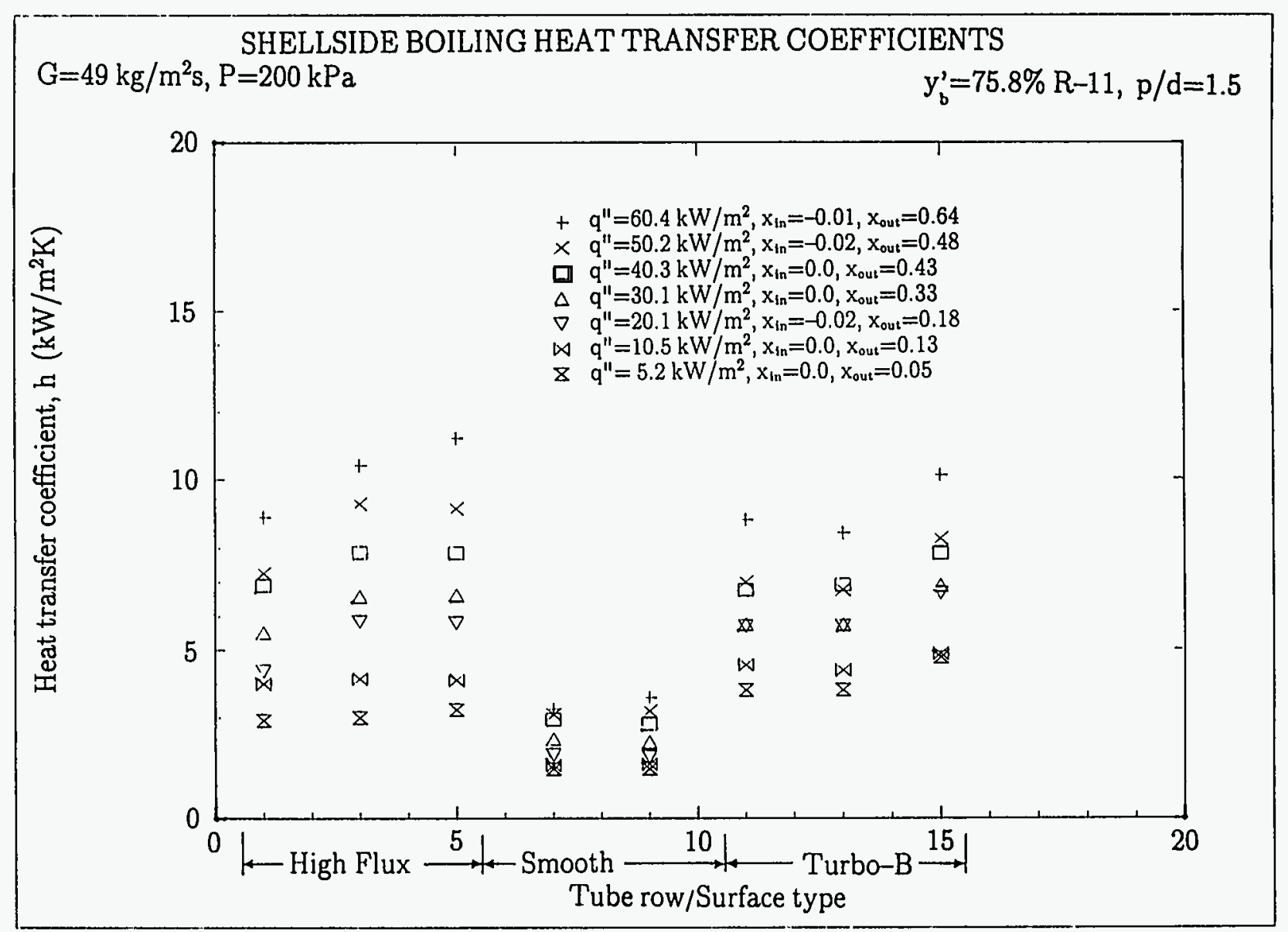

Figure 5.19. Effect of heat flux on the heat transfer coefficients for all three surfaces in a mixture of $75.8 \% \mathrm{R}-11$ and $\mathrm{G}=49 \mathrm{~kg} / \mathrm{m}^{2} \mathrm{~s}$. 
different rates depending on the heat flux. At a heat flux of $10 \mathrm{~kW} / \mathrm{m}^{2}$, the mass concentration of $\mathrm{R}-11$ in the liquid changed by only $1.6 \%$ from the inlet to the exit of the bundle.

The heat transfer coefficients follow the same general trends as those obtained in the pure fluids. The heat transfer coefficients for the High Flux tubes in the first, third, and fifth tube rows exhibit a strong dependency on the heat flux and generally the heat transfer coefficient at the first row is the smallest. The smooth tube heat transfer coefficients were consistently smaller than those for the enhanced tubes. A significant heat flux effect was also observed for the smooth tubes. The heat transfer coefficients for the Turbo-B tubes (shown in rows 11,13 , and 15) exhibit much less variation with heat flux as was the case in the pure fluids, and some exit effects are still present.

The effect of the mass flux on the heat transfer coefficients can be seen by comparing Figs. 5.20 and 5.19; Figure 5.20 shows data at a mass flux of $225 \mathrm{~kg} / \mathrm{m}^{2} \mathrm{~s}$, while Fig. 5.19 shows data at $49 \mathrm{~kg} / \mathrm{m}^{2}$ s. Heat transfer coefficients for each of the three surfaces at a given heat flux are not significantly different for the different mass flux conditions. Note that because the mass concentration of $\mathrm{R}-11$ in the liquid is not an independent parameter, comparing data taken at a similar heat flux, pressure, and inlet concentration but different mass flux results in a comparison between data at different local mixture concentrations as well. For the same nominal inlet concentration and at a given tube row, the mass concentration of $\mathrm{R}-11$ in the liquid is lower for the data taken at a mass flux of $49 \mathrm{~kg} / \mathrm{m}^{2} \mathrm{~s}$ than at $224 \mathrm{~kg} / \mathrm{m}^{2} \mathrm{~s}$, especially for the tubes higher in the bundle and at larger heat fluxes. For the same inlet concentrations and a heat flux of $60 \mathrm{~kW} / \mathrm{m}^{2}$, the mass concentration of $R-11$ at the bundle exit is $73.3 \%$ when the mass flux is $49 \mathrm{~kg} / \mathrm{m}^{2} \mathrm{~s}$, 


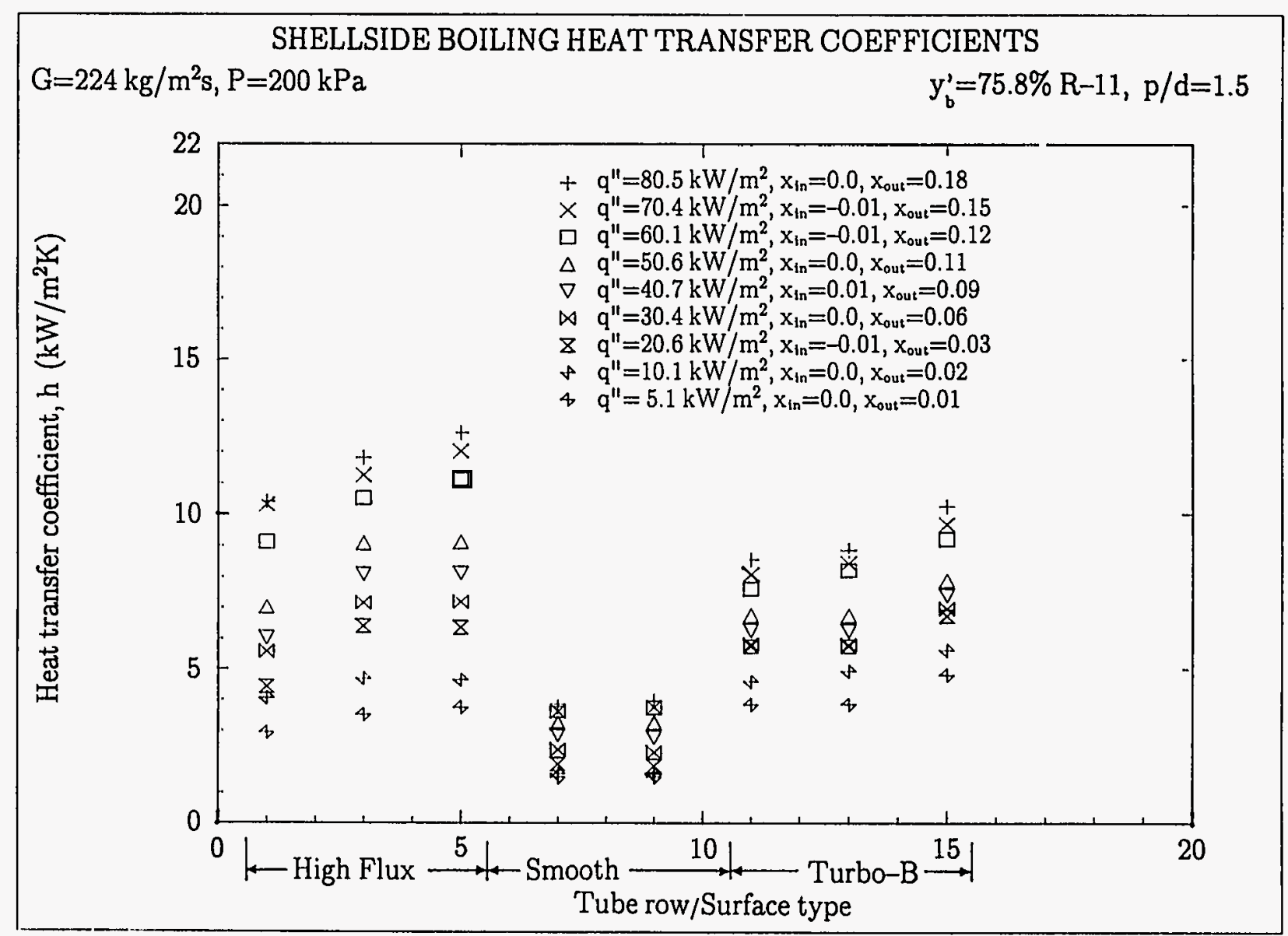

Figure 5.20. Effect of heat flux on the heat transfer coefficients for all three surfaces in a mixture of $75.8 \% \mathrm{R}-11$ and $\mathrm{G}=224 \mathrm{~kg} / \mathrm{m}^{2} \mathrm{~s}$. 
which is 6.3 percentage points higher than at the bundle exit when the mass flux is $224 \mathrm{~kg} / \mathrm{m}^{2} \mathrm{~s}$. However, the mass concentration change and any changes in the free-steam convection due to a larger mass flux apparently do not appreciably affect the concentration gradient at the heated surface and so do not change the mechanisms that reduce the heat transfer.

The magnitudes of the heat transfer coefficients are, however, significantly lower in the binary mixture than in the pure fluids. For example, the heat transfer coefficient for the smooth tubes obtained in a mixture with $72.3 \% \mathrm{R}-11$ in the liquid at $60 \mathrm{~kW} / \mathrm{m}^{2}$ and $200 \mathrm{kPa}$ is approximately $3.4 \mathrm{~kW} / \mathrm{m}^{2} \mathrm{~K}$. This value is $19 \%$ smaller than the value obtained for similar operating conditions in pure R-113 $\left(4.2 \mathrm{~kW} / \mathrm{m}^{2} \mathrm{~K}\right)$ and $12.8 \%$ smaller than the value obtained in pure $\mathrm{R}-11(3.9$ $\left.\mathrm{kW} / \mathrm{m}^{2} \mathrm{~K}\right)$. This trend has been well established and is described in detail by several researchers. Thome and Shock (1984) give some of the reasons for the lower heat transfer coefficient in mixtures: a higher concentration of the less volatile component at the heated surface causing an increased local boiling temperature and a reduced bubble growth rate; a higher enthalpy of vaporization; varying bubble departure frequencies; and reduced nucleation site density due to reduced contact angle.

The magnitudes of the heat transfer coefficients for the enhanced surfaces obtained in the binary mixture also are significantly lower than those obtained in pure fluids. The average heat transfer coefficient obtained in the binary mixture for the High Flux tubes in rows three and five at $60 \mathrm{~kW} / \mathrm{m}^{2}$ is approximately 10.8 $\mathrm{kW} / \mathrm{m}^{2} \mathrm{~K}$. The average value at similar operating parameters is $12.5 \mathrm{~kW} / \mathrm{m}^{2} \mathrm{~K}$ in pure $\mathrm{R}-113$ and $12.2 \mathrm{~kW} / \mathrm{m}^{2} \mathrm{~K}$ in pure $\mathrm{R}-11$. Therefore, the reduction in the heat transfer coefficients obtained in the mixture is approximately $13.6 \%$ and $11.5 \%$ 
compared to the pure $\mathrm{R}-113$ and $\mathrm{R}-11$ data, respectively. The heat transfer coefficient for the Turbo-B tubes with a mass concentration of $70.0 \% \mathrm{R}-11$ in the liquid upstream of the eleventh tube row is $8.4 \mathrm{~kW} / \mathrm{m}^{2} \mathrm{~K}$. This value is $2.3 \%$ smaller than the value of $8.6 \mathrm{~kW} / \mathrm{m}^{2} \mathrm{~K}$ obtained in pure $\mathrm{R}-113$ and $14.3 \%$ smaller than the value of $9.8 \mathrm{~kW} / \mathrm{m}^{2} \mathrm{~K}$ obtained in pure $\mathrm{R}-11$. For a given heat flux larger than $30 \mathrm{~kW} / \mathrm{m}^{2} \mathrm{~K}$, the High Flux heat transfer coefficients generally were larger than those for the Turbo-B tubes. The heat transfer coefficients for the enhanced surfaces are always larger than for the smooth tubes at similar heat fluxes, pressures, and inlet mixture concentrations.

Results from the $50 \% \mathrm{R}-11 / 50 \% \mathrm{R}-113$ mixture

The heat transfer coefficients obtained in a mixture with a nominal inlet mass concentration of $50 \%$ exhibited the same general trends as the data obtained in 75\% R-11. Figure 5.21 shows that the High Flux tubes in rows 1, 3, and 5 performed slightly better than the Turbo-B tubes in rows 11,13 , and 15 and that both enhanced tubes performed better than the smooth tubes in rows 7 and 9 . However, the variation in the mixture concentration throughout the bundle makes a direct comparison of data obtained at different tube rows difficult. Data for the Turbo-B tubes were obtained in mixtures with local liquid concentrations up to 7.6 percentage points lower in $\mathrm{R}-11$ than the local mixture concentration at the High Flux tubes. The lower concentration of $R-11$ could account for some of the difference between the High Flux and Turbo-B tubes but lower heat transfer coefficients for the Turbo-B tubes were also found in the pure fluids, and so the variation in the liquid concentration of $\mathrm{R}-11$ probably plays a minor role. 


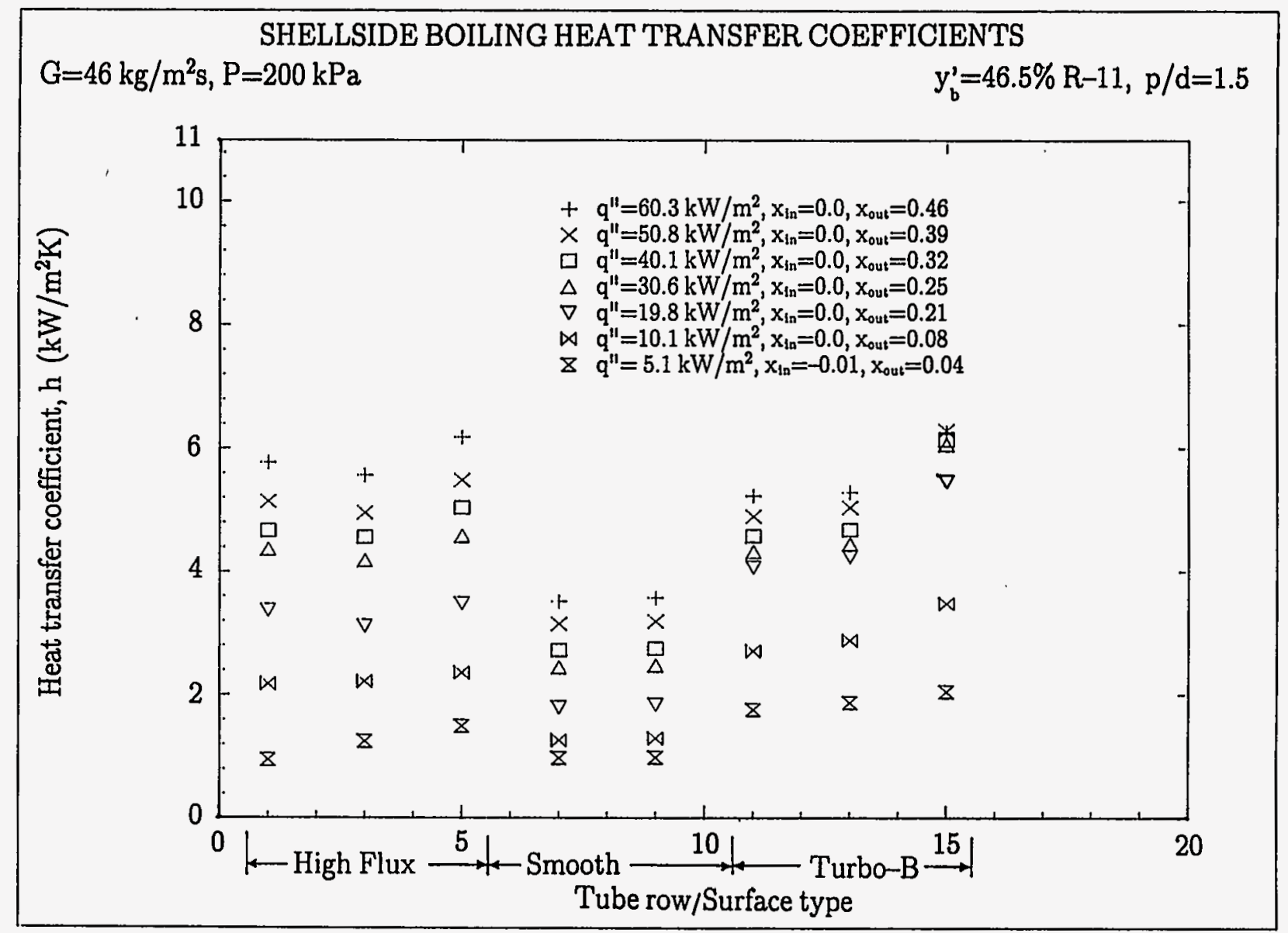

Figure 5.21. Effect of heat flux on the heat transfer coefficients for all three surfaces in a mixture of $46.5 \% \mathrm{R}-11$ and $\mathrm{G}=46 \mathrm{~kg} / \mathrm{m}^{2} \mathrm{~s}$. 
The heat transfer coefficients for the Turbo-B tubes do not vary as much with heat flux as do the heat transfer coefficients for the High Flux tubes. A possible explanation is that the concentration of $R-11$ in the liquid at a given tube row was lower for the larger heat fluxes, and the heat transfer coefficients decrease with decreasing liquid concentrations of $\mathrm{R}-11$. Therefore, the variation in the local concentration of liquid R-11 could contribute to the reduced variation with heat flux in the Turbo-B tubes. However, a similar trend was found in the data obtained in pure fluids and so, again, the variation in the liquid concentration of $\mathrm{R}-11$ probably plays a minor role.

Comparisons between Fig. 5.21 and Fig. 5.19 show that the heat transfer coefficients for the $50 \%$ inlet concentration are generally smaller than those for the $75 \%$ inlet concentration by as much as $48 \%$ for the High Flux tubes, $37 \%$ for the Turbo-B tubes, but only $6 \%$ for the smooth tubes. Large reductions in the heat transfer coefficients for the enhanced tubes and smaller reductions for the smooth tube were also observed in the binary mixture pool boiling results. Similar mechanisms between pool boiling and bundle boiling appear to play significant roles in the heat transfer process.

\section{Results from the $25 \% \mathrm{R}-11 / 75 \% \mathrm{R}-113$ mixture}

Data obtained in a mixture with an inlet mass concentration of $23.8 \% \mathrm{R}-11$ in the liquid are shown in Fig. 5.22 for a mass flux of $217 \mathrm{~kg} / \mathrm{m}^{2} \mathrm{~s}$ and a pressure of $200 \mathrm{kPa}$. At a given heat flux, the heat transfer coefficients for the High Flux tubes are larger than those for the smooth tubes but are slightly smaller than those for the Turbo-B tubes in general. The slightly larger heat transfer coefficients for the Turbo-B tubes compared to the High Flux data is contrary to the trends obtained 


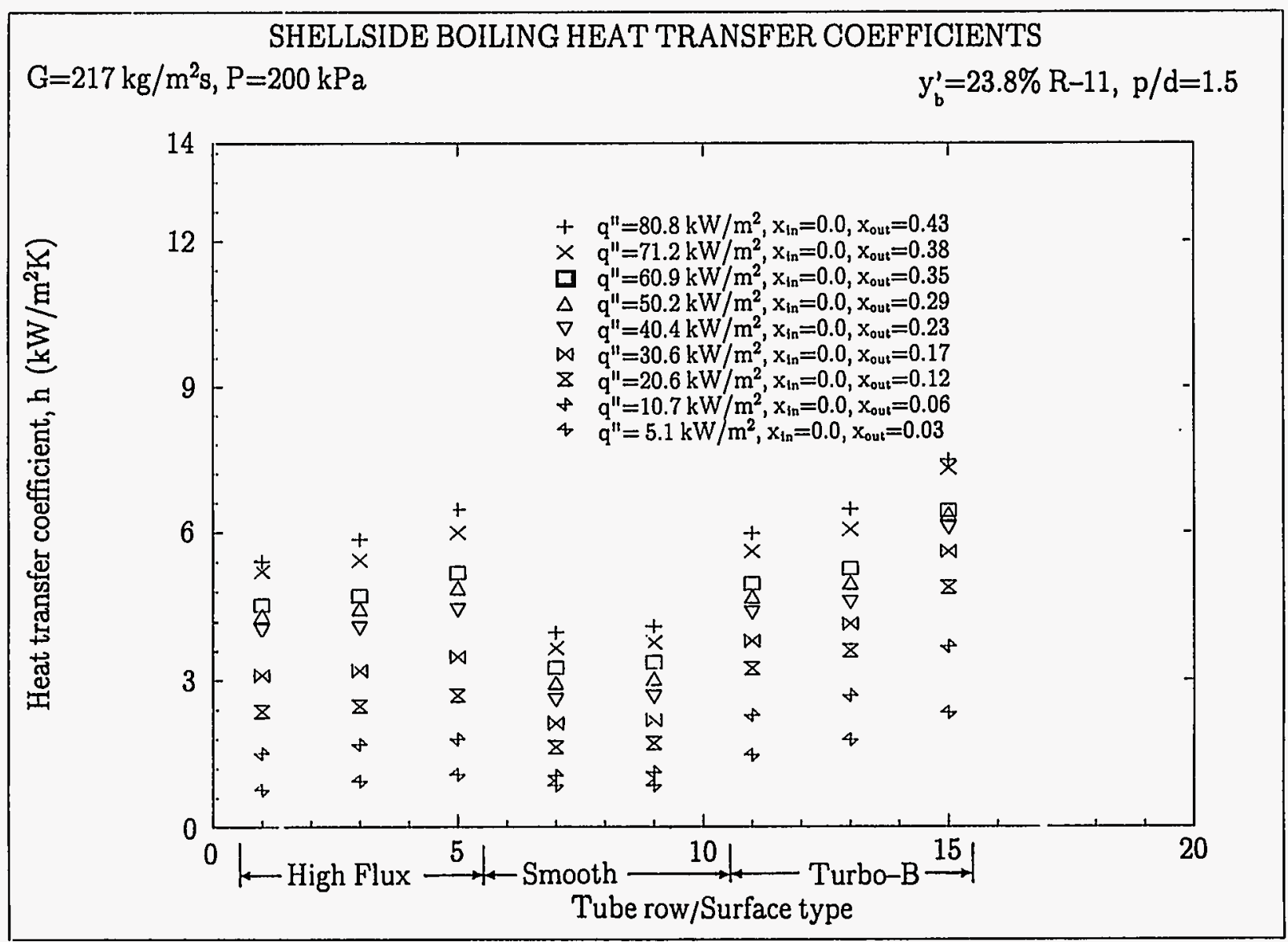

Figure 5.22. Effect of heat flux on the heat transfer coefficients for all three surfaces in a mixture of $23.8 \% \mathrm{R}-11$ and $\mathrm{P}=200 \mathrm{kPa}$. 
in pure fluids and might be the result of the lower local mass concentration of $\mathrm{R}-11$ in the liquid at the Turbo-B tubes.

Insight into the trends of the heat transfer coefficients for the Turbo-B tubes can be gained by comparing heat transfer coefficients obtained in a $25 \% \mathrm{R}-11$ mixture to those obtained in the 50\% R-11 mixture. Comparing Fig. 5.22 with Fig. 5.21 shows that, at a given heat flux, the heat transfer coefficients decreased for each of the surfaces but that those for the High Flux tubes decreased the most. For example, at a heat flux of $60 \mathrm{~kW} / \mathrm{m}^{2}$, the heat transfer coefficient of the High Flux tube at the third row and a liquid mass concentration of $22.7 \% \mathrm{R}-11$ is $13.3 \%$ smaller than the High Flux heat transfer coefficient obtained at a liquid mass concentration of $45.4 \% \mathrm{R}-11$. The smooth tube heat transfer coefficient at the seventh row, a heat flux of $60 \mathrm{~kW} / \mathrm{m}^{2}$, and a liquid mass concentration of $20.6 \%$ $\mathrm{R}-11$ was $5.9 \%$ smaller than that obtained in a mixture of $43.2 \% \mathrm{R}-11$ in the liquid. The heat transfer coefficient for the Turbo-B tube at the eleventh row, at a heat flux of $60 \mathrm{~kW} / \mathrm{m}^{2}$, and a liquid mass concentration of $18.5 \% \mathrm{R}-11$ was $5.9 \%$ smaller than that obtained in a mixture of $41.1 \% \mathrm{R}-11$ in the liquid. The smaller decrease in the heat transfer coefficients for the Turbo-B tubes compared to the High Flux tubes could be the result of an end in the decreasing trend in the heat transfer coefficient with decreasing liquid mass concentration of $R-11$ or perhaps even the result of a beginning in an increasing trend in the heat transfer coefficient with decreasing liquid mass concentration of $\mathrm{R}-11$.

In general, increasing the inlet pressure results in an increase in the heat transfer coefficients for all three tube surface types and at all inlet mixture concentrations. Figure 5.23 shows, for example, heat transfer coefficients as a function of tube row at a pressure of $600 \mathrm{kPa}$, a mass flux of $218 \mathrm{~kg} / \mathrm{m}^{2}$, and heat 


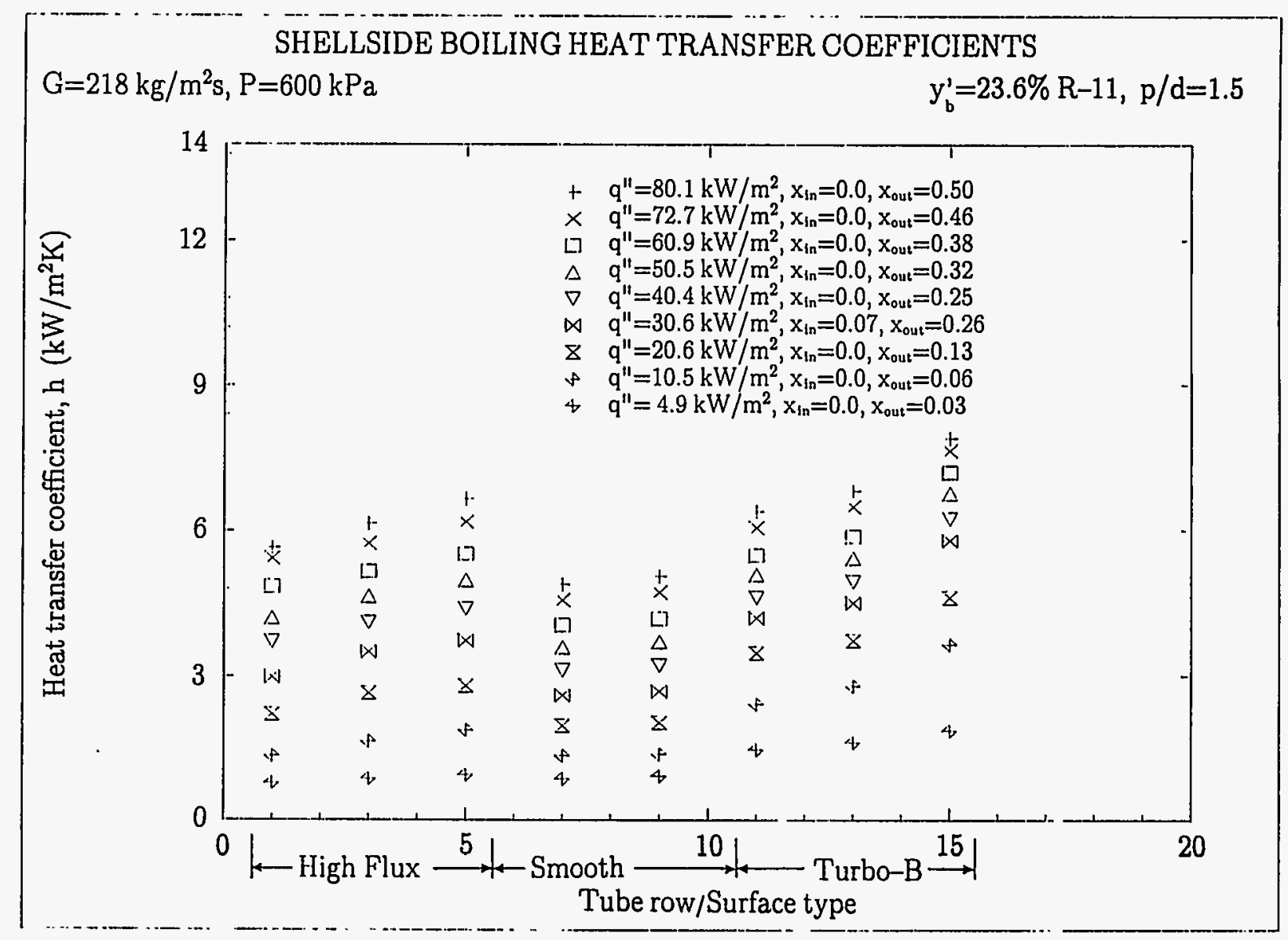

Figure 5.23. Effect of heat flux on the heat transfer coefficients for all three surfaces in a mixture of $23.1 \% \mathrm{R}-11$ and $\mathrm{p}=600 \mathrm{kPa}$. 
fluxes ranging from 5 to $80 \mathrm{~kg} / \mathrm{m}^{2}$. The trends at $600 \mathrm{kPa}$ are similar to those at $200 \mathrm{kPa}$ with the heat transfer coefficients larger for the enhanced tubes than for the smooth tubes. The effect of pressure can be seen by comparing Fig. 5.23 with Fig 5.22. The heat transfer coefficients for the High Flux tubes increase with pressure but generally by only $11 \%$. This increase in data obtained in the mixtures is significantly less than for the data obtained in pure $R-113$, which resulted in an average increase of approximately $30 \%$. The smooth tube heat transfer coefficients obtained in the mixtures were approximately $33 \%$ larger at $600 \mathrm{kPa}$ than at $200 \mathrm{kPa}$, which is consistent with data obtained in pure $\mathrm{R}-113$. The Turbo-B heat transfer coefficients obtained at $600 \mathrm{kPa}$ increased by approximately $9 \%$ over the data obtained at $200 \mathrm{kPa}$ for inlet mass concentrations of $75.8 \%$ and $45.8 \%$ but increased by $23 \%$ for an inlet mass concentration of $23.1 \% \mathrm{R}-11$.

Examples of these data are shown in Fig. 5.24 which is a plot of the heat transfer coefficients versus the mass concentration of $R-11$ in the liquid for the High Flux tube at the third row, the smooth tube at the seventh row, and the Turbo-B tube at the eleventh row for an average mass flux of $204 \mathrm{~kg} / \mathrm{m}^{2} \mathrm{~s}$, and a heat flux of $60 \mathrm{~kW} / \mathrm{m}^{2}$. The Turbo-B heat transfer coefficients obtained at a pressure of 600 $\mathrm{kPa}$ and a local liquid mass concentration of $20.0 \% \mathrm{R}-11$ are now slightly larger than for a liquid concentration of $41.5 \%$. The heat transfer coefficients are beginning to increase with decreasing liquid mass concentration of R-11 and, apparently, the minimum heat transfer coefficients occur in mass concentrations greater than $20.0 \% \mathrm{R}-11$ at $600 \mathrm{kPa}$. 


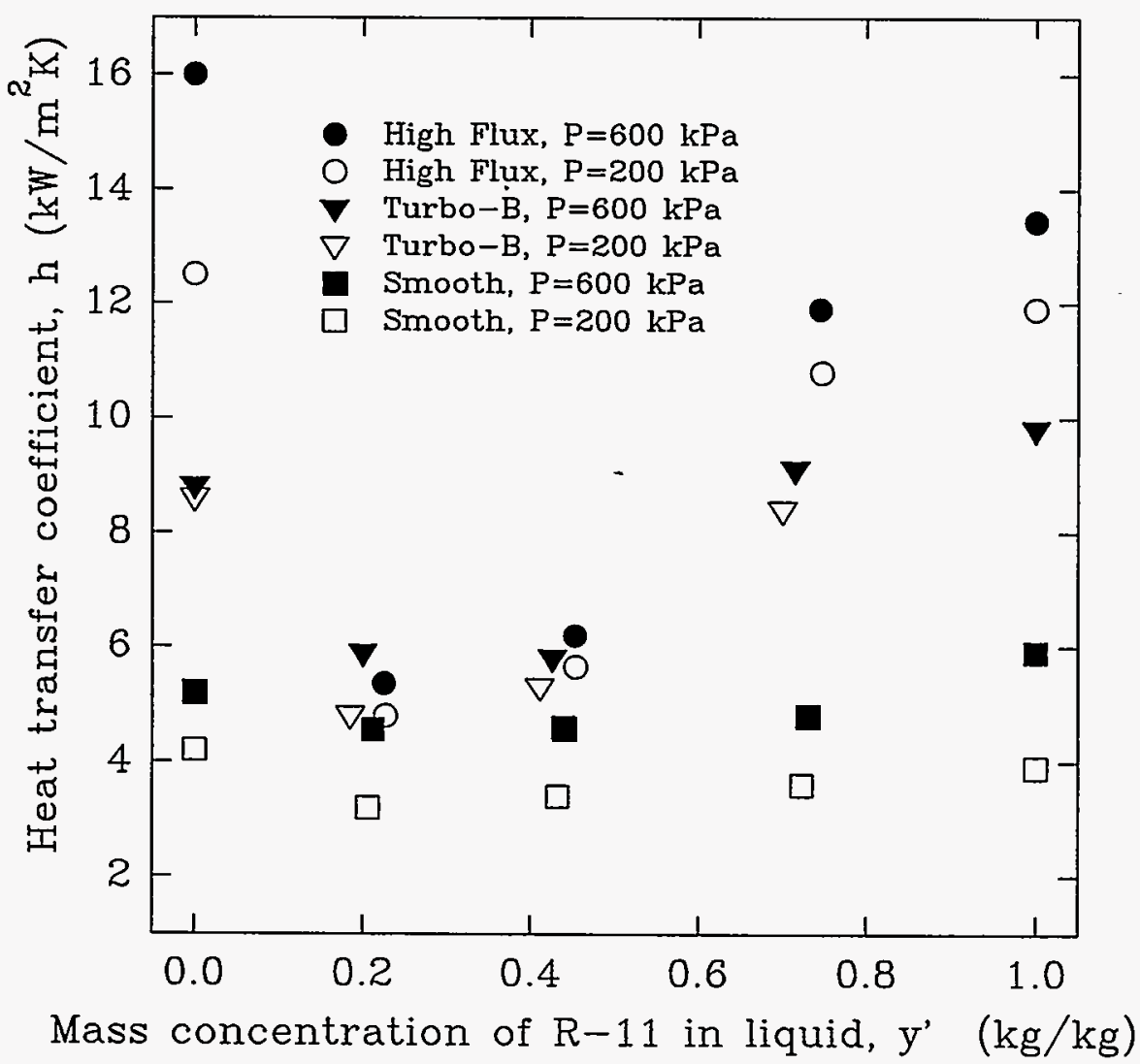

Figure 5.24. Effect of mixture concentration and pressure on the heat transfer coefficients for $q^{\prime \prime}=60 \mathrm{~kW} / \mathrm{m}^{2}$. 


\section{Comparison of results}

The effect of the mass concentration of $\mathrm{R}-11$ in the liquid on the heat transfer coefficient can be more easily seen in a plot such as Fig. 5.25 where heat transfer coefficients for High Flux tubes in the third tube row are plotted versus the local mass concentration of $\mathrm{R}-11$ in the liquid at a pressure of $200 \mathrm{kPa}$ and an average mass flux of $204 \mathrm{~kg} / \mathrm{m}^{2} \mathrm{~s}$. Note that the mass flux is large enough so that the change in the mass concentration with heat flux is small at the third tube row, even for heat fluxes as large as $80 \mathrm{~kW} / \mathrm{m}^{2}$. Therefore, the data shown in Fig. 5.25 were taken in mixture concentrations approximately equal to the inlet concentration.

At a given heat flux, the heat transfer coefficients decrease from the values obtained in pure $\mathrm{R}-11$ to minimum values obtained in the mixture with an inlet mass concentration of $23.1 \% \mathrm{R}-11$. Figure 5.25 shows that the heat transfer coefficients obtained in mixtures with small liquid mass concentrations of $R-11$ are generally smaller than those obtained in mixtures with larger liquid mass concentrations. This non-symmetric decrease in the heat transfer coefficient with liquid mass concentration of $\mathrm{R}-11$ has been reported by other researchers using binary mixtures of different fluids. In a mixture of ethanol and water, for example, Stephan (1982) reports much lower heat transfer coefficients than the ideal values obtained by a linear interpolation between the pure component values. Figure 5.26 shows that the reduction below the ideal value is greatest at a liquid mole fraction of ethanol of approximately $15 \%$.

Stephan (1982) reviewed several heat transfer coefficient correlations and noted that the decrease in the heat transfer coefficient is most pronounced when the difference between the liquid and vapor mole fractions is largest. Heat transfer 


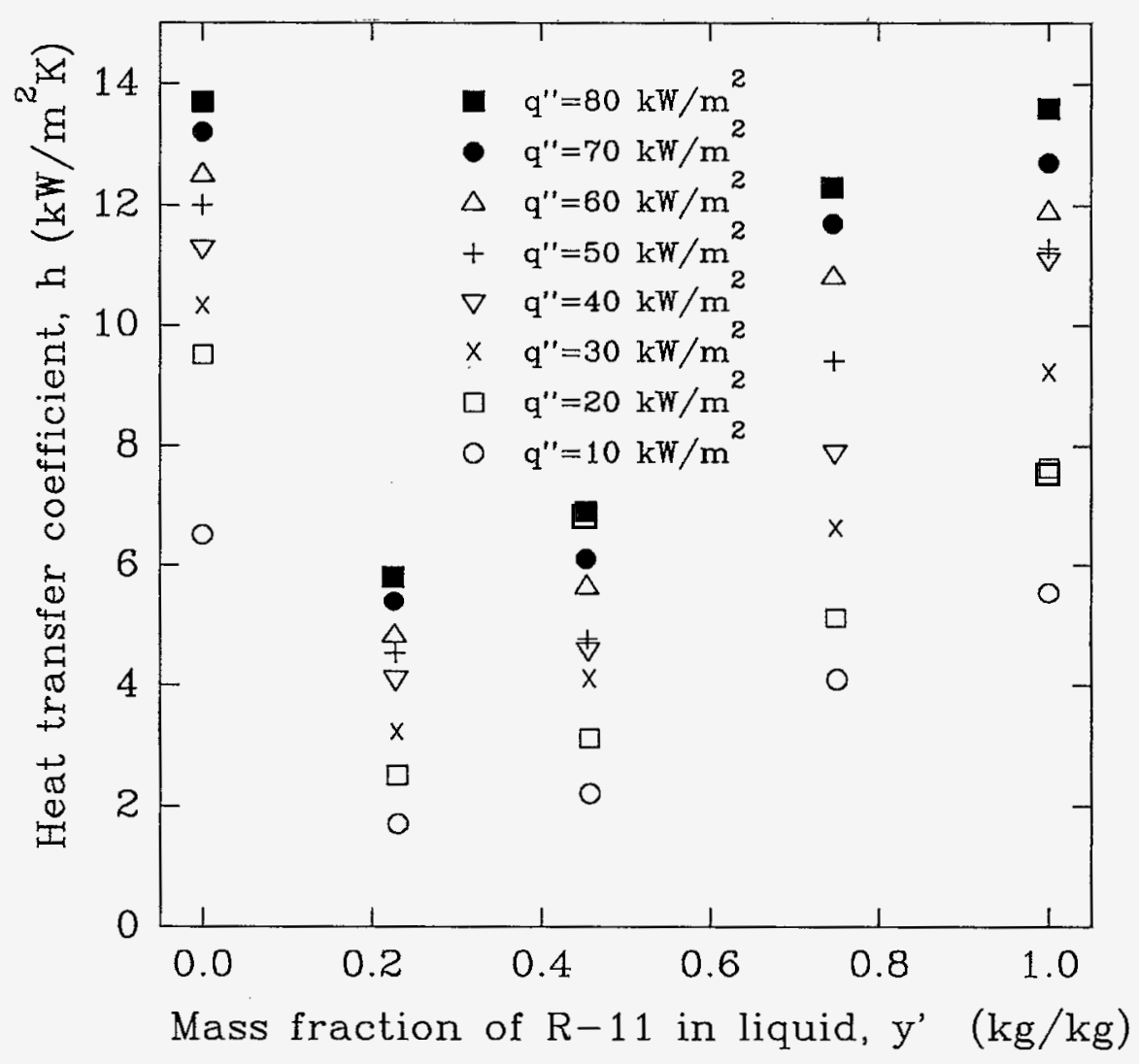

Figure 5.25.

Effect of mixture concentration and heat flux on the High Flux heat transfer coefficients. 

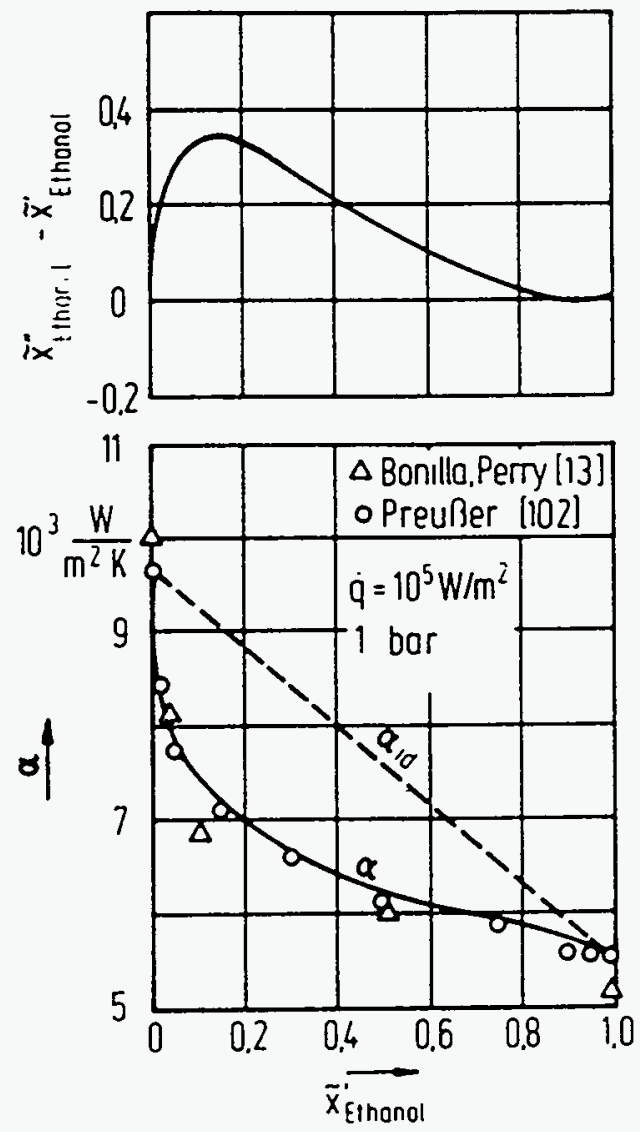

Figure 5.26.

Trends in heat transfer coefficients and the difference between the liquid and vapor mixture concentrations (Stephan 1982). 
coefficients are then correlated using a wall superheat which is a function of the difference between the vapor and liquid mole fractions instead of correlating heat transfer coefficients for the pure components using only the liquid mole fraction of the least volatile component. The difference between the vapor and liquid mole fractions versus the liquid mole fraction is plotted in Fig. 5.27(a) for the $R-11 / R-113$ mixture used in the present study. Also shown is a plot of the heat transfer coefficients versus the liquid mole fraction for all three surfaces at a heat flux of $60 \mathrm{~kW} / \mathrm{m}^{2}$ and a pressure of $200 \mathrm{kPa}$ in Fig. 5.27(b). It appears that the increase in the concentration difference between vapor and liquid $\mathrm{R}-11$ does follow the same trend as the decrease in the heat transfer coefficient. Therefore, the same mechanisms which reduce the heat transfer coefficients for smooth tubes also play a major role in the enhanced surfaces, and a method of correlating the enhanced surfaces similar to that used to correlate smooth tubes might be appropriate. Specifically, Stephan and Körner (1970) suggests that the heat transfer coefficient be defined as

$$
h=q^{\prime \prime} / \Delta T_{\mathrm{a}}
$$

where

$$
\Delta T_{\mathrm{a}}=\Delta T_{\mathrm{id}}+\Delta T_{\mathrm{e}}=\Delta T_{\mathrm{id}}(1+\theta)
$$

and

$$
\Delta T_{\mathrm{id}}=\tilde{y}_{\mathrm{R} 113}^{\prime} \Delta T_{\text {sat }, \mathrm{R} 113}+\tilde{y}_{\mathrm{R} 11}^{\prime} \Delta T_{\text {sat }, \mathrm{R} 11}
$$



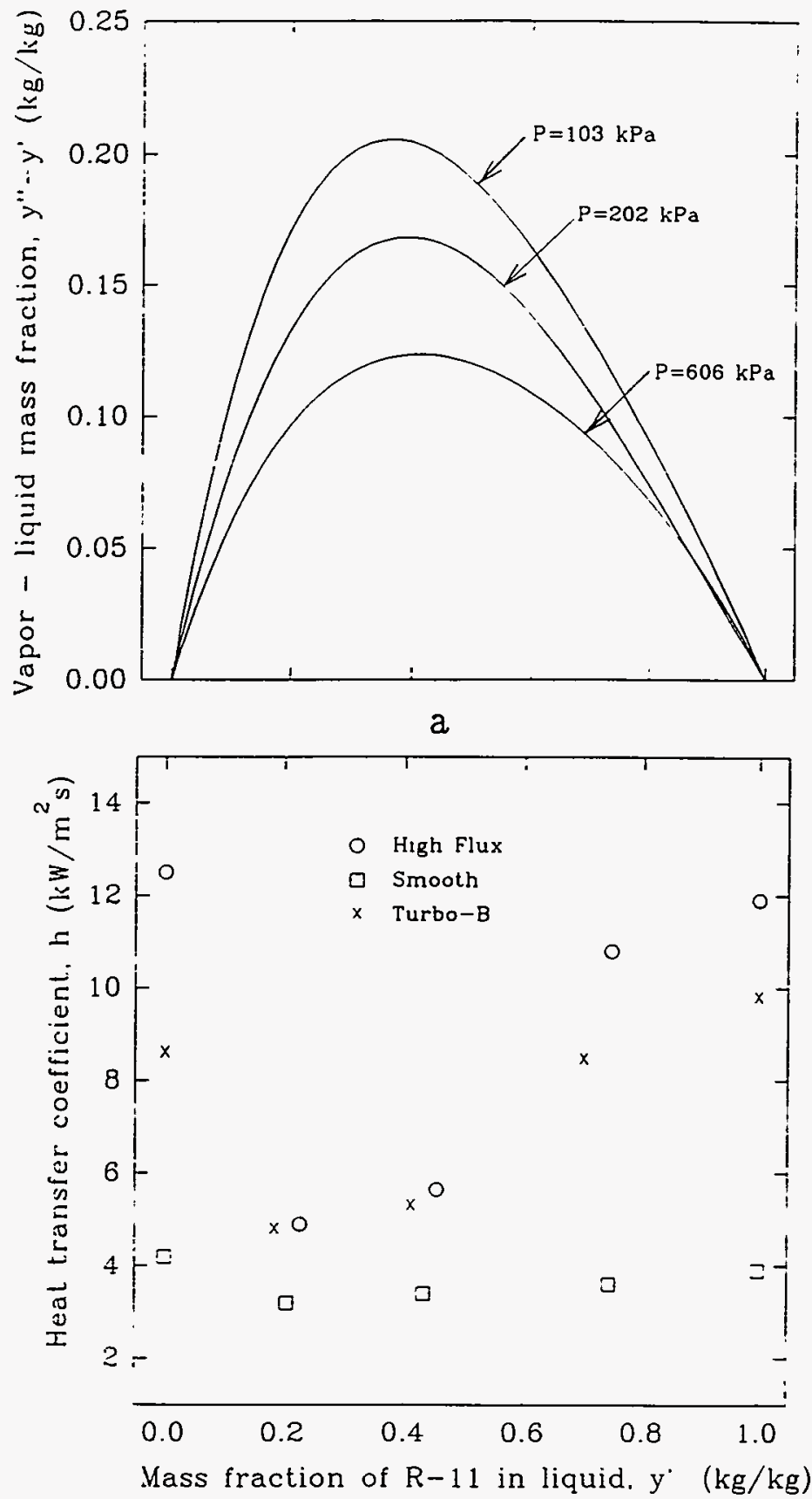

b

Figure 5.27.

A comparison between (a) the difference between the liquid and vapor concentrations of $R-11$ and (b) experimental trends in heat transfer coefficients at $\mathrm{q}^{\prime \prime}=60 \mathrm{~kW} / \mathrm{m}^{2}$ and $\mathrm{P}=200 \mathrm{kPa}$. 
In equation (5.37), the terms $\Delta T_{\text {sat, } \mathrm{R} 113}$ and $\Delta T_{\text {sat, } \mathrm{R} 11}$ refer to the wall superheat for the pure fluids. The only unknown in equation (5.36) is $\theta$ which Stephan and Körner correlate as

$$
\theta=C_{\mathrm{R} 113, \mathrm{R} 11}\left(\tilde{y}_{\mathrm{R} 11}^{\prime \prime}-\tilde{y}_{\mathrm{R} 113}^{\prime}\right)
$$

where $C_{\mathrm{R} 113, \mathrm{R} 11}$ is a positive number independent of the mole fraction. Stephan and Körner (1970) obtained values of $C_{1,2}$ for various binary mixtures but the $\mathrm{R}-11 / \mathrm{R}-113$ combination was not included. Alternatively, Bier et al. (1982), recommend the following correlation:

$$
h / h_{\mathrm{id}}=1-D_{\mathrm{R} 113, \mathrm{R} 11}\left(\tilde{y}_{\mathrm{R} 11}^{\prime \prime}-\tilde{y}_{\mathrm{R} 11}^{\prime}\right)^{0.5}
$$

where

$$
h_{\mathrm{id}}=h_{\mathrm{R} 11} \tilde{y}_{\mathrm{R} 11}^{\prime}+h_{\mathrm{R} 113}\left(1-\tilde{y}_{\mathrm{R} 11}^{\prime}\right)
$$

and $D_{\mathrm{R} 113, \mathrm{R} 11}$ is a function of pressure only. Again, Bier et al. (1982) did not include the $R-11 / R-113$ combination in their study.

The correlation by Stephan and Körner was chosen as representative of the types of correlations reported in the literature. In order to determine the applicability of these types of correlations, the experimental data for the smooth tube were used to determine values of $C_{\mathrm{R} 113, \mathrm{R} 11}$. Generally, the values ranged from 0.5 to 2.2 with an average value of 1.5. This value was used to generate predicted heat transfer coefficients which are represented by the solid lines in Fig. 5.28. The 


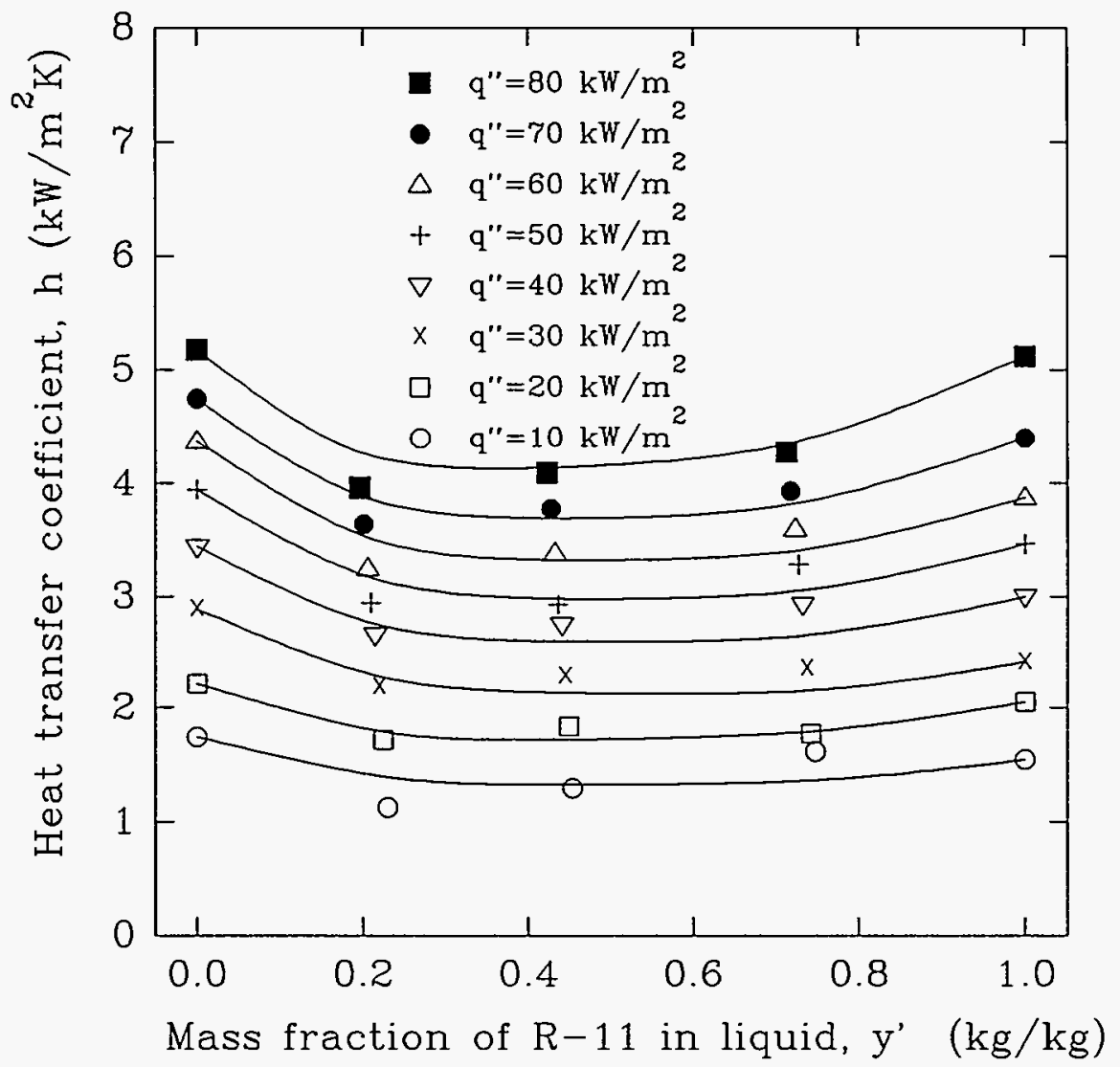

Figure 5.28. Comparison of experimental values for smooth tube heat transfer coefficients and predicted values using a Stephan-Körner type correlation. 
experimental data for liquid mass concentrations of approximately $25 \%$ is generally overpredicted while the data for mass concentrations of approximately $75 \%$ is generally underpredicted, though the trends are followed well.

Experimental data for the enhanced surfaces was also used to determine values of $C_{\mathrm{R} 113, \mathrm{R} 11}$ but with little success. Values of $C_{\mathrm{R} 113, \mathrm{R} 11}$ for the High Flux tubes ranged from 1.1 to 18.6 which indicates that this type of correlation is not applicable for enhanced surfaces. A possible explanation is that the enhanced surfaces is conducive to more of a buildup of the less volatile component next to the heated surface than smooth tubes due to the inability of the free stream to affect the heat transfer process in the subsurface cavities.

\section{Summary}

Single-phase heat transfer and pressure drop tests were conducted in the tube bundles, and the results were found to agree with correlations given by ESDU (1973) and Zukauskas (1987). These results validated the experimental apparatus and procedure and confirmed the applicability of these correlations to the particular bundle geometry and surface types used in this study. The single-phase heat transfer coefficients for the enhanced surfaces were approximately equal to those for the smooth tubes. In addition, pressure drop values for bundles of enhanced tubes were approximately equal to those for bundles of smooth tubes. These results indicate that the surface structure of the enhanced tubes is so small as to not appreciably affect the fluid flow pattern next to the heated surface nor the surface area exposed to the main fluid flow. 
Boiling heat transfer experiments conducted in the tube bundles with pure $\mathrm{R}-113$ revealed that the heat transfer coefficients for the smooth tubes increased significantly with heat flux and pressure. However, the heat transfer coefficients increased only slightly with increasing mass flux and only at very low heat fluxes. The pitch-to-diameter ratio did not affect the heat transfer coefficients appreciably either, except at low heat fluxes and large mass fluxes. In addition, the heat transfer coefficients increased with tube row only at very low heat fluxes. Because the tube row is directly proportional to quality, the effect of quality changes on the heat transfer coefficients is negligible except at very low heat fluxes. Fully developed nucleate boiling was found to dominate the heat transfer process throughout the majority of the tube bundle and accounted for the small influence of mass flux, quality, and bundle geometry on the heat transfer coefficients.

The heat transfer coefficients for the enhanced surfaces were significantly larger than those for the smooth tubes and were comparable to the values obtained in pool boiling. Indeed, the increasing trend in the heat transfer coefficient obtained in the tube bundle due to increasing heat flux was comparable to the trends observed in pool boiling for all three surfaces. The effect of pressure on the heat transfer coefficients for the High Flux surface was only slightly less than that for the smooth surface and was significantly greater than that for the Turbo-B surface. The smaller pressure effect for the Turbo-B tubes in the heat transfer coefficients was attributed to thin film vaporization in the sub-surface channels. The heat transfer coefficients for the enhanced surfaces did not vary significantly with mass flux, quality, or pitch-to-diameter ratio. These results indicated that the enhanced tubes were unaffected by the convective flow in the free stream. The enhanced surface caused the boiling process to occur within the sub-surface structure, and the 
external flow could not intrude into the sub-surface cavities and change the heat transfer mechanisms.

No significant variation of the heat transfer coefficient with tube row was found except at the first row in the High Flux bundle (and the last row in the Turbo-B bundle). The reduced heat transfer coefficient in the first row of the High Flux tube bundle was attributed to non-nucleating areas on the surface of the High Flux tube. Although the heat flux was increased to its maximum value before collecting data, small areas of the High Flux tubes failed to nucleate. Visual observations aided in determining that the initiation of nucleation occurred in patches for the High Flux surface, as was the case for pool boiling. In the tube bundle, however, the free-stream convection increased the heat transfer from the non-nucleating regions and prevented the wall superheat from increasing enough to initiate nucleation everywhere on the tube surface. These non-nucleating patches caused the High Flux heat transfer coefficient for tubes in the first row to sometimes be smaller than the pool boiling values. The onset of nucleation for tubes in the upper rows was aided by vapor rising from the lower tubes.

Heat transfer coefficients obtained in pure $\mathrm{R}-11$ generally followed the same trends as in pure $R-113$. For a given heat flux and pressure, the heat transfer coefficients were slightly larger in pure $R-113$ than in pure $R-11$ for the smooth and High Flux tubes, which is consistent with models based on nucleate boiling. However, the heat transfer coefficients were slightly larger in $R-11$ than in $R-113$ for the Turbo-B tubes. The increase in the Turbo-B heat transfer coefficients in $\mathrm{R}-11$ resulted from a combination of nucleate boiling and thin film vaporization in the sub-surface channels. 
Heat transfer coefficients decreased significantly for all surfaces when refrigerant mixtures were used but the same trends in the mass flux, heat flux, and pressure effects generally were observed, and the enhanced surfaces consistently performed better than the smooth tubes. The reduction in the heat transfer coefficient was largest for an inlet mixture concentration of $23.8 \% \mathrm{R}-11$. The degradation in the smooth tube heat transfer coefficients obtained in fluid mixtures was found to depend on the difference between the molar concentration in the liquid and vapor. However, a correlation similar to the one for smooth tubes was not successful in predicting the heat transfer coefficients for enhanced tubes. 


\section{CHAPTER 6}

\section{CONCLUSIONS AND RECOMMENDATIONS FOR FUTURE WORK}

This investigation sought to establish the boiling heat transfer performance of individual horizontal tubes with enhanced surfaces in a tube bundle. In doing so, insight has been gained that will aid in the design of shell-and-tube heat exchangers with horizontal tube bundles. The investigation included experimental studies of single tubes in pool boiling and of tube bundles with the fluid forced through the bundle in the vertically upward direction.

The studies of two-phase flow boiling in bundles of horizontal tubes were conducted on tubes with smooth and enhanced surfaces. The enhanced surfaces tested included a knurled surface (Wolverine's Turbo-B) and a porous surface (Linde's High Flux). Tests were conducted in two staggered tube bundles consisting of fifteen rows and five columns laid out in equilateral triangular arrays with pitch-to-diameter ratios of 1.17 and 1.50. Experiments were conducted in pure refrigerant $R-113$, pure $R-11$, and mixtures of $R-11$ and $R-113$ with inlet concentrations of approximately 25,50 , and $75 \%$ of $R-11$ by mass in the liquid.

\section{Conclusions}

Pool boiling tests were conducted for each of the three surfaces so that reference values of the heat transfer coefficient could be obtained. Values of the heat transfer coefficient for the enhanced tubes were generally an order of magnitude larger than for the smooth tubes. Heat transfer coefficients for the porous surface were generally the largest; however, a large hysteresis in the boiling curve was 
found. Visual observations revealed that only patches of the High Flux surface nucleated initially and that nucleation covered more of the surface as the heat flux increased. Heat transfer coefficients for the Turbo-B tube, on the other hand, showed very little hysteresis in the boiling curve. The difference was attributed to the sub-surface structure of the enhanced tubes and the ability of vapor generated near the bottom of the tube to travel around the perimeter and initiate boiling in extinct nucleation sites.

The pool boiling experiments conducted in pure $\mathrm{R}-11$ showed that, as for the pure $\mathrm{R}-113$ experiments, the enhanced tubes performed better than the smooth tubes. The performance of the smooth and High Flux tubes in pure R-11 was approximately equal to that in pure $\mathrm{R}-113$, except for heat fluxes less than $10 \mathrm{~kW} / \mathrm{m}^{2}$ where the performance in $\mathrm{R}-11$ was slightly greater than in $\mathrm{R}-113$. The performance of the Turbo-B tube was also slightly better in $R-11$ than in $R-113$.

Pool boiling heat transfer coefficients in fluid mixtures were less than those in pure fluids for all three surfaces. However, for a given heat flux and mixture concentration, the enhanced surfaces consistently performed better than the smooth tube. The High Flux tube performed slightly better than the Turbo-B tube, as was the case for the pure fluid experiments. The performance of all three surfaces decreased as the concentration of R-11 decreased, with the largest performance reduction relative to the pure refrigerant performance occurring in a mixture of $25 \%$ $\mathrm{R}-11 / 75 \% \mathrm{R}-113$.

Single-phase heat transfer and pressure drop tests were conducted in the tube bundles, and the results were found to agree with correlations given by ESDU (1973) and Zukauskas (1987). These results validated the experimental apparatus and procedure and confirmed the applicability of these correlations to the particular 
bundle geometry and surface types used in this study. The single-phase heat transfer coefficients for the enhanced surfaces were approximately equal to those for the smooth tubes. In addition, pressure drop values for bundles of enhanced tubes were approximately equal to those for bundles of smooth tubes. These results indicate that the surface structure of the enhanced tubes is so small as to not appreciably affect the fluid flow pattern next to the heated surface nor the surface area exposed to the main fluid flow.

Boiling heat transfer experiments in the tube bundles were conducted at pressures of 200 and $600 \mathrm{kPa}$, heat flux values from 5 to $80 \mathrm{~kW} / \mathrm{m}^{2}$, mass flux values from 50 to $500 \mathrm{~kg} / \mathrm{m}^{2} \mathrm{~s}$, and qualities from $0 \%$ to $80 \%$. Experiments conducted in pure $\mathrm{R}-113$ revealed that the heat transfer coefficients for the smooth tubes increased significantly with heat flux and pressure. However, the heat transfer coefficients increased only slightly with increasing mass flux and only at very low heat fluxes. The pitch-to-diameter ratio did not affect the heat transfer coefficients appreciably either, except at low heat fluxes and large mass fluxes. In addition, the heat transfer coefficients increased with tube row only at very low heat fluxes. Because the tube row is directly proportional to quality, the effect of quality changes on the heat transfer coefficients is negligible except at very low heat fluxes. Fully developed nucleate boiling was found to dominate the heat transfer process throughout the majority of the tube bundle and accounted for the small influence of mass flux, quality, and bundle geometry on the heat transfer coefficients.

The heat transfer coefficients for the enhanced surfaces were significantly larger than those for the smooth tubes and were comparable to the values obtained in pool boiling. Indeed, the increasing trend in the heat transfer coefficient obtained 
in the tube bundle due to with increasing heat flux was comparable to the trends observed in pool boiling for all three surfaces.

The effect of pressure on the heat transfer coefficients for the High Flux surface was only slightly less than that for the smooth surface and was significantly greater than that for the Turbo-B surface. The smaller pressure effect for the Turbo-B tubes in the heat transfer coefficients was attributed to thin film vaporization in the sub-surface channels.

The heat transfer coefficients for the enhanced surfaces did not vary significantly with mass flux, quality, or pitch-to-diameter ratio. These results indicated that the enhanced tubes were unaffected by the convective flow in the free stream. The enhanced surface caused the boiling process to occur within the sub-surface structure, and the external flow could not intrude into the sub-surface cavities and change the heat transfer mechanisms.

No significant variation of the heat transfer coefficient with tube row was found except at the first row in the High Flux bundle (and the last row in the Turbo-B bundle). The reduced heat transfer coefficient in the first row of the High Flux tube bundle was attributed to non-nucleating areas on the surface of the High Flux tube. Although the heat flux was increased to its maximum value before collecting data, small areas of the High Flux tubes failed to nucleate. Visual observations aided in determining that the initiation of nucleation occurred in patches for the High Flux surface, as was the case for pool boiling. In the tube bundle, however, the free-stream convection increased the heat transfer from the non-nucleating regions and prevented the wall superheat from increasing enough to initiate nucleation everywhere on the tube surface. These non-nucleating patches caused the High Flux heat transfer coefficient for tubes in the first row to sometimes 
be smaller than the pool boiling values. The onset of nucleation for tubes in the upper rows was aided by vapor rising from the lower tubes.

Heat transfer coefficients obtained in pure $R-11$ generally followed the same trends as in pure $\mathrm{R}-113$. For a given heat flux and pressure, the heat transfer coefficients were slightly larger in pure R-113 than in pure R-11 for the smooth and High Flux tubes. However, the heat transfer coefficients were slightly larger in $\mathrm{R}-11$ than in $\mathrm{R}-113$ for the Turbo-B tubes. The increase in the Turbo-B heat transfer coefficients in $\mathrm{R}-11$ resulted from a combination of nucleate boiling and thin film vaporization in the sub-surface channels.

Heat transfer coefficients decreased significantly for all surfaces when refrigerant mixtures were used but the same trends in the mass flux, heat flux, and pressure effects generally were observed, and the enhanced surfaces consistently performed better than the smooth tubes. The reduction in the heat transfer coefficient was largest for an inlet mixture concentration of $23.8 \% \mathrm{R}-11$. The degradation in the smooth tube heat transfer coefficients due to the fluid mixtures was predicted fairly well using a correlation of the form given by Stephan and Körner (1970), which predicts the wall superheat as a function of the difference between the molar concentration in the liquid and vapor. However, experimental data for the enhanced surfaces were not well predicted using a correlation of the same form and indicates that the heat transfer process has been significantly altered by the enhanced surface structure, possibly because of the inability of the free stream to affect the heat transfer process near the heated surface. 


\section{Recommendations for Future Work}

The results of this investigation have made apparent several areas which require further investigation. Perhaps the most obvious is the need to determine if a combination of nucleate boiling and single-phase convection could also account for the lack of a mass flux effect on the smooth tube heat transfer coefficients. Although fully established nucleate boiling was found to dominate the heat transfer process in this study, the alternative possibility might apply to data obtained at low heat flux values and might explain the lack of a mass flux effect for internal flow, such as reported by Kandlikar (1990).

The invariance in the heat transfer coefficient with tube row and quality also might be explored further in light of a possible balance between nucleate boiling and single-phase convection. The explanation presented depends on a decrease in the boiling heat transfer with increasing liquid velocity, which depends on the liquid-to-vapor density ratio. This analysis could explain the density ratio effect reported by Kandlikar (1990).

The presence of thin film vaporization in the sub-surface channels of the Turbo-B tubes would be supported by verifying that liquid enters the pores near the bottom and exits as vapor through pores near the top. This could be facilitated with visual studies of the path of dye injected into the liquid.

Finally, the onset of nucleation for High Flux tubes should be investigated further. Numerical calculations could be performed to determine the maximum surface temperature variation in high conductivity, thick-walled tubes with a uniform heat flux as the inside boundary condition and a variable heat transfer coefficient as the outside boundary condition. In combination with experimental 
temperature overshoot information, such a study would determine whether the temperature of small patches of non--nucleating surface area would be low enough to prevent the onset of nucleation. 


\section{LITERATURE CITED}

Alpay, H. E., and Balkan, F., 1989, "Nucleate Pool Boiling Performance of Acetone-Ethanol and Methylene Chloride-Ethanol Binary Mixtures," Int. J. Heat Mass Trans., vol. 32, no. 12, pp. 2403-2408.

ASHRAE, 1985, Handbook of Fundamentals, American Society of Heating, Refrigerating and Air-Conditioning Engineers, Atlanta, pp. 17.2-17.19.

Arai, N., Fukushima, T., Arai, A., Nakajima, T., Fujie, K., and Nakayama, Y., 1977, "Heat Transfer Tubes Enhancing Boiling and Condensation in Heat Exchangers of a Refrigerating Machine," ASHRAE Transactions, vol. 83, pt. 2, pp. 58-70.

Bajorek, S. M., Lloyd, J. R., and Thome, J. R., 1989, "Experimental Study of Multicomponent Pool Boiling on Smooth and Finned Surfaces," AIChE Symposium Series, vol. 85 , no. 269 , pp. $54-59$.

Bergles, A. E., 1978, "Enhancement of Heat Transfer," 6th Int. Heat Transfer Conf., Toronto, vol. 6, pp. 89-108.

Bergles, A. E., 1981, "Principles of Heat Transfer Augmentation. II: Two-Phase Heat Transfer," Heat Exchangers, Thermal-Hydraulic Fundamentals and Design, eds. Kakac, S.; Bergles, A. E.; and Mayinger, F., Hemisphere Publishing Company, Washington, D. C., pp. 857-881.

Bergles, A. E., 1988, "Heat Transfer Augmentation," Two-Phase Flow Heat Exchangers, eds. Kakac, S.; Bergles, A. E.; and Fernandes, E. O., Kluwer Academic Publishers, Dordrecht, pp. 343-373.

Bergles, A. E., and Chyu, M. C., 1982, "Characteristics of Nucleate Pool Boiling from porous Metallic Coatings," Journal of Heat Transfer, vol. 104, no. 2, pp. 279-285.

Bell, J. J., 1986, "Construction Features of Shell and Tube Heat Exchangers," Heat Exchanger Sourcebook, Edited by J. W. Palen, Hemisphere Publishing Corporation, Washington, p. 85.

Bier, K., Schmadl, J., and Gorenflo, D., 1982, "Pool Boiling Heat Transfer to Mixtures of $\mathrm{SF}_{6}$ and $\mathrm{CF}_{3} \mathrm{Br}$ at Elevated Saturated Pressures," 7 th Int. Heat Transfer Conf., Munich, vol. 4, pp. 35-40.

Bitter, R. C., 1972, "Heat Transfer from a Horizontal Tube with Transverse Flow of Evaporating Saturated R11," International Institute of Refrigeration, pp 97-107.

Borishanski, V. M., 1969, "Correlation of the Effect of Pressure on the Critical Heat Flux and Heat Transfer Rates Using the Theory of Thermodynamic Similarity," Problems of Heat Transfer and Hydraulics of Two-Phase Media, Pergamon Press, pp. 16-37.

Carvalho, R. D. M., 1992, "The Pool Nucleate Boiling and Critical Heat Flux of Vertically Oriented, Small Heaters Boiling on One Side," Ph.D. Thesis, Rensselaer Polytechnic Institute, Troy, NY. 
Chan, A. M. C., and Shoukri, M., 1987, "Boiling Characteristics of Small Multitube Bundles," Journal of Heat Transfer, vol. 109, no. 3, pp. 753-760.

Chen, J. C., 1966, "Correlation for Boiling Heat Transfer to Saturated Fluids in Convective Flow, "I\&EC Process Design and Development, vol. 5, pp. 322-329.

Chyu, M. C., 1979, "Boiling Heat Transfer from a Structures Surface," M.S. Thesis, Iowa State University, Ames, IA.

Cole, R., and Rohsenow, W. M., 1968, "Correlation of Bubble Departure Diameters for Boiling of Saturated Liquids," Chemical Engineering Progress Symposium Series, no. 92, vol. 65, pp. 211-213.

Collier, J. G., 1981, Convective Boiling and Condensation, McGraw-Hill Inc., London, pp. 211-214.

Cornwell, K., 1987, "On Heat Transfer to Sliding Bubbles in Tube Bundles," HTFS Res. Symp., City University, London, RS695.

Cornwell, K., 1990, "The Influence of Bubbly Flow on Boiling from a Tube in a Bundle," Int. J. Heat Mass Trans., vol. 33, no.12, pp. 2579-2584.

Cornwell, K., Duffin, N. W., Schuller, R. B., 1980, "An Experimental Study of the Effects of Fluid Flow on Boiling Within a Kettle Reboiler Tube Bundle," ASME Paper no. $80-\mathrm{HT}-45$.

Cornwell, K. and Schuller, R. B., 1982, "A Study of Boiling Outside a Tube Bundle Using High Speed Photography," Int. J. Heat Mass Trans., vol. 25, pp. 683-690.

Czikk, A. M., Gottzmann, C. F., Ragi, E. G., Withers, J. G., and Habdas, E. P., 1970, "Performance of Advanced Heat Transfer Tubes in Refrigerant-Flooded Liquid Coolers," ASHRAE Transactions, vol. 76, pp. 96-109.

Danilova, G. N., and Dyundin, V. A., 1972, "Heat Transfer with Freons 12 and 22 Boiling at Bundles of Finned Tubes," Heat Transfer - Soviet Research, vol. 4, no. 4, pp. $48-54$.

Dowlati R. and Kawaji, M., 1988, "Void Fraction and Friction Pressure Drop in Two-Phase Flow Across a Horizontal Tube Bundle," AIChE Symposium Series, no. 263, vol 84, pp. 126-132.

Dykas, S., 1989, "Critical Heat Flux in an Inline Horizontal Tube Bundle," M. S. Thesis, Rensselaer Polytechnic Institute, Troy, NY.

ESDU, 1973, "Convective Heat Transfer during Crossflow of Fluids Over Plain Tube Banks," Engineering Science Data Unit, London, item no. 79034.

ESDU, 1979, "Crossflow Pressure Loss Over Banks of Plain Tubes in Square and Triangular Arrays Including Effects of Flow Direction," Engineering Science Data Unit, London, item no. 79034. 
Fand, R. M., Keswani, K. K., Jotwani, M. M., and Ho, R. C. C., 1976, "Simultaneous Boiling and Forced Convection heat Transfer From a Horizontal Cylinder to Water," Journal of Heat Transfer, vol. 98, no. 3, pp. 395-400.

Fink, J., Gaddis, E. S., and Vogelpohl, A., 1982, "Forced Convection Boiling of a Mixture of Freon-11 and Freon-113 Flowing Normal to a Cylinder," 7 th Int. Heat Transfer Conf., Munich, vol. 4, pp. 207-212.

Forster, H. K., and Zuber, N., 1955, "Dynamics of Vapour Bubbles and Boiling Heat Transfer, AIChE Journal, 1 (4), pp. 531-535.

Frost \& Sullivan, 1992, The U.S. Market for Heat Exchangers, Market Research Report \#2547.

Fujita, Y., Ohta, H., Yoshida, K., Hidaka, S., and Nishikawa, K., 1984, "Nucleate Boiling Heat Transfer in Horizontal Tube Bundles (1st Report; Experimental Investigation on Tube Bundle Effect)," Memoirs of the Faculty of Engineering, Kyushu University, vol. 44 , no 4, pp. $427-446$.

Fujita, Y., Ohta, H., Hoshida, K., and Hidaka, S., 1990, "Heat Transfer in Nucleate Boiling Outside Horizontal Tube Bundles, Part 2 - Prediction for Tube Bundle Effect," Heat Transfer - Japanese Research, vol. 19, no. 2, pp. 25-40.

Gottzmann, C. F., O'Neill, P. S., and Minton, P. E., 1973, "High Efficiency Heat Exchangers," Chemical Engineering Progress, vol. 69, no. 7, pp. 69-75.

Grant, I. D. R., Cotchin, D. D., and Henry, J. A. R., 1980, "Tests on a Small Kettle Reboiler," Heat Exchangers for Two-Phase Applications, HTD-vol. 27, ASME, New York, pp. $41-45$.

Hahne, E. and Müller, J., 1983, "Boiling on a Finned Tube and a Finned Tube Bundle," Int. Heat Mass Transfer, vol. 26, no. 6, pp. 849-859.

Hewitt, G. F., 1981, "Introduction to Two Phase Flow Problems in the Process Industry," Two-Phase Flow and Heat Transfer in the Power and Process Industries, eds. A. E. Bergles et al., ed., Hemisphere Publishing Corporation, Washington D. C., p. 508.

Hewitt, G. F., and Hall-Taylor, N. S., 1970, Annular Two-Phase Flow, Pergamon Press, Oxford, pp. 186-192.

Hwang, T. H., and Yao, S. C., 1984, "Boiling Heat Transfer of a Horizontal Cylinder at Low Quality Crossflow," Fundamentals of Phase Change: Boiling and Condensation, HTD-vol. 38, ASME, New York, pp. 9-17.

Hwang, T. H., and Yao, S. C., 1986, "Forced Convective Boiling in Horizontal Tube Bundles," Int. Heat Mass Transfer, vol. 29, pp. 785-794.

Hwang, T. H., and Yao, S. C., 1988, "Boiling Heat Transfer in Kettle Evaporators," Particulate Phenomena and Multiphase Transport, T. N. Veziroglu, ed., vol. 1, pp. 511-528. 
Jensen, M. K., 1980, "Boiling Heat Transfer and Critical Heat Flux in Helical Coils," Ph.D. Thesis, Iowa State University, Ames, NY.

Jensen, M. K., 1988, "Boiling on the Shellside of Horizontal Tube Bundles," Two-Phase Flow Heat Exchangers, Thermal-Hydraulic Fundamentals and Design, S. Kakac et al., ed., Kluwer Academic Publishers, Dordrecht, pp. 707-746.

Jensen, M. K., 1989, "Advances in Shellside Boiling and Two-Phase Flow," Heat Transfer Equipment Fundamentals, Design, Applications, and Operating Problems, HTD-vol. 108, ASME, New York, pp. 1-11.

Jensen, M. K., and Hsu, J.-T., 1987, "A parametric Study of Boiling Heat Transfer in a Tube Bundle," 2nd ASME-JSME Thermal Engineering Joint Conference, Hawaii, pp. $107-115$.

Jung, C., and Bergles, A. E., 1989, "Evaluation of Commercial Enhanced Tubes in Pool Boiling," Department of Energy Report no. DE-FC07-88ID 12722.

Kandlikar, S. G., 1990, "A General Correlation for Saturated Two-Phase Flow Boiling Heat Transfer Inside Horizontal and Vertical Tubes," Journal of Heat Transfer, vol. 112 , no. 1 , pp. 219-228.

Kline, S. J., and McClintock, F. A., 1953, "Describing Uncertainties in Single-Sample Experiments," Mechanical Engineering, vol. 75, no. 1, pp. 3-8.

Koyama, Y., and Hashizume, K., 1983, "Boiling Heat Transfer on Outside of Horizontal Tube Bundles," $16^{\text {th }}$ Int. Cong. of Refrigeration, Proc., vol. 2, pp. 171-177.

Marto, P. J., and Lepere, V. J., 1981, "Pool Boiling Heat Transfer from Enhanced Surfaces to Dielectric Fluids," Advances in Enhanced Heat Transfer, HTD-Vol. 18, ASME, New York, pp. 93-102.

McAdams, W. H., 1954, Heat Transmission, McGraw-Hill Inc., New York, p. 176.

McKee, H. R., and Bell, K. J., 1969, "Forced Convection Boiling From a Cylinder Normal to the Flow," Chemical Engineering Progress Symposium Series, vol. 65, no. 92, pp. 222-230.

Meyers, J. E., and Katz, K. L., 1953, "Boiling Coefficients Outside Horizontal Tubes," Chemical Engineering Progress Symposium Series No 5, vol. 49, pp 107-114.

Mikic, B. B., and Rohsenow, W. M., 1969, "A New Correlation of Pool-Boiling Data Including the Effect of Heating Surface Characteristics," Journal of Heat Transfer, vol. 91 , no. 2, pp. 245-250.

Montgomery, R. T.; and Park, E. L., Jr., 1971, "A Study of Nucleate Boiling of Hydrocarbons from Multiple Tube Arrays," Twelfth ASME-AIChE National Heat Transfer Conference, Tulsa, Oklahoma.

Müller, J., and Hahne, E., 1981, "Boiling Heat Transfer in Finned Tube Bundles," Heat Transfer - Soviet Research, vol. 13, no. 6, pp. 19-25. 
Nakajima, K.-I., 1978, "Boiling Heat Transfer Outside Horizontal Multitube Bundles," Heat Trans.-Jap. Res., vol. 7, no.2, pp. 1-24.

National Bureau of Standards, 1986, "Application of a Hard Sphere Equation of State to Refrigerants and Refrigerant Mixtures,"U. S. Department of Commerce, NBS Technical Note 1266.

Niels, G. H., 1979, "Some Boiling Aspects in Kettle Evaporators," Boiling Phenomena: Physicochemical and Engineering Fundamentals and Applications, vol. 2, Hemisphere Publishing Corp., pp. 937-945.

O'Neill, P. S., King, R. C., and Ragi, E. G., 1980, "Application of High Performance Evaporator Tubing in Refrigeration Systems of Large Olefin Plants", AIChE Symposium Series, no. 199, vol. 76, pp. 289.

Pais, C., and Webb, R. L., 1991, "Literature Survey of Pool Boiling on Enhanced Surfaces," ASHRAE Transactions, vol. 97, pt. 1, pp. 79-89.

Palen, J. W., 1983, "Shell and Tube Reboilers," Heat Exchanger Design Handbook, vol. 3, Hemisphere Publishing Corp., Washington, D. C.

Palen, J. W., and Taborek, J. J., 1962, "Refinery Kettle Reboilers-Proposed Method for Design and Optimization," Chem. Engng. Prog., vol. 58, no. 7, pp. 37-46.

Palen, J. W.; Yarden, A.; and Taborek, J., 1972, "Characteristics of Boiling Outside Large-Scale Horizontal Multitube Bundles," Chemical Engineering Progress Symposium Series, vol. 68 , no. 118 , pp. $50-61$.

Palen, J. W., and Yang, C. C., 1983, "Circulation Boiling Model for Analysis of Kettle and Internal Reboiler Performance," Heat Exchangers for Two-Phase Applications, HTD-vol. 27, ASME, New York, pp. 55-61.

Polley, G. T., Ralston, T., and Grant, I. D. R., 1980, "Forced Crossflow Boiling in an Ideal In-Line Tube Bundle," ASME Paper no. 80-HT-46.

Ragi, E. G., and O'Neill, P. S., 1980, "Refinery Energy Conservation Experience with Enhanced Surface Reboilers," 20th Joint IMIQ/AIChE Conf., Acapulco, Mexico.

Robello, W. J., 1986, "Assessment of Heat Transfer Enhancement and Fouling in Industrial Heat Exchangers," DAR Enterprises Inc. draft report for Mueller Associates, Inc. on DOE Contract 3 DE-AC01-84CE40716, June.

Robinson, D. B., and Katz, K. L., 1951, "Effect of Vapor Agitation on Boiling Coefficients," Chem. Engng. Prog., vol. 47, pp. 317-324.

Shah M. M., 1982, "Chart Correlation for Saturated Boiling Heat Transfer: Equations and Further Study," ASHRAE Transactions, vol. 88, pt. 1, pp. 185-196.

Stephan, K., 1982, "Heat Transfer in Boiling of Mixtures," 7th Int. Heat Transfer Conf., Munich, vol. 1, pp. 59-81. 
Stephan, K., and Abdelsalam, M., 1980 "Heat-Transfer Correlations for Natural Convection Boiling," Int. J. Heat Mass Transfer, vol. 23, pp. 73-87.

Stephan, K., and Körner, M., 1969, "Berechnung des Wärmeübergangs verdampfender binärer Flüssigkeitsgemische," Chemie-Ing.-Techn., vol. 41, no. 7, pp. $409-417$.

Stephan, K., and Mitrovic, J., 1981, "Heat Transfer in Natural Convective Boiling of Refrigerants and Refrigerant-Oil-Mixtures in Bundles of T-Shaped Finned Tubes," Advances in Advanced Heat Transfer, HTD-Vol. 18, ASME, New York, pp. 131-146.

Schrage, D. S., Hsu, J.-T., and Jensen, M. K., 1987, "Void Fraction and Two-Phase Pressure Drop in Crossflow in a Horizontal Tube Bundle," 24th ASME-AIChE National Heat Transfer Conference, Pittsburgh.

Thome, J. R., and Shock, R. A. W., 1984, "Boiling of Multicomponent Liquid Mixtures," Advances in Heat Transfer, J. P. Hartnett and T. F. Irvine, eds., vol. 16, pp. $59-156$.

Wall, K. W.; and Park, E. L., Jr., 1978, "Nucleate Boiling of n-Pentane, n-hexane and Several Mixtures of the Two From Various Tube Arrays," Int. J. Heat Mass Transfer, vol. 21 , pp. 73-75.

Wallner, R., 1971, "Boiling Heat Transfer in Flooded Shell and Tube Evaporators," Proc. 13th Int. Congress of Refrigeration, Paper 22.19, pp. 185-191.

Webb, R. L., 1981, "The Evolution of Enhanced Surface Geometries for Nucleate Boiling," Heat Transfer Engineering, vol. 2, no. 3-4, pp. 46-69.

Webb, R. L., and Pais, C., 1991, "Pool Boiling Data for Five Refrigerants on Three Tube Geometries," ASHRAE Transactions, vol. 97, pt. 1, pp. 72-78.

Wege, and Jensen, 1984, "Boiling Heat Transfer From a Horizontal Tube in an Upward Flowing Two-Phase Crossflow," Journal of Heat Transfer, vol. 106, pp. 849-855.

Yilmaz, S., 1987, "Horizontal Shellside Thermosyphon Reboilers," Chemical Engineering Progress, vol. 83, no. 11, pp. 64-70.

Yilmaz, S., Hwalek, J. J., and Westwater, J. W., 1980, "Pool Boiling Heat Transfer Performance for Commercial Enhanced Tube Surfaces," ASME Paper No. 80-HT-41, presented at 19th National Heat Transfer Conference.

Yilmaz, S., Palen, J. W., and Taborek, J., 1981, "Enhanced Boiling Surfaces as Single Tubes and Tube Bundles," Advances in Enhanced Heat Transfer, HTD-Vol. 18, ASME, New York, pp. 123-129.

Yilmaz, S., and Westwater, J. W., 1980, "Effect of Velocity on Heat Transfer to Boiling Freon-113," Journal of Heat Transfer, vol. 102, no. 1, pp. 26-31. 
Yilmaz, S., and Westwater, J. W., 1981, "Effect of Commercial Enhanced Surfaces on the Boiling Heat Transfer Curve," Advances in Enhanced Heat Transfer, HTD-Vol. 18, ASME, New York, pp. 73-91.

Zukauskas, A., 1987, "Heat Transfer from Tubes in Crossflow," Advances in Heat Transfer, Eds. J. P. Harnett and T. F. Irvine, Jr., Academic Press, New York, vol. 8, pp. 137-142. 


\section{APPENDIX A}

\section{TABULATION OF EXPERIMENTAL DATA}

Tables of pool boiling and bundle data are presented. The tube bundle data are presented by listing all of the heat flux data sets for each mass flux at pressures of $200 \mathrm{kPa}$ and $600 \mathrm{kPa}$. An attempt was made to use a consistent set of nomenclature for the main body of text and the tabulated data headings but slight variations were unavoidable. Therefore a list of the nomenclature is presented next.

\section{Nomenclature}

DELTA $\mathrm{P}$ pressure drop across the bundle, $\mathrm{kPa}$

G

mass flux, $\mathrm{kg} / \mathrm{m}^{2} \cdot \mathrm{s}$

$\mathrm{h}$

heat transfer coefficient, $\mathrm{W} / \mathrm{m}^{2} \cdot \mathrm{K}$ or $\mathrm{kW} / \mathrm{m}^{2} \cdot \mathrm{K}$

$\mathrm{p} / \mathrm{d} \quad$ pitch to diameter ratio

$P$

pressure, $\mathrm{kPa}$

$\mathrm{q}, \mathrm{q}^{\prime \prime}$

heat flux for an individual tube, $\mathrm{W} / \mathrm{m}^{2}$

$\mathrm{T}$

temperature, $\mathrm{K}$

$\mathrm{X}$

thermodynamic quality, equation (3.20a)

$\mathrm{y}^{\prime}$

overall mass fraction in the liquid, $\mathrm{kg} / \mathrm{kg}$

Subscripts

av

average

in

inlet

out

outlet 


$\begin{array}{ll}\text { pool } & \text { reservoir for single-tube experiments } \\ \text { S } & \text { saturation } \\ \text { total } & \text { difference between inlet and outlet values } \\ \text { W } & \text { heated wall } \\ 1 & \text { top of tube (north) } \\ 2 & \text { side of tube (east) } \\ 3 & \text { bottom of tube (south) } \\ 4 & \text { side of tube (west) }\end{array}$




\section{Pool Boiling Data}

Pure R-113 data 


\begin{tabular}{rrrlllllll}
\hline & {$\left[\mathrm{kW} / \mathrm{m}^{\wedge} 2 \mathrm{~K}\right]$} & {$[\mathrm{C}]$} & {$[\mathrm{C}]$} & {$[\mathrm{C}]$} & {$[\mathrm{C}]$} & {$[\mathrm{C}]$} & {$[\mathrm{C}]$} & {$[\mathrm{C}]$} & {$\left[\mathrm{W} / \mathrm{m}^{\wedge}\right]$} \\
1 & 1.033 & .4 & 49.4 & 49.5 & 49.1 & 49.4 & 49.4 & 47.3 & $3.799 \mathrm{E}+2$ \\
2 & .822 & .7 & 49.7 & 49.8 & 49.3 & 49.8 & 49.7 & 47.3 & $5.381 \mathrm{E}+2$ \\
3 & .696 & 1.0 & 50.0 & 50.3 & 49.5 & 50.3 & 50.1 & 47.4 & $7.276 \mathrm{E}+2$ \\
4 & .502 & 2.1 & 51.1 & 51.6 & 50.2 & 51.4 & 51.4 & 47.4 & $1.069 \mathrm{E}+3$ \\
5 & .367 & 4.5 & 53.5 & 54.0 & 52.4 & 53.8 & 53.8 & 47.5 & $1.642 \mathrm{E}+3$ \\
6 & .326 & 7.9 & 56.9 & 57.6 & 55.2 & 57.3 & 57.4 & 47.7 & $2.568 \mathrm{E}+3$ \\
7 & 7.942 & .5 & 49.5 & 49.7 & 49.3 & 49.4 & 49.5 & 47.7 & $3.852 \mathrm{E}+3$ \\
8 & 10.829 & .5 & 49.5 & 49.8 & 49.3 & 49.5 & 49.6 & 47.8 & $5.821 \mathrm{E}+3$ \\
9 & 14.759 & .6 & 49.6 & 49.9 & 49.3 & 49.5 & 49.7 & 47.9 & $9.063 \mathrm{E}+3$ \\
10 & 18.753 & .7 & 49.7 & 50.1 & 49.3 & 49.6 & 49.8 & 48.1 & $1.325 \mathrm{3}+4$ \\
11 & 24.167 & .8 & 49.8 & 50.3 & 49.2 & 49.7 & 50.0 & 48.2 & $1.975 \mathrm{E}+4$ \\
12 & 29.043 & 1.0 & 50.0 & 50.7 & 49.1 & 50.0 & 50.4 & 48.2 & $3.046 \mathrm{E}+4$ \\
13 & 32.465 & 1.4 & 50.4 & 51.3 & 49.1 & 50.5 & 50.8 & 48.3 & $4.630 \mathrm{E}+4$ \\
14 & 35.450 & 1.9 & 50.9 & 52.1 & 49.1 & 51.2 & 51.5 & 48.3 & $6.912 \mathrm{E}+4$ \\
15 & 29.686 & 1.4 & 50.4 & 51.2 & 49.2 & 50.5 & 50.8 & 48.3 & $4.155 \mathrm{E}+4$ \\
16 & 24.394 & 1.0 & 50.0 & 50.6 & 49.2 & 50.0 & 50.3 & 48.3 & $2.539 \mathrm{E}+4$ \\
17 & 18.315 & .8 & 49.8 & 50.3 & 49.3 & 49.8 & 50.0 & 48.3 & $1.553 \mathrm{E}+4$ \\
18 & 13.779 & .7 & 49.7 & 50.0 & 49.3 & 49.6 & 49.8 & 48.3 & $9.468 \mathrm{E}+3$ \\
19 & 9.828 & .6 & 49.6 & 49.8 & 49.3 & 49.5 & 49.6 & 48.3 & $5.591 \mathrm{E}+3$ \\
20 & 6.988 & .5 & 49.5 & 49.7 & 49.3 & 49.5 & 49.5 & 48.3 & $3.556 \mathrm{E}+3$ \\
21 & 4.920 & .5 & 49.5 & 49.6 & 49.3 & 49.5 & 49.5 & 48.2 & $2.251 \mathrm{E}+3$ \\
22 & 3.625 & .4 & 49.4 & 49.5 & 49.2 & 49.4 & 49.4 & 48.2 & $1.445 \mathrm{E}+3$ \\
23 & 2.452 & .3 & 49.3 & 49.5 & 49.2 & 49.4 & 49.3 & 48.1 & $8.320 \mathrm{E}+2$ \\
24 & 1.563 & .3 & 49.3 & 49.4 & 49.2 & 49.3 & 49.3 & 48.0 & $4.522 \mathrm{E}+2$ \\
25 & 1.156 & .2 & 49.2 & 49.3 & 49.2 & 49.3 & 49.2 & 48.0 & $2.705 \mathrm{E}+2$
\end{tabular}

The file 17FEB1989A contains 25 records.

$A$ Hi-Flux, $S$ tube with a surface area of $0.0060805 \mathrm{~m}^{\wedge} 2$, an outer diameter of $0.01905 \mathrm{~m}$ and a correction ratio $\mathrm{R} / \mathrm{x}$ of 1.816 was tested in freon with a saturation temperature of $49 \mathrm{c}$.

$I \quad h(I) \quad \operatorname{Tav}(I)-T s \quad \operatorname{Tav}(I) \quad T 1(I) \quad T 2(I) \quad T 3(I) \quad T 4(I) \quad T p o o I(I) q(I)$

\begin{tabular}{rrrlllllll}
\hline & {$\left[\mathrm{kW} / \mathrm{m}^{\wedge} 2 \mathrm{~K}\right]$} & {$[\mathrm{C}]$} & {$[\mathrm{C}]$} & {$[\mathrm{C}]$} & {$[\mathrm{C}]$} & {$[\mathrm{C}]$} & {$[\mathrm{C}]$} & {$[\mathrm{C}]$} & {$\left[\mathrm{W} / \mathrm{m}^{\wedge} 2\right]$} \\
1 & -.154 & -0.0 & 48.2 & 48.3 & 48.2 & 48.2 & 48.1 & 48.1 & $1.437 \mathrm{E}+0$ \\
2 & .266 & 1.3 & 49.5 & 49.6 & 49.2 & 49.5 & 49.5 & 48.0 & $3.518 \mathrm{E}+2$ \\
3 & .285 & 2.0 & 50.2 & 50.3 & 49.5 & 50.2 & 50.1 & 48.1 & $5.705 \mathrm{E}+2$ \\
4 & .305 & 3.2 & 51.4 & 51.4 & 50.0 & 51.4 & 51.3 & 48.1 & $9.693 \mathrm{E}+2$ \\
5 & .354 & 4.7 & 52.9 & 52.9 & 50.6 & 53.0 & 52.8 & 48.9 & $1.659 \mathrm{E}+3$ \\
6 & 3.013 & .9 & 49.1 & 49.1 & 48.9 & 49.1 & 49.0 & 48.1 & $2.649 \mathrm{E}+3$ \\
7 & 4.663 & 1.0 & 49.2 & 49.2 & 49.0 & 49.3 & 49.1 & 48.1 & $4.580 \mathrm{E}+3$ \\
8 & 7.020 & 1.1 & 49.3 & 49.2 & 49.1 & 49.5 & 49.3 & 48.1 & $7.848 \mathrm{E}+3$ \\
9 & 9.825 & 1.3 & 49.5 & 49.4 & 49.2 & 49.7 & 49.5 & 48.0 & $1.286 \mathrm{E}+4$ \\
10 & 13.017 & 1.6 & 49.8 & 49.6 & 49.3 & 50.0 & 49.7 & 48.0 & $2.058 \mathrm{E}+4$ \\
11 & 16.077 & 2.0 & 50.2 & 50.1 & 49.5 & 50.5 & 50.1 & 48.0 & $3.293 \mathrm{E}+4$ \\
12 & 12.923 & 1.6 & 49.8 & 49.7 & 49.4 & 50.1 & 49.7 & 48.0 & $2.097 \mathrm{E}+4$ \\
13 & 9.688 & 1.4 & 49.6 & 49.4 & 49.2 & 49.8 & 49.5 & 48.1 & $1.317 \mathrm{E}+4$ \\
14 & 7.223 & 1.2 & 49.4 & 49.3 & 49.1 & 49.5 & 49.3 & 48.1 & $8.387 \mathrm{E}+3$ \\
15 & 5.007 & 1.0 & 49.2 & 49.2 & 49.1 & 49.4 & 49.2 & 48.1 & $5.238 \mathrm{E}+3$ \\
16 & 3.142 & .9 & 49.1 & 49.1 & 49.0 & 49.2 & 49.1 & 48.1 & $2.949 \mathrm{E}+3$ \\
17 & 1.747 & .8 & 49.0 & 49.1 & 48.9 & 49.1 & 49.0 & 48.1 & $1.484 \mathrm{E}+3$ \\
18 & 1.066 & .8 & 49.0 & 49.0 & 48.9 & 49.0 & 48.9 & 48.1 & $8.478 \mathrm{E}+2$ \\
19 & .642 & .7 & 48.9 & 49.0 & 48.9 & 48.9 & 48.9 & 48.1 & $4.789 \mathrm{E}+2$ \\
20 & .386 & .7 & 48.9 & 49.0 & 48.8 & 48.9 & 48.8 & 48.1 & $2.663 \mathrm{E}+2$
\end{tabular}

The file 28MAY2989H contains 20 records.

A Hi-Flux, $S$ tube with a surface area of $0.0059889 \mathrm{~m} \wedge 2$, an outer diameter of $0.0188 \mathrm{~m}$ and a correction ratio $\mathrm{R} / \mathrm{r}$ of 1.715 was

tested in freon with a saturation temperature of $48.2 \mathrm{C}$. 


\begin{tabular}{|c|c|c|c|c|c|c|c|c|c|}
\hline$I$ & $h(I)$ & $\operatorname{Tav}(I)-\operatorname{TB}$ & $\operatorname{Tav}(I)$ & $T 1(I)$ & $T 2(I)$ & T3 (I) & $T 4(I)$ & Tpool & I) $q(I)$ \\
\hline & {$\left[\mathrm{kH} / \mathrm{m}^{\wedge} 2 \mathrm{k}\right]$} & [C] & [C] & [C] & [C] & [C] & [C] & {$[\mathrm{C}]$} & {$\left[\omega / m^{\wedge} 2\right]$} \\
\hline 1 & -.027 & -.2 & 48.6 & 48.7 & 48.6 & 48.5 & 48.4 & 48.3 & $5.766 E+0$ \\
\hline 2 & .304 & .9 & 49.7 & 49.8 & 49.8 & 49.6 & 49.5 & 48.2 & $2.763 \mathrm{E}+2$ \\
\hline 3 & .293 & 1.6 & 50.4 & 50.5 & 50.5 & 50.4 & 50.2 & 48.2 & $4.815 \mathrm{E}+2$ \\
\hline 4 & .314 & 2.5 & 51.3 & 51.4 & 51.4 & 51.3 & 51.1 & 48.1 & $7.957 \mathrm{E}+2$ \\
\hline 5 & 2.475 & .6 & 49.3 & 49.4 & 49.4 & 49.3 & 49.2 & 48.0 & $1.363 \mathrm{E}+3$ \\
\hline 6 & 3.454 & .7 & 49.4 & 49.5 & 49.5 & 49.4 & 49.3 & 48.1 & $2.265 E+3$ \\
\hline 7 & 4.395 & .8 & 49.6 & 49.7 & 49.7 & 49.5 & 49.4 & 48.2 & $3.683 E+3$ \\
\hline 8 & 5.747 & 1.1 & 49.8 & 50.0 & 50.0 & 49.7 & 49.6 & 48.2 & $6.181 E+3$ \\
\hline 9 & 6.988 & 1.5 & 50.2 & 50.4 & 50.5 & 50.0 & 50.0 & 48.2 & $1.015 E+4$ \\
\hline 10 & 8.026 & 2.0 & 50.8 & 51.0 & 51.1 & 50.5 & 50.5 & 48.2 & $1.616 E+4$ \\
\hline 11 & 9.418 & 2.8 & 51.6 & 52.1 & 51.8 & 51.2 & 51.3 & 48.2 & $2.649 E+4$ \\
\hline 12 & 8.550 & 2.0 & 50.7 & 51.1 & 51.0 & 50.5 & 50.5 & 48.2 & 1. $699 \mathrm{E}+4$ \\
\hline 13 & 7.182 & 1.5 & 50.3 & 50.5 & 50.5 & 50.1 & 50.0 & 48.2 & $1.084 \mathrm{E}+4$ \\
\hline 14 & 6.017 & 1.2 & 49.9 & 50.1 & 50.1 & 49.8 & 49.7 & 48.2 & $7.025 \mathrm{E}+3$ \\
\hline 15 & 4.741 & .9 & 49.7 & 49.8 & 49.8 & 49.6 & 49.5 & 48.2 & $4.318 E+3$ \\
\hline 16 & 3.855 & .8 & 49.5 & 49.7 & 49.6 & 49.5 & 49.4 & 48.2 & $2.956 \mathrm{E}+3$ \\
\hline 17 & 2.860 & .7 & 49.4 & 49.5 & 49.5 & 49.4 & 49.3 & 48.2 & $1.893 \mathrm{E}+3$ \\
\hline 18 & 2.075 & .6 & 49.3 & 49.4 & 49.4 & 49.3 & 49.2 & 48.2 & $1.219 \mathrm{E}+3$ \\
\hline 19 & 1.597 & .5 & 49.3 & 49.4 & 49.3 & 49.3 & 49.1 & 48.2 & $8.311 \mathrm{E}+2$ \\
\hline 20 & 1.239 & .5 & 49.2 & 49.3 & 49.3 & 49.2 & 49.1 & 48.1 & $5.881 \mathrm{E}+2$ \\
\hline 21 & .834 & .4 & 49.2 & 49.3 & 49.2 & 49.2 & 49.1 & 48.2 & 3. $527 \mathrm{E}+2$ \\
\hline 22 & .595 & .4 & 49.2 & 49.2 & 49.2 & 49.1 & 49.0 & 48.2 & $2.362 \mathrm{E}+2$ \\
\hline
\end{tabular}

The file 8MAR1989 contains 22 records.

$A$ Hi-Flux, $M$ tube with a surface area of $0.0060837 \mathrm{~m}^{\wedge} 2$, an outer diameter of $0.01906 \mathrm{~m}$ and a correction ratio $R / \mathrm{r}$ of 1.745 was tested in freon with a saturation temperature of $48.76 \mathrm{C}$.

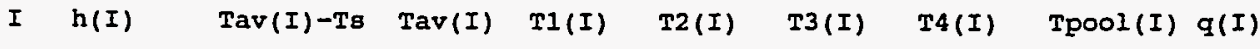

\begin{tabular}{|c|c|c|c|c|c|c|c|c|c|}
\hline & {$\left[\mathrm{kW} / \mathrm{m}^{\wedge} 2 \mathrm{~K}\right]$} & [C] & [C] & [C] & [C] & [C] & {$[C]$} & [C] & {$\left[\mathrm{W} / \mathrm{m}^{\wedge} 2\right]$} \\
\hline 1 & -.008 & -.5 & 47.6 & 47.6 & 47.6 & 47.6 & 47.5 & 47.2 & $4.066 E+0$ \\
\hline 2 & 1.977 & .1 & 48.2 & 48.2 & 48.2 & 48.2 & 48.1 & 47.2 & $2.298 E+2$ \\
\hline 3 & 1.214 & .2 & 48.3 & 48.4 & 48.3 & 48.3 & 48.2 & 47.2 & $2.684 \mathrm{E}+2$ \\
\hline 4 & 1.135 & .3 & 48.4 & 48.4 & 48.4 & 48.3 & 48.3 & 47.2 & $3.329 \mathrm{E}+2$ \\
\hline 5 & 1.247 & .3 & 48.4 & 48.5 & 48.4 & 48.4 & 48.3 & 47.1 & $4.322 \mathrm{E}+2$ \\
\hline 6 & 1.414 & .4 & 48.5 & 48.5 & 48.5 & 48.5 & 48.4 & 47.2 & $5.531 E+2$ \\
\hline 7 & 1.628 & .5 & 48.5 & 48.6 & 48.6 & 48.5 & 48.5 & 47.1 & $7.333 \mathrm{E}+2$ \\
\hline 8 & 1.904 & .5 & 48.6 & 48.6 & 48.6 & 48.6 & 48.5 & 47.1 & $9.435 \mathrm{E}+2$ \\
\hline 9 & 2.183 & .5 & 48.6 & 48.6 & 48.6 & 48.6 & 48.6 & 47.1 & $1.159 \mathrm{E}+3$ \\
\hline 10 & 2.503 & .6 & 48.7 & 48.6 & 48.7 & 48.7 & 48.7 & 47.2 & $1.547 \mathrm{E}+3$ \\
\hline 11 & 2.755 & .7 & 48.8 & 48.7 & 48.8 & 48.8 & 48.8 & 47.1 & $2.006 E+3$ \\
\hline 12 & 2.944 & .8 & 48.9 & 48.8 & 48.9 & 48.9 & 49.0 & 47.2 & $2.502 E+3$ \\
\hline 13 & 3.219 & 1.0 & 49.1 & 49.0 & 49.1 & 49.1 & 49.2 & 47.3 & $3.250 E+3$ \\
\hline 14 & 3.687 & 1.2 & 49.2 & 49.1 & 49.3 & 49.2 & 49.3 & 47.3 & $4.324 E+3$ \\
\hline 15 & 4.065 & 1.4 & 49.4 & 49.2 & 49.4 & 49.4 & 49.6 & 47.3 & $5.513 E+3$ \\
\hline 16 & 4.328 & 1.7 & 49.7 & 49.4 & 49.8 & 49.7 & 50.0 & 47.3 & $7.146 E+3$ \\
\hline 17 & 4.919 & 1.9 & 50.0 & 49.6 & 50.1 & 49.9 & 50.3 & 47.3 & $9.375 E+3$ \\
\hline 18 & 5.375 & 2.3 & 50.3 & 49.8 & 50.5 & 50.2 & 50.8 & 47.3 & $1.222 \mathrm{E}+4$ \\
\hline 19 & 5.813 & 2.6 & 50.7 & 50.0 & 51.0 & 50.6 & 51.4 & 47.3 & $1.536 \mathrm{E}+4$ \\
\hline 20 & 6.522 & 3.0 & 51.1 & 50.2 & 51.3 & 50.9 & 51.9 & 47.4 & $1.972 \mathrm{E}+4$ \\
\hline 21 & 7.284 & 3.5 & 51.5 & 50.4 & 51.8 & 51.3 & 52.6 & 47.3 & $2.521 E+4$ \\
\hline 22 & 10.269 & 3.2 & 51.3 & 50.4 & 51.2 & 51.5 & 52.2 & 47.3 & $3.334 E+4$ \\
\hline 23 & 11.865 & 3.6 & 51.7 & 50.6 & 51.4 & 52.0 & 52.9 & 47.2 & $4.306 \mathrm{E}+4$ \\
\hline 24 & 10.068 & 2.2 & 50.3 & 49.7 & 50.1 & 50.4 & 50.8 & 47.3 & $2.202 E+4$ \\
\hline 25 & 8.009 & 1.5 & 49.5 & 49.2 & 49.4 & 49.7 & 49.8 & 47.4 & $1.174 \mathrm{E}+4$ \\
\hline 26 & 5.870 & 1.1 & 49.1 & 49.0 & 49.1 & 49.2 & 49.3 & 47.5 & $6.224 E+3$ \\
\hline 27 & 4.094 & .8 & 48.9 & 48.8 & 48.9 & 48.9 & 48.9 & 47.5 & $3.261 E+3$ \\
\hline 28 & 2.562 & .7 & 48.7 & 48.7 & 48.8 & 48.7 & 48.7 & 47.4 & $1.674 \mathrm{E}+3$ \\
\hline 29 & 1.498 & .5 & 48.6 & 48.6 & 48.6 & 48.6 & 48.6 & 47.4 & $8.188 \mathrm{E}+2$ \\
\hline 30 & .849 & .5 & 48.6 & 48.6 & 48.6 & 48.5 & 48.5 & 47.4 & $4.087 \mathrm{E}+2$ \\
\hline
\end{tabular}

The file 6AP1989 contains 30 records.

A Hi-Flux, $M$ tube with a surface area of $0.0060837 \mathrm{~m}^{\wedge} 2$, an outer diameter of $0.01906 \mathrm{~m}$ and a correction ratio $\mathrm{R} / \mathrm{r}$ of 1.787 was

tested in freon with a saturation temperature of $48.07 \mathrm{C}$. 
$I h(I) \quad T a v(I)-T s \quad T a v(I) T 1(I) \quad T 2(I) \quad T 3(I) \quad T 4$ (I) $T p o 01(I) q(I)$

\begin{tabular}{rrrlllllll}
\hline & {$\left[\mathrm{kW} / \mathrm{m}^{\wedge} 2 \mathrm{~K}\right]$} & {$[\mathrm{C}]$} & {$[\mathrm{C}]$} & {$[\mathrm{C}]$} & {$[\mathrm{C}]$} & {$[\mathrm{C}]$} & {$[\mathrm{C}]$} & {$[\mathrm{C}]$} & {$\left[\mathrm{W} / \mathrm{m}^{\wedge} 2\right]$} \\
1 & -.025 & -.2 & 47.8 & 47.9 & 47.9 & 47.8 & 47.7 & 47.7 & $4.094 E+0$ \\
2 & .282 & 1.0 & 49.0 & 49.1 & 49.0 & 49.0 & 49.0 & 47.6 & $2.842 E+2$ \\
3 & .356 & 1.2 & 49.2 & 49.3 & 49.2 & 49.2 & 49.1 & 47.5 & $4.290 E+2$ \\
4 & .366 & 1.9 & 49.9 & 50.0 & 49.9 & 49.9 & 49.8 & 47.5 & $6.933 E+2$ \\
5 & .369 & 2.8 & 50.8 & 50.8 & 50.7 & 50.8 & 50.8 & 47.6 & $1.023 E+3$ \\
6 & .393 & 4.0 & 52.0 & 52.1 & 51.9 & 52.0 & 52.0 & 47.6 & $1.568 E+3$ \\
7 & .420 & 6.2 & 54.2 & 54.3 & 54.0 & 54.3 & 54.4 & 47.5 & $2.606 E+3$ \\
8 & .465 & 9.2 & 57.2 & 57.2 & 56.7 & 57.3 & 57.5 & 47.5 & $4.260 E+3$ \\
9 & 5.325 & 1.3 & 49.3 & 49.2 & 50.1 & 48.7 & 49.1 & 47.5 & $6.858 E+3$ \\
10 & 6.044 & 1.8 & 49.8 & 49.6 & 51.1 & 48.9 & 49.6 & 47.4 & $1.075 E+4$ \\
11 & 6.767 & 2.6 & 50.6 & 50.2 & 52.5 & 49.2 & 50.3 & 47.4 & $1.733 E+4$ \\
12 & 7.474 & 3.6 & 51.6 & 51.0 & 54.5 & 49.7 & 51.3 & 47.4 & $2.684 E+4$ \\
13 & 8.123 & 5.1 & 53.1 & 52.3 & 57.1 & 50.5 & 52.6 & 47.4 & $4.157 E+4$ \\
14 & 7.550 & 3.5 & 51.5 & 50.8 & 54.2 & 49.7 & 51.1 & 47.4 & $2.6125+4$ \\
15 & 4.610 & .8 & 48.8 & 48.8 & 49.3 & 48.5 & 48.7 & 47.5 & $3.833 E+3$
\end{tabular}

The file 27JAN1989 contains 15 records.

A Hi-Flux, I tube with a surface area of $0.0060805 \mathrm{~m}^{\wedge} 2$, an outer diameter of $0.0188 \mathrm{~m}$ and a correction ratio $\mathrm{R} / \mathrm{r}$ of 1.715 was tested in freon with a saturation temperature of $48.01 \mathrm{C}$.

\begin{tabular}{|c|c|c|c|c|c|c|c|c|c|}
\hline I & $h(I)$ & $\operatorname{Tav}(I)-T B$ & $\operatorname{Tav}(I)$ & $T I$ (I) & T2 (I) & $T 3(I)$ & T4 (I) & Tpool & I) $q(I)$ \\
\hline & {$\left[\mathrm{kW} / \mathrm{m}^{\wedge} 2 \mathrm{~K}\right]$} & [C] & [C] & [C] & [C] & [C] & [C] & [C] & {$\left[w / m^{n} 2\right]$} \\
\hline 1 & -.004 & -.9 & 47.4 & 47.5 & 47.5 & 47.4 & 47.3 & 47.1 & $4.039 \mathrm{E}+0$ \\
\hline 2 & 2.355 & .1 & 48.4 & 48.5 & 48.5 & 48.4 & 48.3 & 46.9 & $2.629 \mathrm{E}+2$ \\
\hline 3 & 1.833 & .2 & 48.5 & 48.6 & 48.6 & 48.5 & 48.4 & 46.8 & $3.578 \mathrm{E}+2$ \\
\hline 4 & 1.100 & .5 & 48.9 & 48.9 & 48.9 & 48.8 & 48.8 & 46.8 & $5.841 E+2$ \\
\hline 5 & .846 & 1.2 & 49.5 & 49.6 & 49.5 & 49.4 & 49.4 & 47.0 & $9.787 \mathrm{E}+2$ \\
\hline 6 & .910 & 1.7 & 50.0 & 50.1 & 50.0 & 49.9 & 50.0 & 47.0 & $1.514 \mathrm{E}+3$ \\
\hline 7 & 1.061 & 2.3 & 50.6 & 50.7 & 50.6 & 50.5 & 50.6 & 47.0 & $2.390 E+3$ \\
\hline 8 & 1.183 & 3.1 & 51.4 & 51.5 & 51.4 & 51.2 & 51.6 & 47.1 & $3.680 \mathrm{E}+3$ \\
\hline 9 & 1.379 & 4.1 & 52.4 & 52.4 & 52.3 & 52.1 & 52.9 & 47.2 & $5.661 \mathrm{E}+3$ \\
\hline 10 & 2.010 & 4.4 & 52.7 & 52.7 & 52.6 & 51.9 & 53.6 & 47.3 & $8.775 E+3$ \\
\hline 11 & 3.033 & 4.6 & 53.0 & 53.0 & 52.9 & 51.9 & 53.9 & 47.5 & $1.405 \mathrm{E}+4$ \\
\hline 12 & 4.072 & 5.4 & 53.7 & 53.8 & 53.7 & 52.5 & 54.8 & 47.5 & $2.189 \mathrm{E}+4$ \\
\hline 13 & 5.711 & 6.0 & 54.3 & 54.7 & 54.1 & 51.9 & 56.7 & 47.6 & $3.434 E+4$ \\
\hline 14 & 6.769 & 7.6 & 55.9 & 56.2 & 55.4 & 52.7 & 59.3 & 47.6 & $5.120 E+4$ \\
\hline 15 & 6.319 & 5.0 & 53.3 & 53.3 & 53.1 & 51.1 & 55.6 & 47.5 & $3.146 \mathrm{E}+4$ \\
\hline 16 & 5.831 & 3.3 & 51.6 & 51.7 & 51.6 & 50.3 & 53.1 & 47.5 & $1.941 E+4$ \\
\hline 17 & 5.296 & 2.3 & 50.6 & 50.6 & 50.6 & 49.6 & 51.4 & 47.5 & $1.199 \mathrm{E}+4$ \\
\hline 18 & 4.947 & 1.5 & 49.9 & 50.0 & 49.9 & 49.2 & 50.4 & 47.5 & $7.654 \mathrm{E}+3$ \\
\hline 19 & 4.607 & 1.1 & 49.4 & 49.5 & 49.5 & 49.0 & 49.7 & 47.5 & $4.987 \varepsilon+3$ \\
\hline 20 & 4.198 & .7 & 49.1 & 49.1 & 49.1 & 48.8 & 49.2 & 47.5 & $3.112 \mathrm{E}+3$ \\
\hline 21 & 3.301 & .6 & 48.9 & 49.0 & 48.9 & 48.7 & 49.0 & 47.5 & $1.902 E+3$ \\
\hline 22 & 2.504 & .5 & 48.8 & 48.9 & 48.9 & 48.7 & 48.8 & 47.5 & 1. $247 \mathrm{E}+3$ \\
\hline 23 & 1.798 & .4 & 48.7 & 48.8 & 48.8 & 48.6 & 48.7 & 47.5 & $7.383 E+2$ \\
\hline 24 & 1.303 & .4 & 48.7 & 48.7 & 48.7 & 48.6 & 48.6 & 47.5 & $4.598 E+2$ \\
\hline 25 & .905 & .2 & 48.6 & 48.6 & 48.6 & 48.5 & 48.5 & 47.4 & $2.241 E+2$ \\
\hline
\end{tabular}

The file 8 FEB1989 contains 25 records.

$A$ Hi-Flux, L tube with a surface area of $0.0060805 \mathrm{~m}^{4} 2$, an outer diameter of $0.01905 \mathrm{~m}$ and a correction ratio $\mathrm{R} / \mathrm{r}$ of 1.816 was tested in freon with a saturation temperature of $48.32 \mathrm{c}$. 


\begin{tabular}{|c|c|c|c|c|c|c|c|c|c|}
\hline$I$ & $h(I)$ & $\operatorname{Tav}(I)-T B$ & Tav (I) & $T 1$ (I) & $\mathrm{T} 2(\mathrm{I})$ & T3 (I) & $T 4(I)$ & \multicolumn{2}{|c|}{ Tpool(I) $q(I)$} \\
\hline & {$\left[\mathrm{kH} / \mathrm{m}^{\wedge} 2 \mathrm{k}\right]$} & [C] & [C] & [C] & [C] & [C] & [C] & [C] & {$\left[\mathrm{h} / \mathrm{m}^{\wedge} 2\right]$} \\
\hline 1 & -.003 & -.5 & 47.8 & 47.9 & 47.9 & 47.8 & 47.7 & 47.8 & $1.423 \mathrm{E}+0$ \\
\hline 2 & .737 & .4 & 48.6 & 48.7 & 48.7 & 48.6 & 48.5 & 47.7 & $2.639 E+2$ \\
\hline 3 & .968 & .4 & 48.7 & 48.8 & 48.7 & 48.7 & 48.6 & 47.7 & $4.079 E+2$ \\
\hline 4 & 1.287 & .5 & 48.8 & 48.8 & 48.8 & 48.7 & 48.7 & 47.7 & $6.258 \mathrm{E}+2$ \\
\hline 5 & 1.671 & .5 & 48.8 & 48.9 & 48.9 & 48.8 & 48.7 & 47.7 & $8.955 \mathrm{E}+2$ \\
\hline 6 & 2.192 & .6 & 48.9 & 49.0 & 48.9 & 48.9 & 48.8 & 47.7 & $1.403 E+3$ \\
\hline 7 & 2.881 & .8 & 49.0 & 49.2 & 49.1 & 49.0 & 48.9 & 47.6 & $2.239 E+3$ \\
\hline 8 & 3.770 & 1.0 & 49.2 & 49.4 & 49.2 & 49.2 & 49.1 & 47.6 & $3.646 \mathrm{E}+3$ \\
\hline 9 & 4.512 & 1.2 & 49.5 & 49.7 & 49.5 & 49.4 & 49.4 & 47.6 & $5.450 E+3$ \\
\hline 10 & 5.491 & 1.5 & 49.8 & 50.0 & 49.8 & 49.7 & 49.7 & 47.6 & $8.317 E+3$ \\
\hline 11 & 6.394 & 2.0 & 50.3 & 50.6 & 50.2 & 50.2 & 50.1 & 47.7 & $1.286 \mathrm{E}+4$ \\
\hline 12 & 7.108 & 2.8 & 51.1 & 51.6 & 51.0 & 50.9 & 50.9 & 47.7 & $2.003 E+4$ \\
\hline 13 & 5.862 & 2.1 & 50.3 & 50.7 & 50.3 & 50.2 & 50.2 & 47.8 & $1.214 \mathrm{E}+4$ \\
\hline 14 & 4.748 & 1.6 & 49.8 & 50.1 & 49.8 & 49.7 & 49.7 & 47.8 & $7.496 \mathrm{E}+3$ \\
\hline 15 & 3.617 & 1.2 & 49.5 & 49.7 & 49.5 & 49.4 & 49.4 & 47.8 & $4.410 \mathrm{E}+3$ \\
\hline 16 & 2.873 & 1.0 & 49.3 & 49.4 & 49.3 & 49.2 & 49.1 & 47.8 & $2.819 E+3$ \\
\hline 17 & 2.086 & .8 & 49.0 & 49.2 & 49.1 & 49.0 & 48.9 & 47.8 & $1.607 \mathrm{E}+3$ \\
\hline 18 & 1.600 & .6 & 48.9 & 49.0 & 48.9 & 48.8 & 48.7 & 47.8 & $9.342 E+2$ \\
\hline 19 & 1.132 & .5 & 48.8 & 48.8 & 48.8 & 48.7 & 48.7 & 47.7 & $5.446 \mathrm{E}+2$ \\
\hline 20 & .717 & .4 & 48.7 & 48.8 & 48.7 & 48.6 & 48.6 & 47.6 & $2.925 \mathrm{E}+2$ \\
\hline
\end{tabular}

The file 7 JuN1989 containg 20 records.

A Turbo-B, VC tube with a surface area of $0.0060454 \mathrm{~m}^{\wedge} 2$, an outer diameter of $0.01894 \mathrm{~m}$ and a correction ratio $R / \mathrm{r}$ of 1.765 was tested in freon with a saturation temperature of $48.27 \mathrm{C}$.

\begin{tabular}{|c|c|c|c|c|c|c|c|c|c|}
\hline$I$ & $h(I)$ & $\operatorname{Tav}(I)-\operatorname{TB}$ & $\operatorname{Tav}(I)$ & $T 1$ (I) & $T 2(I)$ & T3 (I) & $T 4(I)$ & Tpool (I) & $q(I)$ \\
\hline & {$\left[\mathrm{kH} / \mathrm{m}^{\wedge} 2 \mathrm{~K}\right]$} & [C] & [C] & [C] & {$[\mathrm{C}]$} & [C] & [C] & [C] & {$\left[W / m^{\wedge} 2\right]$} \\
\hline 1 & -.002 & -.6 & 47.6 & 47.7 & 47.7 & 47.6 & 47.5 & 47.4 & $1.431 E+0$ \\
\hline 2 & 1.153 & .2 & 48.5 & 48.6 & 48.6 & 48.5 & 48.4 & 47.4 & $2.881 E+2$ \\
\hline 3 & 1.401 & .3 & 48.6 & 48.7 & 48.6 & 48.6 & 48.5 & 47.4 & $4.421 \mathrm{E}+2$ \\
\hline 4 & 1.868 & .4 & 48.7 & 48.7 & 48.7 & 48.7 & 48.6 & 47.4 & $7.113 E+2$ \\
\hline 5 & 2.143 & .5 & 48.8 & 48.8 & 48.8 & 48.8 & 48.7 & 47.5 & $1.030 E+3$ \\
\hline 6 & 2.474 & .6 & 48.8 & 48.9 & 48.8 & 48.9 & 48.7 & 47.4 & $1.416 \mathrm{E}+3$ \\
\hline 7 & 2.879 & .7 & 49.0 & 49.0 & 49.0 & 49.0 & 48.9 & 47.5 & $2.043 E+3$ \\
\hline 8 & 3.184 & .9 & 49.2 & 49.2 & 49.2 & 49.2 & 49.0 & 47.5 & $2.841 E+3$ \\
\hline 9 & 3.737 & 1.1 & 49.4 & 49.5 & 49.4 & 49.5 & 49.2 & 47.5 & $4.171 E+3$ \\
\hline 10 & 4.180 & 1.4 & 49.7 & 49.8 & 49.6 & 49.8 & 49.5 & 47.5 & $5.784 \mathrm{E}+3$ \\
\hline 11 & 4.553 & 1.7 & 50.0 & 50.1 & 50.0 & 50.2 & 49.8 & 47.6 & $7.908 \mathrm{E}+3$ \\
\hline 12 & 5.556 & 2.0 & 50.3 & 50.4 & 50.2 & 50.5 & 50.1 & 47.6 & 1. $126 \mathrm{E}+4$ \\
\hline 13 & 6.230 & 2.6 & 50.8 & 50.8 & 50.8 & 51.1 & 50.6 & 47.6 & $1.591 \mathrm{E}+4$ \\
\hline 14 & 6.887 & 3.2 & 51.5 & 51.4 & 51.5 & 51.8 & 51.4 & 47.7 & $2.227 E+4$ \\
\hline 15 & 8.250 & 3.7 & 52.0 & 51.9 & 52.0 & 52.3 & 51.9 & 47.7 & 3. $090 \mathrm{E}+4$ \\
\hline 16 & 6.654 & 2.5 & 50.8 & 50.8 & 50.7 & 51.0 & 50.6 & 47.8 & 1. $682 \mathrm{E}+4$ \\
\hline 17 & 5.168 & 1.7 & 50.0 & 50.1 & 49.9 & 50.2 & 49.8 & 47.8 & $8.990 E+3$ \\
\hline 18 & 4.254 & 1.2 & 49.4 & 49.5 & 49.4 & 49.5 & 49.2 & 47.8 & $4.893 E+3$ \\
\hline 19 & 3.465 & .8 & 49.1 & 49.1 & 49.1 & 49.1 & 48.9 & 47.7 & $2.749 E+3$ \\
\hline 20 & 2.678 & .5 & 48.8 & 48.9 & 48.8 & 48.8 & 48.7 & 47.7 & $1.416 \mathrm{E}+3$ \\
\hline 21 & 2.071 & .4 & 48.7 & 48.7 & 48.7 & 48.7 & 48.6 & 47.7 & $8.081 E+2$ \\
\hline 22 & 1.251 & .3 & 48.6 & 48.7 & 48.6 & 48.6 & 48.5 & 47.7 & $4.203 E+2$ \\
\hline 23 & .754 & .3 & 48.6 & 48.6 & 48.6 & 48.6 & 48.5 & 47.7 & $2.373 E+2$ \\
\hline
\end{tabular}

The file 8JuN1989 contains 23. records.

$A$ Turbo-B, vo tube with a surface area of $0.0060454 \mathrm{~m}^{\wedge} 2$, an outer. diameter of $0.01894 \mathrm{~m}$ and a correction ratio $R / \mathrm{r}$ of 1.765 was tested in freon with a saturation temperature of $48.27 \mathrm{C}$. 
Pool Boiling Data

Pure R-11 data 


\begin{tabular}{|c|c|c|c|c|c|c|c|c|c|}
\hline$I$ & $h(I)$ & $\operatorname{Tav}(I)-T s$ & $\operatorname{Tav}(I)$ & TI (I) & T2 (I) & $\mathrm{T} 3(\mathrm{I})$ & T4(I) & Tpool (I) & $q(I)$ \\
\hline & {$\left[\mathrm{kW} / \mathrm{m}^{\wedge} 2 \mathrm{~K}\right]$} & [C] & [C] & [C] & [C] & {$[\mathrm{C}]$} & [C] & [C] & {$\left[w / m^{\wedge} 2\right]$} \\
\hline $\begin{array}{l}1 \\
2\end{array}$ & -.007 & -.4 & 24.0 & 24.1 & 24.1 & 24.0 & 23.9 & 23.8 & $3.096 \mathrm{E}+0$ \\
\hline $\begin{array}{l}2 \\
3\end{array}$ & $\begin{array}{l}.278 \\
.289\end{array}$ & $\begin{array}{l}1.3 \\
1.7\end{array}$ & $\begin{array}{l}25.7 \\
26.2\end{array}$ & $\begin{array}{l}25.8 \\
26.3\end{array}$ & $\begin{array}{l}25.8 \\
26.3\end{array}$ & $\begin{array}{l}25.7 \\
26.1\end{array}$ & $\begin{array}{l}25.6 \\
26.1\end{array}$ & $\begin{array}{l}23.8 \\
23.8\end{array}$ & $\begin{array}{l}3.524 \mathrm{E}+2 \\
5.052 \mathrm{E}+2\end{array}$ \\
\hline 4 & .276 & 2.8 & 27.3 & 27.4 & 27.3 & 27.2 & 27.2 & 23.8 & $7.846 E+2$ \\
\hline 5 & .278 & 4.5 & 29.0 & 29.2 & 29.0 & 28.9 & 28.9 & 23.9 & $1.261 E+3$ \\
\hline 6 & .294 & 6.7 & 31.1 & 31.3 & 31.2 & 30.9 & 31.1 & 23.8 & $1.960 \mathrm{E}+3$ \\
\hline 7 & .361 & 8.7 & 33.1 & 33.4 & 33.1 & 32.8 & 33.1 & 23.8 & 3. $121 \mathrm{E}+3$ \\
\hline 8 & .460 & 10.9 & 35.3 & 35.8 & 35.3 & 34.7 & 35.5 & 23.7 & $5.002 E+3$ \\
\hline 9 & .587 & 13.6 & 38.0 & 38.6 & 38.0 & 37.3 & 38.2 & 23.7 & $7.963 E+3$ \\
\hline 10 & 1.002 & 12.0 & 36.5 & 37.3 & 36.3 & 35.3 & 36.9 & 23.7 & $1.204 \mathrm{E}+4$ \\
\hline 11 & 1.613 & 11.8 & 36.2 & 36.9 & 36.2 & 35.6 & 36.2 & 23.6 & $1.898 E+4$ \\
\hline 12 & 2.261 & 13.4 & 37.9 & 38.6 & 37.7 & 37.2 & 37.9 & 23.5 & $3.031 E+4$ \\
\hline 13 & 1.571 & 12.1 & 36.5 & 37.1 & 36.4 & 35.9 & 36.6 & 23.5 & 1. $895 \mathrm{E}+4$ \\
\hline 14 & 1.127 & 10.5 & 35.0 & 35.5 & 34.9 & 34.4 & 35.1 & 23.6 & $1.185 \mathrm{E}+4$ \\
\hline 15 & .880 & 9.2 & 33.7 & 34.1 & 33.7 & 33.2 & 33.7 & 23.7 & 8. $119 E+3$ \\
\hline 16 & .649 & 8.1 & 32.6 & 32.9 & 32.6 & 32.2 & 32.7 & 23.7 & $5.284 E+3$ \\
\hline 17 & .480 & 7.0 & 31.4 & 31.7 & 31.4 & 31.1 & 31.5 & 23.8 & $3.342 \mathrm{E}+3$ \\
\hline 18 & .365 & 5.9 & 30.3 & 30.6 & 30.3 & 30.1 & 30.3 & 23.8 & $2.142 \mathrm{E}+3$ \\
\hline 19 & .316 & 4.0 & 28.5 & 28.6 & 28.5 & 28.3 & 28.4 & 23.9 & $1.261 E+3$ \\
\hline 20 & .274 & 2.9 & 27.3 & 27.5 & 27.4 & 27.2 & 27.3 & 23.9 & $7.839 \mathrm{E}+2$ \\
\hline 21 & .271 & 1.8 & 26.3 & 26.4 & 26.3 & 26.2 & 26.2 & 23.8 & $4.977 \mathrm{E}+2$ \\
\hline
\end{tabular}

The file PLRII contains 21 records.

A plain tube with a surface area of $0.0060964 \mathrm{~m}^{\wedge} 2$, an outer diameter of $0.0191 \mathrm{~m}$ and a correction ratio $R / \mathrm{r}$ of 1.083 was tested in freon with a saturation temperature of $24.46 \mathrm{C}$.

$I \quad h(I) \quad T a v(I)-T s \quad T a v(I) \quad T 1(I) \quad T 2(I) \quad T 3(I) \quad T 4$ (I) Tpool(I) $q(I)$

\begin{tabular}{rrrlllllll}
\hline & {$\left[\mathrm{kW} / \mathrm{m}^{-2 K}\right]$} & {$[\mathrm{C}]$} & {$[\mathrm{C}]$} & {$[\mathrm{C}]$} & {$[\mathrm{C}]$} & {$[\mathrm{C}]$} & {$[\mathrm{C}]$} & {$[\mathrm{C}]$} & {$\left[\mathrm{W} / \mathrm{m}^{\wedge} 2\right]$} \\
1 & -.008 & -.4 & 24.1 & 24.2 & 23.9 & 24.1 & 24.0 & 23.9 & $3.321 \mathrm{E}+0$ \\
2 & .375 & 2.5 & 26.9 & 27.0 & 24.0 & 27.0 & 26.8 & 23.9 & $9.325 \mathrm{E}+2$ \\
3 & .418 & 3.5 & 28.0 & 28.0 & 24.0 & 28.1 & 27.9 & 23.8 & $1.485 \mathrm{E}+3$ \\
4 & .447 & 5.5 & 30.0 & 30.0 & 24.1 & 30.1 & 29.8 & 23.9 & $2.471 E+3$ \\
5 & 13.629 & .3 & 24.8 & 24.8 & 23.9 & 24.9 & 24.7 & 23.7 & $4.151 E+3$ \\
6 & 14.034 & .3 & 24.8 & 24.8 & 23.9 & 24.9 & 24.7 & 23.6 & $4.478 E+3$ \\
7 & 19.081 & .4 & 24.8 & 24.7 & 23.8 & 25.0 & 24.8 & 23.6 & $7.175 E+3$ \\
8 & 23.245 & .5 & 25.0 & 24.8 & 23.7 & 25.2 & 24.9 & 23.5 & $1.168 E+4$ \\
9 & 22.993 & .8 & 25.3 & 25.1 & 23.7 & 25.6 & 25.2 & 23.6 & $1.848 E+4$ \\
10 & 26.370 & 1.1 & 25.6 & 25.3 & 23.5 & 26.0 & 25.4 & 23.5 & $2.969 E+4$ \\
11 & 23.635 & .8 & 25.3 & 25.0 & 23.7 & 25.6 & 25.2 & 23.5 & $1.905 E+4$ \\
12 & 20.034 & .6 & 25.1 & 24.9 & 23.7 & 25.3 & 25.0 & 23.5 & $1.220 E+4$ \\
13 & 17.707 & .4 & 24.9 & 24.8 & 23.8 & 25.1 & 24.9 & 23.6 & $7.926 E+3$ \\
14 & 13.748 & .4 & 24.8 & 24.8 & 23.9 & 25.0 & 24.8 & 23.6 & $5.035 E+3$ \\
15 & 10.511 & .3 & 24.8 & 24.8 & 23.9 & 24.9 & 24.7 & 23.6 & $3.198 E+3$ \\
16 & 9.707 & .2 & 24.7 & 24.7 & 23.9 & 24.7 & 24.6 & 23.6 & $2.203 E+3$ \\
17 & 6.774 & .2 & 24.7 & 24.7 & 24.0 & 24.7 & 24.6 & 23.6 & $1.386 E+3$ \\
18 & 4.501 & .2 & 24.6 & 24.7 & 23.9 & 24.6 & 24.5 & 23.6 & $7.260 E+2$ \\
19 & 2.831 & .1 & 24.6 & 24.7 & 24.0 & 24.6 & 24.5 & 23.6 & $3.334 E+2$
\end{tabular}

The file HERll contains 19 records.

A Hi-Flux, $S$ tube with a surface area of $0.0060805 \mathrm{~m}^{\wedge} 2$, an outer diameter of $0.01905 \mathrm{~m}$ and a correction ratio $\mathrm{R} / \mathrm{I}$ of 1.816 was tested in freon with a saturation temperature of $24.46 \mathrm{C}$. 


\begin{tabular}{|c|c|c|c|c|c|c|c|c|c|}
\hline$I$ & $h(I)$ & $\operatorname{Tav}(I)-T s$ & $\operatorname{Tav}(I)$ & $T 1(I)$ & $\mathrm{T} 2$ (I) & T3(I) & $T 4(I)$ & \multicolumn{2}{|c|}{ Tpool (I) $q(I)$} \\
\hline & {$\left[\mathrm{kW} / \mathrm{m}^{\wedge} 2 \mathrm{~K}\right]$} & [C] & [C] & {$[\mathrm{C}]$} & [C] & [C] & [C] & [C] & {$\left[\mathrm{W} / \mathrm{m}^{\wedge} 2\right]$} \\
\hline 1 & -.005 & -.7 & 23.2 & 23.3 & 23.2 & 23.2 & 23.1 & 23.0 & $3.798 E+0$ \\
\hline 2 & .941 & .3 & 24.2 & 24.2 & 24.2 & 24.2 & 23.6 & 23.0 & $2.501 E+2$ \\
\hline 3 & 1.282 & .3 & 24.2 & 24.2 & 24.2 & 24.2 & 23.6 & 23.0 & $3.497 \mathrm{E}+2$ \\
\hline 4 & 1.794 & .3 & 24.2 & 24.3 & 24.2 & 24.2 & 23.6 & 23.0 & $4.873 \mathrm{E}+2$ \\
\hline 5 & 2.147 & .3 & 24.2 & 24.3 & 24.2 & 24.2 & 23.6 & 23.0 & $6.543 \mathrm{E}+2$ \\
\hline 6 & 2.105 & .4 & 24.3 & 24.4 & 24.3 & 24.3 & 23.8 & 23.3 & $8.418 \mathrm{E}+2$ \\
\hline 7 & 2.903 & .4 & 24.3 & 24.4 & 24.3 & 24.3 & 23.8 & 23.3 & $1.050 \mathrm{E}+3$ \\
\hline 8 & 3.626 & .4 & 24.3 & 24.4 & 24.3 & 24.3 & 23.8 & 23.3 & $1.399 \mathrm{E}+3$ \\
\hline 9 & 3.817 & .5 & 24.4 & 24.5 & 24.4 & 24.4 & 23.9 & 23.4 & $1.891 \mathrm{E}+3$ \\
\hline 10 & 4.498 & .6 & 24.5 & 24.6 & 24.4 & 24.5 & 24.0 & 23.5 & $2.500 \mathrm{E}+3$ \\
\hline 11 & 4.573 & .7 & 24.6 & 24.7 & 24.5 & 24.7 & 24.1 & 23.6 & $3.169 \mathrm{E}+3$ \\
\hline 12 & 4.974 & .8 & 24.7 & 24.8 & 24.6 & 24.8 & 24.1 & 23.6 & $3.966 \mathrm{E}+3$ \\
\hline 13 & 5.743 & .9 & 24.8 & 24.9 & 24.6 & 24.9 & 24.1 & 23.5 & $4.965 E+3$ \\
\hline 14 & 6.130 & 1.1 & 25.0 & 25.1 & 24.7 & 25.2 & 24.3 & 23.6 & $6.645 \mathrm{E}+3$ \\
\hline 15 & 6.494 & 1.3 & 25.2 & 25.3 & 24.9 & 25.4 & 24.5 & 23.6 & 8. $321 E+3$ \\
\hline 16 & 8.025 & 1.4 & 25.3 & 25.4 & 24.9 & 25.7 & 24.7 & 23.6 & $1.101 E+4$ \\
\hline 17 & 9.801 & 1.5 & 25.4 & 25.4 & 25.0 & 25.8 & 24.8 & 23.6 & $1.438 \mathrm{E}+4$ \\
\hline 18 & 15.891 & 1.6 & 25.6 & 25.5 & 25.1 & 26.0 & 24.5 & 23.5 & $2.586 \mathrm{E}+4$ \\
\hline 19 & 11.215 & 1.3 & 25.2 & 25.3 & 24.7 & 25.7 & 24.2 & 23.5 & $1.440 E+4$ \\
\hline 20 & 6.920 & 1.0 & 24.9 & 25.0 & 24.6 & 25.1 & 24.1 & 23.6 & $6.778 \mathrm{E}+3$ \\
\hline 21 & 4.076 & .8 & 24.8 & 24.8 & 24.6 & 24.8 & 24.0 & 23.6 & $3.312 \mathrm{E}+3$ \\
\hline 22 & 3.447 & .5 & 24.5 & 24.5 & 24.4 & 24.5 & 23.9 & 23.5 & $1.860 \mathrm{E}+3$ \\
\hline 23 & 2.804 & .4 & 24.3 & 24.4 & 24.3 & 24.3 & 23.8 & 23.5 & $1.031 \mathrm{E}+3$ \\
\hline 24 & 1.133 & .3 & 24.3 & 24.3 & 24.3 & 24.2 & 23.8 & 23.5 & $3.575 \mathrm{E}+2$ \\
\hline 25 & .005 & .3 & 24.2 & 24.3 & 24.2 & 24.2 & 23.8 & 23.4 & $1.421 \mathrm{E}+0$ \\
\hline
\end{tabular}

The file TBRIl contains 25 records.

A Turbo-B, $M$ tube with a surface area of $0.0061028 \mathrm{~m}^{\wedge} 2$, an outer diameter of $0.01912 \mathrm{~m}$ and a correction ratio $\mathrm{R} / \mathrm{r}$ of 1.5704 was

tested in freon with a saturation temperature of $23.94 \mathrm{C}$. 


\section{Pool Boiling Data}

Data from the $75 \% \mathrm{R}-11 / 25 \% \mathrm{R}-113$ mixture 


\begin{tabular}{|c|c|c|c|c|c|c|c|c|}
\hline$h(I)$ & $\operatorname{Tav}(I)-\operatorname{Ts}$ & $\operatorname{Tav}(I)$ & $\mathrm{T} 1(\mathrm{I})$ & $\mathrm{T} 2$ (I) & $T 3(I)$ & $T 4$ (I) & Tpool & I) $q(I)$ \\
\hline$\left[\mathrm{kW} / \mathrm{m}^{\wedge} 2 \mathrm{~K}\right]$ & [C] & [C] & [C] & [C] & [C] & [C] & [C] & {$\left[\boldsymbol{\omega} / \mathrm{m}^{\wedge} 2\right]$} \\
\hline-.009 & -.4 & 27.6 & 27.7 & 27.7 & 27.6 & 27.5 & 27.4 & $3.597 \mathrm{E}+0$ \\
\hline .278 & 1.1 & 29.1 & 29.2 & 29.2 & 29.1 & 29.0 & 27.3 & 3. $101 E+2$ \\
\hline .239 & 1.8 & 29.8 & 29.9 & 29.9 & 29.8 & 29.7 & 27.3 & $4.343 E+2$ \\
\hline .236 & 2.7 & 30.7 & 30.9 & 30.8 & 30.7 & 30.6 & 27.3 & $6.451 \mathrm{E}+2$ \\
\hline .245 & 4.3 & 32.3 & 32.5 & 32.4 & 32.3 & 32.2 & 27.4 & $1.064 \mathrm{E}+3$ \\
\hline .266 & 7.1 & 35.1 & 35.3 & 35.2 & 35.0 & 35.1 & 28.1 & $1.899 \mathrm{E}+3$ \\
\hline .331 & 9.6 & 37.6 & 37.9 & 37.7 & 37.3 & 37.7 & 28.4 & $3.192 \mathrm{E}+3$ \\
\hline .485 & 11.5 & 39.5 & 39.8 & 39.6 & 39.1 & 39.5 & 28.9 & $5.575 E+3$ \\
\hline .765 & 12.5 & 40.5 & 40.7 & 40.6 & 40.4 & 40.2 & 27.3 & $9.532 \mathrm{E}+3$ \\
\hline 1.397 & 11.3 & 39.3 & 39.9 & 39.3 & 38.7 & 39.2 & 27.6 & $1.573 \mathrm{E}+4$ \\
\hline 1.808 & 13.6 & 41.6 & 42.3 & 41.5 & 40.9 & 41.5 & 27.6 & $2.455 E+4$ \\
\hline 1.352 & 10.9 & 38.9 & 39.5 & 39.0 & 38.5 & 38.8 & 27.6 & $1.478 \mathrm{E}+4$ \\
\hline 1.004 & 8.9 & 36.9 & 37.3 & 37.0 & 36.5 & 36.7 & 27.7 & $8.893 \mathrm{E}+3$ \\
\hline .733 & 6.8 & 34.8 & 35.1 & 34.9 & 34.6 & 34.7 & 27.9 & $5.011 \mathrm{E}+3$ \\
\hline .519 & 5.4 & 33.4 & 33.6 & 33.5 & 33.2 & 33.4 & 27.8 & $2.816 \mathrm{E}+3$ \\
\hline .369 & 4.3 & 32.3 & 32.5 & 32.4 & 32.2 & 32.3 & 27.3 & $1.596 \mathrm{E}+3$ \\
\hline .267 & 3.1 & 31.1 & 31.2 & 31.1 & 31.0 & 31.0 & 27.3 & $8.171 E+2$ \\
\hline .218 & 2.0 & 30.0 & 30.1 & 30.0 & 29.9 & 29.9 & 27.3 & $4.341 E+2$ \\
\hline .231 & 1.0 & 29.0 & 29.1 & 29.0 & 28.9 & 28.9 & 27.3 & $2.301 \mathrm{E}+2$ \\
\hline
\end{tabular}

The file PL2 contains 19 records.

A plain tube with a surface area of $0.0060964 \mathrm{~m}^{\wedge} 2$, an outer

diameter of $0.0191 \mathrm{~m}$ and a correction ratio $\mathrm{R} / \mathrm{r}$ of 1.083 was

teated in freon with a saturation temperature of $28 \mathrm{c}$.

$I h(I) \quad \operatorname{Tav}(I)-T s \quad \operatorname{Tav}(I) \quad T 1(I) \quad T 2$ (I) T3(I) T4(I) Tpool(I) $q(I)$

\begin{tabular}{rrrlllllll}
\hline & {$\left[\mathrm{kW} / \mathrm{m}^{\wedge} 2 \mathrm{~K}\right]$} & {$[\mathrm{C}]$} & {$[\mathrm{C}]$} & {$[\mathrm{C}]$} & {$[\mathrm{C}]$} & {$[\mathrm{C}]$} & {$[\mathrm{C}]$} & {$[\mathrm{C}]$} & {$\left[\mathrm{W} / \mathrm{m}^{\wedge} 2\right]$} \\
1 & -.007 & -.6 & 27.4 & 27.5 & 27.5 & 27.4 & 27.3 & 27.2 & $3.935 E+0$ \\
2 & .261 & 1.3 & 29.3 & 29.4 & 29.2 & 29.3 & 29.2 & 27.3 & $3.374 E+2$ \\
3 & .245 & 2.6 & 30.6 & 30.7 & 30.3 & 30.6 & 30.5 & 27.3 & $6.321 E+2$ \\
4 & .249 & 4.4 & 32.4 & 32.4 & 31.9 & 32.3 & 32.3 & 27.3 & $1.084 E+3$ \\
5 & .240 & 8.2 & 36.2 & 36.2 & 35.3 & 36.2 & 36.2 & 29.9 & $1.975 E+3$ \\
6 & 3.304 & 1.0 & 29.0 & 29.0 & 28.9 & 29.1 & 29.0 & 27.5 & $3.413 E+3$ \\
7 & 4.616 & 1.2 & 29.2 & 29.2 & 28.9 & 29.3 & 29.2 & 27.4 & $5.690 E+3$ \\
8 & 6.174 & 1.5 & 29.5 & 29.3 & 29.1 & 29.6 & 29.6 & 27.5 & $9.255 E+3$ \\
9 & 8.200 & 1.9 & 29.9 & 29.7 & 29.4 & 30.0 & 29.9 & 27.5 & $1.530 E+4$ \\
10 & 10.311 & 2.4 & 30.4 & 30.2 & 29.6 & 30.6 & 30.4 & 27.5 & $2.460 E+4$ \\
11 & 12.270 & 3.1 & 31.1 & 30.8 & 29.8 & 31.4 & 31.0 & 27.6 & $3.762 E+4$ \\
12 & 9.989 & 2.4 & 30.4 & 30.1 & 29.6 & 30.6 & 30.4 & 27.6 & $2.364 E+4$ \\
13 & 7.596 & 1.9 & 29.9 & 29.7 & 29.4 & 30.0 & 29.9 & 27.6 & $1.412 E+4$ \\
14 & 5.571 & 1.5 & 29.5 & 29.4 & 29.2 & 29.6 & 29.6 & 27.6 & $8.442 E+3$ \\
15 & 3.954 & 1.3 & 29.3 & 29.2 & 29.1 & 29.4 & 29.3 & 27.5 & $5.072 E+3$ \\
16 & 2.698 & 1.0 & 29.0 & 29.0 & 28.9 & 29.1 & 29.0 & 27.6 & $2.829 E+3$ \\
17 & 1.803 & .9 & 28.9 & 28.9 & 28.8 & 28.9 & 28.8 & 27.6 & $1.631 E+3$ \\
18 & 1.120 & .8 & 28.8 & 28.9 & 28.7 & 28.8 & 28.7 & 27.6 & $8.738 E+2$ \\
19 & .747 & .6 & 28.6 & 28.7 & 28.6 & 28.6 & 28.6 & 27.5 & $4.828 E+2$ \\
20 & .486 & .5 & 28.5 & 28.6 & 28.5 & 28.5 & 28.4 & 27.5 & $2.341 E+2$
\end{tabular}

The file HF2 contains 20 records.

A Hi-Flux, s tube with a surface area of $0.0060805 \mathrm{~m} \wedge 2$, an outer diameter of $0.01905 \mathrm{~m}$ and a correction ratio $\mathrm{R} / \mathrm{r}$ of 1.816 was

tested in freon with a saturation temperature of $28 \mathrm{c}$. 
$I h(I) \quad \operatorname{Tav}(I)-T B \quad \operatorname{Tav}(I) \quad T 1(I) \quad T 2(I) \quad T 3(I) \quad T 4(I) \quad T p o o 1(I) q(I)$

\begin{tabular}{rrrlllllll}
\hline & {$\left[\mathrm{kW} / \mathrm{m}^{\wedge} 2 \mathrm{~K}\right]$} & {$[\mathrm{C}]$} & {$[\mathrm{C}]$} & {$[\mathrm{C}]$} & {$[\mathrm{C}]$} & {$[\mathrm{C}]$} & {$[\mathrm{C}]$} & {$[\mathrm{C}]$} & {$\left[\mathrm{W} / \mathrm{m}^{\wedge}\right]$} \\
1 & -.074 & -0.0 & 27.3 & 27.3 & 27.3 & 27.2 & 27.1 & 27.0 & $3.434 \mathrm{E}+0$ \\
2 & .474 & .8 & 28.1 & 28.1 & 28.1 & 28.1 & 27.3 & 26.9 & $3.707 E+2$ \\
3 & .646 & 1.0 & 28.3 & 28.3 & 28.3 & 28.4 & 27.4 & 27.0 & $6.764 E+2$ \\
4 & .875 & 1.3 & 28.6 & 28.6 & 28.6 & 28.7 & 27.5 & 27.1 & $1.150 E+3$ \\
5 & 1.109 & 1.9 & 29.2 & 29.2 & 29.1 & 29.3 & 27.8 & 27.3 & $2.147 \mathrm{E}+3$ \\
6 & 1.716 & 2.3 & 29.6 & 29.6 & 29.5 & 29.8 & 27.9 & 27.3 & $4.030 E+3$ \\
7 & 2.809 & 2.9 & 30.2 & 30.1 & 29.9 & 30.5 & 28.4 & 27.4 & $8.137 E+3$ \\
8 & 4.639 & 3.3 & 30.6 & 30.4 & 30.3 & 31.0 & 28.7 & 27.5 & $1.517 \mathrm{E}+4$ \\
9 & 10.439 & 3.9 & 31.2 & 31.1 & 30.5 & 31.9 & 28.5 & 27.5 & $4.028 \mathrm{E}+4$ \\
10 & 6.577 & 3.3 & 30.6 & 30.5 & 30.3 & 31.1 & 28.2 & 27.5 & $2.200 E+4$ \\
11 & 4.164 & 3.0 & 30.3 & 30.2 & 30.0 & 30.7 & 28.1 & 27.3 & $1.249 E+4$ \\
12 & 2.362 & 2.5 & 29.8 & 29.7 & 29.7 & 30.1 & 27.9 & 27.2 & $5.977 E+3$ \\
13 & 1.572 & 2.2 & 29.5 & 29.5 & 29.3 & 29.7 & 27.9 & 27.3 & $3.434 E+3$ \\
14 & 1.070 & 1.8 & 29.1 & 29.1 & 29.0 & 29.2 & 27.8 & 27.2 & $1.895 E+3$ \\
15 & .751 & 1.1 & 28.4 & 28.4 & 28.4 & 28.5 & 27.5 & 27.1 & $8.505 E+2$ \\
16 & .421 & .8 & 28.1 & 28.1 & 28.1 & 28.1 & 27.4 & 27.0 & $3.401 E+2$ \\
17 & .232 & .6 & 27.9 & 28.0 & 27.9 & 27.9 & 27.4 & 26.9 & $1.482 E+2$
\end{tabular}

The file TB2 contains 17 records.

$A$ Turbo-B, $M$ tube with a surface area of $0.0061028 \mathrm{~m}^{\wedge} 2$, an outer diameter of $0.01912 \mathrm{~m}$ and a correction ratio $\mathrm{R} / \mathrm{r}$ of 1.5704 was tested in freon with a saturation temperature of $27.3 \mathrm{C}$. 


\section{Pool Boiling Data}

Data from the $50 \% \mathrm{R}-11 / 50 \% \mathrm{R}-113$ mixture 
$I \quad h(I) \quad T a v(I)-T s \quad T a v(I) T 1(I) \quad T 2(I) \quad T 3(I) \quad T 4(I) \quad T p o o l(I) q(I)$

\begin{tabular}{rrrlllllll}
\hline & {$\left[\mathrm{kW} / \mathrm{m}^{\wedge} 2 \mathrm{~K}\right]$} & {$[\mathrm{C}]$} & {$[\mathrm{C}]$} & {$[\mathrm{C}]$} & {$[\mathrm{C}]$} & {$[\mathrm{C}]$} & {$[\mathrm{C}]$} & {$[\mathrm{C}]$} & {$\left[\mathrm{W} / \mathrm{m}^{\wedge}\right]$} \\
1 & -.029 & -.1 & 32.1 & 32.2 & 32.2 & 32.1 & 32.0 & 31.8 & $2.989 E+0$ \\
2 & .219 & 1.7 & 33.9 & 34.0 & 33.9 & 33.8 & 33.8 & 31.7 & $3.703 E+2$ \\
3 & .198 & 3.5 & 35.7 & 35.8 & 35.7 & 35.7 & 35.6 & 31.7 & $6.943 E+2$ \\
4 & .203 & 5.7 & 37.9 & 38.0 & 37.9 & 37.8 & 37.8 & 31.8 & $1.155 E+3$ \\
5 & .231 & 8.7 & 40.9 & 41.1 & 40.9 & 40.8 & 40.8 & 32.1 & $2.012 E+3$ \\
6 & .288 & 11.3 & 43.5 & 43.7 & 43.5 & 43.2 & 43.4 & 32.0 & $3.241 E+3$ \\
7 & .400 & 13.6 & 45.8 & 46.3 & 45.8 & 45.2 & 45.9 & 32.1 & $5.446 E+3$ \\
8 & .688 & 12.4 & 44.6 & 44.8 & 44.7 & 44.5 & 44.4 & 32.3 & $8.546 E+3$ \\
9 & 1.199 & 11.5 & 43.7 & 44.3 & 43.7 & 43.1 & 43.5 & 32.4 & $1.375 E+4$ \\
10 & 1.556 & 13.7 & 45.9 & 46.7 & 45.9 & 45.2 & 45.8 & 32.2 & $2.133 E+4$ \\
11 & 2.033 & 16.5 & 48.7 & 49.5 & 48.6 & 48.0 & 48.6 & 32.1 & $3.350 E+4$ \\
12 & 1.525 & 13.6 & 45.8 & 46.6 & 45.8 & 45.2 & 45.7 & 32.4 & $2.072 E+4$ \\
13 & 1.149 & 11.1 & 43.3 & 43.8 & 43.3 & 42.9 & 43.2 & 32.3 & $1.276 E+4$ \\
14 & .864 & 9.3 & 41.5 & 41.9 & 41.5 & 41.2 & 41.4 & 32.2 & $8.005 E+3$ \\
15 & .632 & 7.8 & 40.0 & 40.3 & 40.0 & 39.7 & 39.9 & 32.1 & $4.926 E+3$ \\
16 & .474 & 6.4 & 38.6 & 38.8 & 38.6 & 38.4 & 38.5 & 32.1 & $3.020 E+3$ \\
17 & .365 & 5.2 & 37.4 & 37.6 & 37.4 & 37.3 & 37.3 & 31.9 & $1.905 E+3$ \\
18 & .279 & 4.2 & 36.4 & 36.5 & 36.4 & 36.3 & 36.3 & 31.8 & $1.168 E+3$ \\
19 & .217 & 3.6 & 35.8 & 35.9 & 35.8 & 35.7 & 35.7 & 31.9 & $7.712 E+2$ \\
20 & .185 & 2.5 & 34.7 & 34.8 & 34.7 & 34.6 & 34.6 & 31.8 & $4.614 E+2$
\end{tabular}

The file PL3 containg 20 records.

A plain tube with a surface area of $0.0060964 \mathrm{~m}^{\wedge} 2$, an outer diameter of $0.0191 \mathrm{~m}$ and a correction ratio $R / x$ of 1.083 was

tested in freon with a saturation temperature of $32.2 \mathrm{C}$.

\begin{tabular}{|c|c|c|c|c|c|c|c|c|c|}
\hline I & $h(I)$ & $\operatorname{Tav}(I)-T s$ & $\operatorname{Tav}(I)$ & $T 1(I)$ & $\mathrm{T} 2$ (I) & $T 3(I)$ & T4 (I) & Tpool & I) $q(I)$ \\
\hline & {$\left[\mathrm{kW} / \mathrm{m}^{\wedge} 2 \mathrm{~K}\right]$} & [c] & [C] & [C] & [C] & {$[\mathrm{C}]$} & [C] & [c] & {$\left[\mathrm{w} / \mathrm{m}^{\wedge} 2\right]$} \\
\hline 1 & -.008 & -.4 & $\begin{array}{l}31.8 \\
34.1\end{array}$ & $\begin{array}{l}31.9 \\
34.2\end{array}$ & 31.8 & 31.7 & 31.7 & 31.5 & $\begin{array}{l}3.625 E+0 \\
3.615 E+2\end{array}$ \\
\hline $\begin{array}{l}2 \\
3\end{array}$ & $\begin{array}{l}.190 \\
.197\end{array}$ & $\begin{array}{l}1.9 \\
3.1\end{array}$ & $\begin{array}{l}34.1 \\
35.3\end{array}$ & $\begin{array}{l}34.2 \\
35.4\end{array}$ & $\begin{array}{l}34.0 \\
35.1\end{array}$ & $\begin{array}{l}34.1 \\
35.3\end{array}$ & $\begin{array}{l}34.0 \\
35.3\end{array}$ & $\begin{array}{l}31.8 \\
31.8\end{array}$ & $\begin{array}{l}3.615 E+2 \\
6.201 E+2\end{array}$ \\
\hline 4 & .259 & 4.6 & 36.8 & 36.8 & 35.7 & 36.8 & 36.7 & $\begin{array}{l}31.0 \\
31.7\end{array}$ & $1.189 E+3$ \\
\hline 5 & .287 & 7.4 & 39.6 & 39.6 & 37.6 & 39.7 & 39.6 & 32.2 & $2.127 \mathrm{E}+3$ \\
\hline 6 & 2.123 & 1.7 & 33.9 & 33.9 & 33.7 & 33.9 & 33.8 & 31.9 & $3.555 E+3$ \\
\hline 7 & 2.971 & 2.0 & 34.2 & 34.2 & 33.9 & 34.3 & 34.2 & 32.1 & $6.011 E+3$ \\
\hline 8 & 4.004 & 2.5 & 34.7 & 34.5 & 34.2 & 34.8 & 34.7 & 32.2 & $9.836 E+3$ \\
\hline 9 & 5.620 & 3.0 & 35.2 & 35.0 & 34.5 & 35.4 & 35.2 & 32.2 & $1.683 \mathrm{E}+4$ \\
\hline 10 & 7.192 & 3.7 & 35.9 & 35.6 & 34.9 & 36.1 & 35.8 & 32.2 & $2.625 E+4$ \\
\hline 11 & 8.720 & 4.5 & 36.7 & 36.4 & 35.2 & 37.0 & 36.7 & 32.2 & $3.932 E+4$ \\
\hline 12 & 7.075 & 3.6 & 35.8 & 35.5 & 34.8 & 36.0 & 35.8 & 32.2 & $2.526 \mathrm{E}+4$ \\
\hline 13 & 5.203 & 2.9 & 35.1 & 34.9 & 34.5 & 35.3 & 35.1 & 32.3 & $1.502 E+4$ \\
\hline 14 & 3.694 & 2.4 & 34.6 & 34.5 & 34.2 & 34.7 & 34.7 & 32.2 & $9.043 E+3$ \\
\hline 15 & 2.639 & 2.1 & 34.3 & 34.2 & 34.0 & 34.4 & 34.3 & 32.2 & $5.559 \mathrm{E}+3$ \\
\hline 16 & 1.771 & 1.8 & 34.0 & 34.0 & 33.8 & 34.0 & 33.9 & 32.2 & $3.116 E+3$ \\
\hline 17 & 1.173 & 1.5 & 33.7 & 33.7 & 33.5 & 33.7 & 33.6 & 32.1 & $1.722 \mathrm{E}+3$ \\
\hline 18 & .756 & 1.2 & 33.4 & 33.5 & 33.4 & 33.4 & 33.4 & 32.1 & $9.428 \mathrm{E}+2$ \\
\hline 19 & .498 & 1.1 & 33.3 & 33.3 & 33.2 & 33.3 & 33.2 & 32.0 & $5.281 E+2$ \\
\hline 20 & .291 & .8 & 33.0 & 33.1 & 33.0 & 33.0 & 32.9 & 31.8 & $2.342 E+2$ \\
\hline
\end{tabular}

The file HF3 contains 20 recoṛds.

A Hi-Flux, $S$ tube with a surface area of $0.0060805 \mathrm{~m}^{\wedge} 2$, an outer diameter of $0.01905 \mathrm{~m}$ and a correction ratio $\mathrm{R} / \mathrm{r}$ of 1.816 was tested in freon with a saturation temperature of $32.2 \mathrm{C}$. 


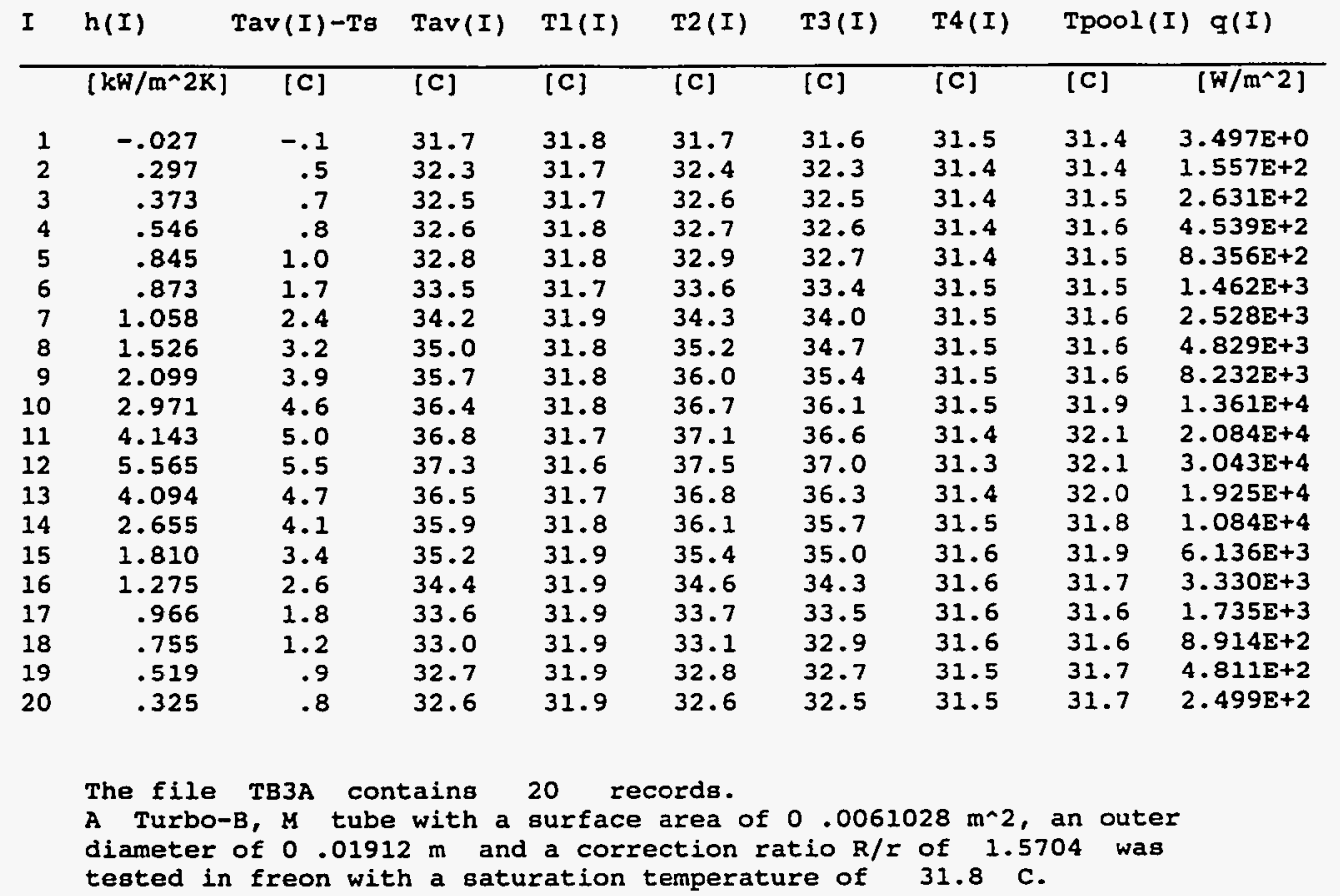




\section{Pool Boiling Data}

Data from the $25 \% \mathrm{R}-11 / 75 \% \mathrm{R}-113$ mixture 


\begin{tabular}{|c|c|c|c|c|c|c|c|c|c|}
\hline$I$ & $h(I)$ & $\operatorname{Tav}(I)-T g$ & Tav (I) & $\mathrm{T} 1$ (I) & T2 (I) & T3 (I) & $T 4(I)$ & Tpool (I) & $q(I)$ \\
\hline & {$\left[\mathrm{kW} / \mathrm{m}^{\wedge} 2 \mathrm{~K}\right]$} & [C] & [C] & [C] & [C] & [C] & {$[\mathrm{C}]$} & [C] & {$\left[W / m^{\wedge} 2\right]$} \\
\hline 1 & -.009 & -.3 & 37.7 & 37.8 & 37.7 & 37.7 & 37.5 & 37.4 & $3.119 \mathrm{E}+0$ \\
\hline 2 & .206 & 2.2 & 40.2 & 40.3 & 40.2 & 40.1 & 40.1 & 37.6 & $4.478 E+2$ \\
\hline 3 & .212 & 3.9 & 41.9 & 42.0 & 42.0 & 41.8 & 41.8 & 37.3 & $8.279 E+2$ \\
\hline 4 & .221 & 6.1 & 44.1 & 44.2 & 44.1 & 44.0 & 44.0 & 37.5 & $1.341 E+3$ \\
\hline 5 & .237 & 9.5 & 47.5 & 47.7 & 47.6 & 47.4 & 47.5 & 38.9 & $2.258 \mathrm{E}+3$ \\
\hline 6 & .323 & 11.7 & 49.7 & 50.1 & 49.8 & 49.3 & 49.7 & 39.6 & 3. $790 \mathrm{E}+3$ \\
\hline 7 & .434 & 14.1 & 52.1 & 52.5 & 52.1 & 51.5 & 52.1 & 39.5 & $6.101 E+3$ \\
\hline 8 & .604 & 16.8 & 54.8 & 55.4 & 54.8 & 54.0 & 55.0 & 37.7 & $1.014 \mathrm{E}+4$ \\
\hline 9 & 1.242 & 12.9 & 50.9 & 51.7 & 50.9 & 50.3 & 50.8 & 38.3 & 1. $607 \varepsilon+4$ \\
\hline 10 & 1.707 & 15.8 & 53.8 & 54.7 & 53.8 & 53.1 & 53.8 & 38.6 & $2.705 E+4$ \\
\hline 11 & 1.951 & 17.0 & 55.0 & 55.8 & 55.0 & 54.3 & 54.9 & 38.4 & $3.318 \mathrm{E}+4$ \\
\hline 12 & 1.419 & 14.2 & 52.2 & 52.9 & 52.1 & 51.6 & 52.1 & 38.5 & $2.012 \mathrm{E}+4$ \\
\hline 13 & 1.018 & 11.6 & 49.6 & 50.2 & 49.6 & 49.2 & 49.5 & 38.4 & $1.183 \mathrm{E}+4$ \\
\hline 14 & .672 & 9.6 & 47.6 & 47.9 & 47.5 & 47.3 & 47.5 & 38.5 & $6.434 E+3$ \\
\hline 15 & .439 & 7.6 & 45.6 & 45.9 & 45.6 & 45.4 & 45.5 & 38.2 & $3.331 \mathrm{E}+3$ \\
\hline 16 & .291 & 5.6 & 43.6 & 43.8 & 43.7 & 43.5 & 43.5 & 37.9 & $1.638 \mathrm{E}+3$ \\
\hline 17 & .214 & 4.1 & 42.1 & 42.2 & 42.2 & 42.0 & 42.0 & 37.9 & $8.770 E+2$ \\
\hline 18 & .173 & 2.1 & 40.1 & 40.3 & 40.2 & 40.1 & 40.0 & 37.5 & 3. $703 \mathrm{E}+2$ \\
\hline 19 & .174 & 1.4 & 39.4 & 39.5 & 39.4 & 39.3 & 39.2 & 37.4 & $2.365 E+2$ \\
\hline
\end{tabular}

The file PL4 contains 19 records.

A plain tube with a surface area of $0.0060964 \mathrm{~m} \wedge 2$, an outer diameter of $0.0191 \mathrm{~m}$ and a correction ratio $\mathrm{R} / \mathrm{r}$ of 1.083 was

tested in freon with a saturation temperature of $38 \mathrm{c}$.

$I \quad h(I) \quad T a v(I)-T g \quad T a v(I) T 1(I) \quad T 2(I) \quad T 3(I) \quad T 4$ (I) $T p o 01(I) q(I)$

\begin{tabular}{rrrlllllll}
\hline & {$\left[\mathrm{kW} / \mathrm{m}^{\wedge} \mathrm{K}\right]$} & {$[\mathrm{C}]$} & {$[\mathrm{C}]$} & {$[\mathrm{C}]$} & {$[\mathrm{C}]$} & {$[\mathrm{C}]$} & {$[\mathrm{C}]$} & {$[\mathrm{C}]$} & {$\left[\mathrm{W} / \mathrm{m}^{\wedge} 2\right]$} \\
1 & -.005 & -.6 & 37.4 & 37.5 & 37.4 & 37.3 & 37.2 & 37.1 & $3.488 \mathrm{E}+0$ \\
2 & .269 & 1.3 & 39.3 & 39.4 & 39.2 & 39.3 & 39.2 & 37.1 & $3.452 \mathrm{E}+2$ \\
3 & .230 & 2.8 & 40.8 & 40.9 & 40.6 & 40.8 & 40.7 & 37.1 & $6.393 \mathrm{E}+2$ \\
4 & .228 & 5.1 & 43.1 & 43.2 & 42.6 & 43.1 & 43.0 & 37.1 & $1.163 \mathrm{E}+3$ \\
5 & .234 & 8.6 & 46.6 & 46.6 & 45.8 & 46.6 & 46.5 & 37.9 & $2.009 \mathrm{E}+3$ \\
6 & 1.614 & 2.1 & 40.1 & 40.1 & 39.9 & 40.1 & 40.0 & 37.3 & $3.389 \mathrm{E}+3$ \\
7 & 2.373 & 2.4 & 40.4 & 40.4 & 40.1 & 40.5 & 40.3 & 37.4 & $5.708 \mathrm{E}+3$ \\
8 & 3.254 & 2.9 & 40.9 & 40.7 & 40.4 & 41.0 & 40.8 & 37.7 & $9.279 E+3$ \\
9 & 4.587 & 3.4 & 41.4 & 41.2 & 40.8 & 41.6 & 41.4 & 37.9 & $1.557 \mathrm{E}+4$ \\
10 & 6.270 & 4.1 & 42.1 & 42.0 & 41.2 & 42.4 & 42.1 & 38.0 & $2.597 \mathrm{E}+4$ \\
11 & 4.708 & 3.5 & 41.5 & 41.3 & 40.9 & 41.7 & 41.5 & 38.0 & $1.661 \mathrm{E}+4$ \\
12 & 3.303 & 3.0 & 41.0 & 40.9 & 40.6 & 41.2 & 41.0 & 38.0 & $1.003 \mathrm{E}+4$ \\
13 & 2.271 & 2.6 & 40.6 & 40.5 & 40.3 & 40.7 & 40.5 & 37.9 & $5.877 \mathrm{E}+3$ \\
14 & 1.588 & 2.2 & 40.2 & 40.2 & 39.9 & 40.3 & 40.1 & 37.9 & $3.486 \mathrm{E}+3$ \\
15 & 1.071 & 1.9 & 39.9 & 39.9 & 39.7 & 39.9 & 39.8 & 37.7 & $2.017 \mathrm{E}+3$ \\
16 & .749 & 1.6 & 39.6 & 39.7 & 39.5 & 39.6 & 39.6 & 37.7 & $1.232 \mathrm{E}+3$ \\
17 & .520 & 1.4 & 39.4 & 39.5 & 39.4 & 39.4 & 39.3 & 37.6 & $7.484 \mathrm{E}+2$ \\
18 & .331 & 1.1 & 39.1 & 39.3 & 39.1 & 39.1 & 39.0 & 37.5 & $3.788 \mathrm{E}+2$ \\
19 & .330 & .7 & 38.7 & 38.9 & 38.7 & 38.7 & 38.6 & 37.3 & $2.400 \mathrm{E}+2$
\end{tabular}

The file HF4 contains 19 records.

A Hi-Flux, $S$ tube with a surface area of $0.0060805 \mathrm{~m}^{n} 2$, an outer diameter of $0.01905 \mathrm{~m}$ and a correction ratio $\mathrm{R} / \mathrm{r}$ of 1.816 was tested in freon with a saturation temperature of $38 \mathrm{C}$. 


\begin{tabular}{|c|c|c|c|c|c|c|c|c|c|}
\hline I & $h(I)$ & $\operatorname{Tav}(I)-T s$ & $\operatorname{Tav}(I)$ & $T I(I)$ & $T 2(I)$ & $T 3(I)$ & T4 (I) & Tpool (I & C) $q(I)$ \\
\hline & {$\left[\mathrm{kW} / \mathrm{m}^{\wedge} 2 \mathrm{~K}\right]$} & [C] & [C] & [C] & [C] & [C] & [c] & [c] & {$\left[\boldsymbol{W} / \mathrm{m}^{\wedge} 2\right]$} \\
\hline 1 & -.006 & -.2 & 37.8 & 37.8 & 37.8 & 37.7 & 37.7 & 37.5 & $1.410 \mathrm{E}+0$ \\
\hline 2 & .204 & 1.3 & 39.3 & 39.5 & 39.3 & 39.2 & 39.3 & 37.5 & $2.698 \mathrm{E}+2$ \\
\hline 3 & .402 & 1.8 & 39.8 & 40.0 & 39.8 & 39.7 & 39.8 & 37.5 & $7.416 \mathrm{E}+2$ \\
\hline 4 & .514 & 2.6 & 40.6 & 40.8 & 40.5 & 40.4 & 40.6 & 37.6 & $1.325 E+3$ \\
\hline 5 & .589 & 4.0 & 42.0 & 42.2 & 41.8 & 41.7 & 42.1 & 38.0 & $2.327 E+3$ \\
\hline 6 & .783 & 4.8 & 42.8 & 43.1 & 42.6 & 42.4 & 43.0 & 38.2 & $3.758 \mathrm{E}+3$ \\
\hline 7 & 1.298 & 5.9 & 43.9 & 44.3 & 43.5 & 43.3 & 44.3 & 38.5 & $7.611 \mathrm{E}+3$ \\
\hline 8 & 1.751 & 6.0 & 44.0 & 44.4 & 43.8 & 43.6 & 44.5 & 38.6 & $1.058 E+4$ \\
\hline 9 & 3.961 & 6.3 & 44.3 & 44.8 & 43.8 & 43.5 & 44.9 & 38.7 & $2.476 E+4$ \\
\hline 10 & 2.231 & 5.8 & 43.8 & 44.1 & 43.6 & 43.4 & 44.2 & 38.8 & $1.302 \mathrm{E}+4$ \\
\hline 11 & 1.421 & 5.2 & 43.2 & 43.5 & 43.0 & 42.9 & 43.4 & 38.6 & $7.367 E+3$ \\
\hline 12 & .884 & 4.6 & 42.6 & 43.0 & 42.4 & 42.3 & 42.9 & 38.4 & $4.110 E+3$ \\
\hline 13 & .609 & 3.9 & 41.9 & 42.2 & 41.7 & 41.6 & 42.0 & 38.4 & $2.366 \mathrm{E}+3$ \\
\hline 14 & .454 & 2.9 & 40.9 & 41.1 & 40.8 & 40.8 & 41.0 & 38.2 & $1.327 \mathrm{E}+3$ \\
\hline 15 & .360 & 2.1 & 40.1 & 40.3 & 40.0 & 39.9 & 40.0 & 38.1 & $7.449 E+2$ \\
\hline 16 & .204 & 1.6 & 39.6 & 39.7 & 39.6 & 39.5 & 39.6 & 37.9 & $3.280 \mathrm{E}+2$ \\
\hline
\end{tabular}

The file TB42 contains 16 records.

$A$ Turbo-B, $M$ tube with a surface area of $0.0061028 \mathrm{~m}^{\wedge} 2$, an outer diameter of $0.01912 \mathrm{~m}$ and a correction ratio $\mathrm{R} / \mathrm{r}$ of 1.5704 was tested in freon with a saturation temperature of $38 \mathrm{c}$. 


\section{Bundle Boiling Data}

Smooth tube data in $\mathrm{R}-113$ for bundle with $\mathrm{p} / \mathrm{d}=1.17$ 


\begin{tabular}{|c|c|c|c|c|c|c|c|c|c|c|c|c|c|c|c|c|c|c|c|c|}
\hline \multicolumn{2}{|c|}{$\begin{array}{l}\text { RUN NUMBER: } \\
\text { P/d }=1.17 \\
\text { PIn }=209.2 \\
\text { Xin }=-.00 \\
\text { SURFACE TYP }\end{array}$} & \multicolumn{2}{|c|}{$\begin{array}{l}173 \\
2 \mathrm{kPa} \\
\mathrm{PE}: \text { SMOOTH }\end{array}$} & \multicolumn{3}{|c|}{$\begin{array}{r}\text { WORKING FLUID: R-113 } \\
G=51.33 \mathrm{~kg} / \mathrm{s}^{\star} \mathrm{m}^{\wedge} 2 \\
\text { ELTA } \mathrm{P} \text { totai }=4.48 \mathrm{kPa} \\
\text { Xout }=0.19\end{array}$} & \multicolumn{4}{|c|}{$\begin{array}{l}\text { RUN NUMBER: } 170 \\
\text { p } / \mathrm{d}=1.17 \\
\text { Pin }=210.7 \mathrm{kPa} \\
\text { Xin }=-.01 \\
\text { SURFACE TYPE: SMOOTH }\end{array}$} & \multicolumn{3}{|c|}{$\begin{array}{r}\text { WORKING FLUID: R-113 } \\
G=51.55 \mathrm{~kg} / \mathrm{g}^{\star} \mathrm{m}^{\wedge} 2 \\
\text { LTA P total }=4.48 \mathrm{kPa} \\
\text { Xout }=0.77\end{array}$} & \multicolumn{4}{|c|}{$\begin{array}{l}\text { RUN NUMBER: } 167 \\
\text { P/d }=1.17 \\
\text { Pin }=211.1 \mathrm{kPa} \\
\text { Xin }=-.01 \\
\text { SURFACE TYPE: SMOOTH }\end{array}$} & \multicolumn{3}{|c|}{$\begin{array}{r}\text { WORKING FLUID: } \mathrm{R}-113 \\
G=104.27 \mathrm{~kg} / \mathrm{s}^{\star} \mathrm{m}^{4} \\
\text { LTA } P \text { total }=4.48 \mathrm{kPa} \\
\text { Xout }=0.57\end{array}$} \\
\hline Row & $\begin{array}{c}\mathrm{P} \\
\mathrm{kPa} \mid\end{array}$ & $\operatorname{lin}$ & & $q^{\prime \prime}$ & Tw & $\stackrel{h}{/ m^{\wedge} 2 c l}$ & RoW & & & & & & $\stackrel{h}{h / m^{\wedge} 2}$ & $\begin{array}{c}\text { Row } \\
\neq\end{array}$ & $\underset{\mathrm{kPa}}{\mathrm{P}}$ & & & $\underset{\left[\mathrm{W} / \mathrm{m}^{\prime \prime 2}\right]}{\mathrm{g}^{\prime \prime}}$ & & $\mathrm{h}$ \\
\hline 1 & 208. & & & $\left.N / m^{n} 2\right]$ & $\begin{array}{l}{[\mathrm{C}]} \\
74.6\end{array}$ & $\left.{ }_{859}^{m^{n} 2}\right]$ & $\begin{array}{l}* \\
1\end{array}$ & & & & & & & 1 & & & & & & \\
\hline 3 & & & & & & & 3 & & & & & & & 3 & & & & & & \\
\hline 5 & & & & & & & 5 & & & & & & & 5 & & & & & & \\
\hline 7 & & & & & & & 7 & & & & & & & 7 & & & & & & \\
\hline 9 & & & & & & & 9 & & & & & & & & & & & & & \\
\hline & & & & & & & & & & & & & & & & & & & & \\
\hline & & & & & & & & & & & & & & & & & & & & \\
\hline & & & 69.5 & 5131 & 73.0 & 1399 & 15 & 206.2 & & & 20807 & & 1804 & 15 & & & & 736 & 83.4 & 2337 \\
\hline
\end{tabular}

\begin{tabular}{|c|c|c|c|c|c|c|c|c|c|c|c|c|c|c|c|c|c|c|c|c|}
\hline \multicolumn{4}{|c|}{$\begin{array}{l}\text { RUN NUMBER: } 163 \\
\text { P/d }=1.17 \\
\text { Pin }=204.1 \mathrm{kPa} \\
\text { Xin }=-.00 \\
\text { SURFACE TYPE: SMOOTH }\end{array}$} & \multicolumn{3}{|c|}{$\begin{array}{r}\text { WORKING FLUID: } \mathrm{R}-113 \\
G=52.8 \mathrm{~kg} / \mathrm{g}^{\pi^{*} \mathrm{~m}^{\wedge} 2} \\
\text { TA } \mathrm{P} \text { total } 4.48 \mathrm{kPa} \\
\text { Xout }=0.39\end{array}$} & \multicolumn{4}{|c|}{$\begin{array}{l}\text { RUN NUMBER: } 169 \\
\text { P/d }=1.17 \\
\text { Pin }=207.3 \mathrm{kPa} \\
\text { Xin }=0.01 \\
\text { SURFACE TYPE: SMOOTH }\end{array}$} & \multicolumn{3}{|c|}{$\begin{array}{r}\text { WORKING FLUID: } \mathrm{R}-113 \\
\text { G }=101.24 \mathrm{~kg} / \mathrm{s}^{\star} \mathrm{m}^{\wedge} 2 \\
\text { TA } P \text { total }=4.48 \mathrm{kPa} \\
\text { Xout }=0.21\end{array}$} & \multicolumn{4}{|c|}{$\begin{array}{l}\text { RUN NUMBER: } 166 \\
\text { P/d }=1.17 \\
\text { Pin }=208.6 \mathrm{kPa} \\
\text { Xin }=-.01 \\
\text { SURFACE TYPE: SMOOTH }\end{array}$} & \multicolumn{3}{|c|}{$\begin{array}{r}\text { WORKING FLUID: } \mathrm{R}-113 \\
\mathrm{G}=105.63 \mathrm{~kg} / \mathrm{s} \mathrm{m}^{\wedge} \\
\text { SA total }=4.48 \mathrm{kPa} \\
\text { Xout }=0.73\end{array}$} \\
\hline ROW & $\begin{array}{c}\mathrm{P} \\
{[\mathrm{kPa}]}\end{array}$ & $\begin{array}{l}x \text { in } \\
{[-1}\end{array}$ & $\begin{array}{l}\text { Tf } \\
\text { (C) }\end{array}$ & $\stackrel{q^{\prime \prime}}{w / m^{\wedge} 21}$ & $\begin{array}{l}T w \\
{[c]}\end{array}$ & $\stackrel{h}{h}$ & $\begin{array}{c}\text { ROW } \\
*\end{array}$ & & & & $\underset{\left.w / m^{\wedge} 2\right]}{q \cdot \cdot}$ & & $\begin{array}{l}h \\
m \wedge 2 \\
m\end{array}$ & $\begin{array}{c}\text { ROW } \\
*\end{array}$ & $\begin{array}{c}P \\
{[k P a]}\end{array}$ & & & $\begin{array}{c}q^{\prime \prime} \\
{[\mathrm{W} / \mathrm{m} \wedge 2]}\end{array}$ & & h \\
\hline 1 & & & & & & & 1 & & & & & & & 1 & & & & & & \\
\hline 3 & & & & & & & 3 & & & & & & & 3 & & & & & & \\
\hline 5 & & & & & & & 5 & & & & & & & 5 & & & & & & \\
\hline 7 & & & & & & & 7 & & & & & & & 7 & & & & & & \\
\hline 9 & & & & & & & 9 & & & & & & & 9 & & & & & & \\
\hline & & & & & & & & & & & & & & & & & & & & \\
\hline & & & & & & & & & & & & & & & & & & & & \\
\hline 5 & 199.6 & & 69.3 & 10527 & 75.9 & 1589 & 15 & 202.8 & & 69.2 & 10452 & 76.0 & 1341 & 15 & 204.1 & & 69.9 & 40564 & 85.5 & 2800 \\
\hline
\end{tabular}

\begin{tabular}{|c|c|c|c|c|c|c|c|c|c|c|c|c|c|c|c|c|c|c|c|c|}
\hline \multicolumn{2}{|c|}{$\begin{array}{l}\text { RUN NUMBER: } \\
\text { p/d }=1.17 \\
\text { Pin }=207.7 \\
\text { Xin }=-.00 \\
\text { SURFACE TYPE }\end{array}$} & \multicolumn{2}{|c|}{$\begin{array}{l}171 \\
\mathrm{kPa} \\
E: \text { SMOOTH }\end{array}$} & \multicolumn{3}{|c|}{$\begin{array}{r}\text { WORKING FLUID: } \mathrm{R}-113 \\
\mathrm{G}=51.97 \mathrm{~kg} / \mathrm{s}^{\star \mathrm{m}^{\wedge} 2} \\
\text { ELTA P total }=4.48 \mathrm{kPa} \\
\text { Xout }=0.57\end{array}$} & \multicolumn{4}{|c|}{$\begin{array}{l}\text { RUN NUMBER: } 168 \\
\text { P/d }=1.17 \\
\text { Pin }=207.9 \mathrm{kPa} \\
\text { Xin }=0.00 \\
\text { SURFACE TYPE: SMOOTH }\end{array}$} & \multicolumn{3}{|c|}{$\begin{array}{r}\text { WORKING FLUID: } \mathrm{R}-113 \\
\mathrm{G}=100.61 \mathrm{~kg} / \mathrm{g}^{\star} \mathrm{m}^{\wedge} 2 \\
\text { ELTA P total }=4.48 \mathrm{kPa} \\
\text { Xout }=0.40\end{array}$} & \multicolumn{4}{|c|}{$\begin{array}{l}\text { RUN NUMBER: } 195 \\
\text { p/d }=1.17 \\
\text { Pin }=214.5 \mathrm{kPa} \\
\text { Xin }=-.01 \\
\text { SUREACE TYPE: SMOOTH }\end{array}$} & \multicolumn{3}{|c|}{$\begin{array}{r}\text { WORKING FLUID: R-113 } \\
G=227.98 \mathrm{~kg} / \mathrm{s}^{\star} \mathrm{m}^{\wedge} \\
\text { CTA total }=5.12 \mathrm{kPa} \\
\text { Xout }=0.03\end{array}$} \\
\hline $\begin{array}{c}\text { ROW } \\
\neq\end{array}$ & $\stackrel{P}{P}$ & $x$ in & $\begin{array}{l}\text { Tf } \\
\text { lc] }\end{array}$ & $\underset{w / m^{\wedge} 21}{q^{\prime \prime}}$ & $T_{W}$ & $\frac{h}{\left(W / m^{\wedge} 2\right.}$ & ROW & $\begin{array}{c}p \\
p_{a}\end{array}$ & $x$ in & Tf & $\stackrel{q \cdot}{q}$ & $T_{w}$ & $\stackrel{h}{\mathrm{~h}}$ & Row & $\stackrel{p}{P}$ & & & $q^{\prime \prime \prime}$ & & \\
\hline$i_{1}^{*}$ & $\begin{array}{l}\text { [kPa] } \\
207.4\end{array}$ & $\begin{array}{l}{[-]} \\
-.00\end{array}$ & 69.1 & 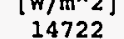 & 80.7 & 1277 & F & & $\begin{array}{l}{[-]} \\
0.00\end{array}$ & $\begin{array}{l}{[\mathrm{C}]} \\
69.3\end{array}$ & {$\left[\begin{array}{l}{\left[\mathrm{W} / \mathrm{m}^{2} 2\right]} \\
19803\end{array}\right.$} & 81.3 & {$\left[\mathrm{~W} / \mathrm{m}^{\wedge} \mathbf{2}\right.$ C] } & i & 214 & $\begin{array}{l}{[-]} \\
-0,01\end{array}$ & $\begin{array}{l}{[c]} \\
69.2\end{array}$ & $\begin{array}{c}\left.W / m^{\wedge} 2\right] \\
4939\end{array}$ & $\begin{array}{l}\text { [c] } \\
76.5\end{array}$ & $\begin{array}{c}m^{\wedge} 2 \\
677\end{array}$ \\
\hline 3 & 206.8 & 0.07 & 70.1 & 14842 & 79.9 & 1524 & 3 & 207. & 0.05 & 69.9 & 20 & 80 & 1819 & 3 & 213.4 & & 70.0 & 4989 & 76.1 & 813 \\
\hline 5 & 206.2 & 0.1 & 70. & 152 & & 156 & 5 & & & & & & & 5 & & & & 51 & 76 & 926 \\
\hline 7 & & & 70. & 152 & 79.5 & 1597 & 7 & 205.8 & 0.3 & 69.8 & 20542 & 80.7 & 1875 & 7 & & & & & & \\
\hline 9 & 205.0 & 0.30 & 69. & 14712 & 79 & 162 & 9 & & & & & & & 9 & 211.4 & 0. & 71.3 & 4971 & 75.8 & 1099 \\
\hline 11 & 204.4 & 0.3 & 69. & 149 & 79 & 162 & 11 & & 0. & & & & & 11 & & & & 50 & .9 & 1067 \\
\hline 13 & & & 69.8 & 15059 & 79. & 1567 & 13 & 204 & 0. & 69 & 203 & 80.4 & 1889 & 13 & & & & & & 1068 \\
\hline 15 & 203.2 & 0.53 & 69.7 & 15330 & 78.6 & 1618 & 15 & 203.5 & 0.37 & 69.6 & 20629 & 79.9 & 2018 & 15 & 209.4 & 0.03 & 71.0 & 5144 & 75.6 & 1109 \\
\hline
\end{tabular}




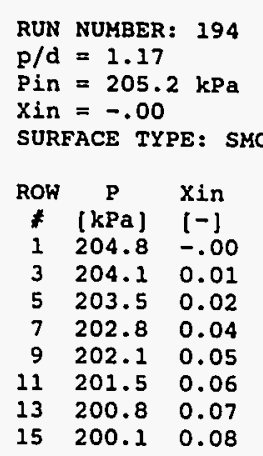

\begin{tabular}{|c|c|c|}
\hline \multicolumn{3}{|c|}{$\begin{array}{r}\text { WORKING FLUID: R-113 } \\
G=230.86 \mathrm{~kg} / \mathrm{s}^{\star} \mathrm{m}^{\wedge} 2 \\
\text { IA P total }=5.11 \mathrm{kPa} \\
\text { Xout }=0.09\end{array}$} \\
\hline$\frac{q^{\prime \prime}}{\left(w^{\prime} / m^{\wedge} 2\right]}$ & Tw & h \\
\hline 10070 & 77.8 & 1105 \\
\hline 10150 & 77.4 & 1314 \\
\hline 10511 & 77.5 & 1395 \\
\hline 10468 & 77.2 & 1417 \\
\hline 10179 & & \\
\hline 1015 & 76.3 & 1518 \\
\hline 10315 & 75.9 & 1609 \\
\hline 10492 & 75.9 & 1613 \\
\hline
\end{tabular}

RUN NUMBER: 138

$\mathrm{p} / \mathrm{d}=1.17$

$\mathrm{Pin}=205 \mathrm{kPa}$
$\mathrm{sur}=-.01$
WORKTMG FIUID: R-113 RUN NUMBER: 140

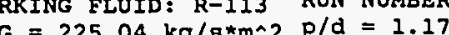
$\begin{aligned} G & =225.04 \mathrm{~kg} / \mathrm{s}^{\star \mathrm{m}^{\wedge} 2} \mathrm{P} / \mathrm{d}=1.17 \\ \mathrm{P} i \mathrm{n} & =208.3 \mathrm{kPa}\end{aligned}$ Xout $=0.34$ XIN $=-.01$
SURFACE TYPE: SMOOTH
WORKING FLUID: R-113 $G=225.61 \mathrm{~kg} / \mathrm{s}^{*} \mathrm{~m}^{\wedge} 2$ DELTA $\mathrm{P}$ total $=4.48 \mathrm{kPa}$ Xout $=0.59$

\begin{tabular}{|c|c|c|c|}
\hline & $q^{\prime \prime}$ & & $\frac{h}{h}$ \\
\hline & {$\left[\right.$ (W/ $\left./ \mathrm{m}^{\wedge} 2\right]$} & & \\
\hline 68.2 & $39857^{\circ}$ & 82.9 & 2723 \\
\hline 9.5 & 40193 & 83.2 & 2935 \\
\hline 9.5 & 40974 & 83.4 & 2944 \\
\hline .4 & 41765 & 83.7 & 2915 \\
\hline . & 40824 & 83.0 & 2979 \\
\hline 59 & 40494 & 83.3 & 2879 \\
\hline .1 & 40750 & 82.2 & 3125 \\
\hline
\end{tabular}

$\begin{array}{lll} & & \\ 1 & {[\mathrm{kPa}]} & {[-]} \\ 1 & 208.0 & -.01\end{array}$

3 207.4 0.07

$\begin{array}{lll}5 & 206.8 & 0.15\end{array}$

$\begin{array}{lll}7 & 206.2 & 0.23\end{array}$

$\begin{array}{rrr}9 & 205.6 & 0.31 \\ 11 & 205.0 & 0.40\end{array}$

$\begin{array}{lll}13 & 204.4 & 0.47 \\ 15 & 203.8 & 0.55\end{array}$

\begin{tabular}{|c|c|c|c|}
\hline Tf & $\underset{[w / m \wedge 2]}{q^{\prime \prime}}$ & $\begin{array}{l}T w \\
{[c]}\end{array}$ & $\stackrel{h}{/ m^{\wedge} 2} \quad c \mid$ \\
\hline 68.5 & 68310 & 85.4 & 4046 \\
\hline 70.3 & 68122 & 86.0 & 4327 \\
\hline 70.2 & 69441 & 85.9 & 4412 \\
\hline 70.1 & 69886 & 86.5 & 4265 \\
\hline 70.0 & 68463 & 85.8 & 4347 \\
\hline 70.0 & 68332 & 86.2 & 4213 \\
\hline 59.9 & 69459 & 85.3 & 4515 \\
\hline & & & \\
\hline
\end{tabular}

RUN NUMBER: 149

$\mathrm{p} / \mathrm{d}=1.17$

$\mathrm{Pin}=207.1 \mathrm{kPa}$

XIN $=-.01$
SURFACE TYPE: SMOOTH
WORKING FLUID: R-113 RUN NUMBER: 137

$G=221.72 \mathrm{~kg} / \mathrm{g}^{\star} \mathrm{m}^{\wedge} \mathrm{P} / \mathrm{d}=1.17$

DELTA $P$ total $=4.48 \mathrm{kPa} \quad$ Pin $=201.2 \mathrm{kPa}$ xout $=0.17 \quad x_{\text {in }}=0.00$ SURFACE TYPE: SMOOTH
WORKING FLUID: R-113 RUN NUMBER: 193 $G=221.45 \mathrm{~kg} / \mathrm{s}^{\star} \mathrm{m}^{\wedge} 2 \mathrm{p} / \mathrm{d}=1.17$

DELTA $P$ tota Xout $=0.45 \quad \mathrm{Xin}=0.00$

SURFACE TYPE: SMOOTH
WORKING FLUID: $\mathrm{R}-113$
$G=349.96 \mathrm{~kg} / \mathrm{s}^{\star} \mathrm{m} / 2$ $\begin{aligned} \text { DELTA P total } & =5.12 \mathrm{kPa} \\ \text { Xout } & =0.06\end{aligned}$

$\begin{array}{rcc}\text { ROW } & \text { P } & \text { Xin } \\ * & {[\mathrm{kPa}]} & {[-]} \\ 1 & 200.9 & 0.00 \\ 3 & 200.3 & 0.06 \\ 5 & 199.7 & 0.12 \\ 7 & 199.1 & 0.18 \\ 9 & 198.5 & 0.24 \\ 11 & 197.9 & 0.30 \\ 13 & 197.3 & 0.36 \\ 15 & 196.7 & 0.42\end{array}$

$\begin{array}{lc}\text { Tf } & q^{\prime \prime} \\ \text { [C] } & \left(w^{\prime} / m^{\wedge}\right) \\ 68.3 & 49301 \\ 68.7 & 49679 \\ 68.7 & 50532 \\ 68.7 & 50522 \\ 68.6 & 49369 \\ 68.6 & 50008 \\ 68.5 & 50366 \\ 68.5 & 51248\end{array}$

$\begin{array}{lc}T w & h \\ (C) & {\left[W / m^{\wedge} 2 C\right]} \\ 82.8 & 3399 \\ 83.1 & 3457 \\ 83.2 & 3479 \\ 83.5 & 3412 \\ 82.8 & 3474 \\ 83.1 & 3431 \\ 82.0 & 3743 \\ 83.5 & 3408\end{array}$

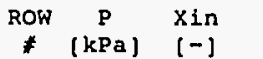

$\begin{array}{lll}* & {[\mathrm{kPa}]} & {[-]} \\ 1 & 204.2 & 0.00 \\ 3 & 203.5 & 0.01\end{array}$

$\begin{array}{lll}3 & 203.5 & 0.01 \\ 5 & 202.8 & 0.02\end{array}$

$\begin{array}{lll}5 & 202.8 & 0.02 \\ 7 & 202.1 & 0.03\end{array}$

$\begin{array}{rrr}9 & 201.5 & 0.04 \\ 11 & 200.8 & 0.04\end{array}$

$\begin{array}{lll}11 & 200.8 & 0.04 \\ 13 & 200.1 & 0.05\end{array}$

$\begin{array}{lclc}\text { Tf } & q^{\prime} & T w & h \\ {[C]} & \left(w^{\prime} / m^{\wedge}\right) & {[C]} & {\left[w / m^{\wedge} 2\right.} \\ 69.0 & 10055 & 77.2 & 1223\end{array}$

$\begin{array}{llll}69.0 & 10055 & 77.2 & 1223 \\ 69.6 & 10138 & 77.0 & 1368\end{array}$

$\begin{array}{llll}69.7 & 10506 & 77.2 & 1368\end{array}$

$\begin{array}{llll}69.6 & 10464 & 76.9 & 1434\end{array}$

$\begin{array}{llll}69.5 & 10173 & 76.1 & 1549\end{array}$

$\begin{array}{lllllll}1 & 203.8 & 0.11 & 69.3 & 19815 & 79.6 & 1921\end{array}$

$\begin{array}{lllllll}15 & 202.6 & 0.13 & 69.2 & 20177 & 79.3 & 1986 \\ & & & & & & \end{array}$

$\begin{array}{lll}15 & 199.5 & 0.06\end{array}$

$\begin{array}{llll}6.3 & 10275 & 75.3 & 1722\end{array}$

RUN NUMBER: 165 $\mathrm{p} / \mathrm{d}=1.17$

$P$ in $=208 \mathrm{kPa}$
$X_{\text {in }}=-.01$ Xin $=-.01$
WORKING FLUID: R-113 RUN NUMBER: 139 $\mathbf{G}=224.56 \mathrm{~kg} / \mathrm{s}^{\star} \mathrm{m}^{\wedge} \quad \mathrm{p} / \mathrm{d}=1.17$ $\begin{array}{ll}\mathbf{G}=224.56 \mathrm{~kg} / \mathrm{B}^{\star} \mathrm{m}^{\wedge} 2 & \mathrm{p} / \mathrm{d}=1.17 \\ \text { DELTA } \mathrm{P} \text { total }=4.48 \mathrm{kPa} & \mathrm{P} \text { in }=203.2 \mathrm{kPa}\end{array}$

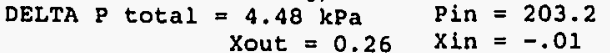
XIn $=-.01$
SURFACE TYPE: SMOOTH
WORKING FLUID: R-113 RUN NUMBER: 148 $G=221.94 \mathrm{~kg} / \mathrm{s}^{*} \mathrm{~m}^{\wedge} 2 \mathrm{p} / \mathrm{d}=1.17$

$\begin{array}{rl}G=221.94 \mathrm{~kg} / \mathrm{s}^{\star} \mathrm{m}^{\wedge} 2 & \mathrm{P} / \mathrm{d}=1.17 \\ \text { DELTA } & \mathrm{P} \text { total }=4.48 \mathrm{kPa} \quad \mathrm{Pin}=211.6 \mathrm{kPa} \\ & \end{array}$ xout $=0.55$ SURFACE TYPE: SMOOTH
WORKING FLUID: R-113 $G=348.22 \mathrm{~kg} / \mathrm{s}^{*} \mathrm{~m}^{\wedge}-2$ DELTA $\mathrm{P}$ total $=4.51 \mathrm{kPa}$ xout $=0.10$

\begin{tabular}{|c|c|c|c|c|c|c|c|c|c|c|c|c|c|c|c|c|c|c|c|c|}
\hline low & $\mathbf{P}$ & $x$ in & TE & $q^{\prime \prime}$ & Tw & $\mathrm{h}$ & ROW & ${ }^{P}$ & $x$ in & $\mathrm{Tf}$ & $q^{\prime \prime}$ & $T w$ & $\mathrm{~h}$ & ROW & $\stackrel{\text { P }}{\text { P }}$ & $\mathrm{Xin}$ & Tf & (1)/m 2 & Tw & h \\
\hline * & [ $\mathrm{KPa}]$ & $(-1)$ & [C] & {$\left[W / m^{\wedge} 2\right]$} & [c] & $\left(W / m^{\wedge} 2 \quad C\right]$ & $\#$ & $\{\mathrm{kPa}\}$ & {$[-]$} & [C] & {$\left[W / m^{\wedge} 2\right]$} & (c) & $\left(W / m^{\wedge} 2 \quad C\right)$ & $\neq$ & [kPa] & & [C] & {$\left[W / m^{n} 2\right]$} & & \\
\hline$i$ & 207.6 & -.01 & 68.8 & 29861 & 82.4 & 2191 & 1 & 202.9 & -.01 & 68.4 & 61815 & 84.4 & 3860 & 1 & 211.2 & -.02 & 68.6 & 20252 & 80.0 & 1782 \\
\hline 3 & 207.0 & 0.03 & 69.8 & 29948 & 82.3 & 2399 & 3 & 202.3 & 0.07 & 69.3 & 61857 & 84.9 & 3969 & 3 & 6 & -.00 & 69.3 & & & 1927 \\
\hline 5 & 206.4 & 0.06 & 69.7 & 30569 & & 2402 & 5 & 201.7 & 0.1 & & & & & 5 & & .02 & 69.6 & & & 2022 \\
\hline 7 & 205.9 & & & 306 & 82. & 2372 & 7 & 201.1 & & & & & & 7 & 209.4 & & & 20828 & & 2051 \\
\hline & 205.3 & 0.1 & 69.6 & 29943 & 81 & 2453 & 9 & 200.5 & 0.30 & & 61533 & 84. & 3974 & 9 & 208 & .05 & .6 & & & 2175 \\
\hline .1 & 204.7 & 0 & 9.6 & & & 2359 & 11 & & & & & & & 11 & 208.3 & & & & & 2150 \\
\hline & 204.1 & 0.20 & 69.5 & 30233 & 81.4 & 2456 & 13 & 199.3 & 0.44 & 69.0 & 62501 & 83.9 & 4177 & 13 & 207.7 & 0.08 & 59.5 & 20730 & 78.6 & 2278 \\
\hline
\end{tabular}




\begin{tabular}{|c|c|c|c|c|c|c|c|c|c|c|c|c|c|c|c|c|c|c|c|c|}
\hline \multicolumn{4}{|c|}{$\begin{array}{l}\text { RUN NUMBER: } 147 \\
\text { P/d }=1.17 \\
\text { Pin }=206.7 \mathrm{kPa} \\
\text { Xin }=-.01 \\
\text { SURFACE TYPE: SMOOTH }\end{array}$} & \multicolumn{3}{|c|}{$\begin{array}{l}\text { WORKING FLUID: } \mathrm{R}-113 \\
G=348.75 \mathrm{~kg} / \mathrm{s}^{\star} \mathrm{m}^{\wedge} 2 \\
\text { ITA total }=4.49 \mathrm{kPa} \\
\text { Xout }=0.16\end{array}$} & \multicolumn{4}{|c|}{$\begin{array}{l}\text { RUN NUMBER: } 144 \\
\text { P/d }=1.17 \\
\text { PIn }=207.7 \mathrm{kPa} \\
\text { XIn }=-.01 \\
\text { SURFACE TYPE: SMOOTH }\end{array}$} & \multicolumn{3}{|c|}{$\begin{array}{r}\text { WORKING FLUID: R-113 } \\
\text { G }=346.45 \mathrm{~kg} / \mathrm{s}^{\star} \mathrm{m}^{\wedge} 2 \\
\text { PTA P total }=4.48 \mathrm{kPa} \\
\text { Xout }=0.34\end{array}$} & \multicolumn{4}{|c|}{$\begin{array}{l}\text { RUN NUMBER: } 192 \\
\text { P/d }=1.17 \\
\text { Pin }=203.7 \mathrm{kPa} \\
\text { Xin }=0.00 \\
\text { SUREACE TYPE: SMOOTH }\end{array}$} & \multicolumn{3}{|c|}{$\begin{array}{r}\text { WORKING FLUID: R-113 } \\
\text { G }=499.24 \mathrm{~kg} / \mathrm{g}^{\star} \mathrm{m}^{\wedge} 2 \\
\text { ELTA P totai }=5.15 \mathrm{kPa} \\
\text { Xout }=0.04\end{array}$} \\
\hline ROW & $\begin{array}{c}\mathrm{P} \\
{[\mathrm{kPa}]}\end{array}$ & $x \operatorname{lin}$ & $\begin{array}{l}\text { Tf } \\
{[\mathrm{C}]}\end{array}$ & $\underset{\left[w / m^{\wedge} 2\right]}{q \cdots}$ & $\begin{array}{l}\text { Tw } \\
{[C]}\end{array}$ & & $\stackrel{\text { ROW }}{*}$ & & & & & Tw & & $\begin{array}{c}\text { ROW } \\
*\end{array}$ & & & & & & \\
\hline 1 & & & 68.6 & & 81.8 & & 1 & & & & & & & 1 & & & & & & \\
\hline 3 & & 0 & 69 & & & 24 & 3 & & 0.1 & & & & & 3 & & & & & & \\
\hline 5 & & & & & & & 5 & & & & & & & 5 & & & & & & \\
\hline 7 & & & & & & & 7 & & & & & & & 7 & & & & & & \\
\hline 9 & & 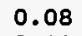 & & & & & 9 & & & & & & & 9 & & & & & & \\
\hline & & & & & & & & & & & & & & & & & & & & \\
\hline & & & & & & & & & & & & & & & & & & & & \\
\hline 15 & 202.2 & .15 & 69. & 31256 & 80.2 & 2788 & 15 & 203.3 & 0.31 & 69.6 & 61905 & 86.0 & 3775 & 15 & 198.6 & & 69.1 & 10431 & 74.7 & 1855 \\
\hline
\end{tabular}

\begin{tabular}{|c|c|c|c|c|c|c|c|c|c|c|c|c|c|c|c|c|c|c|c|c|}
\hline \multicolumn{4}{|c|}{$\begin{array}{l}\text { RUN NUMBER: } 146 \\
\text { P/d }=1.17 \\
\text { Pin }=204 \mathrm{kPa} \\
\text { Xin }=-.01 \\
\text { SUREACE TYPE: SMOOTH }\end{array}$} & \multicolumn{3}{|c|}{$\begin{array}{c}\text { WORKING FLUID: } \mathrm{R}-113 \\
\mathrm{G}=348.84 \mathrm{~kg} / \mathrm{g}^{\star} \mathrm{m}^{\wedge} 2 \\
\text { P total }=4.5 \mathrm{kPa} \\
\text { Xout }=0.22\end{array}$} & \multicolumn{4}{|c|}{$\begin{array}{l}\text { RUN NUMBER: } 143 \\
\text { p/d }=1.17 \\
\text { pin }=203.8 \mathrm{kPa} \\
\text { Xin }=-.01 \\
\text { SURFACE TYPE: SMOOTH }\end{array}$} & \multicolumn{3}{|c|}{$\begin{array}{r}\text { WORKING FLUID: R-113 } \\
G=346.87 \mathrm{~kg} / \mathrm{s}^{\star} \mathrm{m}^{\wedge} 2 \\
\mathrm{TA} P \text { total }=4.51 \mathrm{kPa} \\
\text { Xout }=0.39\end{array}$} & \multicolumn{4}{|c|}{$\begin{array}{l}\text { RUN NUMBER: } 156 \\
\text { P/d }=1.17 \\
\text { Pin }=212.1 \mathrm{kPa} \\
\text { Xin }=-.02 \\
\text { SURFACE TYPE: SMOOTH }\end{array}$} & \multicolumn{3}{|c|}{$\begin{array}{l}\text { WORKING FLUID: R-113 } \\
G=505.76 \mathrm{~kg} / \mathrm{s}^{\star} \mathrm{m}^{\wedge} \\
\text { TA P total }=4.51 \mathrm{kP} \\
\text { Xout }=0.06\end{array}$} \\
\hline ION & $\stackrel{\stackrel{P}{(k P a}]}{ }$ & & & $\underset{[w / m \wedge 2]}{q u}$ & & $\underset{m^{\wedge} 2}{h}$ & Row & & & & & & & ROH & & & & & & \\
\hline 1 & &.- & 2 & $\begin{array}{r}{[\mathrm{H} / \mathrm{m}} \\
404 !\end{array}$ & 8 & & 1 & & & & & & & $\begin{array}{l}* \\
1\end{array}$ & & & & & & \\
\hline 3 & & & & & & & 3 & & & & & & & 3 & & & & & & \\
\hline & & & & & & & 5 & & & & & & & 5 & & & & & & \\
\hline 7 & & & & & & & 7 & & & & & & & 7 & & & & & & \\
\hline & & & & & & & 9 & & & & & & & 9 & & & & & & \\
\hline & & & & & & & & & & & & & & & & & & & & \\
\hline & & & & & & & & & & & & & & 13 & & & & & & \\
\hline & 199.5 & & 58.7 & 11604 & 82.1 & 3110 & & 199.4 & & 68.9 & & & 3982 & 15 & 207.6 & & & & & \\
\hline
\end{tabular}

\begin{tabular}{|c|c|c|c|c|c|c|c|c|c|c|c|c|c|c|c|c|c|c|c|c|}
\hline \multicolumn{2}{|c|}{$\begin{array}{l}\text { RUN NUMBER: } \\
\text { P/d }=1.17 \\
\text { Pin }=205.4 \\
\text { Xin }=-.01 \\
\text { SURFACE TYP }\end{array}$} & \multicolumn{2}{|c|}{$\begin{array}{l}145 \\
\mathrm{KPa} \\
\mathrm{E}: \text { SMOOTH }\end{array}$} & \multicolumn{3}{|c|}{$\begin{array}{l}\text { WORKING FLUID: } R-113 \\
G=346.31 \mathrm{~kg} / \mathrm{s}^{\star} \mathrm{m}^{\wedge} 2 \\
\text { gLTA P total }=4.54 \mathrm{kPa}^{2} \\
\text { Xout }=0.28\end{array}$} & \multicolumn{3}{|c|}{$\begin{array}{l}\text { RUN NUMBER: } 142 \\
\text { P/d }=1.17 \\
\text { Pin }=206 \mathrm{kPa} \\
\text { Xin }=-.01 \\
\text { SURFACE TYPE: S: }\end{array}$} & DEL? & \multicolumn{3}{|c|}{$\begin{array}{r}\text { WORKING FLUID: R-113 } \\
G=347.26 \mathrm{~kg} / \mathrm{s}^{\star \mathrm{m}^{\wedge} 2} \\
\text { CA Potal }=4.48 \mathrm{kPa} \\
\text { Xout }=0.44\end{array}$} & \multicolumn{4}{|c|}{$\begin{array}{l}\text { RUN NUMBER: } 155 \\
\text { P/d }=1.17 \\
\text { Pin }=212.4 \mathrm{kPa} \\
\text { Xin }=-.02 \\
\text { SURFACE TYPE: SMOOTH }\end{array}$} & \multicolumn{3}{|c|}{$\begin{array}{r}\text { WORKING FLUID: R-113 } \\
\text { G }=506.21 \mathrm{~kg} / \mathrm{s}^{\star} \mathrm{m}^{\wedge} \\
\text { TA P total }=4.49 \mathrm{kPa} \\
\text { Xout }=0.10\end{array}$} \\
\hline ROW & $\stackrel{\mathrm{P}}{\mathrm{Pa}}$ & $x$ in & Tf & $q^{\prime \prime}$ & Tw & $\stackrel{h}{{ }^{\prime}}$ & Row & $\begin{array}{c}P \\
\left(1-p_{0}\right.\end{array}$ & $x$ in & Tf & & Tw & & ROW & $\stackrel{p}{\mathbf{P}}$ & & Tf & qu" & $T w$ & $\stackrel{h}{h}$ \\
\hline $\begin{array}{l}F \\
1\end{array}$ & $\begin{array}{l}{[\mathrm{kPa}]} \\
205.1\end{array}$ & $\begin{array}{l}{[-]} \\
-.01\end{array}$ & $\begin{array}{l}{[C]} \\
68.5\end{array}$ & $\begin{array}{c}{\left[W / m^{\wedge} 2\right]} \\
49879\end{array}$ & $\begin{array}{l}{[C]} \\
83.9\end{array}$ & {$\left[\begin{array}{c}{\left[\mathrm{H} / \mathrm{m}^{\wedge} 2 \mathrm{C}\right]} \\
3227\end{array}\right.$} & $\stackrel{*}{1}$ & $\begin{array}{l}{[\mathrm{KPa}]} \\
205.7\end{array}$ & $\begin{array}{l}{[-]} \\
-.01\end{array}$ & $\begin{array}{l}{[c]} \\
68.5\end{array}$ & 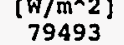 & $\begin{array}{l}{[C]} \\
86.2\end{array}$ & $\left(\begin{array}{l}\mathrm{m}^{\wedge} 2 \\
4489\end{array}\right.$ & $\begin{array}{l}* \\
1\end{array}$ & $\begin{array}{l}{[\mathrm{kPa}]} \\
212.1\end{array}$ & $\begin{array}{l}{[-]} \\
-.02\end{array}$ & $\begin{array}{l}{[c]} \\
68.4\end{array}$ & {$\left[\begin{array}{c}{\left[\mathrm{w} / \mathrm{m}^{\wedge} 2\right]} \\
30111\end{array}\right.$} & $\begin{array}{l}\text { [C] }{ }^{l} \\
82.0\end{array}$ & $\begin{array}{c}/ \mathrm{m}^{\wedge} 2 \mathrm{C} \\
2216\end{array}$ \\
\hline 3 & 204.5 & 0.03 & 69.4 & 49883 & 84.4 & 3337 & 3 & 205.1 & 0.05 & 69.8 & 78951 & 86.9 & 4619 & 3 & 211 & & 69.4 & 303 & 82.0 & 2401 \\
\hline 5 & 203.9 & 0.07 & 69 & 510 & & 33 & 5 & & & & 805 & & & 5 & & & & & & \\
\hline 7 & & & & & & 33 & 7 & & & & & & & 7 & & & & & 82 & 2518 \\
\hline 9 & 202.7 & 0.15 & 69.3 & 49606 & 83 & 3496 & $?$ & 203.3 & 0.2 & & 782 & & 46 & 9 & & & & & & 2668 \\
\hline 11 & 202. & .18 & 69.2 & 49344 & 83 & 3342 & 11 & 202 & 0. & & 785 & & 44 & 11 & & & & & & \\
\hline 13 & & 0.22 & 69.1 & 50138 & 83. & 3519 & 13 & & 0.3 & 69 & & & & 13 & & & & & 80.6 & 2693 \\
\hline 15 & 201.0 & 0.26 & 69.1 & 50921 & 83.9 & 3431 & 15 & 201.5 & 0.41 & 69.3 & 80731 & 88.1 & 4312 & 15 & 208.0 & 0.09 & 69.6 & 31019 & 80.5 & 2840 \\
\hline
\end{tabular}




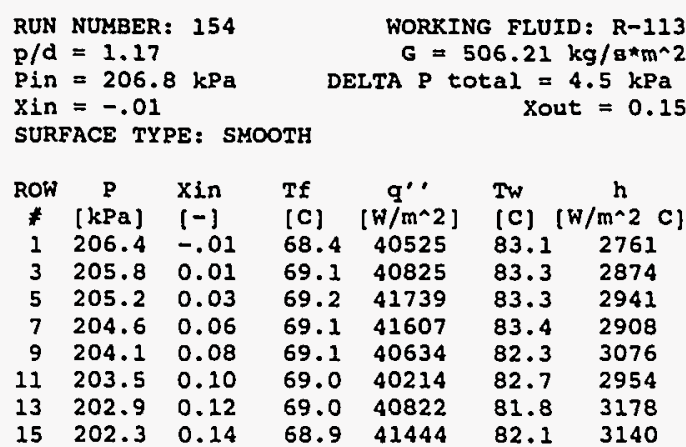

RUN NUMBER: 151

$\mathrm{p} / \mathrm{d}=1.17$

$\mathrm{Pin}=202 \mathrm{kPa}$
$\mathrm{Xin}_{\text {in }}=0.01$

SURFACE TYPE: SMOOTH

Row $P$ Xin

$\begin{array}{lll}* & {[\mathrm{kPa}]} & {[-]} \\ 1 & 201.6 & 0.01\end{array}$

3 201.0 0.04

$7 \quad 199.9 \quad 0.12$

$\begin{array}{lll}9 & 199.3 & 0.16\end{array}$

11 198.7 0.19

$\begin{array}{lllllll}13 & 198.1 & 0.23 & 68.3 & 70903 & 85.0 & 4246 \\ 15 & 197.5 & 0.27 & 68.4 & 71531 & 86.3 & 3998\end{array}$

$\begin{array}{llll}68.7 & 70444 & 85.2 & 4248\end{array}$

$\begin{array}{llll}67.9 & 70109 & 85.8 & 3916\end{array}$

$68.0 \quad 71539-85.7 \quad 4046$

68.171243
RUN NUMBER: 214

$\mathrm{p} / \mathrm{d}=3.17$

WORKING FLUID: $R-113$ $G=498.5 \mathrm{~kg} / \mathrm{s}^{\star} \mathrm{m}^{\wedge} 2$
DELTA $P$ total $=4.56 \mathrm{kPa}$

Xout $=0.29$

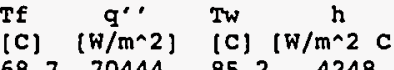

xin $=554.6 \mathrm{kPa}$

SURFACE TYPE: SMOOTH

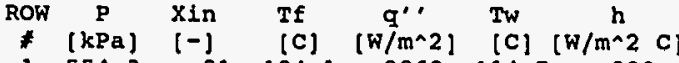
$\begin{array}{llllllll}* & {[\mathrm{kPa}]} & {[-]} & {[\mathrm{C}]} & {\left[\mathrm{W} / \mathrm{m}^{\wedge} 2\right]} & {[\mathrm{C}]} & {\left[\mathrm{W} / \mathrm{m}^{\wedge} 2\right.} & \mathrm{C}\end{array}$ $\begin{array}{rrrrrrr}3 & 553.7 & 0.05 & 108.8 & 9978 & 114.8 & 1647\end{array}$ $\begin{array}{lllllll}5 & 553.1 & 0.12 & 109.8 & 10186 & 115.0 & 1967\end{array}$ $\begin{array}{lllllll}7 & 552.5 & 0.18 & 109.7 & 10227 & 115.5 & 1773\end{array}$ $\begin{array}{rrrrrrr}9 & 551.9 & 0.25 & 109.7 & 9968 & 115.4 & 1743 \\ 11 & 551.3 & 0.31 & 109.6 & 9778 & 115.2 & 1744\end{array}$ $\begin{array}{rrrrrrr}11 & 551.3 & 0.31 & 109.6 & 9778 & 115.2 & 1744 \\ 13 & 550.7 & 0.37 & 109.6 & 10010 & 115.5 & 1786\end{array}$ $\begin{array}{lllllll}15 & 550.1 & 0.43 & 109.5 & 10103 & 115.2 & 1785\end{array}$

$\begin{array}{lr}\text { RUN NUMBER: } 153 & \text { WORKING FLUID: } \mathrm{R}-113 \\ \text { P } / \mathrm{d}=1.17 & G=506.76 \mathrm{~kg} / \mathrm{a}^{\star \mathrm{m}^{\wedge} 2} \\ \text { Pin }=206.9 \mathrm{kPa} & \text { DELTA P total }=4.54 \mathrm{kPa} \\ \text { Xin }=-.02 & \text { Xout }=0.18 \\ \text { SURFACE TYPE: SMOOTH } & \end{array}$

$\begin{array}{ccc}\text { ROW } & \text { P } & \text { Xin } \\ * & {[\mathrm{kPa}]} & 1-1 \\ 1 & 206.5 & -.02\end{array}$

$\begin{array}{lll}1 & 206.5 & -.02 \\ 3 & 205.9 & 0.01\end{array}$

$\begin{array}{lll}5 & 205.4 & 0.04 \\ 7 & 204.8 & 0.06\end{array}$

$9204.2 \quad 0.09$

$\begin{array}{lll}11 & 203.6 & 0.12\end{array}$

$15 \quad 202.4 \quad 0.17$
RUN NUMBER: 150

$\mathrm{p} / \mathrm{d}=1.17$

in $=207.3 \mathrm{kPa}$

in $=0.00$

URFACE TYPE: SMOOTH

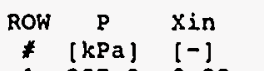

$\begin{array}{lll}1 & 207.0 & 0.00 \\ 3 & 206.4 & 0.04\end{array}$

$\begin{array}{lll}3 & 206.4 & 0.04 \\ 5 & 205.8 & 0.09\end{array}$

7 205.2 0.13

$\begin{array}{rrr}9 & 204.6 & 0.17 \\ 11 & 204.0 & 0.22\end{array}$

$13 \quad 203.4 \quad 0.26$

$\begin{array}{lll}13 & 203.4 & 0.26 \\ 15 & 202.8 & 0.30\end{array}$
WORKING FLUID: R-113
$G=497.71 \mathrm{~kg} / \mathrm{g}^{\star} \mathrm{m}^{\wedge} 2$

DELTA $P$ tota

Xout $=0.32$

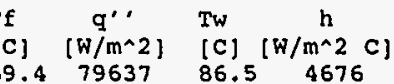

$\begin{array}{llll}69.4 & 79637 & 86.5 & 4676\end{array}$

69.479216

69.480609

69.479104

$\begin{array}{llll}69.4 & 80569 & 86.5 & 4629 \\ 69.4 & 81107 & 87.9 & 4399\end{array}$
RUN NUMBER: 215

$\mathrm{p} / \mathrm{d}=1.17$

Pin $=555.8 \mathrm{kPa}$

Xin $=-.02$
SURFACE TYPE: SMOOTH

\begin{tabular}{|c|c|c|c|c|c|c|}
\hline & p & $x$ in & If & & $T w$ & \\
\hline$\neq$ & [ $\mathrm{kPa}$ ] & {$[-]$} & (c) & $\left\{w / m^{\wedge} 2\right\}$ & [c] & {$[\mathrm{W} / \mathrm{m} \wedge 2$} \\
\hline 1 & 555. & -.02 & 107.0 & $14633^{\circ}$ & 118.3 & 1303 \\
\hline & & & & & & \\
\hline 5 & 554. & $c$ & 9 & 150 & 118.4 & 1766 \\
\hline & 553 & & & & & \\
\hline & & & & & & \\
\hline & 552 & & & $14 \mathrm{C}$ & & 1608 \\
\hline & & 0.49 & 109.7 & 14989 & 118.7 & 1660 \\
\hline
\end{tabular}

\begin{tabular}{|c|c|c|c|c|c|c|}
\hline $\begin{array}{l}\text { RUN } \\
\text { p/d } \\
\text { Pin } \\
\text { Xin } \\
\text { sur }\end{array}$ & $\begin{array}{l}\text { NUMBE } \\
=1.1 \\
=204 \\
=-.0\end{array}$ & $9 \mathrm{kPa}$ & & $\begin{array}{c}\text { WORKI } \\
G= \\
\text { LTA } P\end{array}$ & $7=$ & $\begin{array}{r}D: R-113 \\
\mathrm{~kg} / \mathrm{s}^{\star} \mathrm{m}^{\wedge} 2 \\
4.55 \mathrm{kPa} \\
\mathrm{tt}=0.23\end{array}$ \\
\hline row & ${ }^{p}$ & 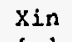 & Tf & $q^{\prime}$ & $T w$ & h \\
\hline \# & {$[\mathrm{kPa}$} & {$[-]$} & (c) & $\left(w / m^{\wedge} 2\right)$ & [C] & {$\left[W / m^{\wedge} 2 C\right]$} \\
\hline 1 & 204. & -.01 & 68.2 & 5992 & 84.6 & 3639 \\
\hline 3 & & & 69 & 599 & 85.3 & 3744 \\
\hline 5 & 203 & & & 611 & & 3807 \\
\hline 7 & & & & & & 3702 \\
\hline 9 & & & & & & \\
\hline 11 & 201 & & & & & \\
\hline & & & & & 84.2 & 39 \\
\hline 5 & 200.5 & $\mathrm{c}$ & 68.9 & 61125 & 85.4 & 3698 \\
\hline
\end{tabular}

RUN NUMBER: 200

$p / d=1.17$

in $=572.2$

SURFACE TYPE: SMOOTH

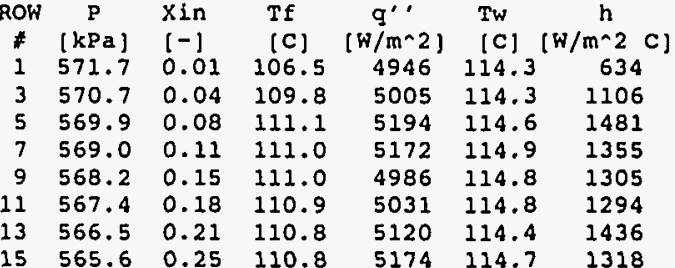

WORKING FLUID: R-113 RUN NUMBER: 216

$\mathrm{p} / \mathrm{d}=1.17$

Pin $=598.7 \mathrm{kPa}$
WORKING FLUID: $R-113$ $G=51.24 \mathrm{~kg} / \mathrm{s}^{\star} \mathrm{m}^{\wedge} 2$ DELTA $P$ total $=4.58 \mathrm{kPa}$ Xout $=0.80$

\begin{tabular}{|c|c|c|c|c|c|c|}
\hline$\partial \mathrm{W}$ & P & $x$ in & Tf & $q^{\prime \prime}$ & $T w$ & $\mathrm{~h}$ \\
\hline & [kPa] & & {$[\mathrm{C}]$} & {$[w / m \wedge 2]$} & (c) & $/ m^{\wedge} 2$ \\
\hline & 598.3 & -.06 & 107.4 & $18679^{\circ}$ & 121.1 & 1360 \\
\hline & 597.8 & 0.05 & 113.3 & 18915 & 121.4 & 2350 \\
\hline & 597.2 & 0.1 & 113.3 & 19273 & 121 & \\
\hline & 596.6 & 0.2 & 113.2 & 19755 & 122.2 & 2195 \\
\hline & 596.0 & 0.40 & 113.2 & 19189 & 122.1 & 2163 \\
\hline & & & 113.1 & 18870 & 121.7 & 2192 \\
\hline & 594.8 & 0.63 & 113.1 & 19359 & 121.7 & 2244 \\
\hline & & & & & & \\
\hline
\end{tabular}




\begin{tabular}{|c|c|c|c|c|c|c|}
\hline \multicolumn{3}{|c|}{$\begin{array}{l}\text { RUN NUMBER: } 213 \\
\text { P/d }=1.17 \\
\text { PIn }=560 \mathrm{kPa} \\
\text { XIn }=-.01 \\
\text { SURFACE TYPE: SR }\end{array}$} & \multicolumn{4}{|c|}{$\begin{array}{r}\text { WORKING FLUID: R-113 } \\
G=105.86 \mathrm{~kg} / \mathrm{a}^{\star *} \mathrm{~m}^{\wedge} 2 \\
\text { P total }=4.52 \mathrm{kPa} \\
\text { xout }=0.09\end{array}$} \\
\hline OW & $\mathbf{P}$ & $x$ in & TE & & Tw & \\
\hline & [kPa & & [C] & {$[W / m \wedge 2\}$} & (c) & \\
\hline & 559.7 & -.01 & 107.8 & 4964 & 113.4 & 883 \\
\hline & 559.1 & 0.0 & 109.4 & 5024 & 113.3 & 1283 \\
\hline & 558. & 0.0 & 110.2 & 5127 & 113 & \\
\hline 7 & 557.9 & 0.03 & 110.2 & 5184 & 113.8 & 1432 \\
\hline & 557.3 & 0.04 & 110.1 & 5062 & 113 & \\
\hline 1 & 556. & 0.0 & 110.1 & 4868 & & \\
\hline 3 & 556.1 & 0.07 & 110.0 & 4985 & 114.7 & 1258 \\
\hline & 555.6 & 0.09 & 110.0 & 5028 & 113.9 & 1285 \\
\hline
\end{tabular}

RUN NUMBER: 196

Pin $=589.2$

SURFACE TYPE: SMOOTH

\begin{tabular}{|c|c|c|c|c|c|c|}
\hline OW & $\mathbf{P}$ & $x$ in & & $a^{\prime}$ & $\mathrm{Tw}$ & h \\
\hline F & & & & $(\mathrm{W} / \mathrm{m} \wedge 2$ & [C] & $m^{\wedge} 2$ \\
\hline 1 & & 0.03 & 111.6 & $10150^{\circ}$ & 118.2 & 1543 \\
\hline 3 & 588 & 0.06 & & 102 & 118.0 & 1860 \\
\hline 5 & & 0.09 & & & & \\
\hline & 586 & 0.12 & 112 & 103 & 118 & 1887 \\
\hline 9 & & & & & & \\
\hline & & 0.18 & & & 11 & 1836 \\
\hline 13 & 584 & 0.21 & 112 & & 117 & 1873 \\
\hline & & & & & & \\
\hline
\end{tabular}

RUN NUMBER: 197 $\mathrm{p} / \mathrm{d}=1.17$

WORKING FLUID: $\mathrm{R}-113$ $\quad G=103.95 \mathrm{~kg} / \mathrm{s}^{\star \mathrm{m}^{\wedge} 2}$ $x_{\text {in }}=-.02$ DELTA P total $=6.61 \mathrm{kPa}$ SURFACE TYPE: SMOOTH Xout $=0.43$

\begin{tabular}{|c|c|c|c|c|c|c|}
\hline ow & P & $x$ in & & & \multirow{2}{*}{\multicolumn{2}{|c|}{$\begin{array}{l}T w \\
\text { [C] } \quad h / m^{\wedge} 2\end{array}$}} \\
\hline * & & {$[-]$} & (C) & {$\left[\omega / m^{\wedge} 2\right]$} & & \\
\hline 1 & 594. & & 109.4 & $20189^{\circ}$ & 120.6 & \\
\hline 3 & 593.3 & 0.04 & 112.8 & & 120.6 & 2574 \\
\hline 5 & 592 & & & & & \\
\hline 7 & 591. & 0.16 & 112.8 & & 121.8 & 2310 \\
\hline 9 & & & & & & \\
\hline & 590. & 0.29 & 112 & 202 & 121 & 2291 \\
\hline & 589.2 & 0.34 & 112.6 & 20591 & 121.6 & 2304 \\
\hline & & & & & & \\
\hline
\end{tabular}

$\mathrm{p} / \mathrm{d}=1.17$

In $=579.5 \mathrm{kPa}$ $\operatorname{lin}=0.02$ SURFACE TYPE: SMOOTH

WORKING FLUID: R-113 RUN NUMBER: 204

$G=96.81 \mathrm{~kg} / \mathrm{g}^{\star} \mathrm{m}^{\wedge} \mathrm{2} \quad \mathrm{p} / \mathrm{d}=1.17$

xout $=0.74$

Pin $=563.6$
Xin $=0.01$

SURFACE TYPE: SMOOTH

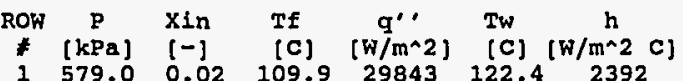

$\begin{array}{lllllll}1 & 579.0 & 0.02 & 109.9 & 29843 & 122.4 & 2392\end{array}$

$\begin{array}{lllllll}3 & 578.1 & 0.12 & 111.8 & 30257 & 122.5 & 2810 \\ 5 & 577.2 & 0.21 & 111.7 & 30860 & 122.7 & 2800\end{array}$

$\begin{array}{lllllll}7 & 576.4 & 0.31 & 111.6 & 30877 & 123.2 & 2661\end{array}$

$\begin{array}{lllllll}9 & 575.6 & 0.41 & 111.6 & 29947 & 122.8 & 2672\end{array}$

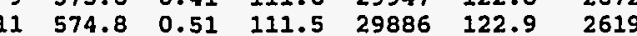

$\begin{array}{llllllll}13 & 573.9 & 0.60 & 111.4 & 30500 & 122.3 & 2799\end{array}$

\begin{tabular}{|c|c|c|c|c|c|c|}
\hline On & & & & & \multirow{2}{*}{\multicolumn{2}{|c|}{$\left.[w] \quad \frac{n}{W / m^{\wedge} 2} \quad C\right]$}} \\
\hline$\neq$ & [kPa] & & {$[c]$} & {$[W / m \wedge 2]$} & & \\
\hline 1 & 563.2 & 0.01 & 109.3 & $29570^{\circ}$ & 119.3 & 2962 \\
\hline 3 & 562 & 0.0 & & & & \\
\hline 5 & 561.8 & 0.09 & & & & 3536 \\
\hline 7 & 561 & & & & & 326 \\
\hline & 560 & 0.2 & 4 & & & \\
\hline & 559 & & 110 & & & 325 \\
\hline & & 0.25 & & 237 & 119.2 & 3368 \\
\hline & & & & & & \\
\hline
\end{tabular}

$\begin{array}{llllllll}15 & 558.5 & 0.29 & 110.2 & 30641 & 119.8 & 3368\end{array}$

WORKING FLUID: R-113 $G=232.37 \mathrm{~kg} / \mathrm{s}^{\star} \mathrm{m}^{\wedge}$ DELTA $P$ total Yout $=0.31$ (1)
RUN NUMBER: 199

\section{RUN NUMBER: 209}

$\mathrm{p} / \mathrm{d}=1.17$

Pin $=577.5 \mathrm{kP}$ SURFACE TYPE: SMOOTH

WORKING FLUID: R-113 RUN NUMBER: 205 $\mathrm{p} / \mathrm{d}=1.17$

Pin $=588 \times P$

$\operatorname{xin}=-.02$

SURFACE TYPE: SMOOTH

WORKING FLUID: R-113

DELTA $P$ tota

\begin{tabular}{|c|c|c|c|c|c|c|}
\hline OW & $\stackrel{\mathrm{P}}{\mathrm{P}}$ & $x$ In & Tf & (Tinon & Tw & $\begin{array}{l}h \\
n^{\wedge} 2\end{array}$ \\
\hline F & [KPa] & {$[-]$} & $\begin{array}{c}{[C]} \\
{[09,3}\end{array}$ & {$\left[\mathrm{W} / \mathrm{m}^{\wedge} \mathrm{2}\right]$} & ${ }_{116,9}^{[C]}$ & 1322 \\
\hline 3 & 576.4 & 0.01 & & & & \\
\hline 5 & & & & & & 1925 \\
\hline & & & & & & \\
\hline & & & & & & \\
\hline & & & & & & \\
\hline & & & & & 118 & 1534 \\
\hline & & & & & & \\
\hline
\end{tabular}

\begin{tabular}{|c|c|c|c|c|c|c|}
\hline$h$ & P & $x$ in & Tf & $q^{\prime \prime}$ & \multirow{2}{*}{\multicolumn{2}{|c|}{$[\mathrm{C}]\left[\mathrm{W} / \mathrm{m}^{\wedge} 2 \mathrm{C}\right]$}} \\
\hline & & & [c] & {$\left[\mathrm{W} / \mathrm{m}^{\wedge} \mathrm{2}\right]$} & & \\
\hline & 587 & -.02 & 109.1 & & & \\
\hline 3 & 58 & 0.04 & 112.3 & 40463 & 122.2 & 4077 \\
\hline & 586.2 & & 12.4 & 41294 & 121.8 & 4194 \\
\hline & 58 & . & 212 & 412 & 12 & \\
\hline 9 & 5 & c & 112.3 & 40233 & 122.3 & 4034 \\
\hline & & & & & 128 & 4042 \\
\hline & & & 112.2 & 40793 & 122.0 & 4148 \\
\hline & & & & & & \\
\hline
\end{tabular}

RUN NUMBER: 203

$\mathrm{p} / \mathrm{d}=1.17$

in $=571.7 \mathrm{kPa}$

Xin $=-.01$.

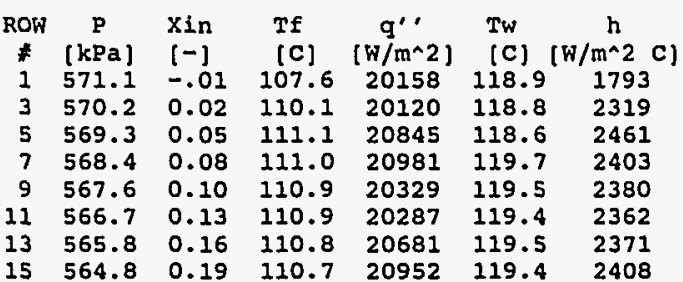

WORKING FLUID: R-113 RUN NUMBER: 206

R $/ d=1.17$ $\mathrm{P}$ in $=590 \mathrm{kP}$

$x$ in $=-.01$

SUREACE TYPE: SMOOTH
WORKING FLUID: R-113 $G=229.05 \mathrm{~kg} / \mathrm{s}^{*} \mathrm{~m}^{\wedge}$
DELTA $\mathrm{P}$ total $=5.12 \mathrm{kPa}$

\begin{tabular}{|c|c|c|c|c|c|c|}
\hline מ & & $x i n$ & $T f$ & & $T w$ & \\
\hline & [kPa] & {$[-]$} & [C] & {$\left[\mathrm{w} / \mathrm{m}^{\wedge} 2\right]$} & [c] & $/ \mathbb{m}^{\wedge} \mathbf{C} C$ \\
\hline 3 & 589.6 & -.01 & 110.0 & 49694 & 122.8 & 3872 \\
\hline & 588 & 0.05 & & & & \\
\hline & 588. & 0.1 & 112 & & 122.7 & 4541 \\
\hline & & & 5 & & & 4459 \\
\hline & 586 & 0.2 & 112 & & 123 & 4684 \\
\hline 1. & $5 \varepsilon$ & & 112 & & & 4700 \\
\hline & & 0.39 & 112.4 & 50634 & 122.9 & 4798 \\
\hline
\end{tabular}




\begin{tabular}{|c|c|c|c|c|c|c|}
\hline \multirow{2}{*}{\multicolumn{4}{|c|}{$\begin{array}{l}\text { RUN NUMBER: } 207 \\
\text { P/d }=1.17 \\
\text { Pin }=593.4 \mathrm{kPa} \\
\text { Xin }=-.02 \\
\text { SURFACE TYPE: SMOOTH }\end{array}$}} & \multirow{2}{*}{\multicolumn{3}{|c|}{$\begin{array}{r}\text { WORKING FLUID: R-113 } \\
G=227.73 \mathrm{~kg} / \mathrm{g}^{\star} \mathrm{m}^{\wedge} 2 \\
\text { ELTA P total }=5.21 \mathrm{kPa} \\
\text { Xout }=0.59\end{array}$}} \\
\hline & & & & & & \\
\hline zow & & & & & & \\
\hline & & & & [W] & & $\mathrm{N} / \mathrm{m}^{\wedge}$ \\
\hline & & & & & & \\
\hline 3 & & & & & & \\
\hline 5 & & & & & & \\
\hline & & & & & & \\
\hline 9 & & & & & & \\
\hline & & & & & & \\
\hline & & & & & & \\
\hline & & & & 61733 & 125.4 & 4820 \\
\hline
\end{tabular}

RUN NUMBER: 208

$\mathrm{p} / \mathrm{d}=1.17$

Pin $=596.3 \mathrm{kPa}$

SURFACE TYPE: SMOOT

WORKING FLUID: R-113 Ba Xout $=0.69$

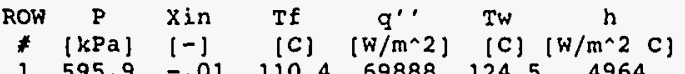

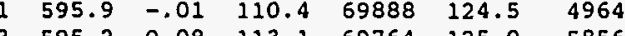

$\begin{array}{lllllll}3 & 595.2 & 0.08 & 113.1 & 69764 & 125.0 & 5856\end{array}$

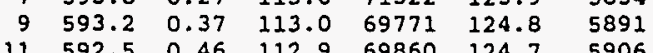

$\begin{array}{llllllll}11 & 592.5 & 0.46 & 112.9 & 69860 & 124.7 & 5906\end{array}$

$\begin{array}{lllllll}13 & 591.9 & 0.56 & 112.9 & 71501 & 124.8 & 5990 \\ 15 & 591.2 & 0.65 & 112.8 & 71974 & 125.7 & 5872\end{array}$ DELTA P total $=5.18 \mathrm{kPa}$

$\begin{array}{lllllll}5 & 594.5 & 0.18 & 113.1 & 71126 & 124.3 & 5820\end{array}$ $\mathrm{p} / \mathrm{d}=1.17$

$\mathrm{Pin}=605 \mathrm{kPa}$

$X$ in $=-.00$

WORKING FLUTD: R-113 DELTA $P=349.37 \mathrm{~kg} / \mathrm{s} * \mathrm{~m}$

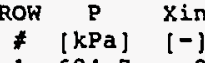

$\begin{array}{lll}1 & 604.7 & -.00 \\ 3 & 604.1 & 0.02\end{array}$

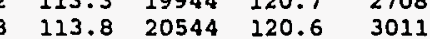

$\begin{array}{lllllll}602.9 & 0.05 & 113.7 & 20689 & 121.0 & 2847\end{array}$

$\begin{array}{lllllll}9 & 602.3 & 0.07 & 113.7 & 20146 & 120.7 & 2848\end{array}$

$\begin{array}{lllllll}11 & 601.7 & 0.08 & 113.6 & 19911 & 120.9 & 2719\end{array}$

$\begin{array}{lllllll}13 & 601.1 & 0.10 & 113.6 & 20364 & 121.2 & 2663 \\ 15 & 600.5 & 0.12 & 113.5 & 20656 & 121.0 & 2780\end{array}$
RUN NUMBER: 190

SURFACE TYPE: SMOOTH
RUN NUMBER: 184

$\mathrm{P} / \mathrm{d}=1.17$

Pin $=571.8$
Xin $=0.02$

SURFACE TYPE: SMOOTH

\begin{tabular}{|c|c|c|c|c|c|c|}
\hline OW & P & tin & $\mathrm{f}$ & & $T w$ & h \\
\hline \# & (KPa) & & & $1 \mathrm{w} / \mathrm{m}^{\wedge} 2$ & & $/ m^{\wedge} 2$ \\
\hline 1 & 571.5 & 0.02 & 110.2 & 50152 & 122.5 & 4075 \\
\hline 3 & 570.9 & 0.0 & & & & 43 \\
\hline 5 & & & & & & \\
\hline 7 & 569 & 0. & & & & 4375 \\
\hline 9 & & & & & & \\
\hline & 568.6 & & & & & 3 \\
\hline 1. & 568.0 & 0.27 & 111.0 & 50429 & & \\
\hline & & & & & & \\
\hline
\end{tabular}
$G=350.91 \mathrm{~kg} / \mathrm{s}^{\star} \mathrm{m}^{\wedge} 2$ xout $=0.34$
WORKING FLUID: R-113
RUN NUMBER: 189

$\mathrm{p} / \mathrm{d}=1.17$

$x_{\text {in }}=0.00 \mathrm{kPa}$

SURFACE TYPE: SMOOT

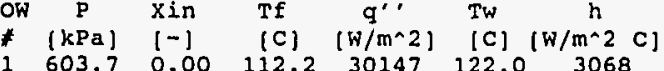

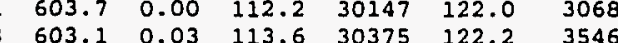

$\begin{array}{lllllll}602.5 & 0.06 & 113.7 & 31012 & 122.2 & 3656\end{array}$

$\begin{array}{lllllll}7 & 601.9 & 0.08 & 113.6 & 30903 & 122.9 & 3528\end{array}$

$9 \begin{array}{lllllll}9 & 601.3 & 0.11 & 113.6 & 30118 & 122.5 & 3388\end{array}$

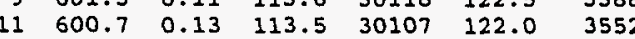

$\begin{array}{lllllll}13 & 600.1 & 0.16 & 113.5 & 30773 & 122.4 & 3472 \\ 15 & 599.5 & 0.18 & 113.5 & 31213 & 122.6 & 3411\end{array}$
RUN NUMBER: 187

$\mathrm{P} / \mathrm{d}=1.17$
$\mathrm{Pin}=596.5 \mathrm{kPa}$

Pin $=596.5$
Xin $=0.01$

SURFACE TYPE: SMOOTH

WORKING FLUID: $8-113$

$G=350.01 \mathrm{~kg} / \mathrm{s}^{*} \mathrm{~m}^{\wedge} 2$ DELTA P total $=4.51 \mathrm{kPa}$

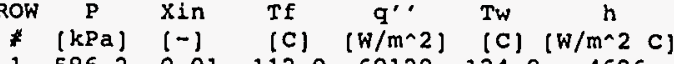

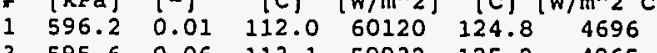

$\begin{array}{lllllll}3 & 595.6 & 0.06 & 113.1 & 59932 & 125.2 & 4965\end{array}$

$\begin{array}{lllllll}5 & 595.0 & 0.12 & 113.1 & 61131 & 124.7 & 5255\end{array}$

$\begin{array}{lllllll}7 & 594.4 & 0.17 & 113.0 & 60716 & 125.7 & 5208 \\ 9 & 593.8 & 0.22 & 113.0 & 59369 & 124.6 & 5113\end{array}$

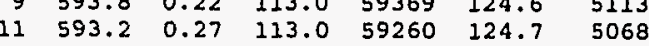

$\begin{array}{lllllll}13 & 592.6 & 0.32 & 112.9 & 60574 & 124.6 & 5181 \\ 15 & 592.0 & 0.37 & 112.9 & 61283 & 125.2 & 4984\end{array}$

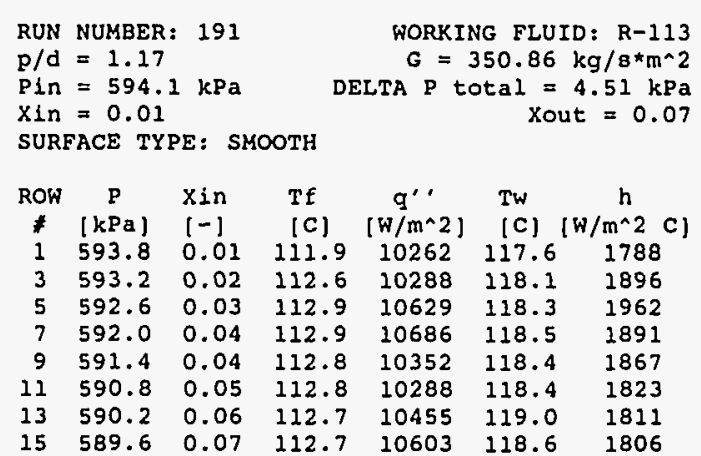

\begin{tabular}{|c|c|c|c|c|c|}
\hline p & $x$ in & Tf & $q^{\prime \prime}$ & Tw & $n$ \\
\hline [kPa] & $1-1$ & [C] & {$\left[W / m^{\wedge} 2\right]$} & (C) & $\left\{w / m^{\wedge} 2 \quad c\right\}$ \\
\hline 593.8 & 0.01 & 111.9 & 10262 & 117.6 & \\
\hline 3.2 & 0.02 & 112.6 & 10288 & 118.1 & 1896 \\
\hline 592.6 & 0.03 & 112.9 & 10629 & 118.3 & 1962 \\
\hline & 0.0 & 112. & 10686 & 118.5 & 1891 \\
\hline 591.4 & 0.04 & 112.8 & 10352 & 118.4 & 1867 \\
\hline 590. & & & & & 1823 \\
\hline 590.2 & 0.06 & 112.7 & 10455 & 119.0 & 1811 \\
\hline
\end{tabular}

$\begin{array}{lllllll}15 & 589.6 & 0.07 & 112.7 & 10603 & 118.6 & 1806\end{array}$ $\begin{array}{ll}\text { xout }=0.26 & \text { Xin }=0.01 \\ & \text { SURFACE TYPE: SMOOTH }\end{array}$ $\begin{array}{ll}\text { xout }=0.26 & \text { Xin }=0.01 \\ & \text { SURFACE TYPE: SMOOTH }\end{array}$

WORKING FLUID: R-113 DELTA P total $=4.51 \mathrm{kPa}$

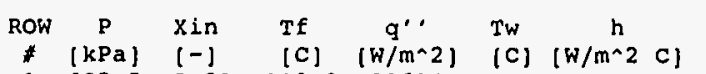

$\begin{array}{llllllll}1 & 602.5 & 0.01 & 112.2 & 39614 & 123.2 & 3585\end{array}$

$\begin{array}{lllllll}3 & 601.9 & 0.04 & 113.6 & 39871 & 123.6 & 3990\end{array}$

$\begin{array}{llllllll}5 & 601.3 & 0.08 & 113.6 & 40736 & 123.3 & 4187 \\ 7 & 600.7 & 0.11 & 113.5 & 40715 & 124.1 & 4060\end{array}$

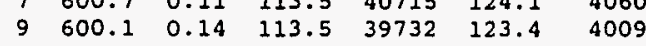

$\begin{array}{rllllll}9 & 600.1 & 0.14 & 113.5 & 39732 & 123.4 & 4009 \\ 11 & 599.5 & 0.18 & 113.5 & 39322 & 123.3 & 3983\end{array}$

$\begin{array}{lllllll}11 & 599.5 & 0.18 & 113.5 & 39322 & 123.3 & 3983 \\ 13 & 598.9 & 0.21 & 113.4 & 40171 & 123.3 & 4043\end{array}$ 


\begin{tabular}{|c|c|c|c|c|c|c|}
\hline \multicolumn{4}{|c|}{$\begin{array}{l}\text { RUN NUMBER: } 185 \\
\text { P/d }=1.17 \\
\text { PIn }=595.8 \mathrm{kPa} \\
\text { XIn }=0.01 \\
\text { SURFACE TYPE: SMOOTH }\end{array}$} & \multicolumn{3}{|c|}{$\begin{array}{r}\text { WORKING FLUID: R-113 } \\
G=348.98 \mathrm{~kg} / \mathrm{g}^{\star} \mathrm{m}^{\wedge} \\
\text { ELTA } \mathrm{p} \text { total }=4.53 \mathrm{kPa} \\
\text { Xout }=0.52\end{array}$} \\
\hline Row & $\begin{array}{c}P \\
{[\mathrm{kPa}]}\end{array}$ & $\begin{array}{l}x \operatorname{lin} \\
(-)\end{array}$ & $\begin{array}{l}\text { Tf } \\
\text { [C] }\end{array}$ & $\underset{\left[w / m^{\wedge} 2\right]}{q \cdot}$ & $\begin{array}{l}T w \\
{[C]}\end{array}$ & $\left.\frac{h}{\left[W / m^{\wedge} 2\right.} \quad c\right]$ \\
\hline 1 & 595.5 & 0.01 & 111.9 & 80202 & 125.5 & 5906 \\
\hline & 594.9 & & & & & \\
\hline 5 & 594.3 & 0.9 & 113.0 & 81190 & 125 & 6527 \\
\hline 7 & 593.7 & & 113 & 81131 & & \\
\hline & & & & & & \\
\hline 11 & 592.6 & & 112 & 80 & & \\
\hline & & & & & & \\
\hline 15 & 1.4 & & 112.8 & 82432 & 125.9 & 6293 \\
\hline
\end{tabular}

RUN NUMBER: 179

$\mathrm{p} / \mathrm{d}=1.17$

Pin $=546.2 \mathrm{kPa}$ SURFACE TYPE: SMOOTH

WORKING FLUID: R-113 DELTA $P$ total $\approx \mathrm{kg} / \mathrm{s}^{\star} \mathrm{m}^{\wedge}$ DELTA P total $\approx$ out $=0.15$

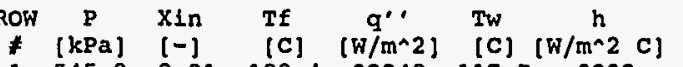
$29948 \quad 117.7 \quad 3222$ $\begin{array}{llll}545.2 & 0.03 & 109.1\end{array}$ \begin{tabular}{l}
$543.5 \quad 0.08 \quad 109.0 \quad 29713 \quad 118.0 \quad 3261$ \\
\hline
\end{tabular} $\begin{array}{llllll}542.9 & 0.10 & 108.9 & 29772 & 117.8 & 3339\end{array}$ $\begin{array}{llllllll}13 & 542.3 & 0.12 & 108.9 & 30353 & 118.1 & 3309\end{array}$ $\begin{array}{lllllll}15 & 541.7 & 0.14 & 108.8 & 30677 & 118.4 & 3187\end{array}$
RUM NUMBER: 176 $\mathrm{p} / \mathrm{d}=1.17$

in $=548.7 \mathrm{kPa}$

SURPACE TYPE: SMOOTH

WORKING FLUID: R-113 DELTA P totai $=4.48 \mathrm{kPa}$ Row $P$ xin Tf q"' Tw h $\begin{array}{lllllll}* & {[\mathrm{kPa}]} & {[-]} & {[\mathrm{C}]} & {\left[\mathrm{W} / \mathrm{m}^{\wedge}\right]} & {[\mathrm{C}]} & {\left[\mathrm{W} / \mathrm{m}^{\wedge} 2\right.} \\ 1 & 548.3 & 0.01 & 108.4 & 60122 & 121.1 & 4723\end{array}$ $\begin{array}{lllllll}3 & 547.7 & 0.04 & 109.3 & 59953 & 121.4 & 4959\end{array}$ $\begin{array}{lllllll}5 & 547.2 & 0.08 & 109.3 & 61129 & 121.3 & 5082\end{array}$ $\begin{array}{lllllll}7 & 546.6 & 0.12 & 109.2 & 61177 & 122.1 & 4767\end{array}$ $\begin{array}{lllllll}9 & 546.0 & 0.15 & 109.2 & 59924 & 120.9 & 5118\end{array}$ $\begin{array}{lllllll}11 & 545.4 & 0.19 & 109.1 & 59748 & 121.1 & 4982\end{array}$ $\begin{array}{lllllll}13 & 544.8 & 0.22 & 109.1 & 61056 & 119.9 & 5151 \\ 15 & 544.2 & 0.26 & 109.0 & 61417 & 121.6 & 4880\end{array}$

\begin{tabular}{|c|c|c|c|c|c|c|}
\hline \multicolumn{4}{|c|}{$\begin{array}{l}\text { RUN NUMBER: } 183 \\
\text { P/d }=1.17 \\
\text { Pin }=534.7 \mathrm{kPa} \\
\text { Xin }=0.01 \\
\text { SURFACE TYPE: SMOOTH }\end{array}$} & \multicolumn{3}{|c|}{$\begin{array}{r}\text { WORKING FLUID: R-113 } \\
\text { G }=495.03 \mathrm{~kg} / \mathrm{g}^{\mathrm{km}} \\
\text { ELTA P total }=4.54 \mathrm{kPa} \\
\text { Xout }=0.06\end{array}$} \\
\hline & $P$ & & & & & \\
\hline * & & & & {$[\omega / \mathrm{m}$} & & $/ m^{\wedge} 2$ \\
\hline 1 & & & & & & \\
\hline 3 & & & & & & \\
\hline 5 & & & & & & \\
\hline 7 & 532 & & & & & \\
\hline & & & & & & \\
\hline & & & & & & \\
\hline & & & & & & \\
\hline & & & & & & \\
\hline
\end{tabular}

\section{RUN NUMBER: 181 \\ $\mathrm{p} / \mathrm{d}=1.17 \mathrm{kPa}$ \\ $x_{\text {in }}=0.01$}

SURFACE TYPE: SMOOTH

WORKING FLUID: R-113 ELTA $=498.26 \mathrm{~kg} / \mathrm{s}^{*} \mathrm{~m}^{\wedge}$ Xout $=0.19$

ROW

\begin{tabular}{|c|c|c|c|c|c|}
\hline & & [C] & {$\left[W / m^{\wedge} 2\right]$} & [C] & $\left(\mathrm{w} / \mathrm{m}^{\wedge} 2\right.$ \\
\hline & 0.01 & 108.0 & 39849 & 118.4 & 3833 \\
\hline 539. & 0.04 & 108.6 & 40081 & 118.6 & 4032 \\
\hline 38.5 & & 108.6 & 40908 & 118.3 & 4092 \\
\hline 538 & 0.09 & 108.5 & 41054 & 119.2 & \\
\hline 537.7 & 0.11 & 108.5 & 39947 & 118.6 & 3967 \\
\hline 537.1 & & & 01 & 118.4 & \\
\hline 536. & 0.16 & 108.4 & 40430 & 118.3 & 4001 \\
\hline & & & & & \\
\hline
\end{tabular}

RUN NUMBER: 178

$\mathrm{p} / \mathrm{d}=1.17$

Pin $=550.2$

SURFACE TYPE: SMOOTH

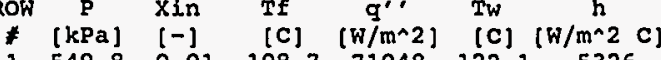

$\begin{array}{lllllll}1 & 549.8 & 0.01 & 108.7 & 71048 & 122.1 & 5326\end{array}$

$\begin{array}{lllllll}3 & 549.3 & 0.06 & 109.4 & 70544 & 122.3 & 5474\end{array}$

$\begin{array}{lllllll}5 & 548.7 & 0.10 & 109.4 & 71846 & 122.3 & 5576\end{array}$

$\begin{array}{lllllll}7 & 548.1 & 0.14 & 109.4 & 71573 & 123.0 & 5563\end{array}$

$11546.9 \quad 0.22 \quad 109.3 \quad 70594 \quad 122.1$

$11546.90 .22 \quad 109.3 \quad 70594 \quad 122.1 \quad 5501$

$\begin{array}{lllllll}15 & 545.7 & 0.31 & 109.2 & 72678 & 122.5 & 5448\end{array}$

\begin{tabular}{|c|c|c|c|c|c|c|c|c|c|c|c|c|c|}
\hline \multicolumn{4}{|c|}{$\begin{array}{l}\text { RUN NUMBER: } 180 \\
\text { P/d }=1.17 \\
\text { Pin }=538.2 \mathrm{kPa} \\
\text { Xin }=0.00 \\
\text { SURFACE TYPE: SMOOTH }\end{array}$} & \multicolumn{3}{|c|}{$\begin{array}{r}\text { WORKING FLUID: R-113 } \\
G=499.58 \mathrm{~kg} / \mathrm{g}^{*} \mathrm{~m}^{\wedge} 2 \\
\text { LTA P total }=4.52 \mathrm{kPa} \\
\text { Xout }=0.09\end{array}$} & \multicolumn{4}{|c|}{$\begin{array}{l}\text { RUN NUMBER: } 182 \\
\text { P/d }=1.17 \\
\text { PIn }=539 \mathrm{kPa} \\
\text { Xin }=0.01 \\
\text { SURFACE TYPE: SMOOTH }\end{array}$} & \multicolumn{3}{|c|}{$\begin{array}{r}\text { WORKING FLUID: R-11 } \\
G=497.32 \mathrm{~kg} / \mathrm{s}^{\star} \mathrm{m}^{n} \\
\text { P total }=4.52 \mathrm{kPa} \\
\text { Xout }=0.2\end{array}$} \\
\hline ROW & $\stackrel{P}{P}$ & & Tf & & Tw & $\stackrel{h}{\stackrel{1}{a} / m^{\wedge} 2}$ & ROW & $\begin{array}{c}P \\
\end{array}$ & & Tf & q'" & Tw & $\stackrel{h}{h}$ \\
\hline $\begin{array}{l}* \\
1\end{array}$ & $\begin{array}{l}{[\mathrm{kP}} \\
537\end{array}$ & $\begin{array}{l}{[-]} \\
0.00\end{array}$ & $\begin{array}{c}\text { [C] } \\
107.6\end{array}$ & $\begin{array}{l}{[\mathrm{W} / \mathrm{m}} \\
203\end{array}$ & $\begin{array}{c}{[\mathrm{C}]} \\
115.3\end{array}$ & {$\left[\begin{array}{c}\left(\mathrm{W} / \mathrm{m}^{\wedge} 2 \mathrm{2}\right. \\
2631\end{array}\right.$} & $\begin{array}{l}* \\
1\end{array}$ & & & $\begin{array}{c}{[C]} \\
107.9\end{array}$ & & & \\
\hline 3 & & & & & & & 3 & & & & & & \\
\hline 5 & & & & & & & 5 & & & & & & \\
\hline 7 & & & & & & & 7 & & & & & & \\
\hline 9 & & & & & & & & & & & & & \\
\hline & & & & & & & & & & & & & \\
\hline & & & & & & & & & & & & & \\
\hline & & 0.08 & & & & & & & .22 & 108.2 & & 119.9 & 4358 \\
\hline
\end{tabular}

RUN NUMBER: 174

$\mathrm{p} / \mathrm{d}=1.17$

WORKING FLUID: R-113 $X_{\text {In }}=-.00 \mathrm{kPa} \quad$ DELTA P total $=4.51 \mathrm{kPa}$ SURFACE TYPE: SMOOTH

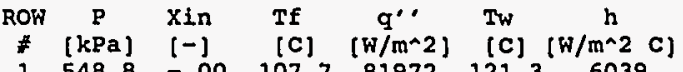

$\begin{array}{lllllll}F & {[\mathrm{kPa}]} & {[-]} & {[\mathrm{C}]} & \left(\mathrm{W} / \mathrm{m}^{\wedge} 2\right) & {[\mathrm{C}]} & {\left[\mathrm{W} / \mathrm{m}^{\wedge} 2\right.} \\ 1 & 548.8 & -.00 & 107.7 & 81972 & 121.3 & 6039\end{array}$

$\begin{array}{lllllll}3 & 548.2 & 0.05 & 108.8 & 81574 & 121.7 & 6302\end{array}$

$\begin{array}{lllllll}5 & 547.6 & 0.10 & 108.8 & 82981 & 121.5 & 6514\end{array}$

$\begin{array}{lllllll}7 & 547.0 & 0.14 & 108.7 & 83055 & 122.3 & 6110\end{array}$

$\begin{array}{rrrrrrr}9 & 546.4 & 0.19 & 108.7 & 81445 & 120.9 & 6652 \\ 11 & 545.8 & 0.24 & 108.7 & 81430 & 121.3 & 6456\end{array}$

$11545.8 \quad 0.24 \quad 108.7 \quad 81430121.3$

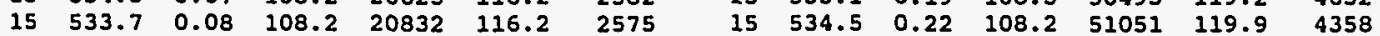

$\begin{array}{lllllll}13 & 545.2 & 0.29 & 108.6 & 83139 & 119.9 & 6394 \\ 15 & 544.7 & 0.33 & 108.6 & 83439 & 122.5 & 6517\end{array}$ 


\section{Bundle Boiling Data}

Smooth tube data in $\mathrm{R}-113$ for bundle with $\mathrm{p} / \mathrm{d}=1.50$ 
RUN NUMBER: 389 $\mathrm{p} / \mathrm{d}=1.5$

in $=206.3 \mathrm{kPa}$

XIn $=-.00$
SURFACE TYPE: SMOOTH
RUN NUMBER: 383 $\mathrm{p} / \mathrm{d}=1.5$

n $=204.6 \mathrm{kP}$ SURFACE TYPE: SMOOTH
WORKING FLUID: R-113 RUN NUMBER: 386 FLUID: $R-113$ DELTA P total $=5.65 \mathrm{kP}$ Xout $=0.39$ DEITA $=5.64 \mathrm{kPa}$

Pin $=212.4 \mathrm{kPa}$ $\mathrm{p} / \mathrm{d}=1.5$

SURFACE TYPE: SMOOTH
WORKING FLUID: R-113 $=50.85 \mathrm{~kg} / \mathrm{s}^{*} \mathrm{~m}^{\wedge 2}$ DELTA $P$ total $=5.72 \mathrm{kPa}$ xout $=0.76$

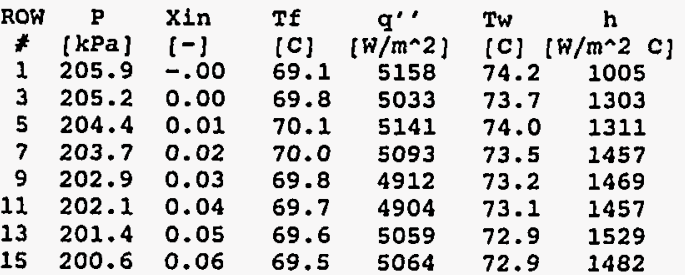

$\begin{array}{rcl}\text { ROW } & \text { P } & \text { Xin } \\ \neq & {[\mathrm{kPa}]} & {[-]} \\ 1 & 204.3 & 0.01 \\ 3 & 203.5 & 0.06 \\ 5 & 202.8 & 0.11 \\ 7 & 202.0 & 0.16 \\ 9 & 201.3 & 0.21 \\ 11 & 200.5 & 0.27 \\ 13 & 199.8 & 0.32 \\ 15 & 199.0 & 0.37\end{array}$

\begin{tabular}{|c|c|c|c|}
\hline & $q^{\prime \prime}$ & $T w$ & $\mathbf{h}$ \\
\hline [C] & $\left\{\omega / m^{\wedge} 2\right\}$ & [C] & $/ m^{\wedge} 2$ \\
\hline $\begin{array}{l}69.2 \\
76.1\end{array}$ & $\begin{array}{l}30889 \\
30153\end{array}$ & 82.7 & $\begin{array}{l}2298 \\
5735\end{array}$ \\
\hline 74.9 & 30722 & 81.2 & 4831 \\
\hline 73.6 & 30790 & 81.0 & 4128 \\
\hline 72.6 & 29777 & 81.2 & 3470 \\
\hline 12.6 & 29831 & 80.6 & 3313 \\
\hline 10.6 & 30571 & 81.8 & 2747 \\
\hline & 30601 & & \\
\hline
\end{tabular}

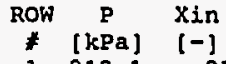

$1212.1-.01$

$\begin{array}{lll}3 & 211.3 & 0.09\end{array}$

$\begin{array}{lll}5 & 210.6 & 0.19 \\ 7 & 209.8 & 0.29\end{array}$

$9209.0 \quad 0.40$

$11208.3 \quad 0.51$

$\begin{array}{llllllll}13 & 207.5 & 0.61 & 70.7 & 59839 & 84.4 & 4377\end{array}$

$\begin{array}{llllllll}15 & 206.8 & 0.71 & 70.5 & 61185 & 85.9 & 4008 \\ & & 85.9 & 3987\end{array}$

\begin{tabular}{|c|c|c|c|c|c|c|}
\hline \multicolumn{4}{|c|}{$\begin{array}{l}\text { QUN NUMBER: } 388 \\
\text { P/d }=1.5 \\
\text { Sin }=205.9 \mathrm{kPa} \\
\text { Sin }=-.00 \\
\text { SURFACE TYPE: SMOOTH }\end{array}$} & \multicolumn{3}{|c|}{$\begin{array}{r}\text { WORKING FLUID: R-113 } \\
\text { G }=50.68 \mathrm{~kg} / \mathrm{g}^{\star} \mathrm{m}^{\wedge} 2 \\
\text { JELTA P total }=5.67 \mathrm{kPa} \\
\text { Xout }=0.13\end{array}$} \\
\hline ROW & P & $x$ in & $T f$ & & $T w$ & $\mathrm{~h}$ \\
\hline & & & (c) & {$\left[\omega / m^{\wedge} 2\right]$} & [C] & $\mathrm{N} / \mathrm{m} \leadsto 2$ \\
\hline$i$ & & & & 10535 & 76.1 & 1510 \\
\hline 3 & 204.8 & 0.01 & 70.0 & 10318 & 75.5 & 1887 \\
\hline 5 & 204.0 & & & 105 & 75.6 & 1873 \\
\hline 7 & & & & 105 & 75.1 & 2019 \\
\hline 9 & 202.5 & 0.0 & & 10197 & 75. & 1931 \\
\hline 11 & 201. & & & & 74.8 & 1955 \\
\hline 13 & & & & & & \\
\hline 15 & 200.2 & .12 & 69.4 & 10424 & 75.0 & 1880 \\
\hline
\end{tabular}

RUN NUMBER: 384

$\mathrm{p} / \mathrm{d}=1.5$

WORKING FLUID: R-113 RUN NUMBER: 365

$\mathrm{p} / \mathrm{d}=1$.

RKING FLUID: $R-113$ Xin $=208.8$
in $=-.00$

$G=50.85 \mathrm{~kg} / \mathrm{s}^{\star} \mathrm{m}^{\wedge} 2$

in $=204.7 \mathrm{kPa}$

$\operatorname{xin}=-.00$

xout $=0.51$ SURFACE TYPE: SMOOTH

$\begin{array}{rcccccc}\text { ROW } & p & \text { Xin } & \text { Tf } & q^{\prime \prime} & \text { Tw } & h \\ \# & {[k P a]} & {[-]} & {[C]} & {\left[W^{\prime} / m^{\wedge} 2\right]} & {[C]} & {\left[W / m^{\wedge} 2\right.} \\ 1 & 208.5 & -.00 & 69.5 & 41386 & 83.7 & 2896 \\ 3 & 207.7 & 0.06 & 70.6 & 40129 & 82.4 & 3408 \\ 5 & 206.9 & 0.13 & 70.5 & 40945 & 82.1 & 3550 \\ 7 & 206.2 & 0.20 & 70.4 & 41054 & 82.0 & 3538 \\ 9 & 205.4 & 0.27 & 70.3 & 39799 & 82.1 & 3390 \\ 11 & 204.7 & 0.34 & 70.2 & 39811 & 81.7 & 3480 \\ 13 & 203.9 & 0.41 & 70.1 & 40798 & 82.8 & 3227 \\ 15 & 203.1 & 0.48 & 70.0 & 40839 & 82.8 & 3194\end{array}$

Row $P \quad x$ in

$\begin{array}{lll}* & {[\mathrm{kPa}]} & {[-]} \\ 1 & 204.3 & -.00 \\ 3 & 203.6 & 0.01 \\ 5 & 202.8 & 0.02 \\ 7 & 202.1 & 0.02 \\ 9 & 201.3 & 0.03 \\ 11 & 200.5 & 0.04 \\ 13 & 199.8 & 0.05 \\ 15 & 199.0 & 0.06\end{array}$

\begin{tabular}{|c|c|c|c|}
\hline $\begin{array}{l}\text { Tf } \\
\text { [C] }\end{array}$ & $\underset{\left(W / m^{\prime \prime 2} 2\right.}{ }$ & $\begin{array}{l}T w \\
\text { (C) }\end{array}$ & $\stackrel{h}{m \wedge 2}$ \\
\hline & 10322 & 76.6 & 2372 \\
\hline 9.5 & 10083 & 75.8 & 1600 \\
\hline 69.6 & 10328 & 76.1 & 1595 \\
\hline & 10327 & 75.7 & 1673 \\
\hline 1.4 & 9940 & 75.5 & 1622 \\
\hline .4 & 9970 & 75.3 & 1675 \\
\hline 69.3 & 10079 & 75.5 & 1627 \\
\hline ? & 10089 & 75.5 & 1609 \\
\hline
\end{tabular}

\begin{tabular}{|c|c|c|c|c|c|c|c|c|c|c|c|c|c|}
\hline \multicolumn{4}{|c|}{$\begin{array}{l}\text { RUN NUMBER: } 382 \\
\text { P/d }=1.5 \\
\text { Pin }=203.6 \mathrm{kPa} \\
\text { Xin }=0.00 \\
\text { SUREACE TYPE: SMOOTH }\end{array}$} & \multicolumn{3}{|c|}{$\begin{array}{r}\text { WORKING FLUID: R-113 } \\
G=50.29 \mathrm{~kg} / \mathrm{s}^{\star} \mathrm{m}^{\wedge} 2 \\
\text { TA P total }=5.65 \mathrm{kPa} \\
\text { Xout }=0.26\end{array}$} & \multicolumn{4}{|c|}{$\begin{array}{l}\text { RUN NUMBER: } 385 \\
\text { p/d }=1.5 \\
\text { Pin }=210.1 \mathrm{kPa} \\
\text { Xin }=-.00 \\
\text { SURFACE TYPE: SMOOTH }\end{array}$} & \multicolumn{3}{|c|}{$\begin{array}{r}\text { WORKING FLUID: } R-113 \\
G=50.53 \mathrm{~kg} / \mathrm{s}^{\star} \mathrm{m}^{\wedge} 2 \\
\text { TA P total }=5.7 \mathrm{kPa} \\
\text { Xout }=0.64\end{array}$} \\
\hline $\begin{array}{l}\text { Row } \\
* \\
2\end{array}$ & $\begin{array}{c}\text { P } \\
{[\mathrm{KPa}]} \\
203.3\end{array}$ & $\begin{array}{l}x \text { in } \\
1-1 \\
0.00\end{array}$ & $\begin{array}{l}\text { Tf } \\
{[\text { C] }} \\
68.9\end{array}$ & $\begin{array}{c}q^{\prime \prime} \\
{\left[\begin{array}{c}\left.w^{\prime} / m^{\wedge} 2\right] \\
20847\end{array}\right]}\end{array}$ & $\begin{array}{l}\text { Tw } \\
{[\mathrm{C}]} \\
80 .\end{array}$ & $\begin{array}{c}h \\
W / m^{\wedge} 2 \\
1843\end{array}$ & $\begin{array}{c}\text { Row } \\
\# \\
2\end{array}$ & $\begin{array}{c}\mathrm{p} \\
{[\mathrm{kPa}]} \\
209.7\end{array}$ & $\begin{array}{l}x \text { in } \\
1-1 \\
-.00\end{array}$ & & $\begin{array}{c}q^{\prime \prime} \\
{\left[\begin{array}{c}W^{\prime} / \mathrm{m}^{\wedge} 2 \\
51238\end{array}\right]}\end{array}$ & $\begin{array}{l}\text { Tw } \\
\text { (C) } \\
85.2\end{array}$ & 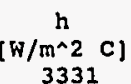 \\
\hline 3 & 202.5 & & & & & & 3 & & & & & & \\
\hline 5 & & & & & & & 5 & & & & & & \\
\hline 7 & 201. & 0 & 69 & & & & 7 & & & & & & 39 \\
\hline 9 & & & & & & & 9 & & & & & & \\
\hline & & & & & & & 11 & & & & & & \\
\hline & & & & & & & 13 & & & & & & \\
\hline 15 & 198.0 & 0.24 & 69.0 & 20472 & 78.8 & 2100 & 15 & 204.4 & 0.60 & 70.1 & 50665 & 84.3 & 3583 \\
\hline
\end{tabular}

RUN NUMBER: 366 $\mathrm{p} / \mathrm{d}=1.5$

Pin $=206.7 \mathrm{kPa}$ $x$ in $=-.01$

SURFACE TYPE: SMOOTH

WORKING FLUID: R-113 $\begin{aligned} G & =99.9 \mathrm{~kg} / \mathrm{s}^{\star} \mathrm{m}^{\wedge} 2 \\ & \end{aligned}$

\begin{tabular}{|c|c|c|c|c|c|}
\hline P & $x$ in & $\mathrm{Tf}$ & $q^{\prime \prime}$ & $T w$ & \\
\hline [KPa] & {$[-]$} & [C] & {$\left[\mathrm{W} / \mathrm{m}^{\wedge} 2\right]$} & (C) & $W / m \wedge 2$ \\
\hline 206.4 & -.01 & 69.2 & 20624 & 79.6 & 199 \\
\hline 205.6 & 0.01 & 70.2 & 19999 & 78.5 & 2394 \\
\hline 204.9 & 0.03 & 70.1 & 20453 & 78.4 & 2471 \\
\hline 204.1 & 0.05 & 70.0 & 20456 & 78.2 & 2506 \\
\hline 203.3 & 0.06 & 69.9 & 19753 & 78.4 & 2323 \\
\hline 202.6 & 0.08 & 69.8 & 20047 & 77.9 & 2471 \\
\hline 201. & 0.10 & 69.7 & 20314 & 78.6 & 2280 \\
\hline & & & & & 225 \\
\hline
\end{tabular}




\begin{tabular}{|c|c|c|c|c|c|c|}
\hline $\begin{array}{l}\text { RUN } \\
\text { P/d } \\
\text { Pin } \\
\text { Xin } \\
\text { SUR }\end{array}$ & $\begin{array}{l}\text { NUMBE } \\
=1.5 \\
=206 \\
=-.0 \\
\text { ACE T }\end{array}$ & : 356 & OTH & $\begin{array}{c}\text { WORKI } \\
G= \\
\text { ILTA } P t\end{array}$ & $\begin{array}{l}\text { G FLU } \\
00.41 \\
\mathrm{tal}= \\
\text { Xo }\end{array}$ & $\begin{array}{l}\text { ID: } \mathrm{R}-113 \\
\mathrm{~kg} / \mathrm{s}^{*} \mathrm{~m}^{n} 2 \\
5.7 \mathrm{kPa} \\
\mathrm{ut}=0.18\end{array}$ \\
\hline ROW & $\begin{array}{c}P \\
P\end{array}$ & $x$ in & Tf & q"' & $T w$ & $\stackrel{h}{h}$ \\
\hline $\begin{array}{l}* \\
1\end{array}$ & $\begin{array}{l}(\mathrm{kPa}) \\
206.5\end{array}$ & $\begin{array}{l}{[-]} \\
-.01\end{array}$ & $\begin{array}{l}{[\mathrm{C}]} \\
68.2\end{array}$ & {$\left[\begin{array}{c}{\left[\mathrm{w} / \mathrm{m}^{\wedge} \mathrm{2}\right]} \\
30704\end{array}\right.$} & $\begin{array}{l}\text { [C] } \\
83.1\end{array}$ & {$\left[\begin{array}{c}\left(\mathrm{W} / \mathrm{m}^{\wedge} 2 \mathrm{C}\right. \\
2055\end{array}\right.$} \\
\hline 3 & 205.7 & 0.01 & 70.1 & 29820 & 81.2 & 2683 \\
\hline 3 & 205.0 & 0.04 & 70.3 & 30462 & 80.7 & 2712 \\
\hline 7 & 204.2 & 0.0 & 70.2 & 30795 & 81.2 & 2780 \\
\hline 9 & 203.5 & 0.0 & 70 & 29773 & 81.5 & 2595 \\
\hline 11 & 202.7 & 0.1 & 69 & 29895 & 80.9 & 2714 \\
\hline 13 & 201.9 & & & 30555 & 81.9 & 2515 \\
\hline 15 & 201.2 & 0.17 & 69.6 & 30585 & 81.9 & 2492 \\
\hline
\end{tabular}

RUN NUMBER: 359

$\mathrm{p} / \mathrm{d}=1.5$

Pin $=210.7 \mathrm{kP}$ SURFACE TYPE: SMOOTH

WORKING FLUID: R-11 $G=99.92 \mathrm{~kg} / \mathrm{g}^{\star} \mathrm{m}^{\wedge} 2$ $\begin{aligned} \text { DELTA P total } & =5.7 \mathrm{kPa} \\ \text { Xout } & =0.38\end{aligned}$ ROW $p \quad x$ in $\begin{array}{lll}* & \text { [kPa] } & {[-]} \\ 1 & 210.4 & -.01\end{array}$ $\begin{array}{lll}3 & 209.6 & 0.04 \\ 5 & 208.9 & 0.09\end{array}$ $\begin{array}{lll}5 & 208.9 & 0.09 \\ 7 & 208.1 & 0.14\end{array}$ $\begin{array}{lll}7 & 208.1 & 0.14 \\ 9 & 207.3 & 0.20\end{array}$ $\begin{array}{lll}11 & 206.6 & 0.25 \\ 13 & 205.8 & 0.30\end{array}$ $\begin{array}{lll}13 & 205.8 & 0.30 \\ 15 & 205.1 & 0.35\end{array}$
RUN NUMBER: 374 $\mathrm{p} / \mathrm{d}=1.5$ Pin $=203.7 \mathrm{kPa}$ $x$ in $=0.00$ SURFACE TYPE: SMOOTH

\begin{tabular}{|c|c|c|c|c|c|c|c|c|c|c|c|c|c|}
\hline \multicolumn{4}{|c|}{$\begin{array}{l}\text { RUN NUMBER: } 357 \\
\text { p/d }=1.5 \\
\text { Pin }=208.1 \mathrm{kPa} \\
\text { Xin }=-.01 \\
\text { SURFACE TYPE: SMOOTH }\end{array}$} & \multicolumn{3}{|c|}{$\begin{array}{r}\text { WORKING FLUID: R-113 } \\
G=100.36 \mathrm{~kg} / \mathrm{s}^{\star} \mathrm{m}^{\wedge} 2 \\
\text { SLTA P total }=5.72 \mathrm{kPa} \\
\text { Xout }=0.25\end{array}$} & \multicolumn{4}{|c|}{$\begin{array}{l}\text { RUN NUMBER: } 360 \\
\text { P/d }=1.5 \\
\text { Pin }=210.6 \mathrm{kPa} \\
\text { Xin }=-.01 \\
\text { SURFACE TYPE: SMOOTH }\end{array}$} & \multicolumn{3}{|c|}{$\begin{array}{r}\text { WORKING FLUID: R-113 } \\
G=100.34 \mathrm{~kg} / \mathrm{s}^{\star} \mathrm{m}^{\wedge} 2 \\
\text { ELTA } \mathrm{P} \text { total }=5.7 \mathrm{kPa} \\
\text { XOut }=0.44\end{array}$} \\
\hline ROW & P & $x$ in & Tf & & Tw & $h$ & ROW & $p$ & & TE & & Tw & $\mathrm{h}$ \\
\hline$\#$ & $\mathrm{kP}$ & {$[-$} & 1C & {$[\mathrm{w} / \mathrm{m}$} & & $(\mathrm{w} / \mathrm{m} \wedge 2 \mathrm{C}$ & $\neq$ & & & & & & \\
\hline 1 & & & & & & & 1 & & & & & & \\
\hline 3 & & & & & & & 3 & & & & & & \\
\hline 5 & & & 70 & & & & 5 & & & & & & \\
\hline 7 & & & & & & & 7 & & & & & & \\
\hline 9 & & & & & & & 9 & & & & & & \\
\hline 11 & & & & & & & 11 & & & & & & \\
\hline 13 & & & & & & & & & & & & & \\
\hline 15 & & & 69.8 & 40789 & 83.4 & 3000 & 15 & 205.0 & & 70.2 & 71146 & 86.6 & 4347 \\
\hline
\end{tabular}

\begin{tabular}{|c|c|c|c|c|c|c|}
\hline \multicolumn{4}{|c|}{$\begin{array}{l}\text { RUN NUMBER: } 358 \\
\text { p/d }=1.5 \\
\text { Pin }=209.1 \mathrm{kPa} \\
\text { Xin }=-.01 \\
\text { SURFACE TYPE: SMOOTH }\end{array}$} & $\begin{array}{c}\text { WORKI } \\
G=\end{array}$ & $\begin{array}{l}\text { G FLU } \\
00.1\end{array}$ & $\begin{array}{l}\text { ID: } R-113 \\
\mathrm{~kg} / \mathrm{s}^{\star} \mathrm{m}^{\wedge} 2 \\
5.66 \mathrm{kPa}\end{array}$ \\
\hline ow & & & & & & $\mathrm{h}$ \\
\hline$\neq$ & & & & & & $/ / \mathrm{m}^{\wedge} 2$ \\
\hline 1 & & & & & 85.6 & \\
\hline 3 & & & & & & \\
\hline 5 & & & & & & \\
\hline 7 & & & & & & \\
\hline 9 & & & & & & \\
\hline 1 & & & & & & \\
\hline & & & & & & \\
\hline 5 & & & 70.0 & 50440 & 5 & 34 \\
\hline
\end{tabular}

\section{RUN NUMBER: 361} $\mathrm{p} / \mathrm{d}=1.5$ Pin $=213.5 \mathrm{kPa}$ Xin $=-.01$
SURFACE TYPE: SMOOTH

WORKING FLUID: R-113 $G=99.97 \mathrm{~kg} / \mathrm{s}^{*} \mathrm{~m}^{\wedge} 2$ $\begin{aligned} \text { DELTA P total } & =5.7 \mathrm{kPa} \\ \text { xout } & =0.5\end{aligned}$ $\begin{array}{ccc}\text { ROW } & P & X \text { in } \\ \# & {[\mathrm{kPa}]} & (-) \\ 1 & 213.3 & -.01 \\ 3 & 212.5 & 0.06 \\ 5 & 211.8 & 0.12 \\ 7 & 211.0 & 0.19 \\ 9 & 210.3 & 0.27 \\ 11 & 209.5 & 0.34 \\ 13 & 208.8 & 0.41 \\ 15 & 208.0 & 0.47\end{array}$
WORKING FLUID: R-113 $\begin{aligned} \text { DELTA P total } & =5.73 \mathrm{kPa} \\ \text { Xout } & =0.03\end{aligned}$

RUN NUMBER: 367 WORKING FLUID: $R-113$ $\mathrm{p} / \mathrm{d}=1.5 \quad G=218.67 \mathrm{~kg} / \mathrm{g}^{\star^{\prime} \mathrm{m}^{\wedge}}$ Pin $=206 \mathrm{kPa} \quad$ DELTA $\mathrm{P}$ total $=5.68 \mathrm{kPa}$ SURFACE TYPE: SMOOTH

\begin{tabular}{|c|c|c|c|c|c|c|}
\hline ROW & $\mathbf{P}$ & $x$ in & $T f$ & $q^{\prime \prime}$ & $T w$ & h \\
\hline$\neq$ & ( $\mathrm{kPa}$ ) & {$[-]$} & [C] & $\left\{\mathrm{W} / \mathrm{m}^{\wedge} 2\right\}$ & [C] & $W / m \sim 2$ \\
\hline 1 & 205.7 & -.00 & 69.2 & 20484 & 80.2 & 1859 \\
\hline 3 & 204.9 & 0.00 & 69.8 & 19888 & 79.0 & 2152 \\
\hline 5 & 204.2 & 0.01 & 70.0 & 20318 & 79.4 & 2155 \\
\hline 7 & 203.4 & 0.02 & 69.9 & 20502 & 79.6 & 2105 \\
\hline 9 & 202.7 & 0.03 & 69.8 & 19797 & 79.7 & 1995 \\
\hline 11 & 201.9 & 0.04 & 69.6 & 20100 & 79.3 & 2086 \\
\hline 13 & 201.2 & 0.04 & & 20356 & & 1911 \\
\hline 15 & 200.4 & 0.05 & 69.4 & 20376 & 80.2 & 1895 \\
\hline
\end{tabular}

RUN NUMBER: 368 $\mathrm{p} / \mathrm{d}=1.5$

WORKING FLUID: R-113 $G=218.21 \mathrm{~kg} / \mathrm{g}^{\star} \mathrm{m}^{\wedge} 2$ $\begin{aligned} \text { Xin } & =-.01 \\ \text { Xout } & =0.08\end{aligned}$ SURFACE TYPE: SMOOTH

\begin{tabular}{|c|c|c|c|c|c|c|}
\hline & $\mathbf{P}$ & $x$ in & $\mathrm{TI}$ & $q^{\prime \prime}$ & $T w$ & $\mathrm{~h}$ \\
\hline & (KPa) & {$[-]$} & [C] & {$\left[W / m^{\wedge} 2\right]$} & (c) & $/ m^{\wedge} 2$ \\
\hline & 210.1 & -.01 & 69.5 & 30811 & 82.5 & 2359 \\
\hline 3 & 209.4 & 0.00 & 70.5 & 298 & 81.1 & 2792 \\
\hline 5 & 208.6 & & & & & 29 \\
\hline & 207.9 & & & & & 2938 \\
\hline & 207.1 & 0.0 & 5 & & 81.2 & 2791 \\
\hline & 206.3 & & & & & \\
\hline & 205.6 & 0.06 & 70.3 & 30387 & 81.8 & 2650 \\
\hline
\end{tabular}




$\begin{array}{lr}\text { RUN NUMBER: } 369 & \text { WORKING FLUTD: } R-113 \\ \text { P/d }=1.5 & G=217.44 \mathrm{~kg} / \mathrm{s}^{*} \mathrm{~m}^{\wedge} 2 \\ \text { PIn }=214.6 \mathrm{kPa} & \text { DELTA P total }=5.69 \mathrm{kPa} \\ \text { XIn }=-.01 & \text { Xout }=0.11 \\ \text { SURFACE PYPE: SHOOTH } & \end{array}$

RUN NUKBER: 372

$\mathrm{P} / \mathrm{d}=1.5$

WORKING FLUID: R-113 RUN NUMBER: 376

$\mathrm{p} / \mathrm{d}=1.5$

WORKING FLUID: R-113 $\mathrm{Pin}=206.2 \mathrm{kPa}$ $\begin{aligned} \text { DELTA } P \text { total } & =5.72 \mathrm{kPa} \\ \text { Xout } & =0.20\end{aligned}$ SURFACE TYPE: SMOOTH

$\operatorname{xin}=-.00$

$P$ total $=5.65 * \mathrm{~m}^{\wedge}$

SUREACE TYPE: SKOOT

\begin{tabular}{|c|c|c|c|c|c|c|}
\hline & $P$ & $x$ in & & $\sigma^{\prime \prime}$ & $T w$ & \\
\hline $\begin{array}{l}* \\
1\end{array}$ & [kPa ] & {$[-]$} & [c] & {$\left[\mathrm{W} / \mathrm{m}^{\wedge} \mathbf{2}\right]$} & [c] 1 & $/ \mathbb{m}^{\wedge} \mathbf{c}$ \\
\hline 3 & 210.8 & 0.02 & 71.1 & 69771 & 86.3 & 4582 \\
\hline & 210. & & & & & \\
\hline & 209.3 & 0.0 & 70.9 & 71252 & 86.3 & 4607 \\
\hline & 208 & & & & & 4562 \\
\hline & 207. & .1 & 0 & 69647 & & 4765 \\
\hline & 207.0 & 0.16 & 0.6 & 70717 & 86.8 & 4349 \\
\hline & & & & & & \\
\hline
\end{tabular}

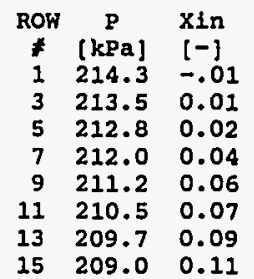

\begin{tabular}{|c|c|c|c|}
\hline & & & \\
\hline$\left[\begin{array}{l}\left.C_{3}\right] \\
70^{2}\end{array}\right.$ & {$\left[\mathrm{W} / \mathrm{m}^{\wedge} \mathbf{2}\right]$} & [C] & \\
\hline 1.3 & 40224 & 83.3 & 357 \\
\hline & 41070 & & 3523 \\
\hline 1.3 & 41103 & 83.2 & 3477 \\
\hline & & & \\
\hline 1.1 & 39887 & & 3465 \\
\hline 10 & 40690 & 830 & 3162 \\
\hline & & & \\
\hline
\end{tabular}

Pin $=210.1$

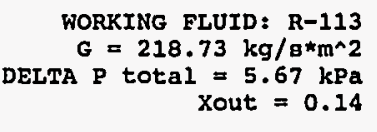

WORKING FLUID: R-113 $G=218.73 \mathrm{~kg} / \mathrm{s}^{*} \mathrm{~m}^{\wedge} 2$ DELTA P total $=5.67 \mathrm{kPa}$ Xout $=0.14$

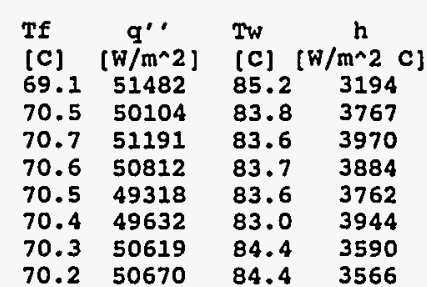

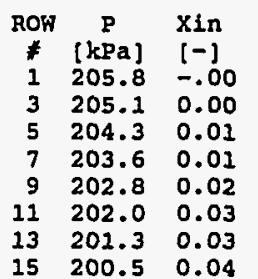

\begin{tabular}{|c|c|c|}
\hline$\underset{\left[W / m^{\wedge} 2\right]}{q^{\prime \prime}}$ & $\begin{array}{l}\text { Tw } \\
{[C] !}\end{array}$ & $\begin{array}{c}h \\
N / m^{\wedge} 2\end{array}$ \\
\hline 20778 & 79.8 & 1926 \\
\hline 20193 & 79.1 & 2127 \\
\hline 20539 & 79.6 & 2141 \\
\hline 20482 & 79.6 & 2135 \\
\hline 19754 & 79.6 & 2013 \\
\hline 20016 & & 2119 \\
\hline 20309 & 79.9 & 1960 \\
\hline
\end{tabular}

\begin{tabular}{|c|c|c|c|c|c|c|}
\hline \multicolumn{4}{|c|}{$\begin{array}{l}\text { RUN NUMBER: } 371 \\
\text { p/d }=1.5 \\
\text { PIn }=209.2 \mathrm{kPa} \\
\text { XIN }=-.01 \\
\text { SURFACE TYPE: SMOOTH }\end{array}$} & \multicolumn{3}{|c|}{$\begin{array}{r}\text { WORKING FLUID: } R-113 \\
G=218.29 \mathrm{~kg} / \mathrm{s}^{\star} \mathrm{m}^{\wedge} 2 \\
\text { LTA P total }=5.72 \mathrm{kPa} \\
\text { Xout }=0.17\end{array}$} \\
\hline KOW & $\mathbf{P}$ & & & & & \\
\hline & & & & & & $(\mathrm{w} / \mathrm{m}$ \\
\hline 1 & & & & & & \\
\hline 3 & & & & & & \\
\hline 5 & & & & & & \\
\hline 7 & & & & & & \\
\hline 9 & & & & & & \\
\hline 11 & & & & & & \\
\hline 13 & & & & & & \\
\hline 15 & & & & 60254 & & \\
\hline
\end{tabular}
SURFACE TYPE: SMOOTH

$\begin{array}{lll}* & \mathrm{kPa} & \mathrm{Kin} \\ 1 & 217.9 & -.01 \\ 3 & 217.1 & 0.02\end{array}$

$\begin{array}{lll}1 & 217.9 & -.01 \\ 217.1 & 0.02\end{array}$

$216.4 \quad 0.05$

\begin{tabular}{lll}
215.6 & 0.09 \\
\hline & 214.9 & 0.12
\end{tabular}

$\begin{array}{rrr}9 & 214.9 & 0.12 \\ 11 & 214.1 & 0.15\end{array}$

$\begin{array}{lll}11 & 214.1 & 0.15 \\ 13 & 213.4 & 0.18\end{array}$

$\begin{array}{lll}13 & 213.4 & 0.18 \\ 15 & 212.6 & 0.22\end{array}$
RUN NUMBER: 375

$\mathrm{p} / \mathrm{d}=1.5$
$\mathrm{P}$ in $=205.7 \mathrm{kPa}$

SURFACE TYPE: SMOOTH

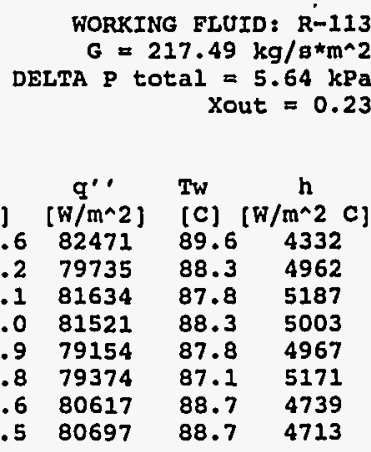

RUN NUMBER
$\mathrm{p} / \mathrm{d}=1.5$

Pin $=-.00$

SURFACE TYPE: SMOOTE

WORKING FLUID: R-113

$G=303.7 \mathrm{~kg} / \mathrm{B} * \mathrm{~m} \wedge 2$

DELTA P total $=5.72 \mathrm{kPa}$

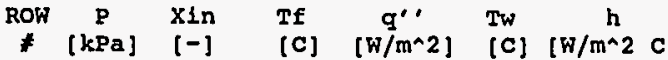

$\begin{array}{lllllll}206.2 & -.00 & 69.0 & 30937 & 82.2 & 2344\end{array}$

$\begin{array}{lllllll}3 & 205.4 & 0.01 & 69.9 & 30009 & 81.0 & 268\end{array}$

$\begin{array}{lllllll}5 & 204.6 & 0.02 & 70.1 & 30585 & 81.5 & 2704\end{array}$

$\begin{array}{lllllll}7 & 203.9 & 0.02 & 70.0 & 30496 & 81.7 & 2612\end{array}$

$\begin{array}{rrrrrrr}9 & 203.1 & 0.03 & 69.9 & 29505 & 82.0 & 2446\end{array}$

$\begin{array}{lllllll}11 & 202.4 & 0.04 & 69.8 & 29509 & 81.4 & 2530\end{array}$

$\begin{array}{lllllll}13 & 201.6 & 0.05 & 69.6 & 30185 & 82.5 & 2356\end{array}$ $\begin{array}{ccc}\text { * } & \text { P } & \text { Xin } \\ 1 & \text { [KPa] } & 1-\text { ] } \\ \text { I } & 205.4 & -.00\end{array}$

$3 \begin{array}{ll}204.6 & 0.00\end{array}$

$5203.9 \quad 0.00$

$7203.1 \quad 0.01$

$\begin{array}{rrr}9 & 202.4 & 0.01 \\ 11 & 201.6 & 0.01\end{array}$

$\begin{array}{lll}13 & 200.9 & 0.02 \\ 15 & 200.1 & 0.02\end{array}$

\begin{tabular}{|c|c|c|}
\hline$\left[\mathrm{w} / \mathrm{m}^{\prime \prime}{ }^{\prime}\right]$ & Tw & h \\
\hline 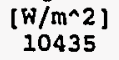 & $\begin{array}{l}\text { [C] } \\
76.5\end{array}$ & $\begin{array}{c}\left.W / m^{\wedge} 2 C\right] \\
1414\end{array}$ \\
\hline 10311 & 76.3 & 1497 \\
\hline 10452 & 76.7 & 1488 \\
\hline 10471 & 76.4 & 1574 \\
\hline 10100 & 76.3 & 1518 \\
\hline 10174 & 76.1 & 1564 \\
\hline 10297 & 76.2 & 1535 \\
\hline 10307 & 76.2 & 1516 \\
\hline
\end{tabular}

WORKING FLUID: R-113 RUN NUMBER: 378

$\mathrm{p} / \mathrm{d}=1.5$

$G=305.06 \mathrm{~kg} / \mathrm{s}^{*} \mathrm{~m}^{\wedge} 2$ DELTA P total $=5.69 \mathrm{kPa}$

SURFACE TYPE: SMOOTH

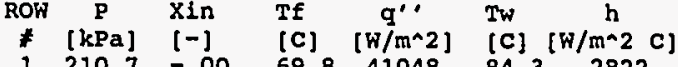

$\begin{array}{lllllll}1 & 210.7 & -.00 & 69.8 & 41048 & 84.3 & 2822 \\ 3 & 210.0 & 0.01 & 70.6 & 39760 & 83.0 & 3217\end{array}$

$\begin{array}{llllllll}5 & 209.2 & 0.02 & 70.8 & 40616 & 83.1 & 3303\end{array}$

$\begin{array}{lllllll}7 & 208.5 & 0.03 & 70.7 & 40829 & 83.5 & 3193\end{array}$

$\begin{array}{rrrrrrr}9 & 207.7 & 0.05 & 70.6 & 39548 & 83.7 & 3028\end{array}$

$\begin{array}{lllllll}11 & 206.9 & 0.06 & 70.5 & 39724 & 83.2 & 3161\end{array}$

$\begin{array}{lllllll}13 & 206.2 & 0.07 & 70.4 & 40584 & 84.5 & 2886 \\ 15 & 205.4 & 0.08 & 70.3 & 40625 & 84.5 & 2870\end{array}$ 


\begin{tabular}{|c|c|c|c|c|c|c|c|c|c|c|c|c|c|}
\hline in & $\begin{array}{l}\text { NUMBE } \\
=1.5 \\
=217 \\
=-.0 \\
\text { FACE T }\end{array}$ & : 379 & OTH & $\begin{array}{r}\text { WORKI } \\
G= \\
\text { SLTA } P t\end{array}$ & $\begin{array}{r}\text { FLU } \\
4.69 \\
=\text { al }= \\
\text { Xo }\end{array}$ & $\begin{array}{l}\text { ID : } R-113 \\
\mathrm{~kg} / \mathrm{s}^{*} \mathrm{~m} \mathrm{~m}^{\wedge} 2 \\
5.66 \mathrm{kPa} \\
\mathrm{Lt}=0.11\end{array}$ & $\begin{array}{l}\text { RUN } \\
\text { P/d } \\
\text { Pin } \\
\text { Xin } \\
\text { SURE }\end{array}$ & $\begin{array}{l}\text { NUMBE } \\
=1.5 \\
=520 \\
=-.0 \\
\text { FACE T }\end{array}$ & 399 & & $\begin{array}{c}\text { WORKI } \\
G= \\
T A P E\end{array}$ & $\begin{array}{l}G \text { FLU } \\
0.09\end{array}$ & $\begin{array}{l}I D: R-12 \\
\mathrm{~kg} / \mathrm{g}^{\star} \mathrm{m}^{\wedge} 2 \\
4.61 \mathrm{kP}\end{array}$ \\
\hline & $\stackrel{P}{P}$ & & $\begin{array}{l}\text { Tf } \\
\text { [C] }\end{array}$ & $\underset{\left[w^{\prime \prime} / m^{\wedge} 2\right.}{\left.q^{\prime}\right)}$ & $\begin{array}{l}T w \\
\text { C }\end{array}$ & $\stackrel{h}{h / m^{\wedge}}$ & ROW & $\stackrel{p}{P}$ & & & $q^{\prime \prime}$ & Tw & $\stackrel{h}{h / m^{\wedge} 2}$ \\
\hline & 217.3 & .00 & 70.8 & & 86.8 & 3198 & i & 520.4 & & $\begin{array}{l}2.1 \\
2.1\end{array}$ & 10371 & 112.7 & 1035 \\
\hline & & & & & & & 3 & & & & & & \\
\hline & & & & & & & 5 & & & & & & \\
\hline & & & & & & & & & & & & & \\
\hline & & & & & & & 9 & & & & & & \\
\hline & & & 71 & & & & & & & & & & \\
\hline & & & & & & & & & & & & & \\
\hline & 21 & 0.10 & 71.4 & 0785 & 86.7 & 3326 & 15 & 516.1 & 0.10 & 106.7 & 10347 & 113.4 & 154 \\
\hline
\end{tabular}

RUN NUMBER: 401

$\mathrm{p} / \mathrm{d}=1.5$

Pin $=545.1 \mathrm{kPa}$

SURFACE TYPE: SMOOTH

HORKING FLUID: $R-113$

$G=50.71 \mathrm{~kg} / \mathrm{s}^{\star} \mathrm{m}^{\wedge} 2$ DELTA P total $=3.51 \mathrm{kPa}$

\begin{tabular}{|c|c|c|c|c|c|c|}
\hline$D F$ & $\stackrel{P}{P}$ & xin & Tf & $q^{\prime \prime}$ & $T w$ & $\mathrm{~h}$ \\
\hline \# & [kPa] & {$[-]$} & {$[C]$} & {$\left[\mathrm{W} / \mathrm{m}^{\wedge} 2\right]$} & [c] & \\
\hline & 544.9 & & 103.1 & 40514 & 121.9 & 2481 \\
\hline 3 & 544.2 & 0.00 & 108.4 & 398 & & 3346 \\
\hline & & & & & & \\
\hline 7 & 543.1 & 0.16 & 109.0 & 41488 & 122. & 3041 \\
\hline & 542 & & & & & \\
\hline & 542. & 0.33 & & & 122.1 & 3198 \\
\hline & 542.0 & 0,41 & 08 & & 121 & 3235 \\
\hline & & & & & & \\
\hline
\end{tabular}

\begin{tabular}{|c|c|c|c|c|c|c|c|c|c|c|c|c|c|}
\hline $\begin{array}{l}\text { RUN } \\
\text { p/d } \\
\text { Pin } \\
\text { Xin } \\
\text { SUR }\end{array}$ & $\begin{array}{l}\text { NUMBE } \\
=1.5 \\
=216 \\
=-.03 \\
\text { FACE TS }\end{array}$ & $\mathrm{PE}: \mathrm{S}$ & & $\begin{array}{c}\text { WORKI } \\
G=\end{array}$ & $\begin{array}{l}\text { FLU } \\
84.39 \\
\mathrm{cal}\end{array}$ & $\begin{array}{r}\text { ID: } R-113 \\
\mathrm{~kg} / \mathrm{s}^{*} \mathrm{~m}^{\wedge} 2 \\
5.72 \mathrm{kPa} \\
\text { ut }=0.12\end{array}$ & $\begin{array}{l}\text { RUN } \\
\text { p/d } \\
\text { Pin } \\
\text { Xin } \\
\text { SUR }\end{array}$ & $\begin{array}{l}\text { NUMBE } \\
=1.5 \\
=540 \\
=-.0 \\
\text { ACE TS }\end{array}$ & 398 & OOTH & WORKI & $\begin{array}{l}\text { NG FLU } \\
50.19\end{array}$ & $\begin{array}{l}D: \quad R-11 \\
g / \mathrm{g}^{\star} \mathfrak{m}^{\wedge} 2 \\
4.4 \mathrm{kPa}\end{array}$ \\
\hline OW & P & $x i$ & Tf & & $T W$ & $\mathrm{~h}$ & ROW & $\mathbf{P}$ & & $T$ & & $T w$ & \\
\hline \# & [ $\mathrm{kP}$ & & & & & $1 / m^{\wedge} 2$ & $\#$ & & & & & & \\
\hline 1 & 215 & . & .9 & & & 3480 & 1 & & & & 191 & 116.6 & \\
\hline 3 & & & & & & & 3 & &.- & & & & \\
\hline 5 & & & & & & & 5 & & & & & & \\
\hline 7 & & c & & & & & 7 & & & & & & \\
\hline 9 & & & & & & & 9 & & & & & & \\
\hline & & & & & & & & & & & & & \\
\hline & & & & & & & & & & & & & \\
\hline 15 & 210.6 & 0.11 & 71.2 & 60575 & 87.0 & 3820 & 15 & 536.0 & .21 & 108.4 & 19355 & 117.3 & 2154 \\
\hline
\end{tabular}

\begin{tabular}{|c|c|c|c|c|c|c|c|c|c|c|c|c|c|}
\hline \multicolumn{4}{|c|}{$\begin{array}{l}\text { RUN NUMBER: } 381 \\
\text { P/d }=1.5 \\
\text { Pin }=219.9 \mathrm{kPa} \\
\text { Xin }=-.01 \\
\text { SURFACE TYPE: SMOOTH }\end{array}$} & \multicolumn{3}{|c|}{$\begin{array}{r}\text { WORKING FLUID: } R-113 \\
G=280.57 \mathrm{~kg} / \mathrm{s}^{\star} \mathrm{m}^{\wedge} 2 \\
\text { LTA P total }=5.69 \mathrm{kPa} \\
\text { Xout }=0.15\end{array}$} & $\begin{array}{l}\text { RUN } \\
\text { p/d } \\
\text { Pin } \\
\text { Xin } \\
\text { SUR }\end{array}$ & $\begin{array}{l}\text { NUMBEF } \\
=1.5 \\
=520 . \\
=-.06 \\
\text { ACE TY }\end{array}$ & $\begin{array}{l}: 400 \\
8 \mathrm{kPa}\end{array}$ & OTH & $\begin{array}{l}\text { WORKIN } \\
G=5 \\
\text { TA } P \text { to }\end{array}$ & $\begin{array}{l}\text { VG FLU } \\
50.8\end{array}$ & $\begin{array}{l}D: R-11 \\
/ 8^{\star} m^{\wedge} 2\end{array}$ \\
\hline Kow & $\begin{array}{c}\mathrm{P} \\
\mathrm{kPa}\end{array}$ & & Tf & $q^{\prime \prime}$ & Tw & $h$ & Row & & & & & Tw & \\
\hline 1 & & $\begin{array}{l}-1 \\
-.01\end{array}$ & 70.7 & 711 & & & 1 & & & & & & \\
\hline 3 & & & 72. & & & & 3 & & & & & & \\
\hline 5 & & & & & & & 5 & & & & & & \\
\hline 7 & & & & & & & 7 & & & & & & \\
\hline & & & 72 & & & & 9 & & & & & & \\
\hline & & & & & & & & & & & & & \\
\hline & & & & & & & & & & & & & \\
\hline & & & & & & & & & & 06.8 & & 17.8 & \\
\hline
\end{tabular}

RUN NUMBER: 402

$\mathrm{p} / \mathrm{d}=1.5$

$\begin{aligned} P \text { in } & =557.4 \mathrm{kPa} & \text { DELTA } P \text { total } & =3.26 \mathrm{kPa} \\ \mathrm{Xin} & =-.08 & \text { Xout } & =0.69\end{aligned}$ SURFACE TYPE: SMOOTH

\begin{tabular}{|c|c|c|c|c|c|c|}
\hline OW & $\begin{array}{c}\mathrm{P} \\
\mathrm{P}\end{array}$ & $x$ in & Tf & $q$ & Tw & h \\
\hline & 557. & -.08 & 103.7 & 50552 & 124.5 & 2856 \\
\hline 3 & 556.4 & 0.0 & 109 & & & 3802 \\
\hline & 555 & & & & & 923 \\
\hline & 555 & & & & & \\
\hline 9 & 555 & 0.3 & & & & 3612 \\
\hline & & & & & & \\
\hline & 1.5 & 0.53 & 109.9 & 50740 & 124. & 3599 \\
\hline
\end{tabular}

RUN NUMBER: 403

RUN NUMBER: $403 \quad$ WORKING FLUID: $R-113$
$\mathrm{p} / \mathrm{d}=1.5$ Pin $=564.8 \mathrm{kPa}$ DELTA P total $=2.67 \mathrm{kPa}$ SURFACE TYPE: SMOOTH

\begin{tabular}{|c|c|c|c|c|c|c|}
\hline OW & P & $x \ln$ & Tf & $q^{\prime \prime}$ & \multirow{2}{*}{\multicolumn{2}{|c|}{ (C) $[\mathrm{W} / \mathrm{t}$}} \\
\hline * & & & [C] & & & \\
\hline 1 & & -.08 & 104.3 & & 126.8 & 32 \\
\hline 3 & 564. & 0.04 & 110.7 & & & \\
\hline 5 & & & & & & \\
\hline 7 & $5 e$ & . & 110 & & & 3 \\
\hline 9 & 562. & 0 & & & & \\
\hline & 5 & 0.5 & & & 12 & 3861 \\
\hline 13 & 562.5 & 0.67 & 110.5 & 61767 & 127.1 & 3742 \\
\hline & & & & & & \\
\hline
\end{tabular}

$G=50.59 \mathrm{~kg} / \mathrm{s}^{*} \mathrm{~m}^{\wedge} 2$ 


\begin{tabular}{|c|c|c|c|c|c|c|c|c|c|c|c|c|c|}
\hline \multicolumn{4}{|c|}{$\begin{array}{l}\text { RUN NUMBER: } 390 \\
\text { P/d }=1.5 \\
\text { Pin }=582 \mathrm{kPa} \\
\text { Xin }=0.01 \\
\text { SURFACE TYPE: SMOOTH }\end{array}$} & \multicolumn{3}{|c|}{$\begin{array}{r}\text { WORKING FLUID: } R-113 \\
G=99.46 \mathrm{~kg} / \mathrm{g}^{\star} \mathrm{m}^{\wedge} 2 \\
\mathrm{P} \text { total }=2.53 \mathrm{kPa} \\
\text { Xout }=0.10\end{array}$} & \multicolumn{4}{|c|}{$\begin{array}{l}\text { RUN NUMBER: } 396 \\
\text { P/d }=1.5 \\
\text { Pin }=600.4 \mathrm{kPa} \\
\text { Xin }=-.00 \\
\text { SURFACE TYPE: SMOOTH }\end{array}$} & \multicolumn{3}{|c|}{$\begin{array}{r}\text { WORKING FIUID: R-113 } \\
G=102.43 \mathrm{~kg} / \mathrm{s}^{\star} \mathrm{m}^{\wedge} \\
\text { IELTA P totai }=1.37 \mathrm{kPa} \\
\text { Xout }=0.33\end{array}$} \\
\hline $\begin{array}{l}\text { Row } \\
*\end{array}$ & $\underset{[\mathrm{kPa}]}{P}$ & & & $\frac{q^{\prime \prime}}{\left[w / m^{\wedge} 2\right]}$ & $\begin{array}{l}\text { Tw } \\
\text { [C] }\end{array}$ & $\stackrel{h}{h}$ & $\stackrel{\text { ROW }}{*}$ & & & & & $\begin{array}{l}\text { Tw } \\
{[\mathbf{C}] !}\end{array}$ & $\stackrel{h}{h m^{\wedge} 2}$ \\
\hline 1 & & & & & & & 1 & & & & & & \\
\hline 3 & & & & & & & 3 & & & & & & \\
\hline 5 & & & & & & & 5 & & & & & & \\
\hline 7 & & & & & & & 7 & & & & & & \\
\hline 9 & & & & & & & 9 & & & & & & \\
\hline & & & & & & & & & & & & & \\
\hline 13 & & & & & & & & & & & & & \\
\hline 5 & & 0.09 & 211.9 & 11249 & 117.4 & 2046 & 15 & & & 113.4 & 41947 & 126.2 & 3275 \\
\hline
\end{tabular}

RUN NUMBER: 393

$\mathrm{p} / \mathrm{d}=1.5$

$G=101.49 \mathrm{~kg} / \mathrm{s}^{\star \mathrm{m}^{\wedge} 2}$

$\begin{aligned} \mathrm{P} i n & =605.8 \mathrm{kPa} \quad \text { DELTA } \mathrm{P} \text { total }=.14 \mathrm{kPa} \\ \mathrm{xout} & =0.55\end{aligned}$ SURFACE TYPE: SMOOTH

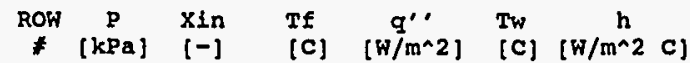

$\begin{array}{lllllllll}1 & 605.6 & -.01 & 113.4 & 70901 & 128.9 & 4577\end{array}$

$\begin{array}{lllllll}3 & 605.2 & 0.06 & 113.9 & 69858 & 127.8 & 5017\end{array}$

$\begin{array}{lllllll}5 & 605.1 & 0.13 & 113.9 & 71242 & 128.0 & 5055\end{array}$

$\begin{array}{lllllll}7 & 605.0 & 0.21 & 113.9 & 70839 & 127.4 & 5260\end{array}$

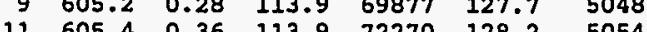

$13 \quad 605.4 \quad 0.36 \quad 113.9 \quad 72270 \quad 128.2 \quad 5054$

$\begin{array}{lllllll}13 & 605.6 & 0.43 & 113.9 & 70389 & 127.9 & 5023 \\ 15 & 605.8 & 0.51 & 113.9 & 70419 & 128.9 & 4691\end{array}$

\begin{tabular}{|c|c|c|c|c|c|c|c|c|c|c|c|c|c|}
\hline \multicolumn{4}{|c|}{$\begin{array}{l}\text { RUN NUMBER: } 391 \\
\text { P/d }=1.5 \\
\text { Pin }=612.6 \mathrm{kPa} \\
\text { Xin }=-.01 \\
\text { SURFACE TYPE: SMOOTH }\end{array}$} & \multicolumn{3}{|c|}{$\begin{array}{r}\text { WORKING FLUID: } \mathrm{R}-113 \\
G=98.8 \mathrm{~kg} / \mathrm{s}^{\star} \mathrm{m}^{\wedge} 2 \\
\text { LTA P total } \\
\text { Xout } 2.68 \mathrm{kPa} \\
\text { Lo.16 }\end{array}$} & \multicolumn{4}{|c|}{$\begin{array}{l}\text { RUN NUMBER: } 395 \\
\text { P/d }=1.5 \\
\text { PIn }=592.6 \mathrm{kPa} \\
\text { Xin }=0.00 \\
\text { SURFACE TYPE: SMOOTH }\end{array}$} & \multicolumn{3}{|c|}{$\begin{array}{r}\text { WORKING FLUID: } \mathrm{R}-113 \\
G=101.26 \mathrm{~kg} / \mathrm{s}^{\star} \mathrm{m}^{\wedge} 2 \\
\text { LITA total }=.82 \mathrm{kPa} \\
\text { Xout }=0.41\end{array}$} \\
\hline ROW & $\begin{array}{c}\mathbf{P} \\
{[\mathrm{kPa}]}\end{array}$ & $x \sin$ & $\begin{array}{l}\text { Tf } \\
\text { [C] }\end{array}$ & $\frac{q^{\prime \prime}}{\left[w / m^{\wedge} 2\right]}$ & $\begin{array}{l}T w \\
\text { C }\end{array}$ & $\stackrel{h}{h}$ & $\begin{array}{c}\text { ROW } \\
\neq\end{array}$ & $\left.\begin{array}{c}P \\
{[\mathrm{kPa}}\end{array}\right]$ & & $\begin{array}{l}\mathrm{Tf} \\
{[\mathrm{C}]}\end{array}$ & $\underset{\left[w / m^{\wedge} 2\right]}{q^{\prime \prime}}$ & Tw & $\stackrel{h}{m \wedge 2} c$ \\
\hline 1 & & -.01 & 112.8 & 20908 & 122 . & 2251 & $i$ & 592 & & & 51149 & 127.0 & \\
\hline 3 & & & & & & & 3 & & & & & & \\
\hline 5 & & & & & & & & & & & & & \\
\hline 7 & & & 114 & 215 & & & 7 & & & & & & \\
\hline 9 & & & & & & & 9 & & & & & & \\
\hline 11 & & & & & & & 12 & & & & & & \\
\hline 13 & & & & & & & & & & & & & \\
\hline 15 & & & & & & & 15 & & & & & & \\
\hline
\end{tabular}

RUN NUMBER: 394 $\mathrm{p} / \mathrm{d}=1.5$

Pin $=591.2 \mathrm{kPa}$ Xin $=-.00$
WORKING FLUID: R-113 $\mathbf{G}=101.05 \mathrm{~kg} / \mathrm{s}^{\star} \mathrm{m}^{\wedge}$ DELTA P total Xout $=0.49$

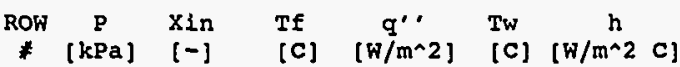

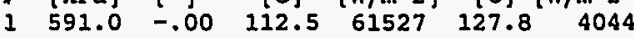
$\begin{array}{lllllll}590.6 & 0.06 & 112.8 & 60895 & 126.1 & 4572\end{array}$ $\begin{array}{lllllll}590.4 & 0.12 & 112.8 & 61882 & 126.2 & 4599\end{array}$ $\begin{array}{lllllll}11 & 590.6 & 0.32 & 112.8 & 63225 & 126.3 & 465\end{array}$ $\begin{array}{lllllll}15 & 590.9 & 0.46 & 112.8 & 61590 & 127.8 & 4104\end{array}$
RUN NUMBER: 392 $\mathrm{p} / \mathrm{d}=1.5 \quad G=100.17 \mathrm{~kg} / \mathrm{g}^{\star} \mathrm{m}^{\wedge}$

พORKING FLUID: R-113 Pin $=591.6 \mathrm{kPa} \quad$ DELTA P total $=.6 \mathrm{kPa}$ SURFACE TYPE: SMOOTH

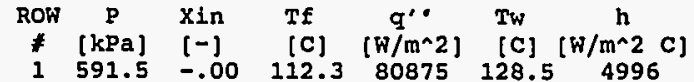

$\begin{array}{lllllll}1 & 591.2 & 0.08 & 112.8 & 79713 & 127.2 & 5554\end{array}$

$\begin{array}{llllllll}5 & 591.1 & 0.16 & 112.8 & 81216 & 127.2 & 5654\end{array}$

$\begin{array}{lllllll}7 & 591.2 & 0.25 & 112.8 & 80734 & 127.1 & 5634\end{array}$

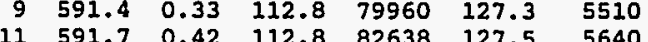

$\begin{array}{lllllll}11 & 591.7 & 0.42 & 112.8 & 82638 & 127.5 & 5640\end{array}$

$\begin{array}{lllllll}15 & 592.2 & 0.51 & 112.9 & 80640 & 127.6 & 5486 \\ & 0.60 & 112.9 & 80494 & 129.0 & 5008\end{array}$

RUN NUMBER: 419

$\mathrm{p} / \mathrm{d}=1.5$

WORKING FLUID: R-113

In $=565.4 \mathrm{kPa}$

$x_{i n}=0.02$

$G=148.74 \mathrm{~kg} / \mathrm{s}^{*} \mathrm{~m}^{\wedge} 2$ DELTA P total $=3.91 \mathrm{kPa}$
Xout $=0.07$

\begin{tabular}{|c|c|c|c|c|c|}
\hline & $\mathrm{xin}$ & & & Tw & \\
\hline$[\mathrm{kPa}]$ & {$[-]$} & [C] & [พ/m^2] & [C] [ & $\left./ \mathrm{m}^{\wedge} 2 \mathbf{2} \mathrm{c}\right]$ \\
\hline 564.6 & 0.03 & 110 & 10196 & 115 & 2077 \\
\hline 564. & 0.04 & 110.6 & 10130 & 115.3 & 2179 \\
\hline 563. & 0.04 & & 10226 & 115 & 2045 \\
\hline 563. & 0.05 & 110 & 1004 & 115.5 & 2012 \\
\hline 562.5 & 0.06 & 110.5 & 10395 & 115 & 2310 \\
\hline & 0.06 & 110.5 & 10214 & 115.5 & 2017 \\
\hline
\end{tabular}




\begin{tabular}{|c|c|c|c|c|c|c|}
\hline \multicolumn{4}{|c|}{$\begin{array}{l}\text { RUN NUMBER: } 412 \\
\text { P/d }=1.5 \\
\text { Pin }=575.4 \mathrm{kPa} \\
\text { XIN }=0.01 \\
\text { SURFACE TYPE: SMOOTH }\end{array}$} & \multicolumn{3}{|c|}{$\begin{array}{l}\text { WORKING FLUID: R-113 } \\
\text { G }=151.01 \mathrm{~kg} / \mathrm{s}^{\star} \mathrm{m}^{\wedge} \\
\text { OELTA P total }=3.97 \mathrm{kPa} \\
\text { Xout }=0.11\end{array}$} \\
\hline ow & & & & & Tw & \\
\hline & & & & & & \\
\hline 1 & & & 110 & & & \\
\hline & & & & & & \\
\hline 5 & & & & & & \\
\hline & & & & & & \\
\hline & & & & & & \\
\hline & & & & & & \\
\hline & & & & & & \\
\hline & & & & & & \\
\hline
\end{tabular}

RUN NUMBER: 413

$\mathrm{p} / \mathrm{d}=1.5$

Pin $=576.2 \mathrm{kPa}$

$\sin =0.02$

SURFACE TYPE: SMOOTH

WORKING FLUID: R-113 RUN NUMBER: 416 $G=149.96 \mathrm{~kg} / \mathrm{s}^{\star} \mathrm{m}^{n}$

$\begin{aligned} \text { DELTA P total } & =3.65 \mathrm{kPa} \\ \text { Xout } & =0.18\end{aligned}$

Xout $=0.18$

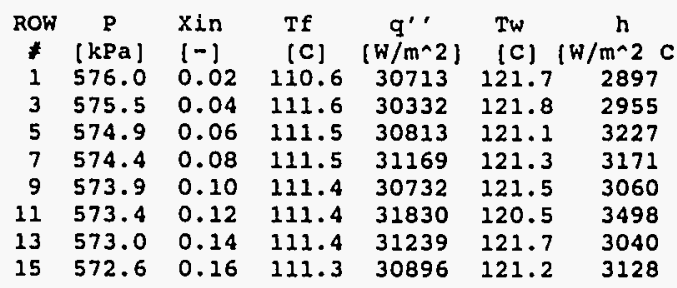

RUN NUMBER: 415

$\mathrm{p} / \mathrm{d}=1.5$

in $=580.9 \mathrm{kPa}$

SURFACE TYPE: SMOOTH

WORKING FLUID: R-113 $G=151.68 \mathrm{~kg} / 8^{*} \mathrm{~m}^{\wedge} 2$ DELTA $\mathrm{P}$ total $=3.43 \mathrm{kPa}$ Xout $=0.27$

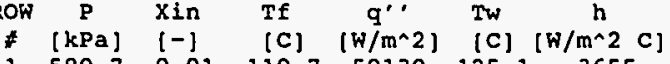
$\begin{array}{llllllll}1 & 580.7 & 0.01 & 110.7 & 50130 & 125.1 & 3655\end{array}$ $\begin{array}{lllllll}3 & 580.1 & 0.04 & 111.9 & 50003 & 125.3 & 3754\end{array}$ $\begin{array}{lllllll}5 & 579.6 & 0.07 & 111.9 & 50562 & 124.5 & 4014\end{array}$ $\begin{array}{lllllll}7 & 579.1 & 0.11 & 111.9 & 50832 & 124.3 & 4085\end{array}$ $\begin{array}{llllll}579.7 & 0.14 & 111.8 & 49665 & 124.8 & 3832\end{array}$ $\begin{array}{lllllll}1 & 578.3 & 0.18 & 111.8 & 52014 & 123.6 & 4396 \\ 3 & 578.0 & 0.21 & 111.8 & 50658 & 124.6 & 3954\end{array}$ $\begin{array}{lllllll}15 & 577.5 & 0.25 & 111.7 & 50583 & 124.4 & 4007\end{array}$
RUN NUMBER: 418 $\mathrm{p} / \mathrm{d}=1.5$

Pin $=608.6 \mathrm{kPa}$

$\mathrm{xin}=-.00$

SURFACE TYPE: SMOOTH

WORKING FLUID: $R-113$ $G=150 \mathrm{~kg} / \mathrm{s} * \mathrm{~m} \wedge 2$ DELTA $P$ total $=3.14 \mathrm{kPa}$ Xout $=0.41$

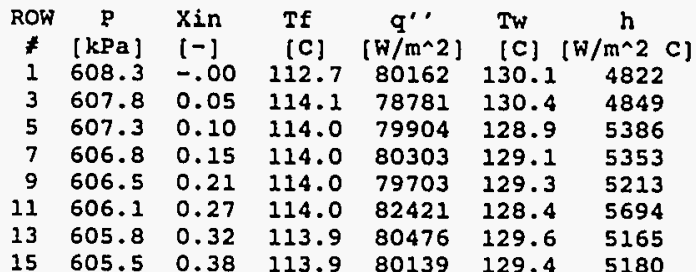

RUN NUMBER: 414

$\mathrm{p} / \mathrm{d}=1.5$

WORKING FLUID: $R-113$ $G=150.51 \mathrm{~kg} / \mathrm{s}^{*} \mathrm{~m}^{\wedge}$

$P_{\text {in }}=578$. $\begin{aligned} \text { DELTA P total } & =3.56 \mathrm{kPa} \\ \text { xout } & =0.21\end{aligned}$

SURFACE TYPE: SMOOTH

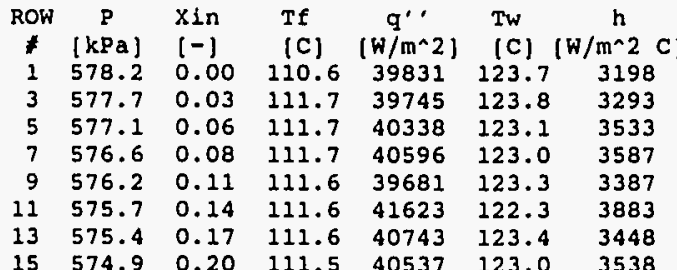

$\mathrm{p} / \mathrm{d}=1.5$

WORKING FLUID: R-113 RUN NUMBER: 406

$G=152.17 \mathrm{~kg} / \mathrm{s}^{*} \mathrm{~m}^{\wedge} \mathbf{2} \quad \mathrm{p} / \mathrm{d}=1.5$

$\mathrm{Pin}=553.9 \mathrm{kPa}$

$x_{\text {in }}=-.01$

SURFACE TYPE: SMOOTH

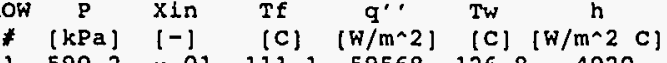

$\begin{array}{lllllll}1 & 590.2 & -.01 & 111.1 & 59568 & 126.8 & 4020\end{array}$

$\begin{array}{lllllll}3 & 589.6 & 0.03 & 112.7 & 59008 & 126.9 & 4164\end{array}$

$\begin{array}{llllllll}5 & 589.1 & 0.07 & 112.7 & 59008 & 126.9 & 4164 \\ 7 & 588.6 & 0.11 & 112.6 & 59797 & 125.9 & 4515\end{array}$

$758.6 \quad 0.11 \quad 112.6 \quad 60238 \quad 126.0 \quad 4523$

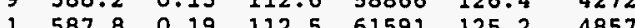

$\begin{array}{lllllll}13 & 587.5 & 0.23 & 112.5 & 59932 & 126.3 & 4366\end{array}$

$\begin{array}{lllllll}15 & 587.1 & 0.27 & 112.5 & 59917 & 126.1 & 4417\end{array}$

WORKING FLUID: R-113 $G=197.97 \mathrm{~kg} / \mathrm{s}^{*} \mathrm{~m}^{\wedge} 2$ Xout $=0.04$

\begin{tabular}{|c|c|c|c|c|c|c|}
\hline$D W$ & p & $x$ in & & & $T w$ & \\
\hline$\neq$ & [kPa] & {$[-]$} & (c) & {$\left[W / m^{\wedge} 2\right]$} & \multirow{2}{*}{\multicolumn{2}{|c|}{ [C] $(\mathrm{W} / \mathrm{m} \wedge \mathrm{2} C)$}} \\
\hline 1 & 553. & & 99.8 & & 121.9 & \\
\hline 3 & 553 & -.07 & & & & \\
\hline 5 & & & & & & \\
\hline 7 & 551 & -.0 & & & & \\
\hline & &.$- c$ & & & & \\
\hline & &. & & & & 2646 \\
\hline & 549. & & & & & 2425 \\
\hline & & & & & & 2385 \\
\hline
\end{tabular}

RUN NUMBER: 417

$\mathrm{p} / \mathrm{d}=1$.

Pin $=600.9 \mathrm{kPa}$

SURFACE TYPE: SMOOTH

WORKING FLUID: R-113 RUN NUMBER: 407

$G=149.65 \mathrm{~kg} / 0^{*} \mathrm{~m}^{\wedge} 2$ RUN NUMBER:

P/d $=1.5$
Pin $=564 \mathrm{k}$

SURFACE TYPE: SMOOT

WORKING FLUID: R-113

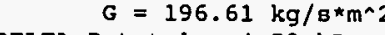
DLTA $P$ total $=4.53 \mathrm{kPa}$

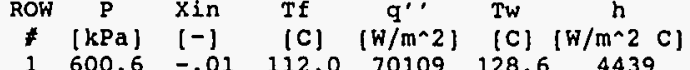

$\begin{array}{llllll}600.6 & -.01 & 112.0 & 70109 & 128.6 & 4439 \\ 600.1 & 0.04 & 113.5 & 69183 & 128.7 & 4560\end{array}$

$\begin{array}{llllllll}5 & 599.6 & 0.09 & 113.5 & 70498 & 127.6 & 4977\end{array}$

$\begin{array}{lllllll}7 & 599.1 & 0.13 & 113.4 & 70543 & 127.7 & 4963\end{array}$

$\begin{array}{lllllll}9 & 598.7 & 0.18 & 113.4 & 69207 & 128.0 & 4749\end{array}$

$\begin{array}{lllllll}11 & 598.4 & 0.23 & 113.4 & 72318 & 127.0 & 5316\end{array}$

$\begin{array}{lllllll}13 & 598.0 & 0.28 & 113.3 & 70436 & 128.2 & 4780 \\ 15 & 597.6 & 0.33 & 113.3 & 70352 & 127.9 & 4822\end{array}$

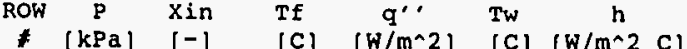
$\begin{array}{lllllll}563.7 & -.08 & 100.8 & 40024 & 124.4 & 1737\end{array}$ $\begin{array}{lllllll}3 & 563.1 & -.06 & 103.2 & 39873 & 125.4 & 1840\end{array}$ $\begin{array}{llllllll}5 & 562.4 & -.04 & 105.5 & 40639 & 124.2 & 2246\end{array}$ $\begin{array}{lllllll}7 & 561.8 & -.02 & 107.9 & 40655 & 123.9 & 2656\end{array}$

$\begin{array}{llllllll}9 & 561.2 & 0.00 & 109.8 & 39635 & 123.9 & 2874\end{array}$

$\begin{array}{lllllll}1 & 560.6 & 0.02 & 110.4 & 41542 & 122.5 & 3421\end{array}$

$\begin{array}{lllllll}13 & 560.1 & 0.04 & 110.3 & 40550 & 124.1 & 2947\end{array}$

$\begin{array}{llllllll}15 & 559.6 & 0.07 & 110.3 & 40415 & 124.0 & 2945\end{array}$ 


\begin{tabular}{|c|c|c|c|c|c|c|c|c|c|c|c|c|c|}
\hline \multicolumn{4}{|c|}{$\begin{array}{l}\text { RUN NUMBER: } 408 \\
\text { P/d }=1.5 \\
\text { Pin }=565.5 \mathrm{kPa} \\
\text { XIn }=-.07 \\
\text { SURFACE TYPE: SMOOTH }\end{array}$} & \multicolumn{3}{|c|}{$\begin{array}{r}\text { WORKING FLUID: } \mathrm{R}-113 \\
G=194.48 \mathrm{~kg} / \mathrm{g}^{\star} \mathrm{m}^{\wedge} 2 \\
\text { TA P total }=4.28 \mathrm{kPa} \\
\text { Xout }=0.13\end{array}$} & \multicolumn{4}{|c|}{$\begin{array}{l}\text { RUN NUMBER: } 411 \\
\text { P/d }=1.5 \\
\text { PIn }=564.5 \mathrm{kPa} \\
\text { XIn }=-.06 \\
\text { SURFACE TYPE: SMOOTH }\end{array}$} & \multicolumn{3}{|c|}{$\begin{array}{r}\text { WORKING FLUID: R-113 } \\
G=193.79 \mathrm{~kg} / \mathrm{s}^{\star} \mathrm{m}^{\wedge} 2 \\
\text { TA P total }=3.72 \mathrm{kPa} \\
\text { Xout }=0.25\end{array}$} \\
\hline Row & $\underset{[\mathrm{kPa}]}{\mathrm{P}}$ & & & & & $/ m^{\wedge} 20$ & $\begin{array}{c}\text { Row } \\
\neq\end{array}$ & $\mathbf{P}$ & & & $\frac{q^{\prime \prime}}{\left[w / m^{\wedge} 2\right]}$ & $\begin{array}{l}\mathrm{TW} \\
\text { (c) }\end{array}$ & $\mathbf{h}$ \\
\hline$i$ & & & & & & & $\begin{array}{l}* \\
1\end{array}$ & & & & & & \\
\hline 3 & & -.0 & & & & & 3 & & & & & & \\
\hline 5 & & & & & & & & & & & & & \\
\hline 7 & & & & & & & 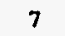 & & & & & & \\
\hline 9 & & & & & & & 9 & & & & & & \\
\hline & & & & & & & & & & & & & \\
\hline & & & & & & & & & & & & & \\
\hline 15 & & 0.11 & 10.4 & 50981 & & 3540 & 15 & 560.9 & & 110.4 & 79769 & 127.0 & 4828 \\
\hline
\end{tabular}
$\begin{array}{lr}\text { RUN NUMBER: } 409 & \text { FORKING FLUID: R-113 } \\ \text { P/d }=1.5 & G=195.87 \mathrm{~kg} / \mathrm{s}^{*} \mathrm{~m}^{\wedge} 2 \\ \text { PIn }=565.6 \mathrm{kPa} & \text { DELTA } P \text { total }=4 \mathrm{kPa}\end{array}$

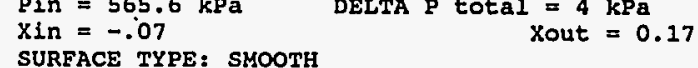

\begin{tabular}{|c|c|c|c|c|c|c|}
\hline ROW & Prou & $x i n$ & Tf & $q^{\prime \prime \prime}$ & Tw & $\frac{h}{h}$ \\
\hline * & [kPa] & {$[-]$} & [C] & {$\left[\mathrm{W} / \mathrm{m}^{\wedge} \mathbf{2}\right]$} & [C] & {$\left[W / m^{\wedge} 2 C\right]$} \\
\hline 1 & 565.3 & & & 60223 & 126.9 & 2719 \\
\hline $\begin{array}{l}3 \\
5\end{array}$ & $\begin{array}{l}564.7 \\
564.1\end{array}$ & $\begin{array}{l}-.04 \\
-.01\end{array}$ & $\begin{array}{l}107.3 \\
109.9\end{array}$ & $\begin{array}{l}59579 \\
60415\end{array}$ & $\begin{array}{l}126.9 \\
125.4\end{array}$ & $\begin{array}{l}3194 \\
3997\end{array}$ \\
\hline 7 & 563.5 & 0.03 & 110.6 & 60341 & 125.5 & 4059 \\
\hline 9 & 563.0 & 0.06 & 110.6 & 59358 & 125.4 & 3996 \\
\hline 11 & 562.5 & 0.09 & 110.5 & 61807 & 124.2 & 4529 \\
\hline 13 & 562.1 & 0.12 & 110.5 & 60040 & 126.0 & 3894 \\
\hline 15 & 1.6 & 0.15 & 10.5 & 60169 & 125.6 & 3992 \\
\hline
\end{tabular}

$\begin{array}{rr}\text { RUN NUMBER: } 410 & \text { WORKING FLUID: } R-113 \\ \text { p } / \mathrm{d}=1.5 & \mathrm{G}=196.56 \mathrm{~kg} / \mathrm{s}^{\star \mathrm{m}} \mathrm{m}-2 \\ \text { Pin }=562.2 \mathrm{kPa} & \text { DELTA P total }=3.85 \mathrm{kPa} \\ \text { Xin }=-.06 & \text { Xout }=0.21\end{array}$

SURFACE TYPE: SMOOTH

\begin{tabular}{|c|c|c|c|c|c|c|}
\hline ROh & $\stackrel{P}{[\mathrm{kPa}]}$ & $\begin{array}{l}x \ln \\
{[-1}\end{array}$ & $\begin{array}{l}\text { Tf } \\
\text { (C) }\end{array}$ & $\stackrel{q^{\prime \prime}}{\left(w / m^{\wedge} 2\right)}$ & Tw & $\stackrel{h}{h \wedge 2}$ \\
\hline 1 & 561.9 & -.06 & 104.0 & 70452 & 227.6 & 3136 \\
\hline 3 & 561.3 & -.03 & 108.1 & 69443 & 127.4 & 3803 \\
\hline 5 & 560.7 & 0.01 & 110.3 & 70363 & 125.9 & 4545 \\
\hline 7 & 560.1 & 0.04 & 110.3 & 70396 & 126.0 & 4511 \\
\hline 9 & 559.7 & 0.08 & 110.3 & 69398 & 126.2 & 4379 \\
\hline 11 & 559.2 & 0.12 & 110.3 & 72134 & 124.8 & 4963 \\
\hline 13 & 558.9 & 0.15 & 110.2 & 70167 & 126.5 & 4345 \\
\hline 15 & 558.4 & 0.19 & 110.2 & 70227 & 126.0 & 4454 \\
\hline
\end{tabular}




\section{Bundle Boiling Data}

Turbo-B data in $\mathrm{R}-113$ for bundle with $\mathrm{p} / \mathrm{d}=1.50$ 


\begin{tabular}{|c|c|c|c|c|c|c|c|c|c|c|c|c|c|}
\hline \multicolumn{4}{|c|}{$\begin{array}{l}\text { RUN NUMBER: } 255 \\
\text { P/d }=1.5 \\
\text { Pin }=207.4 \mathrm{kPa} \\
\text { Xin }=-.00 \\
\text { SUREACE TYPE: TURBO-B }\end{array}$} & \multicolumn{3}{|c|}{$\begin{array}{r}\text { WORKING FLUID: } \mathrm{R}-113 \\
G=50.83 \mathrm{~kg} / \mathrm{s}^{\star} \mathrm{m}^{\wedge} 2 \\
\text { TA } \mathrm{P} \text { total }=6.2 \mathrm{kPa} \\
\text { xout }=0.06\end{array}$} & \multicolumn{4}{|c|}{$\begin{array}{l}\text { RUN NUMBER: } 249 \\
\text { P/d }=1.5 \\
\text { PIn }=204.7 \mathrm{kPa} \\
\text { XIn }=-.00 \\
\text { SURFACE TYPE: TURBO-B }\end{array}$} & \multicolumn{3}{|c|}{$\begin{array}{r}\text { WORKING FLUID: R-113 } \\
G=50.61 \mathrm{~kg} / \mathrm{g}^{*} \mathrm{~m}^{\wedge} 2 \\
\text { TA } \mathrm{P} \text { total }=5.65 \mathrm{kP} \\
\text { xout }=0.40\end{array}$} \\
\hline ROW & $\stackrel{p}{p}$ & $x$ in & Tf & & Tw & $\stackrel{h}{n}$ & Row & $\stackrel{P}{P}$ & & & $\frac{q^{\prime \prime}}{\left[w^{\prime} m^{n}\right.}$ & Tw & $\stackrel{h}{h}$ \\
\hline $\begin{array}{l}7 \\
1\end{array}$ & $\begin{array}{l}{\left[\begin{array}{l}k P a \\
207.0\end{array}\right.} \\
207.0\end{array}$ & $\begin{array}{l}{[-]} \\
-.00\end{array}$ & $\begin{array}{l}{[C]} \\
69.3\end{array}$ & $\begin{array}{c}\left(W / m^{\wedge} 2\right) \\
4887\end{array}$ & $\begin{array}{l}\{c \\
71\end{array}$ & $\begin{array}{l}\left.m^{\wedge} 2 C\right] \\
2099\end{array}$ & $\stackrel{f}{1}$ & & & $\begin{array}{l}{[c]} \\
68.3\end{array}$ & $\begin{array}{c}{\left[W / m^{* 2}\right]} \\
29821\end{array}$ & $\begin{array}{l}{[C]} \\
74.4\end{array}$ & $\begin{array}{l}\left./ m^{n} 2 c\right] \\
4944\end{array}$ \\
\hline 3 & & & & & & & 3 & & & & & & \\
\hline 5 & & & & & & & 5 & & & & & & \\
\hline 7 & & & & 50 & & & 7 & & & & & & 59 \\
\hline 9 & & & & & & & 9 & & & & & & \\
\hline 11 & & & & & & & & & & & & & \\
\hline 13 & & & & & & & 13 & & & & & & \\
\hline 15 & & & & 5091 & & 3393 & 15 & & & 69.2 & 30711 & 73.0 & 8111 \\
\hline
\end{tabular}
$\mathrm{p} / \mathrm{d}=1.5$

Pin $=210.4$
$X$ in $=-.01$

SURFACE TYPE: TURBO-B

\begin{tabular}{|c|c|c|c|c|c|c|}
\hline or & P & $x$ in & & & & $\mathrm{h}$ \\
\hline F & [kPa & {$[-]$} & [C] & {$\left[\mathrm{W} / \mathrm{m}^{\wedge} \mathrm{2}\right]$} & (c) & $1 / m^{\wedge} 2$ \\
\hline 3 & 210.0 & -01 & 69.2 & 59304 & 77.5 & 7099 \\
\hline 5 & 208 & 0. & & 600 & & $\begin{array}{r}7540 \\
7384\end{array}$ \\
\hline 7 & 207. & 0.3 & 70.6 & 60033 & 78 & 7491 \\
\hline & 206 & & & & & 6976 \\
\hline & 205. & 0 & 10.3 & & & 7162 \\
\hline & 205.1 & 0.6 & 70.2 & 60735 & 79.0 & 6908 \\
\hline
\end{tabular}

WORKING ELUID: $\mathrm{R}-11$ WORKING FLUID: R-113 RUN NUMBER: 250 RUN NUMBER: 254 $\mathrm{p} / \mathrm{d}=1.5$ $\mathrm{p} / \mathrm{d}=1.5$

$P=50.49 \mathrm{~kg} / \mathrm{k}^{\circ}$

$x i n=-.01$ DELTA $\mathrm{P}$ total $=7.03 \mathrm{kPa}$ Pin $=207.3 \mathrm{kPa}$ $x_{\text {in }}=-.00$ xout $=0.55$

SURFACE TYPE: TURBO-B xout $=0.13$ XIN

\begin{tabular}{|c|c|c|c|c|c|c|}
\hline ROW & P & $\operatorname{xin}$ & $\mathbf{T f}$ & $q^{\prime \prime}$ & $T w$ & h \\
\hline$\neq$ & [kPa] & {$[-]$} & [c] & {$\left[W / m^{\wedge} 2\right]$} & [c] & $\left(\mathrm{W} / \mathrm{m}^{\wedge} 2 \quad \mathrm{C}\right)$ \\
\hline 1 & 208.2 & & 69.1 & 10085 & 72.3 & 3108 \\
\hline 3 & 207.1 & 0.01 & 70.3 & 10317 & 72.6 & 4496 \\
\hline 5 & 206.1 & 0.03 & & 10528 & 72.3 & 5418 \\
\hline 7 & 205.2 & 0.05 & 70.2 & 10511 & 72.2 & 5336 \\
\hline 9 & 204.3 & 0.06 & 70.1 & 10188 & 72.1 & 5021 \\
\hline 11 & 203.4 & 0.08 & 70.0 & 10236 & 72.2 & 4675 \\
\hline 13 & 202.6 & 0.10 & 69.8 & 10567 & 72.2 & 4440 \\
\hline & & & & 106 & 7 & 5469 \\
\hline
\end{tabular}

$\begin{array}{lclc}\text { Tf } & q^{\prime \prime} & \text { Tw } & h \\ \text { [C] } & {\left[w^{\wedge} / m^{\wedge}\right]} & \text { [C] } & {\left[\mathrm{W} / \mathrm{m}^{\wedge 2} \mathrm{c}\right.} \\ 69.3 & 40077 & 75.6 & 6301 \\ 70.4 & 39746 & 76.1 & 6987 \\ 70.3 & 40396 & 76.3 & 6713 \\ 70.2 & 40165 & 76.3 & 6578 \\ 70.1 & 39830 & 76.6 & 6126 \\ 69.9 & 40076 & 76.2 & 6401 \\ 69.8 & 41100 & 76.5 & 6098 \\ 69.7 & 41259 & 74.1 & 9401\end{array}$

RUN NUMBER: 229 $\mathrm{p} / \mathrm{d}=1.5$

PIn $=208.7 \mathrm{kPa}$

SURFACE TYPE: TURBO-B DELTA $P$ total $=5.66 \mathrm{kPa}$

\begin{tabular}{|c|c|c|c|c|c|c|}
\hline ROW & $\mathbf{P}$ & $\mathrm{Xin}$ & Tf & $q^{\prime \prime}$ & $T w$ & h \\
\hline * & (kPa) & {$[-]$} & (C) & {$\left[\mathrm{W} / \mathrm{m}^{\wedge} 2\right]$} & (c) & $/ / \mathrm{m}^{\wedge} 2 \mathrm{c}$ \\
\hline 1 & 208.3 & & 69.8 & 5006 & 71.5 & 2956 \\
\hline 3 & 207.6 & 0.00 & 69.9 & 4904 & 71.6 & 2991 \\
\hline 5 & 206.8 & 0.01 & 70.0 & 5010 & 71.4 & 3477 \\
\hline 7 & 206.1 & 0.01 & 70.0 & 5060 & 71.4 & 3525 \\
\hline 9 & 205.3 & 0.02 & 70.0 & 4922 & 71.3 & 3705 \\
\hline 11 & 204.5 & 0.02 & 69.9 & 4866 & 71.2 & 3896 \\
\hline 13 & 203.8 & 0.02 & 69.9 & 4940 & 71.0 & 4305 \\
\hline 15 & 203.0 & 0.03 & 69.9 & 5000 & 70.8 & 5279 \\
\hline
\end{tabular}

WORKING FLUID: $\mathrm{R}-113$

\begin{tabular}{|c|c|c|c|c|c|c|c|c|c|c|c|c|c|}
\hline $\begin{array}{l}\text { RUN } \\
\text { p/d } \\
\text { Pin } \\
\text { Xin } \\
\text { SUR }\end{array}$ & $\begin{array}{l}\text { NUMBER: } \\
=1.5 \\
=204.1 \\
=-.00 \\
\text { FACE TYP }\end{array}$ & $\begin{array}{l}252 \\
\mathrm{kPa} \\
\mathrm{PE}: \mathrm{TL}\end{array}$ & BO-B & $\begin{array}{l}\text { WORKI } \\
G= \\
\text { ELTA } P \text { t }\end{array}$ & $\begin{array}{l}6 \text { FLUI } \\
9.71 k \\
\text { tal }= \\
\text { Xou }\end{array}$ & $\begin{array}{l}\text { ID: } R-113 \\
\mathrm{~kg} / \mathrm{s}^{*} \mathrm{~m}^{\wedge} 2 \\
6.17 \mathrm{kPa} \\
\mathrm{at}=0.29\end{array}$ & $\begin{array}{l}\text { RUN } \\
\text { p/d } \\
\text { Pin } \\
\text { Xin } \\
\text { SUR }\end{array}$ & $\begin{array}{l}\text { NUMBER } \\
=1.5 \\
=205 . \\
=-.01 \\
\text { FACE TY }\end{array}$ & $P E: T U$ & 80-B & $\begin{array}{c}\text { WORKI } \\
G= \\
\text { LTA P }\end{array}$ & $\begin{array}{l}\text { Fi } \\
\mathrm{al}=\end{array}$ & $\begin{array}{l}\text { ID: } \mathrm{R}-113 \\
\mathrm{~kg} / \mathrm{g}^{\star} \mathrm{m} \mathrm{m}^{\wedge} \\
5.98 \mathrm{kPa} \\
\text { ut }=0.67\end{array}$ \\
\hline ROW & $P$ & $x$ in & Tf & & $T w$ & $\mathrm{~h}$ & ROW & $P$ & $x i$ & $T f$ & $q^{\prime \prime}$ & Tw & h \\
\hline * & [kPa] & & (C) & & [C] & {$\left[\mathrm{W} / \mathrm{m}^{\wedge} 2\right.$} & $\#$ & & & & {$[\mathrm{\omega} / \mathrm{n}$} & & {$\left[\mathrm{W} / \mathrm{m}^{\wedge} 2\right.$} \\
\hline 1 & & & 68.6 & & & & 1 & & & & & 76.0 & \\
\hline 3 & 202.8 & 0.03 & 69.7 & 2138 & 73.4 & 5880 & 3 & 204.2 & 0.08 & 70.1 & 49634 & 76.9 & 7298 \\
\hline 5 & 202.0 & & 69.6 & & & & 5 & & & & & & \\
\hline 7 & 201.1 & 0 & 69.5 & & 73. & 60 & 7 & 20 & & 69.8 & 503 & 77.0 & \\
\hline 9 & 200.3 & & 6 & & & & 9 & & & & & & 65 \\
\hline 11 & 199.5 & & 69 & 213 & & 57 & 11 & 21.1 & & & & & \\
\hline 13 & 198.7 & 0.23 & 69.1 & 220 & 73.1 & 5500 & 13 & 00.3 & & & 51148 & 77.3 & \\
\hline 15 & 197.9 & 0.27 & 69.0 & 22067 & 71.8 & 7971 & 15 & 199.5 & 0.62 & 69.3 & 51400 & 75.2 & 8761 \\
\hline
\end{tabular}

RUN NUMBER: 228 $\mathrm{p} / \mathrm{d}=1.5$

Pin $=208.3$

SURFACE TYPE: TURBO-
WORKING FLUID: R-113 $G=109.15 \mathrm{~kg} / \mathrm{s}^{*} \mathrm{~m}^{\wedge}$ DELTA P total $=5.7 \mathrm{kPa}$

\begin{tabular}{|c|c|c|c|c|c|c|}
\hline ROW & $\mathbf{P}$ & $x$ in & Tf & $q{ }^{\prime \prime}$ & Tw & h \\
\hline$\neq$ & [ $\mathrm{KPa}$ ] & {$[-]$} & [C] & {$\left[\omega / m^{\wedge} 2\right]$} & [C] & $/ m^{\wedge} 2$ \\
\hline 1 & 208.0 & 0.00 & 69.7 & 10443 & 71.9 & 4633 \\
\hline 3 & 207.2 & 0.01 & 70.2 & 10388 & 72.2 & 5061 \\
\hline 5 & 206.4 & 0.02 & 70.3 & 10514 & 71.7 & 7247 \\
\hline 7 & 205.7 & 0.03 & 70.2 & 10574 & 71.9 & 6313 \\
\hline 9 & 204.9 & 0.03 & 70.1 & 10211 & 71.7 & 6384 \\
\hline 11 & 204.2 & 0.04 & 70.0 & 10250 & 71.6 & 6522 \\
\hline 13 & 203.4 & 0.05 & 70.0 & 10465 & 71.7 & 6086 \\
\hline 1 & 202.6 & 0.06 & 69.9 & 10605 & 71.1 & 8421 \\
\hline
\end{tabular}




\begin{tabular}{|c|c|c|c|c|c|c|}
\hline $\begin{array}{l}\text { RUN } \\
\text { P/d } \\
\text { Pin } \\
\text { Xin } \\
\text { SUR }\end{array}$ & $\begin{array}{l}\text { NUMBER: } \\
=1.5 \\
=209.2 \\
=-.00 \\
\text { ACE TYP }\end{array}$ & $\begin{array}{l}226 \\
2 \mathrm{kPa} \\
\mathrm{PE}: \mathrm{T}\end{array}$ & BO-B & $\begin{array}{c}\text { WORKI } \\
\mathbf{G}= \\
\text { ELTA } P\end{array}$ & $\begin{array}{r}\text { G FLU } \\
08.97 \\
\text { tal }= \\
\text { Xo }\end{array}$ & $\begin{array}{l}\text { ID: } R-113 \\
\mathrm{~kg} / \mathrm{s}^{\star} \mathrm{m}^{\wedge} 2 \\
5.7 \mathrm{kPa} \\
\mathrm{ut}=0.12\end{array}$ \\
\hline ROW & p & $x$ in & Tf & $q^{\prime \prime}$ & Tw & $h$ \\
\hline $\begin{array}{l}* \\
1\end{array}$ & $\begin{array}{l}{[\mathrm{kPa}]} \\
208.9\end{array}$ & $\begin{array}{l}{[-]} \\
-.00\end{array}$ & $\begin{array}{l}\text { [C] } \\
69.5\end{array}$ & $\begin{array}{c}{\left[\mathrm{w} / \mathrm{m}^{\wedge} 2\right]} \\
20565\end{array}$ & $\begin{array}{l}{[c]} \\
73.1\end{array}$ & $\left.\underset{5686}{\left[W / m^{\wedge} 2\right.} c\right]$ \\
\hline 3 & 208.1 & 0.01 & 70.4 & 20450 & 73.6 & 6440 \\
\hline 5 & 207.4 & 0.03 & 70.4 & 20816 & 73.5 & 6925 \\
\hline 7 & 206.6 & 0.05 & 70.4 & 20865 & 73.3 & 6979 \\
\hline 9 & 205.8 & 0.06 & 70.3 & 20340 & 73.4 & 6529 \\
\hline 11 & 205.1 & 0.08 & 70.2 & 20304 & 73.1 & $\begin{array}{l}6964 \\
6964\end{array}$ \\
\hline 13 & 204.3 & & & 20815 & 73.3 & 6436 \\
\hline 15 & 203.6 & .12 & 70.0 & 20940 & 72.1 & 9995 \\
\hline
\end{tabular}

RUN NUMBER: 221

$\mathrm{P} / \mathrm{d}=1.5$

Pin $=216.5 \mathrm{kPa}$

$x_{\text {in }}=-.01$

SURFACE TYPE: TURBO-

\begin{tabular}{|c|c|c|c|c|c|c|}
\hline & & in & & & \multirow{2}{*}{\multicolumn{2}{|c|}{ 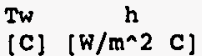 }} \\
\hline$\neq$ & [kPa] & & C] & {$[\mathrm{w} / \mathrm{m} / 2]$} & & \\
\hline 1 & 216.2 & -.01 & 70.0 & 49524 & 77.3 & 6811 \\
\hline 3 & 215.4 & 0.03 & 11.9 & 491 & 78.4 & 7616 \\
\hline 5 & 214.6 & 0.07 & 11.8 & 50046 & 77.3 & 9129 \\
\hline 7 & 213 & & & & & 7751 \\
\hline & 213.1 & 0.1 & 1.6 & & 78.4 & 7175 \\
\hline & 212 & & & & & 7600 \\
\hline & 211.6 & 0.24 & 71.4 & 50960 & 78.2 & 7385 \\
\hline
\end{tabular}

RUN NUMBER: 225

$\mathrm{p} / \mathrm{d}=1.5$

Pin $=217.9 \mathrm{kPa}$ $x_{\text {in }}=-.01$

SUREACE TYPE: TURBO-B

\begin{tabular}{|c|c|c|c|c|c|c|}
\hline ROW & $\stackrel{P}{P}$ & $\mathrm{Xin}$ & Tf & (mimas & Tw & h \\
\hline 1 & [KPa] & {$[-]$} & [C] & {$\left[\mathrm{W} / \mathrm{m}^{\wedge} 2\right]$} & & $/ m^{\wedge} 2$ \\
\hline & 217.5 & $=.01$ & 70.5 & 79700 & 80.6 & 7865 \\
\hline 3 & 216.8 & 0.06 & 72.1 & 78607 & 81.9 & 8019 \\
\hline 5 & 216.0 & 0.12 & 72.0 & 80 & 81.1 & 8850 \\
\hline 7 & 215.3 & 0.19 & 71.9 & 80651 & 81.6 & 8326 \\
\hline 9 & 214.5 & 0.25 & 71.8 & 79213 & & 7808 \\
\hline 11 & 213.7 & 0.32 & 71.7 & 79794 & 81.5 & 8142 \\
\hline 13 & 213.0 & 0.39 & 71.6 & 81700 & 81.7 & 8058 \\
\hline 15 & 212.2 & 0.46 & 71.5 & 82380 & 80.3 & 9351 \\
\hline
\end{tabular}

\begin{tabular}{|c|c|c|c|c|c|c|}
\hline \multirow{2}{*}{\multicolumn{4}{|c|}{$\begin{array}{l}\text { RUN NUMBER: } 227 \\
\text { p/d }=1.5 \\
\text { Pin }=214.1 \mathrm{kPa} \\
\text { Xin }=-.01 \\
\text { SUREACE TYPE: TURBO-B }\end{array}$}} & \multicolumn{3}{|c|}{$\begin{array}{l}\text { WORKING FLUID: R-113 } \\
\mathrm{G}=108.78 \mathrm{~kg} / \mathrm{s}^{*} \mathrm{~m}^{\wedge} \\
\mathrm{TA} \mathrm{P} \text { total }=5.7 \mathrm{kPa}\end{array}$} \\
\hline & & & & & & \\
\hline & $\mathbf{P}$ & $x$ in & TE & & Tw & h \\
\hline * & & & (C) & & & \\
\hline 1 & 213.7 & & 70.0 & 305 & 74.9 & \\
\hline 3 & 213.0 & 0.0 & 71.4 & 303 & 75.5 & \\
\hline 5 & 212.2 & & & & & \\
\hline 7 & 211.5 & & 71. & & 75.5 & \\
\hline & 210.7 & & 71 & 304 & 75 & \\
\hline & & & & 30 & 75.2 & \\
\hline & & & & & & \\
\hline & & & & & 3.5 & \\
\hline
\end{tabular}

RUN NUMBER: 220

$\mathrm{p} / \mathrm{d}=1.5$

$G=109.09 \mathrm{~kg} / \mathbf{g}^{\star} \mathrm{m}^{\wedge} 2$
1.5

$x_{\text {in }}=-.01$

SURPACE TYPE: TURBO-B Xout $=0.25$

\begin{tabular}{|c|c|c|c|c|c|c|}
\hline ROW & P & $x$ in & TE & $q^{\prime}$ & Tw & $\mathrm{h}$ \\
\hline & {$[\mathrm{kPa}]$} & {$[-]$} & [C] & $(w / m \wedge 2)$ & [C] & $\mathrm{w} / \mathrm{m} 22$ \\
\hline 1 & 212.2 & -.01 & 69.9 & 40435 & 75.6 & 7087 \\
\hline 3 & 211.4 & 0.03 & 71.2 & 40146 & 76.5 & 7459 \\
\hline 5 & 210.7 & 0.06 & 71.1 & 40748 & 76.5 & 7551 \\
\hline 7 & 209.9 & 0.09 & 71.0 & 40697 & 76.3 & 7674 \\
\hline 9 & 209.2 & 0.13 & 70.9 & 40040 & 76.5 & 7048 \\
\hline 11 & 208.4 & 0.16 & 70.8 & 40406 & 76.1 & 7517 \\
\hline 13 & 207.6 & 0.19 & 70.7 & 41413 & 76.4 & 7208 \\
\hline 15 & 206.9 & 0.23 & 70.6 & 41637 & 74.3 & 11295 \\
\hline
\end{tabular}

RUN NUMBER: 223

$\mathrm{P} / \mathrm{d}=1.5$

in $=214 \mathrm{kPa}$

SURFACE TYPE: TURBO-B

\begin{tabular}{|c|c|c|c|c|c|c|}
\hline OW & $\mathbf{P}$ & $\mathrm{Xin}$ & Tf & $q^{\prime}$ & \multirow{2}{*}{\multicolumn{2}{|c|}{$\begin{array}{l}\text { Tw } \\
\text { [C] }\left[w / m^{\wedge} 2\right.\end{array}$}} \\
\hline 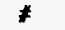 & [ $\mathrm{kPa}]$ & {$[-]$} & [C] & $\left(w / m^{\wedge} 2\right\}$ & & \\
\hline 1 & 213.7 & -.01 & 70.1 & 60158 & 78.2 & 7377 \\
\hline 3 & 213.0 & 0.04 & 71.5 & 59516 & 79.4 & 7540 \\
\hline 5 & 212.2 & 0.09 & 1.4 & 60620 & 78.4 & 8662 \\
\hline 7 & 211.4 & 0.14 & 71.3 & 59791 & 79.1 & 7655 \\
\hline 9 & 210.7 & 0.19 & 71.1 & 59219 & 79.4 & 7154 \\
\hline & 209.9 & 0.24 & 11.0 & 59716 & 78.9 & 7554 \\
\hline & 209.2 & 0.29 & 0.9 & 61086 & 79.2 & 7401 \\
\hline & 208.4 & 0.34 & & 61624 & & \\
\hline
\end{tabular}

WORKING FLUID: R-113 $G=109.14 \mathrm{~kg} / \mathrm{s}^{*} \mathrm{~m}^{\wedge}$ DETTA $P$ total $=5.69 \mathrm{kPa}$ $5.69 \mathrm{kPa}$
Xout $=0.37$
RUN NUMBER: 224 $\mathrm{p} / \mathrm{d}=1.5$ $x_{\text {in }}=-.01$ SURFACE TYPE: TURBO-

WORKING FLUID: R-113
G = $109.06 \mathrm{~kg} / \mathrm{s}^{\star \mathrm{m}^{\wedge} 2}$
ELTA P total $=5.69 \mathrm{kPa}$
Xout $=0.43$
$\begin{array}{ccc}\text { ROW } & \mathbf{P} & \mathrm{Xin} \\ \mathbf{K} & \mathbf{K P a}] & {[-]}\end{array}$

$217.5-.01$ $\begin{array}{lll}3 & 216.7 & 0.05 \\ 5 & 216.0 & 0.10\end{array}$ $7215.2 \quad 0.16$

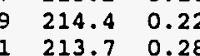
$\begin{array}{lll}13 & 212.9 & 0.34\end{array}$

$\begin{array}{lclc}\text { Tf } & q^{\prime \prime} & \text { Tw } & h \\ \text { (C) } & \left(W / m^{\wedge}\right) & l(C) & \left(w / m^{\wedge} 2\right. \\ 70.4 & 69902 & 79.7 & 7527 \\ 72.1 & 68919 & 80.9 & 7859 \\ 72.0 & 70520 & 80.0 & 8866 \\ 71.9 & 70238 & 80.6 & 8111 \\ 71.8 & 69220 & 80.9 & 7589 \\ 71.7 & 69978 & 80.4 & 7985 \\ 71.6 & 71604 & 80.6 & 7892 \\ 71.5 & 72218 & 78.7 & 9897\end{array}$

RUN NUMBER: 243

$\begin{array}{lr}\text { RUN NUMBER: } 243 & \text { WORKING FLUID: } R-113 \\ \mathrm{P} / \mathrm{d}=1.5 & \mathrm{G}=217.22 \mathrm{~kg} / \mathrm{s}^{*} \mathrm{~m}^{\wedge} 2 \\ \mathrm{P} & \end{array}$ DELTA $\mathrm{P}$ total $=5.72 \mathrm{kPa}$ SURFACE TYPE: TURBO-B

\begin{tabular}{|c|c|c|c|c|c|c|}
\hline Dh & P & $x \operatorname{in}$ & Tf & $q^{\prime \prime}$ & \multicolumn{2}{|c|}{$\mathrm{h}$} \\
\hline \# & [KPa] & {$[-1)$} & [C] & {$\left[W / m^{\wedge} 2\right]$} & [C] & $/ m^{\wedge} 2$ \\
\hline & 205.9 & -.00 & 69.0 & 10122 & 71.8 & 3857 \\
\hline 3 & 205.1 & -.00 & 69.5 & 10141 & 72.0 & 4248 \\
\hline & 204.4 & 0.00 & .9 & & & 4830 \\
\hline & 203. & & & & & 5791 \\
\hline & 202.9 & 0.0 & 9.8 & 10090 & 71.6 & 5491 \\
\hline 13 & & & & & & \\
\hline 13 & 201.4 & 02 & & 10360 & 71.6 & 5193 \\
\hline & & & & & & $616 ?$ \\
\hline
\end{tabular}

RUN NUMBER: 240 $\mathrm{p} / \mathrm{d}=1.5$

WORKING FLUID: R-113 $\quad G=217.6 \mathrm{~kg} / \mathrm{B}^{*} \mathrm{~m}^{\wedge} 2$ $\begin{aligned} X_{\text {in }} & =0.00 \\ \text { Dout } & =0.07\end{aligned}$ XIN

\begin{tabular}{|c|c|c|c|c|c|c|}
\hline ow & 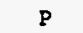 & in & $\mathbf{t}$ & $q^{\prime}$ & Tw & $n$ \\
\hline & [KPa] & {$[-]$} & [C] & {$[\mathrm{W} / \mathrm{m} \wedge 2]$} & & \\
\hline 1 & 204.0 & 0.00 & 58.8 & 2029 & 72.2 & 6402 \\
\hline 3 & 203 & 0.0 & & & 72 & 6823 \\
\hline 5 & 202 & & & & & 47 \\
\hline 7 & & & & & & \\
\hline & 201 & & & & 72.4 & 6926 \\
\hline 11 & & & & & & \\
\hline & 199.5 & 0.05 & 69.3 & 0851 & 72.3 & 6707 \\
\hline
\end{tabular}




\begin{tabular}{|c|c|c|c|c|c|c|}
\hline \multicolumn{4}{|c|}{$\begin{array}{l}\text { RUN NUMBER: } 241 \\
\text { P/d }=1.5 \\
\text { PIn }=208.3 \mathrm{kPa} \\
\text { Xin }=-.00 \\
\text { SURFACE TYPE: TURBO-B }\end{array}$} & \multicolumn{3}{|c|}{$\begin{array}{r}\text { WORKING FLUID: R-113 } \\
G=217.35 \mathrm{~kg} / \mathrm{s}^{*} \mathrm{~m}^{\wedge} \\
\text { TA P total }=5.64 \mathrm{kPa} \\
\text { xout }=0.09\end{array}$} \\
\hline * & $\stackrel{P}{[k P a}]$ & & & $\underset{\left(w / m^{\wedge} 2\right)}{q^{\prime \prime}}$ & $\begin{array}{l}T w \\
\text { (c) }\end{array}$ & $\begin{array}{c}h \\
m^{n} 2\end{array}$ \\
\hline & & & & & & \\
\hline 3 & & & & & & \\
\hline & & & & & & \\
\hline & & & & & & \\
\hline & & & & & & \\
\hline & & & & & & \\
\hline & & & & & & \\
\hline & & & 69.9 & 30919 & 72.8 & 10482 \\
\hline
\end{tabular}

RUN NUMBER: 235 $\mathrm{p} / \mathrm{d}=1.5$

in $=213.2 \mathrm{kPa}$

TCE TYPE: TURBO-B

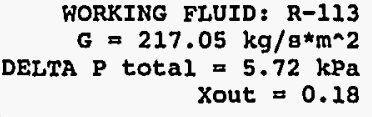

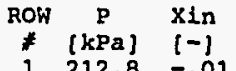

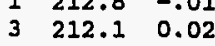

$\begin{array}{llll}5 & 211.3 & 0.04 & \end{array}$

$7 \quad 210.6 \quad 0.07$

$\begin{array}{llll}9 & 209.8 & 0.09 & \\ & & & \end{array}$

$\begin{array}{lll}11 & 209.0 & 0.12\end{array}$

$\begin{array}{lll}15 & 207.5 & 0.17\end{array}$

\begin{tabular}{|c|c|c|c|}
\hline $\begin{array}{l}\text { E } \\
\text { C) }\end{array}$ & $\underset{\left[W / m^{\wedge} 2\right]}{q{ }^{\prime \prime}}$ & $\begin{array}{l}\text { Tw } \\
{[c]}\end{array}$ & \\
\hline $\begin{array}{l}\text { C. } \\
9.7\end{array}$ & $\begin{array}{l}59922 \\
5\end{array}$ & 77.7 & \\
\hline & 596 & 78.4 & 8310 \\
\hline & 606 & & \\
\hline 1.1 & $\begin{array}{l}607 \\
599\end{array}$ & & 8226 \\
\hline & & & 8338 \\
\hline & & 78. & 8261 \\
\hline & & & \\
\hline
\end{tabular}

RUN NUMBER: 244

$\mathrm{p} / \mathrm{d}=1.5$

Pin $=201 \mathrm{kPa}$

$x$ in $=-.00$

SURFACE TYPE: TURBO-B (1) $335.35 \mathrm{~kg} / \mathrm{s}^{\star} \mathrm{m}^{\wedge}$

\begin{tabular}{|c|c|c|c|c|c|c|}
\hline OW & p & $x \ln$ & & & \multirow{3}{*}{\multicolumn{2}{|c|}{ [C] $\frac{h}{\left[W / m^{\wedge} 2 c\right]}$}} \\
\hline * & [KPa] & $1-]$ & [C] & {$\left[\mathrm{W} / \mathrm{m}^{\wedge} 2\right]$} & & \\
\hline & & & & 10030 & & \\
\hline 3 & 199.9 & 0.00 & 68.6 & 101 & & 3953 \\
\hline 5 & 199.2 & 0.00 & & 104 & & 4520 \\
\hline 7 & & & & 104 & 70.9 & 4970 \\
\hline 9 & 197.7 & 0.01 & & & 70 & 4926 \\
\hline & 196. & 0.0 & & 100 & 70.7 & 4967 \\
\hline 13 & 196.2 & 0.02 & 88.6 & 10340 & 70.6 & 5220 \\
\hline & 195 & & & & & \\
\hline
\end{tabular}

WORKING FLUID: R-113 LTA $P$ total $=5.72 \mathrm{kPa}$
RUN NUMBER: 242

$\mathrm{p} / \mathrm{d}=1.5$

Pin $=207.8 \mathrm{kPa}$

$x$ in $=-.00$

SURFACE TYPE: TURBO-
WORKING FLUID: R-113 $G=217.19 \mathrm{~kg} / \mathrm{s}^{\star} \mathrm{m}^{\wedge}$ $\begin{aligned} \text { DELTA P total } & =5.7 \mathrm{kPa} \\ \text { Xout } & =0.13\end{aligned}$
RUN NUMBER: 236 $\mathrm{d}=1.5$

Pin $=212.1 \mathrm{kPa}$ SURFACE TYPE: TURBO-

$\begin{array}{lll}\text { ROW } & \stackrel{P}{x i n} \\ 1 & {[\mathrm{kPa}]} & 1-1\end{array}$

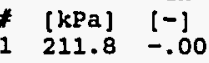

$\begin{array}{lll}211.0 & 0.02 \\ 210.3 & 0.05\end{array}$

$\begin{array}{lll}5 & 210.3 & 0.05 \\ 7 & 209.5 & 0.08\end{array}$

208.80 .11

$11208.0 \quad 0.14$

$\begin{array}{lll}13 & 207.3 & 0.17\end{array}$

$15 \quad 206.50 .20$

\begin{tabular}{|c|c|c|}
\hline \multicolumn{3}{|c|}{$\begin{array}{l}\text { WORKING FLUID: } \mathrm{R}-113 \\
G=217.56 \mathrm{~kg} / \mathrm{s}^{\star} \mathrm{m}^{\wedge} 2 \\
\text { P total }=5.69 \mathrm{kPa} \\
\text { Xout }=0.22\end{array}$} \\
\hline q"' & & \\
\hline 70573 & [C], & {$\left[W / m^{\wedge} 2 \quad c\right]$} \\
\hline 69610 & 79.4 & 8334 \\
\hline 71213 & 79.4 & 8512 \\
\hline 70886 & 79.3 & 8425 \\
\hline 69821 & 79.4 & 8106 \\
\hline 69637 & 78.9 & 8484 \\
\hline 71330 & 78.9 & 8522 \\
\hline 71837 & 77.1 & 10836 \\
\hline
\end{tabular}

RUN NUMBER: 245
p/d $=1.5$

$\mathrm{Pin}=205.3 \mathrm{kPa}$

Xin $=-.00$
SURFACE TYPE: TURBO-B

WORKING FLUID: R-113
$G=334.52 \mathrm{~kg} / \mathrm{s}^{\star m^{\wedge} 2}$ $\begin{aligned} \text { DELTA P total } & =5.69 \mathrm{kPa} \\ \text { Xout } & =0.04\end{aligned}$

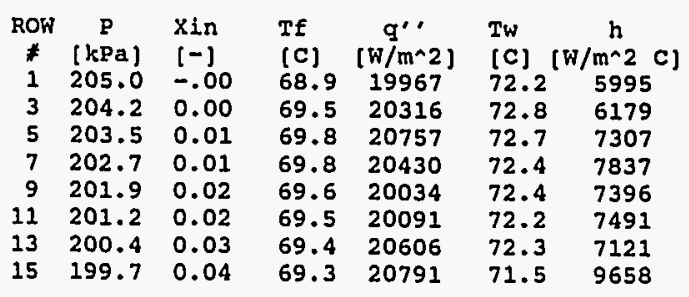

\begin{tabular}{|c|c|c|c|c|c|c|}
\hline \multicolumn{4}{|c|}{$\begin{array}{l}\text { RUN NUMBER: } 234 \\
\text { P/d }=1.5 \\
\text { Pin }=212.1 \mathrm{kPa} \\
\text { Xin }=-.01 \\
\text { SURFACE TXPE: TURBO-B }\end{array}$} & \multicolumn{3}{|c|}{$\begin{array}{r}\text { WORKING FLUID: R-113 } \\
G=217.54 \mathrm{~kg} / \mathrm{g}^{\star} \mathrm{m}^{\wedge} 2 \\
\text { TA P total }=5.65 \mathrm{kPa} \\
\text { Xout }=0.15\end{array}$} \\
\hline & & & & & & \\
\hline$\neq$ & [kP & & & & & \\
\hline 1 & & & & & & \\
\hline 3 & & & & & & \\
\hline & & & & & & \\
\hline 7 & & & & & & \\
\hline & & & & & & \\
\hline & & & & & & \\
\hline & & & & & & \\
\hline 5 & & & & 50888 & 74.8 & 11869 \\
\hline
\end{tabular}

RUN NUMBER: 237 $\mathrm{p} / \mathrm{d}=1.5$ $\mathrm{P} / \mathrm{d}=1.5$
$\mathrm{Pin}=214.3 \mathrm{kPa}$ $X$ In $=-.01$
SURFACE TYPE: TURBO-B

WORKING FLUID: R-113 RUN NUMBER: 246 $\mathrm{p} / \mathrm{d}=1.5$ $\mathrm{p} / \mathrm{d}=1.5$
$\mathrm{P}$ in $=209 \mathrm{kPa}$ $G=216.9 \mathrm{~kg} / \mathrm{s}^{\star} \mathrm{m}^{\wedge} 2$
DELTA $P$ total $=5.66 \mathrm{kPa}$ Xin $=-.01$
SURFACE TYPE: TURBO-B

WORKING FLUID: R-113 $G=334.24 \mathrm{~kg} / \mathrm{g}^{\star} \mathrm{m}^{\wedge}$ ROW $P$ Xin Tf $q^{\prime \prime}$ Tw $h$

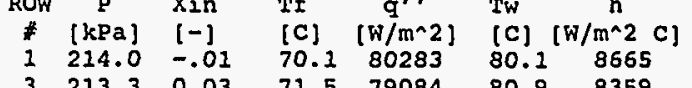
$\begin{array}{lllllll}1 & 214.0 & -.01 & 70.2 & 80283 & 80.1 & 8565 \\ 3 & 213.3 & 0.03 & 71.5 & 79084 & 80.9 & 8359\end{array}$ $\begin{array}{lllllll}5 & 212.5 & 0.06 & 71.4 & 80921 & 80.9 & 8482 \\ 7 & 211.7 & 0.09 & 71.3 & 81097 & 80.7 & 8579\end{array}$ $\begin{array}{llllllll}7 & 211.7 & 0.09 & 71.3 & 81097 & 80.7 & 8579 \\ 9 & 211.0 & 0.13 & 71.2 & 79573 & 80.8 & 8262\end{array}$ $\begin{array}{rlllllll}9 & 211.0 & 0.13 & 71.2 & 79573 & 80.8 & 8262 \\ 11 & 210.2 & 0.16 & 71.1 & 79559 & 80.3 & 8634\end{array}$ $\begin{array}{rrrrrrr}13 & 209.5 & 0.20 & 71.0 & 81449 & 80.3 & 8710 \\ 15 & 208.7 & 0.23 & 70.9 & 82070 & 78.7 & 10485\end{array}$

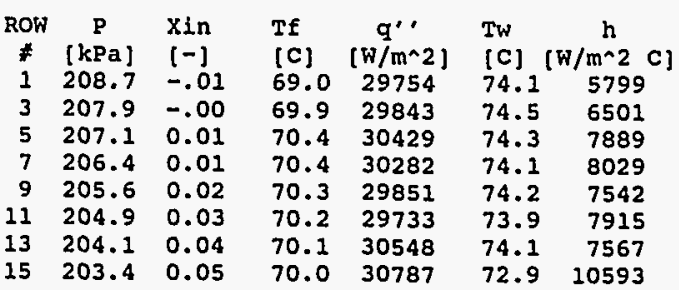


RUN NUMBER: 247 $\mathrm{P} / \mathrm{d}=1.5$

in $=214.7 \mathrm{kPa}$ SURFACE TYPE: TURBO-B

WORKING FLUID: R-113 RUN NUMBER: 285 $\begin{array}{rl}\mathbf{G}=334.83 \mathrm{~kg} / \mathrm{s}^{\star} \mathrm{m}^{\wedge} 2 & \mathrm{p} / \mathrm{d}=1.5 \\ \mathrm{TA} \text { total }=5.71 \mathrm{kPa} & \mathrm{Pin}=603.8 \mathrm{kPa}\end{array}$ $\begin{aligned} \text { DELTA P total } & =5.71 \mathrm{kPa} \\ \text { Xout } & =0.08\end{aligned}$ SURFACE TYPE: TURBO-B

WORKING FLUID: R-113 $G=49.94 \mathrm{~kg} / \mathrm{s}^{\star} \mathrm{m}^{\wedge} 2$ DELTA P total $=5.67 \mathrm{kPa}$ Xout $=0.32$

\begin{tabular}{|c|c|c|c|c|c|c|}
\hline ROW & P & $x$ in & $T \pm$ & $q^{\prime \prime}$ & $T W$ & $\mathrm{~h}$ \\
\hline$\#$ & [kPa] & {$[-]$} & [C] & {$\left[\mathrm{W} / \mathrm{m}^{\wedge} \mathbf{2}\right]$} & [C] & $y / m \ddot{m} \quad c]$ \\
\hline 1 & 214.3 & & 70.2 & $40063^{\circ}$ & 76.4 & 6375 \\
\hline 3 & 213.6 & 0.00 & 71.1 & 39719 & 76.7 & 7124 \\
\hline 5 & 212.8 & 0.01 & 71.5 & 40400 & 76.4 & 8244 \\
\hline 7 & 212.1 & 0.03 & 71.4 & 40223 & 76.5 & 7874 \\
\hline 9 & 211.3 & 0.04 & 71.2 & 39848 & 76.6 & 7469 \\
\hline 11 & 210.5 & 0.05 & 71.1 & 39823 & 76.1 & 8018 \\
\hline 13 & 209.8 & 0.06 & 71.0 & 40850 & 76.3 & 7730 \\
\hline & 209.0 & 0.07 & 70.9 & & 740 & \\
\hline
\end{tabular}

\begin{tabular}{|c|c|c|c|c|c|c|}
\hline OW & $P$ & $x$ in & Tf & n & Tw & $\mathrm{h}$ \\
\hline \# & [KPa] & [-] & (c) & (w/m^2] & \multicolumn{2}{|c|}{ [C] 1} \\
\hline & 603.5 & & 103.9 & 20589 & 108.1 & 4830 \\
\hline 3 & 602.8 & 0.04 & 105.5 & 20318 & 108.5 & 67. \\
\hline 5 & & & & & 108 & 7205 \\
\hline 7 & 601.3 & 0.12 & 105.4 & 20955 & 108.3 & 7192 \\
\hline 9 & & & 105 & & 108 & \\
\hline & 599.7 & 0.21 & 105.3 & 20190 & 108.2 & \\
\hline & & 0.2 & & & 108.6 & \\
\hline & & & & & & \\
\hline
\end{tabular}

RUN NUMBER: 282 $\mathrm{P} / \mathrm{d}=1.5$

$=604.5 \mathrm{kPa}$ in $=0.02$ TURBO-B

WORKING FLUID: R-113 $G=50.75 \mathrm{~kg} / \mathrm{s}^{4} \mathrm{~m}^{2} 2$ $\begin{aligned} \text { DELTA P total } & =5.7 \mathrm{kPa} \\ \text { Xout } & =0.78\end{aligned}$

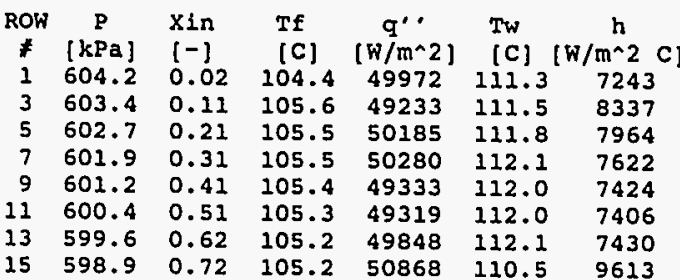

RUN NUMBER: 248

$\mathrm{p} / \mathrm{d}=1.5$

WORKING FLUID: $R-113$ RUN NUMBER: 280

$\mathrm{p} / \mathrm{d}=1.5$

WORKING FLUID: R-113 $\mathbf{G}=50.64 \mathrm{~kg} / \mathrm{s}^{\star} \mathrm{m}^{\wedge} 2$

Pin $=220.3 \mathrm{kPa}$ SURFACE TYPE: TURBO-B DELTA $P$ total $=5 \mathrm{~kg} / \mathrm{s}^{*} \mathrm{~m}$ xout $=0.08 \quad x_{\text {in }}=0.00$ DELTA P total $=5.65 \mathrm{kPa}$ SURFACE TYPE: TURBO-B Xout $=0.46$

\begin{tabular}{|c|c|c|c|c|c|c|}
\hline & $P$ & $x$ in & Tf & & $T w$ & h \\
\hline & [kPa] & {$[-]$} & [C] & {$\left[w / m^{\wedge} 2\right]$} & (c) & $\mathrm{W} / \mathrm{m}^{\wedge} 2 \quad \mathrm{c}$ \\
\hline 1 & 220.0 & -.02 & 70.0 & 50059 & 78.4 & 5958 \\
\hline & 219.2 & -.01 & 71.7 & 49501 & 78.7 & 7041 \\
\hline 5 & 218.4 & 0.01 & 72.5 & 50496 & 78.9 & 7863 \\
\hline & 217.7 & 0.02 & 72.3 & 50448 & 78.7 & 7861 \\
\hline & 216.9 & 0.03 & 72.2 & 50007 & 78.9 & 7455 \\
\hline 1 & 216.2 & 0.05 & 72.1 & 50294 & 78.3 & 8169 \\
\hline & 215.4 & 0.06 & 72.0 & 51505 & 78.5 & 7918 \\
\hline & 214.7 & 0.08 & 71.9 & 51791 & 76.6 & 10910 \\
\hline
\end{tabular}

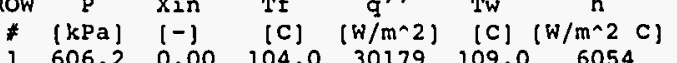

$\begin{array}{lllllll}3 & 605.4 & 0.06 & 104.0 & 30179 & 109.0 & 6054 \\ & 605.8 & 0.06 & 105.8 & 30047 & 109.6 & 7905\end{array}$

$\begin{array}{lllllll}5 & 604.4 & 0.06 & 105.8 & 30047 & 109.6 & 7905 \\ 5 & 604.7 & 0.12 & 105.7 & 30370 & 109.5 & 7897\end{array}$

$\begin{array}{llllllll}7 & 603.9 & 0.18 & 105.6 & 30571 & 109.6 & 7620\end{array}$

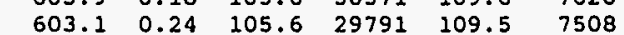

$\begin{array}{lllllll}1 & 602.4 & 0.30 & 105.5 & 29907 & 109.3 & 7786\end{array}$

$\begin{array}{llllllr}15 & 600.9 & 0.43 & 105.4 & 30822 & 108.2 & 10684\end{array}$
RUN NUMBER: 260 $\mathrm{p} / \mathrm{d}=1.5$

in $=544.8 \mathrm{kP}$ $\operatorname{xin}=0.01$ SURFACE TYPE: TURBO-B

\begin{tabular}{|c|c|c|c|c|c|c|}
\hline OW & $\mathbf{p}$ & $x$ in & Tf & & $T w$ & $\mathrm{~h}$ \\
\hline$\#$ & [kPa] & {$[-]$} & [C] & $\left\{W / m^{\wedge} 2\right\}$ & [c] & $(W / m \wedge 2$ \\
\hline 1 & 544.5 & 0.01 & 98.8 & 10255 & 101.8 & 3325 \\
\hline 3 & 543.7 & 0.02 & 99.7 & 10385 & & 4181 \\
\hline 5 & 543. & 0.0 & 100.0 & 10635 & 101.7 & 5465 \\
\hline 7 & 542.2 & 0.0 & .9 & 106 & & 5153 \\
\hline & 541 & & & 102 & 101 & 4971 \\
\hline & 540.7 & 0.0 & 99.8 & 10184 & 101.9 & 4944 \\
\hline & 539.9 & 0 & & & 101.8 & 5075 \\
\hline & & & & & & \\
\hline
\end{tabular}
$G=102.9 \mathrm{~kg} / 8{ }^{*} \mathrm{~m} \uparrow 2$
WORKING FLUID: R-113 DELTA P total $=5.73 \mathrm{kPa}$

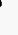

RUN NUMBER: 281

$\mathrm{p} / \mathrm{d}=1.5$
$\mathrm{p}$ in $=605.8 \mathrm{kPa}$

$x_{\text {in }}=0.01$

SURFACE TYPE: TURBO-B

WORKING FLUID: $\mathrm{R}-113$ $G=50.34 \mathrm{~kg} / \mathrm{g}^{\mathrm{k}} \mathrm{ma} 2$ DELTA $\mathrm{P}$ total $=5.65 \mathrm{kPa}$ xout $=0.63$

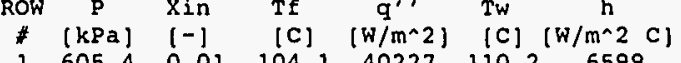
604. 70.09 105.7 39074 110.2 6599 \begin{tabular}{llllllll}
5 & 603.9 & 0.16 & 105.6 & 40498 & 110.7 & 7993 \\
\hline & 603.2 & 0.25 & 105.6 & 40764 & 111.1 & 7365
\end{tabular} $\begin{array}{lllllll}7 & 603.2 & 0.25 & 105.6 & 40764 & 111.1 & 7365\end{array}$ $\begin{array}{lllllll}9 & 602.4 & 0.33 & 105.5 & 39951 & 111.1 & 7112\end{array}$ $\begin{array}{lllllll}11 & 601.6 & 0.41 & 105.4 & 40262 & 111.0 & 7202\end{array}$ $\begin{array}{rrrrrrr}13 & 600.9 & 0.50 & 105.4 & 40696 & 111.2 & 7193 \\ 15 & 600.1 & 0.59 & 105.3 & 41465 & 109.4 & 10095\end{array}$ 


\begin{tabular}{|c|c|c|c|c|c|c|}
\hline \multicolumn{4}{|c|}{$\begin{array}{l}\text { UN NUMBER: } 262 \\
\text { ld }=1.5 \\
\text { In }=588.5 \mathrm{kPa} \\
\text { In }=0.00 \\
\text { URFACE TYPE: TURBO-B }\end{array}$} & \multicolumn{3}{|c|}{$\begin{array}{r}\text { WORKING FLUID: R-113 } \\
\text { G }=101.76 \mathrm{~kg} / \mathrm{g} \times \mathrm{m} 2 \\
\text { TA } \mathrm{P} \text { total }=5.66 \mathrm{kPa} \\
\text { Xout }=0.23\end{array}$} \\
\hline $\begin{array}{c}\text { ROW } \\
\neq\end{array}$ & $\underset{\mathrm{kPa}}{\mathrm{p}}$ & $\begin{array}{l}x \ln \\
1-1\end{array}$ & $\begin{array}{l}\text { TE } \\
\text { (C) }\end{array}$ & $\stackrel{q{ }^{\prime \prime}}{ }$ & Tw & $\stackrel{h}{h}$ \\
\hline$i$ & 588.2 & 0.00 & 103.1 & 30190 & 107.3 & $\begin{array}{l}\left.7 \mathrm{~m}^{*} 2 \mathrm{c}\right] \\
7116\end{array}$ \\
\hline 3 & 587.4 & 0.03 & 104.2 & 30038 & & \\
\hline 5 & & & & & & \\
\hline 7 & 585. & & 104 & 30 & 10 & 8463 \\
\hline 9 & & & & & & \\
\hline 11 & & & & & & \\
\hline 13 & 583.6 & & 103 & & & 7434 \\
\hline 15 & 582.9 & $0: 22$ & 103.8 & 30839 & 106.6 & $6 \quad 10973$ \\
\hline
\end{tabular}

RUN NUMBER: 263

Pin $=580.4$

SURFACE TYPE: TURBO-B

WORKING FLUID: R-113 $\mathbf{G}=101.91 \mathrm{~kg} / \mathrm{s}^{\star} \mathrm{m}^{\wedge} 2$ DELTA P total $=5.7 \mathrm{kPa}$

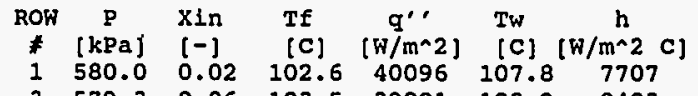
$\begin{array}{lllllll}3 & 579.3 & 0.06 & 103.5 & 39801 & 108.2 & 8403\end{array}$ $\begin{array}{lllllll}5 & 578.5 & 0.09 & 103.4 & 40611 & 108.4 & 8020\end{array}$ $\begin{array}{lllllll}7 & 577.8 & 0.13 & 103.3 & 40640 & 108.2 & 8248\end{array}$ \begin{tabular}{lllllll}
9 & 577.0 & 0.17 & 103.2 & 40003 & 108.4 & 7788 \\
\hline & 576.2 & 0.21 & 103.2 & 40179 & 108.3 & 7764
\end{tabular} $\begin{array}{lllllll}13 & 575.5 & 0.26 & 103.2 & 40179 & 108.3 & 7764\end{array}$ $\begin{array}{rrrrrrr}13 & 575.5 & 0.26 & 103.1 & 40722 & 108.4 & 7647 \\ 15 & 574.7 & 0.30 & 103.0 & 41463 & 107.0 & 10500\end{array}$

\begin{tabular}{|c|c|c|c|c|c|c|}
\hline \multicolumn{4}{|c|}{$\begin{array}{l}\text { RUN NUMBER: } 264 \\
\text { P/d }=1.5 \\
\text { PIn }=580.3 \mathrm{kPa} \\
\text { Xin }=0.02 \\
\text { SURFACE TYPE: TURBO-B }\end{array}$} & \multicolumn{3}{|c|}{$\begin{array}{r}\text { WORKING FLUID: R-113 } \\
\text { G }=101.68 \mathrm{~kg} / \mathrm{s}^{\star} \mathrm{m}^{\wedge} \\
\text { IA P total }=5.7 \mathrm{kPa} \\
\text { xout }=0.40\end{array}$} \\
\hline & & & & & & \\
\hline$\#$ & & & & (พ) & & \\
\hline & & & & & & \\
\hline 3 & & & & & & \\
\hline & & & & & & \\
\hline 7 & & & & & & \\
\hline & & & & & & \\
\hline & & & & & & \\
\hline & & & & & & \\
\hline & & & & & & 10498 \\
\hline
\end{tabular}

RUN NUMBER: 265

$\mathrm{p} / \mathrm{d}=1.5$

$x_{\text {in }}=0.02$

SURFACE TYPE: TURBO-

$G=101.84 \mathrm{~kg} / \mathrm{s}^{\star} \mathrm{m}^{\wedge} 2$
DELTA P total $=5.69 \mathrm{kPa}$
Xout $=0.47$

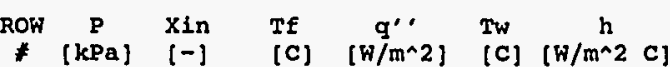

$\begin{array}{lllllll}\text { * } & {[\mathrm{kPa}]} & {[-]} & {[\mathrm{C}]} & {\left[\mathrm{W} / \mathrm{m}^{\wedge} 2\right]} & {[\mathrm{C}]} & {\left[\mathrm{W} / \mathrm{m}^{\wedge} 2\right.} \\ 1 & 580.0 & 0.02 & 102.5 & 59879 & 109.6 & 8464\end{array}$

$\begin{array}{lllllll}1 & 580.0 & 0.02 & 102.5 & 59879 & 109.6 & 8464 \\ 3 & 579.3 & 0.08 & 103.4 & 59074 & 109.9 & 8621\end{array}$

$\begin{array}{lllllll}3 & 579.3 & 0.08 & 103.4 & 59074 & 109.9 & 8621 \\ 5 & 578.5 & 0.13 & 103.4 & 60496 & 110.5 & 8488\end{array}$

$\begin{array}{lllllll}7 & 577.8 & 0.19 & 103.3 & 60371 & 110.1 & 8885\end{array}$

$\begin{array}{llllll}577.0 & 0.25 & 103.2 & 59400 & 110.2 & 8499\end{array}$

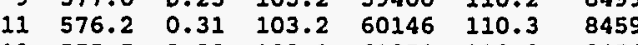

$\begin{array}{lllllll}11 & 576.2 & 0.31 & 103.2 & 60146 & 110.3 & 8459 \\ 13 & 575.5 & 0.38 & 103.1 & 61351 & 110.3 & 8454\end{array}$

$\begin{array}{lllllll}15 & 574.7 & 0.44 & 103.0 & 61980 & 108.7 & 10970\end{array}$
$G=101.84 \mathrm{~kg} / \mathrm{s}^{*} \mathrm{~m}^{\wedge}$

RUN NUMBER: 277

$\mathrm{p} / \mathrm{d}=1.5$

$G=182.99 \mathrm{~kg} / \mathrm{s}^{*} \mathrm{~m}^{\wedge} 2$ $\begin{array}{rlrl}\text { Xin } & =0.00 & \text { DELTA } P \text { total } & =5.72 \mathrm{kPa} \\ \text { xout } & =0.05\end{array}$ SURFACE TYPE: TURBO-

\begin{tabular}{|c|c|c|c|c|c|c|}
\hline ROH & & $2 n$ & $\mathrm{TI}$ & & $1 \mathrm{~W}$ & \\
\hline & [kPa] & & [C] & {$\left[\omega / m^{\wedge} 2\right]$} & [c] & \\
\hline & & & & & & \\
\hline 3 & 614 & 0. & & & & \\
\hline & 613 & 0. & & & & 5979 \\
\hline 7 & & & & & & \\
\hline & 61 & & & & & \\
\hline 11 & 611 & 0. & & & & \\
\hline & & 0.04 & 106.2 & 10533 & 8.3 & 5068 \\
\hline
\end{tabular}

WORKING FLUID: R-113
RUN NUMBER: 266

$\mathrm{p} / \mathrm{d}=1.5$

Pin $=577.2$
$X$ in $=0.02$

SURFACE TYPE: TURBO$G=101.49 \mathrm{~kg} / \mathrm{g} \star^{\wedge} \mathrm{m}^{\wedge} 2$ DELTA P total $=5.69 \mathrm{kPa}$ xout $=0.55$

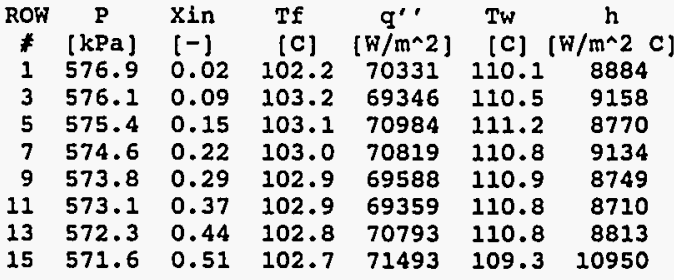

\begin{tabular}{|c|c|c|c|c|c|c|}
\hline $\begin{array}{l}\text { RUN } \\
\text { p/d } \\
\text { Pin } \\
\text { Xin } \\
\text { SUR }\end{array}$ & $\begin{array}{l}\text { NUMBE } \\
=1.5 \\
=624 \\
=0.0 \\
\text { FACE }\end{array}$ & $\mathbf{k P a}$ & & $\begin{array}{c}\text { WORKI } \\
G= \\
\text { LTA P t }\end{array}$ & $\begin{array}{l}\text { NG FLU } \\
183.37 \\
\text { otal }=\end{array}$ & $\begin{array}{r}J D: R-113 \\
\mathrm{~kg} / \mathrm{s}^{\star} \mathrm{m}^{\wedge} 2 \\
5.72 \mathrm{kPa}\end{array}$ \\
\hline ROW & & & Tf & & & $\mathrm{h}$ \\
\hline $\begin{array}{l}* \\
1\end{array}$ & $\begin{array}{l}{[\mathrm{kPa}]} \\
624.6\end{array}$ & & $\begin{array}{c}{[c]} \\
106.1\end{array}$ & $\begin{array}{l}{[W / \mathfrak{m}} \\
205\end{array}$ & $\begin{array}{c}(\mathrm{C}) \\
110.0\end{array}$ & $\begin{array}{l}/ m^{\wedge} 2 \\
5274\end{array}$ \\
\hline & 623. & & & & & \\
\hline & & & & & & \\
\hline 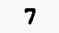 & & & & & & \\
\hline & & & & & & \\
\hline & & & & & & \\
\hline & & & & & & \\
\hline & & & & & 09.5 & 8282 \\
\hline
\end{tabular}

RUN NUMBER: 267

$\mathrm{p} / \mathrm{d}=1.5$

WORKING FLUID: R-113 $\quad G=101.56 \mathrm{~kg} / \mathrm{g}^{\star} \mathrm{m}^{\wedge} 2$ $\begin{aligned} \text { Pin } & =583.6 \mathrm{kPa} & \text { DELTA P total } & =5.67 \mathrm{kPa} \\ \mathrm{Xin} & =0.01 & \text { Xout } & =0.61\end{aligned}$ SURFACE TYPE: TURBO-B

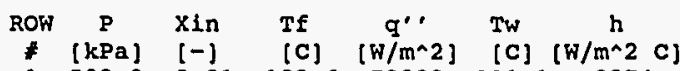
$\begin{array}{lllllll}1 & 583.3 & 0.01 & 102.6 & 79082 & 111.1 & 9374\end{array}$

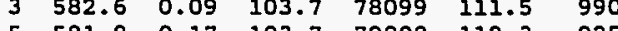

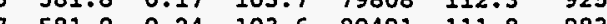
$\begin{array}{lllllll}9 & 580.3 & 0.32 & 103.5 & 78736 & 111.9 & 9415\end{array}$ $\begin{array}{lllllll}11 & 579.5 & 0.40 & 103.5 & 78356 & 111.9 & 9308\end{array}$ $\begin{array}{lllllll}13 & 578.8 & 0.49 & 103.4 & 80204 & 112.0 & 9352\end{array}$ $\begin{array}{rrrrrrr}15 & 578.0 & 0.57 & 103.3 & 80851 & 110.7 & 10923\end{array}$
RUN NUMBER: 276 $\mathrm{p} / \mathrm{d}=1.5$

WORKING FLUID: R-113 PIn $=628.3 \mathrm{kPa} \quad$ DELTA P total $=5.64 \mathrm{kPa}$ Xin $=-.00$
Xout $=0.13$

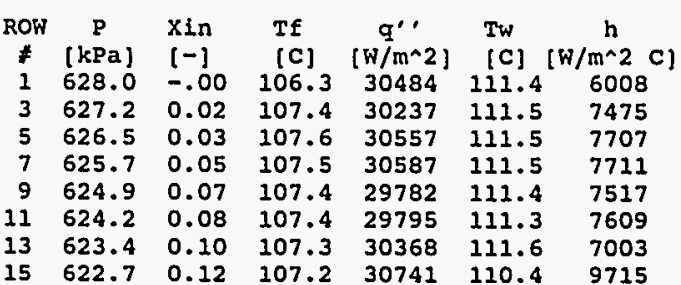




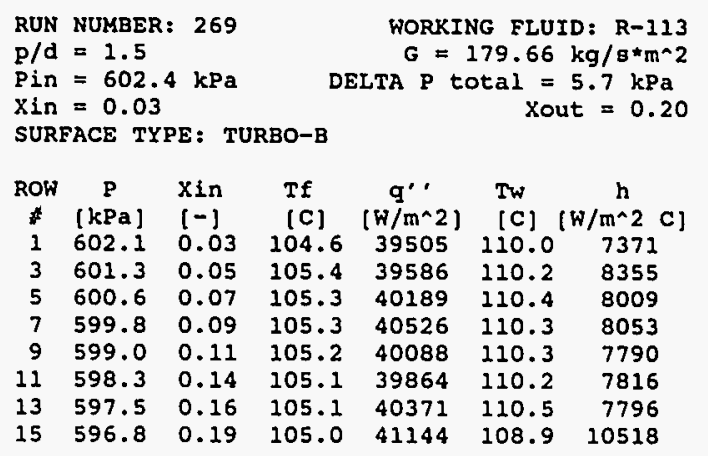
RUN NUMBER: 272
$\begin{array}{lr}\text { RUN NUMBER: } 272 & \text { WORKING FLUID: } R-113 \\ \mathrm{p} / \mathrm{d}=1.5 & \mathrm{G}=182.99 \mathrm{~kg} / \mathrm{\theta}^{*} \mathrm{~m}^{\wedge} 2\end{array}$ Pin $=629.8 \mathrm{kPa} \quad$ DELTA $\mathrm{Patal} \quad 5 / 6 \mathrm{k}^{2} \mathrm{kPa}$ $\begin{array}{ll}\text { Xin }=-.01 & \text { Xout }=0.29 \\ \text { SURFACE TYPE: } & \text { TURBO-B }\end{array}$

\begin{tabular}{|c|c|c|c|c|c|c|}
\hline Low & P & in & TI & $q^{\prime}$ & $T w$ & $\mathrm{~h}$ \\
\hline F & & & [C] & & & $\begin{array}{l}\mathrm{m}^{\wedge} \mathbf{2} \\
7727\end{array}$ \\
\hline & 629.5 & -.01 & 106.1 & 70167 & 115.1 & 7727 \\
\hline $\begin{array}{l}3 \\
5\end{array}$ & $\begin{array}{l}628.7 \\
628.0\end{array}$ & 0.0 & & & & $\begin{array}{r}9438 \\
9203\end{array}$ \\
\hline 7 & & & & & & \\
\hline 9 & 626 & & & & & 9023 \\
\hline 1. & 625 & & & & & \\
\hline 1. & 624 & 10 & & & & 910 \\
\hline & & & & & & \\
\hline
\end{tabular}

\begin{tabular}{|c|c|c|c|c|c|c|}
\hline \multicolumn{4}{|c|}{$\begin{array}{l}\text { RUN NUMBER: } 270 \\
\text { P/d }=1.5 \\
\text { PIn }=603.5 \mathrm{kPa} \\
\text { Xin }=0.01 \\
\text { SURFACE TYPE: TURBO-B }\end{array}$} & $\begin{aligned} \text { WORKII } \\
G=\end{aligned}$ & $\begin{array}{l}\text { NG FLU } \\
179.63\end{array}$ & $\begin{array}{r}I D: R-113 \\
\mathrm{~kg} / \mathrm{g}^{\star} \mathrm{m}^{\wedge} 2 \\
5.65 \mathrm{kPa}\end{array}$ \\
\hline ow & $\mathrm{P}$ & & Tf & & Tw & \\
\hline * & & & & & & \\
\hline$\frac{1}{3}$ & & & & & & \\
\hline 5 & & & & & & \\
\hline & & & & & & \\
\hline & & & & & & \\
\hline & & & & & & \\
\hline & & & & & & \\
\hline & & & & & & 9536 \\
\hline
\end{tabular}
RUN NUMBER: $273 \quad$ WORKING FLUID: $R-113$
$\mathrm{p} / \mathrm{d}=1.5$ $\quad G=182.74 \mathrm{~kg} / \mathrm{g}^{*} \mathrm{~m}^{\wedge} 2$ $\begin{aligned} x_{\text {in }}=-.00 & \text { DELTA P total }=5.66 \mathrm{kPa} \\ \text { Xout } & =0.34\end{aligned}$ XIN

\begin{tabular}{|c|c|c|c|c|c|c|}
\hline ROW & 5 & in & II & & Tw & $\pi$ \\
\hline \# & [kPa] & {$[-]$} & [C] & {$\left[\mathrm{w} / \mathfrak{m}^{\wedge} 2\right]$} & [c] & $1 / \mathrm{m}^{\wedge} 2$ \\
\hline 1 & & -.00 & 106.3 & & 116.0 & 8299 \\
\hline 3 & 631. & 0.04 & & & 115 & 10303 \\
\hline 5 & & & & & & \\
\hline 7 & & & & & & \\
\hline & & & & & & \\
\hline 1. & 628 & & & & & 9621 \\
\hline & & & & 81207 & 116.0 & 9710 \\
\hline
\end{tabular}

\begin{tabular}{|c|c|c|c|c|c|c|}
\hline \multicolumn{4}{|c|}{$\begin{array}{l}\text { RUN NUMBER: } 271 \\
\text { P } / \mathrm{d}=1.5 \\
\text { Pin }=620 \mathrm{kPa} \\
\text { Xin }=-.00 \\
\text { SURFACE TYPE: TURBO-B }\end{array}$} & $\begin{array}{c}\text { WORKI } \\
G= \\
\text { P tot }\end{array}$ & $\begin{array}{l}\text { NG FLU } \\
183.43 \\
a 1=5\end{array}$ & $\begin{array}{l}\text { ID: } \mathrm{R}-113 \\
\mathrm{~kg} / \mathrm{s}^{*} \mathrm{~m}^{\wedge} 2 \\
.72 \mathrm{kPa}\end{array}$ \\
\hline & & $x$ in & $T f$ & & Tw & \\
\hline * & & & & & & \\
\hline & & & & & & \\
\hline 3 & & 0.0 & & & & \\
\hline 5 & & & & & & \\
\hline & & & & & & \\
\hline 9 & & & & & & \\
\hline & & & & & & \\
\hline & & & & & & \\
\hline 5 & & & 106.5 & 62130 & 112.5 & 10431 \\
\hline
\end{tabular}




\section{Bundle Boiling Data}

High Flux data in R-113 for bundle with $\mathrm{p} / \mathrm{d}=1.17$ 


\begin{tabular}{|c|c|c|c|c|c|c|c|c|c|c|c|c|c|}
\hline $\begin{array}{l}\text { RUN } \\
\text { p/d } \\
\text { Pin } \\
\text { Xin } \\
\text { SURE }\end{array}$ & $\begin{array}{l}\text { NUMBEF } \\
=1.17 \\
=200 . \\
=-.00 \\
\text { ACE TY }\end{array}$ & $\begin{array}{l}=299 \\
6 \mathrm{kPa}\end{array}$ & & $\begin{array}{l}\text { WORKII } \\
\mathbf{G}=5 \\
\text { LTA P to }\end{array}$ & $\begin{array}{l}\text { G FLU } \\
2.59 \\
\text { tal }= \\
\text { xo }\end{array}$ & $\begin{array}{l}\text { ID: } \mathrm{R}-113 \\
\mathrm{~kg} / \mathrm{s}^{\star n} \mathrm{~m}^{\wedge} 2 \\
4.48 \mathrm{kPa} \\
\mathrm{ut}=0.18\end{array}$ & $\begin{array}{l}\text { RUN } \\
\text { p/d } \\
\text { Pin } \\
\text { Xin } \\
\text { SUR }\end{array}$ & $\begin{array}{l}\text { NUMBEF } \\
=1.17 \\
=205 \\
=-.00 \\
\text { ACE TY }\end{array}$ & PE: $\mathrm{B}$ & FLUX & $\begin{array}{c}\text { WORKI } \\
G= \\
\text { P tot }\end{array}$ & $\begin{array}{l}\text { FLUI } \\
.85 \mathrm{k} \\
=4 .\end{array}$ & $\begin{array}{l}\text { ID : } R-113 \\
\mathrm{~kg} / \mathrm{s}^{\star} \mathrm{m}^{\wedge} 2 \\
.5 \mathrm{kPa} \\
\mathrm{ut}=0.74\end{array}$ \\
\hline ROW & P & $x$ in & $T f$ & $\mathrm{q}^{\prime \prime}$ & Tw & $\mathrm{h}$ & ROW & $\mathbf{P}$ & $x$ in & Tf & $q^{\prime}$ & Tw & $\mathrm{h}$ \\
\hline$\neq$ & [kPa] & & [C] & {$\left[w / m^{n}\right.$} & [C] & $(\mathrm{W} / \mathrm{m}-2$ & $\neq$ & & & & $1 \omega / \mathrm{m}$ & & \\
\hline 1 & 200.3 & -.0 & 67.8 & 5027 & 70.4 & 1979 & 1 & 204.7 & -.8 & 68.5 & 2059 & 72.9 & 4756 \\
\hline 3 & 199.7 & 0.0 & 69.2 & 486 & 70.2 & 48 & 3 & 204 & & & & 72.0 & \\
\hline 5 & & 0.0 & & 49 & & 509 & 5 & & & & & & \\
\hline 7 & 198.5 & 0.0 & 69.1 & 5059 & 70.1 & 5046 & 7 & 202.9 & & 69 & 20400 & 71.8 & 10725 \\
\hline 9 & 197.9 & 0.0 & & & & & 9 & & & & & 1.8 & \\
\hline 11 & 197. & 0 & & 48 & 69.9 & 489 & 11 & 1.7 & & & 19770 & 71.3 & 11055 \\
\hline 13 & 196.7 & 0.1 & 68. & 49 & & 500 & 13 & & & & & 71.3 & 11813 \\
\hline 15 & 196.1 & 0.16 & 68.7 & 4991 & 69.7 & 4830 & 15 & 200.5 & & 69.5 & 20192 & 71.3 & 11312 \\
\hline
\end{tabular}

RUN NUMBER: 295 $\mathrm{P} / \mathrm{d}=1.17$
$\mathrm{Pin}=206.5 \mathrm{kP}$

WORKING FLUID: $R-113$ in $=-.01 \mathrm{kPa} \quad$ DELTA $P$ total $=4.56 \mathrm{kPa}$ SURFACE TYPE: HIGH FLUX

yout $=0.38$

\begin{tabular}{|c|c|c|c|c|c|c|}
\hline$\partial k$ & $P$ & $x$ in & $T f$ & & Tw & h \\
\hline ; & [kPa] & & [C] & {$\left[w / m^{\wedge} 2\right]$} & [C] & $w / m^{\wedge} 2$ \\
\hline 1 & 206.2 & -.01 & 68.7 & 20706 & 73.2 & 4560 \\
\hline 3 & 205.6 & 0.0 & & & & \\
\hline 5 & 205. & & & 20 & 2.3 & 10044 \\
\hline 7 & 204. & & & & & \\
\hline & 203.8 & 0.2 & & 19 & 71.9 & 10827 \\
\hline & 203.2 & 0.2 & & 197 & & 11573 \\
\hline & & & & 20170 & 71.7 & 10785 \\
\hline
\end{tabular}

RUN NUMBER: 300

$\mathrm{g} / \mathrm{d}=1.17$

Xin $=2.00$

SIn $\approx-.00$
SURFACE TYPE: HIGH FLUX

WORKING FLUID: $R-113$ RUN NUMBER: 303

$G=52.85$ kg: R-113

DELTA P total $=4.51 \mathrm{kPa}$

Xout $=0.38$

$\begin{array}{rcl}\text { ROW } & \text { P } & \text { Xin } \\ \neq & {[\mathrm{kPa}]} & {[-]} \\ 1 & 203.3 & -.00 \\ 3 & 202.7 & 0.05 \\ 5 & 202.1 & 0.09 \\ 7 & 201.5 & 0.14 \\ 9 & 200.9 & 0.20 \\ 11 & 200.3 & 0.25 \\ 13 & 199.7 & 0.30 \\ 15 & 199.1 & 0.35\end{array}$

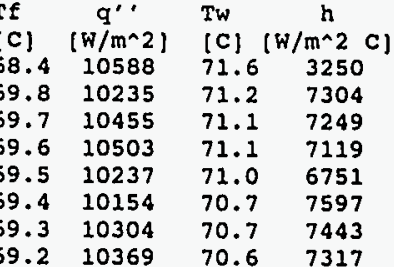

$\mathrm{p} / \mathrm{d}=1.17$

Pin $=202.9 \mathrm{kP}$

XIn $=0.00$
SURFACE TYPE: HIGH FLUX

WORKING FLUID: $R-113$ $G=101.51 \mathrm{~kg} / \mathrm{s}^{\star \mathrm{m}^{\wedge} 2}$ DELTA $P$ total $=4.54 \mathrm{kPa}$

$\begin{array}{ccc}\text { * } & \text { [ } & \\ 1 & \text { kPa } & 1-] \\ 1 & 202.6 & 0.00\end{array}$

$3202.0 \quad 0.01$

$5 \quad 201.4 \quad 0.03$

$9200.2 \quad 0.05$

$\begin{array}{lll}11 & 199.7 & 0.07 \\ 13 & 199.1 & 0.08\end{array}$

$\begin{array}{lll}15 & 198.5 & 0.09\end{array}$
RUN NUMBER: 296

$\mathrm{p} / \mathrm{d}=1.17$

Pin $=207.9 \mathrm{kPa} \quad$ DELTA $P$ total $=4.5 \mathrm{kPa}$

SURFACE TYPE: HIGH FLUX

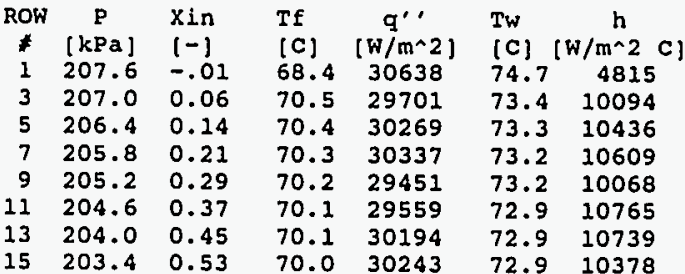

WORKING FLUID: R-113 RUN NUMBER: 294

$\mathrm{p} / \mathrm{d}=1.17$

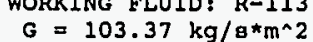

$\operatorname{xin}=0.00$

SURFACE TYPE: HIGH FLUX DELTA P total $=4.55 \mathrm{kPa}$ Xin $=-.00 \quad$ Xout $=0.55$ XUREACE TYPE: HIGH FLUX

$\begin{array}{rcl}\text { ROW } & P & X i n \\ * & {[\mathrm{kPa}]} & {[-1} \\ 1 & 202.6 & 0.00 \\ 3 & 202.0 & 0.03 \\ 5 & 201.4 & 0.05 \\ 7 & 200.8 & 0.07 \\ 9 & 200.2 & 0.10 \\ 11 & 199.6 & 0.13 \\ 13 & 199.0 & 0.15 \\ 15 & 198.4 & 0.18\end{array}$

$\begin{array}{lclc}\text { Tf } & q^{\prime \prime} & T w & h \\ {[C]} & {\left[W^{\prime} m^{\wedge} 2\right]} & l C] & {\left[W / m^{\wedge} 2\right.} \\ 66.7 & 10417 & 71.3 & 2243 \\ 69.0 & 10084 & 70.9 & 5140 \\ 69.6 & 10275 & 70.8 & 8302 \\ 69.5 & 10202 & 70.7 & 8207 \\ 69.4 & 9825 & 70.7 & 7826 \\ 69.3 & 10023 & 70.4 & 8834 \\ 69.2 & 10167 & 70.3 & 8909 \\ 69.1 & 10238 & 70.3 & 8407\end{array}$

RUN NUMBER: 297 $\mathrm{p} / \mathrm{d}=1.17$ $x$ in $=-.01$ SURFACE TYPE: HIGH FLUX

WORKING FLUID: R-113 $201.32 \mathrm{~kg} / \mathrm{a}^{*} \mathrm{~m}^{\wedge}$ DELTA $P$ tota xout $=0.77$

\begin{tabular}{|c|c|c|c|c|c|c|}
\hline DW & P & $x$ in & Tf & & $T w$ & h \\
\hline 7 & ( $k P a$ ) & {$[-]$} & [c] & {$[\mathrm{w} / \mathrm{m} \wedge 2]$} & [C] & $/ m^{n}$ \\
\hline & 208.6 & -.01 & 68.6 & 41418 & 75.9 & 5675 \\
\hline & 208.0 & 0.09 & & & 74.3 & 11053 \\
\hline & 207.4 & 0.1 & 70.6 & 41042 & 74.2 & 11359 \\
\hline & 206.8 & 0.29 & 0.5 & 409 & 74.0 & 11538 \\
\hline & 206.2 & 0.40 & 0.4 & 39858 & 74.1 & 10842 \\
\hline & 205.6 & 0.5 & 0.3 & 39828 & 73.6 & 12030 \\
\hline & & & & 40730 & 73.7 & 11677 \\
\hline & & & & & & \\
\hline
\end{tabular}




\begin{tabular}{|c|c|c|c|c|c|c|}
\hline \multicolumn{3}{|c|}{$\begin{array}{l}\text { RUN NUMBER: } 286 \\
\text { P/d }=1.17 \\
\text { PIn }=200.3 \mathrm{kPa} \\
\text { XIn }=0.00 \\
\text { SURFACE TYPE: HIG }\end{array}$} & \multicolumn{4}{|c|}{$\begin{array}{l}\text { WORKING FLUID: } \mathrm{R}-113 \\
\mathrm{G}=225 \mathrm{~kg} / \mathrm{s}^{*} \mathrm{~m} \mathrm{~m}^{2} \\
\text { DELTA P total }=4.54 \mathrm{kPa} \\
\text { Xout }=0.09 \\
\text { LUX }\end{array}$} \\
\hline ROW & P & $x$ in & Tf & & Tw & h \\
\hline $\begin{array}{l}* \\
1\end{array}$ & $\begin{array}{l}\text { [kPa] } \\
199.9\end{array}$ & $\begin{array}{l}{[-]} \\
0.0\end{array}$ & $\begin{array}{l}{[\mathrm{C}]} \\
68.1\end{array}$ & $\begin{array}{c}{\left[\mathrm{H} / \mathrm{m}^{\wedge} 2\right]} \\
10687\end{array}$ & $\begin{array}{l}\text { [C] } \\
74.3\end{array}$ & $\begin{array}{l}\left.m^{\wedge} 2 c c\right] \\
1735\end{array}$ \\
\hline 3 & 199.3 & 0.01 & 69.0 & 10344 & 70.5 & 6707 \\
\hline 5 & 198 & 0.0 & & 105 & & 7193 \\
\hline 7 & 198.2 & 0.0 & 69.0 & 10875 & 70. & 659 \\
\hline 9 & & & & & & \\
\hline 11 & & & & 101 & 70.3 & 7025 \\
\hline 13 & 196.4 & 0.0 & 68.7 & 10326 & & \\
\hline 15 & 195.8 & 0.09 & 68.6 & 10423 & 70.2 & 6715 \\
\hline
\end{tabular}

RUN NUMBER: 289

$\mathrm{p} / \mathrm{d}=1.27$

Pin $=203.9 \mathrm{kPa}$

Xin $=-.00$
SURFACE TYPE: HIGH FLUX

HORKING FLUID: $R-113$
$G=224.47 \mathrm{~kg} / \mathrm{s}^{\star} \mathrm{m}^{\wedge} 2$

RUN NUMBER: 292

$\mathrm{p} / \mathrm{d}=1.17$

WORKING FLUID: R-113 $x$ in $=-.01$

$G=222.45 \mathrm{~kg} / \mathrm{s}^{\star} \mathrm{m}^{\wedge} 2$ xout $=0.61$

\begin{tabular}{|c|c|c|c|c|c|}
\hline & & & & & \\
\hline $\begin{array}{l}{[\mathrm{kPa}]} \\
203.5\end{array}$ & {$[-]$} & [C] & {$\left[w / m^{\wedge} 2\right]$} & & $\left.W / m^{\wedge} 2 \quad C\right]$ \\
\hline $\begin{array}{l}203.5 \\
203.0\end{array}$ & -.00 & & 41217 & & 4453 \\
\hline $\begin{array}{l}203.0 \\
202.4\end{array}$ & 0.04 & 69. & 40058 & 73.7 & 10488 \\
\hline $\begin{array}{l}202.4 \\
201.8\end{array}$ & 0.08 & 9.7 & 40965 & 73.5 & 10803 \\
\hline $\begin{array}{l}201.8 \\
201.2\end{array}$ & 0.13 & & 411 & $\begin{array}{l}75.7 \\
73.3\end{array}$ & 10280 \\
\hline 200.6 & 0.23 & & 39809 & 72.8 & $\begin{array}{l}10558 \\
11995\end{array}$ \\
\hline & 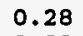 & & & 73.3 & \\
\hline & & & & & \\
\hline
\end{tabular}

$\begin{array}{rcl}\text { ROH } & \text { P } & \text { Xin } \\ \text { F } & {[\mathrm{kPa}]} & {[-]} \\ 1 & 209.5 & -.01 \\ 3 & 208.9 & 0.07 \\ 5 & 208.3 & 0.15 \\ 7 & 207.7 & 0.23 \\ 9 & 207.1 & 0.31 \\ 11 & 206.5 & 0.40 \\ 13 & 205.9 & 0.48 \\ 15 & 205.4 & 0.56\end{array}$

\begin{tabular}{|c|c|c|c|}
\hline & & & \\
\hline c] & {$[w / m \wedge 2]$} & (C) & $/ m \wedge 2$ \\
\hline & 71663 & 79.8 & 6549 \\
\hline & 6963 & 76.9 & 11546 \\
\hline & 710 & & 12029 \\
\hline & & & 11857 \\
\hline & & & 11769 \\
\hline & & & 11593 \\
\hline & 700 & 76.2 & 12012 \\
\hline
\end{tabular}

RUN NUMBER: 287 $\mathrm{p} / \mathrm{d}=1.17$ Pin $=198.2 \mathrm{kPa}$ Xin $=0.00$
SURFACE TYPE: HIGH FLUX

WORKING FLUID: R-113 $G=224.64 \mathrm{~kg} / \mathrm{a}^{\star} \mathrm{m}^{\wedge} 2$ DELTA $P$ total $=4.54 \mathrm{kPa}$

\begin{tabular}{|c|c|c|c|c|c|c|}
\hline OW & $\mathbf{P}$ & $x$ in & $T f$ & & $T w$ & \\
\hline * & [kPa] & & [C] & {$\left[\mathrm{W} / \mathrm{m}^{\wedge} \mathbf{2}\right]$} & \multicolumn{2}{|c|}{ [C] $[\mathrm{W} / \mathrm{m} \sim 2 \mathrm{C}]$} \\
\hline 1 & 197.9 & & & & & \\
\hline 3 & 197.3 & & & 201 & 71.3 & 8181 \\
\hline 5 & 196. & 0. & & & & 7981 \\
\hline 7 & 196.1 & 0.07 & 8.6 & 20632 & 71.3 & 7642 \\
\hline 9 & 195. & & & & & 8036 \\
\hline & 194.9 & 0. & & 20067 & 70.8 & 8671 \\
\hline & 194.3 & & & 20502 & & \\
\hline & & & & & & \\
\hline
\end{tabular}

RUN NUMBER: 290

$\mathrm{p} / \mathrm{d}=1.17$

$P$ in $=206.2$
$X_{\text {in }}=-.01$

XIn $=-.01$
SURFACE TYPE: HIGH FLUX

WORKING FLUID: R-113 RUN NUMBER: 293 $\mathrm{p} / \mathrm{d}=1.17$

Pin $=$

Pin $=213.1$
in $=-.01$

SURFACE TYPE: HIGH FLUX

WORKING FLUID: R-113 $G=222.34 \mathrm{~kg} / \mathrm{s}^{\star} \mathrm{m}^{\wedge} 2$ $\begin{array}{ccccccc}* & P & X \text { in } & \text { Tf } & q^{\prime \prime} & \text { TW } & h \\ 1 & {[\mathrm{kPa}]} & {[-]} & {[\mathrm{C}]} & {\left[\mathrm{W} / \mathrm{m}^{\wedge} 2\right]} & {[\mathrm{C}]} & {\left[\mathrm{W} / \mathrm{m}^{\wedge} 2 \mathrm{C}\right.} \\ 1 & 205.8 & -.01 & 68.7 & 51184 & 78.4 & 5253\end{array}$ $\begin{array}{lllllll}1 & 205.8 & -.01 & 68.7 & 51184 & 78.4 & 5253\end{array}$ $\begin{array}{llllll}204.6 & 0.10 & 70.3 & 49795 & 74.8 & 10967\end{array}$ $\begin{array}{lllllll}7 & 204.1 & 0.16 & 70.1 & 50795 & 74.7 & 11201\end{array}$ $\begin{array}{lllllll}9 & 203.5 & 0.22 & 70.0 & 48952 & 74.4 & 11311\end{array}$ $\begin{array}{lllllll}11 & 202.9 & 0.28 & 69.9 & 49574 & 73.7 & 11918\end{array}$ $\begin{array}{lllllll}13 & 202.3 & 0.35 & 69.8 & 50704 & 74.4 & 11039 \\ 15 & 201.7 & 0.41 & 69.7 & 50748 & 74.0 & 11717\end{array}$ ROW $P$ Xin $T f$

\begin{tabular}{|c|c|c|c|c|c|c|}
\hline \# & $\stackrel{P}{P}$ & $\begin{array}{l}x_{i n} \\
(-]\end{array}$ & TI & $\underset{\left[W / m^{\wedge} 2\right]}{q^{\prime \prime}}$ & $\begin{array}{l}\text { Tw } \\
\text { [C] } 1\end{array}$ & $\mathbf{n}$ \\
\hline 1 & 212.7 & -.01 & 69.1 & 82071 & 81.4 & 665 \\
\hline 3 & 212.1 & 0.08 & & 79763 & 78.1 & 11866 \\
\hline & 221. & 0.1 & & 812 & & 12367 \\
\hline & & & & & & \\
\hline & & & & & & 11987 \\
\hline 11 & 209 & & & & & 12612 \\
\hline 13 & 209. & 0.5 & & 80801 & 128.2 & 12411 \\
\hline & & 0.65 & & 154 & 98 & 12974 \\
\hline
\end{tabular}

\begin{tabular}{|c|c|c|c|c|c|c|}
\hline $\begin{array}{l}\text { RUN } \\
\text { p/d } \\
\text { Pin } \\
\text { Xin } \\
\text { SUR }\end{array}$ & $\begin{array}{l}\text { NUMBER } \\
=1.17 \\
=200 . \\
=0.00 \\
\text { FACE TY }\end{array}$ & $\mathrm{kPa}$ & & $\begin{array}{l}\text { WORKI I } \\
G=\end{array}$ & $\begin{array}{r}\text { FLU } \\
4.445 \\
=21=\end{array}$ & $\begin{array}{l}D: R-113 \\
\mathrm{~kg} / \mathrm{s}^{\star} \mathrm{m}^{\wedge} 2 \\
4.58 \mathrm{kPa} \\
t=0.27\end{array}$ \\
\hline & P & $x i$ & $T f$ & $q^{\prime}$ & Tw & h \\
\hline$\neq$ & [KPa] & & (C) & [W/m & & \\
\hline 1 & 200. & & 68.0 & 3104 & 76.6 & 3642 \\
\hline 3 & 199. & & 69 & & & \\
\hline & & & & & & \\
\hline 7 & 198. & 0 . & & 309 & 72.4 & 9277 \\
\hline & 197 & & & & 72.0 & \\
\hline & & & & & 1.7 & \\
\hline & & & & & 72.1 & 9288 \\
\hline & & & & 30727 & 71.7 & 10060 \\
\hline
\end{tabular}

RUN NUMBER: 291

$\mathrm{p} / \mathrm{d}=1.17$

$\mathrm{kPa}$

Xin $=-.01$.

WORKING FLUID: $R-113$ RUN NUMBER: 320 $\begin{array}{rl}G=223.05 \mathrm{~kg} / \mathrm{s}^{\star} \mathrm{m} \wedge 2 & \mathrm{p} / \mathrm{d}=1.17 \\ \text { DELTA } P \text { total }=4.53 \mathrm{kPa} & \mathrm{Pin}=202.7 \mathrm{kPa}\end{array}$ $\mathrm{Xin}=0.01$

\begin{tabular}{|c|c|c|c|c|c|c|}
\hline ROW & $\mathbf{P}$ & $x$ in & Tf & g'. & Tw & $\mathrm{h}$ \\
\hline$\#$ & (kPa) & {$[-]$} & [C] & $\left\{\mathrm{W} / \mathrm{m}^{\wedge} 2\right\}$ & & $1 / \mathrm{m}^{\wedge} 2$ \\
\hline$i$ & 202.3 & 0.01 & 68.9 & 10699 & 71.5 & 4153 \\
\hline 3 & 201.7 & 0.01 & 69.3 & 10358 & 71.2 & 5495 \\
\hline 5 & 201.1 & 0.02 & 69.4 & 10501 & 71.0 & 6559 \\
\hline 7 & 200.5 & 0.03 & 69.3 & 10576 & 70.9 & 6749 \\
\hline 9 & 200.0 & 0.04 & 69.2 & 10318 & 70.8 & 6485 \\
\hline 11 & 199.4 & 0.04 & 9.2 & 10126 & 70.8 & 6533 \\
\hline 13 & 198.8 & 0.05 & 9.1 & 10353 & 70.7 & 6569 \\
\hline 15 & 198.2 & .06 & 9.0 & 10365 & 70.6 & 6787 \\
\hline
\end{tabular}

WORKING FLUID: $\mathrm{R}-113$ $G=352.23 \mathrm{~kg} / \mathrm{s}^{*} \mathrm{~m}^{\wedge} 2$ $\begin{aligned} \text { DELTA P total } & =4.57 \mathrm{kPa} \\ \text { Xout } & =0.06\end{aligned}$

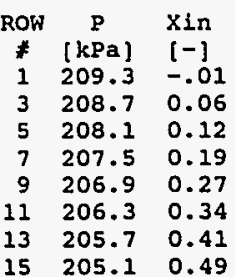

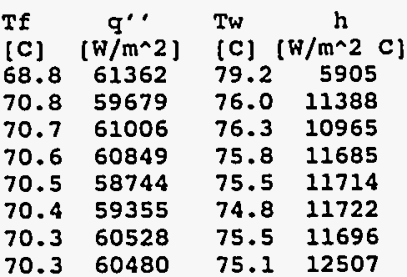

$\begin{array}{lll}13 & 198.8 & 0.05 \\ 15 & 198.2 & 0.06\end{array}$

$69.1 \quad 10353$ 


\begin{tabular}{|c|c|c|c|c|c|c|}
\hline \multicolumn{3}{|c|}{$\begin{array}{l}\text { RUN NUMBER: } 319 \\
\text { P/d }=1.17 \\
\text { Pin }=204.7 \mathrm{kPa} \\
\text { Xin }=0.00 \\
\text { SURFACE TYPE: HIGH }\end{array}$} & \multicolumn{4}{|c|}{$\begin{array}{l}\text { WORKING FLUID: } R-11 \\
\text { G }=351.02 \mathrm{~kg} / \mathrm{s}^{\star} \mathrm{m}^{\wedge} \\
\text { DELTA P total }=4.49 \mathrm{kP} \\
\text { Xout }=0.12 \\
\text { LUX }\end{array}$} \\
\hline Row & $\stackrel{P}{P}$ & $x$ in & Tf & (W/m^s] & Tw & $\stackrel{h}{n}$ \\
\hline 1 & 204.4 & $\begin{array}{l}{[-]} \\
0.00\end{array}$ & $\begin{array}{l}{[c]} \\
69.1\end{array}$ & $\begin{array}{c}{\left[W / \mathrm{m}^{\wedge} 2\right]} \\
21010\end{array}$ & $\begin{array}{l}{[\mathrm{C}]} \\
72.8\end{array}$ & $\begin{array}{l}m^{\wedge} 2 \\
5589\end{array}$ \\
\hline 3 & 203.8 & & & & & 8564 \\
\hline 5 & 203.2 & 0.0 & 69.9 & 207 & 72.0 & 9669 \\
\hline 7 & 202.6 & & & & & \\
\hline 9 & 202.1 & & & & & \\
\hline 11 & 201.5 & 0.08 & 69 & 201 & 71.8 & 9300 \\
\hline 13 & & & & & & \\
\hline 15 & 200.3 & 0.11 & 69.4 & 20641 & 71.5 & 9687 \\
\hline
\end{tabular}

RUN NUMBER: 314 $\mathrm{p} / \mathrm{d}=1.17$

Pin $=205.4 \mathrm{kP}$ Xin $=-.00$
SURFACE TYPE: HIGH FLUX

WORKING FLUID: R-113 $G=349.89 \mathrm{~kg} / \mathrm{s}^{*} \mathrm{~m}^{\wedge} 2$ Row $P$ Xin

$\begin{array}{rcc}\text { ROW } & P & X \text { in } \\ f & {[\mathrm{KPa}]} & 1-1 \\ 1 & 205.1 & -.00 \\ 3 & 204.5 & 0.03 \\ 5 & 203.9 & 0.07 \\ 7 & 203.3 & 0.11 \\ 9 & 202.7 & 0.14 \\ 11 & 202.1 & 0.18 \\ 13 & 201.5 & 0.22 \\ 15 & 201.0 & 0.26\end{array}$

\begin{tabular}{|c|c|c|c|}
\hline c) & {$[\mathrm{W} / \mathrm{m}$} & (c) & \\
\hline & & & \\
\hline & 500 & 74. & \\
\hline & & & \\
\hline & & & \\
\hline & & 44.2 & 112 \\
\hline & & & \\
\hline & & & 11567 \\
\hline & & & \\
\hline
\end{tabular}

RUN NUMBER: 318 $\mathrm{p} / \mathrm{d}=1.17$

WORKING FLUID: R-113 $\mathrm{Pin}_{\text {in }}=204.1 \mathrm{kPa}$ $G=351.14 \mathrm{~kg} / \mathrm{g}^{*} \mathrm{~m}^{\wedge} 2$
DELTA $P$ total $=4.54 \mathrm{kPa}$ SURFACE TYPE: HIGH FLUX Xout $=0.17$

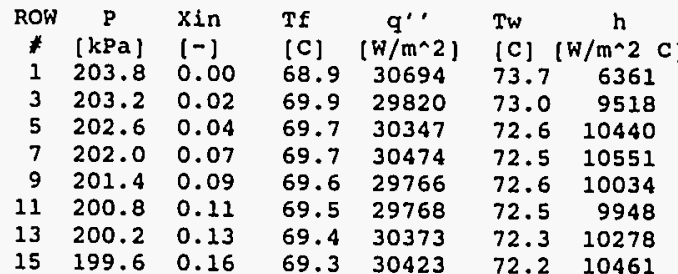

RUN NUMBER: 315 $\mathrm{p} / \mathrm{d}=1.17$ $\mathrm{P} / \mathrm{d}=1.17 \mathrm{kP}$ $\mathrm{Xin}=-.00$ WORKING FLUID: R-113
$G=349.35 \mathrm{~kg} / \mathrm{g}^{*} \mathrm{~m}^{\wedge} 2$ SUREACE TYPE: HIGH FLUX

Xout $=0.34$

Row $P$ Xin $T$

\begin{tabular}{|c|c|c|c|c|c|c|}
\hline OW & P & $x$ in & $T f$ & $q^{\prime \prime}$ & Tw & $\mathrm{h}$ \\
\hline \# & [KPa] & {$[-1]$} & [C] & $\left\{\mathrm{W} / \mathrm{m}^{\wedge} 2\right\}$ & [c] & \\
\hline & 205.7 & -.00 & 69.2 & 61291 & 77.1 & 7721 \\
\hline 3 & 205.1 & 0.04 & 70.2 & 59715 & 75.7 & 10973 \\
\hline 5 & 204.5 & 0.08 & 70.1 & 60643 & 75.1 & 12152 \\
\hline & 203.9 & 0.13 & 10.1 & 60609 & 74.9 & 12490 \\
\hline 9 & 203.3 & 0.17 & 70.0 & 59157 & 75.1 & 11955 \\
\hline & 202.7 & 0.22 & & 59107 & 74.5 & 12579 \\
\hline & 202.1 & 0.27 & 69.7 & 60403 & 74.8 & 11931 \\
\hline
\end{tabular}

RUN NUMBER: 317

$\mathrm{p} / \mathrm{d}=1.17$

in $=206.7 \mathrm{kPa}$ $x$ in $=0.00$ DEa $P$ total $=4.57 \mathrm{kPa}$ IYPE: HIGH FLUX

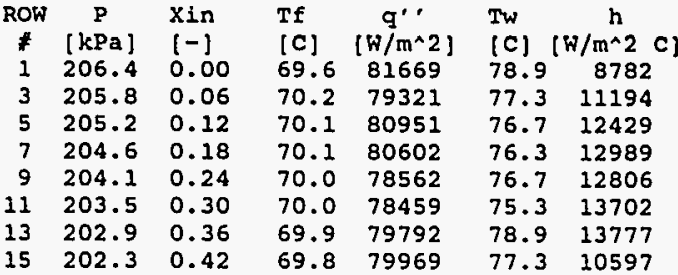

UN NUMBER: 312

$\mathrm{p} / \mathrm{d}=1.17$

$\mathrm{P}$ in $=202.5 \mathrm{kPa}$

$x_{\text {in }}=0.00$

SURFACE TYPE: HIGH FLUX

WORKING FLUID: R-113 $G=503.39 \mathrm{~kg} / \mathrm{s}^{*} \mathrm{~m}^{\wedge} 2$ DELTA P totai $=4.53 \mathrm{kPa}$ ROW $P \quad x$ in

\begin{tabular}{|c|c|c|c|c|c|}
\hline$[\mathrm{kPa}]$ & $\begin{array}{l}x \text { in } \\
{[-1}\end{array}$ & $\begin{array}{l}\mathrm{Tf} \\
\text { (C) }\end{array}$ & $\frac{q^{\prime \prime}}{\left[w / m^{\wedge} 2\right]}$ & $\begin{array}{l}T w \\
{[C]}\end{array}$ & $\begin{array}{c}h \\
W / m^{\wedge} 2\end{array}$ \\
\hline 202.2 & 0.00 & 68.9 & 10373 & 71.5 & 3966 \\
\hline 201.6 & 0.01 & 69.2 & 10035 & 71.2 & 5032 \\
\hline 201.0 & 0.01 & 69.3 & 10143 & 71.0 & 5830 \\
\hline 200.4 & 0.02 & 69.2 & 10272 & 70.9 & 6037 \\
\hline 199.8 & 0.02 & 69.2 & 9888 & 70.8 & 5931 \\
\hline 199.2 & 0.03 & 69.1 & 9951 & & 5848 \\
\hline 198.6 & 0.03 & 69.1 & 10123 & 70.8 & 5759 \\
\hline 198.0 & .04 & 9.0 & 10187 & 70.7 & 5984 \\
\hline
\end{tabular}

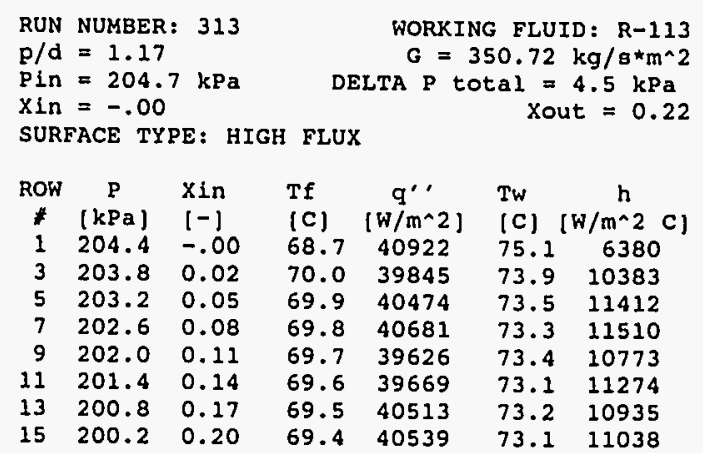

RUN NUMBER: 316

SURFACE TYPE: HIGH FLUX

WORKING FLUID: R-113 $G=349.27 \mathrm{~kg} / \mathbf{s}^{*} \mathrm{~m}^{\wedge} 2$

$\begin{aligned} \text { DELTA P total } & =4.51 \mathrm{kPa} \\ \text { Xout } & =0.39\end{aligned}$

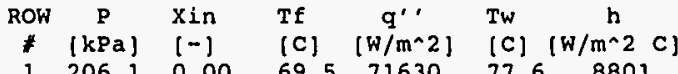

1 206.1 0.00

$\begin{array}{lll}3 & 205.5 & 0.05 \\ 5 & 204.9 & 0.10\end{array}$

7 204.4 0.15

$\begin{array}{lll}9 & 203.8 & 0.21 \\ 11 & 203.2 & 0.26\end{array}$

$\begin{array}{lll}11 & 203.2 & 0.26 \\ 13 & 202.6 & 0.31\end{array}$

$\begin{array}{lll}15 & 202.0 & 0.31\end{array}$ $\begin{array}{llll}70.2 & 69776 & 76.1 & 11809\end{array}$

$\begin{array}{llll}70.1 & 70892 & 75.5 & 13157\end{array}$

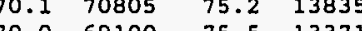

$69.96900 \quad 75.5 \quad 13371$

$\begin{array}{llll}69.8 & 70746 & 74.8 & 13407\end{array}$

$\begin{array}{llll}69.8 & 70746 & 75.1 & 13255\end{array}$
RUN NUMBER: 311

$\mathrm{p} / \mathrm{d}=1.17$

Pin $=203.6 \mathrm{kPa}$

SURFACE TYPE: HIGH FLUX

WORKING FLUID: R-113 $G=503.67 \mathrm{~kg} / \mathrm{g}^{*} \mathrm{~m}^{\wedge}$ DELTA P total $=4.51 \mathrm{kPa}$ $\begin{array}{ccc}\text { ROW } & \mathrm{P} & \mathrm{Xin} \\ * & \mathrm{KPa}] & 1-1\end{array}$

$1203.2-.00$

$\begin{array}{ll}202.6 & 0.01 \\ 202.0 & 0.01\end{array}$

$\begin{array}{lll}5 & 202.0 & 0.01 \\ 7 & 201.5 & 0.03\end{array}$

$9200.9 \quad 0.04$

13 199.7 0.06

15199.10 .07

$\begin{array}{lclc}\text { Tf } & q^{\prime \prime} & T w & h \\ \text { [C] } & \left(W^{\prime} m^{\wedge} 2\right) & \text { (C) } & {\left[\left(W / m^{\wedge} 2 C\right]\right.} \\ 68.7 & 20663 & 72.6 & 5287 \\ 69.5 & 20027 & 71.9 & 8283 \\ 69.7 & 20286 & 71.6 & 10444 \\ 69.6 & 20503 & 71.5 & 10823 \\ 69.5 & 19970 & 71.4 & 10240 \\ 69.4 & 19882 & 71.3 & 10382 \\ 69.3 & 20307 & 71.2 & 10556 \\ 69.2 & 20374 & 71.1 & 10613\end{array}$




\begin{tabular}{|c|c|c|c|c|c|c|}
\hline $\begin{array}{l}\text { RUN } \\
\text { p/d } \\
\text { P In } \\
\text { Xin } \\
\text { SUR }\end{array}$ & $\begin{array}{l}\text { NUMBE } \\
=1.1 \\
=201 \\
=0.0 \\
\text { FACE T }\end{array}$ & 309 & & $\begin{array}{c}\text { WORKI } \\
G= \\
\text { ELTA P } t\end{array}$ & $\begin{array}{l}\text { G FLUI } \\
03.63 \\
\mathrm{tal}=\end{array}$ & $\begin{array}{r}\text { ID: } R-113 \\
\mathrm{~kg} / \mathrm{s}^{\star} \mathrm{m}^{\wedge} 2 \\
4.56 \mathrm{kPa} \\
\text { ut }=0.12\end{array}$ \\
\hline ROW & $\stackrel{p}{P}$ & $x \ln$ & Tf & $\underset{\left(w / m^{\wedge} 2\right)}{q^{\prime \prime}}$ & Tw & $\stackrel{h}{h}$ \\
\hline 1 & 200.8 & 0.0 & 68.5 & 31147 & 73.8 & 59 \\
\hline 3 & 200 & & & & & \\
\hline & 199 & 0. & & & & \\
\hline 7 & 199 & 0. & 1 & 30721 & 72 & \\
\hline 0 & & & & & & \\
\hline 1. & 197 & 0. & & & & \\
\hline 1 & & & & & & \\
\hline 15 & 19 & & & 30527 & 71.8 & 10208 \\
\hline
\end{tabular}

RUN NUMBER: 310

$\mathrm{p} / \mathrm{d}=1.17$

Pin $=202.6 \mathrm{kP}$

Xin $=0.00$
SURFACE TYPE: HIGH FLUX

WORKING FLUID: R-113 $503.23 \mathrm{~kg} / \mathrm{g}^{* \mathrm{~m}^{\wedge} 2}$ $\begin{aligned} \text { DELTA P total } & =4.51 \mathrm{kPa} \\ \text { xout } & =0.16\end{aligned}$ $\begin{array}{ccc}\text { ROW } & \text { P } & \text { Xin } \\ \text { \# } & {[\mathrm{kPaj}} & {[-]} \\ 1 & 202.3 & 0.00 \\ 3 & 201.7 & 0.02 \\ 5 & 201.1 & 0.04 \\ 7 & 200.5 & 0.06 \\ 9 & 199.9 & 0.08 \\ 11 & 199.3 & 0.10 \\ 13 & 198.7 & 0.12 \\ 15 & 198.2 & 0.15\end{array}$

\begin{tabular}{|c|c|c|c|}
\hline Ist & $q^{\prime \prime}$ & $T w$ & Iman \\
\hline$[\mathrm{C}]$ & $\begin{array}{c}{\left[\mathrm{w} / \mathrm{m}^{\wedge} 2\right]} \\
409887\end{array}$ & $\begin{array}{l}{[C]} \\
75.1\end{array}$ & $\begin{array}{l}m^{\wedge} 2 \\
6661\end{array}$ \\
\hline 69.4 & 39868 & 73.9 & 8879 \\
\hline 9.3 & 40457 & 73.4 & 9880 \\
\hline 9.3 & 40437 & 73.2 & 10214 \\
\hline ?. & 39436 & 73.2 & 10082 \\
\hline . & 39541 & 72.7 & 10968 \\
\hline & 40351 & 72.8 & 10865 \\
\hline & 40364 & 72.6 & 11194 \\
\hline
\end{tabular}

RUN NUMBER: 305

$\mathrm{p} / \mathrm{d}=1.17$
$\mathrm{Pin}=203.8 \mathrm{kPa}$ $x_{\text {in }}=-.00$ SURFACE TYPE: HIGH FLUX

WORKING FLUID: R-113 $G=504.75 \mathrm{~kg} / \mathrm{s}^{\star} \mathrm{m}^{\wedge} 2$ DELTA P total $=4.52 \mathrm{kPa}$

\begin{tabular}{|c|c|c|c|c|c|c|}
\hline Kow & $P$ & $x$ in & TE & $\sigma^{\circ}$ & Tw & h \\
\hline$\neq$ & [kPa] & {$[-]$} & [C] & {$\left[w / m^{\wedge} 2\right]$} & & $1 / m^{\wedge} 2$ \\
\hline 1 & 203.4 & -.00 & 68.9 & 49358 & 77.6 & 5652 \\
\hline 3 & 202.8 & 0.02 & 69.8 & 4808 & 75.0 & 9133 \\
\hline & 202 & 0.0 & & & & \\
\hline & 201. & $0.0^{\circ}$ & & & 74.3 & 10405 \\
\hline 9 & 201 & & & & & \\
\hline & 200.5 & 0.12 & & & 3.8 & 10923 \\
\hline & 199.9 & 0.14 & & 491 & 74.0 & 10593 \\
\hline
\end{tabular}

RUN NUMBER: 306 $\mathrm{p} / \mathrm{d}=1.17$ $\mathrm{P}$ in $=207.3$ SURFACE TYPE: HIGH FLUX

$\begin{array}{ccc}\text { ROW } & P & \text { Xin } \\ \# & {[\mathrm{kPa}]} & {[-]} \\ 1 & 206.9 & -.00 \\ 3 & 206.4 & 0.03 \\ 5 & 205.8 & 0.05 \\ 7 & 205.2 & 0.09 \\ 9 & 204.6 & 0.12 \\ 11 & 204.0 & 0.15 \\ 13 & 203.4 & 0.18 \\ 15 & 202.8 & 0.21\end{array}$

$\begin{array}{lc}\text { Tf } & q^{\prime \prime} \\ {[C]} & {\left[W / \mathrm{m}^{\wedge} \text { 2] }\right.} \\ 69.6 & 61180 \\ 70.4 & 59545 \\ 70.3 & 60705 \\ 70.2 & 60334 \\ 70.2 & 58924 \\ 70.1 & 58858 \\ 70.0 & 60265 \\ 69.9 & 60121\end{array}$

WORKING FLUID: R-113 $G=502.52 \mathrm{~kg} / \mathrm{s}^{\star \mathrm{m}^{\wedge} 2}$ $\begin{aligned} \text { DELTA P total } & =4.5 \mathrm{kPa} \\ \text { Xout } & =0.23\end{aligned}$ Tw $\frac{h}{2}$ [C] $\left[\mathrm{W} / \mathrm{m}^{\wedge} 2 \mathrm{C}\right]$
$79.0 \mathrm{6446}$
$76.4 \quad 9970$ $75.7 \quad 11254$ $75.4 \quad 11619$ $75.4 \quad 11225$ 74.811440 $75.0 \quad 11921$ $74.8 \quad 12200$
RUN NUMBER: 353

$\begin{array}{rl}\text { RUN NUKBER: } 353 & \text { WORKING FLUID: R-113 } \\ \text { p/d }=1.17 & G=50.04 \mathrm{~kg} / \mathrm{g}^{*} \mathrm{~m}-2 \\ \text { Pin }=596.3 \mathrm{kPa} & \text { DELTA } \mathrm{P} \text { total }=5.32 \mathrm{kPa}\end{array}$ SURFACE TYPE: HIGH FLUX

\begin{tabular}{|c|c|c|c|c|c|c|}
\hline OH & p & $x$ in & Tf & (1) Iman & Tw & $\mathrm{h}$ \\
\hline & [kPa] & & [C] & {$\left[\mathrm{w} / \mathrm{m}^{\wedge} \mathbf{2}\right]$} & (c) & \\
\hline & 595.8 & & 111.7 & & 114.0 & 1953 \\
\hline & 594.9 & 0.0 & & & 113.8 & 7036 \\
\hline & & & & & & \\
\hline & 593. & 0.0 & 113 & 5307 & 113.7 & 6957 \\
\hline & 592 & & & & & 6752 \\
\hline & 592.1 & & 112 & 5254 & & 6485 \\
\hline 13 & 591.6 & 0.18 & 112.8 & 5389 & 113.7 & 6450 \\
\hline & & & & & & \\
\hline
\end{tabular}

RUN NUMBER: 307

$\mathrm{p} / \mathrm{d}=1.17$

$\begin{aligned} \text { Pin } & =209.6 \mathrm{kPa} & \text { DELTA P total } & =4.53 \mathrm{kPa} \\ \mathrm{Xin} & =-.00 & \text { Xout } & =0.27\end{aligned}$ SURFACE TYPE: HIGH FLUX

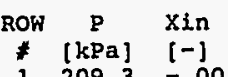

$\begin{array}{lll}1 & 209.3 & -.00 \\ 3 & 208.7 & 0.03\end{array}$

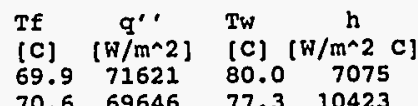

5 208.1 0.07

$70.6 \quad 70851$

$\begin{array}{ll}70.5 & 70647 \\ 70.4 & 68937\end{array}$

$9206.9 \quad 0.14$

$11206.3 \quad 0.18$

$\begin{array}{llll}70.4 & 68937 & 76.3 & 11687 \\ 70.4 & 69385 & 75.6 & 12288\end{array}$

$\begin{array}{llllllll}13 & 205.7 & 0.21 & 70.3 & 70964 & 76.0 & 12581 \\ 15 & 205.1 & 0.25 & 70.2 & 70907 & 75.7 & 12971\end{array}$

\begin{tabular}{|c|c|c|c|c|c|c|}
\hline \multicolumn{4}{|c|}{$\begin{array}{l}\text { RUN NUMBER: } 354 \\
\text { P/d }=1.17 \\
\text { PIn }=594.1 \mathrm{kPa} \\
\text { XIn }=-.00 \\
\text { SUREACE TYPE: HIGH FLUS }\end{array}$} & \multicolumn{3}{|c|}{$\begin{array}{r}\text { WORKING FLUID: } R-113 \\
G=50.35 \mathrm{~kg} / \mathrm{g}^{\star} \mathrm{m}^{\wedge} 2 \\
\text { TA P total }=5.27 \mathrm{kPa} \\
\text { Xout }=0.44\end{array}$} \\
\hline & $\mathrm{P}$ & & $T$ & & & \\
\hline * & & & & & & \\
\hline & & & & & & \\
\hline $\begin{array}{l}3 \\
5\end{array}$ & & & & & & \\
\hline & & & & & & \\
\hline 9 & & & & & & \\
\hline & & & & & & \\
\hline & & & & & & \\
\hline 5 & & & 112.6 & & & \\
\hline
\end{tabular}

\begin{tabular}{|c|c|c|c|c|c|c|}
\hline $\begin{array}{l}\text { RUN } \\
\mathrm{p} / \mathrm{d} \\
\mathrm{P} \text { in } \\
\mathrm{Xin} \\
\mathrm{suR}\end{array}$ & $\begin{array}{l}\text { NUMBER } \\
=1.17 \\
=207 . \\
=0.01\end{array}$ & $9 \mathrm{kPa}$ & & WORK & $\begin{array}{l}\mathrm{b} 2.49 \\
\mathrm{tal}=\end{array}$ & $\begin{array}{l}\mathrm{kg} / \mathrm{s}^{\star} \mathrm{m}^{\wedge} 2 \\
4.54 \mathrm{kPa} \\
\mathrm{ut}=0.32\end{array}$ \\
\hline OW & P & $x i$ & Tf & $q^{\prime}$ & Tw & h \\
\hline $\begin{array}{l}* \\
1\end{array}$ & lkP & $1-$ & [C & $\begin{array}{c}{[\mathrm{W} / \mathrm{n}} \\
82]\end{array}$ & $\begin{array}{l}{[\mathrm{C}]} \\
79.9\end{array}$ & {$\left[\mathrm{~W} / \mathrm{m}^{2}\right.$} \\
\hline 3 & 206. & 0. & 70.7 & 797 & 77.7 & \\
\hline 5 & & & & & & \\
\hline 7 & 205 & & & & & \\
\hline 9 & & & & & 76.8 & \\
\hline 3 & 204 & & & & & \\
\hline & 204 & & 70.1 & & & \\
\hline 15 & 203.4 & 0.30 & 70.0 & 80370 & 75.8 & 13717 \\
\hline
\end{tabular}

RUN NUMBER: 350

$\mathrm{p} / \mathrm{d}=1.17$

Pin $=590.5 \mathrm{kPa}$

$x_{1 n}=-.01$

SURFACE TYPE: HIGH FLUX
WORKING FLUID: R-113 $G=50.87 \mathrm{~kg} / \mathrm{s} * \mathrm{~m}^{\wedge} 2$ Xout $=0.61$

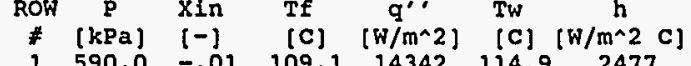
$\begin{array}{llllllll}1 & 590.0 & -.01 & 109.1 & 14342 & 114.9 & 2477\end{array}$ $\begin{array}{lllllll}3 & 589.0 & 0.07 & 112.6 & 14880 & 114.3 & 8856\end{array}$ $\begin{array}{lllllll}5 & 588.1 & 0.15 & 112.6 & 15308 & 114.3 & 9057\end{array}$ $\begin{array}{lllllll}7 & 587.3 & 0.23 & 112.5 & 15514 & 114.3 & 8839\end{array}$ $\begin{array}{rrrrrrr}9 & 586.9 & 0.32 & 112.5 & 15117 & 114.1 & 9128 \\ 11 & 586.4 & 0.41 & 112.4 & 15290 & 114.1 & 8918\end{array}$ $\begin{array}{lllllll}11 & 586.4 & 0.41 & 112.4 & 15290 & 114.1 & 8918 \\ 13 & 586.1 & 0.49 & 112.4 & 15377 & 114.2 & 8502\end{array}$ $\begin{array}{lllllll}13 & 586.1 & 0.49 & 112.4 & 15377 & 114.2 & 8502 \\ 15 & 585.6 & 0.57 & 112.4 & 15296 & 114.2 & 8132\end{array}$ 


\begin{tabular}{|c|c|c|c|c|c|c|}
\hline \multicolumn{7}{|c|}{ 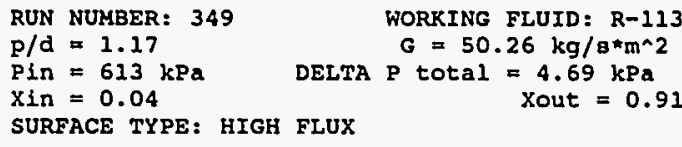 } \\
\hline Row & $P$ & & Tf & $q^{\prime \prime}$ & Tw & h \\
\hline$\neq$ & $\begin{array}{l}\text { [KPa] } \\
612.5\end{array}$ & $1-$ & [C] & {$\left[\mathrm{w} / \mathrm{m}^{\wedge} \mathrm{2}\right]$} & [C] & \\
\hline & & & $\begin{array}{l}111.3 \\
114.4\end{array}$ & & & \\
\hline & 610 & & & & & \\
\hline 7 & 609 & & 114 & 21092 & & 10076 \\
\hline & & & & & & \\
\hline & & & & & & \\
\hline & & & & & & \\
\hline 15 & 608.4 & & & 20921 & 116.3 & 9578 \\
\hline
\end{tabular}

RUN NUMBER: 355 $\mathrm{p} / \mathrm{d}=1.17$ $\begin{array}{lrl}\text { Pin }=617.4 \mathrm{kPa} & \text { DELTA P total }=5.26 \mathrm{kPa} \\ \text { Xin }=-.01 & \text { Xout }=0.20 \\ \text { SURFACE TYPE: HIGH FLUX } & \end{array}$

\begin{tabular}{|c|c|c|c|c|c|c|}
\hline ROW & $\mathrm{P}$ & $x$ in & $\mathrm{Tf}$ & $q^{\prime \cdot}$ & $T w$ & $\mathrm{~h}$ \\
\hline \# & [kPa] & $(-)$ & [C] & {$[w / m \wedge 2]$} & [C] & $\left(W / m^{\wedge} 2 \quad c\right)$ \\
\hline 1 & 616.9 & -.02 & 113.2 & $10510^{\circ}$ & 116.3 & 3371 \\
\hline 3 & 616.0 & 0.01 & 114.6 & 10913 & 115.9 & 8316 \\
\hline 5 & 615.1 & 0.04 & 114.6 & 11170 & 115.9 & 8578 \\
\hline 7 & 614.3 & 0.07 & 114.6 & 11214 & 116.0 & 8035 \\
\hline 9 & 613.8 & 0.10 & 114.5 & 10913 & 115.9 & 8189 \\
\hline 11 & 613.3 & 0.13 & 114.5 & 11139 & 115.9 & 7711 \\
\hline 13 & 612.8 & 0.16 & 114.5 & 11206 & 115.8 & 8095 \\
\hline 15 & 612.2 & 0.19 & 114.4 & 11105 & 115.9 & 7718 \\
\hline
\end{tabular}

RUN NUMBER: 347 $\mathrm{p} / \mathrm{d}=1.17$ Pin $=595.2 \mathrm{kPa}$ $\mathrm{xin}=-.01$ SURFACE TYPE: HIGH FLUX

WORKING FLUID: R-113 DELTA $=93.73 \mathrm{~kg} / \mathrm{s}^{\star} \mathrm{m}^{\wedge} 2$

\section{ROW $P$ TIR}

\begin{tabular}{|c|c|c|c|c|c|c|}
\hline Row & $\mathbf{P}$ & $x$ in & TE & $q^{\prime \prime}$ & Tw & $h$ \\
\hline \# & [kPa] & {$[-]$} & [C] & {$\left[\mathrm{W} / \mathrm{m}^{\wedge} 2\right]$} & [C] & $W / m^{\wedge} 2 \quad C$ \\
\hline 1 & 594.7 & -.01 & 109.6 & 19402 & 115.3 & 3409 \\
\hline 3 & 593.8 & 0.05 & 112.8 & 19822 & 114.8 & 10043 \\
\hline 5 & 592.8 & 0.11 & 112.9 & 20245 & 114.8 & 11045 \\
\hline 7 & 592.1 & 0.17 & 112.9 & 20260 & 114.8 & 10704 \\
\hline 9 & 591.6 & 0.23 & 112.8 & 19614 & 114.6 & 10804 \\
\hline & 591.1 & 0.30 & 112.8 & 20423 & 114.7 & 10522 \\
\hline 13 & 590.6 & 0.36 & 112.8 & 20535 & 114.8 & 10093 \\
\hline & 590.1 & 0.41 & 112.7 & 20435 & 114.9 & 9568 \\
\hline
\end{tabular}

RUN NUMBER: 346

$\mathrm{p} / \mathrm{d}=1.17$

Pin $=599.8$
$X_{\text {in }}=0.01$

SURFACE TYPE: HIGH FLUX

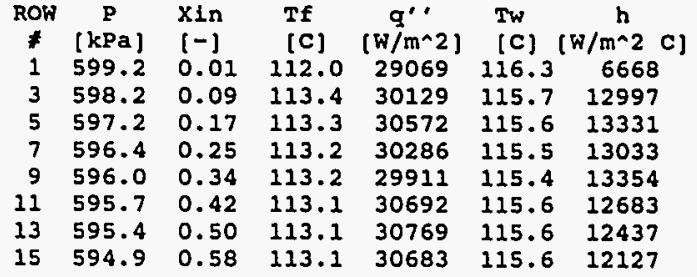

WORKING FLUID: R-113 RUN NUMBER: 343

$G=103.35 \mathrm{~kg} / \mathrm{s}^{*} \mathrm{~m}^{\wedge} \mathbf{2} \quad \mathrm{g} / \mathrm{d}=1.17$

p/d $=1.17$

$X_{\text {in }}=0.01$

SURFACE TYPE: HIGH FLUX

WORKING FLUID: R-113

$G=251.93 \mathrm{~kg} / \mathrm{s}^{\star} \mathrm{m}^{\wedge} 2$ DTA $P$ total $=2.61 \mathrm{kPa}$

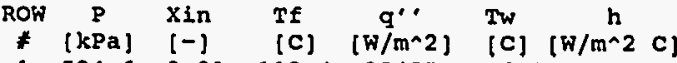

$\begin{array}{lllllll}1 & 594.6 & 0.01 & 112.4 & 20487 & 116.0 & 5746\end{array}$

\begin{tabular}{rrrrrrr}
5 & 594.0 & 0.03 & 113.0 & 20634 & 115.1 & 9775 \\
\hline & 594.4 & 0.05 & 113.0 & 21030 & 115.0 & 10586
\end{tabular}

$\begin{array}{lllllll}7 & 594.4 & 0.05 & 113.0 & 21030 & 115.0 & 10586 \\ 9 & 594.0 & 0.08 & 113.0 & 20508 & 114.8 & 11732\end{array}$

$\begin{array}{lllllll}9 & 594.1 & 0.10 & 113.0 & 20118 & 114.6 & 12462\end{array}$

$\begin{array}{lllllll}11 & 593.6 & 0.12 & 113.0 & 20566 & 114.9 & 10978\end{array}$

$\begin{array}{lllllll}13 & 593.0 & 0.15 & 112.9 & 20555 & 114.8 & 10866\end{array}$

$\begin{array}{lllllll}15 & 592.5 & 0.17 & 112.9 & 20507 & 115.0 & 9875\end{array}$

\section{RUN NUMBER: 345 \\ $\mathrm{p} / \mathrm{d}=1.17$ \\ Pin $=599.1 \mathrm{kPa}$ \\ SURFACE TYPE: HIGH FLUX \\ WORKING FLUID: $R-113$ $G=108.77 \mathrm{~kg} / \mathrm{g}^{\star_{\mathrm{m}} \wedge 2}$ $\begin{aligned} \text { DELTA P total } & =4.92 \mathrm{kPa} \\ \text { Xout } & =0.77\end{aligned}$

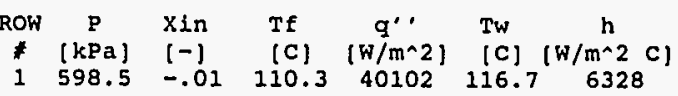 $\begin{array}{rrrrrrr}1 & 598.5 & -.01 & 110.3 & 40102 & 116.7 & 6328 \\ 3 & 597.5 & 0.09 & 113.3 & 40441 & 116.0 & 15175\end{array}$

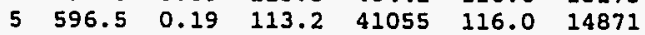 $\begin{array}{lllllll}7 & 595.7 & 0.29 & 113.2 & 40886 & 115.9 & 14800\end{array}$

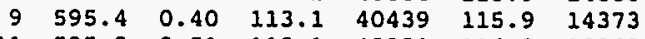

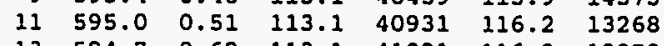 \\ $\begin{array}{lllllll}13 & 594.7 & 0.62 & 113.1 & 41091 & 116.2 & 13078 \\ 15 & 594.2 & 0.72 & 113.0 & 40888 & 116.2 & 12983\end{array}$}

RUN NUMBER: 342

$\mathrm{p} / \mathrm{d}=1.17$ $x$ in $=0.02$

SURFACE TYPE: HIGH FLUX

WORKING FLUID: $R-113$ DELTA $P$ total $=6.03 \mathrm{kPa}^{2}$

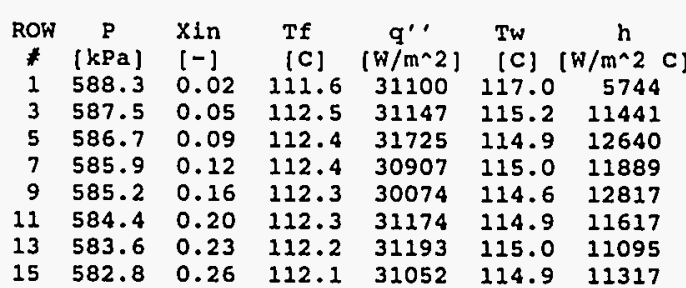

RUN NUMBER: 344

$\mathrm{p} / \mathrm{d}=1.17$

Pin $=596.5 \mathrm{kPa}$ $x \ln =0.00$ SUCE TYPE: HIGH FLUX

\begin{tabular}{|c|c|c|c|c|c|c|}
\hline$D W$ & $\mathbf{P}$ & in & 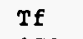 & & $T_{w}$ & $h$ \\
\hline 1 & {$[\mathrm{kPa}]$} & $(-)$ & (C) & {$\left[\mathrm{W} / \mathrm{m}^{\wedge} 2\right]$} & (C) & $\begin{array}{l}m^{\wedge} 2 \\
3979\end{array}$ \\
\hline 3 & 595 & & & & & 6675 \\
\hline & & & & & & \\
\hline & & & 13 & 102 & & 8147 \\
\hline 9 & 593 & & & & & \\
\hline & & & & 100 & & 9864 \\
\hline 13 & 592.8 & 0.07 & 112.9 & 101 & & 795 \\
\hline & & & & & & \\
\hline
\end{tabular}

WORKING FLUID: R-113 RUN NUMBER: 341

$\mathrm{p} / \mathrm{d}=1.17$

Pln $=584.2 \mathrm{kPa}$ SURFACE TYPE: HIGH FLUX
WORKING FLUID: R-113 $G=250.89 \mathrm{~kg} / \mathrm{B}^{\star} \mathrm{m}^{\wedge} 2$

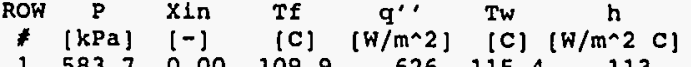
$\begin{array}{rrrrrrr}1 & 583.7 & 0.00 & 109.9 & 626 & 115.4 & 113 \\ 3 & 582.8 & 0.05 & 112.1 & 42323 & 115.2 & 13783\end{array}$ $\begin{array}{lllllll}5 & 581.9 & 0.09 & 112.1 & 42323 & 115.2 & 13783 \\ & 112.1 & 43102 & 114.9 & 15043\end{array}$ $\begin{array}{lllllll}7 & 581.1 & 0.14 & 112.0 & 42853 & 114.9 & 14913\end{array}$ $\begin{array}{rrrrrrr}9 & 580.5 & 0.19 & 111.9 & 42145 & 114.7 & 15059\end{array}$ $\begin{array}{lllllll}11 & 579.8 & 0.24 & 111.9 & 43120 & 114.8 & 14984\end{array}$ $\begin{array}{lllllll}13 & 579.0 & 0.28 & 111.8 & 43214 & 114.9 & 14126 \\ 15 & 578.2 & 0.33 & 111.8 & 43070 & 114.7 & 14985\end{array}$ 


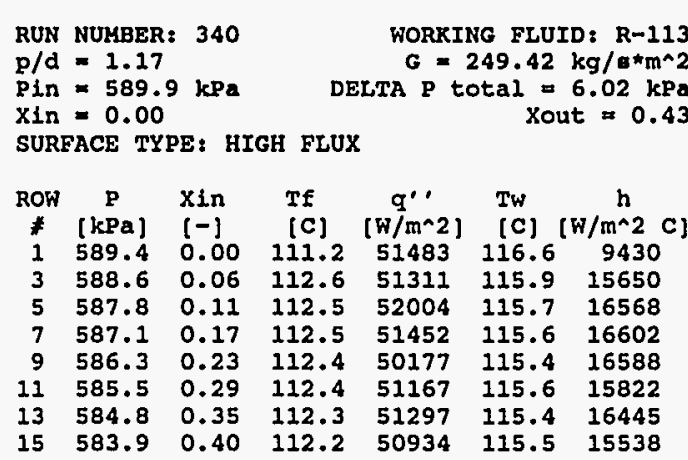

RUN NUMBER: 325

$\mathrm{p} / \mathrm{d}=1.17$

Pin $=580.8$
$X$ in $=0.00$

SURFACE TYPE: HIGH FLUX

WORKING FLUID: R-113 $G=346.62 \mathrm{~kg} / \mathrm{s}^{\star} \mathrm{m}^{\wedge} 2$ DELTA $P$ total $=4.54 \mathrm{kPa}$

\begin{tabular}{|c|c|c|c|c|c|c|}
\hline low & $\stackrel{\mathrm{P}}{\mathrm{kPa}]}$ & $\begin{array}{l}x i n \\
{[-1}\end{array}$ & $\begin{array}{l}\text { Tf } \\
{[C]}\end{array}$ & $\underset{\left[\mathrm{w} / \mathrm{m}^{\wedge} 2\right.}{\mathrm{q}^{\prime \prime}}$ & $\begin{array}{l}T w \\
{[C]}\end{array}$ & $\AA_{2}$ \\
\hline$i$ & 580.5 & 0.00 & 111.0 & 10733 & 113.3 & 473 \\
\hline 3 & 579. & 0.01 & 111.6 & 10444 & 112.8 & 9019 \\
\hline 5 & 579. & .0 & 111.9 & 10573 & 112.6 & 11413 \\
\hline & & & & & & \\
\hline & 5 & .0 & 11.8 & 10 & 112.8 & 10281 \\
\hline & & & & & & 10515 \\
\hline & & 0 & 111.7 & & & 9679 \\
\hline & & & & & & \\
\hline
\end{tabular}

RUN NUMBER: 324

$\mathrm{p} / \mathrm{d}=1.17$

Pin $=589.4 \mathrm{kPa} \quad$ DELTA P total $=4.55 \mathrm{kPa}$

$x$ in $=0.01$

SURFACE TYPE: HIGH FLUX

xout $=0.14$

\begin{tabular}{|c|c|c|c|c|c|c|}
\hline ROW & P & $X$ in & Tf & $q^{\prime}$ & Tw & h \\
\hline$\star$ & {$[\mathrm{kPa}]$} & & [C] & & & \\
\hline 1 & 589.0 & 0.01 & 111.7 & 20819 & 114.8 & 6641 \\
\hline 3 & 588.4 & 0.02 & 112.5 & 20192 & 114.2 & 12120 \\
\hline 5 & 587.8 & 0.04 & 112.5 & 20576 & 114.0 & 12932 \\
\hline & 587.3 & 0.06 & 112.5 & 20771 & 114.2 & 12306 \\
\hline 9 & 586.7 & 0.07 & 112.4 & 20239 & 114.3 & 10772 \\
\hline 11 & 586.1 & 0.09 & 112.4 & 20174 & 114.6 & 10017 \\
\hline 13 & 585.5 & 0.11 & 112.4 & 20624 & 114.3 & 10818 \\
\hline 15 & 584.9 & 0.13 & & 0569 & 114.3 & 1046 \\
\hline
\end{tabular}

RUN NUMBER: 328

$\mathrm{p} / \mathrm{d}=1.17$

Pin $=577.7 \mathrm{kP}$

$\mathrm{xin}=0.01$

SURFACE TYPE: HIGH FLUX

WORKING FLUID: R-113 $G=352.36 \mathrm{~kg} / \mathrm{g}$

$\begin{aligned} \text { DELTA P total } & =4.56 \mathrm{kPa} \\ \text { Xout } & =0.20\end{aligned}$

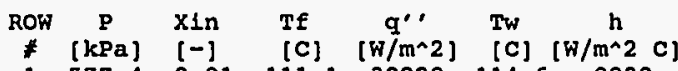

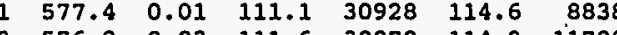

$\begin{array}{llllll}576.8 & 0.03 & 111.6 & 30070 & 114.2 & 11788\end{array}$

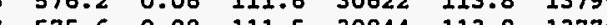

75.60 .08 111.5 30844 113.8 13776

$9575.00 .11 \quad 111.5 \quad 30075$ 113.8 13333

1157.40 .14 111.5 29856113.713553

$\begin{array}{lllllll}13 & 573.8 & 0.16 & 111.4 & 30513 & 113.6 & 13918 \\ 15 & 573.3 & 0.19 & 111.4 & 30370 & 113.5 & 14406\end{array}$

$\begin{array}{ll}\text { RUN NUMBER: } 322 & \text { WORRING FLUID: } R-113 \\ \mathrm{p} / \mathrm{d}=1.17 & \mathrm{G}=350.73 \mathrm{~kg} / \mathrm{s}^{\star} \mathrm{m}^{\wedge} 2\end{array}$ Pin $=576.9 \mathrm{kPa} \quad$ DELTA p total $=4.5 \mathrm{kPa}$ SURFACE TYPE: HIGH FLUX

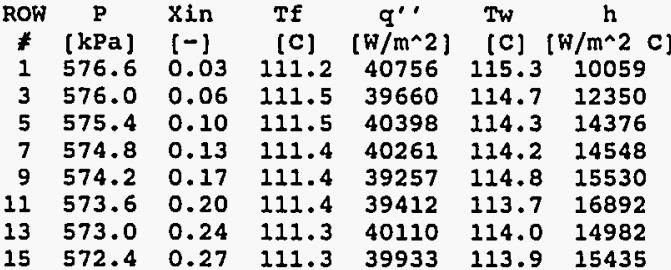

RUN NUMBER: 330

$\mathrm{p} / \mathrm{d}=1.17$ Xout $=0.36$ SURFACE TYPE: HIGH FLUX

\begin{tabular}{|c|c|c|c|c|c|c|}
\hline OW & $=$ & $\operatorname{lin}$ & & & & h \\
\hline$\star$ & [kPa] & & [c] & {$\left[\mathrm{W} / \mathrm{m}^{\wedge} 2\right]$} & [C] & \\
\hline 1 & 595.3 & 0.01 & 112.3 & $59675^{\circ}$ & 117.0 & 12660 \\
\hline & 594. & 0.05 & 113.1 & 59498 & & 15547 \\
\hline & 593 & 0.1 & & & & \\
\hline & 593 & 0.1 & & 598 & & \\
\hline & & & & & & \\
\hline & 592 & 0. & & & & \\
\hline & 500 & 0.2 & & & & \\
\hline & & & & & & \\
\hline
\end{tabular}

RUN NUMBER: 331 $\mathrm{p} / \mathrm{d}=1.17$

in $=588.6$
$X_{\text {in }}=0.01$ SURFACE TYPE: HIGH FLUX

\begin{tabular}{|c|c|c|c|c|c|c|}
\hline$\delta k$ & p & $x$ in & $\mathrm{Tf}$ & $q^{\prime \prime}$ & Tw & h \\
\hline & [kPa] & & [C] & {$\left[\mathrm{W} / \mathrm{m}^{\wedge} 2\right]$} & [C] & \\
\hline & 588.2 & 0.0 & 111.9 & & & \\
\hline & 587. & 0.0 & 112. & 70433 & & \\
\hline & 586.8 & 0.1 & 112 & 712 & & 16576 \\
\hline & 58 & 0. & & & & \\
\hline 9 & 585. & 0.23 & 112 & & & 16310 \\
\hline & & & & & & 17414 \\
\hline 1 & & 12 & & 70836 & 116.4 & 17497 \\
\hline & & & & & & \\
\hline
\end{tabular}

RUN NUMBER: 329

$\mathrm{p} / \mathrm{d}=1.17$

$x_{\text {in }}=0.03$

SURFACE TYPE: HIGH FLUX

WORKING FLUID: $R-113$ $G=356 \mathrm{~kg} / \mathrm{s}^{*} \mathrm{~m}^{\wedge} 2$
DELTA P total $=4.54 \mathrm{kPa}$
Xout $=0.35$

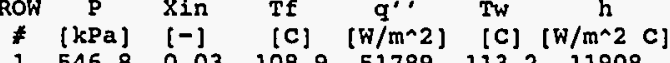

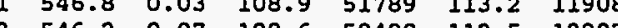
$\begin{array}{lllllll}5 & 546.2 & 0.07 & 108.6 & 50400 & 112.5 & 12907\end{array}$ $\begin{array}{lllllll}7 & 545.6 & 0.11 & 108.6 & 51419 & 112.1 & 14956\end{array}$ 7 . $544.40 .19 \quad 108.751268 \quad 112.015307$ $9544.4 \quad 0.19108 .7 \quad 4966 \quad 112.0 \quad 15228$ $13543.2 \quad 0.28 \quad 108.851140$ 111.9 15740 $\begin{array}{lllllll}15 & 542.6 & 0.32 & 108.9 & 51043 & 111.8 & 17608\end{array}$
RUN NUMBER: 332

$\begin{array}{rl}\mathrm{p} / \mathrm{d}=1.17 & \mathrm{G}=349.7 \mathrm{~kg} / \mathrm{s}^{*} \mathrm{~m}^{\wedge} 2\end{array}$

$\begin{array}{rlrl}\text { Xin } & =-.01 & \text { DELTA P total } & =4.1 \mathrm{kPa} \\ \text { Xout } & =0.47\end{array}$ SURFACE TYPE: HIGH FLUX
WORKING FLUID: R-113 $\mathrm{G}=352.56 \mathrm{~kg} / \mathrm{s}^{\star} \mathrm{m}^{\wedge} 2$ DELTA P total $=4.07 \mathrm{kPa}$ . c]

10 414 22 


\begin{tabular}{|c|c|c|c|c|c|c|}
\hline $\begin{array}{l}\text { RUN } \\
\mathrm{p} / \mathrm{d} \\
\mathrm{P} \text { in } \\
\mathrm{X} \text { in } \\
\text { suR }\end{array}$ & $\begin{array}{l}\text { NUMBE } \\
=1.1 \\
=587 \\
=-.0 \\
A C E\end{array}$ & $5 \mathrm{kPa}$ & FH FLU & $\begin{array}{r}\text { WORKI } \\
G= \\
\text { LTA P t }\end{array}$ & $\begin{array}{l}\text { NG FLU } \\
451.52 \\
\text { otal }\end{array}$ & $\begin{array}{l}\text { ID: } R-113 \\
\mathrm{~kg} / \mathrm{s}^{*} \mathrm{~m}^{-2} \\
4.05 \mathrm{kPa} \\
4 \mathrm{t}=0.09\end{array}$ \\
\hline ROW & P & xin & If & $q^{\prime \prime}$ & Tw & $\mathrm{h}$ \\
\hline$\#$ & [ $\mathrm{KPa}$ ] & {$[-]$} & [C] & {$[w / m \wedge 2]$} & [C] & {$\left[W / m^{\wedge} 2 C\right]$} \\
\hline 1 & 587.1 & -.00 & 111.6 & 19851 & 114.6 & $5 \quad 6627$ \\
\hline 3 & 586.3 & 0.01 & 112.3 & 20161 & 114.6 & 8820 \\
\hline 5 & 585.7 & 0.02 & 112.4 & 20465 & 114.4 & 9952 \\
\hline 7 & 585.1 & 0.04 & 112.3 & 20332 & 114.5 & 9634 \\
\hline 9 & 584.7 & 0.05 & 112.3 & 19996 & 114.4 & 9767 \\
\hline 11 & 584.3 & 0.06 & 112.3 & 20337 & 114.3 & 9870 \\
\hline 13 & 583.9 & 0.07 & 112.2 & 20497 & 114.4 & 9672 \\
\hline 15 & 583.5 & 0.09 & 112.2 & 20314 & 114.4 & 9329 \\
\hline
\end{tabular}

RUN NUMBER: 338

$\mathrm{p} / \mathrm{d}=1.17$

WORKING FLUID: R-113

(9.7 kP DELTA $P$ total $=4.06 \mathrm{kPa}$

SURFACE TYPE: HIGH FLUX

Xout $=0.15$

\begin{tabular}{|c|c|c|c|c|c|c|}
\hline OW & $\mathbf{P}$ & $X$ in & Tf & $q^{\prime \prime}$ & $T w$ & $\mathrm{~h}$ \\
\hline & [KPa] & & (c) & $\left(W / m^{\wedge} 2\right)$ & [C] & \\
\hline 1 & 590. & 0.01 & 112.3 & $29819^{\circ}$ & 115.3 & \\
\hline 3 & 589. & 0.03 & 112.6 & 30074 & 115.2 & 11920 \\
\hline & 588.8 & 0.05 & 112.6 & 30497 & 115.1 & 12300 \\
\hline & 588. & 0.0 & 112 . & 304 & 115 & \\
\hline 9 & 587.9 & 0.09 & 112.5 & 30107 & 114.8 & 1310 \\
\hline & 587 & & & & 114 & 13565 \\
\hline & 887 & .13 & 2 & 30637 & 114.8 & 13527 \\
\hline & & & & & & \\
\hline
\end{tabular}

$\begin{array}{lllllll}15 & 586.7 & 0.14 & 112.5 & 30384 & 114.9 & 12455\end{array}$
RUN NUMBER: 336

$P$ in $=592.1$
$X$ in $=0.00$ SURFACE TYPE: HIGH FLUX

WORKING FLUID: R-113 $G=448.42 \mathrm{~kg} / \mathrm{s} * \mathrm{~m}^{\wedge} 2$ Xout $=0.24$

\begin{tabular}{|c|c|c|c|c|c|}
\hline$(\mathrm{kPa})$ & $1-1$ & (c) & $\left(\mathrm{w} / \mathrm{m}^{\wedge} 2\right]$ & (C) & {$\left[W / m^{\wedge} 2\right.$} \\
\hline 591.6 & 0.00 & 112.1 & 50145 & 116.5 & 11363 \\
\hline 590.8 & 0.03 & 112.8 & 50382 & 116.3 & 14342 \\
\hline 590.2 & 0.06 & 112.7 & 51031 & 116.2 & 24657 \\
\hline 589.7 & 0.09 & 112.7 & 50770 & 115.9 & 15834 \\
\hline 589 & 0.13 & 112.7 & 50287 & 116.0 & 14891 \\
\hline 588, & 0.16 & 112.6 & 50467 & 116.1 & 14546 \\
\hline 588. & 0.19 & 112.6 & 50767 & 115.8 & 1589 \\
\hline 588 & 0.22 & 212.6 & 50443 & 136.0 & 14528 \\
\hline
\end{tabular}

RUN NUMBER: 333 $\mathrm{p} / \mathrm{d}=1.17$ Pin
in $=-.01$ SURFACE TYPE: HIGH FLUX

ORKING FLUID: R-113 $G=448.4 \mathrm{~kg} / \theta^{\star} \mathrm{m}^{\wedge} 2$ Xout $=0.37$ ROW $p$ xin Tf $q$ ' Tw $h$ * [kPa] $[-] \quad[\mathrm{C}] \quad\left[\mathrm{W} / \mathrm{m}^{\wedge} 2\right] \quad[\mathrm{C}]\left[\mathrm{W} / \mathrm{m}^{\wedge} 2 \mathrm{C}\right]$

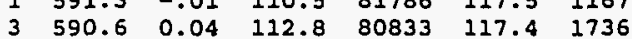
$\begin{array}{lllllll}5 & 590.0 & 0.09 & 112.7 & 81738 & 117.2 & 18406\end{array}$ $\begin{array}{lllllll}7 & 589.4 & 0.14 & 112.7 & 81511 & 116.9 & 19403\end{array}$ $9589.0 \quad 0.19 \quad 112.7 \quad 81227 \quad 116.7 \quad 19863$ $\begin{array}{lllllll}11 & 588.6 & 0.24 & 112.6 & 80528 & 117.0 & 18409\end{array}$ $13588.20 .29 \quad 112.6 \quad 81018116.7 \quad 19803$

\begin{tabular}{|c|c|c|c|c|c|c|c|c|c|c|c|c|c|}
\hline $\begin{array}{l}\text { RUN } \\
\text { p/d } \\
\text { Pin } \\
\text { Xin } \\
\text { SURF }\end{array}$ & $\begin{array}{l}\text { NUMBER: } \\
=1.17 \\
=586.5 \\
=0.01\end{array}$ & $\begin{array}{l}337 \\
\mathrm{kPa} \\
\mathrm{E}: \mathrm{HI}\end{array}$ & GH & $\begin{array}{c}\text { WORKI } \\
G= \\
\text { ELTA } P \text { t }\end{array}$ & $\begin{array}{r}\text { NG FLU } \\
447.41 \\
\text { otal }= \\
x o\end{array}$ & $\begin{array}{r}\text { ID: } R-113 \\
\mathrm{~kg} / \mathrm{g}^{*} \mathrm{~m}^{\wedge} 2 \\
4.05 \mathrm{kPa} \\
\mathrm{ut}=0.19\end{array}$ & $\begin{array}{l}\text { RUN } \\
\text { p/d } \\
\text { Pin } \\
\text { Xin } \\
\text { SURI }\end{array}$ & $\begin{array}{l}\text { NUMBER } \\
=1.17 \\
=588 . \\
=0.01 \\
\text { PCE TY }\end{array}$ & $\begin{array}{l}: 334 \\
6 \mathrm{kPa}\end{array}$ & D & $\begin{array}{c}\text { WORKI } \\
G= \\
\text { ELTA P } t\end{array}$ & $\begin{array}{l}\text { VG FLU } \\
446.03 \\
0+03=\end{array}$ & $\begin{array}{r}I D: R-113 \\
\mathrm{~kg} / \mathrm{s}^{\star} \mathrm{m}^{\wedge} 2 \\
4.09 \mathrm{kPa} \\
\mathrm{ut}=0.34\end{array}$ \\
\hline ROW & $\begin{array}{c}\mathrm{P} \\
\mathrm{kPa}\end{array}$ & & $\begin{array}{l}\text { Tf } \\
\text { (c) }\end{array}$ & $\underset{\left[W / m^{\wedge} 2\right]}{q{ }^{\prime}}$ & Tw & $\stackrel{h}{h}$ & ROW & $P$ & & Tf & & $T w$ & $\begin{array}{c}\mathrm{h} \\
\mathrm{c}\end{array}$ \\
\hline 1 & 586.0 & & 9 111.9 & 39674 & $\begin{array}{l}{[\mathrm{C}]} \\
115 .\end{array}$ & {$\left[\begin{array}{c}{\left[W / m^{\wedge} 2 C\right]} \\
11520\end{array}\right.$} & $\begin{array}{l}\# \\
1\end{array}$ & & & $\begin{array}{c}{[c]} \\
111.9\end{array}$ & $\begin{array}{c}\left(\mathrm{w} / \mathrm{m}^{\wedge} 2\right) \\
71078\end{array}$ & $\begin{array}{l}\text { [C] } \\
117.4\end{array}$ & $\begin{array}{c}{\left[\mathrm{w} / \mathrm{m}^{\wedge} 2 \mathrm{C}\right]} \\
12969\end{array}$ \\
\hline 3 & 585.2 & & & & 115.2 & & 3 & & & & & & \\
\hline 5 & & & & & & & 5 & & & & & & \\
\hline 7 & 584.1 & & & 402 & & & 7 & & & & & & 16407 \\
\hline 9 & & & & & & & 9 & & & & & & \\
\hline 11 & & & & & & & & & & & & & \\
\hline 13 & & & & & & & & & & & & & \\
\hline 15 & 582.5 & 0.18 & 112.1 & 40154 & 114.9 & 14426 & 15 & 584.6 & 0.31 & 112.3 & 70154 & 116.9 & 15294 \\
\hline
\end{tabular}


Bundle Boiling Data

Data obtained in pure $\mathrm{R}-11$ 
RUN NUMBER: 437

$\mathrm{P} / \mathrm{d}=1.5$

Pin $=202.76 \mathrm{kPa}$ $\begin{array}{rcl}\text { ROW } & \text { P } & \text { Xin } \\ \neq & (\mathrm{kPa}) & 1-1 \\ 1 & 202.1 & 0.00 \\ 3 & 200.9 & 0.01 \\ 5 & 200.1 & 0.02 \\ 7 & 199.2 & 0.02 \\ 9 & 198.2 & 0.03 \\ 11 & 197.3 & 0.04 \\ 13 & 196.3 & 0.04 \\ 15 & 195.2 & 0.05\end{array}$

$15 \quad 195.20 .05$

RUN NUMBER: 436

$\mathrm{p} / \mathrm{d}=1.5$

Pin $=205.17 \mathrm{kPa}$

$x_{\text {in }}=0.00$

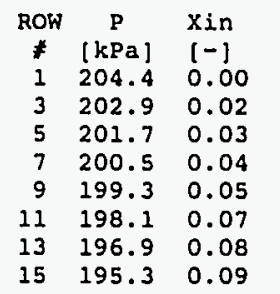

$\begin{array}{lll}15 & 195.3 & 0.09\end{array}$

RUN NUMBER: 430

$\mathrm{p} / \mathrm{d}=1.5$

Pin $=208.42 \mathrm{kPa}$

$x_{\text {in }}=-.00$

$\begin{array}{lllll}43.7 & 5226 & 45.2 & 3512 & \text { H.F. }\end{array}$

$\begin{array}{lllll}43.6 & 5094 & 45.0 & 3763 & \text { H.F. }\end{array}$

$\begin{array}{lllll}43.6 & 5250 & 47.6 & 1328 & \mathrm{SM} .\end{array}$

$\begin{array}{lllll}43.6 & 5065 & 47.3 & 1390 & \mathrm{SM} .\end{array}$

$\begin{array}{lllll}43.6 & 5174 & 44.5 & 5960 & \text { T.B. } \\ 43.6 & 5242 & 44.3 & 7312 & \text { T.B. }\end{array}$

$\begin{array}{lllll}43.6 & 5242 & 44.3 & 7312 & \text { T.B. } \\ 43.6 & 5162 & 44.2 & 8441 & \text { T.B. }\end{array}$

\begin{tabular}{|c|c|c|c|c|c|c|c|}
\hline $\begin{array}{c}\text { ROW } \\
\star\end{array}$ & $\begin{array}{c}\mathrm{P} \\
{[\mathrm{kPa}]}\end{array}$ & $\begin{array}{l}x \text { in } \\
{[-1}\end{array}$ & $\begin{array}{l}\text { Tf } \\
{[C]}\end{array}$ & $\begin{array}{c}q^{\prime \prime} \\
\left(w / m^{\wedge} 2\right)\end{array}$ & $\begin{array}{l}\text { Tw } \\
\text { (c) }\end{array}$ & $\begin{array}{c}h \\
\left(W / m^{\wedge} 2\right.\end{array}$ & $\begin{array}{l}\text { SURF } \\
\text { TYPE }\end{array}$ \\
\hline 1 & 207.7 & -.00 & 43.9 & 20754 & 46.5 & 8030 & 2125 \\
\hline 3 & 206.2 & 0.02 & 44.0 & 20511 & 46.7 & 7633 & \\
\hline 5 & 205.0 & 0.04 & 44.0 & 20138 & 46.5 & 8066 & \\
\hline 7 & 203.8 & 0.0 & 4. & 20586 & 54. & 1927 & \\
\hline 9 & 202.5 & 0.09 & $\$ 4.0$ & 19847 & 54.3 & 1928 & \\
\hline 11 & 201.2 & 0.12 & & 20494 & 46.5 & 8368 & \\
\hline 13 & 199.9 & 0.14 & 14.0 & 20546 & 46.6 & 8198 & \\
\hline 15 & 198.2 & 0.17 & 44.0 & 20278 & 46.0 & 10180 & \\
\hline
\end{tabular}

WORKING FLUID: $R-1$

DELTA $P$ total $=9.83 \mathrm{kPa}$

Xout $=0.10$

\begin{tabular}{|c|c|c|c|c|}
\hline $\begin{array}{l}\mathrm{Tf} \\
\text { [C] }\end{array}$ & $\frac{q^{\prime \prime}}{\left(w / m^{\wedge} 2\right]}$ & Tw & {$\left[w / m^{\wedge} 2 \quad c\right)$} & $\begin{array}{l}\text { SURF } \\
\text { TYPE }\end{array}$ \\
\hline 43.7 & 10687 & 45.7 & 5347 & H.F. \\
\hline 43.6 & 10792 & 45.7 & 5199 & H.F. \\
\hline 43.6 & 10386 & 45.5 & 5585 & H.F. \\
\hline 43.6 & 10823 & 51.1 & 1450 & SM. \\
\hline 43.6 & 10457 & 50.5 & 1518 & SM. \\
\hline 43.6 & 10303 & 45.4 & 5681 & T.B. \\
\hline 43.6 & 10418 & 45.2 & 6372 & \\
\hline 3. & 10209 & 45.0 & 7330 & 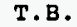 \\
\hline
\end{tabular}
$\begin{array}{lllll}43.6 & 10418 & 45.2 & 6372 & \text { T.B. } \\ 43.6 & 10209 & 45.0 & 7330 & T . B .\end{array}$

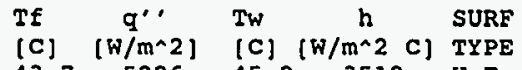

$\begin{array}{lllll}43.6 & 5295 & 45.1 & 3558 & \text { H.F. }\end{array}$

RUN NUMBER: 431

$\mathrm{p} / \mathrm{d}=1.5$

$\mathrm{Pin}=206.47 \mathrm{kPa}$

$x$ in $=-.01$

$\begin{array}{rcc}\text { ROW } & \text { P } & \text { Xin } \\ \text { \# } & {[\mathrm{kPa}]} & {[-]} \\ 1 & 205.8 & -.01 \\ 3 & 204.3 & 0.03 \\ 5 & 203.1 & 0.07 \\ 7 & 201.8 & 0.11 \\ 9 & 200.5 & 0.15 \\ 11 & 199.2 & 0.19 \\ 13 & 197.9 & 0.23 \\ 15 & 196.3 & 0.27\end{array}$

$q^{\prime \prime}$
$[\mathrm{Cl}]$
42.7
$\left[\mathrm{w}^{\prime} / \mathrm{m}^{\wedge}\right]$

$42.7 \quad 30869$

$\begin{array}{ll}43.7 & 30491 \\ 43.7 & 29909\end{array}$

$43.7 \quad 30379$

43.729369

43.730110

$43.7 \quad 29731$

WORKING FLUID: $\mathrm{R}-11$

$G=50.41 \mathrm{~kg} / \mathrm{s}^{*} \mathrm{~m}^{\wedge} 2$

DELTA $P$ total $=10.2 \mathrm{kPa}$

Xout $=0.29$

\begin{tabular}{|c|c|c|}
\hline Ww & $\stackrel{\mathrm{h}}{\mathrm{A}}$ & SURF \\
\hline 47.4 & 6675 & H.F. \\
\hline 47.6 & 7905 & H.F. \\
\hline 47.4 & 8258 & H.F. \\
\hline 56.9 & 2304 & \\
\hline 56.7 & 2263 & SM. \\
\hline 48.6 & 6156 & T.B. \\
\hline 47.9 & 7174 & T.B. \\
\hline 47.1 & 8970 & \\
\hline
\end{tabular}

RUN NUMBER: 432

\section{$\mathrm{p} / \mathrm{d}=1.5$}

WORKING FLUID: $R-11$

Pin $=204.45 \mathrm{kPa}$

$G=50.53 \mathrm{~kg} / \mathrm{s} \star_{\mathrm{m}^{\wedge} 2}$

DELTA $P$ total $=9.22 \mathrm{kPa}$ Xout $=0.40$

$\begin{array}{ccl}\text { ROW } & \text { P } & \text { Xin } \\ \text { \# } & {[\mathrm{kPa}]} & {[-]} \\ 1 & 203.8 & 0.00 \\ 3 & 202.5 & 0.05 \\ 5 & 201.4 & 0.10 \\ 7 & 200.2 & 0.16 \\ 9 & 199.1 & 0.21 \\ 11 & 197.9 & 0.27 \\ 13 & 196.7 & 0.32 \\ 15 & 195.2 & 0.37\end{array}$

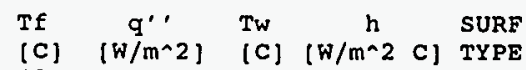
$\begin{array}{lllll}43.1 & 41556 & 47.0 & 10894 & \text { H.F. }\end{array}$ $\begin{array}{lllll}43.6 & 40918 & 47.2 & 11312 & \text { H.F. }\end{array}$ $43.640243 \quad 46.8 \quad 12429$ H.F. 43.6 3123957.52966 SM. $43.6 \quad 39948 \quad 57.4 \quad 2893 \quad$ SM. $\begin{array}{lllll}43.6 & 40656 & 48.2 & 8740 & \text { T.B. }\end{array}$ $\begin{array}{lllll}43.6 & 40756 & 48.1 & 9003 & \text { T.B. }\end{array}$

RUN NUMBER: 433 $\mathrm{p} / \mathrm{d}=1.5$

Pin $=208.17 \mathrm{kPa}$ $x$ in $=-.01$

WORKING FLUID: $R-11$ $G=51.25 \mathrm{~kg} / \theta^{*} m^{\wedge}-11$ $\begin{aligned} \text { DELTA P total } & =9.62 \mathrm{kPa} \\ \text { Xout } & =0.48\end{aligned}$

$\begin{array}{rcl}\text { ROW } & \begin{array}{c}\text { P } \\ \text { X }\end{array} & \text { Xin } \\ 1 & \mathrm{kPa}] & {[-]} \\ 1 & 207.5 & -.01 \\ 3 & 206.0 & 0.05 \\ 5 & 204.9 & 0.12 \\ 7 & 203.7 & 0.18 \\ 9 & 202.4 & 0.25 \\ 11 & 201.2 & 0.32 \\ 13 & 200.0 & 0.38 \\ 15 & 198.6 & 0.44\end{array}$

Tf $q$ '” Tw $\stackrel{\text { Th }}{\text { SURF }}$ [C] $\left[W / m^{\wedge} 2\right]$ (C) [W/m^2 C] TYPE $\begin{array}{lllll}43.9 & 51344 & 48.4 & 11464 & \text { H.F. } \\ 44.1 & 50549 & 48.6 & 11376 & \text { H.F. }\end{array}$ $\begin{array}{lllll}44.1 & 49695 & 48.1 & 12627 & \text { H.F. }\end{array}$ $44.1 \quad 50686 \quad 59.9 \quad 3228 \quad$ SM. $\begin{array}{lllll}44.1 & 49207 & 59.8 & 3138 & S M\end{array}$ $\begin{array}{lllll}44.1 & 50329 & 49.7 & 9014 & \text { T.B. }\end{array}$ $\begin{array}{lllll}44.1 & 50348 & 49.7 & 9104 & \text { T.B. }\end{array}$ 


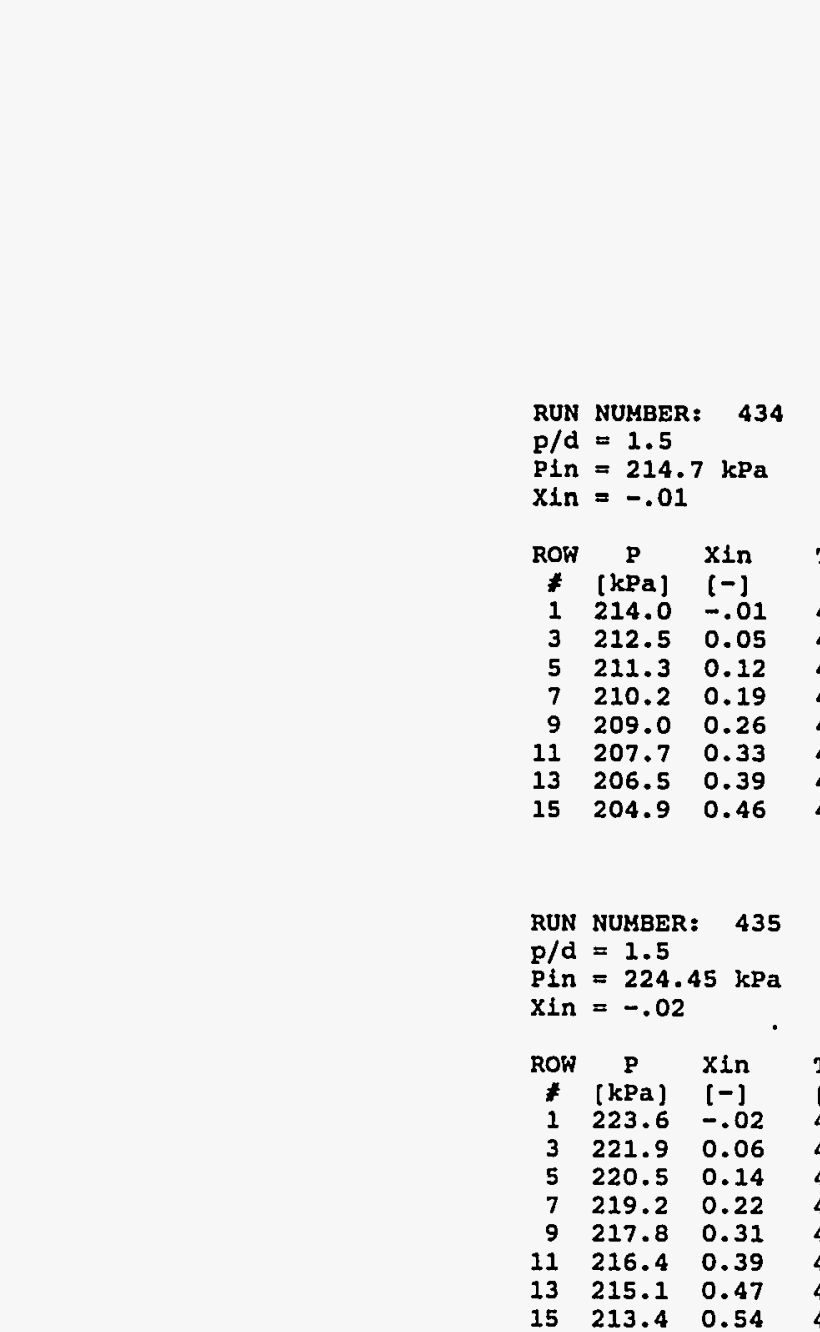

\begin{tabular}{|c|c|c|c|c|}
\hline \multirow{3}{*}{$\begin{array}{l}\text { Tf } \\
{[C]} \\
44.2 \\
45.2\end{array}$} & DELTA & $\begin{array}{l}\text { HORKI } \\
G=6 \\
P \text { tot }\end{array}$ & $\begin{array}{l}\text { NG FLUID: } \\
0.05 \mathrm{~kg} / \mathrm{s} \\
\text { al }=9.82 \\
\text { Xout }=\end{array}$ & $\begin{array}{c}R-11 \\
n^{\wedge} 2 \\
k P a \\
0.49\end{array}$ \\
\hline & $\underset{\left[W / m^{\wedge} 2\right]}{q^{\circ}}$ & $\begin{array}{l}\text { Tw } \\
{[C]}\end{array}$ & $\left.\begin{array}{c}h \\
{\left[w / m^{\wedge} 2\right.}\end{array}\right]$ & $\begin{array}{l}\text { SURF } \\
\text { TYPE }\end{array}$ \\
\hline & $\begin{array}{l}61922 \\
60833\end{array}$ & $\begin{array}{l}49.5 \\
49.7\end{array}$ & $\begin{array}{l}11763 \\
13442\end{array}$ & $\begin{array}{l}\text { H.F. } \\
\text { H.F. }\end{array}$ \\
\hline 45.2 & 59902 & 49.1 & 15182 & H.F. \\
\hline 45.2 & 61313 & & 3971 & \\
\hline & & 60 & 386 & SM. \\
\hline & 60364 & 51.6 & 9348 & T.B. \\
\hline & & & & T.B. \\
\hline 45.2 & 60002 & 50.2 & 11968 & T.B. \\
\hline
\end{tabular}

RUN NUMBER: 427

$\mathrm{p} / \mathrm{d}=1.5$

$\mathrm{Pin}=192.29 \mathrm{kPa}$

Xin $=-.00$

$\begin{array}{ccc}\text { ROW } & \text { P } & \text { Xin } \\ \text { * } & {[\mathrm{kPa}]} & {[-1} \\ 1 & 192.2 & -.00 \\ 3 & 192.0 & 0.01 \\ 5 & 191.9 & 0.01 \\ 7 & 191.7 & 0.02 \\ 9 & 191.6 & 0.02 \\ 11 & 191.5 & 0.03 \\ 13 & 191.3 & 0.04 \\ 15 & 191.1 & 0.04\end{array}$

RUN NUMBER: 426 $\mathrm{p} / \mathrm{d}=1.5$

$\operatorname{Pin}=191.68 \mathrm{kPa}$

$\mathrm{p} / \mathrm{d}=1.5$

Pin $=224.45 \mathrm{kPa}$
$X$ in $=-.02$

ROW $P \quad x$ in

$\begin{array}{rcl}\text { ROW } & P & \text { Xin } \\ * & {[\mathrm{kPa}]} & {[-]} \\ 1 & 223.6 & -.02 \\ 3 & 221.9 & 0.06 \\ 5 & 220.5 & 0.14 \\ 7 & 219.2 & 0.22 \\ 9 & 217.8 & 0.31 \\ 11 & 216.4 & 0.39 \\ 13 & 215.1 & 0.47 \\ 15 & 213.4 & 0.54\end{array}$

\section{RUN NUMBER: 428} $\mathrm{p} / \mathrm{d}=1.5$ Pin $=193 \mathrm{kPa}$ $x_{\text {in }}=0.00$

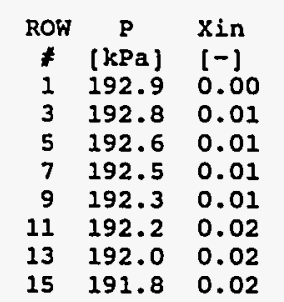

$\begin{array}{lll}15 & 191.8 & 0.02\end{array}$

\begin{tabular}{|c|c|c|c|}
\hline $\begin{array}{l}q^{\prime \prime} \\
\left./ m^{\wedge} 2\right]\end{array}$ & $\begin{array}{l}T w \\
{[C]}\end{array}$ & $\stackrel{h}{h}$ & $\begin{array}{l}\text { SURF } \\
\text { TYPE }\end{array}$ \\
\hline 1705 & 51.6 & 9821 & H.F. \\
\hline 0519 & 51.9 & 13006 & H.F. \\
\hline 9261 & 51.2 & 14654 & H.F. \\
\hline 0391 & 62.8 & 4322 & SM. \\
\hline 8463 & 62.8 & 4189 & SM. \\
\hline 7837 & $\begin{array}{l}54.8 \\
54.3\end{array}$ & 8671 & T.B. \\
\hline 7566 & 52.8 & 10677 & T. \\
\hline
\end{tabular}

WORKING FLUID: $R-11$ $G=110.35 \mathrm{~kg} / \mathrm{s}^{\star} \mathrm{m}^{\wedge} 2$ $\begin{aligned} \text { DELTA P total } & =1.17 \mathrm{kPa} \\ \text { Xout } & =0.02\end{aligned}$

Tf $q^{\prime \prime}$ Tw $h$ SURF [C] [W/m^2] [C] [W/ $\mathrm{m}^{\wedge} 2$ C] TYPE $42.95172 \quad 45.0 \quad 2548$ H.F $\begin{array}{lllll}43.2 & 5173 & 45.0 & 2945 & \text { H.F. } \\ 43.3 & 5055 & 44.9 & 3193 & \text { H.F. }\end{array}$ 43.35191 47.2 3193 H.F. $43.2 \quad 5005$ 46.2 1309 SM. 43.25103 44.5 4013 SM. $\begin{array}{lllll}43.2 & 5103 & 44.5 & 4013 & \text { T.B. }\end{array}$

$\begin{array}{lllll}43.2 & 5117 & 44.2 & 5165 & \text { T.B. } \\ 43.2 & 5035 & 44.0 & 5940 & \text { T.B. }\end{array}$

$\ln =-.00$

$\begin{array}{rcc}\text { ROW } & \begin{array}{c}P \\ \text { * }\end{array} & \text { Xin } \\ 1 & 191.6 & {[-.00} \\ 3 & 191.4 & 0.01 \\ 5 & 191.3 & 0.02 \\ 7 & 191.1 & 0.04 \\ 9 & 191.0 & 0.05 \\ 11 & 190.8 & 0.06 \\ 13 & 190.7 & 0.07 \\ 15 & 190.5 & 0.09\end{array}$

RUN NUMBER: 420

Pin $=206.76 \mathrm{kPa}$ ROW $P$ Xin $T$

\begin{tabular}{|c|c|c|c|c|c|c|c|}
\hline ROW & $\begin{array}{c}P \\
{[k \mathrm{~Pa}]}\end{array}$ & $\begin{array}{l}x \text { in } \\
{[-]}\end{array}$ & $\begin{array}{l}\text { Tf } \\
\text { [C] }\end{array}$ & $\begin{array}{c}q^{\prime \prime} \\
{\left[w / m^{\wedge} 2\right]}\end{array}$ & $\begin{array}{l}T w \\
\text { [C] }\end{array}$ & $\left.\frac{h}{\left[W / m^{\wedge} 2\right.} c\right]$ & $\begin{array}{l}\text { SUR } \\
\text { TYP }\end{array}$ \\
\hline 1 & 206.2 & -.01 & 43.1 & 30568 & 47.9 & 6346 & \\
\hline 3 & 205.1 & 0.01 & 44.1 & 30106 & 47.5 & 8751 & \\
\hline $\begin{array}{l}5 \\
7\end{array}$ & $\begin{array}{l}204.1 \\
203.1\end{array}$ & $\begin{array}{l}0.03 \\
0.04\end{array}$ & $\begin{array}{l}44.1 \\
44.1\end{array}$ & $\begin{array}{l}29700 \\
30478\end{array}$ & $\begin{array}{l}47.3 \\
56.0\end{array}$ & $\begin{array}{l}9426 \\
2560\end{array}$ & \\
\hline & 202.1 & 0.06 & 44.1 & 29527 & 55.8 & 2524 & \\
\hline & 201.0 & 0.08 & 44.1 & 30466 & & 9733 & \\
\hline & 199.8 & 0.10 & 44.1 & 30267 & 47.1 & 9994 & \\
\hline & 198.4 & 0,12 & & & & & \\
\hline
\end{tabular}

Tf " $^{\circ} \mathrm{Tw} h \mathrm{~h}$ SURF [C] $\left[W / m^{\wedge} 2\right] \quad[C]\left[W / m^{\wedge} 2\right.$ C] TYPE $\begin{array}{lllll}42.3 & 20823 & 46.2 & 5414 & \text { H.F. } \\ 43.1 & 20573 & 46.1 & 6922 & H . F .\end{array}$ $43.120193 \quad 45.8 \quad 7269$ H.F. $\begin{array}{lllll}43.0 & 20724 & 54.5 & 1808 & S M\end{array}$ $43.020015 \quad 54.0 \quad 1822 \quad S M$. $\begin{array}{lllll}43.0 & 20547 & 46.1 & 6691 & \text { T.B. }\end{array}$ $\begin{array}{lllll}43.0 & 20608 & 46.0 & 6816 & \text { T.B. } \\ 42.9 & 20337 & 45.5 & 7821 & \text { T.B. }\end{array}$

$44.130009 \quad 46.5 \quad 12450 \quad$ T.B.
WORKING FLUID: R-11 $68 \mathrm{~kg} / \mathrm{s}^{*} \mathrm{~m}^{\wedge} 2$
$=1.16 \mathrm{kPa}$ $\begin{aligned} \text { DELTA P total } & =1.16 \mathrm{kPa} \\ \text { Xout } & =0.05\end{aligned}$

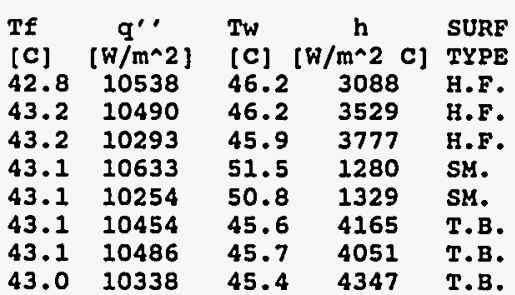




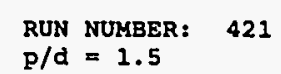

$\mathrm{P} / \mathrm{d}=1.5$

$\operatorname{Pin}=210.27 \mathrm{kPa}$

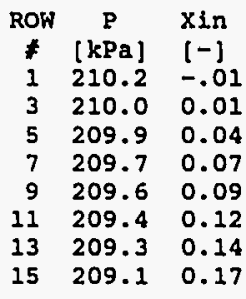

RUN NUMBER: 422

$\mathrm{p} / \mathrm{d}=1.5$

Pin $=204 \mathrm{kP}$

$x$ in $=-.00$

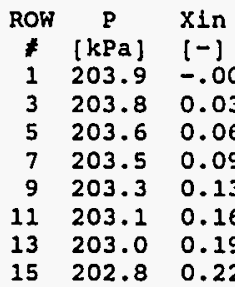

423 $\mathrm{p} / \mathrm{d}=1.5$

$\mathrm{Pin}=202.45 \mathrm{kPa}$ $x$ in $=0.01$

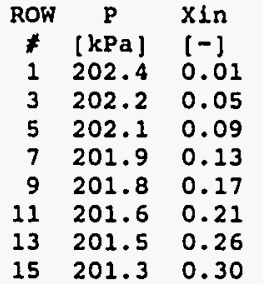

WORKING FLUID: R-1I $G=105.17 \mathrm{~kg} / \mathrm{s}^{*} \mathrm{~m}^{\wedge} 2$ Xout $=0.18$

\begin{tabular}{|c|c|c|c|c|}
\hline $\begin{array}{l}\mathrm{TE} \\
\text { [C] }\end{array}$ & $\begin{array}{c}q^{\prime \prime} \\
{\left[\mathrm{w} / \mathrm{m}^{\wedge} 2\right]}\end{array}$ & $\begin{array}{l}\mathrm{Tw} \\
{[\mathrm{C}]}\end{array}$ & 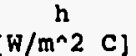 & $\begin{array}{l}\text { SURF } \\
\text { TYPE }\end{array}$ \\
\hline $\begin{array}{l}44.3 \\
46.1\end{array}$ & $\begin{array}{l}41234 \\
40498\end{array}$ & $\begin{array}{l}49.3 \\
48.9\end{array}$ & $\begin{array}{c}8131 \\
14660\end{array}$ & $\begin{array}{l}\text { H.F. } \\
\text { H.F. }\end{array}$ \\
\hline 6.1 & 39953 & 48.4 & 17241 & H.F. \\
\hline 5.1 & 40539 & 58.1 & 3367 & SM. \\
\hline & 39337 & 58.0 & 3305 & SM. \\
\hline .0 & 40474 & 49.5 & 11749 & T.B. \\
\hline & & 49.1 & 12944 & \\
\hline .0 & 9959 & 48.2 & 18168 & T.B \\
\hline
\end{tabular}

RUN NUMBER: 424 $\mathrm{p} / \mathrm{d}=1.5$

Pn $=201.24 \mathrm{kPa}$ $x$ in $=0.01$

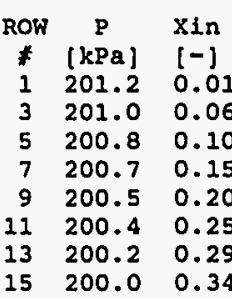

RUN NUMBER: 425 $\mathrm{p} / \mathrm{d}=1.5$

Pin $=203.1 \mathrm{kP}$ $\mathrm{Xin}=0.00$ DELTA $G=103.34 \mathrm{~kg} / \mathrm{g} / \mathrm{m}$ Xout $=0.24$

\section{Tf}

[C] $\left[\mathrm{w} / \mathrm{m}^{\prime \prime 2}\right]$

Tw $\stackrel{h}{\text { SURF }}$ /m^2 C] TYPE $44.2 \quad 51534 \quad 48.9$ 10834 H.F. $\begin{array}{lllll}45.1 & 50581 & 48.5 & 15061 & \text { H.F. }\end{array}$ $45.149849 \quad 48.0 \quad 17301$ H.F. $\begin{array}{lllll}45.1 & 51052 & 58.6 & 3769 & \text { SM. }\end{array}$

$\begin{array}{lllll}45.1 & 49628 & 58.4 & 3713 & \text { SM. }\end{array}$ $\begin{array}{lllll}45.0 & 50807 & 49.6 & 11017 & \text { T.B. } \\ 45.0 & 50487 & 49.3 & 11762 & T . B .\end{array}$ $\begin{array}{lllll}45.0 & 50487 & 49.3 & 11762 & \text { T.B. } \\ 45.0 & 50307 & 48.1 & 16273 & \text { T.B. }\end{array}$

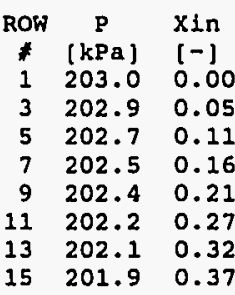

$\begin{array}{lll}15 & 201.9 & 0.37\end{array}$
WORKING FLUID: R-11

DELTA P total $=1.21 \mathrm{kPa}$
Xout $=0.36$

$\begin{aligned} \text { DELTA P total } & =1.21 \mathrm{kPa} \\ \text { Xout } & =0.36\end{aligned}$

\begin{tabular}{|c|c|c|c|c|}
\hline TI & {$\left[w / m^{\wedge} 2\right]$} & $\begin{array}{l}T w \\
{[C]}\end{array}$ & $\left.w / m^{n} 2 c\right]$ & $\begin{array}{l}\text { SUR } \\
\text { TYP }\end{array}$ \\
\hline 4.3 & 72211 & 49.8 & 13104 & \\
\hline 1.7 & 70957 & 49.5 & 14819 & \\
\hline & 6982 & 48.6 & & \\
\hline .6 & 71373 & 60.5 & 4490 & \\
\hline & 69377 & 80.4 & 4395 & \\
\hline $\begin{array}{l}44.6 \\
44.6\end{array}$ & $\begin{array}{l}70929 \\
70997\end{array}$ & $\begin{array}{l}51.7 \\
51.2\end{array}$ & $\begin{array}{r}9905 \\
10668\end{array}$ & \\
\hline & 70548 & 49.9 & 13069 & \\
\hline
\end{tabular}

RUN NUMBER: 446

$\mathrm{p} / \mathrm{d}=1.5$

Pin $=199.89 \mathrm{kPa}$

$x \ln =-.00$

$\begin{array}{ccc}\text { ROW } & \text { P } & \text { Xin } \\ * & {[\mathrm{kPa}]} & 1-\text { 1 } \\ 1 & 199.5 & -.00 \\ 3 & 198.7 & -.00 \\ 5 & 197.9 & 0.00 \\ 7 & 197.1 & 0.00 \\ 9 & 196.3 & 0.00 \\ 11 & 195.5 & 0.00 \\ 13 & 194.7 & 0.01 \\ 15 & 193.9 & 0.01\end{array}$

WORKING FLUID: $R-11$ $G=101.29 \mathrm{~kg} / \mathrm{s}^{*} \mathrm{~m}^{\wedge}$ $\begin{aligned} \text { DELTA P total } & =1.17 \mathrm{kPa} \\ \text { Xout } & =0.40\end{aligned}$

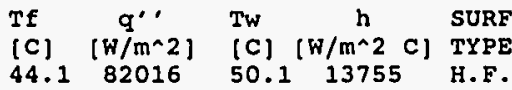
$\begin{array}{lllll}45.0 & 80810 & 49.7 & 17170 & \text { H.F. }\end{array}$ $\begin{array}{lllll}45.0 & 79300 & 48.8 & 20612 & \text { H.F. }\end{array}$ $44.9 \quad 81255 \quad 61.1 \quad 5030 \quad \mathrm{SM}$. $44.978954 \quad 60.9 \quad 4936 \quad$ SM. $\begin{array}{lllll}44.9 & 80266 & 52.3 & 10845 & \text { T.B. }\end{array}$ $44.980522 \quad 51.8 \quad 11578$ T.B. $\begin{array}{lllll}44.8 & 79807 & 50.5 & 14117 & \text { T. B. }\end{array}$ DELTA $=96.5 \mathrm{~kg} / \mathrm{s}^{*} \mathrm{~m} 2 \mathrm{2}$ Xout $=0.32$

\begin{tabular}{|c|c|c|c|c|}
\hline \multicolumn{5}{|c|}{$q^{\prime \prime}$} \\
\hline 44.2 & 61508 & 49.4 & 21881 & \\
\hline 1.9 & 6032 & 49.0 & 14573 & \\
\hline & & & & \\
\hline . & 61120 & & 4127 & \\
\hline • & & & & \\
\hline & 60420 & & 102 & \\
\hline & & & & \\
\hline & & & & \\
\hline
\end{tabular}

WORKING FLUID: R-11 $G=228.92 \mathrm{~kg} / \mathrm{g}^{\star} \mathrm{m}^{\wedge} 2$ $\begin{aligned} \text { DELTA P total } & =6.01 \mathrm{kPa} \\ \text { Xout } & =0.01\end{aligned}$

\begin{tabular}{|c|c|c|c|c|}
\hline $\begin{array}{l}\text { Tf } \\
\text { [C] }\end{array}$ & $\underset{\left[W / m^{\wedge} 2\right]}{q^{\prime \prime}}$ & $\begin{array}{l}T w \\
\text { (c) }\end{array}$ & $\stackrel{h}{h \sim 2} \quad c]$ & $\begin{array}{l}\text { SURF } \\
\text { TYPE }\end{array}$ \\
\hline 43.4 & 5058 & 45.7 & 2166 & H.F. \\
\hline 43.4 & 5076 & 45.6 & 2305 & H.F. \\
\hline $\begin{array}{l}43.4 \\
43.4\end{array}$ & $\begin{array}{l}4919 \\
5079\end{array}$ & $\begin{array}{l}45.5 \\
47.6\end{array}$ & $\begin{array}{l}2396 \\
1214\end{array}$ & $\begin{array}{l}\text { H.F. } \\
\text { SM. }\end{array}$ \\
\hline 13.4 & 4899 & 47.4 & 1235 & SM. \\
\hline 3.4 & 4999 & 45.0 & 3134 & T.B. \\
\hline 3.4 & 5038 & 44.9 & 3458 & \\
\hline 43.4 & 4937 & 44.7 & 3813 & T.B. \\
\hline
\end{tabular}


RUN NUMBER: 445
P/d $=1.5$
p $=197.67 \mathrm{kPa}$

$\mathrm{P} / \mathrm{d}=1.5$
$\mathrm{P}$ In $=197.67 \mathrm{kPa}$

Row $P$ in

$\begin{array}{ccc}\text { ROW } & \text { P } & \text { Xin } \\ * & {[\mathrm{kPa}]} & {[-]} \\ 1 & 197.3 & -.00 \\ 3 & 196.5 & 0.00\end{array}$

$\begin{array}{lll}3 & 196.5 & 0.00 \\ 5 & 195.6 & 0.01\end{array}$

$\begin{array}{lll}7 & 194.8 & 0.01\end{array}$

$\begin{array}{lll}9 & 194.0 & 0.01 \\ 1 & 193.2 & 0.02\end{array}$

$13 \quad 192.4 \quad 0.02$

$\begin{array}{lll}15 & 191.6 & 0.02\end{array}$

RUN NUMBER: 438

$\mathrm{p} / \mathrm{d}=1.5$

Pin $=199.77 \mathrm{kPa}$

in $=-.00$

ROW $P$ Xin

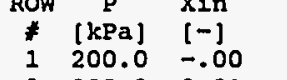

$\begin{array}{lll}1 & 200.3 & 0.01\end{array}$

$5 \quad 200.2 \quad 0.01$

$7200.2 \quad 0.02$

9200.10 .02

$11 \quad 200.0 \quad 0.03$

$\begin{array}{lll}13 & 200.0 & 0.04 \\ 15 & 200.5 & 0.04\end{array}$

RUN NUMBER: 439

$\mathrm{p} / \mathrm{d}=1.5$

Pin $=207.85 \mathrm{kPa}$

in $=-.00$

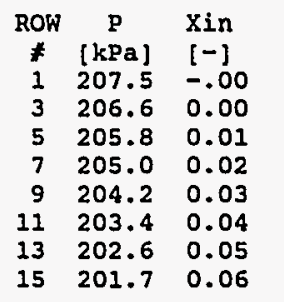

DELTA P total $=6.12 \mathrm{kPa}$
xout $=0.02$

xout $=0.02$

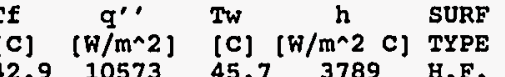

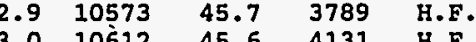

$\begin{array}{lllll}43.0 & 10612 & 45.6 & 4131 & \text { H.F. } \\ \mathbf{4 3 . 0} & 10287 & \mathbf{4 5 . 4} & \mathbf{4 3 7 4} & \text { H.F. }\end{array}$

$\begin{array}{lllll}43.0 & 10466 & 45.1 & 5128 & \text { T.B. } \\ 43.0 & 10212 & 44.9 & 5593 & \end{array}$
WORKING FLUID: R-11

$\begin{array}{lllll}3.0 & 10630 & 50.5 & 1424 & \text { SM. }\end{array}$

$\begin{array}{lllll}43.0 & 10383 & 44.3 & 8104 & \text { T.B. }\end{array}$

RUN NUMBER: 440

$\mathrm{p} / \mathrm{d}=1.5$

$\mathrm{Pin}=206.84 \mathrm{kPa}$

$x_{\text {in }}=-.00$

$\begin{array}{ccc}\text { ROW } & \text { P } & \text { Xin } \\ \# & {[\mathrm{kPa}]} & {[-]} \\ 1 & 206.5 & -.00 \\ 3 & 205.6 & 0.01 \\ 5 & 204.8 & 0.02 \\ 7 & 203.9 & 0.03 \\ 9 & 203.1 & 0.04 \\ 11 & 202.3 & 0.06 \\ 13 & 201.5 & 0.07 \\ 15 & 200.6 & 0.08\end{array}$

RUN NUMBER: 441

$\mathrm{p} / \mathrm{d}=1.5$

Pin $=208.31 \mathrm{kPa}$

$G=231.91 \mathrm{~kg} / \mathrm{s}^{*} \mathrm{~m}^{\wedge}$

$=-.72 \mathrm{kPa}$
Xout $=0.04$

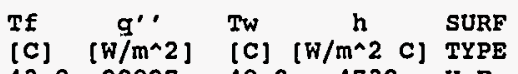

$43.820827 \quad 48.2 \quad 4730$ H.F.

$\begin{array}{lllll}44.7 & 20818 & 48.1 & 6238 & H . F\end{array}$

$\begin{array}{lllll}44.7 & 20276 & 47.5 & 7383 & \text { H.F. }\end{array}$

$\begin{array}{lllll}44.7 & 20778 & 54.8 & 2054 & \text { SM. }\end{array}$

$\begin{array}{lllll}44.7 & 20095 & 54.6 & 2023 & \text { SM. }\end{array}$

$\begin{array}{lllll}44.7 & 20415 & 47.1 & 8545 & \text { T.B. }\end{array}$

$\begin{array}{lllll}44.7 & 20575 & 47.2 & 8404 & \text { T.B. } \\ 44.7 & 20268 & 46.8 & 9904 & \text { T.B. }\end{array}$

\begin{tabular}{|c|c|c|c|c|}
\hline & \multicolumn{3}{|c|}{$\begin{array}{l}\text { WORKING FLUID: } R-1 \\
G=229.85 \mathrm{~kg} / 8^{*} \mathrm{~m}^{n}\end{array}$} & $\begin{array}{r}\mathrm{R}-11 \\
\mathrm{~g}^{\star} \mathrm{m}^{\wedge} 2 \\
8 \mathrm{kPa} \\
0.06\end{array}$ \\
\hline & $\frac{q^{\prime \prime}}{\left(w^{\prime} / m^{\wedge} 2\right)}$ & $T w$ & $\begin{array}{c}h \\
.\end{array}$ & SURF \\
\hline 44 & $\begin{array}{c}{\left[\mathrm{W} / \mathrm{m}^{2} \mathrm{~L}\right]} \\
30990\end{array}$ & $\begin{array}{l}{[C]} \\
48.7\end{array}$ & {$\left[\begin{array}{c}{[w / m} \\
6653\end{array}\right.$} & $\begin{array}{l}\text { TYPE } \\
\text { H.F. }\end{array}$ \\
\hline 4.7 & 30654 & 48.5 & 8208 & H.F. \\
\hline & 298 & 47.8 & 9641 & H.F. \\
\hline 44.7 & 30586 & 56.9 & 2523 & \\
\hline & 29635 & 56.8 & 2461 & \\
\hline 44 & 30321 & 48.2 & 8614 & T.B. \\
\hline & 30470 & 48.0 & 9203 & T.B. \\
\hline 44.7 & 30052 & 47.4 & 11416 & T.B. \\
\hline
\end{tabular}

ROW $P \quad x$ in

\begin{tabular}{|c|c|c|c|c|c|c|c|}
\hline $\begin{array}{c}\text { ROW } \\
\neq\end{array}$ & $\stackrel{\mathrm{P}}{[\mathrm{kPa}]}$ & $\begin{array}{l}x i n \\
{[-]}\end{array}$ & $\begin{array}{l}\text { Tf } \\
{[C]}\end{array}$ & $\frac{q^{\prime \prime}}{\left[w / m^{\wedge} 2\right]}$ & $\begin{array}{l}T w \\
\text { [C] }\end{array}$ & $\left.\begin{array}{c}h \\
{\left[w / m^{\wedge} 2\right.}\end{array}\right]$ & $\begin{array}{l}\text { SURF } \\
\text { TYPE }\end{array}$ \\
\hline 1 & 207.9 & -.00 & 44.3 & 51628 & 49.7 & 9548 & H.F. \\
\hline 3 & 207.1 & 0.01 & 44.8 & 50827 & 49.6 & 10698 & H.F. \\
\hline 5 & 206.3 & 0.03 & 44.8 & 49869 & 48.8 & 12401 & H.F. \\
\hline 7 & 205.4 & 0.04 & 44.8 & 51127 & 59.6 & 3464 & SM. \\
\hline 9 & 204.6 & 0.06 & 44.8 & 49655 & 59.6 & 3364 & SM. \\
\hline 11 & 203.8 & 0.07 & 4.8 & 50850 & 50.4 & 9143 & \\
\hline 13 & 203.0 & 0.09 & 4.8 & 50834 & 50.0 & 9747 & T.B. \\
\hline 15 & 202.1 & 0.10 & 44. & 50522 & 48.9 & 12443 & T.B. \\
\hline
\end{tabular}

RUN NUMBER: 442

$\mathrm{p} / \mathrm{d}=1.5$

$\mathrm{Pin}=207.78 \mathrm{kPa}$

$\operatorname{xin}=-.00$

WORKING FLUID: $R-11$

$G=228.85 \mathrm{~kg} / \mathrm{s}^{*} \mathrm{~m}^{\wedge} 2$

DELTA $P$ total $=6.18 \mathrm{kPa}$

$\begin{array}{rcc}\text { ROW } & \text { P } & \text { Xin } \\ 7 & {[\mathrm{kPa}]} & {[-]} \\ 1 & 207.4 & -.00 \\ 3 & 206.5 & 0.01 \\ 5 & 205.7 & 0.03 \\ 7 & 204.9 & 0.05 \\ 9 & 204.1 & 0.07 \\ 11 & 203.3 & 0.08 \\ 13 & 202.5 & 0.10 \\ 15 & 201.6 & 0.12\end{array}$

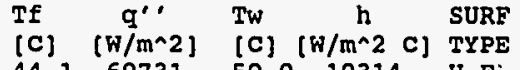

$44.1 \quad 6073150.0 \quad 10314$ H.F :

$44.759583 \quad 49.7 \quad 11940$ H.F.

$\begin{array}{rrrrr}44.7 & 58662 & 48.9 & 13909 & \text { H.F. } \\ 44.7 & 59870 & 60.2 & 3874 & \text { SM. }\end{array}$

$44.758180 \quad 60.2 \quad 3766 \quad$ SM.

$\begin{array}{lllll}44.7 & 59482 & 50.8 & 9842 & \text { T.B }\end{array}$

$\begin{array}{lllll}44.7 & 59505 & 50.5 & 10266 & \text { T.B. } \\ 44.7 & 59312 & 49.3 & 12980 & \text { T.B. }\end{array}$ 


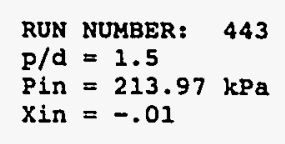

$\begin{array}{ccc}\text { ROW } & P & X \text { in } \\ \neq & {[\mathrm{kPa}]} & {[-]} \\ 1 & 213.6 & -.01 \\ 3 & 212.7 & 0.01 \\ 5 & 211.9 & 0.03 \\ 7 & 211.1 & 0.05 \\ 9 & 210.2 & 0.07 \\ 11 & 209.4 & 0.10 \\ 13 & 208.6 & 0.12 \\ 15 & 207.8 & 0.14\end{array}$

RUN NUMBER: 444

$\mathrm{p} / \mathrm{d}=1.5$

Pin $=214.39 \mathrm{kPa}$

$\begin{array}{rcc}\text { ROW } & \text { P } & X \text { in } \\ * & {[\mathrm{kPa}]} & {[-]} \\ 1 & 214.0 & -.01 \\ 3 & 213.1 & 0.01 \\ 5 & 212.3 & 0.04 \\ 7 & 211.5 & 0.06 \\ 9 & 210.6 & 0.09 \\ 11 & 209.8 & 0.11 \\ 13 & 209.0 & 0.14 \\ 15 & 208.1 & 0.16\end{array}$

RUN NUMBER: 455

$\mathrm{p} / \mathrm{d}=1.5$

Pin $=202.48 \mathrm{kPa}$

$x$ in $=0.01$

ROW $\mathrm{p} \quad \mathrm{X}$ in

\begin{tabular}{|c|c|c|c|c|c|c|}
\hline $\begin{array}{c}\mathrm{P} \\
{[\mathrm{kPa}]}\end{array}$ & $x$ in & Tf & $q^{\prime \prime \prime}$ & $T w$ & & $\begin{array}{l}\text { SUY } \\
\text { TYI }\end{array}$ \\
\hline [kPa] & & [C] & {$\left[\mathrm{w} / \mathrm{m}^{\wedge} 2\right]$} & (c) & $1 / m^{\wedge} 2 \quad c \mid$ & \\
\hline $\begin{array}{l}202, \\
201 .\end{array}$ & 0.01 & 44.1 & 5292 & .7 & 3175 & \\
\hline 200. & 0.0 & 43 & 521 & & 2907 & \\
\hline 199.3 & 0.01 & 43.7 & 5417 & & 1350 & \\
\hline & 0.6 & 13 & 5215 & 47. & 1377 & \\
\hline 197.5 & 0.0 & & 5234 & 45.0 & 3957 & \\
\hline & & 3.7 & 5249 & 44.9 & 4331 & \\
\hline
\end{tabular}
$G=225.38 \mathrm{~kg} / \mathrm{s}^{*} \mathrm{~m}^{\wedge}$ DELTA $\mathrm{G}=224.21 \mathrm{~kg} / \mathrm{s}^{\star} \mathrm{m}^{\wedge}$ Xout $=0.17$

\begin{tabular}{|c|c|c|c|c|}
\hline c] & $\underset{[W / m \wedge 2]}{q^{\prime \prime}}$ & $\begin{array}{l}T w \\
\text { [C] }\end{array}$ & 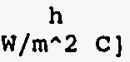 & \\
\hline 4.7 & & 51.9 & 11425 & \\
\hline $5.12 x-1$ & 810 & 51.7 & 13512 & \\
\hline 8 & 795 & & 161 & \\
\hline 5. & 805 & .5 & 4827 & \\
\hline & & & & \\
\hline & 80476 & .6 & 10240 & \\
\hline & & 3.2 & 10826 & \\
\hline
\end{tabular}

RUN NUMBER: 454

$\mathrm{P} / \mathrm{d}=1.5$ $1=6.2 \mathrm{kPa}$
Xout $=0.15$

\begin{tabular}{|c|c|c|c|c|}
\hline $\begin{array}{l}\text { Tf } \\
\text { ICl }\end{array}$ & $\stackrel{q^{\prime \prime}}{\left(w / m^{\wedge} 2\right]}$ & Tw & $\stackrel{h}{W / m^{\wedge} 2} C_{1}$ & $\begin{array}{l}\text { SUR: } \\
\text { TYP }\end{array}$ \\
\hline 44.5 & 72317 & 51.5 & 10379 & \\
\hline 45.7 & 71136 & 51.3 & 12680 & \\
\hline 45.7 & 69894 & 50.3 & 15135 & \\
\hline 45.7 & 71318 & 61.9 & 4410 & \\
\hline 45.7 & 69328 & 61.9 & 4295 & \\
\hline 15. & 70473 & 52.7 & 10037 & \\
\hline 15.7 & 70671 & 52.5 & 10438 & \\
\hline 15.7 & 70195 & 51.2 & 12828 & \\
\hline
\end{tabular}

$45.7 \quad 70195$
Row $P$ in

* [kPa] [-]

$\begin{array}{lll}1 & 202.5 & 0.01 \\ 3 & 201.5 & 0.01\end{array}$

5 200.7 0.01

$\begin{array}{lll}7 & 199.8 & 0.01\end{array}$

$\begin{array}{lll}9 & 198.9 & 0.01 \\ 11 & 198.1 & 0.02\end{array}$

$11 \quad 198.1 \quad 0.02$

$\begin{array}{lll}15 & 196.3 & 0.02\end{array}$
$\mathrm{Pin}=202.92 \mathrm{kPa}$

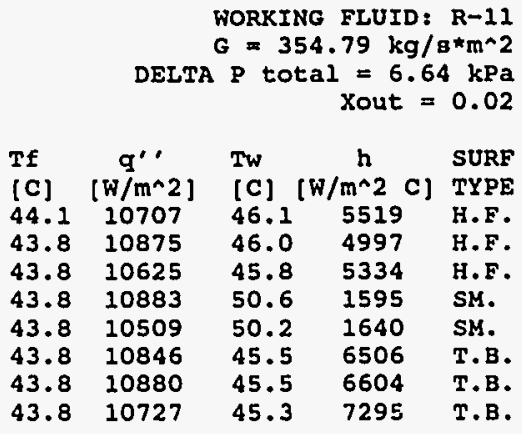

RUN NUMBER: 447

$\mathrm{p} / \mathrm{d}=1.5$

Pin $=204.47 \mathrm{kPa}$ $x$ in $=0.00$

ROW $\begin{array}{cc}\mathrm{P} & \mathrm{xin} \\ \text { \# }[\mathrm{kPa}] & {[-]}\end{array}$

$204.0 \quad 0.00$

$\begin{array}{lll}202.9 & 0.01\end{array}$

$\begin{array}{lll}5 & 202.0 & 0.01 \\ 7 & 201.1 & 0.01\end{array}$

7201.10 .01

$\begin{array}{rrr}9 & 200.1 & 0.01 \\ 11 & 199.2 & 0.02\end{array}$

$\begin{array}{lll}11 & 199.2 & 0.02 \\ 13 & 198.3 & 0.02\end{array}$

$\begin{array}{lll}15 & 197.2 & 0.02\end{array}$

\section{$\rightarrow 11$ Pa \\ URF \\ F. \\ . \\ .}

WORKING FLUID: R-11 $G=353.28 \mathrm{~kg} / \mathrm{g}^{*} \mathrm{~m} \wedge 2$
DELTA P total $=7.25 \mathrm{kPa}$ Xout $=0.02$
X

\begin{tabular}{|c|c|c|c|c|}
\hline $\begin{array}{l}\text { Tf } \\
{[\mathrm{C}]}\end{array}$ & $\underset{\left[w / m^{\wedge} 2\right]}{q{ }^{\prime \prime}}$ & $\begin{array}{l}\text { Tw } \\
\text { [C] }\end{array}$ & $\begin{array}{cc}h \\
/ m^{\wedge} 2 & C]\end{array}$ & $\begin{array}{l}\text { SURF } \\
\text { TYPE }\end{array}$ \\
\hline 44.0 & 20669 & 46.7 & 7815 & H.F. \\
\hline 44.0 & 20521 & 46.6 & 7714 & H.F. \\
\hline 44.0 & 20047 & 46.3 & 8644 & H.F. \\
\hline 44.0 & 20460 & 54.0 & 2041 & SM. \\
\hline 44.0 & 19762 & 53.6 & 2045 & SM. \\
\hline 44.0 & 20322 & 46.6 & 7708 & T.B. \\
\hline $\begin{array}{l}44.0 \\
44.0\end{array}$ & $\begin{array}{l}20447 \\
20066\end{array}$ & $\begin{array}{l}46.3 \\
46.0\end{array}$ & 8654 & T.B. \\
\hline
\end{tabular}

RUN NUMBER: 448

$\mathrm{p} / \mathrm{d}=1.5$

$.68 \mathrm{kPa}$

$\operatorname{xin}=0.00$

WORKING FLUID: R-11 $G=351.06 \mathrm{~kg} / \mathrm{s}^{\star} \mathrm{m}^{\wedge} 2$ $\begin{aligned} \text { DELTA P total } & =7.09 \mathrm{kPa} \\ \text { xout } & =0.03\end{aligned}$

\begin{tabular}{|c|c|c|c|c|c|c|c|}
\hline ROW & $\mathbf{p}$ & $x$ in & Tf & $q^{\prime \prime}$ & $T w$ & h & SURF \\
\hline$\neq$ & [ $\mathrm{kPa}]$ & {$[-]$} & (C) & {$\left[\mathrm{w} / \mathrm{m}^{\wedge} 2\right]$} & (C) & $\left(\mathrm{w} / \mathrm{m}^{\wedge} 2 \quad \mathrm{C}\right)$ & TYPE \\
\hline 1 & $209 . \dot{2}$ & 0.00 & 44.7 & 30752 & 48.2 & 8763 & H.F. \\
\hline 3 & 208.2 & 0.01 & 44.9 & 30462 & 48.2 & 9195 & H.F. \\
\hline 5 & 207.3 & 0.0 & & 29761 & 47.7 & 10397 & \\
\hline 7 & 206.4 & 0.02 & 44.9 & 30715 & 57.3 & 2471 & SM. \\
\hline 9 & 205.4 & 0.02 & & 29715 & & 2414 & SH. \\
\hline 11 & 204.5 & 0.02 & 44.9 & 30208 & 48.4 & 8539 & T.B. \\
\hline 13 & 203.6 & 0.02 & & 30388 & 48.2 & 9147 & \\
\hline 15 & 202.6 & 0.03 & 44.9 & 29853 & 47.6 & 10795 & B B \\
\hline
\end{tabular}




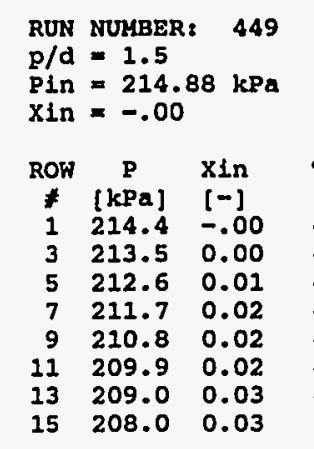

RUN NUMBER: 450
P/d $=1.5$
Pin $=221.23 \mathrm{kPa}$
Xin $=-.00$

ROW $p \quad x$ in

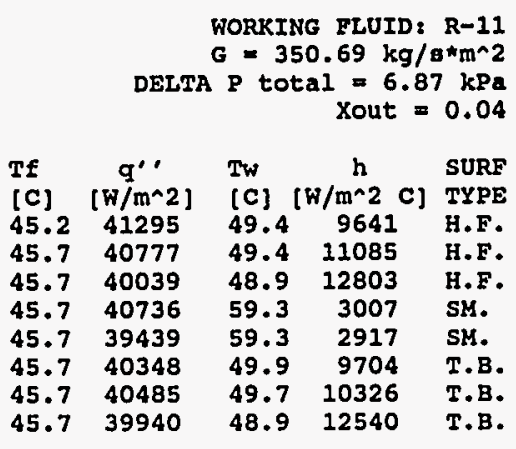

$\begin{array}{lllll}45.7 & 39940 & 48.9 & 12540 & \text { T.B. }\end{array}$
RUN NUMBER: 452 $\mathrm{p} / \mathrm{d}=1.5$

Pin $=239.95 \mathrm{kPa}$

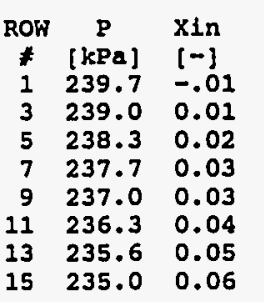

RUN NUMBER: 453 $\mathrm{p} / \mathrm{d}=1.5$

$\operatorname{Pin}=251.67 \mathrm{kPa}$ $x$ in $=-.00$

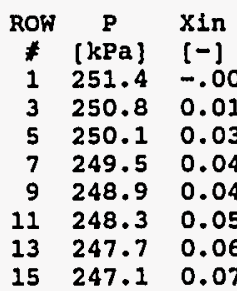

\begin{tabular}{rcc}
\multicolumn{1}{c}{ ROW } & P & Xin \\
$*$ & {$[k P a]$} & {$[-]$} \\
1 & 251.4 & -.00 \\
3 & 250.8 & 0.01 \\
5 & 250.1 & 0.03 \\
7 & 249.5 & 0.04 \\
9 & 248.9 & 0.04 \\
11 & 248.3 & 0.05 \\
13 & 247.7 & 0.06 \\
15 & 247.1 & 0.07
\end{tabular} DELTA $=348.67 \mathrm{~kg} / \mathrm{s} * \mathrm{~m} 2$ Xout $=0.05$

\begin{tabular}{|c|c|c|c|c|}
\hline & $\begin{array}{c}q^{\prime \prime} \\
{\left[\mathrm{W} / \mathrm{m}^{\wedge} 2\right]}\end{array}$ & $\begin{array}{l}\text { Tw } \\
\text { (c) }\end{array}$ & $\left.\stackrel{h}{W / m^{\wedge} 2} c\right)$ & $\begin{array}{l}\text { SURF } \\
\text { TYPE }\end{array}$ \\
\hline .2 & 51624 & 51.3 & 10014 & B.F. \\
\hline & 50808 & 51.3 & 11307 & \\
\hline . & 49942 & 50.7 & 12930 & \\
\hline & 50922 & 61.5 & 3474 & \\
\hline 5.8 & 49357 & 61.5 & 3360 & \\
\hline & 50357 & & 9694 & \\
\hline & 50513 & 51.8 & 10165 & \\
\hline & 501 & 51.0 & 12097 & \\
\hline
\end{tabular}

RUN NUMBER: 451 $\mathrm{p} / \mathrm{d}=1.5$

Pin $=229.51 \mathrm{kPa}$

$\operatorname{xin}=-.01$

$\begin{array}{rcc}\text { ROW } & \text { P } & \text { Xin } \\ * & {[\mathrm{kPa}]} & {[-]} \\ 1 & 229.1 & -.01 \\ 3 & 228.3 & 0.00 \\ 5 & 227.5 & 0.02 \\ 7 & 226.7 & 0.02 \\ 9 & 225.9 & 0.02 \\ 11 & 225.1 & 0.03 \\ 13 & 224.3 & 0.04 \\ 15 & 223.5 & 0.05\end{array}$

\begin{tabular}{|c|c|c|c|c|}
\hline \multirow{10}{*}{$\begin{array}{l}T f \\
{[C]} \\
47.1 \\
48.1 \\
48.2 \\
48.2 \\
48.2 \\
48.2 \\
48.2\end{array}$} & DELT & \multicolumn{3}{|c|}{$\begin{array}{r}\text { WORKING FLUID: R-11 } \\
G=346.24 \mathrm{~kg} / \mathrm{B}^{\star} \mathrm{m}^{\wedge} 2 \\
\mathrm{P} \text { total }=6.06 \mathrm{kPa} \\
\text { Xout }=0.05\end{array}$} \\
\hline & $\frac{q^{\prime \prime}}{\left[w / m^{\wedge} 2\right]}$ & $\begin{array}{l}T w \\
{[C]}\end{array}$ & $\left.\begin{array}{c}h \\
{\left[W / m^{\wedge} 2\right.}\end{array}\right]$ & $\begin{array}{l}\text { SURF } \\
\text { TYPE }\end{array}$ \\
\hline & 62196 & 53.3 & 10006 & H.F. \\
\hline & 61184 & & 1176 & \\
\hline & & & 135 & \\
\hline & 61470 & 63 & 4023 & \\
\hline & & & & \\
\hline & 60782 & 54. & 9863 & T.B. \\
\hline & & & & \\
\hline & & & & \\
\hline
\end{tabular}

RUN NUMBER: 475

$\mathrm{p} / \mathrm{d}=1.5$

$\mathrm{Pin}=535.23 \mathrm{kPa}$

$\begin{array}{rcl}\text { ROW } & \text { P } & \text { Xin } \\ \mathbf{f} & {[\mathrm{kPa}]} & {[-]} \\ 1 & 534.8 & 0.08 \\ 3 & 533.9 & 0.08 \\ 5 & 533.1 & 0.09 \\ 7 & 532.2 & 0.10 \\ 9 & 531.4 & 0.11 \\ 11 & 530.6 & 0.11 \\ 13 & 529.9 & 0.12 \\ 15 & 529.1 & 0.13\end{array}$

$\mathrm{Xin}=0.08$

WORKING FLUID: $R-11$ DELTA P total $=4.99 \mathrm{kPa}$ Xout $=0.07$

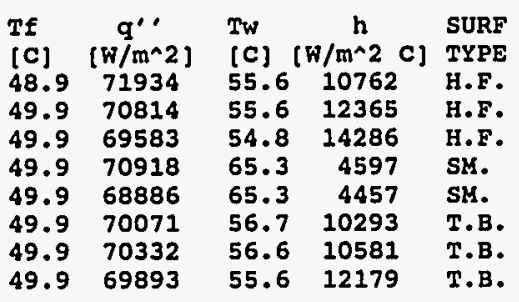

Tf $q^{\prime \prime}$ Tw $h$ SURF

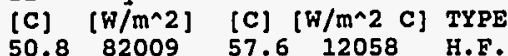

$\begin{array}{lllll}50.8 & 82009 & 57.6 & 12058 & \text { H.F. } \\ 51.6 & 80868 & 57.7 & 13391 & \text { H.F. }\end{array}$

$\begin{array}{lllll}51.6 & 80868 & 57.7 & 13391 & \text { H.F. } \\ 51.6 & 79405 & 56.7 & 15629 & \text { H.F. }\end{array}$

$\begin{array}{rrrrr}51.6 & 79405 & 56.7 & 15629 & \text { H.F. } \\ 51.6 & 80813 & 67.1 & 5234 & \text { SM. }\end{array}$

$51.6 \quad 78512 \quad 67.1 \quad 5093 \quad S M$.

$\begin{array}{lllll}51.6 & 80150 & 59.1 & 10726 & \text { T.B. }\end{array}$

$\begin{array}{lllll}51.6 & 80626 & 58.8 & 11215 & \text { T.B. }\end{array}$

$\begin{array}{lllll}51.6 & 79905 & 57.9 & 12729 & \text { T.B. }\end{array}$ $G=52.04 \mathrm{~kg} / \mathrm{g}^{\star} \mathrm{m}^{\wedge} 2$ $\begin{aligned} \text { DELTA P total } & =6.1 \mathrm{kPa} \\ \text { Xout } & =0.13\end{aligned}$

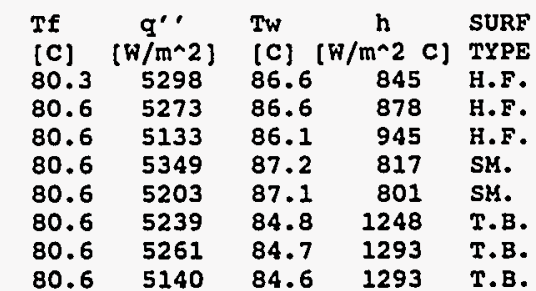

WORKING FLUID: $\mathrm{R}-11$ 
RUN NUMBER: 484 $\mathrm{p} / \mathrm{d}=1.5$

Pin $=600.67 \mathrm{kPa}$

$\mathrm{Xin}=0.01$

$\begin{array}{rcc}\text { ROW } & \text { P } & \text { Xin } \\ \# & {[\mathrm{kPa}]} & {[-]} \\ 1 & 600.2 & 0.01 \\ 3 & 599.0 & 0.02 \\ 5 & 598.1 & 0.03 \\ 7 & 597.1 & 0.05 \\ 9 & 596.1 & 0.06 \\ 11 & 595.2 & 0.08 \\ 13 & 594.3 & 0.09 \\ 15 & 593.4 & 0.11\end{array}$

RUN NUMBER: 482 $\mathrm{p} / \mathrm{d}=1.5$

$\mathrm{Pin}=609.43 \mathrm{kPa}$ $x \ln =-.00$

$\begin{array}{rcc}\text { ROW } & \text { P } & \text { Xin } \\ * & {[\mathrm{kPa}]} & {[-]} \\ 1 & 608.9 & -.00 \\ 3 & 607.8 & 0.03 \\ 5 & 606.9 & 0.06 \\ 7 & 605.9 & 0.09 \\ 9 & 604.9 & 0.13 \\ 11 & 604.0 & 0.16 \\ 13 & 603.1 & 0.19 \\ 15 & 602.2 & 0.22\end{array}$

\begin{tabular}{|c|c|c|c|c|}
\hline $\begin{array}{l}\mathrm{Tf} \\
{[\mathrm{C}]}\end{array}$ & $\underset{\left[\mathrm{w} / \mathrm{m}^{\prime \prime} 2\right]}{q^{\prime \prime}}$ & $\begin{array}{l}\text { Tw } \\
\text { [C] } 1\end{array}$ & $\underset{W / m^{\wedge} 2}{h} \quad C_{J}$ & $\begin{array}{l}\text { SURF } \\
\text { TYPE }\end{array}$ \\
\hline $\begin{array}{l}84.8 \\
85.9\end{array}$ & $\begin{array}{l}10437 \\
10386\end{array}$ & $\begin{array}{l}86.7 \\
86.9\end{array}$ & $\begin{array}{l}5528 \\
9929\end{array}$ & $\begin{array}{l}\text { H.F. } \\
\text { H.F. }\end{array}$ \\
\hline 85.8 & 10155 & 86.8 & 10077 & \\
\hline 85.8 & 10469 & 89.7 & $\begin{array}{l}2625 \\
2522\end{array}$ & $\begin{array}{l}\text { SM. } \\
\text { SM. }\end{array}$ \\
\hline 35.6 & $\begin{array}{l}1018 \\
1022\end{array}$ & 87.3 & $\begin{array}{l}5984 \\
6812\end{array}$ & \\
\hline & & & & \\
\hline
\end{tabular}

WORKING FLUID: R-11

$\pi m-2$

DELTA $P$ tOtal $=7.32 \mathrm{kPa}$ xout $=0.11$

$\mathrm{p} / \mathrm{d}=1.5$

p/d $=1.5$

$\mathrm{Pin}=603.16$
$\mathrm{Xin}=-.01$

$\begin{array}{ccc}\text { ROW } & \text { P } & \text { Xin } \\ * & {[\mathrm{kPa})} & {[-]} \\ 1 & 602.7 & -.01 \\ 3 & 601.6 & 0.05 \\ 5 & 600.7 & 0.11 \\ 7 & 599.7 & 0.17 \\ 9 & 598.7 & 0.23 \\ 11 & 597.8 & 0.30 \\ 13 & 596.8 & 0.36 \\ 15 & 595.8 & 0.42\end{array}$

RUN NUMBER: 479 $\mathrm{p} / \mathrm{d}=1.5$

Pin $=611.59 \mathrm{kPa}$ $x$ in $=0.00$

DEL $=52.07 \mathrm{~kg} / \mathrm{g}^{*} \mathrm{~m}^{2} 2$ xout $=0.24$

\begin{tabular}{|c|c|c|c|c|}
\hline & $\underset{[w / m \wedge 2]}{q^{\prime \prime}}$ & $\begin{array}{l}\text { Tw } \\
{[C]}\end{array}$ & $\left.\stackrel{\mathrm{h}}{/ \mathrm{m}^{\wedge}} \quad \mathrm{c}\right]$ & \\
\hline 84.9 & 21901 & & 6679 & \\
\hline & 217 & 88.7 & 102 & \\
\hline & & & 100 & \\
\hline & & & 3537 & \\
\hline & & & 33 & \\
\hline & & & & \\
\hline & 21222 & 8.6 & 8753 & \\
\hline
\end{tabular}

RUN NUMBER: 481 $\mathrm{p} / \mathrm{d}=1.5$

$\mathrm{Pin}=587.75 \mathrm{kPa}$ $x_{\text {in }}=0.90$

WORKING FLUID: R-11

$\begin{aligned} \text { DELTA P total } & =7.92 \mathrm{kPa} \\ \text { Xout } & =1.20\end{aligned}$

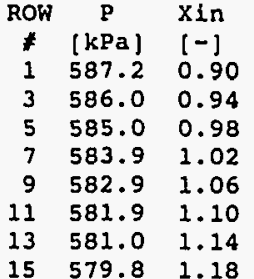

\begin{tabular}{|c|c|c|c|c|}
\hline $\begin{array}{l}\mathrm{Tf} \\
{[\mathrm{C}]}\end{array}$ & $\underset{[w / m \wedge 2]}{q^{\prime \prime}}$ & & $\begin{array}{c}h \\
W / m^{\wedge} 2\end{array}$ & SURF \\
\hline $\begin{array}{l}84.0 \\
84.9\end{array}$ & $\begin{array}{l}30360 \\
30020\end{array}$ & $\begin{array}{l}87.8 \\
87.9\end{array}$ & & \\
\hline & & & & \\
\hline .8 & 300 & & 4516 & \\
\hline & & & & \\
\hline & 298 & & & \\
\hline & & & 8338 & \\
\hline
\end{tabular}

\begin{tabular}{rcl}
\multicolumn{1}{c}{ ROW } & P & Xin \\
$*$ & {$[\mathrm{kPa}]$} & {$[-]$} \\
1 & 611.0 & 0.00 \\
3 & 609.9 & 0.08 \\
5 & 608.8 & 0.15 \\
7 & 607.9 & 0.22 \\
9 & 607.1 & 0.30 \\
11 & 606.3 & 0.37 \\
13 & 605.5 & 0.44 \\
15 & 604.7 & 0.51
\end{tabular}

RUN NUMBER: 478

$\mathrm{p} / \mathrm{d}=1.5$

Pin $=577.78 \mathrm{kPa}$

\begin{tabular}{rcl}
\multicolumn{1}{c}{ ROW } & $P$ & Xin \\
$*$ & {$[\mathrm{kPa})$} & {$[-]$} \\
1 & 577.2 & 0.02 \\
3 & 576.0 & 0.11 \\
5 & 574.9 & 0.19 \\
7 & 573.9 & 0.29 \\
9 & 573.0 & 0.38 \\
11 & 572.2 & 0.47 \\
13 & 571.4 & 0.56 \\
15 & 570.5 & 0.65
\end{tabular}

$15 \quad 570.5 \quad 0.65$ $\begin{array}{lll}15 & 579.8 & 1.18\end{array}$

29540

$87.79216 \quad$ T.B.
WORKING FLUID: R-12

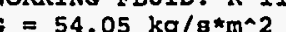
DELTA $P$ total $\approx 7.38 \mathrm{kPa}$ Xout $=0.45$

\begin{tabular}{|c|c|c|c|c|}
\hline $\begin{array}{l}T f \\
{[C]}\end{array}$ & $\underset{\left[W / m^{\wedge} 2\right]}{q^{\prime}}$ & $\begin{array}{l}\text { Tw } \\
\text { [C] }\end{array}$ & {$\left[\begin{array}{lll}W / m^{\wedge} 2 & c\end{array}\right]$} & $\begin{array}{l}\text { SURF } \\
\text { TYPE }\end{array}$ \\
\hline $\begin{array}{l}83.6 \\
86.1\end{array}$ & $\begin{array}{l}43696 \\
43236\end{array}$ & $\begin{array}{l}88.3 \\
89.7\end{array}$ & $\begin{array}{r}9307 \\
12083\end{array}$ & $\begin{array}{l}\text { H.F. } \\
\text { H.F. }\end{array}$ \\
\hline 6. & 42450 & & 12702 & \\
\hline 6.0 & 43231 & 94.6 & 4987 & \\
\hline $\begin{array}{l}85.9 \\
85.8\end{array}$ & $\begin{array}{l}41866 \\
43092\end{array}$ & 94.8 & $\begin{array}{l}4712 \\
9380\end{array}$ & SM. \\
\hline & & & & \\
\hline & & & & \\
\hline
\end{tabular}




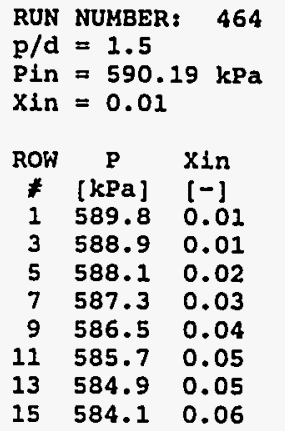

$\begin{array}{lll}15 & 584.1 & 0.06\end{array}$

RUN NUMBER: 463 $\mathrm{p} / \mathrm{d}=1.5$ $\mathrm{Pin}=598.6 \mathrm{kPa}$
$\mathrm{Xin}=-.00$

$\begin{array}{ccc}\text { ROW } & P & \text { Xin } \\ * & {[\mathrm{kPa}]} & {[-]} \\ 1 & 598.1 & -.00 \\ 3 & 597.0 & 0.01 \\ 5 & 596.0 & 0.03 \\ 7 & 595.0 & 0.04 \\ 9 & 594.1 & 0.06 \\ 11 & 593.1 & 0.08 \\ 13 & 592.3 & 0.09 \\ 15 & 591.3 & 0.11\end{array}$

RUN NUMBER: 457 $\mathrm{p} / \mathrm{d}=1.5$ $P$ in $=577.41 \mathrm{kPa}$
$\mathrm{Xin}=0.01$

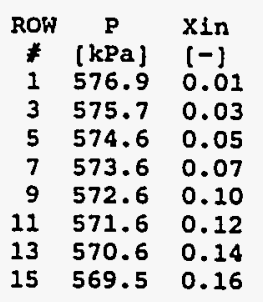

WORKING FLUID: $\mathrm{R}-11$ $G=98.53 \mathrm{~kg} / \mathrm{g}^{*} \mathrm{~m}^{\wedge} 2$ DELTA P total $=6.07 \mathrm{kPa}$ Xout $=0.07$

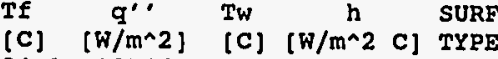

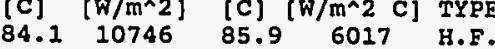

$\begin{array}{lllrr}84.1 & 10746 & 85.9 & 6017 & \text { H.F. } \\ 84.8 & 10694 & 85.8 & 10504 & \text { H.F. }\end{array}$

$\begin{array}{lllll}84.8 & 10456 & 85.8 & 10564 & \text { H.F }\end{array}$

$\begin{array}{lllll}84.8 & 10778 & 88.8 & 2698 & \text { SM. }\end{array}$

$\begin{array}{lllll}84.8 & 10376 & 88.9 & 2542 & \text { SM. }\end{array}$

$\begin{array}{lllll}84.8 & 10530 & 86.2 & 7520 & \text { T.B. }\end{array}$

86.18133 T.B.

WORKING FLUID: $R-11$ $G=98.87 \mathrm{~kg} / \mathrm{s}^{\star \mathrm{m}^{\wedge} 2}$ $G=98.87 \mathrm{~kg} / \mathrm{g}^{\star} \mathrm{m}^{\wedge} 2$
DELTA $P$ total $=7.27 \mathrm{kPa}$ Xout $=0.11$

\begin{tabular}{|c|c|c|c|c|}
\hline [C] & $\frac{q^{\prime \prime}}{\left(w / m^{\wedge} 2\right]}$ & $\begin{array}{l}T w \\
{[C]}\end{array}$ & 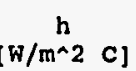 & $\begin{array}{l}\text { SURE } \\
\text { TYPE }\end{array}$ \\
\hline 84.1 & 20652 & 87.3 & 6472 & \\
\hline 5.3 & 20548 & 87.3 & 10230 & \\
\hline 3 & 20110 & 87.2 & 10723 & \\
\hline & 20508 & 91.0 & 3608 & \\
\hline & 19761 & 91.0 & 3492 & \\
\hline & 1991 & 38.2 & 7046 & \\
\hline & 20015 & 37.8 & 8021 & \\
\hline & 19666 & 87.4 & 9370 & \\
\hline
\end{tabular}

85.320015 $\begin{array}{lllll}84.8 & 10483 & 86.5 & 6085 & \text { T.B. }\end{array}$
RUN NUMBER: 477

$\mathrm{P} / \mathrm{d}=1.5$

in $=585.91 \mathrm{kPa}$

ROW $P$ Pin

$\begin{array}{ccl}\text { * } & \text { P } & \text { XPa] } \\ 1 & 585.4 & {[-]} \\ 3 & 58.00\end{array}$

$\begin{array}{lll}1 & 585.4 & 0.00 \\ 3 & 584.2 & 0.10\end{array}$

$\begin{array}{lll}5 & 583.2 & 0.19\end{array}$

$\begin{array}{lll}582.2 & 0.29\end{array}$

$\begin{array}{lll}9 & 581.2 & 0.39\end{array}$

$\begin{array}{lll}11 & 580.3 & 0.49\end{array}$

$\begin{array}{lll}13 & 579.3 & 0.58\end{array}$

$\begin{array}{lll}15 & 578.3 & 0.68\end{array}$

RUN NUMBER: 476

$\mathrm{p} / \mathrm{d}=1.5$

$P_{\text {in }}=600.4 \mathrm{kPa}$

$\sin =0.00$

$\begin{array}{rcl}\text { ROW } & \begin{array}{c}P \\ \text { * }\end{array} & \text { Xin } \\ 1 & 599.9 & {[-]} \\ 3 & 598.7 & 0.00 \\ 5 & 597.7 & 0.10 \\ 7 & 596.6 & 0.29 \\ 9 & 595.6 & 0.40 \\ 11 & 594.7 & 0.50 \\ 13 & 593.9 & 0.60 \\ 15 & 592.9 & 0.69\end{array}$

RUN NUMBER: 456 $\mathrm{p} / \mathrm{d}=1.5$

Pin $=591.5 \mathrm{kP}$

$\mathrm{x}$ in $=0.01$

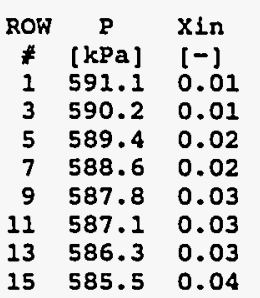

WORKING FLUID: R-11

$G=52.86 \mathrm{~kg} / \mathrm{s}^{\star} \mathrm{m}^{\wedge} 2$

DELTA P total $=7.62 \mathrm{kPa}$

\begin{tabular}{|c|c|c|c|c|}
\hline is & $\stackrel{q}{q^{\prime}}$ & Tw & $\stackrel{h}{h}$ & $\begin{array}{l}\text { SURF } \\
\text { TYPE }\end{array}$ \\
\hline & 71738 & 89.8 & 11218 & H.F. \\
\hline & 70662 & 90.1 & 13399 & \\
\hline & 69393 & 89.7 & 14112 & H. \\
\hline & $\begin{array}{l}70763 \\
68696\end{array}$ & 95.5 & $\begin{array}{l}6563 \\
6653\end{array}$ & \\
\hline & $\begin{array}{l}68696 \\
69915\end{array}$ & $\begin{array}{l}94.9 \\
91.4\end{array}$ & $\begin{array}{r}6653 \\
10153\end{array}$ & $\begin{array}{l}\text { SM. } \\
\text { T. }\end{array}$ \\
\hline & 70337 & 91.3 & 10258 & \\
\hline & 69741 & 90.5 & 11492 & \\
\hline
\end{tabular}

$\begin{array}{llll} & 91.3 & 10258 & T . B\end{array}$ DEI Xout $=0.17$

\begin{tabular}{|c|c|c|c|c|}
\hline TI & $\frac{q^{\prime \prime}}{\left[w / m^{\wedge} 2\right]}$ & $\begin{array}{l}T w \\
\text { [C] }\end{array}$ & {$\left[W / m^{\wedge} 2 C\right]$} & $\begin{array}{l}\text { SURE } \\
\text { TYPE }\end{array}$ \\
\hline & 31262 & 87.9 & 6703 & H. \\
\hline 1.7 & 30912 & 86.8 & 10128 & н. \\
\hline & 302 & & 10999 & H. \\
\hline 3.7 & 30956 & 90.4 & 4602 & \\
\hline & 29932 & & 4357 & \\
\hline 3.7 & 30716 & 87.4 & 8397 & \\
\hline & & & 85 & \\
\hline & & 6.9 & 9403 & \\
\hline
\end{tabular}

WORKING FLUID: R-11 $G=52.15 \mathrm{~kg} / \mathrm{g}^{*} \mathrm{~m} \wedge 2$ DELTA $\mathrm{P}$ total $=7.48 \mathrm{kPa}$ xout $=0.83$

\begin{tabular}{|c|c|c|c|c|}
\hline Tf & $\begin{array}{c}q^{\prime \prime} \\
{\left[w / m^{\wedge} 2\right]}\end{array}$ & $\begin{array}{l}T w \\
{[C]}\end{array}$ & $\begin{array}{c}h \\
W / m^{\wedge} 2 \\
c]\end{array}$ & $\begin{array}{l}\text { SURF } \\
\text { TYPE }\end{array}$ \\
\hline & 81198 & 91.5 & 11231 & \\
\hline 85.9 & 80337 & 91.8 & 13663 & \\
\hline 5.8 & 78679 & 91.3 & 14303 & \\
\hline 5.7 & 80366 & 97.1 & 7057 & \\
\hline 5.7 & 79450 & 97.0 & 7008 & \\
\hline & 795 & 93.8 & 9732 & \\
\hline & & 93.5 & 10063 & \\
\hline & 79034 & 92.1 & 11902 & \\
\hline
\end{tabular}

85.5 79034 93.5 10063 T.B. 
RUN NUMBER: 458 $\mathrm{p} / \mathrm{d}=1.5$

$P$ in $=592.43 \mathrm{kPa}$

$\mathrm{xin}=-.01$

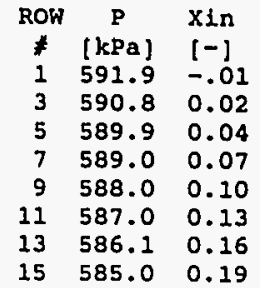

$15 \quad 585.0 \quad 0.19$

RUN NUMBER: 460 $\mathrm{p} / \mathrm{d}=1.5$

Pin $=600.63 \mathrm{kPa}$

$x_{\text {in }}=0.00$
WORKING FLUID: R-11

$\begin{aligned} \text { DELTA P total } & =7.41 \mathrm{kPa} \\ \text { Xout } & =0.21\end{aligned}$

\begin{tabular}{|c|c|c|c|c|}
\hline Tf & $\underset{\left[W / m^{\wedge} 2\right]}{q^{\prime}}$ & $\begin{array}{l}T w \\
{[C]}\end{array}$ & $\begin{array}{c}h \\
\left(W / m^{\wedge} 2\right.\end{array}$ & $\begin{array}{l}\text { SURF } \\
\text { TYPE }\end{array}$ \\
\hline 82.8 & 41193 & 88.1 & 7823 & $\begin{array}{l}\text { H.F. } \\
\text { H.F. }\end{array}$ \\
\hline 85.2 & 40759 & 88.4 & 12571 & H.F. \\
\hline 85.2 & 40019 & 88.4 & 12912 & H.F. \\
\hline 85.2 & 40750 & 93.4 & 4990 & SM. \\
\hline 5.1 & 39464 & 93.2 & 4871 & \\
\hline 85.0 & 40617 & 89.3 & 9456 & T.B. \\
\hline 85.0 & 40821 & 89.2 & 9584 & T.8. \\
\hline 34.9 & 40222 & 88.6 & 10989 & \\
\hline
\end{tabular}

RUN NUMBER: 461

$\mathrm{p} / \mathrm{d}=1.5$

in $=575.56 \mathrm{kPa}$

$\mathrm{xin}=0.00$

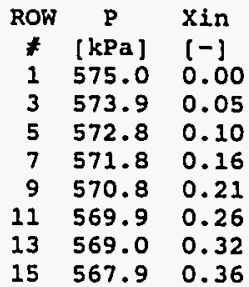

$15 \quad 567.90 .36$

RUN NUMBER: 462

$\mathrm{p} / \mathrm{d}=1.5$

Pin $=585.26 \mathrm{kPa}$

$x$ in $=0.00$

ROW $P$ xin

* [kPa] $1-]$

3 584.0 0.06

$\begin{array}{lll}5 & 583.2 & 0.12\end{array}$

$\begin{array}{lll}7 & 582.3 & 0.18\end{array}$

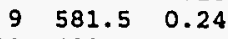

$\begin{array}{lll}11 & 580.7 & 0.30\end{array}$

$\begin{array}{lll}13 & 579.9 & 0.36\end{array}$

$\begin{array}{lll}15 & 579.1 & 0.42\end{array}$

$\begin{array}{rrrrrrrr}15 & 594.5 & 0.24 & 85.6 & 49835 & 90.7 & 9623 & \text { T.B. } \\ & 593.7 & 0.28 & 85.5 & 49616 & 90.0 & 11037 & T . B .\end{array}$

RUN NUMBER: 465

$\mathrm{p} / \mathrm{d}=1.5$

Pin $=566.55 \mathrm{kPa}$
$\mathrm{X}$ in $=0.02$

$\begin{array}{rcl}\text { ROW } & P & X \text { in } \\ * & {[\mathrm{kPa}]} & {[-]} \\ 1 & 566.1 & 0.02 \\ 3 & 565.2 & 0.06 \\ 5 & 564.4 & 0.11 \\ 7 & 563.6 & 0.15 \\ 9 & 562.8 & 0.20 \\ 11 & 562.0 & 0.25 \\ 13 & 561.3 & 0.29 \\ 15 & 560.5 & 0.33\end{array}$
WORKING FLUID: R-11 $G=98.13 \mathrm{~kg} / \mathrm{s}^{*} \mathrm{~m}^{\wedge} 2$ DELTA $P$ total $=6.04 \mathrm{kPa}$ Xout $=0.36$

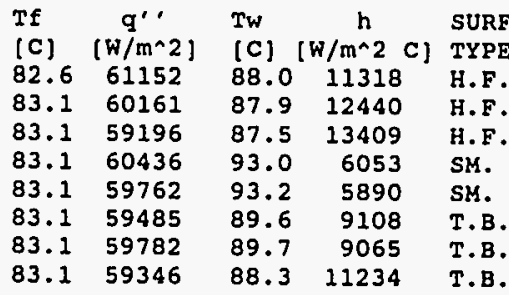

RUN NUMBER: 474 $\mathrm{p} / \mathrm{d}=1.5$

Pin $=585.84 \mathrm{kPa}$ $\mathrm{xin}=0.00$

WORKING FLUID: R- 11 $17.02 \mathrm{~kg} / \mathrm{g}^{\star} \mathrm{m}^{\wedge} 2$ DELTA total $=7.06 \mathrm{kPa}$ xout $=0.01$

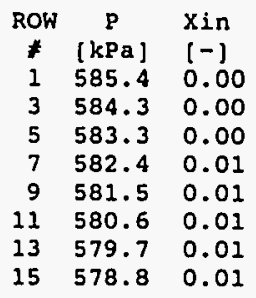

WORKING FLUID: R-11 $\begin{aligned} \text { DELTA P total } & =7.64 \mathrm{kPa} \\ \text { Xout } & =0.39\end{aligned}$

\begin{tabular}{|c|c|c|c|c|}
\hline $\begin{array}{l}\text { Tf } \\
\text { [c] }\end{array}$ & $\underset{\left[W / m^{\wedge} 2\right]}{q^{\prime \prime}}$ & $\begin{array}{l}T w \\
\text { (c) }\end{array}$ & $\begin{array}{c}h \\
\left(W / m^{\wedge} 2\right.\end{array}$ & $\begin{array}{l}\text { SURF } \\
\text { TYPE }\end{array}$ \\
\hline 82.6 & 71756 & 89.0 & 11273 & H.F. \\
\hline 84.1 & 70679 & 89.3 & 13460 & H.F. \\
\hline 84.0 & 69409 & 88.9 & 14258 & H.F. \\
\hline 33.9 & 70791 & 94.5 & 6688 & SM. \\
\hline 3.8 & 68722 & 94.4 & 6483 & SM. \\
\hline 13.8 & 69945 & 90.6 & 10266 & T.B. \\
\hline 3 . & 70368 & 90.5 & 10379 & T.B. \\
\hline 3. & 69770 & 89.5 & 11886 & T.B. \\
\hline
\end{tabular}

Tf $q^{\prime \prime}$ Tw $h$ SURF $83.381220 \quad 90.5\left(\mathrm{~W} / \mathrm{m}^{2} 2 \mathrm{C}\right)$ TYPE $84.480358 \quad 90.3 \quad 13720$ H.F. $\begin{array}{lllll}84.4 & 78700 & 89.9 & 14475 & \text { H.F. }\end{array}$ $84.479487 \quad 95.87025 \mathrm{SM}$. $\begin{array}{lllll}84.4 & 79550 & 92.6 & 9740 & \text { T.B. }\end{array}$ $\begin{array}{llllll}84.4 & 80134 & 92.4 & 10081 & \text { T.B. }\end{array}$ 84.47907591 .111913 T.B. 


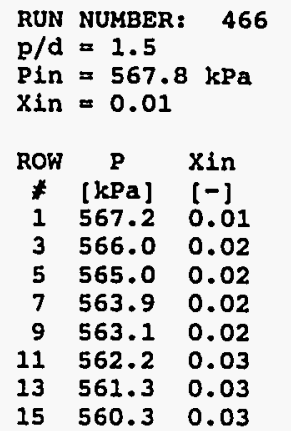

RUN NUMBER: 467

$\mathrm{p} / \mathrm{d}=1.5$
$\mathrm{P}$ in $=564.48 \mathrm{kPa}$

$\operatorname{xin}=0.00$

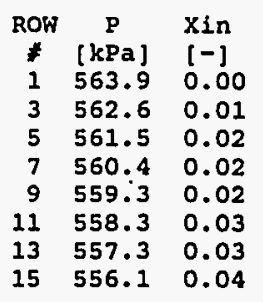

J
00
01
02
02
02
03
03
04

WORKING FLUID: R-11

$=210.79 \mathrm{~kg} / \mathrm{s}^{\star} \mathrm{m} \wedge$

DELTA $P$ total $=7.55 \mathrm{kPa}$ Xout $=0.03$

\begin{tabular}{|c|c|c|c|c|}
\hline $\begin{array}{l}T f \\
\text { (c) }\end{array}$ & $\frac{q^{\prime \prime}}{\left[w / m^{\wedge} 2\right]}$ & $\begin{array}{l}T w \\
\text { (c) }\end{array}$ & $\left.\underset{W / m^{\wedge} 2}{h} \quad c\right]$ & $\begin{array}{l}\text { SURF } \\
\text { TYPE }\end{array}$ \\
\hline 82.8 & $10819^{\circ}$ & 84.6 & 5838 & H.F. \\
\hline 3.2 & 10765 & 84.3 & 10033 & H.F. \\
\hline 83.3 & 10580 & 84.4 & 10231 & H.F. \\
\hline • & 10775 & 87.2 & 2760 & SM. \\
\hline 83.2 & 10583 & 87.1 & 2732 & SM. \\
\hline 3.2 & 10615 & & 7876 & T.B. \\
\hline 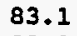 & 10646 & 84.4 & 8311 & T.B. \\
\hline 3. & 10527 & 84.1 & 9745 & \\
\hline
\end{tabular}

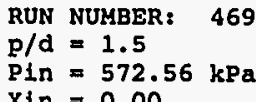

$\mathrm{Pin}=572.56$

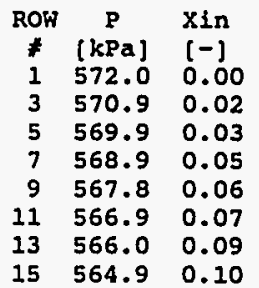

$\begin{array}{lll}13 & 566.0 & 0.09\end{array}$

RUN NUMBER: 470 $\mathrm{p} / \mathrm{d}=1.5$

Pin $=575.98 \mathrm{kPa}$

$\begin{array}{rcl}\text { ROW } & \text { P } & \text { Xin } \\ \mathbf{F} & {[\mathrm{kPa}]} & {[-]} \\ 1 & 575.4 & 0.00 \\ 3 & 574.3 & 0.02 \\ 5 & 573.2 & 0.04 \\ 7 & 572.2 & 0.05 \\ 9 & 571.3 & 0.06 \\ 11 & 570.4 & 0.07 \\ 13 & 569.5 & 0.09 \\ 15 & 568.4 & 0.10\end{array}$

WORKING FLUID: R-11 DELTA P total $=7.62 \mathrm{kPa}$ Xout $=0.11$

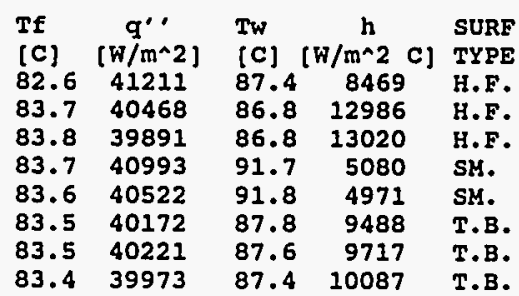

\begin{tabular}{|c|c|c|c|c|c|c|c|}
\hline $\begin{array}{l}\text { RUN } \\
\text { P/d } \\
\text { Pin } \\
\text { Xin }\end{array}$ & $\begin{array}{l}\text { NUMBEF } \\
=1.5 \\
=562 . \\
=0.01\end{array}$ & $41 \mathrm{kPa}$ & & DELT & $\begin{array}{l}\text { WORKI } \\
G=2 \\
\text { P to }\end{array}$ & $\begin{array}{r}\text { NG FLUID: } \\
12.23 \mathrm{~kg} / \\
\mathrm{tal}=7.5 \\
\text { xout }=\end{array}$ & $\begin{array}{l}\mathrm{R}- \\
\mathbf{c}^{\star} \boldsymbol{\pi} \\
\mathrm{kF} \\
0 .\end{array}$ \\
\hline OW & $P$ & $x$ in & Tf & $q^{\prime \prime}$ & Tw & h & \\
\hline $\begin{array}{l}* \\
1\end{array}$ & $\begin{array}{l}{[\mathrm{KPa}]} \\
561.8\end{array}$ & & $\begin{array}{l}{[\mathrm{C}]} \\
82.3\end{array}$ & $\begin{array}{c}{\left[\mathrm{H} / \mathrm{m}^{\wedge} 2\right]} \\
30817\end{array}$ & $\begin{array}{l}{[c]} \\
86.1\end{array}$ & {$\left[\mathrm{~W} / \mathrm{m} \mathrm{m}^{\circ} 2 \mathrm{~s}\right.$} & \\
\hline 3 & 560.6 & 0.0 & 83.0 & & & 11926 & \\
\hline 5 & 559.5 & 0.0 & 83.0 & 29968 & 85.5 & 11931 & \\
\hline 7 & 558.5 & 0. & & & & & \\
\hline & & & & & 8 & 493 & \\
\hline 1 & 556. & 0. & & & & 9283 & \\
\hline & & & & & & & \\
\hline & & .06 & 82.6 & 29855 & 85.4 & 10940 & \\
\hline
\end{tabular}

RUN NUMBER: 471 $\mathrm{p} / \mathrm{d}=1.5$ Pin $=543.13 \mathrm{kPa}$
$X$ in $=-.00$

WORKING FLUID: R-11 DELTA $=211.32 \mathrm{~kg} / \mathrm{axm}^{2}$ Xout $=0.11$

\begin{tabular}{|c|c|c|c|c|}
\hline \multicolumn{5}{|c|}{$q^{\prime \prime}$} \\
\hline 82.7 & 51113 & 88.6 & 8746 & \\
\hline 84.1 & 50165 & 87.9 & 13180 & \\
\hline 4.0 & 49457 & 87.8 & 13022 & \\
\hline 3.9 & 50685 & 93.1 & 5523 & \\
\hline 3.9 & 50148 & 93.5 & 5217 & \\
\hline 3.8 & 49809 & 89.0 & 9592 & \\
\hline 3 & & 88.8 & 9801 & \\
\hline 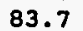 & 675 & 88.2 & 11090 & \\
\hline
\end{tabular}

$83.74967588 .2 \quad 11090$ T.B.

\begin{tabular}{|c|c|c|c|c|c|c|c|}
\hline ROW & $\stackrel{P}{\mathrm{P}}$ & $x \ln$ & $\begin{array}{l}\text { Tf } \\
\text { [c] }\end{array}$ & 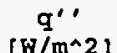 & Tw & $\stackrel{h}{/ m^{\wedge} 2}$ & $\begin{array}{l}\text { SURF } \\
\text { TYPE }\end{array}$ \\
\hline 1 & 542.5 & -.00 & 80.9 & 62328 & 88.1 & 8663 & H.F. \\
\hline 3 & 541.1 & 0.02 & 81.0 & & 85.9 & & H.F. \\
\hline 5 & 540.0 & 0.04 & 81.0 & 60254 & 85.5 & 13644 & H.F. \\
\hline & 538.9 & 0.06 & 0 & 6144 & 92.2 & 5526 & \\
\hline 9 & 537.8 & 0.07 & 81.0 & 60829 & 92.2 & 5445 & SM. \\
\hline & 536.8 & & & 605 & 81.3 & 104 & \\
\hline 13 & 535.7 & 0.10 & 81.0 & 60897 & 87.2 & 9930 & \\
\hline 15 & 534.5 & .12 & .0 & & 36.6 & 10851 & \\
\hline
\end{tabular}




\begin{tabular}{|c|c|c|c|c|c|c|c|}
\hline $\begin{array}{l}\text { RuN } \\
\text { p/d } \\
\text { Pin } \\
\text { Xin }\end{array}$ & $\begin{array}{l}\text { NUMBER } \\
=1.5 \\
=602 . \\
=0.03\end{array}$ & $59 \mathrm{kPa}$ & & DELT & $\begin{array}{l}\text { NORKI } \\
\begin{array}{r}=2 \\
P \text { to }\end{array}\end{array}$ & $\begin{array}{c}\text { NG FLUID } \\
18.99 \mathrm{~kg} \\
\text { tal }=5 . \\
\text { xout }\end{array}$ & $\begin{array}{l}R-11 \\
8 * m^{\wedge} 2 \\
k P a \\
0.20\end{array}$ \\
\hline ROW & $P$ & $x$ in & Tf & $\frac{q^{\prime \prime}}{\left(\mathfrak{m} / \mathrm{m}^{\wedge} 2\right)}$ & Tw & $\stackrel{h}{h}$ & SURF \\
\hline $\begin{array}{l}* \\
1\end{array}$ & $\begin{array}{l}{[\mathrm{kPa}]} \\
602.2\end{array}$ & $\begin{array}{l}{[-]} \\
0.03\end{array}$ & $\begin{array}{l}{[C]} \\
82.8\end{array}$ & $\begin{array}{c}{\left[\mathrm{w} / \mathrm{m}^{\wedge} 2\right]} \\
71763\end{array}$ & $\begin{array}{l}\text { [C] } \\
90.9\end{array}$ & $\begin{array}{c}{\left[\mathrm{W} / \mathrm{m}^{\wedge} 2 \mathrm{C}\right.} \\
8777\end{array}$ & $\begin{array}{l}\text { TYPE } \\
\text { H.F. }\end{array}$ \\
\hline 3 & 601.4 & 0.05 & 85.7 & 70665 & 90.8 & 13912 & H.F. \\
\hline 5 & 600.5 & 0.07 & 85.7 & 69442 & 90.5 & 14670 & H.F. \\
\hline 7 & 599.8 & 0.10 & 85.7 & 71106 & 95.7 & 7147 & SM. \\
\hline 9 & 599.0 & 0.1 & 85 & 70401 & 95.8 & 6986 & SM. \\
\hline 11 & 598.2 & 0.14 & 85.7 & 70131 & 92.5 & 10339 & T.B. \\
\hline 13 & 597.5 & 0.1 & 85 & & 92.5 & 10477 & T.B. \\
\hline 15 & 596.7 & 0.19 & 85.7 & 69817 & 91.3 & 12497 & T.B. \\
\hline
\end{tabular}

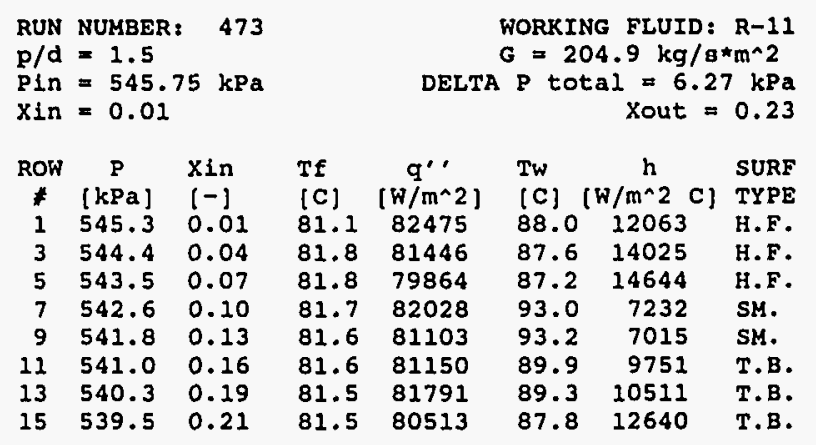


Bundle Boiling Data

Data from the $25 \% \mathrm{R}-11 / 75 \% \mathrm{R}-113$ mixture 


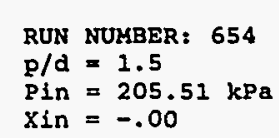

$\begin{array}{rccc}\text { ROW } & P & \text { Xin } & Y^{\prime} \\ * & {[k P a]} & {[-]} & R-11 \\ 1 & 205.1 & -.00 & 0.238 \\ 3 & 204.0 & 0.00 & 0.238 \\ 5 & 203.1 & 0.01 & 0.237 \\ 7 & 202.2 & 0.02 & 0.237 \\ 9 & 201.3 & 0.03 & 0.236 \\ 11 & 200.5 & 0.03 & 0.236 \\ 13 & 199.6 & 0.04 & 0.235 \\ 15 & 198.7 & 0.05 & 0.235\end{array}$

RUN NUMBER: 653 $\mathrm{p} / \mathrm{d}=1.5$
Pin $=202.07 \mathrm{kPa}$
$\mathrm{xin}=-.00$

$\begin{array}{rccl}\text { ROW } & \begin{array}{c}\text { p } \\ \text { * }\end{array} & \text { Xin } & \mathbf{y}^{\prime} \\ 1 & 201.6 & {[-]} & \mathbf{R - 1 1} \\ 3 & 200.6 & 0.00 & 0.238 \\ 5 & 199.6 & 0.03 & 0.237 \\ 7 & 198.7 & 0.04 & 0.236 \\ 9 & 197.9 & 0.06 & 0.234 \\ 11 & 197.1 & 0.08 & 0.233 \\ 13 & 196.3 & 0.09 & 0.232 \\ 15 & 195.5 & 0.11 & 0.232\end{array}$

RUN NUMBER: 657

$\mathrm{p} / \mathrm{d}=1.5$

$\mathrm{Pin}=199.31 \mathrm{kPa}$

$\mathrm{X}$ in $=0.00$

$\begin{array}{rccc}\text { ROW } & P & \text { Xin } & y^{\prime} \\ \# & (k P a) & {[-1} & \text { R-11 } \\ 1 & 198.8 & 0.00 & 0.238 \\ 3 & 197.8 & 0.03 & 0.236 \\ 5 & 196.8 & 0.06 & 0.234 \\ 7 & 195.9 & 0.09 & 0.233 \\ 9 & 195.0 & 0.12 & 0.231 \\ 11 & 194.3 & 0.15 & 0.229 \\ 13 & 193.5 & 0.19 & 0.227 \\ 15 & 192.8 & 0.22 & 0.226\end{array}$ $y^{\prime}$ in $=23.8 \otimes R-11 / 76.2 \times R_{G}^{R-113}$ $\begin{aligned} \text { DELTA P total } & =6.82 \mathrm{kPa} \\ \text { Xout } & =0.05\end{aligned}$ $\begin{array}{lclcl}\text { Tf } & q^{\prime \prime} & \text { Tw } & h & \text { SURF } \\ {[C]} & {\left[W / \mathrm{m}^{\wedge} 2\right]} & {[\mathrm{C}]} & {\left[\mathrm{W} / \mathrm{m}^{\wedge} 2 \mathrm{C}\right.} & \text { TYPE } \\ 52.4 & 5277 & 59.9 & 705 & \text { H.F. }\end{array}$ $\begin{array}{lllrl}53.6 & 5218 & 59.6 & 865 & \text { H.F. }\end{array}$ $54.5 \quad 5118 \quad 59.5 \quad 1024 \quad$ H.F. $\begin{array}{lllll}55.1 & 5179 & 61.1 & 864 & \text { SM. }\end{array}$ $\begin{array}{lllll}55.6 & 5049 & 61.5 & 861 & \text { SM. }\end{array}$ $\begin{array}{lllll}56.1 & 5117 & 59.6 & 1462 & \text { T.B }\end{array}$ $\begin{array}{lllll}56.5 & 5115 & 59.5 & 1722 & \text { T.B. } \\ 57.0 & 5035 & 59.2 & 2244 & \text { T.B. }\end{array}$

$Y^{\prime}$ in $=23.8 \& R-11 / 76.2 \& R-113$ $G=49.66 \mathrm{~kg} / \mathrm{g}^{\star} \mathrm{m}^{\wedge} 2$ $\begin{aligned} \text { DELTA P total } & =6.56 \mathrm{kPa} \\ \text { Xout } & =0.12\end{aligned}$

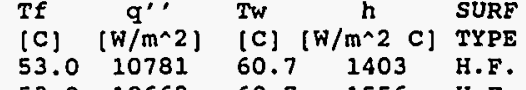
$\begin{array}{lllll}53.8 & 10662 & 60.7 & 1556 & \text { H.F. }\end{array}$ $54.410470 \quad 60.7 \quad 1663$ H.F. $\begin{array}{lllll}54.9 & 10561 & 64.7 & 1075 & \text { SM. }\end{array}$ $\begin{array}{lllll}54.5 & 10373 & 64.5 & 1154 & \mathrm{SM} .\end{array}$ $\begin{array}{lllll}56.6 & 10456 & 60.6 & 2301 & \text { T.B. } \\ & 60.4 & 2691 & \text { T.B. }\end{array}$ $\begin{array}{lllll}57.1 & 10307 & 60.0 & 3598 & \text { T.B. }\end{array}$

\begin{tabular}{|c|c|c|c|c|}
\hline \multicolumn{5}{|c|}{$\begin{array}{r}y^{\prime} \text { in }=23.8 \& \mathrm{R}-11 / 76.2 \& \mathrm{R}-113 \\
\mathrm{G}=49.97 \mathrm{~kg} / \mathrm{s}^{\star} \mathrm{m}^{\wedge} 2 \\
\text { DELTA P total }=6.51 \mathrm{kPa} \\
\text { Xout }=0.23\end{array}$} \\
\hline $\begin{array}{l}T f \\
\text { (C) }\end{array}$ & $\frac{q^{\prime \prime}}{\left[w / m^{\wedge} 2\right]}$ & $\begin{array}{l}T w \\
(C)\end{array}$ & $\left.\stackrel{h}{h / m^{\wedge} 2} \quad c\right)^{-}$ & $\begin{array}{l}\text { SURF } \\
\text { TYPE }\end{array}$ \\
\hline $\begin{array}{l}53.2 \\
54.0\end{array}$ & $\begin{array}{l}20858 \\
20619\end{array}$ & $\begin{array}{l}62.1 \\
62.4\end{array}$ & & $\begin{array}{l}\text { H.F. } \\
\text { H.F. }\end{array}$ \\
\hline & & & & \\
\hline 55. & 207 & & 15 & \\
\hline & & & & \\
\hline & 205 & & 3071 & T.B. \\
\hline & & & & $T$ \\
\hline & & & 4486 & T.B. \\
\hline
\end{tabular}

RUN NUMBER: 658

$\mathrm{p} / \mathrm{d}=1.5$

Pin $=200 \mathrm{kPa}$

Pin $=200$
$X$ in $=-.00$

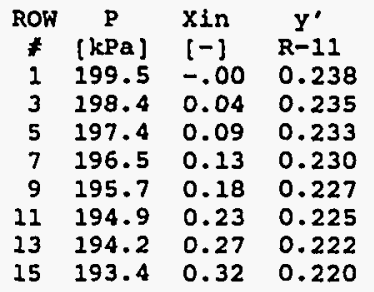

RUN NUMBER: 644

$\mathrm{p} / \mathrm{d}=1.5$

Pin $=200 \mathrm{kPa}$

$x_{\text {in }}=0.00$

$\begin{array}{rccl}\text { ROW } & \begin{array}{c}P \\ *\end{array} & \text { Xin } & Y^{\prime} \\ \text { [kPa }] & {[-]} & R^{\prime}-11 \\ 1 & 199.6 & 0.00 & 0.238 \\ 3 & 198.6 & 0.06 & 0.234 \\ 5 & 197.7 & 0.12 & 0.231 \\ 7 & 196.9 & 0.18 & 0.227 \\ 9 & 196.2 & 0.25 & 0.224 \\ 11 & 195.5 & 0.31 & 0.220 \\ 13 & 195.0 & 0.37 & 0.217 \\ 15 & 194.5 & 0.43 & 0.214\end{array}$

RUN NUMBER: 660

$\mathrm{p} / \mathrm{d}=1.5$

$\mathrm{Pin}_{\text {in }}=203.44 \mathrm{kPa}$

$x$ in $=-.00$

$\begin{array}{rccc}\text { ROW } & \text { P } & \text { Xin } & Y^{\prime} \\ * & {[\mathrm{KPa}]} & {[-]} & \mathrm{R}-11 \\ 1 & 202.9 & -.00 & 0.238 \\ 3 & 201.8 & 0.07 & 0.234 \\ 5 & 200.7 & 0.14 & 0.229 \\ 7 & 199.7 & 0.22 & 0.225 \\ 9 & 198.9 & 0.30 & 0.220 \\ 11 & 198.1 & 0.38 & 0.216 \\ 13 & 197.4 & 0.45 & 0.211 \\ 15 & 196.6 & 0.53 & 0.207\end{array}$ $\begin{aligned} & y^{\prime} \text { in }=23.8 \& R-11 / 76.2 \& R-113 \\ & G=49.98 \mathrm{~kg} / 8 \mathrm{~g}^{\wedge} 2\end{aligned}$

DELTA P total $=6.55 \mathrm{kPa}$

Xout $=0.34$

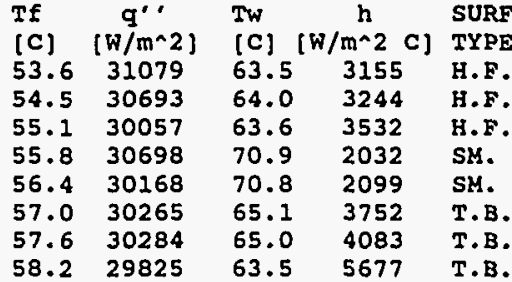

$y^{\prime}$ in $=23.8 \& \mathrm{R}-11 / 76.2 \& \mathrm{R}-113$ DELTA $P$ total $=5.51 \mathrm{kPa}$

Xout $=0.46$

\begin{tabular}{|c|c|c|c|c|}
\hline $\begin{array}{l}T E \\
{[C]}\end{array}$ & $\left(W / m^{\wedge} 2\right)$ & & $\begin{array}{cc}n \\
1 / m^{n} 2 & c l\end{array}$ & $\begin{array}{l}\text { SURF } \\
\text { TYPE }\end{array}$ \\
\hline 54. & 41206 & 65.2 & 3785 & H.F. \\
\hline 5. & 40587 & 65.8 & 3833 & \\
\hline 5. & 39877 & 35.6 & 4086 & \\
\hline & 406 & 2. & 2558 & SM. \\
\hline 7.0 & 399 & & 2630 & SM. \\
\hline & 399 & 6.9 & 4279 & \\
\hline & 39882 & 57.0 & 4520 & T.B. \\
\hline
\end{tabular}

$y^{\prime}$ in $=23.8 \& \mathrm{R}-11 / 76.2 \& \mathrm{R}-113$
$\mathrm{G}=49.97 \mathrm{~kg} / \mathrm{s}^{\star} \mathrm{m}^{\wedge} 2$

$\begin{aligned} \text { DELTA P total } & =6.85 \mathrm{kPa} \\ \text { xout } & =0.57\end{aligned}$

\begin{tabular}{|c|c|c|c|c|}
\hline C) & {$\left[w / m^{\wedge} 2\right]$} & & {$\left[\begin{array}{cc}n \\
{\left[m^{\wedge} 2\right.} & c\end{array}\right.$} & SURR \\
\hline & 51421 & 66.3 & 4003 & \\
\hline & & & & \\
\hline & & & & \\
\hline & 50 & & 28 & \\
\hline & & & & \\
\hline & & & 4520 & \\
\hline & & 9.4 & 4925 & \\
\hline
\end{tabular}




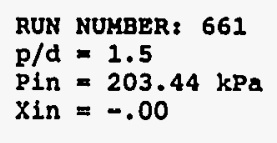

$\begin{array}{cccc}\text { ROW } & P & \text { Xin } & Y^{\prime} \\ F & {[\mathrm{kPa}]} & {[-]} & \mathrm{R}-11 \\ 1 & 202.9 & -.00 & 0.238 \\ 3 & 201.8 & 0.08 & 0.233 \\ 5 & 200.7 & 0.17 & 0.227 \\ 7 & 199.7 & 0.26 & 0.222 \\ 9 & 198.9 & 0.36 & 0.217 \\ 11 & 198.1 & 0.46 & 0.211 \\ 13 & 197.4 & 0.55 & 0.206 \\ 15 & 196.6 & 0.64 & 0.201\end{array}$

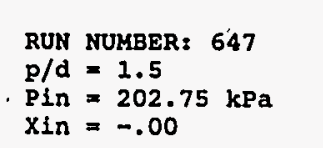

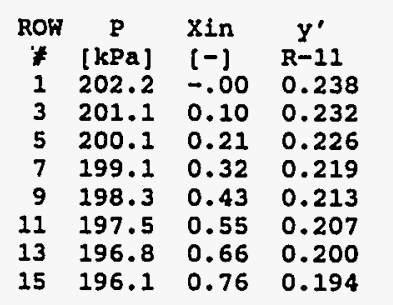

RUN NUMBER: 655

P/d $=202.75 \mathrm{kPa}$
Xin $=-.00$

$\begin{array}{cccc}\text { ROW } & P & X i n & Y^{\prime} \\ * & {[k P a]} & {[-]} & R-11 \\ 1 & 202.3 & -.00 & 0.238 \\ 3 & 201.3 & 0.01 & 0.238 \\ 5 & 200.4 & 0.01 & 0.237 \\ 7 & 199.5 & 0.02 & 0.237 \\ 9 & 198.7 & 0.03 & 0.236 \\ 11 & 197.8 & 0.04 & 0.236 \\ 13 & 197.0 & 0.04 & 0.235 \\ 15 & 196.1 & 0.05 & 0.235\end{array}$ $y^{\prime}$ In $=23.8 \& \quad R-11 / 76.2 \& R-113$
$G=50.07 \mathrm{~kg} / \mathrm{g}^{\star} \mathrm{m}^{\wedge} 2$ DELTA P total $=6.82 \mathrm{kPa}$
Xout $=0.68$

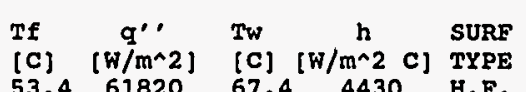
$\begin{array}{lllll}5 . .4 & 61820 & 67.4 & 4430 & \text { H.F. } \\ 54.8 & 60798 & 67.9 & 4639 & \text { H.F. }\end{array}$ 55.759785 67.5 5086 H.F. 56.75785 67.5 5086 H.F. 57.56109875 .93176 SM. $58.56048271 .8 \quad 4296$ SK. $59.4 \quad 60718 \quad 71.1 \quad 5172 \quad 7$. $\begin{array}{lllll}60.3 & 60217 & 69.8 & 6351 & \text { T.B. }\end{array}$
RUN NUMBER: 656

$\mathrm{p} / \mathrm{d}=1.5$ $x$ in $=0.00$

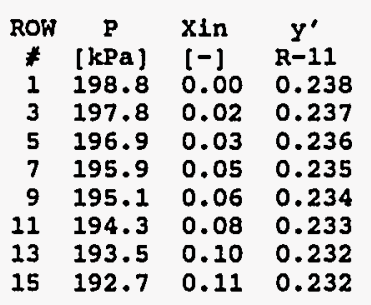

$\begin{array}{llll}15 & 192.7 & 0.11 & 0.232\end{array}$
$P$ in $=199.31 \mathrm{kPa}$

$y^{\prime}$ in $=23.8: R-11 / 76.2: R-113$ $G=99.78 \mathrm{~kg} / g^{*} m^{\wedge} 2$ DELTA $P$ total $=6.6 \mathrm{kPa}$ Xout $=0.12$

\begin{tabular}{|c|c|c|c|c|}
\hline C & $\underset{\left[w / m^{\wedge} 2\right]}{q^{\prime \prime}}$ & $\begin{array}{l}\text { Tw } \\
\text { (c) }\end{array}$ & $\left.\stackrel{h}{h m^{\wedge} 2} c\right]$ & SUR: \\
\hline .8 & 11053 & 60.2 & 1515 & \\
\hline 1.6 & 10927 & 60.0 & 1696 & \\
\hline 1 & 10731 & 60.0 & 1802 & \\
\hline & 10742 & & 1057 & \\
\hline 1 & 10545 & 64.4 & 1128 & \\
\hline & 10693 & & 2290 & \\
\hline & 10687 & 60.0 & 2686 & \\
\hline & 10526 & 59.4 & 3684 & \\
\hline
\end{tabular}

\section{RUN NUMBER: 652 \\ $\mathrm{p} / \mathrm{d}=1.5$ \\ Pin $=200.69 \mathrm{kPa}$}

$\begin{aligned} \text { DELTA P total } & =6.68 \mathrm{kPa} \\ \text { Xout } & =0.82\end{aligned}$

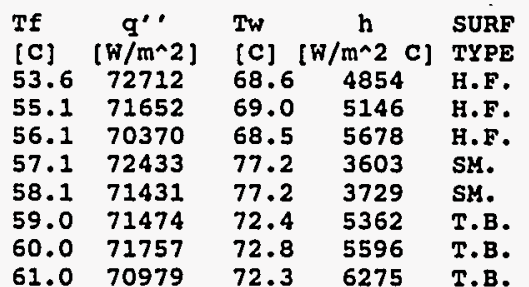

$y^{\prime}$ in $=23.8 \& R-11 / 76.2 \& R-113$ DELTA $P$ total $=6.68 \mathrm{kPa}$ Xout $=0.06$

\begin{tabular}{|c|c|c|c|c|}
\hline $\begin{array}{l}\text { Tf } \\
\text { [C] }\end{array}$ & $\underset{\left[w / m^{\wedge} 2\right]}{q^{\prime \prime}}$ & $\begin{array}{l}\text { Tw } \\
{[C]}\end{array}$ & $\stackrel{h}{h}$ & $\begin{array}{l}\text { SURE } \\
\text { TYPE }\end{array}$ \\
\hline 52.4 & 5275 & 59.3 & 762 & H.F. \\
\hline 53.5 & 5218 & 59.0 & 946 & H.F. \\
\hline 54.2 & 5120 & 58.9 & 1085 & H.F. \\
\hline 54.6 & 5180 & 60.7 & 856 & SM. \\
\hline 5.1 & 5050 & 60.9 & 861 & SM. \\
\hline 5.5 & 5129 & 59.0 & 1488 & T.B. \\
\hline & $\begin{array}{l}5126 \\
5049\end{array}$ & $\begin{array}{l}58.8 \\
58.5\end{array}$ & $\begin{array}{l}1790 \\
2339\end{array}$ & . B. \\
\hline
\end{tabular}

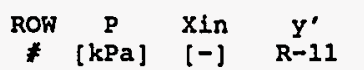

$1200.2 \quad-.00 \quad 0.238$

$\begin{array}{llll}3 & 199.2 & 0.03 & 0.236\end{array}$

$\begin{array}{llll}5 & 198.2 & 0.06 & 0.234 \\ 7 & 197.3 & 0.09 & 0.232\end{array}$

$\begin{array}{llll}7 & 197.3 & 0.09 & 0.232\end{array}$

$\begin{array}{rrrr}9 & 196.4 & 0.12 & 0.231 \\ 11 & 195.6 & 0.16 & 0.229\end{array}$

$\begin{array}{llll}11 & 195.6 & 0.16 & 0.229 \\ 13 & 194.9 & 0.19 & 0.227\end{array}$

$15 \quad 194.1 \quad 0.22 \quad 0.225$

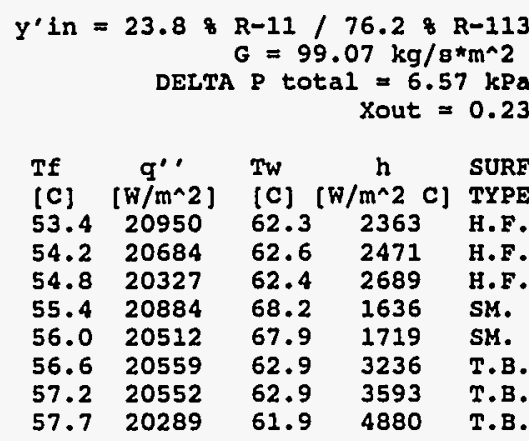
$\begin{aligned} & y^{\prime} \text { in }=23.8 \& R-11 / 76.2 \& \mathrm{R}-113 \\ & G=99.52 \mathrm{~kg} / \mathrm{s}^{\star} \mathrm{m}^{\wedge} 2\end{aligned}$ $\begin{aligned} \text { DELTA P total } & =6.41 \mathrm{kPa} \\ \text { Xout } & =0.35\end{aligned}$
RUN NUMBER: 651

$\mathrm{Xin}=0.00 \mathrm{kPa}$

\begin{tabular}{|c|c|c|c|c|c|c|c|c|}
\hline ROW & $\begin{array}{c}\mathrm{P} \\
\mathrm{kPa}\end{array}$ & $x$ in & $\begin{array}{c}y^{\prime} \\
R-11\end{array}$ & $\begin{array}{l}\text { Tf } \\
\text { [C] }\end{array}$ & $\frac{q^{\prime \prime}}{\left[w / m^{\wedge} 2\right]}$ & $\begin{array}{l}T w \\
{[C]}\end{array}$ & 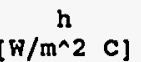 & $\begin{array}{l}\text { SURE } \\
\text { TYPE }\end{array}$ \\
\hline 1 & 198.8 & 0.00 & 0.238 & 53.5 & 31118 & 63.6 & 3099 & 2020 \\
\hline 3 & 197.7 & 0.05 & & & 30589 & 64.0 & 3195 & \\
\hline 5 & 196.7 & 0.09 & 0.233 & 55.0 & 30031 & 63.7 & 3472 & \\
\hline 7 & 195.8 & 0.14 & 0. & & 31083 & 70.3 & 2117 & \\
\hline 9 & 195.0 & 0.19 & 0.227 & 56.2 & 30546 & 70.2 & 2187 & \\
\hline 11 & 194.2 & 0.23 & 0.224 & .8 & 30653 & 64.9 & 3792 & \\
\hline 13 & 193.5 & 0.28 & 0.222 & 57.4 & 30599 & 64.8 & 4138 & \\
\hline & 192.9 & 0.3 & 0.219 & & 30321 & 63.4 & 5604 & \\
\hline
\end{tabular}


RUN NUMBER: 650

$\mathrm{p} / \mathrm{d}=2.5$

$P$ in $=197.93 \mathrm{kPa}$

$y^{\prime}$ in $=23.8 \& R-11 / 76.2 \& R-113$

$G=99.49 \mathrm{~kg} / \mathrm{s}^{*} \mathrm{~m}^{\wedge} 2$

DELTA P total $=6.51 \mathrm{kPa}$

$\begin{array}{llll}\text { ROW } & \mathrm{P} & \mathrm{Xin} & \mathrm{Y}^{\prime} \\ \text { * } & \mathrm{kPa}] & {[-]} & \mathrm{R}-11\end{array}$

$\begin{array}{llll}\text { * } & \text { (kPa] } & {[-]} & \mathrm{R}-11 \\ 1 & 197.4 & 0.00 & 0.238\end{array}$

$\begin{array}{lll}197.4 & 0.00 & 0.238 \\ 196.3 & 0.06 & 0.234\end{array}$

$\begin{array}{llll}195.3 & 0.12 & 0.231 \\ 7 & 194.4 & 0.18 & 0.227\end{array}$

$\begin{array}{llll}193.7 & 0.25 & 0.224\end{array}$

$11 \quad 193.0 \quad 0.31 \quad 0.220$

$\begin{array}{llll}13 & 192.2 & 0.37 & 0.217\end{array}$

$\begin{array}{llll}15 & 191.4 & 0.43 & 0.213\end{array}$

RUN NUMBER: 649

$\mathrm{p} / \mathrm{d}=1.5$

$P \ln =199.31 \mathrm{kPa}$

$\mathrm{xin}=0.00$

$\begin{array}{cccc}\text { ROW } & \begin{array}{c}\mathrm{P} \\ \text { * }\end{array} & \text { Xin } & \mathrm{Y}^{\prime} \\ 1 & \mathrm{kPa}) & {[-]} & \mathrm{R}-11 \\ 1 & 198.8 & 0.00 & 0.238 \\ 3 & 197.7 & 0.08 & 0.234 \\ 5 & 196.6 & 0.15 & 0.229 \\ 7 & 195.7 & 0.23 & 0.225 \\ 9 & 194.8 & 0.31 & 0.220 \\ 11 & 194.0 & 0.39 & 0.216 \\ 13 & 193.3 & 0.47 & 0.212 \\ 15 & 192.5 & 0.54 & 0.207\end{array}$

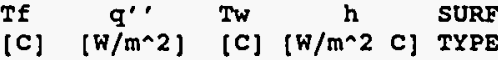

54.24107764 .54024 H.F.

55.14048565 .0405 H.F.

55.639680 64.6 4422 H.F.

$\begin{array}{lllll}56.1 & 40637 & 71.9 & 2587 & \text { SM. }\end{array}$

$\begin{array}{lllll}56.7 & 39989 & 71.8 & 2656 & \text { SM. }\end{array}$

$\begin{array}{llllll}57.2 & 40633 & 66.5 & 4360 & \text { T.B. }\end{array}$

$\begin{array}{lllll}57.8 & 40581 & 66.7 & 4571 & \text { T.B. }\end{array}$

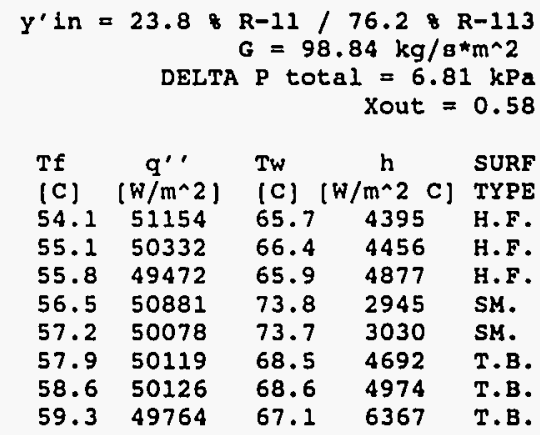

RUN NUMBER: 648

$\mathrm{p} / \mathrm{d}=1.5$

Pin $=201.38 \mathrm{kPa}$

$\mathrm{Y}^{\prime}$ in $=23.8 \& \mathrm{R}-11 / 76.2 \& \mathrm{R}-113$

$G=99.33 \mathrm{~kg} / 8 \mathrm{~g}^{\wedge} 2$

$\begin{aligned} \text { DELTA P total } & =6.72 \mathrm{kPa} \\ \text { Xout } & =0.70\end{aligned}$

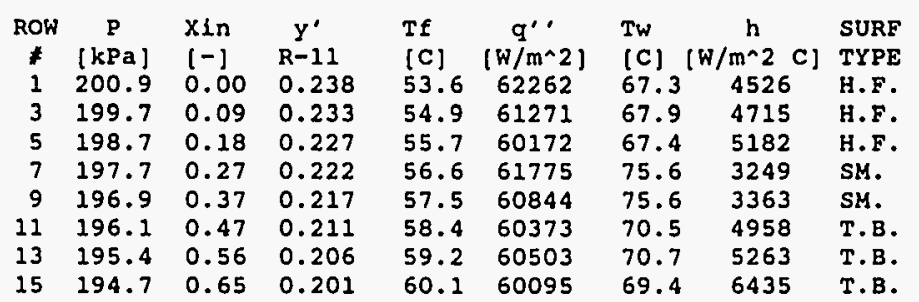

RUN NUMBER: 663

$\mathrm{p} / \mathrm{d}=1.5$

Pin $=202.07 \mathrm{kPa}$

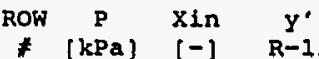

$\begin{array}{lll}{[\mathrm{KPa}]} & {[-]} & \mathrm{R}-11 \\ 201.6 & -.00 & 0.238\end{array}$

$\begin{array}{lll}200.5 & 0.05 & 0.235\end{array}$

$\begin{array}{lll}199.4 & 0.10 & 0.232\end{array}$

$\begin{array}{lll}198.4 & 0.15 & 0.22\end{array}$

$\begin{array}{lll}197.6 & 0.20 & 0.22\end{array}$

$\begin{array}{llll}13 & 196.1 & 0.30 & 0.219\end{array}$

$\begin{array}{llll}15 & 195.4 & 0.35 & 0.216\end{array}$

RUN NUMBER: 664

$\mathrm{p} / \mathrm{d}=1.5$

Pin $=204.82 \mathrm{kPa}$

$\operatorname{lin}=-.01$

$\begin{array}{rccc}\text { ROW } & \mathrm{P} & \mathrm{Xin} & \mathrm{Y}^{\prime} \\ \text { H } & {[\mathrm{kPa}]} & {[-]} & \mathrm{R}-11 \\ 1 & 204.3 & -.01 & 0.238 \\ 3 & 203.2 & 0.05 & 0.234 \\ 5 & 202.1 & 0.11 & 0.231 \\ 7 & 201.2 & 0.17 & 0.227 \\ 9 & 200.3 & 0.23 & 0.224 \\ 11 & 199.5 & 0.29 & 0.220 \\ 13 & 198.8 & 0.35 & 0.217 \\ 15 & 198.0 & 0.40 & 0.213\end{array}$

RUN NUMBER: 682

$\mathrm{p} / \mathrm{d}=1.5$

Pin $=546.2 \mathrm{kP}$

$\operatorname{xin}=0.00$

$\begin{array}{rccc}\text { ROW } & P & X \text { in } & Y^{\prime} \\ * & {[\mathrm{KPa}]} & {[-]} & \mathrm{R}^{\prime}-11 \\ 1 & 545.7 & 0.00 & 0.231 \\ 3 & 544.6 & 0.01 & 0.231 \\ 5 & 543.7 & 0.02 & 0.231 \\ 7 & 542.7 & 0.02 & 0.230 \\ 9 & 541.8 & 0.03 & 0.230 \\ 11 & 540.9 & 0.04 & 0.230 \\ 13 & 540.0 & 0.05 & 0.230 \\ 15 & 539.1 & 0.05 & 0.229\end{array}$ $y^{\prime}$ in $=23.8 * R-11 / 76.2 / R-113$ $G=212.23 \mathrm{~kg} / \mathrm{s}^{\star} \mathrm{m}^{\wedge} 2$ DELTA P total $=6.69 \mathrm{kPa}$ Xout $=0.38$

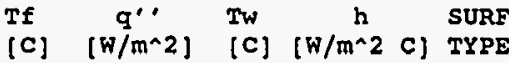
$53.07263467 .0 \quad 5207$ H.F. $\begin{array}{lllll}54.2 & 71550 & 67.3 & 5437 & \text { H.F. }\end{array}$ $54.97023166 .6 \quad 5992$ H.F. $\begin{array}{llll}75.3 & 3646 \quad S M\end{array}$ $\begin{array}{llll}75.3 & 3760 & \text { SM. }\end{array}$

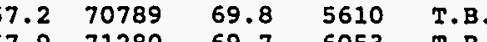
$57.97128069 .76053 \quad$ T.B.

$y \cdot$ in $=23.8 \& \mathrm{R}-11 / 76.2 \& \mathrm{R}-113$ $G=208.38 \mathrm{~kg} / \mathrm{g}^{\star} \mathrm{m}^{\wedge} 2$ DELTA P total $=6.86 \mathrm{kPa}$ Xout $=0.43$

\begin{tabular}{|c|c|c|c|c|}
\hline If & $q^{\prime \prime}$ & $T w$ & h & SURF \\
\hline [C] & {$[w / m \wedge 2]$} & [C] & $1 / m \wedge 2 c]$ & TYPE \\
\hline 54.6 & 81235 & 68.7 & 5773 & H.F. \\
\hline 5.5 & 79700 & 68.0 & 6358 & H.F. \\
\hline 6.3 & 81364 & 77.0 & 3926 & \\
\hline 7.1 & 80402 & 76.9 & 4049 & SM. \\
\hline 7.9 & 80496 & 71.6 & 5853 & \\
\hline 88.7 & 81189 & 71.5 & 6334 & T.B. \\
\hline 9. & 80101 & 70.4 & 7318 & B. \\
\hline
\end{tabular}

$\mathrm{Y}^{\prime}$ in $=23.18 \mathrm{R}-11 / 76.9 \& \mathrm{R}-113$ $=49.11 \mathrm{~kg} / \mathrm{g}^{\mathrm{m}} \mathrm{m}$ $\begin{aligned} \text { DELTA P total } & =7.15 \mathrm{kPa} \\ \text { xout } & =0.06\end{aligned}$

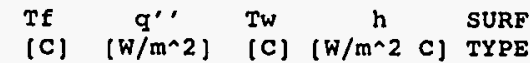
$82.0466988 .0 \quad 775$ $\begin{array}{lllll}82.5 & 4630 & 87.9 & 869 \quad \text { H.F. }\end{array}$ $83.04455 \quad 87.7 \quad 950$ H.F. $83.6 \quad 4758 \quad 89.2 \quad 853$ SM.

$84.0 \quad 4669 \quad 89.1 \quad 919 \quad 5 M$.

$\begin{array}{lllll}84.3 & 4448 & 87.3 & 1486 & \text { T.B. }\end{array}$

$\begin{array}{lllll}84.5 & 4456 & 87.2 & 1649 & \text { T.B. }\end{array}$

$\begin{array}{lllll}84.8 & 4393 & 87.1 & 1935 & \text { T.B. }\end{array}$ 


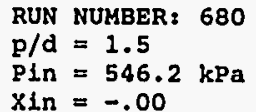

$y^{\prime}$ In $=23.1 \& R-11 / 76.9 \& R-113$ DELTA P total $=6.98 \mathrm{kPa}$

Xout $=0.13$
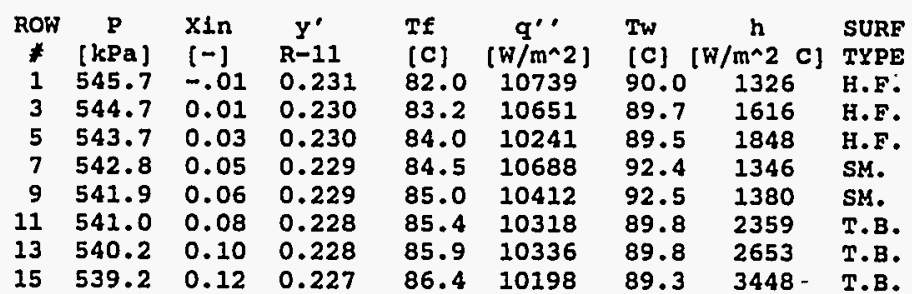

RUN NUMBER: 679

$\mathrm{p} / \mathrm{d}=1.5$
$\mathrm{Pin}=546.2 \mathrm{kPa}$

$\mathrm{Xin}=-.00$

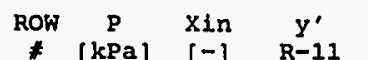

$\begin{array}{llll}* & {[\mathrm{kPa}]} & {[-]} & \mathrm{R}-11 \\ 1 & 545.7 & -.00 & 0.231\end{array}$

$3 \quad 544.6 \cdot 0.03 \quad 0.230$

$\begin{array}{lllll}5 & 543.6 & 0.06 & 0.229\end{array}$

$\begin{array}{llll}7 & 542.7 & 0.10 & 0.228\end{array}$

$\begin{array}{lllll}9 & 541.8 & 0.13 & 0.227\end{array}$

$\begin{array}{llll}11 & 541.0 & 0.17 & 0.226\end{array}$

$15 \quad 539.3 \quad 0.24 \quad 0.225$

RUN NUMBER: 677

$\mathrm{p} / \mathrm{d}=1.5$
Pin $=546.2 \mathrm{kPa}$

$x$ in $=0.07$

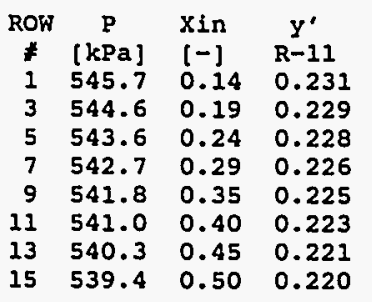

$\mathrm{Y}^{\prime}$ in $=23.1 \& \mathrm{R}-11 / 76.9 \& \mathrm{R}-113$ $G=49.12 \mathrm{~kg} / 8^{*} \mathrm{~m}^{\wedge} 2$ $G=49.12 \mathrm{~kg} / \mathbf{g}^{*} \mathrm{~m}^{\wedge} 2$
DELTA $P$ total $=6.77 \mathrm{kPa}$ xout $=0.53$

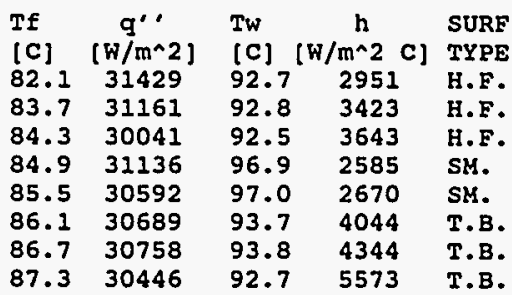

RUN NUMBER: 675

$\mathrm{p} / \mathrm{d}=1.5$
$\mathrm{Pin}=546.2 \mathrm{kPa}$

$x$ in $=-.00$

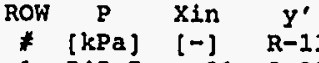

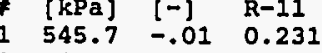

$\begin{array}{llll}3 & 544.7 & 0.06 & 0.229\end{array}$

$\begin{array}{llll}5 & 543.8 & 0.12 & 0.227\end{array}$

$\begin{array}{llll}7 & 542.9 & 0.19 & 0.225\end{array}$

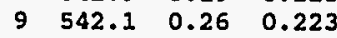

$\begin{array}{llll}11 & 541.3 & 0.33 & 0.221\end{array}$

$\begin{array}{llll}13 & 540.6 & 0.40 & 0.218\end{array}$

$\begin{array}{llll}15 & 539.8 & 0.47 & 0.216\end{array}$
RUN NUMBER: 673

$\mathrm{p} / \mathrm{d}=1.5$
$\mathrm{p}$ in $=549.65 \mathrm{kPa}$

$\mathrm{Xin}=-.00$

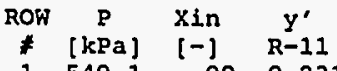

$\begin{array}{llll}{[\mathrm{kPa}]} & {[-]} & \mathrm{R}-11 \\ 1 & 549.1 & -.00 & 0.231\end{array}$

$\begin{array}{llll}548.1 & 0.08 & 0.228\end{array}$

$\begin{array}{lll}546.3 & 0.25 & 0.223\end{array}$

$\begin{array}{llll}9 & 545.5 & 0.34 & 0.221\end{array}$

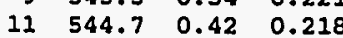

$\begin{array}{llll}13 & 543.9 & 0.51 & 0.215\end{array}$

$\begin{array}{llll}15 & 543.1 & 0.59 & 0.213\end{array}$

RUN NUMBER: 670

$\mathrm{p} / \mathrm{d}=1.5$

Pin $=549.65 \mathrm{kPa}$

$\begin{array}{rccc}\text { ROW } & \text { P } & \text { Xin } & Y^{\prime} \\ \# & {[k P a]} & {[-]} & R-11 \\ 1 & 549.1 & -.00 & 0.231 \\ 3 & 548.0 & 0.10 & 0.228 \\ 5 & 546.9 & 0.19 & 0.225 \\ 7 & 546.0 & 0.29 & 0.221 \\ 9 & 545.1 & 0.39 & 0.218 \\ 11 & 544.3 & 0.49 & 0.215 \\ 13 & 543.6 & 0.58 & 0.212 \\ 15 & 542.8 & 0.67 & 0.209\end{array}$ $\mathrm{y}^{\prime}$ in $=23.18 \mathrm{R}-11 / 76.9 \& \mathrm{R}-113$ $G=49.04 \mathrm{~kg} / \mathrm{B}^{\star} \mathrm{m} \wedge 2$
DELTA $P$ total $=6.43 \mathrm{kPa}$ xout $=0.50$

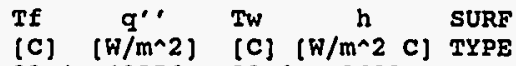
$82.4 \quad 40976 \quad 93.6 \quad 3639$ H.F. $83.740597 \quad 93.8 \quad 4035 \quad H$. $84.3 \quad 39680$ 93.5 4316 H.E. $84.940555 \quad 98.2 \quad 3070$ SH. $85.64001908 .2 \quad 3160$ SH. 86.240265 95.1 4525 . $\begin{array}{lllll}86.8 & 40388 & 95.1 & 4858 & \text { T.B. }\end{array}$

$y^{\prime}$ in $=23.1 \& R-11 / 76.9 \& R-113$ $G=48.73 \mathrm{~kg} / \mathrm{g}^{\star} \mathrm{m}^{\wedge} 2$ DELTA $P$ total $=6.59 \mathrm{kPa}$ Xout $=0.63$

\begin{tabular}{|c|c|c|c|c|}
\hline [C] & $\underset{\left[w / m^{\wedge} 2\right]}{q^{\prime \prime}}$ & $\begin{array}{l}T w \\
{[C]}\end{array}$ & {$\left[\begin{array}{lll}\stackrel{h}{h} & c\end{array}\right]$} & $\begin{array}{l}\text { SURF } \\
\text { TYPE }\end{array}$ \\
\hline 82.6 & 51265 & 95.5 & 3970 & H.F. \\
\hline 84.1 & 50713 & 95.8 & 4348 & H.F. \\
\hline 84.8 & 49446 & 95.5 & 4628 & H.F. \\
\hline 85.5 & 50611 & 100.2 & 3440 & SM. \\
\hline 86.1 & 50047 & 100.3 & 3546 & SM. \\
\hline & 50216 & 97 & 4766 & T.B. \\
\hline 87. & 50390 & 97 & 5078 & T.B. \\
\hline & & 96 & 6224 & \\
\hline
\end{tabular}

$Y^{\prime}$ in $=23.1 \& R-11 / 76.9 \& R-113$ $G=48.83 \mathrm{~kg} / g^{*} m^{\wedge} 2$ $\begin{aligned} \text { DELTA P total } & =6.87 \mathrm{kPa} \\ \text { Xout } & =0.77\end{aligned}$

\begin{tabular}{|c|c|c|c|c|}
\hline $\begin{array}{l}\text { Tf } \\
\text { [C] }\end{array}$ & $\underset{\left[w / m^{\wedge} 2\right]}{q^{\prime \prime}}$ & $\begin{array}{l}T w \\
\text { [C] }\end{array}$ & $\left.\frac{h}{/ m^{\wedge} 2} \quad c\right]$ & $\begin{array}{l}\text { SURF } \\
\text { TYPE }\end{array}$ \\
\hline 32.9 & $62639^{\circ}$ & 95.9 & 4826 & H.F. \\
\hline 84.2 & 62010 & 96.2 & 5141 & H.F. \\
\hline 84.8 & 60501 & 95.8 & 5508 & H.F. \\
\hline 85.5 & 61792 & 100.8 & 4053 & SM. \\
\hline 86.2 & 61064 & 100.9 & 4162 & SM. \\
\hline & 60789 & & 5476 & T.B. \\
\hline 37.6 & 61120 & 98. & 5857 & T.B. \\
\hline 3.3 & 60565 & 96.8 & 7098 & $B$ \\
\hline
\end{tabular}


RUN NUMBER: 683

$\mathrm{P} / \mathrm{d}=1.5$

$\operatorname{xin}=-.00$

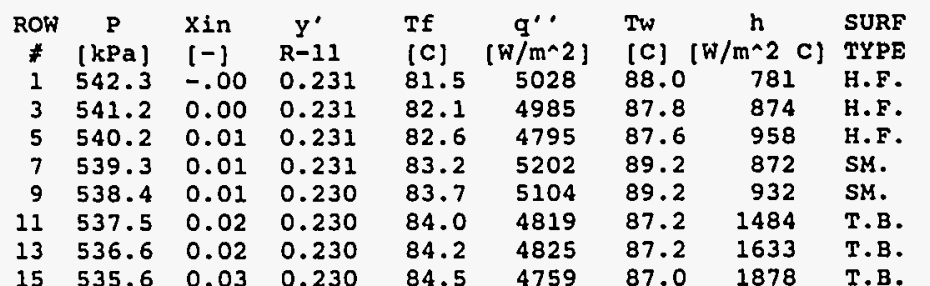

RUN NUMBER: 681

$\mathrm{p} / \mathrm{d}=1.5$

Pin $=546.2 \mathrm{kPa}$

$\operatorname{xin}=-.00$

\begin{tabular}{rccc} 
ROW & P & Xin & \multicolumn{1}{c}{$\mathbf{Y}^{\prime}$} \\
* & {$[\mathrm{kPa}]$} & {$[-]$} & $\mathrm{R}-11$ \\
1 & 545.7 & -.00 & 0.231 \\
3 & 544.7 & 0.01 & 0.231 \\
5 & 543.7 & 0.01 & 0.230 \\
7 & 542.8 & 0.02 & 0.230 \\
9 & 541.9 & 0.03 & 0.230 \\
11 & 541.0 & 0.04 & 0.230 \\
13 & 540.1 & 0.05 & 0.229 \\
15 & 539.2 & 0.06 & 0.229
\end{tabular}

$y^{\prime}$ in $=23.18 R-11 / 76.9 \& R-113$ $\begin{aligned} \text { DELTA } P \text { total } & =7.02 \mathrm{kPa} \\ \text { Xout } & =0.06\end{aligned}$

\begin{tabular}{|c|c|c|c|c|}
\hline $\begin{array}{l}T f \\
\text { [C] }\end{array}$ & $\begin{array}{c}q^{\prime \prime} \\
{\left[w / m^{\wedge} 2\right]}\end{array}$ & $\begin{array}{l}T w \\
\text { ( }) \text { ] }\end{array}$ & 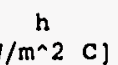 & $\begin{array}{l}\text { SURF } \\
\text { TYPE }\end{array}$ \\
\hline 82.0 & 10808 & 90.0 & 1350 & H.F. \\
\hline 83.2 & 10719 & 89.6 & 1655 & H.F. \\
\hline 84.0 & 10304 & 89.5 & 1889 & H.F. \\
\hline 84.5 & 10763 & 92.4 & 1356 & SM. \\
\hline 85.0 & 10517 & 92.5 & 1390 & SM. \\
\hline 85.4 & 10397 & 89.7 & 2428 & T. B. \\
\hline & 10411 & & 2803 & T. B. \\
\hline & 10271 & 39 . & 3655 & T. B. \\
\hline
\end{tabular}

RUN NUMBER: 678

$\mathrm{p} / \mathrm{d}=1.5$

Pin $=546.2 \mathrm{kPa}$

ROW $P$ Xin $Y^{\circ}$

$\begin{array}{llll}\text { \# } & {[\mathrm{kPa}]} & {[-]} & \mathrm{R}-11 \\ 1 & 545.7 & -.00 & 0.231\end{array}$

$\begin{array}{lll}545.7 & -.00 & 0.231 \\ 344.6 & 0.01 & 0.230\end{array}$

$\begin{array}{llll}5 & 543.7 & 0.03 & 0.230\end{array}$

$\begin{array}{llll}542.7 & 0.05 & 0.229\end{array}$

$\begin{array}{llll}9 & 541.8 & 0.07 & 0.229\end{array}$

$\begin{array}{llll}11 & 541.0 & 0.08 & 0.228\end{array}$

$\begin{array}{llll}15 & 539.3 & 0.12 & 0.227\end{array}$ $y^{\prime}$ in $=23.18 R-11 / 76.9 \& R-113$

$=7.14 \mathrm{kPa}$
xout $=0.03$

\section{RF}

DELTA P total $=6.9 \mathrm{kPa}$

xout $=0.13$

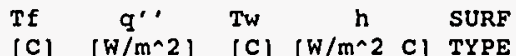

$\left.82.1 \mathrm{~W} / \mathrm{m}^{\wedge} 2\right]$ [C] $\left[\mathrm{W} / \mathrm{m}^{\wedge} 2\right.$ C] TYPE

83.621045 91.6 2209 H.F.

$84.220096 \quad 91.4 \quad 2808$ H.F.

$84.820775 \quad 95.3 \quad 1976$ SM.

$85.420369 \quad 95.4 \quad 2043 \quad$ SM.

$\begin{array}{lllll}86.0 & 20504 & 91.9 & 3477 & \text { T.B. } \\ 86.5 & 20538 & 92.0 & 3730 & T . B .\end{array}$

$\begin{array}{lllll}86.5 & 20538 & 92.0 & 3730 & \text { T.B. } \\ 87.1 & 20299 & 91.5 & 4612 & \text { T.B. }\end{array}$
RUN NUMBER: 674
RUN NUMBER: 676

$\mathrm{p} / \mathrm{d}=1.5$

Pin $=546.2 \mathrm{kPa}$

$\operatorname{xin}=0.07$

$\begin{array}{rccc}\text { ROW } & \mathrm{P} & \mathrm{Xin} & \mathrm{Y} \\ \# & {[\mathrm{kPa}]} & {[-]} & \mathrm{R}-11 \\ 1 & 545.7 & 0.07 & 0.231 \\ 3 & 544.6 & 0.10 & 0.230 \\ 5 & 543.7 & 0.12 & 0.229 \\ 7 & 542.7 & 0.15 & 0.229 \\ 9 & 541.9 & 0.17 & 0.228 \\ 11 & 541.1 & 0.20 & 0.227 \\ 13 & 540.4 & 0.23 & 0.226 \\ 15 & 539.6 & 0.25 & 0.226\end{array}$

$\mathrm{p} / \mathrm{d}=1.5$

Pin $=546.2 \mathrm{kPa}$
$x$ in $=-.00$

$\begin{array}{rccc}\text { ROW } & \text { P } & \text { Xin } & Y^{\prime} \\ * & (\mathrm{kPa}) & (-) & \mathrm{R}^{\prime}-11 \\ 1 & 545.7 & -.00 & 0.231 \\ 3 & 544.6 & 0.03 & 0.230 \\ 5 & 543.6 & 0.06 & 0.229 \\ 7 & 542.6 & 0.10 & 0.228 \\ 9 & 541.8 & 0.13 & 0.227 \\ 11 & 541.0 & 0.17 & 0.226 \\ 13 & 540.2 & 0.20 & 0.225 \\ 15 & 539.4 & 0.23 & 0.224\end{array}$

RUN NUMBER: 672

Pin $=549.65 \mathrm{kPa}$

$y^{\prime}$ in $=23.1$ \& $R-11 / 76.9 \& R-113$ DELTA $P$ total $=6.64 \mathrm{kPa}$ Xout $=0.26$

\begin{tabular}{|c|c|c|c|c|}
\hline $\begin{array}{l}\text { Tf } \\
\text { (c) }\end{array}$ & $\underset{[w / m-2]}{q^{\prime \prime}}$ & & $\stackrel{\substack{h \\
/ m^{\wedge} 2}}{c}$ & $\begin{array}{l}\text { SURF } \\
\text { TYPE }\end{array}$ \\
\hline & 31242 & 92.5 & 2981 & H.F. \\
\hline 1.7 & 30977 & 92.5 & 3501 & H.F. \\
\hline 4.3 & 29840 & 92.3 & 3730 & H.F. \\
\hline 34.9 & 30890 & 96.7 & 2607 & SM. \\
\hline 35.5 & 30396 & 96.8 & 2691 & SM. \\
\hline 6.1 & 30512 & 93.4 & 4196 & T.B. \\
\hline 6.7 & 30573 & 93.5 & 4505 & T.B. \\
\hline 7.3 & 30267 & 92.5 & 5798 & \\
\hline
\end{tabular}

$y^{\prime}$ in $=23.1 \& \mathrm{R}-11 / 76.9 \& \mathrm{R}-113$ DELTA $P$ total $=6.81 \mathrm{kPa}$ Xout $=0.25$

\begin{tabular}{|c|c|c|c|c|}
\hline c) & {$\left[W / m^{\wedge} 2\right]$} & [C] & {$\left[W / m^{n} 2 \quad c\right]$} & \\
\hline 2 . & 41003 & 93.4 & 3703 & \\
\hline & & & 4100 & \\
\hline & 395 & & 4384 & \\
\hline${ }^{\circ}$ & 406 & & & \\
\hline & 401 & & 3222 & \\
\hline & 403 & & 4615 & \\
\hline & $404 \epsilon$ & & 4940 & \\
\hline & & & & \\
\hline
\end{tabular}

ROW $\begin{array}{ccc}P & X i n & y^{\prime} \\ \text { [KPa] } & {[-]} & R-11\end{array}$

$1 \quad 549.1 \quad-.00 \quad 0.231$

3 548.0 $0.04 \quad 0.230$

$\begin{array}{llll}5 & 547.0 & 0.08 & 0.228\end{array}$

$\begin{array}{llll}7 & 546.0 & 0.12 & 0.227\end{array}$

$\begin{array}{llll}9 & 545.2 & 0.17 & 0.226\end{array}$

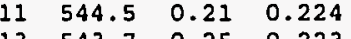

$\begin{array}{lllll}15 & 543.0 & 0.30 & 0.222\end{array}$ $y^{\prime}$ in $=23.18 R-11 / 76.98 R-113$
$G=195.47 \mathrm{~kg} / \mathrm{s}^{*} \mathrm{~m}^{\wedge} 2$ DELTA P total $=6.68 \mathrm{kPa}$ xout $=0.32$

\begin{tabular}{|c|c|c|c|c|}
\hline $\begin{array}{l}\text { Tf } \\
(\mathrm{C})\end{array}$ & $\underset{[w / m \wedge 2]}{q \cdots}$ & (c) & $\stackrel{h}{h}\left(m^{\wedge} 2 c\right)$ & SURE \\
\hline 82.6 & 51441 & 94.9 & 4194 & \\
\hline $\begin{array}{l}84.1 \\
84.8\end{array}$ & $\begin{array}{l}50939 \\
49657\end{array}$ & $\begin{array}{l}95.1 \\
94.8\end{array}$ & $\begin{array}{l}4642 \\
4974\end{array}$ & \\
\hline 5.5 & 50780 & 99.6 & 3594 & \\
\hline 6.1 & 50172 & 99.7 & 3712 & \\
\hline 6.8 & 50307 & 96.7 & 5089 & \\
\hline 7.5 & 50525 & 96.8 & 5432 & \\
\hline 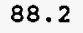 & 50147 & $a r$ & 6774 & \\
\hline
\end{tabular}




\begin{tabular}{|c|c|c|c|c|c|c|c|c|}
\hline $\begin{array}{l}\text { RUN } \\
\text { p/d } \\
\text { Pin } \\
\text { Xin }\end{array}$ & $\begin{array}{l}\text { NUMBE } \\
=1.5 \\
=549 \\
=-.0\end{array}$ & $5 \mathrm{kPz}$ & & In & $\begin{array}{r}23.18 \\
\text { DELT }\end{array}$ & $\begin{array}{l}R-11 \\
G=1 \\
A P \text { tot }\end{array}$ & $\begin{array}{r}76.98 \\
95.1 \mathrm{~kg} / \\
\text { tal }=6.5 \\
\text { xout }\end{array}$ & $\begin{array}{l}R-113 \\
\pi_{\mathrm{m}^{\wedge} 2} \\
1 \mathrm{kPa} \\
0.38\end{array}$ \\
\hline ROW & $\stackrel{P}{P}$ & $x$ in & $y^{\prime}$ & $T f$ & $q^{\prime \prime}$ & $T w$ & $h$ & SURF \\
\hline$\neq$ & [kPa] & {$[-]$} & $R-11$ & [C] & {$\left[W / m^{\wedge} 2\right]$} & [c] & {$\left[W / m^{\wedge} 2 \quad c\right]$} & TYPE \\
\hline 1 & 549.1 & -.00 & 0.231 & 82.9 & 6225 & 95.8 & 4839 & H.F. \\
\hline 3 & 548.0 & 0.05 & & 2 & & & 5149 & \\
\hline 5 & 547.0 & 0.10 & 0.228 & 84.8 & 60016 & 95.7 & 5516 & H.F. \\
\hline 7 & 546.0 & 0. & 0.2 & & & & 4052 & SM. \\
\hline 9 & 545.1 & 0.20 & 0.22 & & 60589 & 100.7 & 4183 & SM. \\
\hline & & & & & & & & \\
\hline 13 & 543 & 0 & & & & & 5885 & Т.в. \\
\hline 15 & 542.7 & .36 & 0.220 & 88.3 & 60170 & 96.6 & 7202 & T.B. \\
\hline
\end{tabular}

\begin{tabular}{|c|c|c|c|c|c|c|c|c|}
\hline \multicolumn{4}{|c|}{$\begin{array}{l}\text { RUN NUMBER: } 668 \\
\text { p/d }=1.5 \\
\text { Pin }=549.65 \mathrm{kPa} \\
\text { Xin }=-.00\end{array}$} & \multicolumn{5}{|c|}{$\begin{array}{r}y^{\prime} \text { in }=23.1 \& \mathrm{R}-11 / 76.98 \mathrm{R}-113 \\
\mathrm{G}=195.54 \mathrm{~kg} / \mathrm{s}^{\star} \mathrm{m}^{\wedge} 2 \\
\text { DELTA P total }=6.81 \mathrm{kPa} \\
\text { Xout }=0.46\end{array}$} \\
\hline ROW & $\stackrel{P}{\stackrel{\mathrm{kPa}}{2}]}$ & & $\underset{R-11}{y^{\prime}}$ & Tf & $\underset{\left[w / m^{\wedge} 2\right]}{q \cdots}$ & $\begin{array}{l}T w \\
C \\
C\end{array}$ & $\stackrel{h}{h m^{\wedge} 2} c$ & $\begin{array}{l}\text { SURF } \\
\text { TYPE }\end{array}$ \\
\hline 1 & & & & & & 96.7 & 5416 & H.F. \\
\hline 3 & 548.0 & 0.0 & & & & & 57 & H.F. \\
\hline 5 & & & & & & & & \\
\hline 7 & 546.0 & 0 & 0.2 & & 734 & & 45 & \\
\hline 9 & & & & & & & & \\
\hline & & & & & & & & \\
\hline 1 & & & & & & & & B. \\
\hline 15 & & & & & & 98.0 & 7648 & T.B. \\
\hline
\end{tabular}

\begin{tabular}{|c|c|c|c|c|c|c|c|c|}
\hline $\begin{array}{l}\text { RUN } \\
\text { p/d } \\
\text { Pin } \\
\text { Xin }\end{array}$ & $\begin{array}{l}\text { NUMBE } \\
=1.5 \\
=549 \\
=-.0\end{array}$ & $65 \mathrm{kP}$ & & in & $\begin{array}{r}23.18 \\
\text { DELT }\end{array}$ & $\begin{array}{l}R-11 \\
G=1 \\
P \text { P tc }\end{array}$ & $\begin{array}{l}76.98 \\
6.21 \mathrm{~kg} / \\
a 1=6.8 \\
\text { Xout }=\end{array}$ & $\begin{array}{l}\mathrm{R}-113 \\
\mathrm{~g} \mathrm{~m}^{-2}-2 \\
\mathrm{kPa} \\
0.50\end{array}$ \\
\hline ROW & $\stackrel{p}{P}$ & $x$ in & $\underset{8-11}{y^{\prime}}$ & $\begin{array}{l}\text { Tf } \\
\text { (c) }\end{array}$ & $\stackrel{q \cdot}{q \cdot}$ & $T w$ & $\stackrel{h}{W / m^{\wedge} 2}$ & SURE \\
\hline 1 & 549.1 & -.00 & 0.231 & 82.5 & & 97.0 & 5649 & H.F. \\
\hline 3 & & 0. & & & & & & \\
\hline 5 & 546.9 & 0.1 & 0.2 & 85 & 78 & 96.8 & 6660 & H.F. \\
\hline 7 & 545.9 & 0. & & & & & & \\
\hline 9 & 545.2 & 0 & & & & & 50 & SM. \\
\hline 11 & 544.4 & 0 & & & & & 64 & T.B. \\
\hline 12 & & 0 & & & & & 6820 & T.B. \\
\hline 15 & 542.9 & 0.45 & 0.217 & 88.6 & 79258 & 98.7 & 7904 & Т. B. \\
\hline
\end{tabular}




\section{Bundle Boiling Data}

Data from the $50 \% \mathrm{R}-11 / 50 \% \mathrm{R}-113$ mixture 


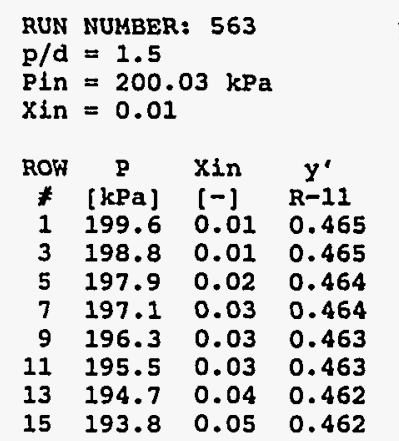

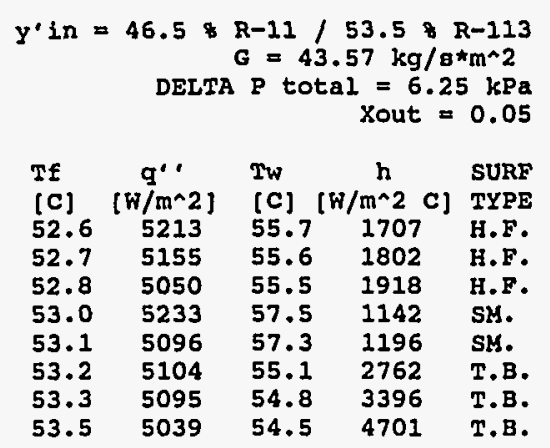

RUN NUMBER: 561

$\mathrm{p} / \mathrm{d}=1.5$

Pin $=200.03 \mathrm{kPa}$

$\begin{array}{cccc}\text { ROW } & P & \text { Xin } & y^{\prime} \\ * & {[\mathrm{kPa}]} & {[-]} & \mathrm{R}-11\end{array}$

$\begin{array}{llll}* & {[\mathrm{kPa}]} & {[-]} & \mathrm{R}-11 \\ 1 & 199.6 & 0.00 & 0.465\end{array}$

$\begin{array}{llll}3 & 198.8 & 0.02 & 0.464\end{array}$

$\begin{array}{llll}5 & 198.0 & 0.03 & 0.463\end{array}$

9 196.3 0.050 .462

$\begin{array}{llll}11 & 195.4 & 0.05 & 0.460\end{array}$

$\begin{array}{llll}13 & 194.6 & 0.06 & 0.459\end{array}$

$\begin{array}{lllll}15 & 193.6 & 0.08 & 0.459\end{array}$

\section{RUN NUMBER: 550}

$\mathrm{p} / \mathrm{d}=1.5$

Pin $=198.65 \mathrm{kPa}$

$\begin{array}{rrrr}\text { ROW } & \text { P } & \text { Xin } & y^{\prime} \\ \text { \# } & {[\mathrm{kPa}]} & {[-]} & \mathrm{R}-11 \\ 1 & 198.2 & -.00 & 0.465 \\ 3 & 197.2 & 0.02 & 0.463 \\ 5 & 196.3 & 0.05 & 0.461 \\ 7 & 195.4 & 0.08 & 0.460 \\ 9 & 194.5 & 0.11 & 0.458 \\ 11 & 193.5 & 0.14 & 0.456 \\ 13 & 192.5 & 0.17 & 0.454 \\ 15 & 191.5 & 0.19 & 0.453\end{array}$

\begin{tabular}{|c|c|c|c|c|}
\hline $\begin{array}{l}\text { Tf } \\
\text { (c) }\end{array}$ & $\underset{\left[w / m^{\wedge} 2\right.}{q^{\prime \prime}}$ & $\begin{array}{l}\mathrm{TW} \\
\text { (c) }\end{array}$ & $\stackrel{h}{h m^{\wedge} 2 c}$ & $\begin{array}{l}\text { SURF } \\
\text { TYPE }\end{array}$ \\
\hline 51.9 & 20125 & 57.8 & 3365 & H.F. \\
\hline 2.0 & 19826 & 58.4 & 3109 & H.F. \\
\hline 52.2 & 19466 & 57.8 & 3482 & H.F. \\
\hline 52.3 & 20086 & 63.5 & 1793 & SM. \\
\hline 52.5 & 19684 & 63.1 & 1840 & SM. \\
\hline 52.6 & 19789 & & 4074 & T.B. \\
\hline 52.7 & 19725 & 57.4 & 4244 & T.B. \\
\hline 52.9 & 19537 & 56.4 & 5.463 & 7 \\
\hline
\end{tabular}

RUN NUMBER: 559

$\mathrm{p} / \mathrm{d}=1.5$

Pin $=202.79 \mathrm{kPa}$

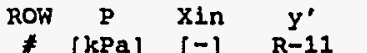

$\begin{array}{llll}* & {[\mathrm{KPa}]} & {[-]} & \mathrm{R}-11 \\ 1 & 202.7 & 0.00 & 0.465\end{array}$

$\begin{array}{llll}3 & 202.4 & 0.04 & 0.462\end{array}$

$\begin{array}{llll}5 & 201.9 & 0.09 & 0.460\end{array}$

$\begin{array}{llll}7 & 201.2 & 0.11 & 0.457\end{array}$

$\begin{array}{llll}9 & 200.2 & 0.12 & 0.454\end{array}$

$\begin{array}{llll}11 & 199.2 & 0.13 & 0.451\end{array}$

$\begin{array}{lllll}15 & 196.9 & 0.21 & 0.446\end{array}$

RUN NUMBER: 558

Pin $=202.1 \mathrm{kPa}$

$\mathrm{xin}=0.00$

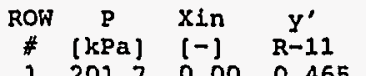

$\begin{array}{llll}1 & 201.7 & 0.00 & 0.465 \\ 3 & 200.7 & 0.06 & 0.461\end{array}$

$\begin{array}{llll}5 & 199.8 & 0.12 & 0.458\end{array}$

$\begin{array}{llll}7 & 198.9 & 0.16 & 0.454\end{array}$

$\begin{array}{llll}9 & 198.0 & 0.17 & 0.450\end{array}$

$\begin{array}{llll}11 & 197.2 & 0.19 & 0.447\end{array}$

$\begin{array}{llll}13 & 196.3 & 0.24 & 0.443\end{array}$

$\begin{array}{llll}15 & 195.3 & 0.30 & 0.440\end{array}$

RUN NUMBER: 557

$\mathrm{p} / \mathrm{d}=1.5$

Pin $=204.86 \mathrm{kPa}$

$x$ in $=-.01$

$\begin{array}{rccc}\text { ROW } & \text { P } & \text { Xin } & Y^{\prime} \\ \# & {[k P a]} & {[-]} & R-11 \\ 1 & 204.4 & -.01 & 0.465 \\ 3 & 203.4 & 0.07 & 0.460 \\ 5 & 202.6 & 0.14 & 0.456 \\ 7 & 201.7 & 0.18 & 0.451 \\ 9 & 200.8 & 0.19 & 0.447 \\ 11 & 199.9 & 0.22 & 0.442 \\ 13 & 199.0 & 0.27 & 0.438 \\ 15 & 198.0 & 0.34 & 0.434\end{array}$ $y^{\prime}$ in $=46.5 \& R-11 / 53.5 \& R-113$ $G=51.59 \times g^{2} / \mathrm{R}^{2} 2$ Xout $=0.23$

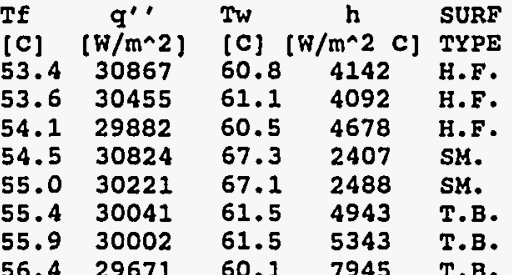

$y^{\prime}$ in $=46.5 \& \mathrm{R}-11 / 53.5 \& \mathrm{R}-113$ $G=48.68 \mathrm{~kg} / \mathrm{s}^{*} \mathrm{~m}^{\wedge}$ DELTA $\mathrm{p}$ total $=6.79 \mathrm{kPa}$ xout $=0.32$

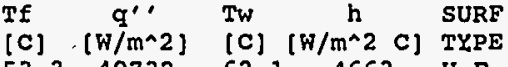
$53.34073262 .1 \quad 4663$ H.F. $\begin{array}{lllll}53.5 & 40113 & 62.3 & 4561 & \text { H.F. }\end{array}$ $53.8 \quad 39367 \quad 61.6 \quad 5037$ H.F. $\begin{array}{lllll}54.1 & 40729 & 69.1 & 2718 & \text { SM. }\end{array}$ $\begin{array}{lllll}54.5 & 40090 & 69.1 & 2748 & \text { SM. }\end{array}$ $\begin{array}{llllll}54.8 & 39997 & 63.5 & 4581 & \text { T.B. }\end{array}$ $\begin{array}{lllll}55.1 & 39917 & 63.7 & 4682 & \text { T.B. }\end{array}$ $y^{\prime}$ in $=46.5 \& R-11 / 53.5 \& R-113$ $G=50.82 \mathrm{~kg} / \mathrm{s}^{\star} \mathrm{m}^{\wedge} 2$ DELTA $P$ total $=6.9 \mathrm{kPa}$ xout $=0.38$

\begin{tabular}{|c|c|c|c|c|}
\hline & $\frac{q^{\prime \prime}}{\left[w / m^{\wedge} 2\right]}$ & $\begin{array}{l}\text { TW } \\
\text { [C] }\end{array}$ & $\stackrel{h}{h}$ & \\
\hline 52.6 & 51194 & 63.4 & 4748 & H.I \\
\hline & 50355 & 63.8 & 4744 & \\
\hline 3.4 & 49492 & 63.1 & 5079 & H. \\
\hline & 50931 & 71.0 & 2927 & \\
\hline 3.8 & 50222 & 70.9 & 2928 & \\
\hline & 49932 & 65. & 4230 & \\
\hline 1. & 49855 & 65.9 & 4259 & \\
\hline & 49646 & 64.2 & 5078 & \\
\hline
\end{tabular}




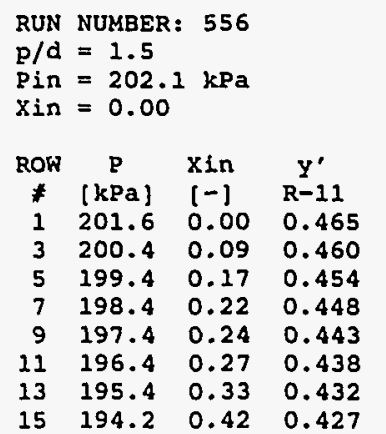
$Y^{\prime}$ in $=46.5 \& R-11 / 53.5 \& R-113$
$G=51.18 \mathrm{~kg} / \mathrm{s}^{*} \mathrm{~m}^{\wedge} 2$
DELTA $P$ total $=7.87 \mathrm{kPa}$
Xout $=0.46$

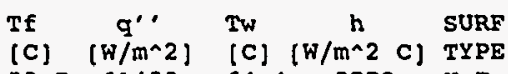

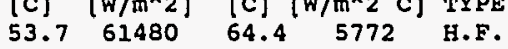
$\begin{array}{lllll}53.7 & 61480 & 64.4 & 5772 & \text { H.F. } \\ 54.0 & 60472 & 64.9 & 5566 & \text { H.F. }\end{array}$
$54.5 \quad 59536 \quad 64.1 \quad 6183$ H.F.
$\begin{array}{lllll}54.9 & 61132 & 72.4 & 3514 & \text { SM. }\end{array}$
$\begin{array}{lllll}55.4 & 60358 & 72.3 & 3574 & \mathrm{SM} .\end{array}$
$\begin{array}{lllll}55.9 & 60000 & 67.4 & 5232 & \text { T.B. }\end{array}$
$\begin{array}{lllll}56.4 & 60104 & 67.8 & 5287 & \text { T.B. } \\ 56.9 & 59716 & 66.4 & 6266 & \text { T.B. }\end{array}$

RUN NUMBER: 562
$\mathrm{p} / \mathrm{d}=1.5$

$\mathrm{p} / \mathrm{d}=1.5$
pin $=202.1 \mathrm{kPa}$

$x_{\text {in }}=-.01$

$\begin{array}{rccc}\text { ROW } & \text { P } & \text { Xin } & y^{\prime} \\ \# & {[k P a]} & {[-]} & R-11 \\ 1 & 201.7 & -.00 & 0.465 \\ 3 & 200.7 & 0.00 & 0.465 \\ 5 & 199.9 & 0.00 & 0.465 \\ 7 & 199.0 & 0.01 & 0.464 \\ 9 & 198.1 & 0.01 & 0.464 \\ 11 & 197.2 & 0.01 & 0.464 \\ 13 & 196.4 & 0.01 & 0.464 \\ 15 & 195.5 & 0.02 & 0.463\end{array}$

RUN NUMBER: 560

$\mathrm{p} / \mathrm{d}=1.5$

Pin $=199.34 \mathrm{kPa}$

$x$ in $=0.02$

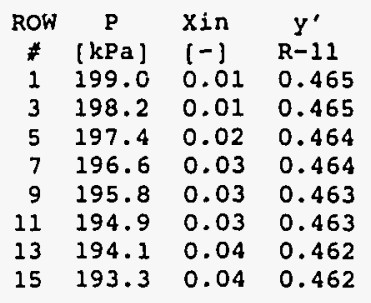

$y^{\prime}$ in $=46.5 \& R-11 / 53.5 \& R-113$ $G=91.65 \mathrm{~kg} / \mathrm{g}^{*} \mathrm{~m}^{\wedge} 2$
DELTA $P$ total $=6.64 \mathrm{kPa}$ xout $=0.02$

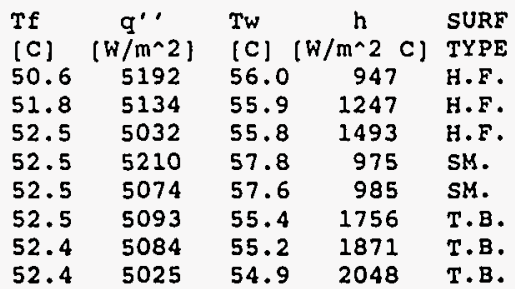

$\mathrm{y}^{\prime}$ in $=46.5 \otimes R-11 / 53.5 \& \mathrm{R}-113$ $G=98.44 \mathrm{~kg} / \mathrm{s}^{\star} \mathrm{m}^{\wedge} 2$ DELTA $P$ total $=6.1 \mathrm{kPa}$ xout $=0.05$

\begin{tabular}{|c|c|c|c|c|}
\hline $\begin{array}{l}\text { Tf } \\
\text { (C) }\end{array}$ & $\underset{\left(w / m^{\wedge} 2\right)}{q{ }^{\prime \prime}}$ & $\begin{array}{l}T w \\
\text { (C) }\end{array}$ & $\frac{h}{1 / m^{\wedge} 2 \quad c \mid}$ & $\begin{array}{l}\text { SURF } \\
\text { TYPE }\end{array}$ \\
\hline 3.0 & $10289^{\circ}$ & 56.7 & 2803 & H.F. \\
\hline 53.1 & 10165 & 56.6 & 2900 & H.F. \\
\hline . & 9966 & 56.4 & 3220 & \\
\hline 53.5 & 10173 & 60.3 & 1495 & SM. \\
\hline 53.6 & 9887 & 59.9 & 1569 & SM. \\
\hline 53.8 & 10096 & 56.1 & 4363 & T.B. \\
\hline .0 & 10077 & 56.0 & 5126 & T. \\
\hline 4.2 & 9968 & 55.4 & 7929 & T.B. \\
\hline
\end{tabular}

RUN NUMBER: 551

$\mathrm{p} / \mathrm{d}=1.5$

Pin $=198.65 \mathrm{kPa}$

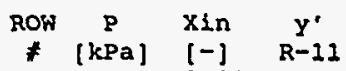

$\begin{array}{llll}\text { \# } & {[\mathrm{kPa}]} & {[-]} & \mathrm{R}-11 \\ 1 & 198.2 & 0.00 & 0.465\end{array}$

$3 \begin{array}{lll}197.2 & 0.02 & 0.464\end{array}$

$\begin{array}{llll}196.3 & 0.03 & 0.463\end{array}$

$\begin{array}{llll}7 & 195.3 & 0.04 & 0.462\end{array}$

$\begin{array}{llll}194.4 & 0.05 & 0.461\end{array}$

$11 \quad 193.4 \quad 0.05 \quad 0.460$

$\begin{array}{llll}13 & 192.4 & 0.07 & 0.459 \\ 15 & 191.4 & 0.08 & 0.459\end{array}$

RUN NUMBER: 552

$\mathrm{p} / \mathrm{d}=1.5$

Pin $=202.1 \mathrm{kPa}$

$\begin{array}{rccc}\text { ROW } & p & x \text { in } & y^{\prime} \\ * & {[\mathrm{kPa}]} & {[-]} & \mathrm{R}^{-11} \\ 1 & 201.6 & 0.00 & 0.465 \\ 3 & 200.5 & 0.02 & 0.464 \\ 5 & 199.6 & 0.05 & 0.462 \\ 7 & 198.6 & 0.06 & 0.461 \\ 9 & 197.6 & 0.06 & 0.459 \\ 11 & 196.7 & 0.07 & 0.458 \\ 13 & 195.7 & 0.09 & 0.457 \\ 15 & 194.6 & 0.11 & 0.455\end{array}$

RUN NUMBER: 553

$\mathrm{p} / \mathrm{d}=1.5$

in $=202.1 \mathrm{kPa}$

$x_{\text {in }}=0.00$

$\begin{array}{rccl}\text { ROW } & \begin{array}{c}\mathrm{P} \\ \text { \# }\end{array} & \text { Xin } & \mathrm{Y}^{\prime} \\ 1 & {[\mathrm{kPa}]} & {[-]} & \mathrm{R}-11 \\ 1 & 201.7 & 0.00 & 0.465 \\ 3 & 200.9 & 0.03 & 0.463 \\ 5 & 200.2 & 0.06 & 0.461 \\ 7 & 199.4 & 0.08 & 0.459 \\ 9 & 198.6 & 0.08 & 0.458 \\ 11 & 197.8 & 0.09 & 0.456 \\ 13 & 197.0 & 0.11 & 0.454 \\ 15 & 196.2 & 0.14 & 0.452\end{array}$
$Y^{\prime}$ in $=46.5 \& R-11 / 53.5 \& R-113$ $G=92.48 \mathrm{~kg} / \mathrm{g}^{\star} \mathrm{m}^{\wedge} 2$ DELTA P total $=7.25 \mathrm{kPa}$ out $=0.09$

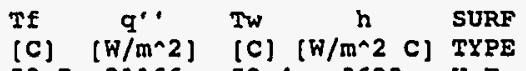
$53.7 \begin{array}{lllll}21166 & 59.4 & 3693 & \text { H.F. }\end{array}$ $53.920803 \quad 59.8 \quad 3535$ H.F. $54.420426 \quad 59.5$ 4011 H.F. $55.320574 \quad 64.92161$ SM. $55.8 \quad 20638 \quad 59.4 \quad 5710$ SM. $\begin{array}{lllll}56.3 & 20555 & 59.3 & 6762 & T . B .\end{array}$ $\begin{array}{lllll}56.8 & 20557 & 59.3 & 6762 & \text { T.B. }\end{array}$

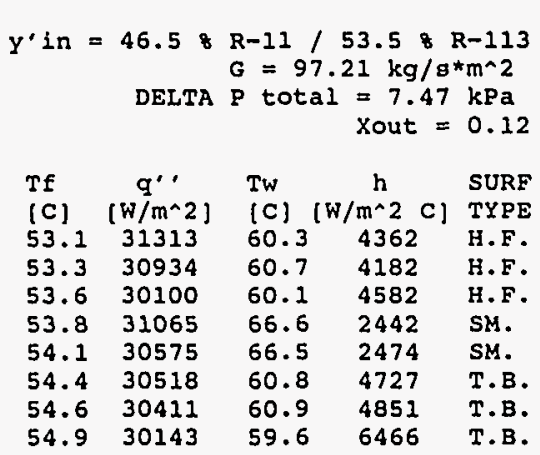

$Y^{\prime}$ In $=46.5 \& \mathrm{R}-11 / 53.5 \& \mathrm{R}-113$ $G=100.76 \mathrm{~kg} / 8 \mathrm{~s}^{\wedge} 2$ DELTA $P$ total $=5.87 \mathrm{kPa}$ xout $=0.16$

\begin{tabular}{|c|c|c|c|c|}
\hline & $q^{\prime \prime}$ & $\begin{array}{l}\text { Tw } \\
\text { [C] }\end{array}$ & $\stackrel{h}{m \wedge 2}$ & $\begin{array}{l}\text { SURF } \\
\text { TYPE }\end{array}$ \\
\hline 52.6 & 41572 & 61.8 & 4552 & H.F. \\
\hline 52.7 & 41051 & 62.1 & 4362 & H.F. \\
\hline 52.8 & 40380 & 61.4 & 4676 & H.F. \\
\hline 52.9 & 41119 & 68.5 & 2630 & SM. \\
\hline 53.0 & 40484 & 68.4 & 2615 & SM. \\
\hline 53.1 & 40246 & 63.0 & 4036 & T.B. \\
\hline 53.1 & 40078 & 63.1 & 4050 & T.B. \\
\hline 53.2 & 39821 & 61.7 & 4733 & T. B \\
\hline
\end{tabular}




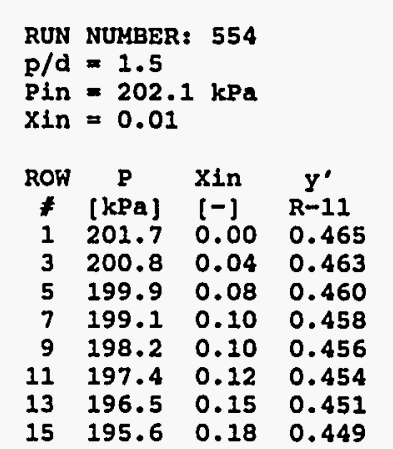

$Y^{\prime}$ In $=46.5 \& R-11 / 53.5 \& R-113$ $G=101.26 \mathrm{~kg} / \mathrm{g}^{\wedge} \mathrm{m}^{\wedge} 2$
DELTA $P$ total $=6.49 \mathrm{kPa}$
Xout $=0.20$

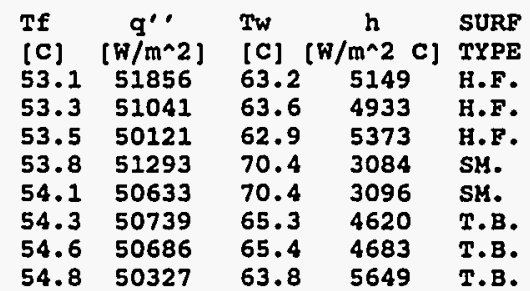

RUN NUMBER: 555

$\mathrm{p} / \mathrm{d}=1.5$

Pin $=202.1 \mathrm{kPa}$

$\begin{array}{cccc}\text { ROW } & P & \text { Xin } & y^{\prime} \\ \text { [kPa }] & {[-]} & R-11\end{array}$

$\begin{array}{llll}* & {[\mathrm{kPa}]} & {[-]} & \mathrm{R}-11 \\ 1 & 201.6 & 0.00 & 0.465\end{array}$

$\begin{array}{llll}1 & 201.6 & 0.00 & 0.465 \\ 3 & 200.5 & 0.04 & 0.462\end{array}$

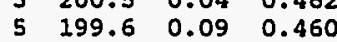

$\begin{array}{llll}7 & 198.6 & 0.11 & 0.457\end{array}$

$\begin{array}{llll}9 & 197.7 & 0.12 & 0.454\end{array}$

$\begin{array}{llll}11 & 196.7 & 0.13 & 0.451\end{array}$

$\begin{array}{llll}13 & 195.8 & 0.17 & 0.449 \\ 15 & 194.7 & 0.21 & 0.446\end{array}$

RUN NUMBER: 564

$\mathrm{p} / \mathrm{d}=1.5$

Pin $=202.07 \mathrm{kPa}$

$\begin{array}{rccc}\text { ROW } & \text { P } & \text { Xin } & Y^{\prime} \\ \neq & {[\mathrm{kPa}]} & {[-]} & \mathrm{R}-11 \\ 1 & 201.6 & -.00 & 0.465 \\ 3 & 200.5 & 0.02 & 0.462 \\ 5 & 199.4 & 0.05 & 0.459 \\ 7 & 198.4 & 0.07 & 0.455 \\ 9 & 197.6 & 0.10 & 0.452 \\ 11 & 196.9 & 0.13 & 0.449 \\ 13 & 196.1 & 0.15 & 0.446 \\ 15 & 195.4 & 0.18 & 0.443\end{array}$

$y^{\prime}$ in $=46.5 \approx R-11 / 53.5 * R-113$. $R=106.11 \mathrm{~kg} / \mathrm{g}^{\star} \mathrm{m}^{\wedge} 2$ DELTA P total $=6.69 \mathrm{kPa}$ Xout $=0.19$

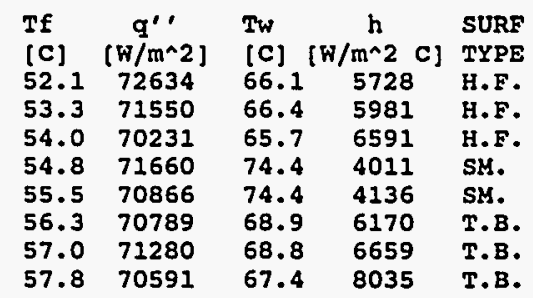

RUN NUMBER: 581

$\mathrm{p} / \mathrm{d}=1.5$

$\mathrm{Pin}=589.06 \mathrm{kPa}$

$x_{\text {in }}=-.00$

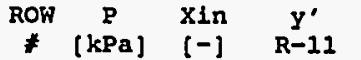

$1588.6 \quad-.00 \quad 0.461$

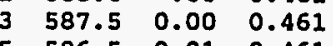

$\begin{array}{llll}5 & 586.5 & 0.01 & 0.461\end{array}$

$\begin{array}{llll}7885.6 & 0.01 & 0.460\end{array}$

$\begin{array}{llll}584.7 & 0.02 & 0.460\end{array}$

$11583.8 \quad 0.03 \quad 0.460$

$\begin{array}{llll}13 & 582.9 & 0.03 & 0.460\end{array}$

$\begin{array}{llll}15 & 581.9 & 0.04 & 0.460\end{array}$

RUN NUMBER: 580

$\mathrm{p} / \mathrm{d}=1.5$

$P$ in $=592.5 \mathrm{kPa}$

$\mathrm{X}$ in $=-.00$

ROW $\underset{\text { F }}{\mathrm{P}}-\mathrm{Xin} \quad \mathrm{Y}^{\prime}$

$\begin{array}{llll}* & {[\mathrm{kPa}]} & {[-]} & \mathrm{R}-11 \\ 1 & 592.0 & -.00 & 0.461\end{array}$

$3591.0 \quad 0.01 \quad 0.461$

$\begin{array}{lllll}5 & 590.0 & 0.02 & 0.460\end{array}$

$\begin{array}{lllll}7 & 589.1 & 0.03 & 0.460\end{array}$

$\begin{array}{llll}9 & 588.2 & 0.05 & 0.459\end{array}$

$\begin{array}{llll}11 & 587.3 & 0.06 & 0.459\end{array}$

$\begin{array}{llll}13 & 586.5 & 0.07 & 0.458\end{array}$

$\begin{array}{llll}15 & 585.5 & 0.08 & 0.458\end{array}$

RUN NUMBER: 579

$\mathrm{p} / \mathrm{d}=1.5$
$\mathrm{Pin}=592.5 \mathrm{kPa}$

$x$ in $=-.00$

$\begin{array}{rccc}\text { ROW } & \text { p } & \text { Xin } & y^{\prime} \\ * & {[\mathrm{kPa}]} & {[-]} & \mathrm{R}^{\prime}-11 \\ 1 & 592.0 & -.00 & 0.461 \\ 3 & 590.9 & 0.02 & 0.460 \\ 5 & 590.0 & 0.04 & 0.459 \\ 7 & 589.0 & 0.07 & 0.458 \\ 9 & 588.1 & 0.09 & 0.458 \\ 11 & 587.3 & 0.12 & 0.457 \\ 13 & 586.5 & 0.14 & 0.456 \\ 15 & 585.6 & 0.17 & 0.455\end{array}$ $y^{\prime}$ In $=46.18 \mathrm{R}-11 / 53.98 \mathrm{R}-113$ $G=49.13 \mathrm{~kg} / \mathrm{s}^{*} \mathrm{~m}^{\wedge} 2$

$\begin{aligned} \text { DELTA P total } & =6.8 \mathrm{kPa} \\ \text { xout } & =0.04\end{aligned}$

\begin{tabular}{|c|c|c|c|c|}
\hline (C) & {$[w / m \wedge 2]$} & [C] & $\left.1 / \mathrm{m}^{\wedge} 2 \quad \mathrm{c}\right]$ & \\
\hline 1.3 & $5251^{\circ}$ & 97.1 & 906 & \\
\hline & & 97.0 & 1014 & \\
\hline & 5126 & & 1111 & \\
\hline & 5539 & 19 & 88 & \\
\hline & 5467 & & 941 & \\
\hline & 5072 & 97.2 & 1454 & \\
\hline & 152 & 97.2 & 1601 & \\
\hline
\end{tabular}

$y^{\prime}$ in $=46.1 \& R-11 / 53.9 \& R-113$ DELTA $P$ total $=6 \mathrm{kPa}$

Xout $=0.09$

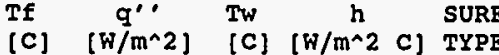
91.811027 99.0 1539 H.F. $93.0 \quad 10973 \quad 98.9 \quad 1874$ H.F. $93.9 \quad 10545 \quad 98.8 \quad 2143 \quad$ H.F. $\begin{array}{lllll}94.3 & 10961 & 102.4 & 1359 & \text { SM }\end{array}$ $\begin{array}{lllll}94.8 & 10781 & 102.6 & 1394 & \text { SM. }\end{array}$ $\begin{array}{lllll}95.3 & 10693 & 99.9 & 2312 & \text { T.B. }\end{array}$ $\begin{array}{lllll}95.8 & 10556 & 99.8 & 2600 & \text { T.B. } \\ 96.3 & 10527 & 99.4 & 3379 & 9 . B .\end{array}$

$y \cdot$ In $=46.1 \& R-11 / 53.9 \& R-113$ $G=49.27 \mathrm{~kg} / \mathrm{s}^{*} \mathrm{~m} \wedge 2$ DELTA $\mathrm{P}$ total $=6.04 \mathrm{kPa}$ xout $=0.18$

\begin{tabular}{|c|c|c|c|c|}
\hline Tf & q“" & Tw & $\frac{h}{2}$ & SURE \\
\hline $\begin{array}{l}{[C]} \\
91.9\end{array}$ & {$\left[\mathrm{~W} / \mathrm{m}^{\wedge} \mathbf{2}\right]$} & {$[\mathrm{C}]$} & {$\left[\mathrm{W} / \mathrm{m}^{\wedge} 2 \mathrm{C}\right]$} & $\begin{array}{l}\text { TYPE } \\
\text { H.F. }\end{array}$ \\
\hline 93.4 & 21161 & 100.3 & $\begin{array}{l}2562 \\
3079\end{array}$ & $\begin{array}{l}\text { H.F. } \\
\text { H.F. }\end{array}$ \\
\hline 94.1 & 20478 & 100.4 & 3257 & H.F. \\
\hline 94.6 & 21080 & 105.2 & 1995 & \\
\hline 95.2 & 20641 & 105.2 & 2063 & \\
\hline 95.8 & 20865 & 101.9 & 3407 & \\
\hline 96.4 & 20797 & 102.0 & 3656 & T \\
\hline 16. & 20590 & 101.5 & 4520 & \\
\hline
\end{tabular}




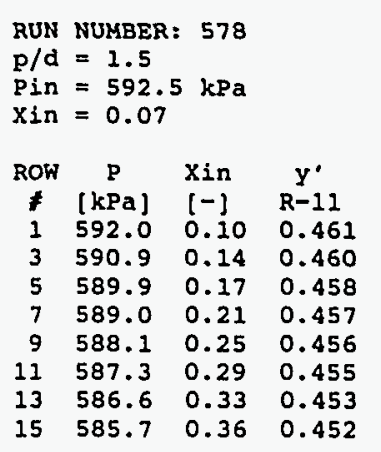
$y^{\prime}$ in $=46.18 \mathrm{R}-11 / 53.98 \mathrm{R}-113$
$\begin{aligned} \text { DELTA P total } & =6.23 \mathrm{kPa} \\ \text { Xout } & =0.38\end{aligned}$

\begin{tabular}{|c|c|c|c|c|}
\hline & Z & Tw & h & $\begin{array}{l}\text { SURE } \\
\text { TYPE }\end{array}$ \\
\hline $\begin{array}{l}{[C]} \\
91.9\end{array}$ & $\begin{array}{c}{\left[W / m^{\wedge} 2\right]} \\
31744\end{array}$ & $\begin{array}{c}{[\mathrm{C}]} \\
101.2\end{array}$ & $\begin{array}{c}{\left[W / m^{n} 2 C\right]} \\
3423\end{array}$ & \\
\hline 93.5 & 31446 & 101.4 & 3971 & \\
\hline 1 & 30301 & 101.3 & 4226 & \\
\hline & 31506 & 106.8 & 2611 & \\
\hline 5.3 & 30878 & 106.8 & 2697 & \\
\hline & 30902 & 103.7 & 3963 & \\
\hline 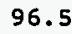 & 31007 & 103.8 & 4258 & \\
\hline & 30705 & 102.7 & 5462 & \\
\hline
\end{tabular}

RUN NUMBER: 577

$\mathrm{p} / \mathrm{d}=1.5$

$\mathrm{P}$ in $=592.5 \mathrm{kPa}$

$x_{\text {in }}=-.00$

$\begin{array}{rccc}\text { ROW } & \text { P } & \text { Xin } & Y^{\prime} \\ * & {[\mathrm{kPa}]} & {[-]} & \mathrm{R}-11 \\ 1 & 592.0 & -.00 & 0.461 \\ 3 & 590.9 & 0.04 & 0.459 \\ 5 & 589.9 & 0.09 & 0.458 \\ 7 & 588.9 & 0.14 & 0.456 \\ 9 & 588.1 & 0.19 & 0.454 \\ 11 & 587.3 & 0.24 & 0.453 \\ 13 & 586.5 & 0.29 & 0.451 \\ 15 & 585.7 & 0.34 & 0.449\end{array}$

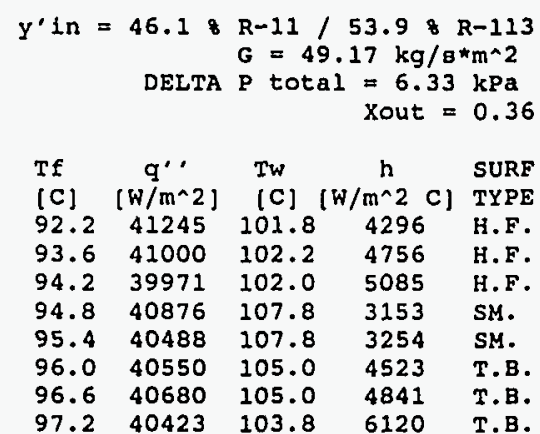

RUN NUMBER: 576

$\mathrm{p} / \mathrm{d}=1.5$

$P_{\text {in }}=595.95 \mathrm{kPa}$

$X$ in $=-.00$

$\begin{array}{cccc}\text { ROW } & \begin{array}{c}\mathrm{P} \\ \text { * }\end{array}[\mathrm{kPa}] & \mathrm{X} \text { in } & \mathrm{y}^{\prime} \\ 1 & 595.4 & -.00 & 0.461 \\ 3 & 594.4 & 0.06 & 0.459 \\ 5 & 593.4 & 0.12 & 0.457 \\ 7 & 592.6 & 0.18 & 0.455 \\ 9 & 591.8 & 0.24 & 0.453 \\ 11 & 591.0 & 0.30 & 0.451 \\ 13 & 590.2 & 0.37 & 0.448 \\ 15 & 589.4 & 0.43 & 0.446\end{array}$ $y^{\prime}$ in $=46.1 \& \begin{aligned} & R-11 / 53.9 \& R-113 \\ & G=48.73 \mathrm{~kg} / \mathrm{g}^{*} \mathrm{~m}^{\wedge} 2\end{aligned}$ $\begin{aligned} \text { DELTA P total } & =6.43 \mathrm{kPa} \\ \text { Xout } & =0.46\end{aligned}$$$
\text { Xout }=0.46
$$

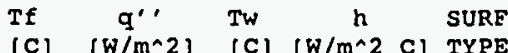

(C) $\left[\mathrm{W} / \mathrm{m}^{\wedge} 2\right\}$ [C] $\left(\mathrm{W} / \mathrm{m}^{\wedge} 2 \mathrm{C}\right]$ TYPE

94.051054104 .14606 H.F.

94.749809 103.9 5369 H.F.

$95.3 \quad 50919 \quad 110.0 \quad 3475 \mathrm{sM}$.

$96.0 \quad 50400 \quad 110.1 \quad 3581 \quad$ SM.

$96.7 \quad 50539 \quad 107.5 \quad 4670 \quad$ T.B.

$\begin{array}{lllll}97.3 & 50605 & 107.5 & 4976 & \text { T.B. }\end{array}$
RUN NUMBER: 575

$\mathrm{P} / \mathrm{d}=1.5$

Pin $=595.95 \mathrm{kPa}$

$\operatorname{xin}=-.00$

$\begin{array}{rccc}\text { ROW } & \mathrm{P} & \mathrm{Xin} & \mathrm{Y}^{\prime} \\ \neq & {[\mathrm{kPa}]} & {[-]} & \mathrm{R}^{-11} \\ 1 & 595.4 & -.00 & 0.461 \\ 3 & 594.3 & 0.07 & 0.458 \\ 5 & 593.3 & 0.14 & 0.456 \\ 7 & 592.3 & 0.22 & 0.453 \\ 9 & 591.4 & 0.29 & 0.451 \\ 11 & 590.6 & 0.37 & 0.448 \\ 13 & 589.9 & 0.44 & 0.446 \\ 15 & 589.0 & 0.52 & 0.443\end{array}$

RUN NUMBER: 589

$\mathrm{p} / \mathrm{d}=1.5$

Pin $=592.5 \mathrm{kPa}$

$\mathrm{X}$ in $=0.00$

$\begin{array}{cccc}\text { ROW } & \text { p } & \text { Xin } & Y^{\prime} \\ \text { F } & {[\mathrm{kPa}]} & {[-]} & \mathrm{R}-11 \\ 1 & 592.0 & 0.00 & 0.461 \\ 3 & 590.9 & 0.00 & 0.461 \\ 5 & 590.0 & 0.01 & 0.461 \\ 7 & 589.0 & 0.01 & 0.461 \\ 9 & 588.1 & 0.01 & 0.461 \\ 11 & 587.2 & 0.02 & 0.461 \\ 13 & 586.3 & 0.02 & 0.460 \\ 15 & 585.4 & 0.02 & 0.460\end{array}$

RUN NUMBER: 588

$\mathrm{p} / \mathrm{d}=1.5$

Pin $=592.5 \mathrm{kPa}$

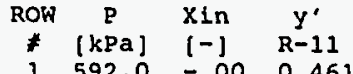

$1592.0 \quad-.00 \quad 0.461$

$\begin{array}{lllll}5 & 590.0 & 0.01 & 0.461\end{array}$

$\begin{array}{llll}7 & 589.1 & 0.02 & 0.460\end{array}$

$\begin{array}{llll}9 & 588.2 & 0.03 & 0.460\end{array}$

11 587.3 $0.04 \quad 0.460$

$\begin{array}{llll}13 & 586.4 & 0.05 & 0.460\end{array}$ $y^{\prime}$ in $=46.1 * R-11 / 53.9 * R-113$ $\begin{aligned} G & =48.78 \mathrm{~kg} / \mathrm{s}^{\star} \mathrm{m}^{\wedge} 2 \\ \text { DELTA } P \text { total } & =6.53 \mathrm{k}^{\mathrm{p}}\end{aligned}$ $=6.53 \mathrm{kPa}$
Xout $=0.55$

\begin{tabular}{|c|c|c|c|c|}
\hline $\begin{array}{l}\text { Tf } \\
{[c]}\end{array}$ & $\frac{q^{\prime \prime}}{\left[W / m^{\wedge} 2\right]}$ & $\begin{array}{l}\text { Tw } \\
\text { [C] }\end{array}$ & $\left.\stackrel{\substack{h \\
\left(w / m^{\wedge} 2\right.}}{c}\right)$ & $\begin{array}{l}\text { SURF } \\
\text { TYPE }\end{array}$ \\
\hline 92.7 & 62502 & 103.9 & 5613 & H.F. \\
\hline 94.0 & 62924 & 104.3 & 5973 & H.F. \\
\hline 94.6 & 60385 & 104.1 & 6398 & H.F. \\
\hline . & 61797 & 110.4 & 4093 & SM. \\
\hline 6.0 & 60799 & 110.4 & 4225 & SM. \\
\hline & 60712 & 108.0 & 5382 & \\
\hline 7.4 & 61053 & 108.0 & 5767 & T. B. \\
\hline & 60399 & 106.6 & 7057 & I \\
\hline
\end{tabular}
$y^{\prime}$ in $=46.1 \& R-11 / 53.9 \& R-113$
$G=196.45 \mathrm{~kg} / \mathrm{B}^{\star} \mathrm{m}^{\wedge} 2$ $\begin{aligned} \text { DELTA } P \text { total } & =6.81 \mathrm{kPa} \\ \text { Xout } & =0.03\end{aligned}$

\begin{tabular}{|c|c|c|c|c|}
\hline $\begin{array}{l}\text { Tf } \\
{[C]}\end{array}$ & $\underset{\left[W / m^{\wedge} 2\right]}{q^{\prime}}$ & $\begin{array}{l}T w \\
\text { (C) }\end{array}$ & $\stackrel{h}{/ m^{\wedge} 2} c \mid$ & $\begin{array}{l}\text { SURF } \\
\text { TYPE }\end{array}$ \\
\hline 91.8 & 4892 & 97.3 & 898 & H.F. \\
\hline 92.3 & 4865 & 97.2 & 1008 & H.F. \\
\hline $\begin{array}{l}92.8 \\
93.4\end{array}$ & $\begin{array}{l}4786 \\
5095\end{array}$ & $\begin{array}{l}97.2 \\
99.3\end{array}$ & $\begin{array}{r}1102 \\
862\end{array}$ & $\begin{array}{l}\text { H.F. } \\
\text { SM. }\end{array}$ \\
\hline 93.8 & 5032 & 99.2 & 928 & SM. \\
\hline 94.1 & 4701 & 97.3 & 1457 & T.B. \\
\hline 94.3 & 4783 & 97.3 & 1616 & T.B. \\
\hline 94.6 & 4719 & 97.1 & 1897 & T.B. \\
\hline
\end{tabular}

$y^{\prime}$ in $=46.1 \& R-11 / 53.9 \& R-113$ $\begin{aligned} \text { DELTA P total } & =6.04 \mathrm{kPa} \\ \text { Xout } & =0.06\end{aligned}$

\begin{tabular}{|c|c|c|c|c|}
\hline [C] & $\begin{array}{c}q^{\prime \prime} \\
{[w / m \wedge 2]}\end{array}$ & Tw & $\left.\begin{array}{cc}h \\
{[m \wedge 2} & c\end{array}\right]$ & $\begin{array}{l}\text { SURF } \\
\text { TYPE }\end{array}$ \\
\hline 91.8 & & 98.9 & 1565 & H.F. \\
\hline 3.0 & 11041 & 98.8 & 1920 & н. \\
\hline & & 98.7 & 2191 & \\
\hline 4.3 & 11036 & 102.4 & 1369 & \\
\hline 4.8 & 10886 & 102 & 1404 & \\
\hline 5. & 10771 & & & \\
\hline & 10631 & 99.6 & 2747 & T.B. \\
\hline
\end{tabular}




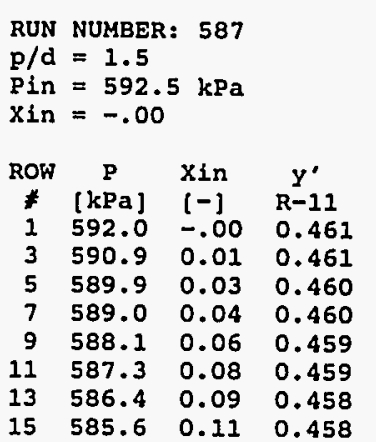
$y^{\prime} \cdot n=46.1 \& R-11 / 53.9 \& R-113$ $\mathbf{G}=195.9 \mathrm{~kg} / \mathrm{s}^{\star} \mathrm{m}^{\wedge} 2$ DELTA $P$ total $=6.09 \mathrm{kPa}$ xout $=0.11$

\begin{tabular}{|c|c|c|c|c|}
\hline & & $\begin{array}{l}\text { Tw } \\
\text { (c) }\end{array}$ & $\stackrel{h}{h / m^{\wedge} 2}$ & SURF \\
\hline [C] & {$\left[\mathrm{W} / \mathrm{m}^{\wedge} \mathbf{2}\right]$} & $\begin{array}{c}{[C]} \\
100.3\end{array}$ & {$\left[\begin{array}{c}\left(w / m^{\wedge} 2\right. \\
2537\end{array}\right]$} & TYPE \\
\hline 3.4 & 21158 & 100.5 & 3017 & H.F. \\
\hline 94.1 & 20476 & 100.3 & 3306 & H.F. \\
\hline & 21081 & 105.2 & 2001 & \\
\hline 35.2 & 20569 & 105.2 & 2056 & SM. \\
\hline & 20865 & 102.1 & 3284 & T.B. \\
\hline 6.6 & 20789 & 102.1 & 3646 & т.в. \\
\hline 6. & 20548 & 101.3 & 4697 & T. B. \\
\hline
\end{tabular}

RUN NUMBER: 586 $\mathrm{p} / \mathrm{d}=1.5$

Pin $=592.5 \mathrm{kPa}$

$\mathrm{Xin}=0.07$

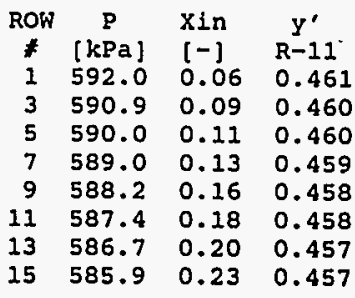

RUN NUMBER: 585 $\mathrm{p} / \mathrm{d}=1.5$

Pin $=592.5 \mathrm{kPa}$

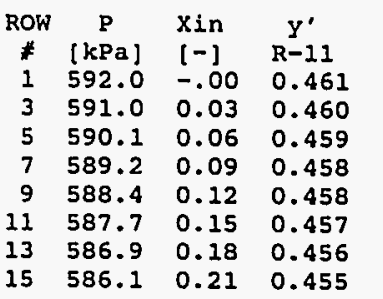

\begin{tabular}{|c|c|c|c|c|}
\hline \multicolumn{5}{|c|}{$q^{\prime \prime}$} \\
\hline & & & 3458 & \\
\hline 93.5 & 31261 & 101.2 & 4061 & \\
\hline 4.1 & 30100 & 101.1 & 4326 & \\
\hline .7 & 31259 & 106.6 & 2633 & \\
\hline & 30682 & 106.6 & 2718 & \\
\hline 3.9 & 30725 & 103.4 & 4112 & \\
\hline 10. & 30821 & 103.5 & 4415 & \\
\hline 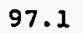 & 30526 & 102.5 & 5682 & \\
\hline
\end{tabular}

$y^{\prime}$ in $=46.1 \& R-11 / 53.9 \& R-113$ $R=196.16 \mathrm{~kg} / \mathrm{s}^{*} \mathrm{~m}^{\wedge}$ DELTA $\mathrm{P}$ total $=5.95 \mathrm{kPa}$ Xout $=0.22$

\begin{tabular}{|c|c|c|c|c|}
\hline $\begin{array}{l}\text { Tf } \\
\text { [C] }\end{array}$ & {$\left[\begin{array}{c}q^{\prime \prime} \\
{\left[W / m^{\wedge} 2\right]}\end{array}\right.$} & $\begin{array}{l}T w \\
{[C]}\end{array}$ & {$\left[\begin{array}{c}h \\
{\left[W / m^{\wedge} 2\right.}\end{array}\right)$} & $\begin{array}{l}\text { SURF } \\
\text { TYPE }\end{array}$ \\
\hline .2 & 41218 & 102.0 & 4221 & H.F. \\
\hline 3.6 & 40952 & 102.3 & 4681 & H.F. \\
\hline 14.2 & 40062 & 102.2 & 5006 & H.F. \\
\hline 4.8 & 40792 & 108.0 & 3101 & SM. \\
\hline * & 40392 & 108.1 & 3192 & \\
\hline 5.0 & 40488 & 105.1 & 4435 & T.B. \\
\hline & 40 & 105.2 & 4760 & T.B. \\
\hline .2 & 40363 & 103.9 & 6017 & B \\
\hline
\end{tabular}

RUN NUMBER: 584

$\mathrm{p} / \mathrm{d}=1.5$

Pin $=595.95 \mathrm{kPa}$

$\operatorname{xin}=-.00$

$\begin{array}{rccc}\text { ROW } & \text { P } & \text { Xin } & Y^{\prime} \\ \# & {[k P a]} & {[-]} & \text { R-11 } \\ 1 & 595.4 & -.00 & 0.461 \\ 3 & 594.3 & 0.04 & 0.460 \\ 5 & 593.3 & 0.07 & 0.459 \\ 7 & 592.3 & 0.11 & 0.458 \\ 9 & 591.5 & 0.15 & 0.457 \\ 11 & 590.7 & 0.19 & 0.456 \\ 13 & 590.0 & 0.23 & 0.455 \\ 15 & 589.3 & 0.27 & 0.454\end{array}$

RUN NUMBER: 583

\section{$\mathrm{p} / \mathrm{d}=1.5$}

$\mathrm{Pin}=595.95 \mathrm{kPa}$

$X$ in $=-.00$

$\begin{array}{rccc}\text { ROW } & \mathrm{P} & \mathrm{Xin} & \mathrm{Y}^{\prime} \\ \# & {[\mathrm{kPa}]} & {[-]} & \mathrm{R}^{\prime}-11 \\ 1 & 595.4 & -.00 & 0.461 \\ 3 & 594.3 & 0.04 & 0.460 \\ 5 & 593.2 & 0.09 & 0.458 \\ 7 & 592.3 & 0.13 & 0.457 \\ 9 & 591.4 & 0.18 & 0.456 \\ 11 & 590.6 & 0.22 & 0.455 \\ 13 & 589.9 & 0.26 & 0.453 \\ 15 & 589.1 & 0.30 & 0.452\end{array}$ RUN NUMBER: 582
$\mathrm{p} / \mathrm{d}=1.5$

Pin $=595.95 \mathrm{kPa}$ $x$ in $=-.00$

$\begin{array}{cccc}\text { ROW } & \begin{array}{c}\mathrm{P} \\ \#\end{array} & \mathrm{Xin} & \mathrm{Y}^{\prime} \\ {[\mathrm{kPa}]} & {[-]} & \mathrm{R}-11 \\ 1 & 595.4 & -.00 & 0.461 \\ 3 & 594.3 & 0.05 & 0.459 \\ 5 & 593.3 & 0.10 & 0.458 \\ 7 & 592.3 & 0.16 & 0.456 \\ 9 & 591.4 & 0.22 & 0.455 \\ 11 & 590.6 & 0.28 & 0.453 \\ 13 & 589.9 & 0.33 & 0.452 \\ 15 & 589.1 & 0.38 & 0.451\end{array}$ $\mathrm{y}^{\prime}$ in $=46.1 \& \mathrm{R}-11 / 53.9 \& \mathrm{R}-113$ $G=195.47 \mathrm{~kg} / \mathrm{s}^{* \mathrm{~m}^{\wedge}}$ DELTA $P$ total $=6.52 \mathrm{kPa}$ Xout $=0.28$

\begin{tabular}{|c|c|c|c|c|}
\hline $\begin{array}{l}\text { Tf } \\
{[C]}\end{array}$ & $\frac{q^{\prime \prime}}{\left[w / m^{\wedge} 2\right]}$ & $\begin{array}{l}T w \\
{[C]}\end{array}$ & $\left.\begin{array}{c}h \\
{\left[w / m^{\wedge} 2\right.}\end{array}\right]$ & $\begin{array}{l}\text { SURF } \\
\text { TYPE }\end{array}$ \\
\hline 92.5 & 51812 & 103.1 & 4865 & H.F. \\
\hline 1.0 & 51280 & 103.5 & $\begin{array}{l}5384 \\
5770\end{array}$ & H.F. \\
\hline 95.3 & 51088 & 109.4 & 3630 & SM. \\
\hline 96.0 & 50526 & 109.5 & 3749 & SM. \\
\hline 0.1 & 50631 & 106.8 & 4987 & \\
\hline 97.3 & 50740 & 106.9 & 5323 & T.B. \\
\hline 3.0 & 50492 & 105.6 & 6639 & \\
\hline
\end{tabular}

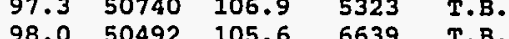

$y^{\prime}$ in $=46.1 \& R-11 / 53,98 R-113$ $=195.33 \mathrm{~kg} / \mathbf{s}^{*} \mathrm{~m}^{\wedge} 2$ DELTA $P$ total $=5.9 \mathrm{kPa}$ Xout $=0.35$

\begin{tabular}{|c|c|c|c|c|}
\hline $\begin{array}{l}T f \\
\text { [C] }\end{array}$ & $\frac{q^{\prime \prime}}{[w / m \wedge 2]}$ & $\begin{array}{l}\mathrm{Tw} \\
{[\mathrm{C}]}\end{array}$ & $\left(w / m^{\wedge} 2 \quad c\right)$ & $\begin{array}{l}\text { SURF } \\
\text { TYPE }\end{array}$ \\
\hline 92.8 & 62855 & 104.1 & 5598 & H.F. \\
\hline 4.1 & 62320 & 104.5 & 5964 & H.F. \\
\hline 4.7 & 60740 & 104.3 & 6389 & H.F. \\
\hline & 62101 & 110.6 & 4093 & SM. \\
\hline 0.1 & 61300 & 110.7 & 4204 & SM. \\
\hline 6. & 61146 & 108.2 & 5367 & \\
\hline 7. & 61477 & 108.2 & 5739 & T.B. \\
\hline 3. & 60888 & 106.9 & 6956 & T.B. \\
\hline
\end{tabular}
$y^{\prime}$ in $=46.1 \& \quad R-11 / 53.98 R-113$ $\begin{aligned} \text { DELTA P total } & =6.43 \mathrm{kPa} \\ \text { Xout } & =0.41\end{aligned}$

\begin{tabular}{|c|c|c|c|c|}
\hline $\begin{array}{l}\text { Tf } \\
{[C]}\end{array}$ & $\begin{array}{c}q^{\prime \prime} \\
{\left[w / m^{\wedge} 2\right]}\end{array}$ & $\begin{array}{l}T w \\
{[C]}\end{array}$ & $\begin{array}{c}h \\
\left.g / m^{\wedge} \quad c\right]\end{array}$ & $\begin{array}{l}\text { SURF } \\
\text { TYPE }\end{array}$ \\
\hline 92.8 & 74427 & 104.6 & 6282 & H.F. \\
\hline 94.0 & 73917 & 105.1 & 6651 & H.F. \\
\hline 94.8 & 72247 & 104.8 & 7170 & H.F. \\
\hline 95.5 & 73847 & 111.5 & 4606 & SM. \\
\hline 6.2 & 72829 & 111.5 & 4770 & SM. \\
\hline 6.9 & 72431 & 109.1 & 5941 & \\
\hline 7.7 & 72913 & 109.1 & 6364 & B. \\
\hline 8.4 & 71880 & 108.0 & 7495 & $P$ \\
\hline
\end{tabular}




\section{Bundle Boiling Data}

Data from the $75 \% \mathrm{R}-11 / 25 \% \mathrm{R}-113$ mixture 
RUN NUMBER: 509

$\mathrm{P} / \mathrm{d}=1.5$
$\mathrm{xin}=209.33 \mathrm{kPa}$ $y \cdot$ in $=75.8 \& R-11 / 24.28 R-113$
$G=48.58 \mathrm{~kg} / \mathrm{g}^{\star} \mathrm{m}^{\wedge} 2$

$\mathrm{P} / \mathrm{d}=1.5$
$\mathrm{Pin}=201.02 \mathrm{kPa}$
$\mathrm{X}$ in $=0.00$

$\begin{array}{cccc}\text { ROW } & P & \text { Xin } & y^{\prime} \\ * & {[k P a]} & {[-]} & R-11 \\ 1 & 200.6 & 0.00 & 0.758 \\ 3 & 199.8 & 0.02 & 0.757 \\ 5 & 199.0 & 0.03 & 0.757 \\ 7 & 198.1 & 0.05 & 0.756 \\ 9 & 197.3 & 0.06 & 0.755 \\ 11 & 196.4 & 0.08 & 0.754 \\ 13 & 195.6 & 0.10 & 0.754 \\ 15 & 194.8 & 0.11 & 0.753\end{array}$

RUN NUMBER: 510

$\mathrm{p} / \mathrm{d}=1.5$

Pin $=229.62 \mathrm{kPa}$

\begin{tabular}{rccc}
\multicolumn{1}{c}{ ROW } & $\begin{array}{c}\mathrm{P} \\
\text { \# }\end{array}$ & Xin & $\mathrm{Y}^{\prime}$ \\
$1 \mathrm{PPa}]$ & {$[-]$} & $\mathrm{R}-11$ \\
1 & 229.3 & -.02 & 0.758 \\
3 & 228.5 & 0.01 & 0.757 \\
5 & 227.6 & 0.04 & 0.755 \\
7 & 226.8 & 0.06 & 0.754 \\
9 & 225.9 & 0.09 & 0.753 \\
11 & 225.0 & 0.12 & 0.751 \\
13 & 224.2 & 0.14 & 0.750 \\
15 & 223.2 & 0.17 & 0.748
\end{tabular}

\begin{tabular}{|c|c|c|c|c|}
\hline $\begin{array}{l}\mathrm{Tf} \\
\text { (c) }\end{array}$ & $\begin{array}{c}q^{\prime \prime} \\
{\left[w / m^{\wedge} 2\right]}\end{array}$ & $\begin{array}{l}\text { Tw } \\
{[C]}\end{array}$ & $\begin{array}{c}h \\
g / m^{\wedge} 2\end{array}$ & $\begin{array}{l}\text { SURF } \\
\text { TYPE }\end{array}$ \\
\hline 46.7 & 20603 & 51.4 & 4374 & H.F. \\
\hline 48.9 & 20256 & 52.4 & 5836 & H.F. \\
\hline 48.8 & 19786 & 53.4 & 5791 & H.F. \\
\hline 48.7 & 20116 & 59.3 & 1891 & \\
\hline 48.6 & 19666 & 59.3 & 1836 & SM. \\
\hline 48.4 & 20261 & 52.0 & 5685 & T.B. \\
\hline 48.3 & 20288 & 51.9 & 5689 & T.B. \\
\hline 48.2 & 19907 & 51.2 & 6656 & \\
\hline
\end{tabular}
DELTA P total $=6.26 \mathrm{kPa}$
Xout $=0.05$

\begin{tabular}{|c|c|c|c|c|}
\hline Tf & {$\left[\omega / m^{\wedge} 2\right]$} & $\begin{array}{l}T w \\
{[C]}\end{array}$ & $\stackrel{h}{\left.h m^{\wedge} 2 \quad c\right]}$ & $\begin{array}{l}\text { SURF } \\
\text { TYPE }\end{array}$ \\
\hline 48.2 & 5343 & 50.0 & 2908 & H.F. \\
\hline 49.1 & 5288 & 49.9 & 2991 & H.F. \\
\hline 9.0 & 5137 & 49.8 & 3223 & H.F. \\
\hline 8.8 & 5212 & 52.3 & 1474 & SM. \\
\hline 8.6 & 5106 & 52.0 & 1481 & SM. \\
\hline 8. & 5078 & 49.4 & 4806 & T.B. \\
\hline 8. & 5086 & & 4812 & T.B. \\
\hline . & 4990 & 49.1 & 4768 & T.B. \\
\hline
\end{tabular}

$y^{\prime}$ in $=75.8 \& R-11 / 24.2 \& R-113$ $G=48.65 \mathrm{~kg} / \mathrm{g}^{*} \mathrm{~m}^{\wedge} 2$ DELTA P total $=6.26 \mathrm{kPa}$ Xout $=0.12$

RUN NUMBER: 507

$\mathrm{p} / \mathrm{d}=1.5$

Pin $=201.83 \mathrm{kPa}$

$x$ in $=0.00$

$\begin{array}{llll}\text { ROW } & \mathrm{P} & \mathrm{Xin} & \mathrm{Y}^{\prime} \\ \text { [ } \mathrm{kPa}] & {[-]} & \mathrm{R}-11\end{array}$

$\begin{array}{llll}\text { * } & {[\mathrm{kPa}]} & {[-]} & \mathrm{R}-11 \\ 1 & 201.3 & 0.00 & 0.758\end{array}$

$\begin{array}{llll}200.3 & 0.04 & 0.756\end{array}$

$\begin{array}{llll}5 & 199.3 & 0.09 & 0.754\end{array}$

$\begin{array}{llll}7 & 198.3 & 0.13 & 0.752\end{array}$

$\begin{array}{lllll}9 & 197.4 & 0.18 & 0.750\end{array}$

$\begin{array}{llll}11 & 196.5 & 0.22 & 0.747\end{array}$

$\begin{array}{llll}13 & 195.7 & 0.27 & 0.745\end{array}$

$\begin{array}{llll}15 & 194.7 & 0.31 & 0.743\end{array}$

RUN NUMBER: 504

$\mathrm{p} / \mathrm{d}=1.5$
$\mathrm{P}$ in $=203.65 \mathrm{kPa}$

$x_{\text {in }}=0.00$

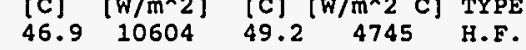

$\begin{array}{lllll}46.9 & 10604 & 49.2 & 4745 & \text { H.F. }\end{array}$

$47.510185 \quad 48.9 \quad 3943$ H.F.

47.310718 54.1 1580 SM.

$\begin{array}{lllll}47.1 & 10478 & 53.5 & 1636 & \text { SM. }\end{array}$

$\begin{array}{lllll}46.9 & 10540 & 48.8 & 5558 & \text { T.B. }\end{array}$

$\begin{array}{lllll}46.9 & 10540 & 48.8 & 5558 & \text { T.B. } \\ 46.8 & 10551 & 48.7 & 5565 & \text { T.B. }\end{array}$

$\begin{array}{lllll}46.6 & 10336 & 48.2 & 6402 & \text { T.B. }\end{array}$

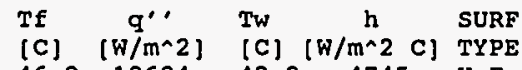

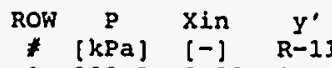

$\begin{array}{llll}\text { * } & {[\mathrm{kPa}]} & {[-]} & \mathrm{R}-11 \\ 1 & 203.2 & 0.00 & 0.758\end{array}$

$\begin{array}{llll}202.2 & 0.06 & 0.755\end{array}$

$\begin{array}{lll}201.3 & 0.11 & 0.752\end{array}$

$\begin{array}{lll}200.5 & 0.17 & 0.750\end{array}$

$\begin{array}{llll}199.6 & 0.23 & 0.747\end{array}$

$\begin{array}{lllll}11 & 198.7 & 0.29 & 0.744\end{array}$

$\begin{array}{llll}13 & 197.8 & 0.35 & 0.741\end{array}$

$\begin{array}{llll}15 & 196.9 & 0.40 & 0.739\end{array}$

RUN NUMBER: 511

$\mathrm{p} / \mathrm{d}=1.5$

$\mathrm{Pin}=234.86 \mathrm{kPa}$

$x_{\text {in }}=-.02$

$\begin{array}{rccl}\text { ROW } & \text { P } & \text { Xin } & Y^{\prime} \\ \# & {[\mathrm{kPa}]} & {[-]} & \mathrm{R}^{\prime}-11 \\ 1 & 234.5 & -.02 & 0.758 \\ 3 & 233.6 & 0.05 & 0.755 \\ 5 & 232.8 & 0.11 & 0.751 \\ 7 & 232.0 & 0.18 & 0.748 \\ 9 & 231.2 & 0.25 & 0.744 \\ 11 & 230.4 & 0.32 & 0.741 \\ 13 & 229.6 & 0.39 & 0.737 \\ 15 & 228.7 & 0.45 & 0.734\end{array}$ $y^{\prime}$ in $=75.8 \& R-11 / 24.2 \& R-113$ $G=48.75 \mathrm{~kg} / \mathrm{g}^{*} \mathrm{~m}^{\wedge} 2$

DELTA $P$ total $=7.15 \mathrm{kPa}$

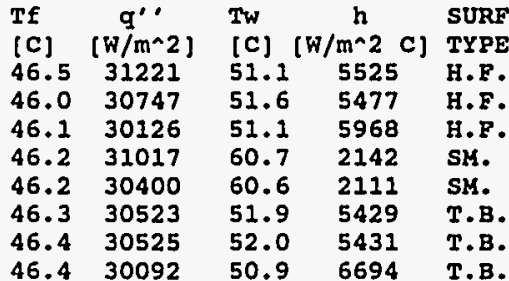

$y^{\prime}$ in $=75.8 \& \mathrm{R}-11 / 24.2 \& \mathrm{R}-113$ $G=49.04 \mathrm{~kg} / \mathrm{s}^{\star} \mathrm{m}^{\wedge} 2$ DELTA $P$ total $=6.8 \mathrm{kPa}$ xout $=0.43$

\begin{tabular}{|c|c|c|c|c|}
\hline $\begin{array}{l}\text { If } \\
{[C]}\end{array}$ & 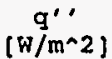 & $\begin{array}{l}T w \\
{[C]}\end{array}$ & $\left.\stackrel{h}{h m^{\wedge} 2} \quad c\right]$ & $\begin{array}{l}\text { SURE } \\
\text { TYPE }\end{array}$ \\
\hline 46.7 & & 51.8 & 7671 & \\
\hline 47.5 & 40902 & 53.0 & $\begin{array}{l}7867 \\
7854\end{array}$ & \\
\hline $\begin{array}{l}47.4 \\
47.3\end{array}$ & $\begin{array}{l}40030 \\
40572\end{array}$ & $\begin{array}{l}52.5 \\
61.2\end{array}$ & $\begin{array}{l}7854 \\
2933\end{array}$ & \\
\hline 47.2 & 39868 & 61.4 & 2805 & \\
\hline 7.1 & 40056 & 53.1 & 6755 & \\
\hline 7. & 40182 & 53.2 & 6902 & \\
\hline 5. & 39577 & 52.0 & 7836 & \\
\hline
\end{tabular}

$y^{\prime}$ in $=75.8 \& \mathrm{R}-11 / 24.2 \& \mathrm{R}-113$ $G=50.19 \mathrm{~kg} / \mathrm{s}^{*} \mathrm{~m}^{\wedge} 2$ DELTA $\mathrm{P}$ total $=6.16 \mathrm{kP}$ Xout $=0.48$

\begin{tabular}{|c|c|c|c|c|}
\hline $\begin{array}{l}\text { Tf } \\
\text { [C] }\end{array}$ & $\frac{q^{\prime \prime}}{\left[w / m^{\wedge} 2\right]}$ & $\begin{array}{l}T w \\
\text { [C] }\end{array}$ & {$\left[\begin{array}{cc}h \\
{\left[w / m^{\wedge} 2\right.} & c\end{array}\right)$} & $\begin{array}{l}\text { SURF } \\
\text { TYPE }\end{array}$ \\
\hline 47.0 & 51141 & 54.1 & 7259 & H.F. \\
\hline 19.7 & 50382 & 55.1 & 9282 & H.F. \\
\hline 99.6 & 49580 & 55.0 & 9141 & H.F. \\
\hline 49.5 & 50594 & 64.0 & 3478 & SM. \\
\hline 9. & 49813 & 64.5 & 3282 & SM. \\
\hline 19. & 50139 & 56.4 & 6986 & T.B. \\
\hline 19.1 & 50133 & 56.6 & 6756 & T.B. \\
\hline I. & 49779 & 55.1 & 8256 & T.B. \\
\hline
\end{tabular}


RUN NUMBER: 506 $\mathrm{p} / \mathrm{d}=1.5$

Pin $=219.45 \mathrm{kPa}$
$\mathrm{Xin}=-.01$

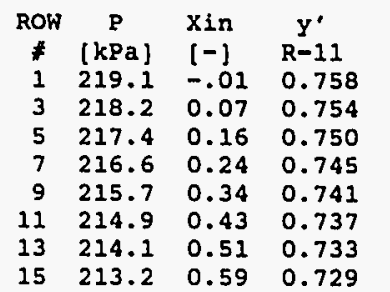
$y^{\prime}$ in $=75.8 \& R-11 / 24.2 \& R-113$
DELTA P total $=6.25 \mathrm{kPa}$
Xout $=0.64$

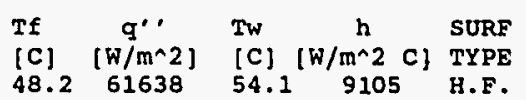
$50.46068954 .9 \quad 10420$ H.F.
$50.259663 \quad 54.2 \quad 11221$ H.F.
$50.160985 \quad 64.5 \quad 4238$ SM.
$50.060207 \quad 65.1 \quad 3985$ SM.
49.960078 56.7 8809 T.B.
$\begin{array}{rrrrr}49.7 & 60219 & 56.9 & 8418 & \text { T.B. } \\ 49.6 & 59784 & 55.5 & 10115 & \text { T.B. }\end{array}$

\section{RUN NUMBER: 516}

$\mathrm{p} / \mathrm{d}=1.5$

Pin $=209.17 \mathrm{kPa}$

$x \ln =-.00$

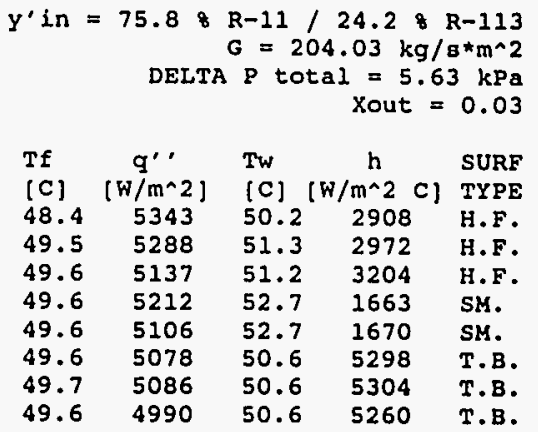

$\begin{array}{rccl}\text { ROW } & \text { P } & \text { Xin } & Y^{\prime} \\ * & {[\mathrm{kPa}]} & {[-]} & \mathrm{R}-11 \\ 1 & 208.8 & -.00 & 0.758 \\ 3 & 207.9 & 0.00 & 0.758 \\ 5 & 207.1 & 0.01 & 0.758 \\ 7 & 206.3 & 0.01 & 0.757 \\ 9 & 205.4 & 0.02 & 0.757 \\ 11 & 204.6 & 0.02 & 0.757 \\ 13 & 203.8 & 0.02 & 0.757 \\ 15 & 202.9 & 0.03 & 0.757\end{array}$

RUN NUMBER: 502

$\mathrm{p} / \mathrm{d}=1.5$

Pin $=200.86 \mathrm{kPa}$

$X$ in $=0.00$

$y^{\prime}$ in $=75.8 \& \underset{R-11}{\mathrm{G}} / 24.28 \mathrm{R}-113$
$\mathrm{G}=204.34 \mathrm{~kg} / \mathrm{g}^{\star} \mathrm{m}^{\wedge} 2$

$\begin{aligned} \text { DELTA P total } & =5.63 \mathrm{kPa} \\ \text { Xout } & =0.07\end{aligned}$

$\begin{array}{rccl}\text { ROW } & \text { P } & \text { Xin } & Y^{\prime} \\ \text { \# } & {[\mathrm{kPa}]} & {[-]} & \mathrm{R}^{\prime}-11 \\ 1 & 200.5 & 0.00 & 0.758 \\ 3 & 199.6 & 0.01 & 0.758 \\ 5 & 198.8 & 0.02 & 0.757 \\ 7 & 198.0 & 0.03 & 0.757 \\ 9 & 197.1 & 0.04 & 0.757 \\ 11 & 196.3 & 0.04 & 0.756 \\ 13 & 195.5 & 0.05 & 0.756 \\ 15 & 194.6 & 0.06 & 0.756\end{array}$

Tf $q^{\prime \prime}$ Tw $\stackrel{\text { h }}{\text { SURF }}$

[C] [w/ $\left.\mathrm{m}^{\wedge} 2\right] \quad$ [C] $\left(\mathrm{W} / \mathrm{m}^{\wedge} 2\right.$ C] TYPE

$\begin{array}{lllll}47.1 & 10604 & 49.4 & 4745 & \text { H.F. } \\ 48.1 & 10487 & 50.8 & 3835 & \text { H.F. }\end{array}$

$\begin{array}{lllll}48.1 & 10185 & 50.6 & 4024 & \text { H.F. }\end{array}$

$48.1 \quad 10718 \quad 54.2 \quad 1769$ SM.

$\begin{array}{lllll}48.2 & 10478 & 53.9 & 1825 & \text { SM. }\end{array}$

$\begin{array}{lllll}48.2 & 10540 & 50.0 & 6050 & T . B .\end{array}$

$\begin{array}{lllll}48.3 & 10551 & 50.0 & 6057 & \text { T.B. } \\ 48.2 & 10336 & 49.7 & 6894 & \text { T. }\end{array}$

RUN NUMBER: 501

$\mathrm{p} / \mathrm{d}=1.5$

$\mathrm{Pin}=201.27 \mathrm{kPa}$

ROW $P$

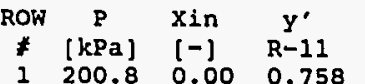

$\begin{array}{llll}1 & 200.8 & 0.00 & 0.758 \\ 3 & 199.8 & 0.02 & 0.757\end{array}$

$\begin{array}{lll}199.8 & 0.02 & 0.757\end{array}$

$\begin{array}{lll}198.9 & 0.03 & 0.757 \\ 198.0 & 0.05 & 0.756\end{array}$

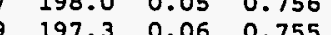

$\begin{array}{rrrr}9 & 197.3 & 0.06 & 0.755 \\ 11 & 196.5 & 0.08 & 0.755\end{array}$

$\begin{array}{llll}11 & 196.5 & 0.08 & 0.755 \\ 13 & 195.6 & 0.09 & 0.754\end{array}$

$\begin{array}{lllll}15 & 194.6 & 0.11 & 0.753\end{array}$

RUN NUMBER: 503

$\mathrm{p} / \mathrm{d}=1.5$

Pin $=207.52 \mathrm{kPa}$

$\mathrm{x}$ in $=-.00$

$\begin{array}{cccc}\text { ROW } & \mathrm{P} & \mathrm{Xin} & \mathrm{Y}^{\prime} \\ * & {[\mathrm{kPa}]} & {[-]} & \mathrm{R}-11 \\ 1 & 207.1 & -.00 & 0.758\end{array}$

$\begin{array}{llll}3 & 206.2 & 0.02 & 0.757 \\ 5 & 205.3 & 0.04 & 0.756\end{array}$

$\begin{array}{llll}5 & 205.3 & 0.04 & 0.756 \\ 7 & 204.5 & 0.06 & 0.755\end{array}$

7 \begin{tabular}{llll}
204.5 & 0.06 & 0.755 \\
\hline & 203.6 & 0.09 & 0.754
\end{tabular}

$\begin{array}{rrrr}9 & 203.6 & 0.09 & 0.754\end{array}$

$\begin{array}{llll}11 & 202.7 & 0.11 & 0.753 \\ 13 & 201.9 & 0.13 & 0.752\end{array}$

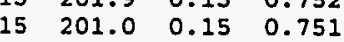

RUN NUMBER: 515

$\mathrm{p} / \mathrm{d}=1.5$

$\mathrm{Xin}=0.00 \mathrm{kPa}$

$x_{\text {in }}=0.00$

$\begin{array}{rccl}\text { ROW } & P & X i n & Y^{\prime} \\ * & {[\mathrm{kPa}]} & 1-] & \mathrm{R}^{\prime}-11 \\ 1 & 203.0 & 0.00 & 0.758 \\ 3 & 202.0 & 0.03 & 0.757 \\ 5 & 201.2 & 0.06 & 0.755 \\ 7 & 200.3 & 0.10 & 0.754 \\ 9 & 199.4 & 0.13 & 0.752 \\ 11 & 198.5 & 0.16 & 0.751 \\ 13 & 197.6 & 0.19 & 0.750 \\ 15 & 196.7 & 0.22 & 0.748\end{array}$ $\begin{aligned} & Y^{\prime} \text { in }=75.8 \& R-11 / 24.2 \& R-113 \\ & G=194.42 \mathrm{~kg} / \mathrm{s}^{\star} \mathrm{m}^{\wedge}\end{aligned}$ $\begin{aligned} \text { DELTA P total } & =6.68 \mathrm{kPa} \\ \text { Xout } & =0.11\end{aligned}$

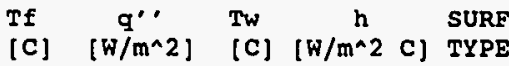
$46.521480 \quad 50.34949$ H.F. $46.421300 \quad 51.6 \quad 5096$ H.F 46.420680 51.9 4939 H.F. $\begin{array}{llll}46.4 & 20886 & 58.2 & 1773 \\ \text { SM. }\end{array}$

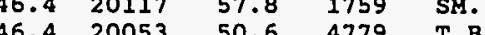

46.42012050 .6 4779 T.B.

$\begin{array}{lllll}46.5 & 19670 & 49.8 & 5849 & \text { T.B. }\end{array}$

$Y^{\prime}$ in $=75.8$ \& $R-11 / 24.2 \& R-113$ $\begin{aligned} \text { DELTA P total } & =6.52 \mathrm{kPa} \\ \text { Xout } & =0.16\end{aligned}$

\begin{tabular}{|c|c|c|c|c|}
\hline \\
\hline \multicolumn{5}{|c|}{ 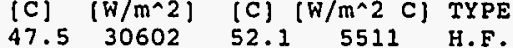 } \\
\hline \multicolumn{5}{|c|}{$\begin{array}{lllll}17.5 & 30602 & 52.1 & 5511 & \text { H.F } \\
18.0 & 30411 & 53.4 & 5582 & \text { H.F }\end{array}$} \\
\hline & & & & \\
\hline & & & & \\
\hline & & & & \\
\hline & & & & \\
\hline & & & & \\
\hline
\end{tabular}

$R-11 / 24.2$
$G=205.96 \mathrm{~kg} / \mathrm{s} * \mathrm{~m}^{\wedge} 2$ $\begin{aligned} \text { DELTA P total } & =6.12 \mathrm{kPa} \\ \text { Xout } & =0.24\end{aligned}$

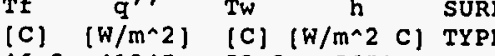
$46.941245 \quad 52.37671$ H.F. $\begin{array}{lllll}48.0 & 40902 & 53.0 & 8048 & \text { H.F. }\end{array}$ $\begin{array}{lllll}48.0 & 40030 & 53.0 & 8035 & \text { H.F. }\end{array}$ $48.1 \quad 40572 \quad 61.1 \quad 3120$ SM. $48.3 \quad 39868 \quad 61.6 \quad 2992 \quad S M$. $\begin{array}{lllll}48.4 & 40056 & 54.2 & 6947 & \text { T.B. }\end{array}$ $\begin{array}{lllll}48.5 & 40182 & 54.2 & 7094 & \text { T.B }\end{array}$ 
RUN NUMBER: 505
P/d $=1.5$

$P_{\text {in }}=234.67 \mathrm{kPa}$

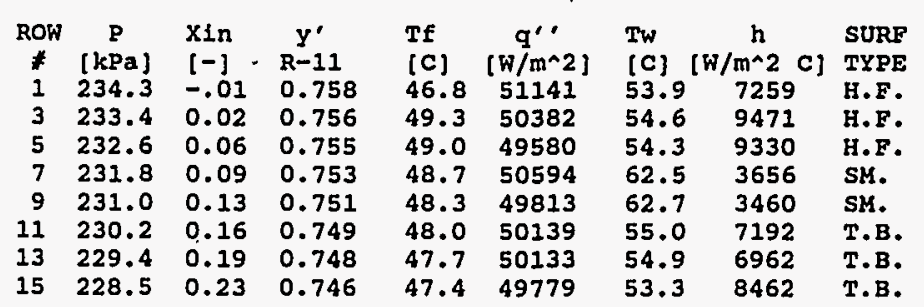

RUN NUMBER: 514
$\mathrm{p} / \mathrm{d}=1.5$

$\mathrm{p} / \mathrm{d}=1.5$

Pin $=219.29 \mathrm{kPa}$
$\mathrm{Xin}=-.01$

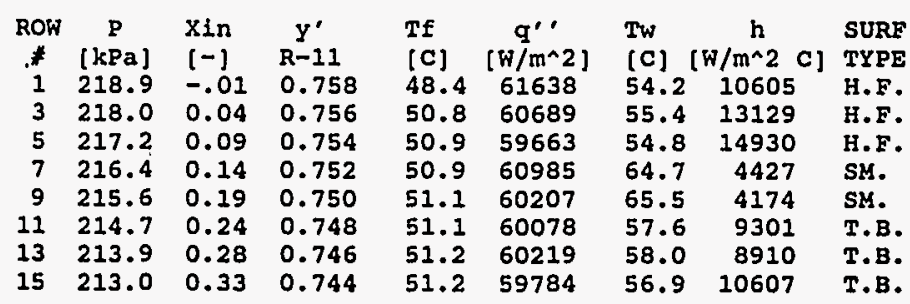

\section{RUN NUMBER: 513 \\ $\mathrm{p} / \mathrm{d}=1.5$ \\ Pin $=219.29 \mathrm{kPa}$}

$\begin{array}{cccc}\text { ROW } & \text { P } & \text { Xin } & y^{\prime} \\ \text { \# } & {[\mathrm{kPa}]} & {[-]} & \mathrm{R}-11 \\ 1 & 218.9 & -.01 & 0.758 \\ 3 & 218.0 & 0.04 & 0.756 \\ 5 & 217.2 & 0.09 & 0.753 \\ 7 & 216.4 & 0.14 & 0.751 \\ 9 & 215.6 & 0.19 & 0.748 \\ 11 & 214.7 & 0.24 & 0.746 \\ 13 & 213.9 & 0.28 & 0.743 \\ 15 & 213.0 & 0.33 & 0.741\end{array}$

$\begin{aligned} & y^{\prime} \text { in }=75.8 \& R-11 / 24.2 \& R-113 \\ & G=203.79 \mathrm{~kg} / \mathrm{s}^{\star} \mathrm{m}^{\wedge} 2\end{aligned}$

DELTA P total $=5.62 \mathrm{kPa}$
Xout $=0.35$

Xout $=0.35$

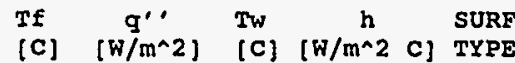

48.472117 (C) (W/ma C)

$50.871006 \quad 55.6 \quad 14917$ H.F.

$50.969806 \quad 55.0 \quad 16718$ H.F.

$50.9 \quad 71352$

$\begin{array}{ll}51.1 & 70442 \\ 51.1 & 70292\end{array}$

$\begin{array}{ll}51.1 & 70292 \\ 51.2 & 70456\end{array}$

$51.2 \quad 69948$

$67.0 \quad 4427$ SM.

$\begin{array}{lll}67.9 & 4174 & \text { SM. } \\ 58.7 & 9301 & \text { T.B. }\end{array}$

$\begin{array}{lll}58.7 & 9301 & \text { T.B. } \\ 59.1 & 8910 & \text { T.B. }\end{array}$

$\begin{array}{rrr}59.8 & 8910 & \text { T.B. } \\ 57.8 & 10607 & \text { T.B. }\end{array}$

RUN NUMBER; 543

$\mathrm{p} / \mathrm{d}=1.5$

Pin $=575.96 \mathrm{kPa}$

$\begin{array}{rccc}\text { ROW } & \text { P } & \text { Xin } & Y^{\prime} \\ \text { \# } & {[\text { kPa] }} & {[-]} & R-11 \\ 1 & 575.5 & -.00 & 0.751 \\ 3 & 574.4 & 0.00 & 0.751 \\ 5 & 573.4 & 0.01 & 0.751 \\ 7 & 572.5 & 0.01 & 0.750 \\ 9 & 571.6 & 0.02 & 0.750 \\ 11 & 570.7 & 0.02 & 0.750 \\ 13 & 569.8 & 0.03 & 0.750 \\ 15 & 568.8 & 0.03 & 0.750\end{array}$

RUN NUMBER: 542

$\mathrm{p} / \mathrm{d}=1.5$

Pin $=579.4 \mathrm{kP}$

$\operatorname{xin}=-.00$

$\begin{array}{cccc}\text { ROW } & P & X 1 n & Y^{\prime} \\ * & {[\mathrm{kPa}]} & {[-]} & \mathrm{R}-11 \\ 1 & 578.9 & -.00 & 0.751 \\ 3 & 577.9 & 0.01 & 0.751 \\ 5 & 576.9 & 0.02 & 0.750 \\ 7 & 576.0 & 0.03 & 0.750 \\ 9 & 575.1 & 0.04 & 0.749 \\ 11 & 574.2 & 0.05 & 0.749 \\ 13 & 573.4 & 0.06 & 0.748 \\ 15 & 572.4 & 0.08 & 0.748\end{array}$

$\begin{array}{llll}15 & 572.4 & 0.08 & 0.748\end{array}$

RUN NUMBER: 541

$\mathrm{p} / \mathrm{d}=1.5$

$.4 \mathrm{kPa}$

$x_{\text {in }}=-.00$

$\begin{array}{rccc}\text { ROW } & \mathrm{P} & \mathrm{Xin} & \mathrm{Y}^{\prime} \\ \neq & {[\mathrm{kPa}]} & {[-]} & \mathrm{R}^{\prime}-11 \\ 1 & 578.9 & -.00 & 0.751 \\ 3 & 577.8 & 0.02 & 0.750 \\ 5 & 576.9 & 0.04 & 0.749 \\ 7 & 575.9 & 0.06 & 0.748 \\ 9 & 575.0 & 0.09 & 0.748 \\ 11 & 574.2 & 0.11 & 0.747 \\ 13 & 573.4 & 0.13 & 0.746 \\ 15 & 572.5 & 0.15 & 0.745\end{array}$ $y^{\prime}$ in $=75.1 \& R-11 / 24.9 \& R-113$

$G=51.44 \mathrm{~kg} / \theta^{*} \mathrm{~m}^{\wedge} 2$

DELTA P total $=6.8 \mathrm{kPa}$

Xout $=0.04$

\begin{tabular}{|c|c|c|c|c|}
\hline [C] & $\underset{[W / m \wedge 2]}{q^{\prime \prime}}$ & $\begin{array}{l}T w \\
{[C]}\end{array}$ & $\left.\stackrel{h}{h / m^{\wedge} 2} \quad c\right]$ & $\begin{array}{l}\text { SURF } \\
\text { TYPE }\end{array}$ \\
\hline 90.0 & $5346^{\circ}$ & 93.1 & 1734 & H.F. \\
\hline & 5309 & 93.2 & 1941 & \\
\hline & 5167 & 93.4 & 2127 & H.F \\
\hline & 5577 & 810 & 916 & \\
\hline & 5491 & 97.4 & 978 & SM. \\
\hline & 5151 & 94.2 & 2300 & \\
\hline & 5195 & 94.2 & 2532 & 1 \\
\hline & 5127 & 94.0 & 2911 & \\
\hline
\end{tabular}

$y^{\prime}$ in $=75.1 \& R-11 / 24.9 \& R-113$ $=51.19 \mathrm{~kg} / \mathrm{s}^{*} \mathrm{~m}^{\wedge} 2$

DELTA $P$ total $=6 \mathrm{kPa}$

xout $=0.08$

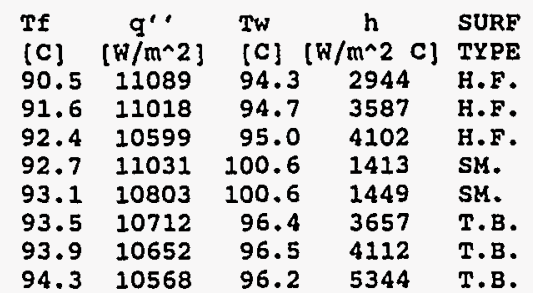

$y^{\prime}$ in $=75.1 \& R-11 / 24.9 \& R-113$ DELTA $\mathrm{P}$ total $=6.59 \mathrm{~kg} / \mathrm{s}^{\star} \mathrm{m}^{\wedge} 2$ Xout $=0.16$

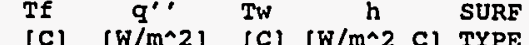

[C] [W/m^2] [C] [W/m^2 C] TYPE

$\begin{array}{lllll}92.1 & 21249 & 95.0 & 4903 & \text { H.F. }\end{array}$

$\begin{array}{lllll}92.6 & 20432 & 95.9 & 6233 & \text { H.F. }\end{array}$

$\begin{array}{lllll}93.0 & 21165 & 103.2 & 2074 & \mathrm{SM}\end{array}$

$\begin{array}{lllll}93.5 & 20718 & 103.2 & 2145 & \text { SM. }\end{array}$

$\begin{array}{lllll}94.0 & 20817 & 97.9 & 5389 & \text { T.B. }\end{array}$

$\begin{array}{lllll}94.9 & 20635 & 98.1 & 5782 & \text { T.B. } \\ & & & & \end{array}$ 
RUN NUMBER: 540

$\mathrm{P} / \mathrm{d}=1.5$

in $=579.4 \mathrm{kPa}$

$\operatorname{in}=0.07$

$\begin{array}{rccc}\text { ROW } & \mathbf{p} & \mathrm{xin} & \mathbf{y}^{\prime} \\ \# & {[\mathrm{kPa}]} & {[-]} & \mathrm{R}-11 \\ 1 & 578.9 & 0.09 & 0.751 \\ 3 & 577.8 & 0.13 & 0.750 \\ 5 & 576.8 & 0.16 & 0.748 \\ 7 & 575.9 & 0.19 & 0.747 \\ 9 & 575.0 & 0.23 & 0.746 \\ 11 & 574.2 & 0.26 & 0.744 \\ 13 & 573.5 & 0.29 & 0.743 \\ 15 & 572.6 & 0.33 & 0.742\end{array}$

RUN NUMBER: 539

$\mathrm{p} / \mathrm{d}=1.5$

$P_{\text {in }}=579.4 \mathrm{kPa}$

$\mathrm{Xin}=-.00$

$\begin{array}{rccc}\text { ROW } & \text { P } & \text { Xin } & y^{\prime} \\ * & {[\mathrm{kPa}]} & {[-]} & \mathrm{R}-11 \\ 1 & 578.9 & -.00 & 0.751 \\ 3 & 577.8 & 0.04 & 0.749 \\ 5 & 576.8 & 0.08 & 0.748 \\ 7 & 575.8 & 0.12 & 0.746 \\ 9 & 575.0 & 0.17 & 0.744 \\ 11 & 574.2 & 0.22 & 0.742 \\ 13 & 573.4 & 0.26 & 0.741 \\ 15 & 572.6 & 0.30 & 0.739\end{array}$

RUN NUMBER: 538

$\mathrm{p} / \mathrm{d}=1.5$

$P_{\text {in }}=582.85 \mathrm{kPa}$
$X_{\text {in }}=-.00$

$y^{\prime}$ in $=75.1 \& R-11 / 24.9 \& R-113$ $G=51.03 \mathrm{~kg} / \mathrm{s}^{\star} \mathrm{m}^{\wedge} 2$ DELTA P total $=5.62 \mathrm{kPa}$

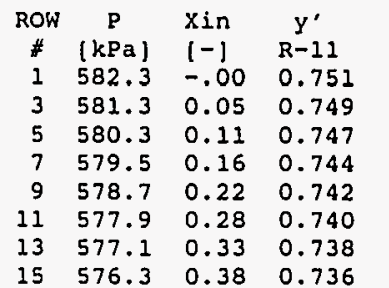

RUN NUMBER: 537

$\mathrm{P} / \mathrm{d}=1.5$

$\mathrm{P}_{\text {in }}=582.85 \mathrm{kPa}$

$x_{\text {in }}=-.00$

$\begin{array}{rccc}\text { ROW } & P & X \text { in } & Y^{\prime} \\ \# & {[\mathrm{kPa})} & 1-1 & \mathrm{R}-11 \\ 1 & 582.3 & -.00 & 0.751 \\ 3 & 581.2 & 0.06 & 0.748 \\ 5 & 580.2 & 0.13 & 0.746 \\ 7 & 579.2 & 0.20 & 0.743 \\ 9 & 578.3 & 0.27 & 0.741 \\ 11 & 577.5 & 0.33 & 0.738 \\ 13 & 576.8 & 0.40 & 0.735 \\ 15 & 575.9 & 0.47 & 0.733\end{array}$

RUN NUMBER: 531

$\mathrm{p} / \mathrm{d}=1.5$

$\mathrm{Pin}=579.4 \mathrm{kPa}$

$x_{\text {in }}=0.00$

$\begin{array}{rccc}\text { ROW } & \text { P } & \text { Xin } & Y^{\prime} \\ \# & {[\mathrm{kPa}]} & {[-]} & R-11 \\ 1 & 578.9 & 0.00 & 0.751 \\ 3 & 577.8 & 0.00 & 0.751 \\ 5 & 576.9 & 0.01 & 0.751 \\ 7 & 575.9 & 0.01 & 0.751 \\ 9 & 575.0 & 0.01 & 0.751 \\ 11 & 574.1 & 0.02 & 0.751 \\ 13 & 573.2 & 0.02 & 0.750 \\ 15 & 572.3 & 0.02 & 0.750\end{array}$

RUN NUMBER: 530

$\mathrm{p} / \mathrm{d}=1.5$

Pin $=579.4 \mathrm{kPa}$

ROW

* (kPa) $\begin{array}{cc}\mathrm{Xin} & \mathrm{Y}^{\prime} \\ \mathrm{L} & \mathrm{R}-11\end{array}$

$\begin{array}{lll}578.9 & -.00 & 0.751\end{array}$

$\begin{array}{llll}3 & 577.9 & 0.00 & 0.751\end{array}$

$\begin{array}{llll}576.9 & 0.01 & 0.751 \\ 7 & 576.0 & 0.02 & 0.750\end{array}$

575.10 .030 .750

$\begin{array}{llllll}11 & 574.2 & 0.03 & 0.750\end{array}$

$\begin{array}{lllll}13 & 573.3 & 0.04 & 0.750\end{array}$

$\begin{array}{lllll}15 & 572.4 & 0.05 & 0.749\end{array}$ $Y^{\prime}$ in $=75.1 \& R-11 / 24.9 \& R-113$
$G=51.07 \mathrm{~kg} / \mathrm{g} \mathrm{m}^{\wedge} 2$ $\begin{aligned} \text { DELTA P total } & =6.53 \mathrm{kPa} \\ \text { xout } & =0.50\end{aligned}$

\begin{tabular}{|c|c|c|c|c|}
\hline $\begin{array}{l}\text { If } \\
\text { (c) }\end{array}$ & $\begin{array}{c}q^{\prime \prime} \\
\left(w / m^{\wedge} 2\right)\end{array}$ & $\begin{array}{l}T w \\
\text { (c) }\end{array}$ & $\left.\frac{h}{W / m^{\wedge} 2} \quad c\right]$ & $\begin{array}{l}\text { SURF } \\
\text { TYPE }\end{array}$ \\
\hline 1.4 & 62584 & 97.3 & 10743 & 202 \\
\hline $\begin{array}{l}2.6 \\
3.1\end{array}$ & $\begin{array}{l}61955 \\
60406\end{array}$ & $\begin{array}{l}98.0 \\
98.1\end{array}$ & $\begin{array}{l}11431 \\
12245\end{array}$ & \\
\hline 3.7 & 61808 & 108.3 & 4255 & \\
\hline 1.3 & 60900 & 108.2 & 4392 & \\
\hline 1.9 & 60746 & 102.0 & 8512 & \\
\hline .5 & 61083 & 102.2 & 9122 & \\
\hline .1 & 60490 & 101.5 & 11162 & \\
\hline
\end{tabular}

$y^{\prime}$ in $=75.1 \& R-11 / 24.9 \& R-113$
$G=217.08 \mathrm{~kg} / \mathrm{s}^{*} \mathrm{~m}^{\wedge} 2$ $\begin{aligned} \text { DELTA P total } & =6.81 \mathrm{kPa} \\ \text { xout } & =0.02\end{aligned}$

\begin{tabular}{|c|c|c|c|c|}
\hline $\begin{array}{l}\text { Tf } \\
\text { (c) }\end{array}$ & $\begin{array}{l}q^{\prime \prime} \\
{\left[w / m^{\wedge} 2\right]}\end{array}$ & $\begin{array}{l}T w \\
\text { (c) }\end{array}$ & 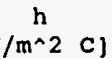 & $\begin{array}{l}\text { SURF } \\
\text { TYPE }\end{array}$ \\
\hline 90.6 & 4892 & 93.5 & 1720 & \\
\hline & 4865 & 93.7 & 1929 & \\
\hline 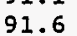 & 4786 & & 2110 & \\
\hline 2 & 5095 & 97.9 & 896 & \\
\hline & 5032 & & 965 & \\
\hline 2. & 4701 & 94.9 & 2304 & \\
\hline 3.1 & 4783 & 95.0 & 2557 & T.B \\
\hline
\end{tabular}

$y^{\prime}$ in $=75.18 \mathrm{R}-11 / 24.98 \mathrm{R}-113$ DELTA $P$ total $=6.04 \mathrm{kPa}$ xout $=0.05$

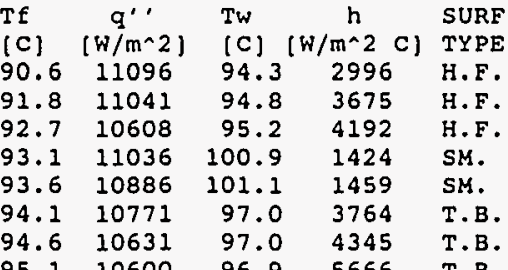




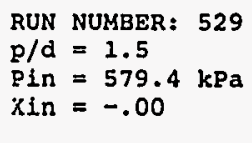

$\begin{array}{cccc}\text { ROW } & P & \text { Xin } & Y^{\prime} \\ \# & {[\mathrm{kPa}]} & {[-]} & \mathrm{R}-11 \\ 1 & 578.9 & -.00 & 0.751 \\ 3 & 577.8 & 0.01 & 0.751 \\ 5 & 576.8 & 0.02 & 0.750 \\ 7 & 575.9 & 0.04 & 0.750 \\ 9 & 575.0 & 0.05 & 0.749 \\ 11 & 574.2 & 0.07 & 0.749 \\ 13 & 573.3 & 0.08 & 0.748 \\ 15 & 572.5 & 0.09 & 0.748\end{array}$

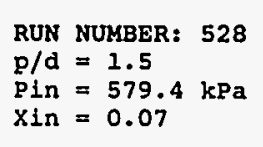

$\begin{array}{cccc}\text { ROW } & \begin{array}{c}\text { P } \\ \text { \# }\end{array} \text { [kPa] } & \text { Xin } & Y^{\prime} \\ 1 & 578.9 & 0.06 & 0.751 \\ 3 & 577.8 & 0.08 & 0.750 \\ 5 & 576.9 & 0.10 & 0.750 \\ 7 & 575.9 & 0.12 & 0.749 \\ 9 & 575.1 & 0.14 & 0.748 \\ 11 & 574.3 & 0.16 & 0.748 \\ 13 & 573.6 & 0.18 & 0.747 \\ 15 & 572.8 & 0.20 & 0.746\end{array}$

\section{RUN NUMBER: 527}

$4 \mathrm{kPa}$

$\mathrm{xin}=-.00$ $y^{\prime}$ In $=75.1 \& R-11 / 24.9 \& R-113$ $=216.47 \mathrm{~kg} / 0^{*} \mathrm{~m}^{\wedge}$ DELTA $P$ total $=6.61 \mathrm{kPa}$ Xout $=0.10$

\begin{tabular}{|c|c|c|c|c|}
\hline $\begin{array}{l}\text { Tf } \\
\text { [C] }\end{array}$ & {$\left[w / m^{\wedge} 2\right]$} & $\begin{array}{l}T w \\
{[C]}\end{array}$ & $\left.\frac{h}{\left[W / m^{\wedge} 2\right.} \quad C\right]$ & $\begin{array}{l}\text { SURF } \\
\text { TYPE }\end{array}$ \\
\hline 90.5 & 21273 & 94.9 & 4856 & H.F. \\
\hline 91.8 & 21133 & 95.5 & 5774 & H.F. \\
\hline 92.2 & 20425 & 95.5 & 6326 & H.F. \\
\hline 2.6 & 21113 & 102.8 & 2080 & SM. \\
\hline 3. & 20661 & 102.7 & 2138 & SH. \\
\hline . 4 & 20758 & 97.4 & 5194 & T.B. \\
\hline 3.7 & 20858 & 97.4 & 5766 & т.B. \\
\hline & 20583 & 96.9 & 7429 & T.B. \\
\hline
\end{tabular}

$y^{\prime}$ in $=75.1 \& R-11 / 24.9 \& R-113$ $G=216.66 \mathrm{~kg} / \mathrm{B}^{\star} \mathrm{m}^{\wedge}$ $\begin{aligned} \text { DELTA P total } & =5.67 \mathrm{kPa} \\ \text { Xout } & =0.21\end{aligned}$

\begin{tabular}{|c|c|c|c|c|}
\hline \multicolumn{5}{|c|}{$q^{\prime \prime}$} \\
\hline 90.5 & 31530 & 95.3 & 6618 & \\
\hline 2.0 & 31299 & 96.0 & 7772 & \\
\hline 2.4 & 30144 & 96.0 & 8280 & \\
\hline 2.8 & 31163 & 104.1 & 2738 & \\
\hline 3.2 & 30766 & 104.1 & 2826 & \\
\hline & 30886 & 98.3 & 6504 & \\
\hline 4.0 & 30793 & 98.4 & 6983 & \\
\hline & 30596 & 97.8 & 8986 & \\
\hline
\end{tabular}

RUN NUMBER: 526

$\mathrm{p} / \mathrm{d}=1.5$

$\mathrm{Pin}=582.85 \mathrm{kPa}$

$x$ in $=-.00$

$\begin{array}{cccc}\text { ROW } & \begin{array}{c}P \\ \text { * }\end{array} & \text { Xin } & \mathbf{Y}^{\prime} \\ 1 & 582.3 & {[-]} & R^{\prime}-11 \\ 3 & 581.2 & 0.00 & 0.751 \\ 5 & 580.2 & 0.06 & 0.750 \\ 7 & 579.2 & 0.10 & 0.749 \\ 9 & 578.4 & 0.13 & 0.748 \\ 11 & 577.7 & 0.17 & 0.746 \\ 13 & 576.9 & 0.20 & 0.745 \\ 15 & 576.2 & 0.24 & 0.743\end{array}$

RUN NUMBER: 525 $\mathrm{p} / \mathrm{d}=1.5$

Pin $=582.85 \mathrm{kPa}$

$\begin{array}{cccc}\text { ROW } & \text { P } & \text { Xin } & y^{\prime} \\ * & {[k P a]} & l-] & R^{\prime}-11 \\ 1 & 582.3 & -.00 & 0.751 \\ 3 & 581.2 & 0.04 & 0.750 \\ 5 & 580.1 & 0.08 & 0.748 \\ 7 & 579.2 & 0.12 & 0.747 \\ 9 & 578.3 & 0.16 & 0.746 \\ 11 & 577.5 & 0.20 & 0.744 \\ 13 & 576.8 & 0.23 & 0.743 \\ 15 & 576.0 & 0.27 & 0.742\end{array}$

$y^{\prime}$ in $=75.1 \& R-11 / 24.9 \& R-113$ $G=216 \mathrm{~kg} / \mathrm{g}^{*} \mathrm{~m}^{\wedge} 2$ DELTA $\mathrm{p}$ total $=6.14 \mathrm{kPa}$ Xout $=0.25$

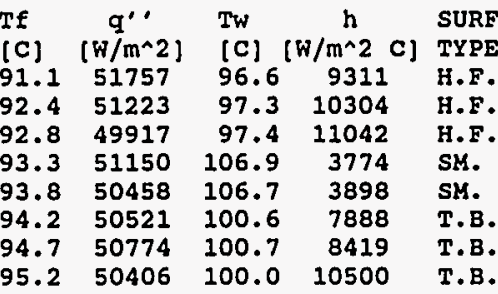
$y^{\prime}$ in $=75.1 \& \mathrm{R}-11 / 24.98 \mathrm{R}-113$
$G=215.84 \mathrm{~kg} / \mathrm{s}^{\star} \mathrm{m}^{\wedge} 2$ $\begin{aligned} \text { DELTA P toțal } & =6.4 \mathrm{kPa} \\ \text { Xout } & =0.31\end{aligned}$

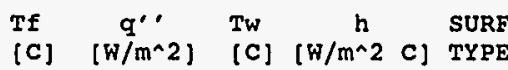
310713 H.E. $92.462366 \quad 97.9 \quad 11413 \quad$ H.F. $92.960883 \quad 97.9 \quad 12227$ H.F. $93.462029108 .0 \quad 4255$ SM. $93.961437 \quad 107.9 \quad 4370 \quad$ SM. $94.461012 \quad 101.5 \quad 8488$ T.B. $\begin{array}{rrrrr}94.8 & 61337 & 101.6 & 9078 & \text { T.B. } \\ 95.3 & 60874 & 100.9 & 11002 & \text { T.B. }\end{array}$

RUN NUMBER: 536 $\mathrm{p} / \mathrm{d}=1.5$

Pin $=582.85 \mathrm{kPa}$

$x_{\text {in }}=-.00$ $y^{\prime}$ in $=75.1 \& R-11 / 24.9 \& \mathrm{R}-113$
$G=207.12 \mathrm{~kg} / \mathrm{g}^{\star} \mathrm{m}^{\wedge} 2$ $\begin{aligned} \text { DELTA P total } & =6.46 \mathrm{kPa} \\ \text { Xout } & =0.40\end{aligned}$

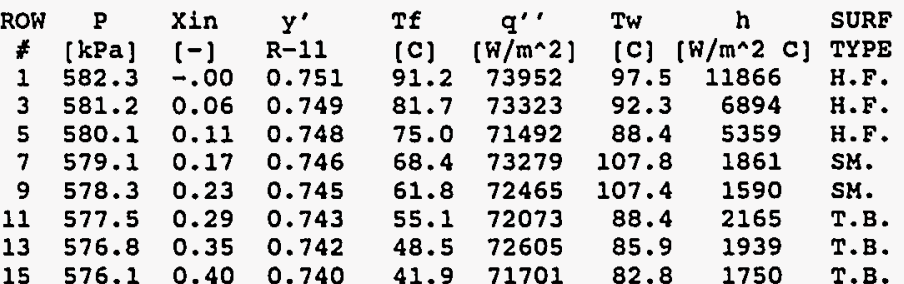


Single-Phase Data 


\begin{tabular}{|c|c|c|c|c|c|c|c|c|c|c|c|c|c|c|c|c|c|c|c|c|}
\hline \multicolumn{4}{|c|}{$\begin{array}{l}\text { RUN NUMBER: } 6 \\
\text { P/d }=1.5 \\
\text { PIn }=115.9 \mathrm{kPa} \\
\text { XIn }=-.24 \\
\text { SURFACE TYPE: SMOOTH }\end{array}$} & \multicolumn{3}{|c|}{$\begin{array}{r}\text { WORKING FLUID: } \mathrm{R}-113 \\
G=101.84 \mathrm{~kg} / \mathrm{g}^{\star \mathrm{m}^{\wedge} 2} \\
\text { LTA P total }=6.28 \mathrm{kPa} \\
\text { Xout }=-.20\end{array}$} & \multicolumn{4}{|c|}{$\begin{array}{l}\text { RUN NUMBER: } 9 \\
\text { P/d }=1.5 \\
\text { PIn }=146.8 \mathrm{kPa} \\
\text { XIn }=-.32 \\
\text { SURFACE TYPE: SMOOTH }\end{array}$} & \multicolumn{3}{|c|}{$\begin{array}{r}\text { WORKING FLUID: } \mathrm{R}-113 \\
G=297.27 \mathrm{~kg} / \mathrm{s}^{\star} \mathrm{m}^{\wedge} 2 \\
\text { ELTA P total } 6.43 \mathrm{kPa} \\
\text { Xout }=-.29\end{array}$} & \multicolumn{4}{|c|}{$\begin{array}{l}\text { RUN NUMBER: } 12 \\
\text { p/d }=1.5 \\
\text { Pin }=171 \mathrm{kPa} \\
\text { Xin }=-.37 \\
\text { SUREACE TYPE: SMOOT }\end{array}$} & \multicolumn{3}{|c|}{$\begin{array}{r}\text { WORKING FLUID: R-113 } \\
G=393.46 \mathrm{~kg} / \mathrm{g}^{*} \mathrm{~m}^{\wedge} 2 \\
\mathrm{P} \text { total }=7.08 \mathrm{kPa} \\
\text { Xout }=-.35\end{array}$} \\
\hline $\begin{array}{c}\text { Row } \\
\ddagger\end{array}$ & $\stackrel{P}{\stackrel{P}{k P a}]}$ & $x \sin$ & & $\begin{array}{c}q^{\prime \prime} \\
{\left[w / m^{\wedge} 2\right]}\end{array}$ & $\begin{array}{l}\text { Tw } \\
\text { [C] }\end{array}$ & $\stackrel{h}{\left(m^{\wedge} 2 c \mid\right.}$ & $\begin{array}{c}\text { ROW } \\
*\end{array}$ & & & & $\underset{\left[\mathrm{w} / \mathrm{m}^{\wedge} 2\right]}{ }$ & Tw & $\stackrel{h}{m^{\wedge} 2}$ & $\begin{array}{c}\text { Row } \\
\neq\end{array}$ & & & & & & $\stackrel{h}{h}$ \\
\hline 1 & 115.5 & & & & & & $i$ & & & & & & & 1 & & & & & & \\
\hline 3 & 114 & .2 & & & & & 3 & & & & & & & 3 & & & & & & \\
\hline 5 & & & & & & & 5 & & & & & & & 5 & & & & & & \\
\hline 7 & & & & & & & 7 & & & & & & & 7 & & & & & & \\
\hline 9 & & .2 & & & & & 9 & & & & & & & 9 & & & & & & \\
\hline & & .2 & & & & & & & & & & & & & & & & & & \\
\hline & & & & & & & & & & & & & & & & & & & & \\
\hline 15 & 109.6 & -.21 & 29.2 & 5291 & 46.6 & 314 & 15 & 140.6 & -.30 & 26.4 & 14244 & 47.6 & 682 & 15 & 164.7 & -.35 & 25.4 & 12072 & 41.0 & 784 \\
\hline
\end{tabular}

\begin{tabular}{|c|c|c|c|c|c|c|c|c|c|c|c|c|c|c|c|c|c|c|c|c|}
\hline $\begin{array}{l}\text { RUN } \\
\text { p/d } \\
\text { Pin } \\
\text { Xin } \\
\text { SUR }\end{array}$ & $\begin{array}{l}\text { NUMBER: } \\
=1.5 \\
=119.3 \\
=-.23\end{array}$ & $\begin{array}{l}7 \\
\mathrm{kPa}\end{array}$ & & $\begin{array}{c}\text { WORKIN } \\
\text { G }= \\
\text { ELTA P }\end{array}$ & $\begin{array}{l}\text { FLUI } \\
1.55 \\
\text { tal }= \\
\times 0\end{array}$ & $\begin{array}{l}D: R-113 \\
\mathrm{~kg} / \mathrm{s}^{\star} \mathrm{m}^{\wedge} 2 \\
6.6 \mathrm{kPa} \\
\mathrm{ut}=-.20\end{array}$ & $\begin{array}{l}\text { RUN } \\
\text { p/d } \\
\text { Pin } \\
\text { Xin } \\
\text { SUR }\end{array}$ & $\begin{array}{l}\text { NUMBE } \\
=1.5 \\
=115 \\
=-.2 \\
\text { FACE T }\end{array}$ & $: 10$ & ОтН & $\begin{array}{l}\text { WORKIN } \\
G= \\
\text { ELTA } P \text { to }\end{array}$ & $\begin{array}{l}\text { G FLU } \\
9.74 \\
\text { ta1 }= \\
\times 0\end{array}$ & $\begin{array}{l}\text { ID : } R-113 \\
\mathrm{~kg} / \mathrm{g}^{*} \mathrm{~m}^{\wedge} 2 \\
6.91 \mathrm{kPa} \\
\mathrm{ut}=-.20\end{array}$ & $\begin{array}{l}\text { RUN } \\
\text { p/d } \\
\text { Pin } \\
\text { Xin } \\
\text { SURF }\end{array}$ & $\begin{array}{l}\text { NUMBE } \\
=1.5 \\
=160 \\
=-.3 \\
\text { FACE T }\end{array}$ & $\begin{array}{l}: 13 \\
6 \mathrm{kPa}\end{array}$ & & $\begin{array}{c}\text { WORKI } \\
G= \\
\text { TA } P=\end{array}$ & $\begin{array}{l}\text { G FLU } \\
54.63 \\
\mathrm{tal}=\end{array}$ & $\begin{array}{l}\text { ID: } R-113 \\
\mathrm{~kg} / \mathrm{s}^{*} \mathrm{~m}^{\wedge} 2 \\
6.01 \mathrm{kPa} \\
\mathrm{ut}=-.32\end{array}$ \\
\hline ow & $\underset{\mathrm{kPa}}{\mathrm{P}}$ & & $\begin{array}{l}\text { Tf } \\
{[\mathrm{Cl}}\end{array}$ & $\underset{\left[W / m^{\wedge} 2\right]}{q^{\prime \prime}}$ & Tw & $\mathrm{h}$ & $\begin{array}{c}\text { ROW } \\
t\end{array}$ & & & Tf & $q^{\prime \prime}$ & & $m^{\wedge} 2 c$ & ROW & & & & & Tw & $\mathrm{h}$ \\
\hline$i$ & 118 & $\begin{array}{l}{[-]} \\
-.23\end{array}$ & 26.0 & $\begin{array}{r}{[\mathrm{w} / \mathrm{m}} \\
382\end{array}$ & $\begin{array}{l}{[C]} \\
42.8\end{array}$ & $\begin{array}{l}m^{\wedge} 2(c) \\
232\end{array}$ & 1 & $\begin{array}{l}\text { kP } \\
115\end{array}$ & $1-1$ & & $\begin{array}{r}w / m \\
62\end{array}$ & $\begin{array}{l}\text { lC } \\
43\end{array}$ & $\begin{array}{c}\left.\mathrm{m}^{\wedge} 2 c\right] \\
337\end{array}$ & $\begin{array}{l}* \\
1\end{array}$ & & & .7 & & $\begin{array}{l}{[\mathrm{C}]} \\
42.1\end{array}$ & \\
\hline 3 & & & & & & 24 & 3 & 114 & -.2 & 25 & 632 & 43 & 35 & 3 & & -. & 24.0 & 102 & 41.5 & \\
\hline 5 & 117 & .2 & 27 & 37 & & & 5 & & & & & & & 5 & & & & & & \\
\hline 7 & & .2 & & & & & 7 & & & & & & & 7 & & & & & & \\
\hline 9 & & & & & & & 9 & & & & & & & 9 & & & & & & \\
\hline & 114 & .2 & & & & & 11 & & & & & & & 11 & & & & & .4 & \\
\hline & & - & & 411 & & 26 & 13 & & & & & & & & & & & & & \\
\hline & 113.0 & -.20 & 30.6 & 4209 & 46.4 & 275 & 15 & 109.6 & -.20 & 29.5 & 6609 & 46.8 & $\begin{array}{l}312 \\
393\end{array}$ & 15 & 154.9 & -.32 & 25.4 & 11036 & 43.9 & \\
\hline
\end{tabular}

\begin{tabular}{|c|c|c|c|c|c|c|c|c|c|c|c|c|c|c|c|c|c|c|c|c|}
\hline \multicolumn{4}{|c|}{$\begin{array}{l}\text { RUN NUMBER: } 8 \\
\text { P/d }=1.5 \\
\text { Pin }=119.3 \mathrm{kPa} \\
\text { Xin }=-.26 \\
\text { SURFACE TYPE: SMOOTH }\end{array}$} & \multicolumn{3}{|c|}{$\begin{array}{r}\text { WORKING FLUID: R-113 } \\
G=198.08 \mathrm{~kg} / \mathrm{s}^{*} \mathrm{~m}^{\wedge} 2 \\
\text { ELTA P total }=6.37 \mathrm{kPa} \\
\text { Xout }=-.24\end{array}$} & \multicolumn{4}{|c|}{$\begin{array}{l}\text { RUN NUMBER: } 11 \\
\text { P/d }=1.5 \\
\text { Pin }=112.4 \mathrm{kPa} \\
\text { Xin }=-.21 \\
\text { SURFACE TYPE: SMOOTH }\end{array}$} & \multicolumn{3}{|c|}{$\begin{array}{r}\text { WORKING FLUID: R-113 } \\
\text { G }=50 \mathrm{~kg} / \mathrm{s}^{*} \mathrm{~m} \wedge \\
\text { ELTA P total }=6.94 \mathrm{kPa} \\
\text { xout }=-.16\end{array}$} & \multicolumn{4}{|c|}{$\begin{array}{l}\text { RUN NUMBER: } 14 \\
\text { P/d }=1.5 \\
\text { Pin }=186.8 \mathrm{kPa} \\
\text { Xin }=-.30 \\
\text { SURFACE TYPE: SMOOTH }\end{array}$} & \multicolumn{3}{|c|}{$\begin{array}{r}\text { WORKING FLUID: } R-113 \\
G=47.62 \mathrm{~kg} / \mathrm{s}^{*} \mathrm{~m} 2 \\
\text { TA P total }=6.34 \mathrm{kP} \\
\text { Xout }=-.15\end{array}$} \\
\hline zow & $\begin{array}{c}P \\
{[k P a]}\end{array}$ & & $\begin{array}{l}\text { Tf } \\
\text { [C] }\end{array}$ & $\underset{\left[w / m^{\wedge} 2\right]}{q^{\prime \prime}}$ & $\begin{array}{l}T w \\
\text { (C) }\end{array}$ & $\stackrel{\substack{h \\
W / m^{\wedge} 2}}{c}$ & $\begin{array}{c}\text { Row } \\
\#\end{array}$ & $\underset{[\mathrm{kPa}]}{\mathrm{P}}$ & & & $\underset{\left[w / m^{\wedge} 2\right]}{q^{\prime \prime}}$ & $\begin{array}{l}T w \\
\text { [C] }\end{array}$ & $\frac{h}{(W / m \wedge 2 \quad C]}$ & $\begin{array}{c}\text { ROW } \\
\#\end{array}$ & $\underset{\left[\mathrm{Pa}^{\mathrm{P}}\right]}{\mathrm{P}}$ & & & $\underset{\left[W / m^{\wedge} 2\right]}{q \cdots}$ & $\begin{array}{l}T w \\
{[C]}\end{array}$ & $\frac{h}{m^{\wedge} 2}$ \\
\hline 1 & & & & & 37.5 & 483 & 1 & & & & & & & 1 & & & & & & \\
\hline 3 & & & & & & & 3 & & & & & & & 3 & & & & & & \\
\hline 5 & &. & & & & & 5 & & & & & & & 5 & & & & & & \\
\hline 7 & & . & & & & & 7 & & & & & & & 7 & & & & & & \\
\hline 9 & & & & & & & 9 & & & & & & & 9 & & & & & & \\
\hline & & -.0 & & & & & & & & & & & & & & & & & & \\
\hline & & .2 & & & & & & & & & & & & & & & & & & \\
\hline 5 & 113.0 & -.24 & 25.8 & 7328 & 39.5 & $545^{\circ}$ & 15 & 106.1 & -.17 & 31.9 & 4113 & 46.6 & 294 & 15 & 181.1 & -.19 & 38.7 & 10069 & & \\
\hline
\end{tabular}




\begin{tabular}{|c|c|c|c|c|c|c|c|c|c|c|c|c|c|}
\hline \multicolumn{4}{|c|}{$\begin{array}{l}\text { RUN NUMBER: } 16 \\
\text { P/d }=1.5 \\
\text { Pin }=202 \mathrm{kPa} \\
\text { Xin }=-.33 \\
\text { SUREACE TYPE: SMOOTH }\end{array}$} & \multicolumn{3}{|c|}{$\begin{array}{c}\text { WORKING FLUID: R-113 } \\
G=49.05 \mathrm{~kg} / \mathrm{s}^{*} \mathrm{~m}^{\mathrm{m}} 2 \\
\text { A P total }=5.59 \mathrm{kPa} \\
\text { Xout }=-.22\end{array}$} & \multicolumn{4}{|c|}{$\begin{array}{l}\text { RUN NUMBER: } 19 \\
\text { P/d }=1.5 \\
\text { Pin }=115.8 \mathrm{kPa} \\
\text { Xin }=-.20 \\
\text { SURFACE TYPE: TURBO-B }\end{array}$} & \multicolumn{3}{|c|}{$\begin{array}{r}\text { WORKING FLUID: R-113 } \\
G=125.43 \mathrm{~kg} / \mathrm{s}^{\star} \mathrm{m}^{\wedge} 2 \\
\text { TA P total }=5.77 \mathrm{kPa} \\
\text { Xout }=-. .15\end{array}$} \\
\hline$\stackrel{\text { ROW }}{\star}$ & $\begin{array}{c}P \\
{[\mathrm{kPa}]}\end{array}$ & $\begin{array}{l}\text { Xin } \\
{[-]}\end{array}$ & $\begin{array}{l}\text { Tf } \\
{[C]}\end{array}$ & $\frac{q^{\prime \prime}}{\left[w / m^{\wedge} 2\right]}$ & $\begin{array}{l}\text { Tw } \\
{[C]}\end{array}$ & $\begin{array}{ll}h \\
m^{\wedge} 2 & c]\end{array}$ & $\stackrel{\text { ROW }}{f}$ & $\begin{array}{c}\mathrm{P} \\
{[\mathrm{kPa}]}\end{array}$ & & $\begin{array}{l}\text { Tf } \\
\text { [C] }\end{array}$ & $\underset{\left[w / m^{\wedge} 2\right]}{q^{\prime \prime}}$ & $\begin{array}{l}T w \\
\text { [c] }\end{array}$ & 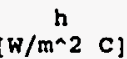 \\
\hline 1 & 201.6 & -.33 & 22.6 & 8657 & 55.7 & 265 & $i$ & & & 21.1 & & 44.8 & 379 \\
\hline 3 & 200.9 & -.31 & 24. & 89 & 53 & & 3 & 114.7 & -.20 & 22.0 & 9080 & 41.9 & 457 \\
\hline 5 & & & & & & & 5 & & & & 927 & & 419 \\
\hline 7 & 199 & & & & & 31 & 7 & & & & & & \\
\hline 9 & & -.2 & & & & & & & & 25 & 91 & 45 . & 437 \\
\hline 11 & 197.9 & -.2 & 33. & 86 & 61 & & 11 & 111.6 & & & & 46.6 & 438 \\
\hline 13 & & & & & & & 13 & & & & & & 450 \\
\hline 15 & 196.4 & -.23 & 37.5 & 8902 & 65.7 & 323 & 15 & 110.1 & -.16 & 28.1 & 9270 & 47.8 & 470 \\
\hline
\end{tabular}

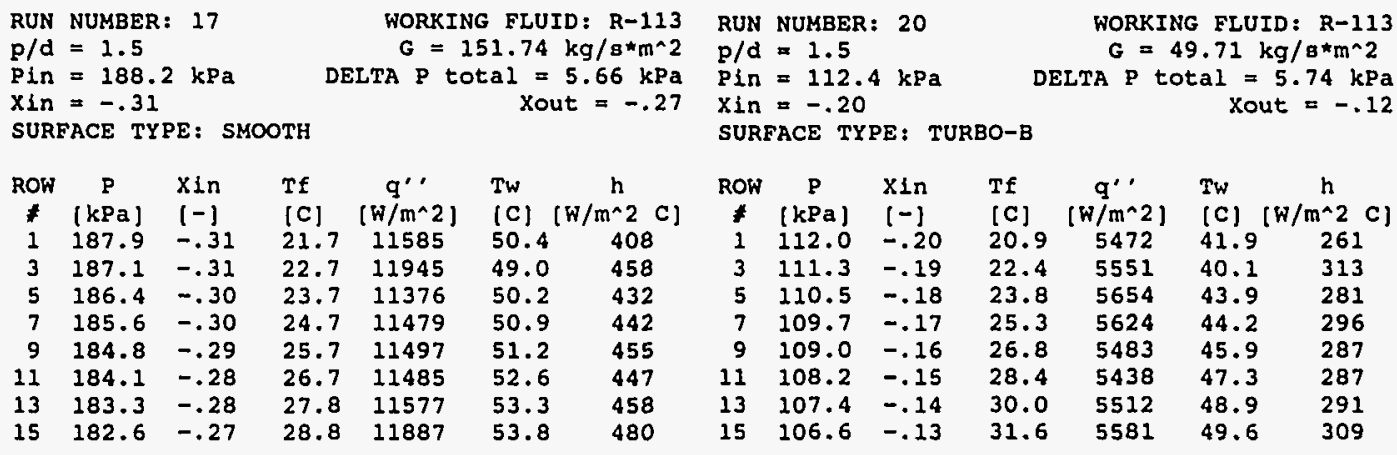

RUN NUMBER: 22

$\begin{array}{lr}\text { RUN NUMBER: } 22 & \text { WORKING FLUID: } \mathrm{R}-113 \\ \mathrm{p} / \mathrm{d}=1.5 & \mathrm{G}=227.03 \mathrm{~kg} / \mathrm{g}^{\star} \mathrm{m}^{\wedge} 2 \\ \mathrm{Pin}=126.2 \mathrm{kPa} & \text { DELTA } \mathrm{P} \text { total }=5.75 \mathrm{kPa}\end{array}$ $X$ in $=-.22 \quad$ DELTA $P$ total $=5.75 \mathrm{kPa}$ SURFACE TYPE: TURBO-B

\begin{tabular}{|c|c|c|c|c|c|c|}
\hline Low & $\mathbf{P}$ & $x$ in & ff & & Tw & \\
\hline$\neq$ & $\{k P a]$ & {$[-]$} & & {$\left[W / m^{\wedge} 2\right]$} & [C] & $n \bumpeq 2$ \\
\hline & 125. & & 1.3 & & 39.9 & \\
\hline 3 & 125.0 & -.2 & & & & 794 \\
\hline 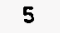 & & & & & & \\
\hline 7 & 123.5 & .21 & & & & \\
\hline 9 & & .2 & & & & \\
\hline 11 & 1 & .20 & & & & 685 \\
\hline 13 & 121.2 & -.19 & 5.2 & 10561 & 40.1 & 712 \\
\hline & & & & & & \\
\hline
\end{tabular}

RUN NUMBER: 23

$\mathrm{p} / \mathrm{d}=1.5$
$\mathrm{Pin}=126.2 \mathrm{kPa}$

Pin $=126.2$
$X$ in $=-.22$

SIn $=-.22$ KUREAC TYPE: TURBO-B

WORKING FLUID: R-113

$G=227.72 \mathrm{~kg} / \mathrm{B}^{*} \mathrm{~m}^{\wedge} 2$ DELTA $P$ total $=5.67 \mathrm{kPa}$

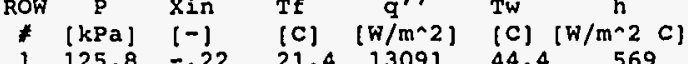
$\begin{array}{llll}21.4 & 13091 & 44.4 & 569\end{array}$

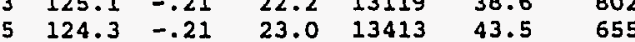
$\begin{array}{lllllll}7 & 123.5 & -.20 & 23.8 & 13343 & 42.9 & 698\end{array}$ $\begin{array}{lllllll}9 & 122.8 & -.20 & 24.7 & 12979 & 43.4 & 691\end{array}$ $\begin{array}{lllllll}11 & 122.0 & -.19 & 25.5 & 13145 & 44.4 & 697\end{array}$ $\begin{array}{lllllll}13 & 121.3 & -.19 & 26.4 & 13435 & 44.9 & 723\end{array}$ $\begin{array}{lllllll}15 & 120.5 & -.18 & 27.2 & 13535 & 45.2 & 752\end{array}$

\begin{tabular}{|c|c|c|c|c|c|c|c|c|c|c|c|c|c|}
\hline \multicolumn{4}{|c|}{$\begin{array}{l}\text { RUN NUMBER: } 18 \\
\text { p/d }=1.5 \\
\text { Pin }=126.2 \mathrm{kPa} \\
\text { XIn }=-.26 \\
\text { SURACE TYPE: SMOOTH }\end{array}$} & \multicolumn{3}{|c|}{ 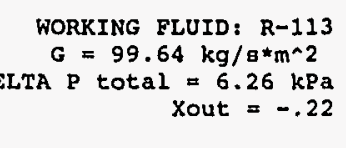 } & \multicolumn{4}{|c|}{$\begin{array}{l}\text { RUN NUMBER: } 21 \\
\text { P/d }=1.5 \\
\text { Pin }=164.1 \mathrm{kPa} \\
\text { Xin }=-.28 \\
\text { SURFACE TYPE: TURBO-B }\end{array}$} & \multicolumn{3}{|c|}{$\begin{array}{r}\text { WORKING FLUID: R-113 } \\
\mathrm{G}=347.73 \mathrm{~kg} / \mathrm{g}^{\star} \mathrm{m}^{\wedge} 2 \\
\text { TA P total }=5.93 \mathrm{kPa} \\
\text { Xout }=-.25\end{array}$} \\
\hline Row & p & & TE & & Tw & $h$ & Row & $\mathrm{P}$ & & & & & h \\
\hline * & & & & & & & 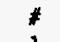 & & & & & & \\
\hline 1 & & & & & & & 1 & & & & & & \\
\hline 3 & & & & & & & 3 & & & & & & \\
\hline 5 & & & & & & & 5 & & & & & & \\
\hline 7 & & & & & & & 7 & & & & & & \\
\hline 9 & & & & & & & 9 & & & & & & \\
\hline & & & & & & & & & & & & & \\
\hline & & & & & & & & & & & & & \\
\hline & 119.9 & .22 & & 3591 & & 206 & 15 & 158.2 & & 26.9 & 16372 & 41.8 & 1104 \\
\hline
\end{tabular}

RUN NUMBER: 24

$\mathrm{p} / \mathrm{d}=1.5$

$P$ in $=202 \mathrm{kPa}$
$\mathrm{Xin}=-.33$ SURFACE TYPE: TURBO-
WORKING FLUID: $R-113$ $G=442.32 \mathrm{~kg} / \mathrm{g} * \mathrm{~m}^{\wedge}$ DELTA $P$ total $=5.78$, xout $=-.30$

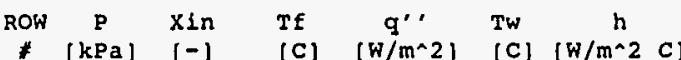

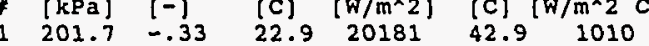

$\begin{array}{lllllll}3 & 200.9 & -.32 & 23.5 & 20583 & 37.9 & 1437\end{array}$

$\begin{array}{lllllll}5 & 200.1 & -.32 & 24.2 & 20961 & 42.2 & 1164\end{array}$

$9 \begin{array}{llllll}198.5 & -.31 & 25.5 & 20289 & 42.3 & 1204\end{array}$

$\begin{array}{lllllll}11 & 197.8 & -.31 & 26.2 & 20574 & 42.7 & 1245\end{array}$

$\begin{array}{lllllll}13 & 197.0 & -.30 & 26.9 & 21100 & 43.2 & 1287 \\ 15 & 196.2 & -.30 & 27.6 & 21254 & 43.1 & 1363\end{array}$ 


\begin{tabular}{|c|c|c|c|c|c|c|c|c|c|c|c|c|c|}
\hline \multicolumn{4}{|c|}{$\begin{array}{l}\text { RUN NUMBER: } 25 \\
\text { P/A }=1.5 \\
\text { PIn }=208.9 \mathrm{kPa} \\
\text { XIN }=-.33 \\
\text { SURFACE TYPE: TURBO-B }\end{array}$} & \multicolumn{3}{|c|}{$\begin{array}{r}\text { WORKING FLUID: } \mathrm{R}-113 \\
\mathrm{G}=451.46 \mathrm{~kg} / \mathrm{s}^{\star} \mathrm{m}^{\wedge} 2 \\
\text { TA P total }=5.76 \mathrm{kPa} \\
\text { Xout }=-.28\end{array}$} & \multicolumn{4}{|c|}{$\begin{array}{l}\text { RUN NUMBER: } 29 \\
\text { P/d }=1.17 \\
\text { PIn }=166.9 \mathrm{kPa} \\
\text { XIn }=-.29 \\
\text { SURFACE TYPE: HIGH FLUX }\end{array}$} & \multicolumn{3}{|c|}{$\begin{array}{r}\text { WORKING FLUID: R-113 } \\
G=250.67 \mathrm{~kg} / \mathrm{a}^{\star} \mathrm{m}^{\wedge} 2 \\
\text { CWA total }=4.48 \mathrm{kPa} \\
\text { Xout }=-.23\end{array}$} \\
\hline Low & $\mathbf{p}$ & & & & & $\stackrel{h}{h \wedge 2} c_{1}$ & Row & & & & & & \\
\hline i & & & & $\begin{array}{c}{[\mathrm{W} / \mathrm{m}} \\
314\end{array}$ & $\begin{array}{l}\text { lc } \\
53\end{array}$ & 10 & $\begin{array}{l}* \\
1\end{array}$ & & & & & & \\
\hline 3 & & & & & & & 3 & & & & & & \\
\hline 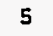 & & & & & & & & & & & & & \\
\hline 7 & & & & & & & 7 & & & & & & \\
\hline & & & & & & & 9 & & & & & & \\
\hline & & & & & & & 11 & & & & & & \\
\hline & & & & & & & & & & & & & \\
\hline & 203.1 & & 31.4 & 33079 & 53.8 & 1480 & 15 & 162.4 & & 28.6 & 7966 & 39.1 & 757 \\
\hline
\end{tabular}

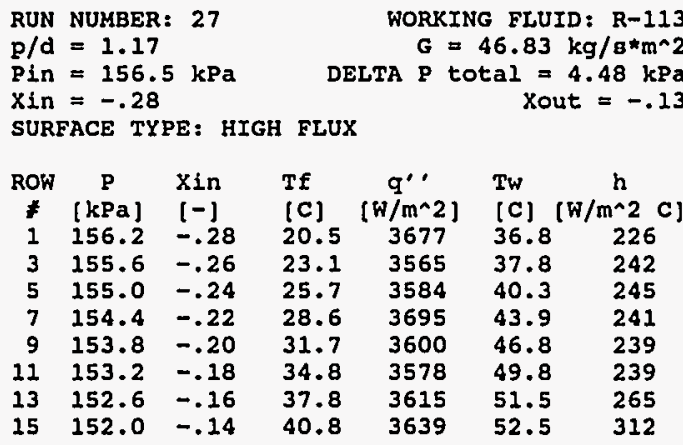

RUN NUMBER: 30 $\mathrm{p} / \mathrm{d}=1.17 \quad G=502.75 \mathrm{~kg} / \mathrm{g} * \mathrm{~m}^{\wedge} 2$

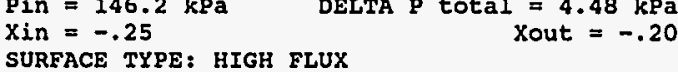

\begin{tabular}{|c|c|c|c|c|c|c|}
\hline low & $\stackrel{\mathrm{P}}{\mathrm{P}}$ & $x \ln$ & Tf & (W/mAn & $T w$ & h \\
\hline $\begin{array}{l}* \\
1\end{array}$ & $\begin{array}{l}{[\mathrm{KPa}]} \\
145.8\end{array}$ & $\begin{array}{l}{[-]} \\
-.25\end{array}$ & {$\left[\begin{array}{l}\text { [C] } \\
21.2\end{array}\right.$} & $\begin{array}{c}\left.\left[W / m^{\wedge} 2\right\}\right] \\
13745\end{array}$ & [C] & 2 \\
\hline 3 & 145.2 & -.25 & 22.0 & 13300 & 34.5 & 1063 \\
\hline 5 & 144.7 & -.26 & & & & 1116 \\
\hline 7 & 144.1 & .24 & 3.6 & 13611 & 36.8 & 1029 \\
\hline 9 & 143. & -.23 & & & & 992 \\
\hline & 142.9 & .22 & & 13133 & 39.2 & 944 \\
\hline 13 & 142.3 & .21 & 6.1 & 13395 & 393 & 1020 \\
\hline & & & & & & \\
\hline
\end{tabular}

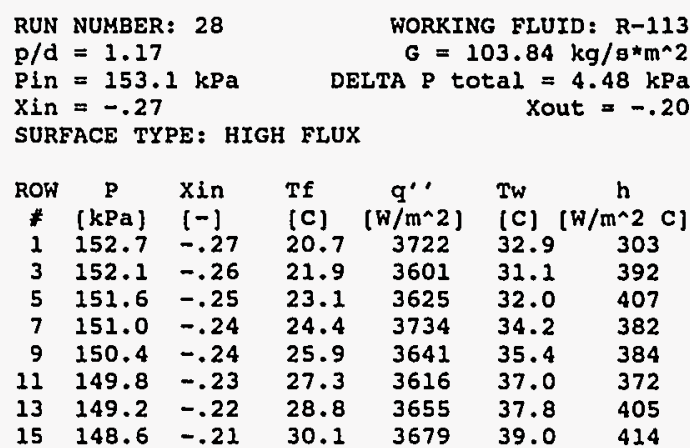
RUN NUMBER: 31 $/ \mathrm{d}=1.17$ WORKING FLUID: $\mathrm{R}-113$ $\quad G=350.22 \mathrm{~kg} / \mathrm{s}^{\star} \mathrm{m}^{\wedge} 2$ $\begin{aligned} \text { Pin } & =164.8 \mathrm{kPa} & \text { DELTA P total } & =5.28 \mathrm{kPa} \\ X_{\text {in }} & =-.28 & \text { Xout } & =-.19\end{aligned}$ SURFACE TYPE: HIGH FLUX

ROW $p$ xin $T f \quad q{ }^{\prime}$ Tw $h$

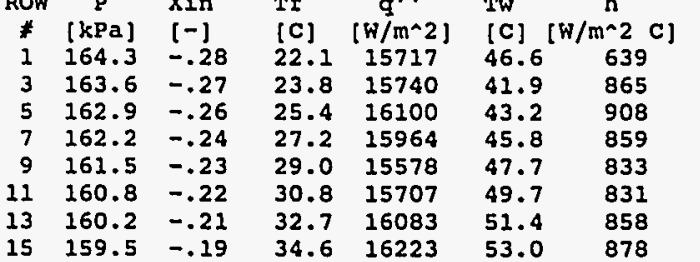




\section{APPENDIX B \\ SAMPLE CALCULATIONS}

A sample of calculations performed in the tube bundle data reduction programs is presented below. Two sample calculations are presented. The first is a sample of the data reduction process for data obtained in pure $R-113$ and includes calculations for the heat transfer coefficients, pressure drop, quality, and mass flow rate. The second shows the additional steps required to determine the local concentration and quality of the refrigerant mixtures.

\section{NOMENCLATURE}

$A_{\mathrm{s}} \quad$ heat transfer surface area of single tube, $\mathrm{m}^{2}$

$c_{\mathrm{p}} \quad$ specific heat at constant pressure, $\mathrm{J} / \mathrm{Kg} \cdot \mathrm{K}$

$D_{0} \quad$ tube outside diameter, $\mathrm{m}$

$G \quad$ mass flux, $\mathrm{kg} / \mathrm{m}^{2} \cdot \mathrm{s}$

$h$ heat transfer coefficient, $\mathrm{W} / \mathrm{m}^{2} \cdot \mathrm{K}$

$h_{\mathrm{n}} \quad$ local heat transfer coefficient at row $\mathrm{n}, \mathrm{W} / \mathrm{m}^{2} \cdot \mathrm{K}$

$i \quad$ enthalpy, $\mathrm{J} / \mathrm{kg}$

I electrical current, A

$k_{t} \quad$ copper thermal conductivity, $\mathrm{W} / \mathrm{m} \cdot \mathrm{K}$

$L \quad$ tube length, $\mathrm{m}$

$\dot{m} \quad$ mass flow rate, $\mathrm{kg} / \mathrm{s}$

$n \quad$ tube row number

$p \quad$ tube pitch, $\mathrm{m}$ 
$P \quad$ pressure, $\mathrm{kPa}$

$q^{\prime \prime} \quad$ heat flux for an individual tube, $\mathrm{W} / \mathrm{m}^{2}$

$q_{n}^{\prime \prime} \quad$ heat flux for an individual tube at row $\mathrm{n}, \mathrm{W} / \mathrm{m}^{2}$

$Q_{1-\mathrm{n}}$ total heat transfer rate from tube s in rows 1 through $\mathrm{n}, \mathrm{W}$

$R_{\text {tc }} \quad$ radial distance from tube axis to thermocouple location, $\mathrm{m}$

$T_{\mathrm{fv}} \quad$ temperature at flashing valves, ${ }^{\circ} \mathrm{C}$ or $\mathrm{K}$

$T_{\text {sat }} \quad$ saturation or bubble point temperature, $\mathrm{K}$

$T_{\text {tc }} \quad$ local temperature at thermocouple, ${ }^{\circ} \mathrm{C}$ or $\mathrm{K}$

$T_{\mathrm{w}} \quad$ local tube surface temperature, ${ }^{\circ} \mathrm{C}$ or $\mathrm{K}$

$T_{\mathrm{W}, \text { ave }} \quad$ tube average wall temperature, ${ }^{\circ} \mathrm{C}$ or $\mathrm{K}$

$V \quad$ electrical voltage, $\mathrm{V}$

$\dot{V}$ volume flow rate, $\mathrm{m}^{3} / \mathrm{s}$

$x \quad$ thermodynamic quality

$x_{n} \quad$ thermodynamic quality at tube row $\mathbf{n}$

$\tilde{y}_{\mathbf{i}}^{\prime} \quad$ mole fraction in the liquid phase of component $\mathrm{i}, \mathrm{kmol} / \mathrm{kmol}$

$\tilde{y}_{i}^{\prime \prime} \quad$ mole fraction in the vapor phase of component $\mathrm{i}, \mathrm{kmol} / \mathrm{kmol}$

$\tilde{y}_{\mathrm{b}, \mathrm{i}}^{\mathrm{i}}$ overall mole fraction of component $\mathrm{i}$ in the fluid, $\mathrm{kmol} / \mathrm{kmol}$

Greek Symbols

$\Delta \quad$ difference

$\rho$ density, $\mathrm{kg} / \mathrm{m}^{3}$ 


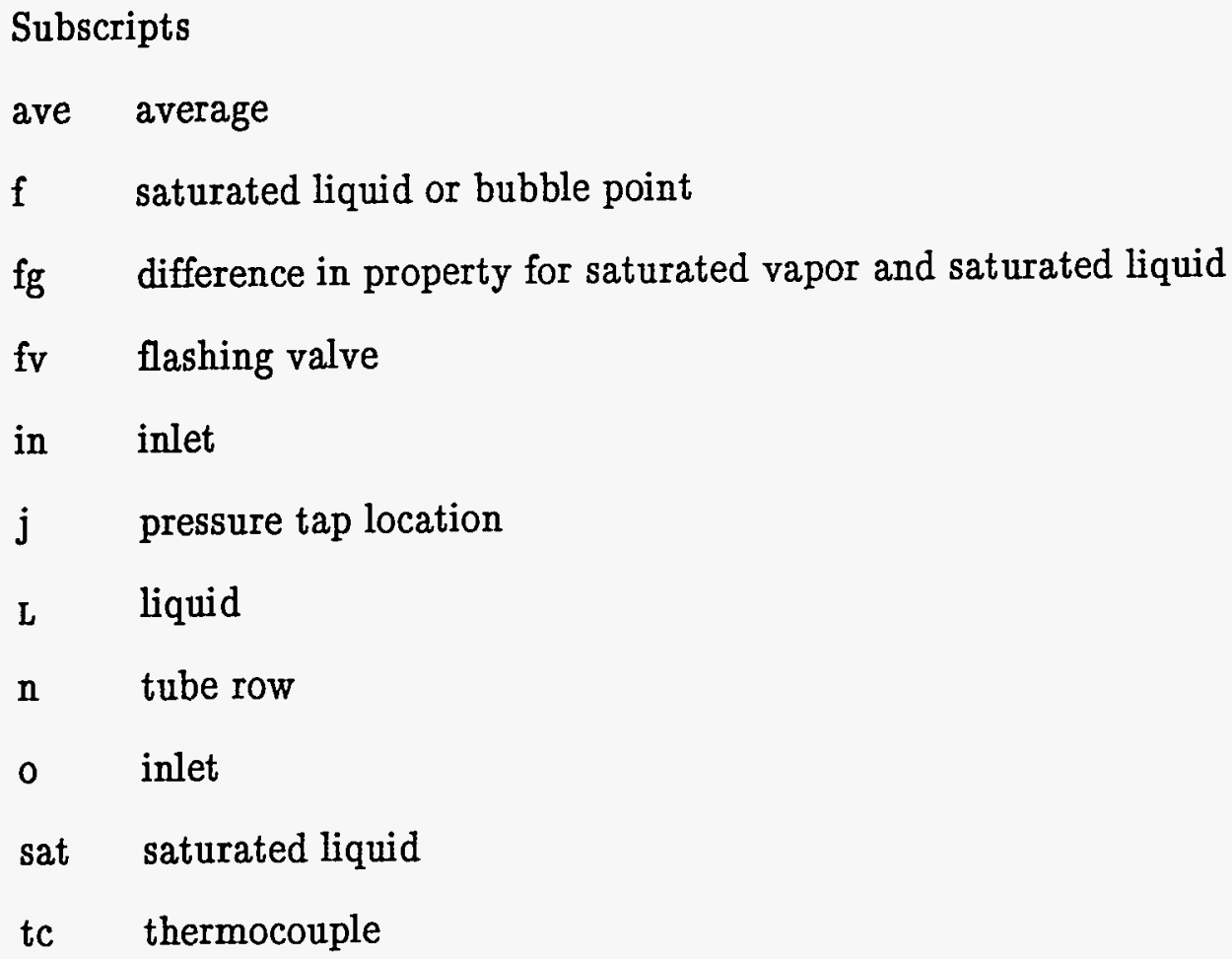

\section{Superscripts}

I liquid phase

" vapor phase

$\sim \quad$ molar property

\section{Data Reduction for Pure $\mathrm{R}-113$}

Raw data collected as run number 138 was obtained in pure $\mathrm{R}-113$ in a bundle of smooth tubes. The pertinent bundle geometry information is as follows:

$$
\begin{aligned}
& p / D_{\mathrm{o}}=1.17 \\
& D_{\mathrm{o}}=0.01905 \mathrm{~m} \\
& R_{\mathrm{tc}}=5.6 \mathrm{~mm}
\end{aligned}
$$




$$
A_{\mathrm{s}}=0.00608 \mathrm{~m}^{2}
$$

and the properties of the copper tube and refrigerant were as follows:

$$
\begin{aligned}
& k_{\mathrm{t}}=386 \mathrm{~W} / \mathrm{m} \mathrm{K} \\
& i_{\mathrm{fg}}=138.9 \mathrm{~kJ} / \mathrm{kg} \\
& c_{\mathrm{p}}=1003.7 \mathrm{~J} / \mathrm{kg} \mathrm{K}
\end{aligned}
$$

Information recorded by the DAS included

$$
\begin{aligned}
& P_{0}=206.46 \mathrm{kPa} \\
& \dot{V}=0.186 \mathrm{~L} / \mathrm{s} \\
& \Delta \mathrm{P}_{0-1}=0.59 \mathrm{kPa} \\
& \Delta \mathrm{P}_{1-2}=1.16 \mathrm{kPa} \\
& \Delta \mathrm{P}_{2-3}=1.05 \mathrm{kPa} \\
& \Delta \mathrm{P}_{3-4}=1.15 \mathrm{kPa} \\
& \Delta \mathrm{P}_{4-5}=0.54 \mathrm{kPa} \\
& T_{0}=69.67^{\circ} \mathrm{C} \\
& T_{\mathrm{fv}}=69.28^{\circ} \mathrm{C}
\end{aligned}
$$

and for the third tube row,

$$
\begin{aligned}
& V_{3}=133.54 \mathrm{~V} \\
& I_{3}=1.866 \mathrm{~A} \\
& T_{\text {tc } 1}=83.80^{\circ} \mathrm{C} \\
& T_{\text {tc } 2}=83.61^{\circ} \mathrm{C} \\
& T_{\text {tc } 3}=83.33^{\circ} \mathrm{C} \\
& T_{\text {tc } 4}=83.67{ }^{\circ} \mathrm{C}
\end{aligned}
$$

The heat transfer coefficients calculated for the two-phase experiments were defined as the ratio of the heat flux from the heated tube to the difference between the average tube wall surface temperature and the saturation temperature of the 
refrigerant at the local pressure just upstream of the tube; this pressure was obtained by linear interpolation of the pressures at the closest pressure taps.

Because the refrigerant at the outlet was saturated, the outlet pressure was assumed to be the saturation pressure based on the outlet temperature. The saturation pressure at the outlet, $P_{5}(\mathrm{kPa})$, was calculated using an equation based on the results of Downing (1974):

$$
\log \left(6.89 P_{5}\right)=\mathrm{C}_{1}-\mathrm{C}_{2} / T_{0}-\mathrm{C}_{3} \log \left(9 T_{0} / 5\right)+\mathrm{C}_{4}
$$

where

$$
\begin{array}{ll}
\mathrm{C}_{1} & =33.0655 \\
\mathrm{C}_{2} & =-2406.1 \\
\mathrm{C}_{3} & =-9.2635 \\
\mathrm{C}_{4} & =0.003697 \\
\text { so that } \quad P_{5} & =201.45 \mathrm{kPa}
\end{array}
$$

The pressures at the pressure taps were then calculated using the pressure drops measured across adjacent pressure taps as

$$
P_{5-\mathrm{j}}=P_{5}-\sum_{\mathrm{i}=1}^{\mathrm{j}} \Delta P_{(5-\mathrm{i})} \text { to }(6-\mathrm{i})
$$

so that $P_{4}=205.85, P_{3}=204.69, P_{2}=203.64, P_{1}=202.49$, and $P_{0}=201.95 \mathrm{kPa}$. the total pressure drop was the difference between $P_{5}$ and $P_{0}$, or $4.51 \mathrm{kPa}$. 
The saturation temperature of the refrigerant was calculated as a function of the pressure. For example, the pressure at the third tube row was calculated as $205.54 \mathrm{kPa}$ by interpolation and the saturation temperature was

$$
\begin{gathered}
T_{\text {sat }}=545.741+2.862 P_{\mathrm{n}}-0.01423 P_{\mathrm{n}}^{2} \\
T_{\text {sat }}=70.3^{\circ} \mathrm{C}
\end{gathered}
$$

The heat flux for an individual tube was defined as the ratio of the supplied power to the surface area exposed to the fluid. The power supplied to the heated tube was calculated as the product of the current through the cartridge heater and the voltage across the cartridge heater:

$$
q_{\mathrm{n}}^{\prime \prime}=\frac{I_{\mathrm{n}} V_{\mathrm{n}}}{A_{\mathrm{s}}}=40970 \mathrm{~W} / \mathrm{m}^{2}
$$

The surface temperatures of the heated tubes were then calculated using a one-dimensional, steady-state heat conduction equation for a cylinder:

$$
T_{\mathrm{w}}=T_{\mathrm{tc}}-\frac{q_{\mathrm{n}}^{\prime \prime}}{2} D_{\mathrm{o}} \ln \left[\frac{D_{\mathrm{o}}}{2 R_{\mathrm{tc}}}\right]
$$

for the third tube row, which resulted in tube wall temperatures of $T_{\mathrm{w} 1}=83.57^{\circ} \mathrm{C}$, $T_{\mathrm{w} 2}=83.38^{\circ} \mathrm{C}, T_{\mathrm{w} 3}=83.10^{\circ} \mathrm{C}$, and $T_{\mathrm{w} 4}=83.44^{\circ} \mathrm{C}$. The average tube wall surface temperature, $T_{\mathrm{w} \text {,ave }}$, was then calculated as the arithmetic average of the four temperatures calculated as $83.21^{\circ} \mathrm{C}$. 
The heat transfer coefficient at the third tube could then be calculated as:

$$
\begin{gathered}
h_{\mathrm{n}}=\frac{q_{\mathrm{n}}^{\prime \prime}}{T_{\mathrm{w}, \text { ave }}-T_{\text {sat }}} \\
h_{\mathrm{n}}=3127 \mathrm{~W} / \mathrm{m}^{2}
\end{gathered}
$$

The mass flux was calculated using the volume flow rate measured by the turbine flowmeters and the density of the refrigerant. The volumetric flow rate, $V$, was calculated as a function of the frequency of the pulses generated by the turbine flowmeter. The total mass flow rate, $\dot{m}$, was then calculated as the product of the volumetric flow rate and the refrigerant liquid density. The mass flux, $G$, was calculated based on the minimum flow area between the heated tubes. The equation used to calculate the mass flux was

$$
G=\frac{V \rho_{\mathrm{L}}}{4\left(p-D_{0}\right) L}
$$

where $p$ is the tube bundle pitch and the 4 in the denominator is a result of having five heated tubes (four flow areas) in each row. For this case, $G=225.1 \mathrm{~kg} / \mathrm{m}^{2} \mathrm{~s}$.

The quality at the inlet to the tube bundle was calculated using the inlet temperature and the saturation temperature corresponding to the inlet pressure. Assuming that the refrigerant flowing through the flashing valves underwent an 
isenthalpic process, the inlet quality could be calculated as:

$$
x_{\text {in }}=\frac{c_{\mathrm{p}}\left(T_{\mathrm{fv}}-T_{\text {sat,in }}\right)}{{ }_{\mathrm{ig}}}
$$

where $c_{\mathrm{p}}$ is the specific heat of the pure refrigerant, $T_{\mathrm{fv}}$ is the temperature immediately upstream of the flashing valves, $T_{\text {sat, in }}$ is the saturation temperature corresponding to the tube bundle inlet pressure, and $i_{\mathrm{fg}}$ is the enthalpy of vaporization for the pure refrigerant. The quality immediately downstream of the $3^{\text {th }}$ tube row was calculated by performing an energy balance on the first 3 tube rows:

so that

$$
x_{3}=x_{\text {in }}+\frac{Q_{1-3}}{\dot{m} i_{f g}}
$$

The procedure for reducing data taken in pure $\mathrm{R}-11$ was the same as for pure $\mathrm{R}-113$ except that routines for calculating the thermodynamic and physical properties of $\mathrm{R}-11$ had to be substituted for those of $\mathrm{R}-113$. A computer program to calculate properties of refrigerant mixtures, developed by the National Institute of Science and Technology (National Bureau of Standards 1986) was used to calculate the properties of pure $\mathrm{R}-11$. 


\section{Data Reduction in Refrigerant Mixtures}

The procedure for reducing data taken in mixtures of $R-11$ and $R-113$ was generally similar to the procedure for pure refrigerants except that additional procedures for determining the properties of the mixture and for determining the mixture concentration throughout the bundle were required. Because the tube bundle used in the experiments involving refrigerant mixtures contained all three surfaces, the local mole fractions were determined so that the local quality and mixture concentration were known.

Raw data stored as run number 506 was obtained in a mixture of $75.8 \%$ $\mathrm{R}-11$ and $24.2 \% \mathrm{R}-113$ by mass. Additional values for the fluid were as follows:

$$
\begin{aligned}
& \tilde{y}_{\mathrm{b}, \mathrm{R}-113}^{\prime}=0.305 \\
& \tilde{y}_{\mathrm{b}, \mathrm{R}-11}^{\prime}=0.695 \\
& \dot{m}=0.188 \mathrm{~kg} / \mathrm{s}
\end{aligned}
$$

The mixture properties were calculated using the computer program developed by the National Institute of Science and Technology (National Bureau of Standards 1986) which calculates thermodynamic properties (saturation pressure, specific volume, enthalpy, specific heats, etc.) for a given temperature or saturation temperature for a given pressure. In either case, the concentration of the mixture is required. 
The inlet was slightly subcooled, therefore the inlet quality was calculated as

$$
\begin{gathered}
x_{\text {in }}=\tilde{c}_{\mathrm{p}}\left(T_{\text {in }}-T_{\mathrm{f}}\right) / \tilde{i}_{\mathrm{fg}} \\
x_{\text {in }}=-0.01
\end{gathered}
$$

where $\tilde{c}_{\mathrm{p}}, T_{\mathrm{f}}$, and $\tilde{i}_{\mathrm{fg}}$ were calculated using the mixture property program and the measured inlet pressure.

The procedure for calculating the local temperature and mass concentration in the mixture began with a guess for the temperature so that the mixture properties could be calculated using the mixture property program.

The estimated value of outlet temperature and an estimate for the mole fraction of R-113 in the liquid phase, $\tilde{y}_{\mathrm{R} 113}^{\prime}$, were input to the computer program and the saturation pressure was calculated. This value was compared with the experimentally determined value for the outlet pressure. The mole fraction, $y_{\mathrm{R} 113}^{\prime}$, was adjusted until the output saturation pressure was within $0.1 \%$ of the experimental value. The mole fraction of $\mathrm{R}-11$ in the liquid, $\tilde{y}_{\mathrm{R} 11}^{1}$, was calculated from

$$
\tilde{y}_{\mathrm{R} 11}^{\prime}=1-\tilde{y}_{\mathrm{R} 113}^{\prime}
$$

The same iterative procedure was used to determine the vapor mole fractions of $\mathrm{R}-113, \tilde{y}_{\mathrm{R} 113}^{\prime \prime}$, and R-11, $\tilde{y}_{\mathrm{R} 11}^{\prime \prime}$. 
The same values of pressure and estimated temperature were used to calculate $\mathrm{K}$-values as

$$
K \approx \exp (A-B / T) / P
$$

These K-values could then be used to calculate $\tilde{\dot{m}}_{\mathrm{L}}$ from

$$
1=\frac{\tilde{y}_{\mathrm{b}, \mathrm{R} 113}^{\prime} \tilde{\dot{m}}}{\dot{\dot{m}}_{\mathrm{L}}+K_{\mathrm{R} 113}\left(\tilde{\dot{m}}-\tilde{\dot{m}}_{\mathrm{L}}\right)}+\frac{\tilde{y}_{\mathrm{b}, \mathrm{R} 11}^{\prime} \dot{\dot{m}}}{\tilde{\dot{m}}_{\mathrm{L}}+K_{\mathrm{R} 11}\left(\tilde{\dot{m}}-\tilde{\dot{m}}_{\mathrm{L}}\right)}
$$

The mixture enthalpy could then be calculated as

$$
\begin{aligned}
\tilde{i}_{\mathrm{n}}=\left(\tilde{y}_{\mathrm{R} 113}^{1} \tilde{\dot{m}}_{\mathrm{L}} \tilde{i}_{\mathrm{R} 113}+\tilde{y}_{\mathrm{R} 11}^{\prime} \tilde{\dot{m}}_{\mathrm{L}} \tilde{i}_{\mathrm{R} 11}\right. \\
\left.\quad+\tilde{y}_{\mathrm{R} 113}^{\prime \prime} \tilde{\dot{m}}_{\mathrm{V}} \tilde{i}_{\mathrm{R} 113}+\tilde{y}_{\mathrm{R} 11}^{\prime \prime} \tilde{\dot{m}}_{\mathrm{V}} \tilde{i}_{\mathrm{R} 11}\right) / \tilde{\dot{m}}
\end{aligned}
$$

where the molar enthalpies and molar flow rates were evaluated using the local values for the molar concentrations.

The procedure for determining the local molar concentrations involved iterating on the local fluid temperature until the enthalpy as calculated using equation (4.26) was within $0.1 \%$ of the value obtained by performing an energy balance on the portion of the tube bundle:

$$
\tilde{i}_{\mathrm{n}}=\tilde{i}_{\text {in }}+Q_{1-\mathrm{n}} / \tilde{\dot{m}}
$$

where $Q_{1-\mathrm{n}}$ is an integral value of the measured heat input from the inlet to row $n$. A new guess for the local temperature was made and the process was repeated until $\tilde{i}_{\mathrm{n}}$ from equation (4.26) was within $0.1 \%$ of the value from equation (4.25). The enthalpy at the third tube row was calculated using the above procedure and found to be $111.8 \mathrm{~kJ} / \mathrm{kmol}$. 
Once the local enthalpy was known, the quality at row $n$ was calculated as:

$$
x_{\mathrm{n}}=\frac{\tilde{i}_{\mathrm{n}}-\tilde{i}_{\mathrm{f}}}{\tilde{i}_{\mathrm{fg}}}
$$

At the third tube row, the quality was $x_{3}=0.07$. This procedure was repeated to find the local conditions at each tube row. After the thermodynamic state had been fixed for the $15^{\text {th }}$ row, the temperature could be compared with the measured outlet temperature as an additional check. The value for the outlet temperature as computed above was generally within $0.2^{\circ} \mathrm{C}$ of the measured value. 


\section{APPENDIX C \\ PROPAGATION OF UNCERTAINTY}

An uncertainty analysis was performed on the experimental data using the method given by Kline and McClintock (1953). The uncertainty, $W$, of variable $\mathrm{R}$ is given as

$$
W_{\mathrm{R}}=\left\{\left[\frac{\partial R}{\partial v_{1}} W_{v_{1}}\right]^{2}+\left[\frac{\partial R}{\partial v_{2}} W_{v_{2}}\right]^{2}+\cdots+\left[\frac{\partial R}{\partial v_{\mathrm{n}}} W_{v_{\mathrm{n}}}\right]^{2}\right\}
$$

where

$$
R=R\left(v_{1}, v_{2}, \cdots, v_{\mathrm{n}}\right)
$$

The equation for the heat transfer coefficient is given as

$$
h=\frac{q^{\prime \prime}}{T_{\mathrm{w}}-T_{\mathrm{s}}}
$$

Therefore, the uncertainty in the heat transfer coefficient can be expressed as

$$
\begin{gathered}
W_{\mathrm{h}}=\left\{\left[\frac{1}{T_{\mathrm{w}}-T_{\mathrm{s}}} W_{\mathrm{q}_{\mathrm{t}}^{\prime \prime}}\right]^{2}+\left[\frac{-q_{\mathrm{t}}^{\prime \prime}}{\left(T_{\mathrm{w}}-T_{\mathrm{s}}\right)^{2}} W_{\mathrm{T}_{\mathrm{w}}}\right]^{2}\right. \\
\left.+\left[\frac{q_{\mathrm{t}}^{\prime \prime}}{\left[T_{\mathrm{w}}-T_{\mathrm{s}}\right]^{2}} W_{\mathrm{T}_{\mathrm{s}}}\right]^{2}\right\}^{\frac{1}{2}}
\end{gathered}
$$


From equation (C.4) we find that the expression for $W_{\mathrm{h}}$ is a function of $W_{\mathrm{q}_{\mathrm{t}}^{\prime \prime}}, W_{\mathrm{T}_{\mathrm{w}}}$, and $W_{\mathrm{T}_{\mathrm{s}}}$. Beginning with the $W_{\mathrm{q}_{\mathrm{t}}^{\prime \prime}}$ term we require the following expression for the heat flux

$$
q_{\mathrm{t}}^{\prime \prime}=\frac{I_{\mathrm{t}} V_{\mathrm{t}}}{A_{\mathrm{t}}}
$$

Therefore

$$
W_{\mathrm{q}_{\mathrm{t}}^{\prime \prime}}=\left\{\left[\frac{V_{\mathrm{t}}}{A_{\mathrm{t}}} W_{\mathrm{I}_{\mathrm{t}}}\right]^{2}+\left[\frac{I_{\mathrm{t}}}{A_{\mathrm{t}}} W_{\mathrm{V}_{\mathrm{t}}}\right]^{2}+\left[\frac{-I_{\mathrm{t}} V_{\mathrm{t}}}{\left[A_{\mathrm{t}}\right]^{2}} W_{\mathrm{A}_{\mathrm{t}}}\right]^{2}\right\}^{\frac{1}{2}}
$$

The uncertainty in the current supplied to each instrumented tube was determined from the calibration of the shunts. Each shunt was calibrated using a digital voltmeter having an accuracy of $\pm 0.001 \mathrm{mV}$ so that the voltage readings could be considered negligible. The maximum difference between the actual voltage drop measured across the shunt and the value obtained from the calibration curve was $0.0003 \mathrm{~V}$. The resulting uncertainty in the current measurements for the 5 amp $/ 200 \mathrm{mV}$ shunts was then 0.0075 amps. The shunts themselves had an inherent uncertainty of $0.25 \%$ of full scale which caused an additional uncertainty of 0.0125 amps. Thus, the total uncertainty in the instrumented tube current measurements was $W_{\mathrm{I}_{\mathrm{t}}}=0.02$ amps.

The uncertainty in the instrumented tube voltage measurements was determined from the calibration of the data acquisition system voltage 
measurements. By determining the maximum difference between the measured voltage supplied to the instrumented tubes and the voltage obtained from the calibration curve, the uncertainty was calculated to be $W_{\mathrm{V}_{\mathrm{t}}}=0.3 \mathrm{~V}$.

The uncertainty in the surface area of the instrumented tubes was determined using the equation for the surface area

$$
A_{\mathrm{t}}=\pi D L_{\mathrm{t}}
$$

Therefore, the uncertainty is

$$
W_{\mathrm{A}_{\mathrm{t}}}=\pi\left\{\left[L_{\mathrm{t}} W_{\mathrm{D}}\right]^{2}+\left[D W_{\mathrm{L}_{\mathrm{t}}}\right]^{2}\right\}^{\frac{1}{2}}
$$

The lengths of the instrumented tubes were measured to be within $0.15 \mathrm{~mm}$ of the design length of $0.1016 \mathrm{~m}$. The diameters of the enhanced tubes were measured at the outside of the enhancement material. The diameters of the enhanced tubes and the smooth tubes were all within $0.08 \mathrm{~mm}$ of the average value of $0.01906 \mathrm{~m}$. The uncertainty in the surface area was calculated to be $W_{\mathrm{A}_{\mathrm{t}}}=27.07 \mathrm{~mm}^{2}$. Values for $W_{\mathrm{I}_{\mathrm{t}}}, W_{\mathrm{V}_{\mathrm{t}}}$, and $W_{\mathrm{A}}$ can be inserted into equation (C.6) and $W_{\mathrm{q}_{\mathrm{t}}^{\prime \prime}}$ is found to be less than $1.0 \%$ of $q_{t}^{\prime \prime}$ 
In order to calculate the term involving $W_{\mathrm{T}_{\mathrm{w}}}$ from equation (C.4), we begin with the expression for $\mathrm{T}_{\mathrm{w}}$,

$$
T_{\mathrm{w}}=T_{\mathrm{tc}}-\frac{q_{\mathrm{t}}^{\prime \prime} D}{2} k_{\mathrm{t}} \ln \left[\frac{D}{d}\right]
$$

The uncertainty can then be expressed as

$$
\begin{gathered}
W_{\mathrm{T}_{\mathrm{w}}}=\left\{\left[W_{\mathrm{T}_{\mathrm{tc}}}\right]^{2}+\left[\frac{-q_{\mathrm{t}}^{\prime \prime}}{2 k_{\mathrm{t}}}\left[\ln \left[\frac{D}{d}\right]+1\right] W_{\mathrm{D}}\right]^{2}+\left[\frac{q_{\mathrm{t}}^{\prime \prime} D}{2 k_{\mathrm{t}} d} W_{\mathrm{d}}\right]^{2}\right. \\
\left.+\left[\frac{-D}{2} k_{\mathrm{t}} \ln \left[\frac{D}{d}\right] W_{\mathrm{q}_{\mathrm{t}}^{\prime \prime}}\right]^{2}+\left[\frac{q_{\mathrm{t}}^{\prime \prime} D}{2 k_{\mathrm{t}}^{2}} \ln \left[\frac{D}{d}\right] W_{\mathrm{k}_{\mathrm{t}}}\right]^{2}\right\}^{\frac{1}{2}}
\end{gathered}
$$

The uncertainty of the temperature inside the tube wall at the thermocouple location, $W_{\mathrm{T}_{\mathrm{tc}}}$, was determined by calibrating the thermocouples in boiling water. The agreement between the values for the temperatures as calculated by the data acquisition system was checked so that the random errors associated with the impurities in the wire, the quality of the bead, the electrical connections between the thermocouple, ice point and voltmeter, the electrical noise, and the voltage-to-temperature calibration curve errors were all accounted for. The uncertainty in the temperature measurements at the thermocouple location was calculated to be $W_{\mathrm{T}_{\mathrm{tc}}}=0.12^{\circ} \mathrm{C}$.

The uncertainty in the thermal conductivity of the tube material was determined by calculating the difference between the values for the conductivity of 
copper at the extreme values of the temperature range. The uncertainty in the thermal conductivity was found to be $W_{\mathrm{k}_{\mathrm{t}}}=8 \mathrm{~W} / \mathrm{m} \mathrm{K}$.

The uncertainty in the thermocouple location was calculated by assuming that the distance between the wall of the thermocouple well and the inside tube wall was the maximum possible error. This is reasonable because the thermocouple well never broke through the inside tube surface. The uncertainty of the thermocouple location was measured to be $W_{\mathrm{d}}=1.0 \mathrm{~mm}$. Values for $W_{\mathrm{tc}}$ ' $W_{\mathrm{D}}, W_{\mathrm{q}_{\mathrm{t}}^{\prime \prime}}$, and $W_{\mathrm{k}_{\mathrm{t}}}$ can be inserted into equation (C.10) in order to calculate a value for $W_{\mathrm{T}_{\mathrm{w}}}$ of $0.15^{\circ} \mathrm{C}$.

The final term in equation (C.4) involving the uncertainty of the saturation temperature, $W_{\mathrm{T}_{\mathrm{s}}}$, was calculated using the expression for the saturation temperature. The expression for the saturation pressure in the low pressure range $(29.48 \mathrm{psi}<\mathrm{P}<58.49 \mathrm{psi})$ was given as

$$
T_{\mathrm{S}}=545.741+2.862 P_{\mathrm{n}}-0.01423 P_{\mathrm{n}}^{2}
$$

and at the high pressures $(58.49 \mathrm{psi}<\mathrm{P}<108.2 \mathrm{psi})$ as

$$
T_{\mathrm{s}}=578.073+1.741 P_{\mathrm{n}}-0.004424 P_{\mathrm{n}}^{2}
$$

where $P_{\mathrm{n}}$ is the local pressure at tube $\mathrm{n}$. The uncertainty in the saturation 
temperature could be calculated for both pressure ranges as

$$
W_{\mathrm{T}_{\mathrm{s}}}=\left\{\left[\frac{\partial T_{\mathrm{s}}}{\partial P_{\mathrm{n}}} W_{\mathrm{p}}\right]^{2}\right\}^{\frac{1}{2}}
$$

or

$$
W_{\mathrm{T}_{\mathrm{s}}}=\frac{\mathrm{d} T_{\mathrm{s}}}{\mathrm{d} P_{\mathrm{n}}} W_{\mathrm{p}_{\mathbf{n}}}
$$

Differentiating the expression for the saturation temperature at low pressures

$$
\frac{\mathrm{d} T_{\mathrm{s}}}{\mathrm{d} P_{\mathrm{n}}}=2.862-0.02846 P_{\mathrm{n}}
$$

and at high pressures

$$
\frac{\mathrm{d} T_{\mathrm{s}}}{\mathrm{d} P_{\mathrm{n}}}=1.741-0.008848 P_{\mathrm{n}}
$$

The local pressure is calculated using the saturation pressure at the outlet (which is a function of the measured outlet temperature, $T_{0}$ ) and the measured pressure drops throughout the bundle, $\Delta P_{i}$. The pressure at the $n^{\text {th }}$ tube location is expressed as

$$
P_{\mathrm{n}}=P_{\mathrm{s}}+\sum_{\mathrm{i}=1}^{\mathrm{n}} \Delta P_{\mathrm{i}}
$$


Assuming that the uncertainty for each pressure drop is equal to $\Delta P_{\mathrm{i}}$, the uncertainty in the local pressure is

$$
W_{\mathrm{P}_{\mathrm{n}}}=\left\{\left[W_{\mathrm{P}_{\mathrm{s} \mathrm{o}}}\right]^{2}+\left[i W_{\Delta \mathrm{P}_{\mathrm{i}}}\right]^{2}\right\}^{\frac{1}{2}}
$$

where $i$ is the number of $\Delta P^{\prime}$ s used to calculate $P_{\mathrm{n}}$. The pressure drop is given by

$$
\Delta P_{\mathrm{i}}=\Delta \mathrm{P}_{\mathrm{t}}+\mathrm{L}_{\mathrm{p}} \rho_{\mathrm{R}-113} \mathrm{~g}
$$

were $\Delta \mathrm{P}_{\mathrm{t}}$ is the pressure transducer measurement. Assuming that the uncertainty in the density the $\mathrm{R}-113$, the distance between pressure taps, and the gravitational constant to be negligible, the uncertainty in the pressure drop is $W_{\Delta \mathrm{P}_{\mathrm{i}}}=W_{\Delta \mathrm{P}_{\mathrm{t}}}$. The pressure transducer was calibrated and the uncertainty was estimated to be $W_{\Delta \mathrm{P}_{\mathbf{t}}}=0.05$ in. $\mathrm{H}_{2} \mathrm{O}$. The saturation pressure is calculated as

$P_{\mathrm{s}, \mathrm{O}}=10^{\left(33.0655-4330.98 / T_{\mathrm{o}}-9.2635 \log \left(T_{0}\right)+20539 \cdot 10^{-4} T_{0}\right)}$

(C.19)

Therefore, the uncertainty in the saturation pressure can be expressed as

$$
W_{\mathrm{P}_{\mathrm{s}, \mathrm{o}}}=\frac{\mathrm{d} P}{\mathrm{~d} T_{\mathrm{o}}} W_{\mathrm{T}_{\mathrm{o}}}
$$


where

$$
\frac{\mathrm{d} P}{\mathrm{~d} T}=P_{\mathrm{s}, \mathrm{o}}\left\{\left[\frac{4330.98}{T_{\mathrm{o}}^{2}}+0.00020539\right] \ln (10)-\frac{9.2635}{T_{\mathrm{o}}}\right\}
$$

Inserting equation (C.20) and the value for $\Delta P_{\mathrm{i}}$ into equation (C.17) allows for the uncertainty of the local pressure to be calculated as within $0.5 \%$ of the local pressure. Equation (C.17) and either equation (C.14) or (C.15) can be inserted into the equation for the saturation temperature uncertainty given by equation (C.13) and the uncertainty is found to be $0.12{ }^{\circ} \mathrm{C}$. The uncertainty in the heat transfer coefficient can now be calculated by inserting equations (C.6), (C.10), and (C.13) into equation (C.4). The uncertainty is usually found to be less than $3.5 \%$ of the absolute value, although uncertainties as large as $12.9 \%$ occur when the corresponding wall superheat is less than $1^{\circ} \mathrm{C}$.

The uncertainty in the mass flux readings is obtained from the equation for the mass flux,

$$
G=\rho \dot{V} / A_{\min }
$$

where $\dot{V}$ is the volume flow rate measured by the flow meter and $A_{\min }$ is the minimum flow area between the tubes. Hence, the uncertainty in the mass flux is

$$
W_{\mathrm{G}}=\left\{\left[\left[\frac{\dot{V}}{A_{\mathrm{min}}}\right] W_{\rho}\right]^{2}+\left[\left[\frac{\rho}{A_{\min }}\right] W_{\dot{V}}\right]^{2}+\left[\left[\frac{-\rho \dot{V}}{A_{\min }^{2}}\right] W_{A_{\min }}\right]^{2}\right\}^{\frac{1}{2}}
$$


The volumetric flow rate was measured by the turbine flow meter which had an accuracy of $\pm 0.5 \%$. The minimum flow area was calculated from

$$
A_{\text {min }}=\left(\mathrm{p}-\mathrm{D}_{\mathrm{o}}\right) L_{\mathrm{t}}
$$

so that the uncertainty in the minimum flow area is

$$
W_{A_{\min }}=\left[\left[L_{\mathrm{t}} W_{\mathrm{p}}\right]^{2}+\left[-L_{\mathrm{t}} W_{\mathrm{D}_{\mathrm{o}}}\right]^{2}+\left[\left(\mathrm{p}-\mathrm{D}_{\mathrm{o}}\right) W_{\mathrm{L}_{\mathrm{t}}}\right]^{2}\right]^{\frac{1}{2}}
$$

The liquid density of $\mathrm{R}-113$ was calculated from

$$
\rho=103.555-0.07126 T-6.36 \cdot 10^{-5} T^{2}
$$

so the uncertainty is

$$
W_{\rho}=\left(-0.07126-1.272 \cdot 10^{-4} T\right) W_{\mathrm{T}}
$$

The resulting uncertainty in the mass flux is $\pm 3.0 \%$.

The quality was calculated from

$$
x=\frac{c_{\mathrm{p}}\left(T_{\mathrm{fv}}-T_{\mathrm{s}}\right)}{i_{\mathrm{fg}}}
$$


so the uncertainty is

$$
\begin{gathered}
W_{x}=\left\{\left[\left[\frac{T_{\mathrm{fv}}-T_{\mathrm{s}}}{i_{\mathrm{fg}}}\right] W_{c_{\mathrm{p}}}\right]^{2}+\left[\left[\frac{c_{\mathrm{p}}}{i_{\mathrm{fg}}}\right] W_{T_{\mathrm{fv}}}\right]^{2}+\left[\left[\frac{-c_{\mathrm{p}}}{i_{\mathrm{fg}}}\right] W_{T_{\mathrm{s}}}\right]^{2}\right. \\
\left.+\left[\left[\frac{-c_{\mathrm{p}}\left(T_{\mathrm{fv}}-T_{\mathrm{s}}\right)}{i_{\mathrm{fg}}^{2}}\right] W_{i_{\mathrm{fg}}}\right]^{2}\right\}^{\frac{1}{2}}
\end{gathered}
$$

Values of $W_{c_{\mathrm{p}}}$ and $W_{i_{\mathrm{fg}}}$ were approximated as $0.04 \%$ and $0.05 \%$, respectively, so that the uncertainty on the quality was usually less than $0.5 \%$. 


\section{APPENDIX D \\ SATURATION TEMPERATURE DETERMINATION}

An experimental apparatus was used to measure the saturation temperature of $\mathrm{R}-113$ at atmospheric pressure so that a comparison could be made with the correlation used in the data reduction program. For this experiment, the saturation temperature was defined as the refrigerant temperature corresponding to the minimum heated surface temperature for which boiling could be maintained.

The design of the experimental apparatus was guided by the concern that commercially available $\mathrm{R}-113$ is not strictly pure but contains small amounts of other refrigerants. In this case, the concentration of the least volatile component would decrease in the liquid as the fluid is vaporized unless the vapor is condensed and put back into the liquid.

Minimizing the wall superheat accomplished several goals. First, the vapor generation was minimized so that any concentration gradients in the liquid and vapor was minimized. Second, the low wall temperature minimized the temperature gradients that might arise even in pure fluids.

The wall superheat was minimized through the use of boiling ships. The boiling chips provided a range of nucleation site sizes so that the optimum size was available.

The experimental apparatus was a modification of the design suggested in ASTM D1120-83 and is shown in Fig. D.1. A round-bottom, short-neck, heat resistant glass flask with a side-entering tube contained the refrigerant and boiling chips. A water-cooled reflux condenser was connected to the flask neck in order to condense vapors back to the pool. Two thermocouples were inserted into the flask 


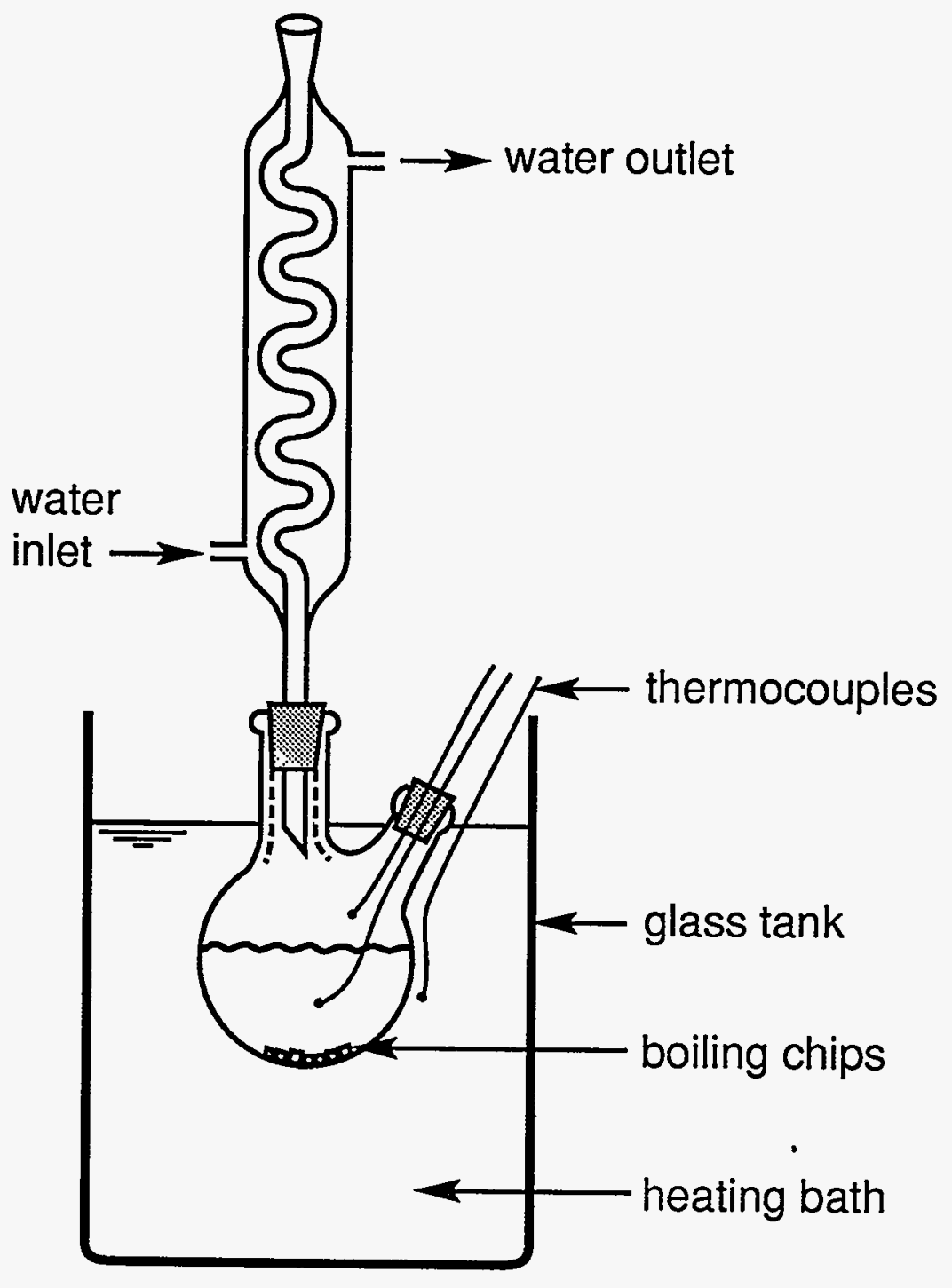

Figure D.1.

Experimental apparatus for measuring the boiling point. 
through the side neck, one to monitor the vapor temperature and the other to monitor the liquid temperature.

An important improvement over the design suggested in ASTM D1120-83 was the use of a water bath connected to a constant-temperature recirculating bath for heating instead of using a bunsen burner or electric heater. A third thermocouple, placed next to the external wall of the flask, was used to monitor the bath temperature.

Prior to measuring the boiling the point, the bath temperature was increased to approximately $5^{\circ} \mathrm{C}$ above the minimal boiling point of the fluid, as shown in Fig. D.2. This caused vigorous boiling in the flask, which was maintained for approximately 30 minutes in order to degass the fluid. Once degassing was complete, the bath temperature was lowered to approximately $2^{\circ} \mathrm{C}$ higher than the liquid temperature measured during degassing as shown in Fig. D.3. Lowering the bath temperature reduced the superheat in the liquid and provided a better approximation for the boiling point than the tabulated values. Once the bath temperature reached steady state, the bath temperature was slowly decreased, maintaining quasi-steady state, until boiling stopped. The arithmetic average of the vapor and liquid temperatures last recorded when boiling on the chips stopped was the experimental value of the boiling point.

The experimental values were $47.8^{\circ} \mathrm{C}$ for the liquid $\mathrm{R}-113$ and $47.6^{\circ} \mathrm{C}$ for the vapor. as shown in Fig. D.4. Boiling stopped when the bath temperature was $48.4^{\circ} \mathrm{C}$. The experimental value of $47.7^{\circ} \mathrm{C}$ agreed well with the value of 47.56 reported by ASHRAE (1989) and correlated by Jensen (1980). The predicted values were used in the data reduction program so that a consistent set of data at various pressures could be utilized. 


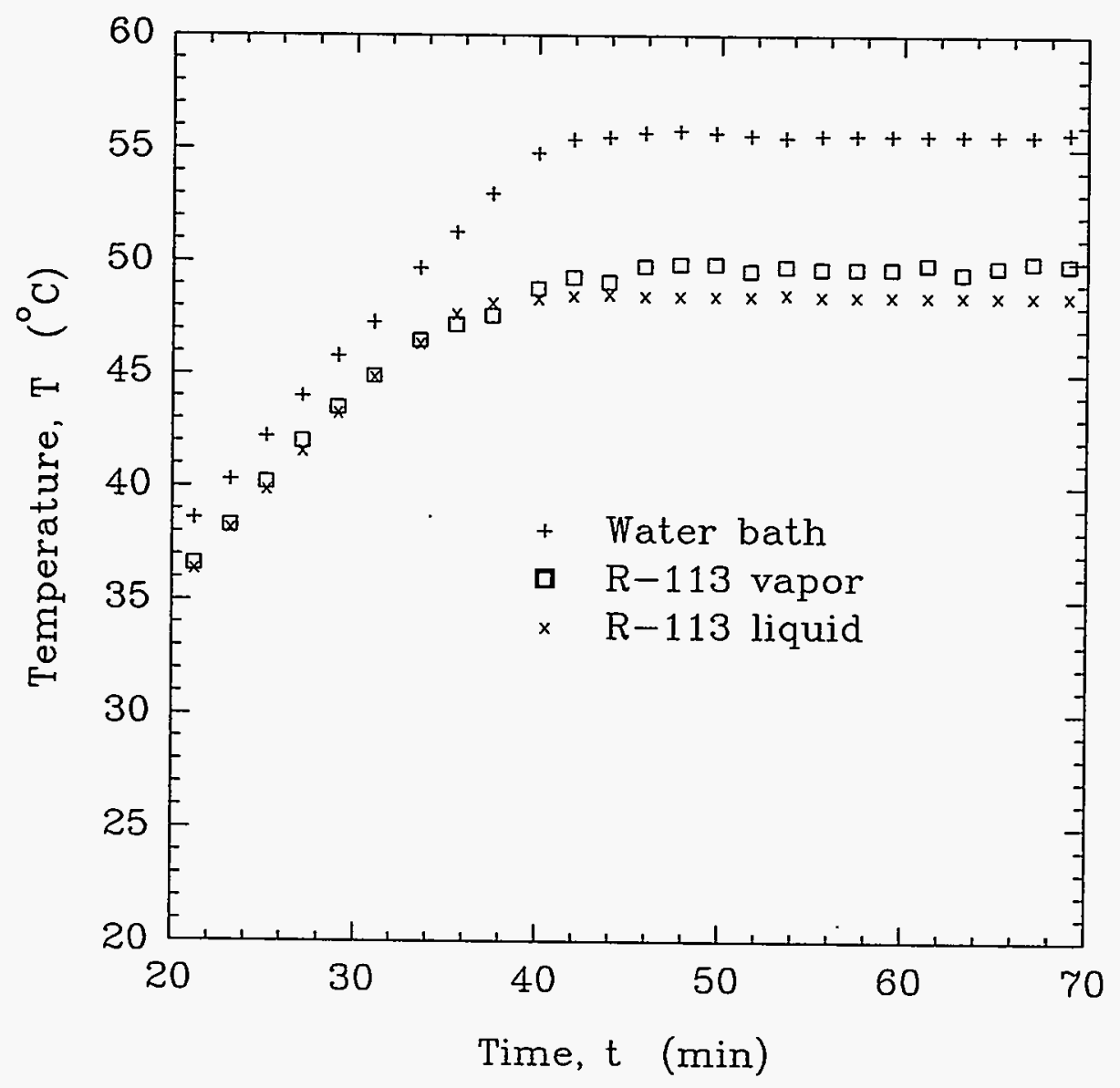

Figure D.2. Bath temperature is increased to about $5^{\circ} \mathrm{C}$ above the minimal boiling point of the fluid. 


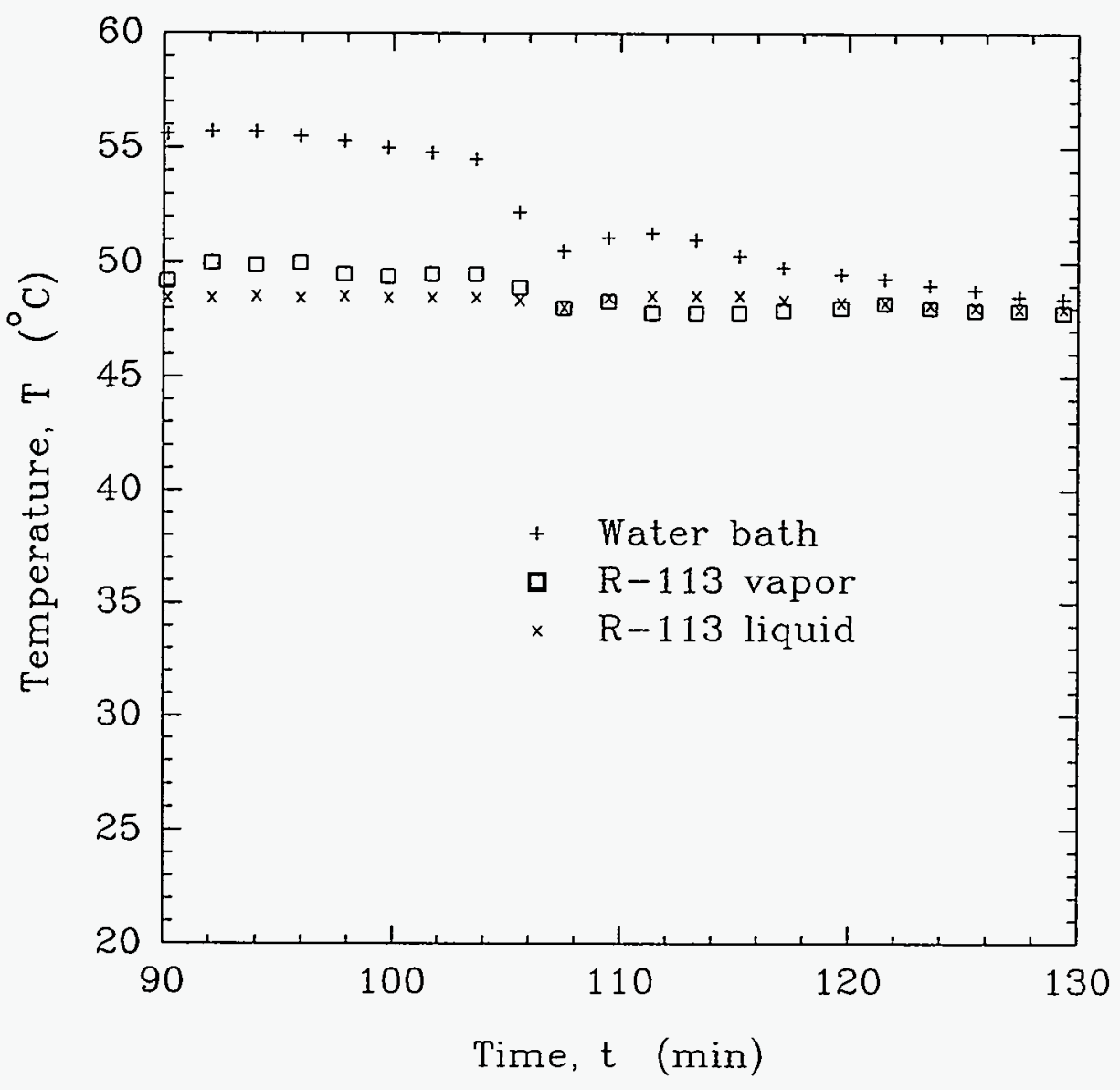

Figure D.3. Bath temperature is lowered to about $2^{\circ} \mathrm{C}$ below liquid temperature during degassing. 


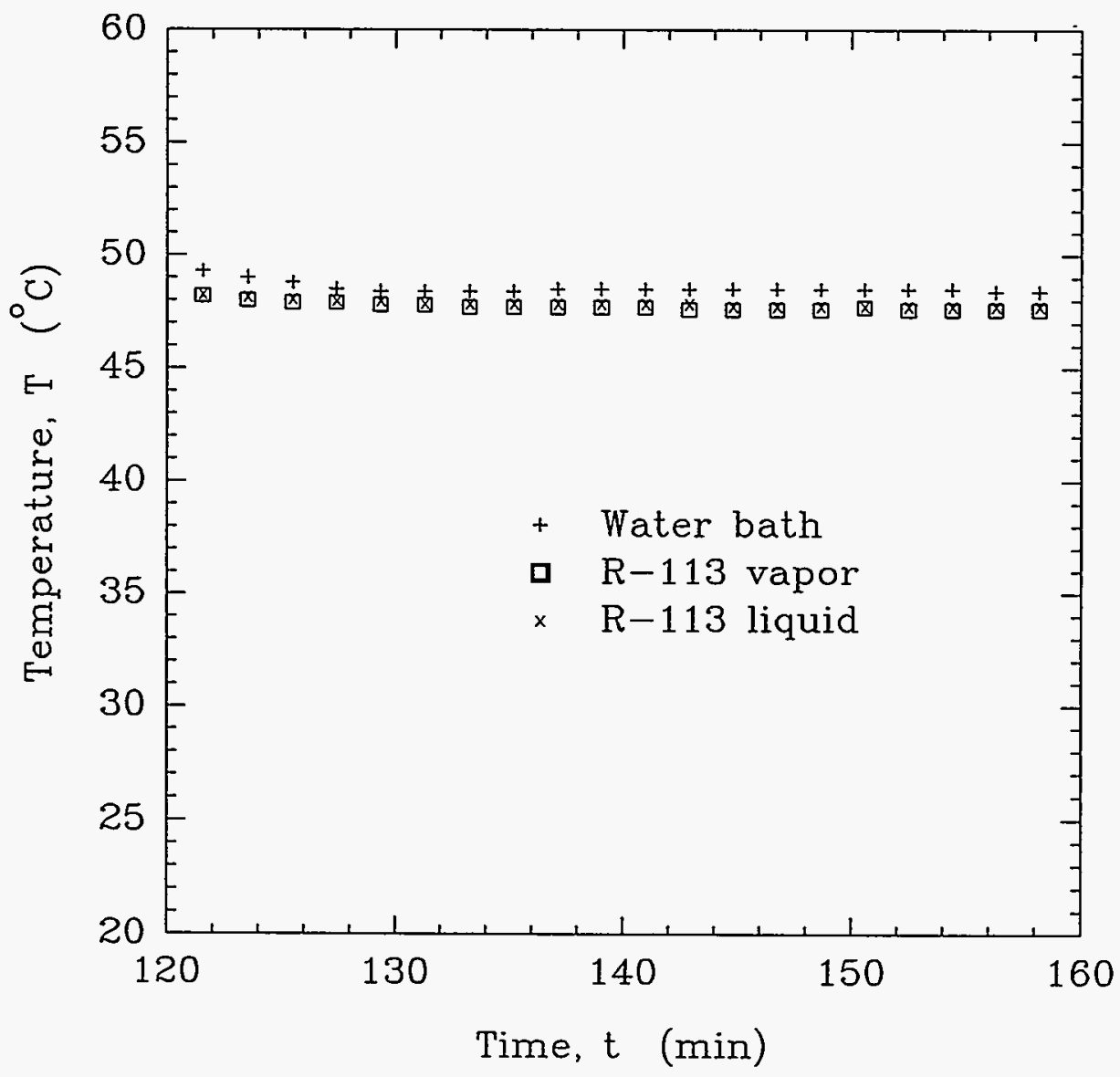

Figure D.4. Experimental values for saturation temperature of liquid and vapor $R-113$. 